Universidade de Brasília

Instituto de Ciências Humanas

Departamento de Geografia

Programa de Pós-Graduação em Geografia

\author{
UNIVERSIDADE DE BRASÍLIA \\ PÓS-GRADUAÇÃO EM GEOGRAFIA
}

\begin{abstract}
APRENDIZAGEM DA QUANTIFICAÇÃO NO PROCESSO DA FORMAÇÃO DO GRADUANDO DE CURSOS DE GEOGRAFIA
\end{abstract}

Luis Alberto Martins Palhares de Melo

Tese de Doutorado

Brasília-DF: setembro de 2015 
Universidade de Brasília

Instituto de Ciências Humanas

Departamento de Geografia

Programa de Pós-Graduação em Geografia

\author{
UNIVERSIDADE DE BRASÍLIA \\ PÓS-GRADUAÇÃO EM GEOGRAFIA
}

\title{
APRENDIZAGEM DA QUANTIFICAÇÃO NO PROCESSO DA FORMAÇÃO DO GRADUANDO DE CURSOS DE GEOGRAFIA
}

Luis Alberto Martins Palhares de Melo

Orientadora: Ercília Torres Steinke

Tese de Doutorado

Brasília-DF: setembro de 2015 
UNIVERSIDADE DE BRASÍLIA

DEPARTAMENTO DE GEOGRAFIA

\section{APRENDIZAGEM DA QUANTIFICAÇÃO NO PROCESSO DA FORMAÇÃO DO GRADUANDO DE CURSOS DE GEOGRAFIA}

\section{Luis Alberto Martins Palhares de Melo}

Tese de Doutorado submetida ao Departamento de Geografia da Universidade de Brasília, como parte dos requisitos necessários para a obtenção do Grau de Doutor em Geografia, área de concentração Gestão Ambiental e Territorial.

Aprovado por:

Ercília Torres Steinke, Doutor, (UnB)

Ruth Elias de Paula Laranja, Doutor, (UNESP)

Valdir Adilson Steinke, Doutor, (UnB)

Charlei Aparecido da Silva, Doutor, (UFGD)

Denis Richter, Doutor, (UFG)

Brasília-DF, 18 de setembro de 2015 
Palhares-Melo, Luis Alberto Martins

Aprendizagem da quantificação no processo da formação do graduando de cursos de Geografia / Luis Alberto Martins Palhares de Melo. - 2015

347 f. :il,

Tese de Doutorado - Universidade de Brasília. Programa de Pós-Graduação em Geografia, Brasília-DF, 2015.

Orientação: Prof ${ }^{\mathrm{a}}$. Dra. Ercília Torres Steinke.

1. Quantificação em Geografia. 2. Análise espacial de dados geográficos. 3. Formação em quantificação. 4. Graduandos em Geografia. I. UnB-PPGGEA II. Título

É concedida à Universidade de Brasília permissão para reproduzir cópias desta tese e emprestar ou vender tais cópias somente para propósitos acadêmicos e científicos. O autor reserva outros direitos de publicação e nenhuma parte desta tese de doutorado pode ser reproduzida sem a autorização por escrito do autor.

Luis Alberto Martins Palhares de Melo 
DEDICATÓRIA

Para Magaly, Luísa, Luis Guilherme e Flor. Esta é mais uma jornada do nosso time.

Juntos mais uma vez. 


\section{AGRADECIMENTOS}

Ao Criador, seja quem for, pois nos deu o dom do pensamento.

Aos meus pais Luiz Alberto e Aila, que me ensinaram nesta vida a amar a busca do conhecimento.

À minha esposa Magaly, companheira nesta jornada.

À professora Ercília Torres Steinke, por acreditar na importância da quantificação.

Ao professor Valdir Adilson Steinke, por acreditar na importância da quantificação.

A todos os professores do Departamento de Geografia da UnB, que colaboraram com a coleta de dados deste trabalho, em especial Ercília Torres Steinke, Helen da Costa Gurgel, Roselir de Oliveira Nascimento, Rogério Uagoda, Dante Flávio da Costa Reis Júnior, Waleska Valença Manyari, Fábio Cunha Andrade e Renan Boscariol, pois sem suas colaborações os dados não seriam obtidos.

Aos professores Cássio Arthur Wollmann (UFSM), Charlei Aparecido da Silva (UFGD), Denis Richter (UFG), Lucas Barbosa e Souza (UFT) e Maria Lígia Cassol Pinto (UEPG) que colaboraram com a coleta de dados deste trabalho nas suas instituições de ensino, pois sem suas colaborações os dados não seriam obtidos.

Ao colega Marcus Fábio que colaborou com a coleta de dados deste trabalho.

Aos funcionários da secretaria do GEA, Henrique, Teka, Jorge Luis, o outro Jorge Luis e Agnelo pelo fundamental auxílio prestado para a realização das atividades do curso de extensão realizado dentro do escopo neste trabalho.

A todos aqueles que responderam aos questionários de coleta de dados no escopo deste trabalho, pois sem suas colaborações os dados não seriam obtidos.

Aos participantes que efetivamente participaram de forma proativa no curso de extensão realizado no escopo deste trabalho, muito obrigado. 
À EMBRAPA - Empresa Brasileira de Pesquisa Agropecuária - que muito valoriza e incentiva o desenvolvimento do Capital Humano, onde trabalho há 26 anos e me sinto privilegiado por pertencer ao seu quadro de funcionários. 
"Olhamos para o nosso tempo para constatar que a ciência e a tecnologia enriqueceram imensamente o volume de dados que temos sobre a realidade; é impensável a quantidade de informações de que hoje dispomos sobre o ambiente do homem (...). Aí estão os computadores empanturrados de verdade fragmentária, e nós, ao lado deles, abismados com nossa ciência que gerou tal pluralidade e rapidez e, ao mesmo tempo metidos numa impotência horrorosa de reestruturarmos uma visão coerente ou pelo menos plausível de nós mesmos como seres humanos."

Régis de Morais (Educação em tempos obscuros - 1991) 


\section{RESUMO}

Quem é o geógrafo? De forma sucinta pode-se responder que o geógrafo é um cientista social, analista do espaço, ou seja, um analista das organizações espaciais e suas dinâmicas. O geógrafo, ao analisar determinado fenômeno sobre um espaço geográfico necessitará, em alguma instância, com maior ou menor intensidade, proceder à quantificação do mesmo. E afirma-se isto porque o geógrafo, em seu trabalho, realiza análise espacial de dados geográficos, uma atividade que envolve quantificação. A quantificação permite ao geógrafo delinear com maior precisão a forma e a estrutura das organizações espaciais. Esta quantificação é uma importante atividade complementar ao trabalho qualitativo de delineamento das funções da forma e dos processos inerentes à estrutura das organizações espaciais. Uma vez que se reconhece a importância da quantificação em Geografia, surge a seguinte pergunta: a formação acadêmica do geógrafo o capacita a realização de quantificação em Geografia? Este foi um objetivo de investigação deste trabalho. Além disso, o atual aparato tecnológico à disposição da sociedade permite que na área educacional recursos multimídia possam ser utilizados em prol de uma aprendizagem significativa de conteúdos. Assim, outro objetivo de investigação deste trabalho foi avaliar se a utilização de um software tutor para ensino de conceitos/técnicas de quantificação poderia ser útil para uma efetiva aprendizagem de tais conceitos/técnicas. Para realização deste trabalho foram realizadas as seguintes atividades: (1) análise da matriz curricular de diversos cursos de graduação em Geografia do País; (2) elaboração e aplicação de questionário para mapeamento da familiaridade de conceitos matemáticos básicos de alunos da Geografia; (3) elaboração e aplicação de questionário para mapeamento da importância dada pelos alunos à quantificação e (4) foi desenvolvido um software tutor para ensino de alguns conceitos/técnicas de quantificação e o mesmo foi testado em sala de aula e em curso de extensão. Como resultado geral, com base nas amostras coletadas, observou-se pouca familiaridade e pouca afetividade por parte do aluno com relação a conceitos matemáticos, mesmo reconhecendo a importância da quantificação para a Geografia. E com relação às matrizes curriculares dos cursos de Geografia, verificou-se que são limitadas para propiciar uma razoável capacitação do graduando em Geografia para trabalhar com quantificação.

Palavras-chave: graduando em Geografia, quantificação, análise espacial de dados geográficos 


\begin{abstract}
Who is the geographer? Briefly one can say that the geographer is a social scientist, an analyst of the space, that is, an analyst of the spatial organizations and their dynamics. Many times, the Geographer, an analyst of the spatial organizations, When studing some phenomena on a geographical space, the geographer will be forced, with greater or lesser intensity, to deal with the quantification of the space. This is said because the geographer, in his work, performs spatial analysis of geographical data that deals with quantification. Quantification leads to a more precise outlining of the form and structure of spatial organizations. This quantification is an important complementary activity to the qualitative work of delineation of functions of the form and process inherent to the structure of the spatial organizations. Once it recognizes the importance of quantification in geography, the following question arises: Does the school education enable the future geographer apply quantitative methods in Geography? This was one objective of investigation in this work. In addition, the current technological apparatus available to society allows the use of multimedia resources in education and this can be used in support for a meaningful learning content. In this context, another purpose of investigation of this work was to evaluate if the use of a tutor software for teaching some concepts/techniques of quantification could be useful for an effective learning of such concepts/ techniques. For this work the following activities were carried out: (1) curricular analysis of several undergraduate courses in Brazilian Geography; (2) elaboration and application of a test for mapping the familiarity of basic mathematical concepts to students of geography; (3) development and application of questionnaire for mapping the importance given by students to quantification and (4) it was developed a tutor software for teaching some concepts / quantification techniques that has been tested in the classroom and on-going extension. As a general result, based on the samples collected, there was little familiarity and little affection by the undergraduate student of Geography in relation to mathematical concepts, although recognizing the importance of quantification for Geography. With respect to school education curriculum of the undergraduate student of Geography, it was found that it is limited to prepare the student to work with quantification applied to Geography.
\end{abstract}

Keywords: undergraduate student of Geography, quantification, spatial data analysis 


\section{SUMÁRIO}

\section{LISTA DE FIGURAS}

\section{LISTA DE TABELAS}

\section{LISTA DE QUADROS}

\section{LISTA DE ABREVIATURAS E SIGLAS}

INTRODUÇÃO

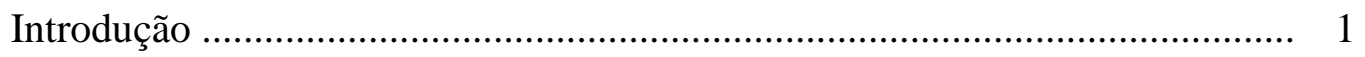

Quantificação em Geografia ..................................................................... 2

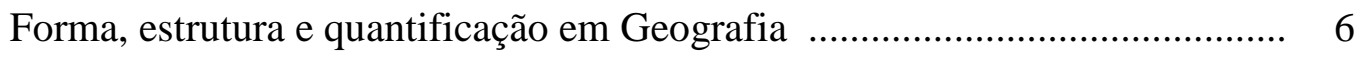

O entendimento da forma e estrutura via quantificação por parte do geógrafo 10

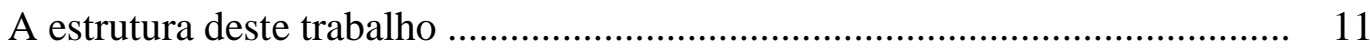

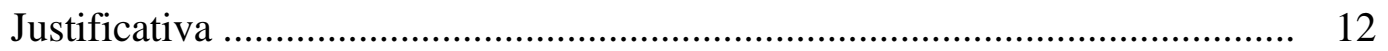

Questões e hipóteses de pesquisa ......................................................... 17

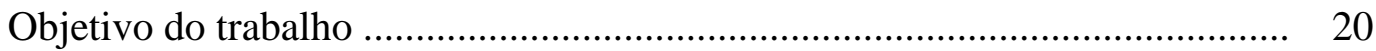

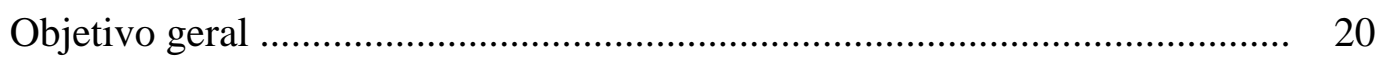

Objetivos específicos ......................................................................... 20

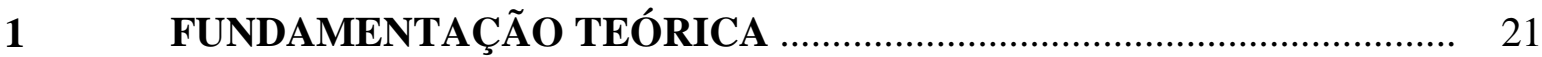

$1.1 \quad$ INTRODUÇÃ

1.2 A ANÁLISE ESPACIAL DE DADOS GEOGRÁFICOS …........................... 22

1.3 ALGUNS CONCEITOS BÁSICOS DE QUANTIFICAÇÃO EMBUTIDOS NAS TÉCNICAS DE ANÁLISE ESPACIAL ………………................... 29

1.4 OS PCN E OS CONTEÚDOS DE MATEMÁTICA E ESTATÍSTICA ......... 37 
1.5 SOBRE EDUCAÇÃO ESTATÍSTICA

1.6 APRENDIZAGEM SIGNIFICATIVA ATRAVÉS DE CONTEÚDO IMAGÉTICO.

2.1 INTRODUÇÃO 67

2.2 AULAS EXPOSITIVAS REALIZADAS EM ABRIL/2012 70

2.3 ELABORAÇÃO E APLICAÇÃO DE UM QUESTIONÁRIO PARA MAPEAMENTO DA FAMILIARIDADE DE CONCEITOS MATEMÁTICOS POR PARTE DO ALUNO GRADUANDO EM GEOGRAFIA

2.4 DESENVOLVIMENTO DAS LIÇÕES 1 A 14 DO SOFTWARE EDH ......... 80

2.5 LEVANTAMENTO DE DISCIPLINAS DO CURSO DE GEOGRAFIA LIGADAS À QUANTIFICAÇÃO

2.6 AULAS EXPOSITIVAS REALIZADAS EM AGOSTO/2013 SOBRE MÉDIA, VARIÂNCIA, DESVIO PADRÃO E COEFICIENTE DE VARIAÇÃO USANDO O SOFTWARE EDH

2.7 AULAS EXPOSITIVAS REALIZADAS EM MARÇO/2014 A JUNHO/2014 DAS LIÇÕES 1 A 8 DO EDH E OUTROS TEMAS DE QUANTIFICAÇÃO.

2.8 REALIZAÇÃO DE CURSO DE EXTENSÃO SOBRE QUANTIFICAÇÃO EM GEOGRAFIA DE SETEMBRO/2014 A NOVEMBRO/2014 USANDO $\mathrm{EDH}$

2.9 USO DO EDH COMO MATERIAL DE AUTOESTUDO SOBRE MÉDIA, VARIÂNCIA, DESVIO PADRÃO E COEFICIENTE DE CORRELAÇÃO EM MARÇO DE 2015 
3.1 INTRODUÇÃO

3.2 OS 384 QUESTIONÁRIOS PARA MAPEAMENTO DA FAMILIARIDADE DE CONCEITOS MATEMÁTICOS POR PARTE DO ALUNO GRADUANDO EM GEOGRAFIA

3.2.1 Questão 1 do questionário

3.2.2 Questão 2 do questionário

102

3.2.3 Questão 3 do questionário

3.2.4 Questão 4 do questionário 105

3.2.5 Questão 5 do questionário

107

3.2.6 Questão 7 do questionário

108

3.2.7 Considerações sobre os resultados obtidos

3.3 LEVANTAMENTO DE DISCIPLINAS DO CURSO DE GEOGRAFIA LIGADAS À QUANTIFICAÇÃO

3.4 AVALIAÇÃO DO USO DO EDH EM AGOSTO/2013 NA TURMA DE CLIMATOLOGIA GERAL

3.5 AVALIAÇÃO DO USO DO EDH EM MARÇO/2014 E OUTROS TEMAS DE QUANTIFICAÇÃO

3.6 O CURSO DE EXTENSÃO SOBRE QUANTIFICAÇÃO EM GEOGRAFIA DE SETEMBRO/2014 A NOVEMBRO/2014 USANDO EDH

3.6.1 Primeiro encontro - questionário de mapeamento da familiaridade de conceitos matemáticos básicos (questionário 1) 
3.6.2 Segundo encontro - questionário sobre conceitos de objeto, variável, população e amostra (assunto das lições 3 a 6 do EDH) (questionário 2) .......

3.6.2.1 Respostas dos participantes ao questionário 2 - objetos, variáveis, população e amostra

3.6.3 Terceiro encontro - questionário sobre conceitos de média aritmética simples (assunto da lição 7 do EDH) (questionário 3)

3.6.3.1 Respostas dos participantes ao questionário 3 - média aritmética simples .....

3.6.4 Quarto encontro - questionário sobre conceitos de variância, desvio padrão e coeficiente de variação (assunto da lição 8 do EDH) (questionário 4)

3.6.4.1 Respostas dos participantes ao questionário 4 - variância, desvio padrão e coeficiente de variação

3.6.5 Quinto encontro - questionário sobre conceitos de centro médio espacial (assunto da lição 9 do EDH) (questionário 5)

3.6.5.1 Respostas dos participantes ao questionário 5 - estatística espacial - centro médio espacial

3.6.6 Sexto encontro - questionário sobre conceitos de distância padrão (assunto da lição 10 do EDH) (questionário 6)

3.6.6.1 Respostas dos participantes ao questionário 6 - estatística espacial distância padrão

3.6.7 Sétimo encontro - questionário sobre conceitos de medidas de posição (separatrizes) e box plot (assunto da lição 12 do EDH) (questionário 7) .........

3.6.7.1 Respostas dos participantes ao questionário 7 - medidas de posição (separatrizes) e box plot 
3.6.8 Oitavo encontro - questionário sobre conceitos de curva de Lorenz e coeficiente de Gini (assunto da lição 14 do EDH) (questionário 8)

3.6.8.1 Respostas dos participantes ao questionário 8 - curva de Lorenz e coeficiente de Gini

3.7 SÍNTESE DOS RESULTADOS DO CURSO DE EXTENSÃO SOBRE QUANTIFICAÇÃO EM GEOGRAFIA DE SETEMBRO/2014 A NOVEMBRO/2014 USANDO EDH

3.8 A UTILIDADE DO EDH COMO FERRAMENTA DE AUXÍLIO NO ENSINO DE QUANTIFICAÇÃO APLICADA EM GEOGRAFIA

3.9 MAPEAMENTO DA IMPORTÂNCIA DADA PELO GRADUANDO EM GEOGRAFIA PARA A QUESTÃO DE QUANTIFICAÇÃO EM GEOGRAFIA

3.10 O USO DO EDH COMO FERRAMENTA DE AUTOESTUDO DE MÉDIA, VARIÂNCIA, DESVIO PADRÃO E COEFICIENTE DE VARIAÇÃO

3.10.1 O teste 1 aplicado na turma de Climatologia Geral do semestre letivo 1/2015

3.10.2 O teste 2 aplicado na turma de Climatologia Geral do semestre letivo 1/2015

3.11 Sobre a formação acadêmica do Geógrafo para compreensão das técnicas quantitativas de análise espacial de dados geográficos

APÊNDICE 1 - QUESTIONARIO DE ENTRADA DO CURSO DE EXTENSÃO

APÊNDICE 2 - QUESTIONARIO DE ENTRADA DO CURSO DE EXTENSÃO - QUESTÃO 1 
APÊNDICE 3 - QUESTIONARIO DE ENTRADA DO CURSO DE EXTENSÃO - QUESTÃO 2

APÊNDICE 4 - QUESTIONARIO DE ENTRADA DO CURSO DE EXTENSÃO - QUESTÃO 3

APÊNDICE 5 - QUESTIONARIO DE ENTRADA DO CURSO DE EXTENSÃO - QUESTÃO 4

APÊNDICE 6 - QUESTIONARIO DE ENTRADA DO CURSO DE EXTENSÃO - QUESTÃO 5

APÊNDICE 7 - QUESTIONARIO 2 - Sobre objetos, variáveis, população e amostra

APÊNDICE 8 - QUESTIONARIO 3 - Média aritmética simples

APÊNDICE 9 - QUESTIONARIO 4 - Variância e desvio padrão

279

APÊNDICE 10 - QUESTIONARIO 5 - Estatística espacial - centro médio espacial

APÊNDICE 11 - QUESTIONARIO 6 - Estatística espacial - distância padrão

APÊNDICE 12 - QUESTIONARIO 7 - Medidas de posição (separatrizes) e box plot

APÊNDICE 13 - QUESTIONARIO 8 - Curva de Lorenz e coeficiente de Gini

APÊNDICE 14 - Pontos positivos da disciplina "Estatística Aplicada" segundo graduandos de Geografia da UnB que cursaram a disciplina

APÊNDICE 15 - Pontos negativos da disciplina "Estatística Aplicada" segundo graduandos de Geografia da UnB que cursaram a disciplina 
APÊNDICE 16 - Teste 2 aplicado aos alunos de Climatologia Geral no semestre letivo 1/2015 sobre média variância, desvio padrão e coeficiente de variação 


\section{LISTA DE FIGURAS}

Figura 1 - O geógrafo é um analista das organizações espaciais.

Figura 2 - Distribuição de respondentes ao Censo Demográfico 2010 com relação às variáveis cor/raça autodeclarada e região geográfica de residência segundo o IBGE.

Figura 3 - $\quad$ Resultado da aplicação do teste de hipótese no ambiente de software $\mathrm{R}$.

Figura 4 - A quantificação auxilia na compreensão da forma e a estrutura da realidade (organizações espaciais).

Figura 5 - Um esboço pictórico do exemplo de regressão linear citado por Assunção (2001).

Figura 6 - Tabelas de dados de entrada para análise de variância (ANOVA) dos $\operatorname{casos}(1)$ e (2).

Figura 7 - Taxonomia usada para caracterizar os problemas de análise espacial segundo Druck et. al. (2004).

Figura 8 - Problemas de análise espacial abrangendo interação espacial.

Figura 9 - Pirâmide de pilares de conhecimentos necessários para entendimento de técnicas quantitativas usadas em análise espacial de dados geográficos.

Figura 10 - Esquemas de relacionamento entre as três capacidades conforme delMar(2002) apud Campos (2007). (A) primeira interpretação de relacionamento. (B) segunda interpretação.

Figura 11 - Relacionamento entre as três capacidades proposto por Campos (2007, p. 65). 
Figura 12 - O ápice da educação estatística: formar consumidor de informação estatística.

Figura 13 - Pirâmide de pilares de conhecimentos necessários para entendimento quantificação em análise espacial de dados geográficos (realçando a importância da educação estatística).

Figura 14 - Esquema pictórico para representar a ideia de aprendizagem significativa na teoria de Ausubel.

Figura 15 - Esquema pictórico para representar a ideia de aprendizagem mecânica.

Figura 16 - Esquema pictórico para representar a ideia de contínuo das aprendizagens mecânica e significativa.

Figura 17 - Interface de um software que se for usado para ensino, transmite apenas os "aspectos marginais" da Estatística.

Figura 18 - Fluxograma de atividades de coleta de dados realizadas no escopo deste trabalho.

Figura 19 - Trecho da apostila preparada para ensino de alguns conceitos quantitativos usada em abril/2012. A imagem tenta auxiliar o aprendiz a fixar o conceito de média aritmética.

Figura 20 - Trecho da apostila preparada para ensino de alguns conceitos quantitativos usada em abril/2012. A imagem prepara a apresentação do conceito de desvio padrão, apresentado em seguida.

Figura 21 - Trecho da apostila preparada para ensino de alguns conceitos quantitativos usada em abril/2012. A imagem apresenta o conceito de desvio padrão.

Figura 22 - Trecho da apostila preparada para ensino de alguns conceitos quantitativos usada em abril/2012. Imagem para motivação para uso das ferramentas de quantificação. 
Figura 23 - Capa do questionário para mapeamento da familiaridade de conceitos matemáticos por parte do graduando em Geografia. Aplicado em maio/junho/agosto 2013 e abril/2014.

Figura 24 - Tela para digitação dos dados dos questionários aplicados com valores de um questionário digitados.

Figura 25 - Tela de menu principal do software EDH.

Figura 26 - Tela de menu da lista de lições do software EDH.

Figura 27 - Exemplo de página realçando a interface de navegação "para frente" e "para trás".

Figura 28 - "Aproximação" aos conceitos de variância e desvio padrão. A imagem de dados (representados por bolinhas) espalhados. E a palavra espalhamento sendo destacada.

Figura 29 - Interação do usuário como tentativa de entendimento dos cálculos. ....

Figura 30 - A abordagem da fórmula de cálculo da variância.

Figura 31 - A análise de dados após o entendimento do conceito de variância e desvio padrão.

Figura 32 - Exemplo de imagem dinâmica (GIF animado) da lição 9 do software EDH. As imagens (A), (B), (C), (D) e (E) se sucedem na tela causando impressão de movimento do centro médio espacial ponderado dos anos de 2008 a 2012.

Figura 33 - Última tela da lição 12 estimulando o leitor a realizar atividades propostas referentes ao tema da lição.

Figura 34 - Primeira tela da lição 1 do EDH para realçar a importância da motivação como fator de aprendizagem.

Figura 35 - Segunda tela da lição 1 do EDH para realçar a importância da motivação como fator de aprendizagem. 
Figura 36 - Assertivas dos itens (1) e (2) do Exercício 1 assinaladas como correta pelo usuário. Contudo, o item (2) é errado e o software EDH informa ao usuário.

Figura 37 - Explicação do resultado do item (2).

Figura 38 - A questão 6 do questionário com resolução e resposta.

Figura 39 - Estatísticas descritivas para a variável total de questões certas.

Figura 40 - Distribuição de frequência da variável gosta de matemática/estatística.

Figura 41 - Percentual de acertos, erros e não resolução das questões 1 , 2, 3, 4, 5 e 7 pelos 384 respondentes.

Figura 42 - A questão 1 do questionário.

101

Figura 43 - Resolução e resposta da questão 1 do questionário.

102

Figura 44 - A questão 2 do questionário, resolução e resposta. 103

Figura 45 - A questão 3 do questionário, resolução e resposta. 104

Figura 46 - A questão 4 do questionário. 106

Figura 47 - Resolução e resposta da questão 4 do questionário.

Figura 48 - A questão 5 do questionário, resolução e resposta. 108

Figura 49 - A questão 7 do questionário, resolução e resposta. 109

Figura 50 - Tela inclusa na lição 7 para ensinar a ideia de somatório

Figura 51 - Tela inclusa na lição 7 para ensinar a ideia de somatório

Figura 52 - Questão referente a conceitos de média, variância, desvio padrão e coeficiente de variação da primeira prova da disciplina Climatologia Geral na UnB no período 2/2013.

Figura 53 - Uma imagem estática da apostila apresentado uma etapa do cálculo do coeficiente de Gini. 
Figura 54 - Uma cena de uma imagem dinâmica do EDH apresentado uma etapa do cálculo do coeficiente de Gini.

Figura 55 - Primeira parte dos itens para mapeamento da dinâmica de aprendizagem do respondente.

Figura 56- Segunda parte dos itens para mapeamento da dinâmica de aprendizagem do respondente

Figura 57- Terceira parte dos itens para mapeamento da dinâmica de aprendizagem do respondente.

Figura 58 - Figura apresentando contexto pictórico para cálculo de G.

Figura 59 - Figura apresentando contexto pictórico de uso da média aritmética ponderada.

Figura 60 - Contextualização de uso de uma estrutura matricial.

Figura 61 - Exemplo de cálculo do coeficiente de localização para feijão e milho, com base em dados dispostos em estrutura matricial.

Figura 62 - Distribuição de frequência da variável familiaridade de conceitos matemáticos.

Figura 63 - Percentual de acertos, erros e não resolução das questões 1 a 5 pelos 38 respondentes.

Figura 64 - Uma tela da lição 3 - objeto e atributos.

Figura 65 - Uma tela da lição 3 - exemplo de objeto e atributos do objeto.

Figura 66 - Uma tela da lição 4 - exemplo de relacionamento entre o objeto, os atributos de objetos e um grupo (população - conjunto) de atributos do objeto.

Figura 67 - $\quad$ Síntese da lição 4. 
Figura 68 - Uma tela para propiciar o entendimento intuitivo do conceito de variável.

Figura 69 - Uma tela com exemplo para tentar "concretizar" o conceito de variável.

Figura 70 - Outra tela com exemplo para tentar "concretizar" o conceito de variável.

Figura 71 - Síntese da lição 5.

Figura 72 - Conceito de população e amostra apresentado de forma visual .

Figura 73 - Conceito de população e amostra apresentado de forma visual.

Figura 74 - Conceito de média aritmética como "número síntese".

Figura 75 - Conceito de média aritmética como "número síntese".

Figura 76 - A média calculada com o primeiro valor da série $(72,7 \mathrm{~mm})$.

Figura 77 - A média calculada com os dois primeiros valores (72,7 e 231,8 mm).

166

Figura 78 - A média dos três primeiros valores $(72,7 ; 231,8 ; 233,4 \mathrm{~mm})$.

166

Figura 79 - A média dos quatro primeiros valores $(72,7 ; 231,8 ; 233,4 ; 297,1$ $\mathrm{mm})$.

Figura 80 - A média do grupo de valores.

Figura 81 - Uma tela apresentando o conceito de variância como "espalhamento de dados".

Figura 82 - Outra tela apresentando o conceito de variância como "espalhamento de dados".

Figura 83 - Tela interativa para calcular a distância (desvio) do valor observado para a média. À medida em que o usuário clica o botão "Valor Média = ?" o programa EDH mostra o valor do desvio e um "mapa" do desvio calculado mostrando a média (o triângulo vermelho) e a observação (a bolinha verde) 
Figura 84 - Tela com a imagem dinâmica de moscas voando nos limites do desvio padrão de três grupos de dados.

Figura 85 - Fórmula de cálculo da variância e desvio padrão para população.

Figura 86 - Tela com imagem para explicar o "espalhamento de dados".

Figura 87 - Abordagem para apresentação do conceito de centro médio espacial.

Figura 88 - Abordagem para apresentação do conceito de centro médio espacial ponderado.

Figura 89 - Abordagem para apresentação do conceito de centro médio espacial ponderado.

Figura 90 - Tela mostrando o centro médio espacial e o centro médio espacial ponderado.

Figura 91 - Tela para abordagem ao conceito de distância padrão.

Figura 92 - Tela para abordagem ao cálculo da distância padrão.

Figura 93 - Tela onde o usuário interage clicando no botão "Quadrado dist.” para calcular a distância padrão.

Figura 94 - Tela mostrando o resultado do cálculo da distância padrão.

Figura 95 - Tela dinâmica calculando a distância padrão ponderada.

Figura 96 - Tela exemplificando a mediana.

Figura 97 - Tela abordando a mediana, primeiro e terceiro quartis.

Figura 98 - Tela abordando diversos quantis (separatrizes).

Figura 99 - Tela mostrando o resultado da construção do box plot para um grupo de dados.

Figura 100 - Tela abordando a utilidade da curva de Lorenz. 
Figura 101 - Tela abordando a utilidade da curva de Lorenz.

Figura 102 - Tela abordando a "leitura" de informações na curva de Lorenz.

Figura 103 - Tela abordando a ligação conceitual entre a curva de Lorenz e o coeficiente de Gini.

Figura 104 - Tela abordando a ligação conceitual entre a curva de Lorenz e o coeficiente de Gini.

Figura 105 - Tela exemplificando uma análise com base na curva de Lorenz e coeficiente de Gini.

Figura 106 - Primeira parte do questionário para mapear a importância dada pelos graduandos de Geografia para a questão de quantificação em Geografia.

Figura 107 - Segunda parte do questionário para mapear a importância dada pelos graduandos de Geografia para a questão de quantificação em Geografia.

Figura 108 - Distribuição de frequência da variável gosta de matemáticalestatística.

Figura 109 - Distribuição de frequência da variável relevância de métodos quantitativos.

Figura 110 - Respostas dos 62 respondentes do curso de Geografia que já haviam cursado a disciplina Estatística Aplicada sobre o aprendizado de fato de alguns conceitos que foram ou deveriam ter sido ministrados na disciplina.

Figura 111 - A questão 6 do teste 1 de mapeamento de familiaridade de conceitos matemáticos básicos.

Figura 112 - Distribuição de frequência da variável gosta de matemáticalestatística. 
Figura 113 - Distribuição de frequência da variável familiaridade de conceitos matemáticos.

Figura 114- Percentual de acertos e erros das questões 1 a 5 pelos 28 respondentes.

Figura 115 - Desempenho dos 32 alunos que realizaram o teste 2.

Figura 116 - A questão 2 do teste 2 e os três primeiros itens, denominados de (11), (12) e (13) com respectivos gabaritos.

Figura 117 - Proposta de disciplinas ligadas à quantificação para cursos de graduação em Geografia. 


\section{LISTA DE TABELAS}

Tabela 1 - Frequência absoluta e relativa de respondentes em relação ao total de questões respondidas corretamente

Tabela 2 - Distribuição de frequência do total de questões respondidas corretamente com base na variável gosta de matemática/estatística......

Tabela 3 - Distribuição de frequência de questões respondidas corretamente conforme as categorias baixo, médio e alto com base na variável gosta de matemáticalestatística.

Tabela 4- Distribuição de frequência de questões respondidas corretamente conforme as categorias baixo, médio e alto com base na variável sexo..

Tabela 5 - Frequência absoluta e relativa de respostas certas, erradas e em branco das questões 1, 2, 3, 4, 5 e 7 dos 384 questionários respondidos.

Tabela 6- Total de respondentes do questionário que acertaram ao menos as questões 1, 2 e 7 ou que acertaram ao menos as questões 1 e 2

Tabela 7 - Marcações e total de acertos dos 29 alunos para os itens envolvendo conceitos de média, variância, desvio padrão e coeficiente de variação.

Tabela 8 - Marcações dos 29 alunos nos itens 3 e 5.

Tabela 9 - Marcações dos 29 alunos nos itens 4, 7 e 8.

Tabela 10 - Marcações dos 29 alunos nos itens 9 e 10.

Tabela 11 - Síntese dos principais resultados obtidos.

Tabela 12 - Lições do EDH abordadas e assuntos dos questionários aplicados durante os oito encontros presenciais

Tabela 13 - Mapa de indicação de resolução do questionário. 150 
Tabela 14 - Designações qualitativas para a familiaridade com conceitos matemáticos básicos em nível de Ensino Médio.

Tabela 15 - Familiaridade com conceitos matemáticos dos 40 participantes.

Tabela 16 - Frequência absoluta e relativa de respostas certas, erradas e em branco das questões 1 a 5 dos 38 questionários respondidos

Tabela 17 - Respostas dos participantes P1, P9, P10, P11, P13, P14, P27 e P28.......

Tabela 18 - Respostas dos participantes P3, P4, P5, P8, P15, P16, P17, P18, P19 e $\mathrm{P} 20$.

Tabela 19 - Pontos positivos do software EDH citados pelos participantes que responderam o questionário 2

Tabela 20 - Pontos negativos do software EDH citados pelos participantes que responderam o questionário 2

Tabela 21 - Respostas dos participantes P1, P4, P5, P6, P7, P8, P10, P11, P13, P17, P18, P21, P23 e P40.

Tabela 22 - Respostas dos participantes P2, P9, P16 e P22.

Tabela 23 - Respostas dos participantes P12, P14.

Tabela 24 - Respostas do participante P19.

Tabela 25 - Pontos positivos do software EDH citados pelos participantes que responderam o questionário 3.

Tabela 26 - Pontos negativos do software EDH citados pelos participantes que responderam o questionário 3.

Tabela 27 - Respostas dos participantes P1, P7, P10, P17 e P19. 177

Tabela 28 - Respostas dos participantes P3, P4, P5, P8 e P9. 177

Tabela 29 - Respostas dos participantes P6 e P16. 
Tabela 30 - Respostas dos participantes P12 e P18.

Tabela 31 - Respostas do participante P11

Tabela 32 - Pontos positivos do software EDH citados pelos participantes que responderam o questionário 4 .

Tabela 33 - Pontos negativos do software EDH citados pelos participantes que responderam o questionário 4 .

Tabela 34 - Respostas dos participantes P1, P2, P4, P5, P7, P10, P13, P16 e P17.....

Tabela 35 - Respostas dos participantes P3, P11, P12, P18

Tabela 36 - Respostas do participante P6

Tabela 37 - Respostas dos participantes P8 e P9.

186

Tabela 38 - Pontos positivos do software EDH citados pelos participantes que responderam o questionário 5

Tabela 39 - Pontos negativos do software EDH citados pelos participantes que responderam o questionário 5 .

Tabela 40 - Respostas dos participantes P1, P5, P7, P9 e P10..

Tabela 41 - Respostas do participante P8

Tabela 42 - Respostas dos participantes P3 e P4.

Tabela 43 - Pontos positivos do software EDH citados pelos participantes que responderam o questionário 6 ,

Tabela 44 - Pontos negativos do software EDH citados pelos participantes que responderam o questionário 6 .

Tabela 45 - Respostas dos participantes P1, P4, P5, P7, P9 e P10. 196

Tabela 46 - Respostas do participante P8. 196 
Tabela 47 - Respostas dos participantes P3, P11, P12 e P14.

Tabela 48 - Pontos positivos do software EDH citados pelos participantes que responderam o questionário 7

Tabela 49 - Pontos negativos do software EDH citados pelos participantes que responderam o questionário 7

Tabela 50 - Respostas dos participantes P1, P4, P5, P7 e P16.

Tabela 51 - Pontos positivos do software EDH citados pelos participantes que responderam o questionário 8

Tabela 52 - Pontos negativos do software EDH citados pelos participantes que responderam o questionário 8

Tabela 53 - Mapa de desempenho dos 19 participantes que concluíram o curso de extensão

Tabela 54 - Distribuição de frequência de afetividade por matemática/estatística conforme as categorias detesto, gosto um pouco e gosto/gosto muito com base na variável sexo.

Tabela 55 - Familiaridade com conceitos matemáticos dos 28 alunos.

Tabela 56- Agrupamento das variáveis gosta de matemática/estatística e familiaridade de conceitos matemáticos em duas categorias qualitativas para uso no teste de Fischer.

Tabela 57 - Frequência absoluta e relativa de respostas certas e Erradas das questões 1 a 5 dos 28 questionários respondidos

Tabela 58 - Desempenho no teste 1 e total de itens certos, errados, em branco e desempenho dos alunos no teste 2

Tabela 59 - Agrupamento das variáveis familiaridade matemática e desempenho no teste 2 em duas categorias qualitativas para uso no teste de Fischer. 
Tabela 60 - Estatísticas de respondentes à questão (apresentada na Figura 4.15) com dez itens dicotômicos sobre média, desvio padrão e coeficiente de variação aplicada em 2013 e em 2015

Tabela 61 - Marcações dos 32 alunos nos itens 3 e 5............................................... 233

Tabela 62 - Marcações dos 32 alunos nos itens 4, 7 e 8......................................... 233

Tabela 63 - Marcações dos 32 alunos nos itens 9 e 10............................................. 234

Tabela 64 - Síntese dos principais resultados obtidos pelas turmas de 2013 e 2015 na questão 1 do teste 2

Tabela 65 - Marcações dos 32 alunos nos itens (11), (12) e (13).

Tabela 66 - Frequência absoluta e relativa de respondentes em relação ao total de questões respondidas corretamente pelos 211 alunos da UnB e 173 alunos das demais instituições no questionário de mapeamento de familiaridade de conceitos matemáticos básicos aplicado em 2013 e abril/2014.

Tabela 67 - Alguns temas para composição da ementa das disciplinas "Fundamentos Matemáticos para Geografia", "Estatística Aplicada à Geografia" e "Estatística Espacial". 


\section{LISTA DE QUADROS}

Quadro 1- Alguns conhecimentos e habilidades a serem promovidos durante o Ensino Médio na área de ciências da natureza, matemática e suas tecnologias

Quadro 2 - Habilidades estatísticas propostas nos PCN para o Ensino Fundamental......

Quadro 3 - Habilidades estatísticas propostas nos PCN para o Ensino Médio

Quadro 4 Alguns conhecimentos e habilidades necessários para resolução das questões do questionário.

Quadro 5 - $\quad$ Temas estruturadores para matemática no Ensino Médio segundo os PCNEM e associação das questões do questionário com os temas

Quadro 6 - Ementa e programa da disciplina "Estatística Aplicada" da UnB.........

Quadro 7 - Disciplina "Estatística Básica I" - UFRGS.

Quadro 8 - Disciplina “Análise Estatística em Geociências” - UFSC.

Quadro 9 - D Disciplina “Análise Estatística em Geociências” - UFPR.

Quadro 10 - Disciplinas "Complementos de Matemática I" e "Estatistica" UFRJ.

Quadro 11 - Disciplina "Noções de Estatística" - USP.

Quadro 12 - Disciplina "Estatística Aplicada à Geografia" - UNESP (Campus Ourinhos)

Quadro 13 - Disciplina "Estatística Aplicada à Geografia" - UNESP (Campus Presidente Prudente)

Quadro 14 - Disciplina "Geoestatística" - UFU. 
Quadro 15 - Disciplinas "Estatística D I" e "Estatística D II" - UFMG......

Quadro 16 - Disciplina "Estatística Aplicada à Geografia" - UFG.

Quadro 17 - Disciplina "Estatística Geral I" - UFMT.

Quadro 18 - Disciplina "Introdução à Estatística" - UFAM..

Quadro 19 - Disciplina "Modelos Estatísticos em Geociências" - UFC.

Quadro 20 - Disciplinas “Complementos de Matemática I" e "Estatistica I B” UFBA

Quadro 21 - Disciplinas "Quantificação em Geografia " e "Geoestatística" UFAL

Quadro 22 - Respostas e condições do RESPONDENTE 1

Quadro 23 - Respostas e condições do RESPONDENTE 2.......

Quadro 24 - Respostas e condições do RESPONDENTE 3...

Quadro 25 - Respostas e condições do RESPONDENTE 4...

Quadro 26 - Respostas e condições do RESPONDENTE 5.

Quadro 27 - Ideias centrais dos pontos positivos e pontos negativos sobre o EDH citados pelos usuários do EDH.

Quadro 28 - Ideias centrais dos pontos positivos e pontos negativos sobre a disciplina "Estatística Aplicada" 
LISTA DE ABREVIATURAS E SIGLAS

\begin{tabular}{|c|c|}
\hline $\mathrm{EDH}$ & Estatística em Doses Homeopáticas \\
\hline GPS & Global Positioning System \\
\hline PCN & Parâmetros Curriculares Nacionais \\
\hline SIG & Sistemas de Informação Geográfica \\
\hline UEPG & Universidade Estadual de Ponta Grossa \\
\hline UFAL & Universidade Federal de Alagoas \\
\hline UFAM & Universidade Federal do Amazonas \\
\hline UFBA & Universidade Federal da Bahia \\
\hline UFC & Universidade Federal do Ceará \\
\hline UFG & Universidade Federal de Goiás \\
\hline UFGD & Universidade Federal da Grande Dourados \\
\hline UFMT & Universidade Federal de Mato Grosso \\
\hline UFMG & Universidade Federal de Minas Gerais \\
\hline UFRJ & Universidade Federal do Rio de Janeiro \\
\hline UFSC & Universidade Federal de Santa Catarina \\
\hline UFPR & Universidade Federal do Paraná \\
\hline UFRGS & Universidade Federal do Rio Grande do Sul \\
\hline UFRJ & Universidade Federal do Rio de Janeiro \\
\hline UFSM & Universidade Federal de Santa Maria \\
\hline UFT & Universidade Federal de Tocantins \\
\hline
\end{tabular}


UnB Universidade de Brasília

UNICEUB Centro Universitário de Brasília

UNESP Universidade Estadual Paulista

USP Universidade Federal de São Paulo 


\section{INTRODUÇÃO}

\section{Introdução}

A Geografia é uma ciência social que ocupa cada vez mais importância na sociedade global atual no sentido de oferecer explicações e soluções aos inúmeros fenômenos/eventos naturais e humanos que ocorrem em diversas instâncias espaciais da realidade, sejam elas em nível local, regional e/ou mundial. Dado a reconhecida importância da Geografia, uma pergunta que surge é: quem é o geógrafo?

Antes de responder a esta pergunta, coloca-se outra pergunta: O que é um sistema? Na década de 1950 o biólogo alemão Ludwig von Bertalanffy elaborou a Teoria Geral de Sistemas e, no escopo desta teoria, é possível propor uma definição de sistema da seguinte forma: sistema é um conjunto de elementos (conjunto de partes) que interagem dinamicamente entre si e, com base em entradas (informação e/ou matéria) devidamente processadas, produzem saídas (informação e/ou matéria) que se constituem nos objetivos a serem alcançados. Vale (2012) exemplifica as entradas e saídas de alguns sistemas:

Os sistemas apresentam ainda entrada e saída, input e output, respectivamente. A entrada é composta por aquilo que o sistema recebe, é o alimento do sistema, por exemplo, um rio recebe água da precipitação e sedimentos fornecidos pelas vertentes; a Terra recebe energia solar; um animal recebe alimentação. Pode-se exemplificar com outros tipos de entrada como uma fábrica que recebe matéria-prima para sua produção. Cada sistema é alimentado por determinados tipos de entradas. Essas entradas que o sistema recebe sofrem transformações em seu interior e, posteriormente, são enviadas para fora, isso constitui a saída ou o output, portanto, toda entrada corresponde a um tipo de saída. (VALE, 2012, p.92)

Assim, quando alguém se propõe a estudar ou entender um sistema, esse alguém comporta-se como um analista do sistema. Irá analisar/estudar as partes componentes e suas interações que ocorrem de forma dinâmica, bem como as entradas e saídas do sistema. Neste contexto pode-se afirmar que um médico é um analista de sistema. Seu universo sistêmico é o 
corpo humano. Igualmente, o dentista também é um analista de sistema, cujo universo sistêmico é o aparelho bucal. O biólogo é também um analista de sistema, assim como o sociólogo, o engenheiro, o economista, o administrador, o cientista político, o astrônomo, o meteorologista e outros.

Então, neste contexto, retomando-se a pergunta sobre quem é o geógrafo, pode-se responder que o geógrafo é um analista de sistema, mais precisamente um analista das organizações espaciais e suas dinâmicas.
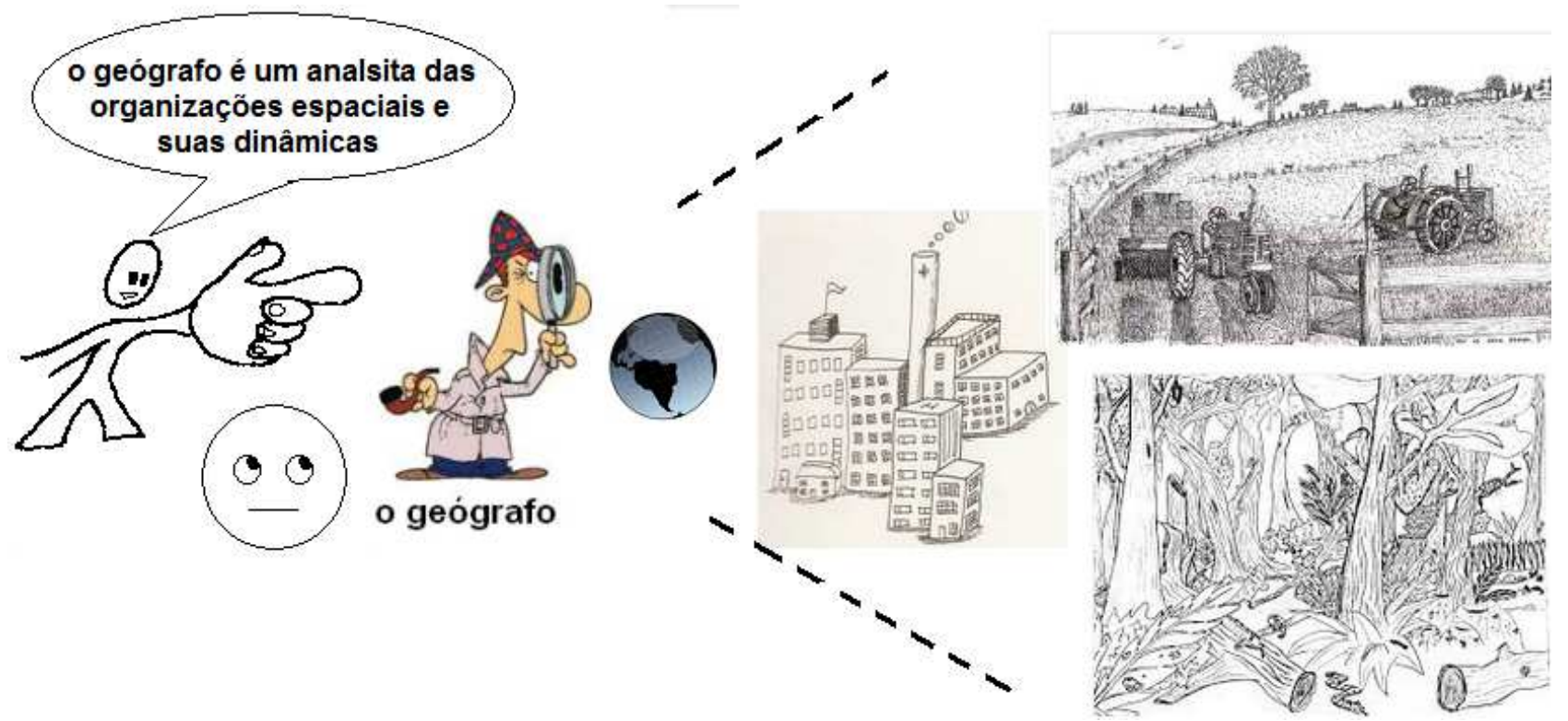

Figura 1 - O geógrafo é um analista das organizações espaciais e suas dinâmicas.

Fonte: Elaborado pelo autor.

\section{Quantificação em Geografia}

O geógrafo, analista das organizações espaciais, em diversas situações, ao analisar determinado fenômeno sobre um espaço geográfico, necessitará, em alguma instância, com maior ou menor intensidade, proceder à quantificação do mesmo. E afirma-se isto porque o geógrafo, em seu trabalho, realiza análise espacial de dados geográficos. A análise espacial de dados geográficos está, portanto, vinculada à quantificação (total ou parcial) do fenômeno em questão sobre um espaço geográfico.

Mas afirmar a necessidade de quantificação de fenômenos sobre um espaço geográfico pode suscitar questionamentos acerca de sua validade. Afinal, fenômenos que sejam predominantemente caracterizados por variáveis de natureza quantitativa certamente podem requerer, para sua melhor compreensão, a aplicação de técnicas quantitativas. Mas será que 
fenômenos que sejam predominantemente subjetivos, caracterizados por variáveis de natureza qualitativa, precisam ou mesmo podem ser tratados por alguma abordagem quantitativa?

Para responder a este questionamento, inicialmente considere a caracterização da área urbana e rural de determinado espaço geográfico, onde é possível usar diversas variáveis de natureza quantitativa para esta caracterização: precipitação média mensal, temperatura mínima diária, temperatura máxima diária, nebulosidade, incidência de radiação solar, volume disponível de água, densidade populacional de determinado tipo de praga agrícola, renda média mensal e horas semanais trabalhadas de trabalhadores rurais, lucro sobre a produção semanal e/ou mensal das culturas dentre outras, são variáveis quantitativas que permitem delinear o espaço rural e, tratadas de forma adequada por alguma técnica quantitativa podem, por exemplo, auxiliar no planejamento da produção agrícola.

Para o mapeamento para fins de planejamento do espaço urbano, pode-se considerar variáveis que quantifiquem equipamentos urbanos (escolas, hospitais, creches, hipermercados, farmácias, bairros residenciais, pontos de ônibus, etc) e equipamentos de cadeias produtivas (fábricas, fazendas, armazéns, rodovias, hidrovias, etc) sobre o espaço urbano e rural. Com variáveis quantitativas que delineiam os equipamentos urbanos e de cadeias produtivas, pode-se aplicar típicos modelos matemáticos voltados para questões locacionais. Assim, através destes modelos, é possível apontar cenários que otimizam a distribuição dos recursos (escolas, hospitais, creches, hipermercados, farmácias, bairros residenciais, pontos de ônibus, fábricas, fazendas, armazéns, rodovias, hidrovias, etc) sobre o espaço, minimizando custos (tempo de produção, tempo de acesso aos hospitais e escolas, quantidade de fertilizantes e defensivos agrícolas aplicados nas parcelas dos campos cultivados, alocação de recursos humanos especializados, etc), proporcionando melhor qualidade de vida para a sociedade.

Mas e os fenômenos que sejam predominantemente caracterizados por variáveis de natureza qualitativa? É preciso ou mesmo podem ser tratados por alguma abordagem quantitativa? Para responder este questionamento, suponha que o fenômeno a ser analisado esteja relacionado a uma temática da Geografia Cultural.

Por exemplo, deseja-se avaliar a importância de determinado tipo de dança tradicional em diversas comunidades de um determinado espaço geográfico. É possível, por exemplo, abordar inicialmente o fenômeno usando quantificação, através da técnica de regressão logística. A variável dependente Y poderia ser "o indivíduo aprecia ou não a dança tradicional?" (uma variável qualitativa dicotômica, pois pode assumir apenas um entre os dois 
valores: SIM ou NÃO). E como variáveis independentes poderiam ser utilizadas: X1 - idade do indivíduo (quantitativa); X2 - sexo (qualitativa); X3 - os pais do indivíduo dançam ou não dançam a dança tradicional? (qualitativa); X4 - número de festas/ano que o indivíduo vai e ocorre a dança tradicional (quantitativo) ; X5 - número de festas/ano que o indivíduo vai cujas músicas e danças são da mídia televisiva (quantitativa) e X6 - espaço geográfico (bairro, município, etc) (qualitativo).

Assim, pelo modelo de regressão logística, conhecendo-se o valor das variáveis preditoras X1, X2, X3, X4, X5 e X6 para um determinado indivíduo, é possível prever o valor da variável resposta Y (se o indivíduo gosta ou não da dança). É certo que a pesquisa deve ser conduzida de forma qualitativa, dado a extrema subjetividade do assunto. Mas o tratamento inicial quantitativo (no caso, usando regressão logística) certamente auxilia a apontar para um determinado rumo investigativo.

Outro exemplo, também dentro da temática de Geografia Cultural, envolvendo contexto essencialmente qualitativo: um geógrafo deseja avaliar se a autodeclaração de cor/raça dos brasileiros está relacionada com sua região geográfica de residência. Ou seja, será que há algum tipo de associação entre a cor/raça autodeclarada pela pessoa com sua localidade geográfica de residência? Será que, por exemplo, residentes na Região Sul do Brasil tendem a se autodeclarar de cor/raça branca e residentes na Região Centro-Oeste tendem a se declarar de cor parda? As variáveis qualitativas são: cor/raça autodeclarada que pode assumir os valores branca, preta, amarela, parda ou indígena e região geográfica de residência que pode assumir os valores Norte, Nordeste, Centro-Oeste, Sul ou Sudeste.

É possível realizar uma pesquisa de natureza exclusivamente qualitativa mas, uma abordagem inicial por meio de um tratamento quantitativo dos dados pode vir a ser útil. Por exemplo, o geógrafo pode acessar os dados da região geográfica de residência e de cor/raça autodeclarados pelos brasileiros no Censo Demográfico de 2010, calcular a estatística quiquadrado $\left(\chi^{2}\right)$ e aplicar o teste estatístico não paramétrico $\chi^{2}$ onde a hipótese nula do teste é $\mathrm{H}_{0}=$ as variáveis cor/raça autodeclarada e região geográfica de residência não estão associadas entre si. A hipótese alternativa do teste é $\mathrm{H}_{1}=$ há associação entre as variáveis cor/raça autodeclarada e região geográfica de residência. A tabela de contingência contendo os dados de 2010 pode ser obtida junto ao sistema SIDRA do sítio do IBGE, e está apresentada na Figura 2. 


\begin{tabular}{|c|c|c|c|c|c|c|}
\hline \multicolumn{7}{|c|}{ Variável = População residente (Pessoas) } \\
\hline \multicolumn{7}{|c|}{ Sexo $=$ Total } \\
\hline \multicolumn{7}{|c|}{ Situação do domicílio = Total } \\
\hline \multirow{2}{*}{ Grande Região } & \multicolumn{6}{|c|}{ Cor ou raça } \\
\hline & Branca & Preta & Amarela & Parda & Indígena & Sem declaração \\
\hline Sudeste & 44.330 .981 & 6.356 .320 & 890.267 & 28.684 .715 & 97.960 & 4.167 \\
\hline Sul & 21.490 .997 & 1.109 .810 & 184.904 & 4.525 .979 & 74.945 & 256 \\
\hline Centro-Oeste & 5.881 .790 & 939.976 & 204.599 & 6.900 .822 & 130.494 & 413 \\
\hline
\end{tabular}

Nota: 1 - Os dados são dos Resultados Preliminares do Universo.

Fonte: IBGE - Censo Demográfico

Figura 2 - Distribuição de respondentes ao Censo Demográfico 2010 com relação às variáveis cor/raça autodeclarada e região geográfica de residência segundo o IBGE.

Fonte: sistema SIDRA - IBGE - http://www.sidra.ibge.gov.br.

Executando-se o teste no ambiente de software $\mathrm{R}$ obtém-se como resultado $\chi^{2}=$ 25.056.867 e p-valor do teste $2,2 \times 10^{-16}$ (ver Figura 3). O p-valor extremamente baixo sugere rejeitar a hipótese $\mathrm{H}_{0}$, aceitando-se $\mathrm{H}_{1}$, ou seja, as variáveis parecem apresentar associação entre si.

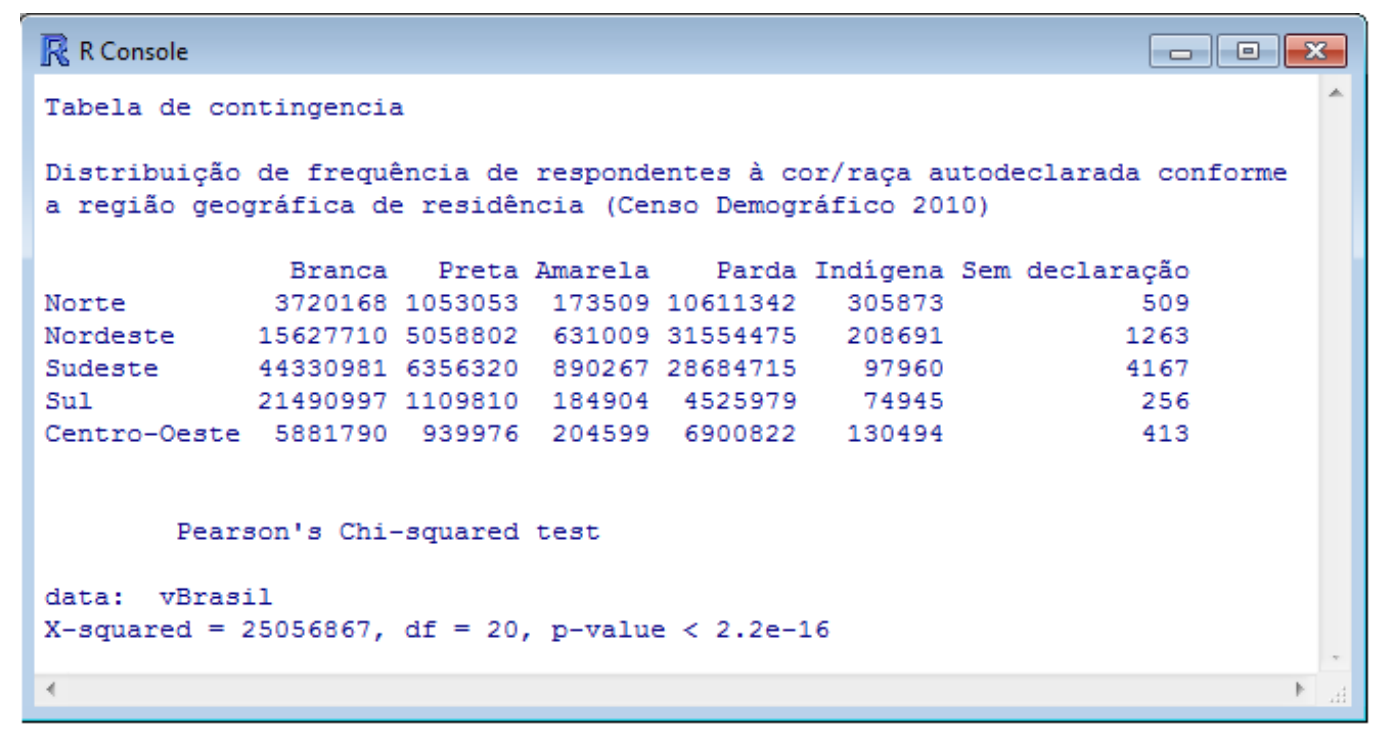

Figura 3 - resultado da aplicação do teste de hipótese no ambiente de software R.

Fonte: Elaborado pelo autor.

Como no exemplo anterior, ressalta-se que qualquer técnica quantitativa utilizada deve sempre ser considerada como uma forma de auxílio ao trabalho investigativo. Os resultados obtidos pela quantificação jamais devem ser considerados como "verdades absolutas". Ainda que o processo quantitativo aplicado apresente indícios de que as variáveis estão associadas, 
isto é, a autodeclaração de cor/raça parece estar associada à região geográfica de residência do respondente, o pesquisador (o geógrafo, no caso exemplificado) poderia, com base em seu conhecimento sobre o assunto, desconsiderar o resultado da quantificação e optar em considerar que não há associação entre as variáveis cor/raça autodeclarada e região geográfica de residência.

\section{Forma, estrutura e quantificação em Geografia}

Do exposto anteriormente, vale explicitar que a quantificação é tão somente uma ferramenta de apoio, útil para a pesquisa geográfica. É um instrumento auxiliar, que não substitui o conhecimento especializado do pesquisador do fenômeno sendo avaliado.

Com relação ao caráter auxiliar das técnicas de quantificação, Câmara (2001, p.34) ao analisar o papel das geotecnologias na prática geográfica da atualidade, cita duas afirmações do geógrafo Milton Santos que diz que "o espaço é um conjunto de objetos e um conjunto de ações" e, além disso, "geometrias não são Geografias". Desta forma, raciocina o autor que não cabe às geotecnologias responderem sozinhas às questões referentes ao entendimento da realidade, pois "o processo de entendimento da realidade geográfica vai muito além da produção de mapas coloridos".

Os "mapas coloridos" e as "geometrias" citados por Milton Santos são, em última instância, resultados de diversas técnicas quantitativas aplicadas para entendimento do fenômeno analisado, e Câmara (2001) aponta, com outras palavras, que somente os "mapas coloridos" e as "geometrias" (resultados de quantificação) são insuficientes para o entendimento da realidade das organizações espaciais, que para ser efetivamente compreendida, precisa de medidas que vão além da produção de números para explicá-la.

Para uma prática geográfica que permita ao geógrafo analisar as organizações espaciais em sua totalidade, Santos (1985) aponta que

forma, função, estrutura e processo são quatro termos disjuntivos associados, a empregar segundo um contexto do mundo de todo dia. Tomados individualmente, representam apenas realidades parciais, limitadas, do mundo. Considerados em conjunto, porém, e relacionados entre si, constroem uma base teórica e metodológica a partir da qual podemos discutir os fenômenos espaciais em totalidade. (SANTOS, 1985, p.52) 
E Câmara et. al. (2004) de forma magistral sintetizam o entendimento da realidade das organizações espaciais, que vai "muito além da produção de mapas coloridos", através da caracterização da forma, função, estrutura e processo dos fenômenos espaciais. Segundo os autores,

para usar a formulação de Milton Santos, o espaço é uma totalidade expressa pelas dualidades entre forma e função e entre estrutura e processo. Estas polaridades são evidenciadas quando utilizamos ferramentas analíticas. Com o uso de SIG e análise espacial, podemos caracterizar adequadamente a forma de organização do espaço, mas não a função de cada um de seus componentes. Podemos ainda estabelecer qual a estrutura do espaço, ao modelar o fenômeno em estudo, mas dificilmente podemos estabelecer a natureza dinâmica dos processos, sejam naturais ou sociais. A relação entre estrutura e processo apenas poderá se resolver quando da combinação entre técnicas analíticas (que descrevem a estrutura e organização do espaço) e o especialista (que compreende a dinâmica do processo). (CÂMARA et. al., 2004, p.24)

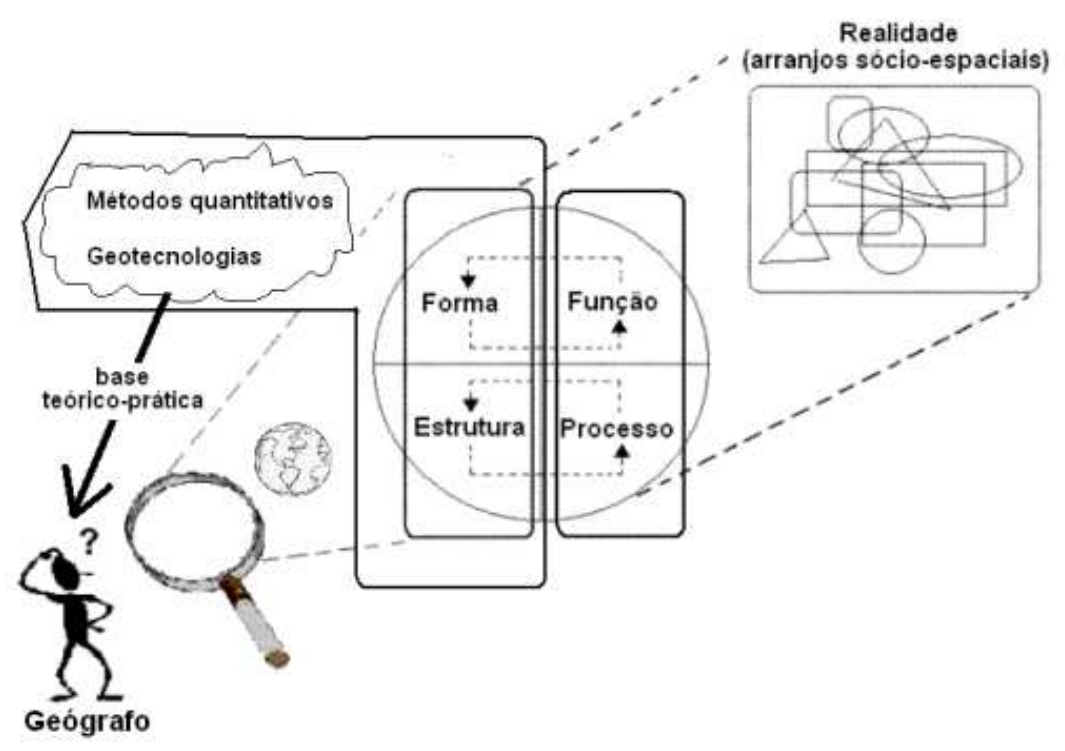

Figura 4 - A quantificação auxilia na compreensão da forma e da estrutura da realidade (organizações espaciais).

Fonte: Elaborado pelo autor. 
Em outras palavras, a realidade das organizações espaciais é apreendida através da integração entre a quantificação que explicita a forma e estrutura do espaço geográfico e o trabalho crítico do geógrafo, que irá explicar a função e os processos da realidade em questão. Forma, função, estrutura e processo caracterizariam então a análise espacial de dados geográficos A Figura 4 apresenta um esboço conceitual onde se ressalta a aplicação da quantificação por parte do geógrafo para compreender a forma e a estrutura.

$\mathrm{Na}$ Figura 4, a aplicação da quantificação (via geotecnologias e/ou técnicas matemáticas e estatísticas) ajuda a evidenciar as formas e os padrões estruturais do espaço geográfico em estudo. Para exemplificar, suponha que um geógrafo, estudando a localização espacial de supermercados verificou que no tempo $\boldsymbol{t}$ a forma deste fenômeno poderia ser representada pela relação quantitativa de, em média, quatro supermercados existentes em cada quilômetro quadrado do espaço geográfico considerado (por exemplo, uma cidade). Esta forma, analisada cuidadosamente pelo geógrafo, levando-se em conta seu conhecimento do fenômeno o faz concluir que tem a função de suprir uma moderada demanda dos consumidores.

Usando-se algum software de SIG, a distribuição espacial pontual dos supermercados no tempo $\boldsymbol{t}$ sobre a região geográfica analisada (a cidade) aponta para uma estrutura típica de concentração, isto é, a maioria dos supermercados encontra-se localizada de forma agrupada, próximos entre si, em determinadas subáreas da cidade. Suponha que tais subáreas correspondem a bairros de pessoas residentes com maior poder aquisitivo. Acompanhando a dinâmica do processo de expansão da oferta de supermercados na cidade, no tempo $\boldsymbol{t + 5}$ o geógrafo reanalisa a localização espacial dos supermercados e constata que houve um aumento do número destes estabelecimentos na cidade, em média nove supermercados por quilômetro quadrado e, novamente com a ajuda de SIG, constata que os supermercados estão mais dispersos entre si, mas com presença significativa em bairros residenciais de moradores com menor poder aquisitivo. O conhecimento sobre a política de estímulo ao consumo pelo crédito promovida pelo governo neste período (entre $\boldsymbol{t}$ e $\boldsymbol{t}+5$ ), faz o geógrafo concluir pela eficácia do objetivo governamental de ampliação do consumo. Em suma, a forma e estrutura do espaço geográfico são analisadas no escopo temporal dos diversos processos que continuamente ocorrem.

Inúmeros trabalhos podem ser citados onde se aplicam técnicas de quantificação que auxiliam na compreensão da forma e estrutura de diversas instâncias de diversos espaços 
geográficos. No que se segue, são citados apenas a título de ilustração, alguns trabalhos desta natureza.

Campos et. al. (2002) estimaram áreas de risco para a ocorrência de carga parasitária produzida pelo Ascaris lumbricoides, por meio da utilização de técnicas de geoprocessamento e análise geoestatística. Para estudar a diversidade e distribuição espacial e temporal de anfíbios, Vasconcelos e Rossa-Feres (2005) tomaram amostras de corpos d'água e, entre outras análises, para verificar se a distância geográfica entre os corpos d'água influenciou a composição das espécies de anfíbio estudadas, aplicaram o teste de correlação de Mantel entre as matrizes de distância e de similaridade (coeficiente de Jaccard) na composição de espécies.

Grizzi-Campos et. al. (2009) relatam que "sistemas de informação geográfica constituem importantes instrumentos dentro da Saúde Pública como técnicas de análise da distribuição de agravos à população" e utilizaram SIG para avaliar a distribuição da população de sessenta anos e mais no município de Botucatu, São Paulo. Souza et. al. (2009) empregaram a técnica estatística da análise fatorial para caracterizar $\mathrm{o}$ grau de desenvolvimento tecnológico das regiões Norte e Noroeste do estado do Rio de Janeiro. Farias et. al. (2003) utilizaram geoestatística para avaliar a variabilidade espacial de produtividade e tamanho de frutos em pomares de laranja irrigados e não irrigados, localizados no município de Luiz Antônio (SP) determinando, através dos mapas de krigagem, áreas de alta e baixa produtividade dos talhões dos pomares.

Bando (2008) analisou os padrões espaciais das ocorrências de suicídio no município de São Paulo, no período de 1996 a 2005, com base em algumas variáveis socioeconômicoculturais (estado civil, renda, instrução, religião, migração) que segundo o autor são fatores de risco ao suicídio levantados pela OMS, OPAS e apontadas na teoria sobre o suicídio de Durkheim. Para a identificação do padrão espacial das taxas de suicídio foi utilizado o teste de varredura espacial e para a verificação da associação com as variáveis socioeconômicas e culturais foi utilizada análise de regressão logística.

Finalmente, para terminar a citação de exemplos de trabalhos que analisam quantitativamente a forma e a estrutura de instâncias de espaços geográficos, Ribeiro et al. (2012) estudaram o processo recente de metropolização brasileira tendo como unidade básica espacial o município. Para avaliarem o grau de integração dos municípios, foram usadas as técnicas estatísticas de análise em componentes principais (ACP) e análise de cluster por classificação hierárquica ascendente (CHA). 
Com base nos exemplos acima citados, pode-se perceber a utilidade que a quantificação em Geografia pode ter para a real compreensão das organizações espaciais. Vale ressaltar também que no atual patamar tecnológico, as geotecnologias disponíveis, tais como imagens de satélite, GPS, softwares de processamento de imagem e sistemas de informação geográfica (SIG), são ferramentas que cada vez mais são básicas a serem usadas pelo geógrafo. CP.GEOGRAFIA (2009) ressalta este aspecto:

O estudo e o mapeamento da distribuição de recursos naturais e do arranjo social sempre valeram para a Geografia um papel essencial nas sociedades organizadas. Até recentemente, essas atividades eram realizadas apenas em documentos e mapas em papel, o que limitava o cruzamento de diversos mapas e dados. Com o desenvolvimento tecnológico, tornou-se possível armazenar e representar tais informações no computador, o que abriu espaço para o geoprocessamento (C.P. GEOGRAFIA, 2009, p.51).

Segundo Vitiello (2008, p.14), o geoprocessamento pode ser, de fato, empregado em diversas atividades típicas de serem desenvolvidas por geógrafos tais como elaboração de relatórios de impacto ambiental, planos de recuperação de áreas degradas e de manejo de bacias hidrográficas, planos diretores urbanos, rurais e regionais, estruturação de redes de transportes, pesquisa de mercado, mapeamentos temáticos diversos, cartas de declividade e hipsometria e projetos e serviços de turismo ecológico dentre outros.

Em outras palavras, as geotecnologias são, portanto, ferramentas de desvelamento da forma e estrutura das organizações espaciais. E a quantificação está presente de forma marcante nestas ferramentas.

\section{O entendimento da forma e estrutura via quantificação por parte do geógrafo}

Rosa (2009, p.41) pondera que "o conhecimento e a análise do espaço geográfico têm se apresentado como grandes colaboradores na solução de problemas da sociedade moderna". Neste contexto, a responsabilidade do geógrafo torna-se maior, pois é ele um analista das organizações espaciais, que realiza análise espacial de dados geográficos.

Em última instância, para exercer atividades que colaborem na "solução de problemas da sociedade moderna", o geógrafo deve ter um razoável domínio de técnicas de quantificação que auxiliarão no desvelamento da forma e estrutura da realidade das organizações espaciais. As diversas técnicas de quantificação são essencialmente de natureza 
matemática, heurística e principalmente estatística, no âmbito descritivo e inferencial, como análise multivariada, análise de variância, correlação espacial, regressão linear e não linear, regressão logística, uso de lógica fuzzy, análise de agrupamentos, análise fatorial, autômatos celulares, cadeias de Markov, mapas de krigagem, e Redes Bayesianas dentre outros temas são técnicas que podem ser aplicadas para auxiliar o entendimento da forma e estrutura. Mas o aprendizado destas diversas técnicas não é, de fato, trivial. Requer tempo e dedicação continuada de estudos para um efetivo entendimento do universo conceitual e consequente aplicação em situações concretas.

E assim, a questão que se coloca é: a formação acadêmica que o geógrafo recebe em seu curso de graduação o capacita a fazer uso de técnicas de quantificação que o auxiliem na análise espacial de dados geográficos? Ou seja, será que durante sua formação acadêmica o geógrafo adquire conhecimentos de ao menos algumas das diversas técnicas matemáticas e estatísticas usadas para o desvelamento da forma e estrutura?

Essencialmente, o propósito deste trabalho é investigar o questionamento acima colocado. Procede-se a seguir a apresentação da estrutura do corpo deste trabalho e, em seguida, o trabalho propriamente dito.

\section{A estrutura deste trabalho}

O tema central deste trabalho, conforme citado acima, está ligado à questão da formação escolar voltada à capacitação do geógrafo para aplicação de técnicas de quantificação que auxiliem a explicitar a forma e estrutura das organizações espaciais. No restante desta Introdução apresenta-se a justificativa para o desenvolvimento do trabalho, as perguntas de partida e as hipóteses norteadoras deste trabalho e finalmente apresentam-se os objetivos do mesmo.

No Capítulo 1 apresenta-se a fundamentação teórica sobre análise espacial de dados geográficos e sobre requisitos para a capacitação do educando - no caso, o geógrafo - para entendimento e uso de técnicas usadas na análise espacial. O Capítulo 2 é dedicado aos materiais e métodos utilizados. No Capítulo 3 são apresentados os resultados e discussões dos resultados obtidos e, finalmente, no Capítulo 4, são apresentadas considerações finais resultantes deste trabalho. 


\section{Justificativa}

Conforme esquematizado na Figura 4, o entendimento das organizações espaciais por parte do geógrafo passa pelo entendimento da forma, função, estrutura e processo da totalidade (realidade sócio-espacial). E o entendimento da forma e estrutura dentro de um contexto mais amplo de análise espacial de dados geográficos impõe ao geógrafo, uma razoável - para não dizer sólida - formação que permita o entendimento de técnicas diversas de quantificação, para proporcionar um trabalho geográfico investigativo com bases mais robustas.

E pensar em quantificação aplicada à Geografia nos leva a refletir sobre uma escolarização que proporcione capacitar o educando para manipular números. No contexto de formação geográfica, Rosa (2009) aponta que

ao geógrafo educador cabe incluir propostas contextualizadas e de relevância social para que o aluno ultrapasse o campo da alfabetização cartográfica e torne-se realmente um mapeador consciente, leitor e usuário de mapas na busca da construção de novos significados em seu cotidiano. (ROSA, 2009, p. 42)

Formar um geógrafo "mapeador consciente" significa formar um profissional que sabe compreender a realidade geográfica indo muito além da mera "produção de mapas coloridos" citada por Milton Santos. E os mapas coloridos conforme anteriormente já comentado são, em última instância, resultados de diversas técnicas quantitativas que explicitam a forma e estrutura. Mas para ir além dos mapas coloridos, quando se desvendam a função e os processos da realidade, é preciso primeiro saber produzi-los, ou seja, primeiro é preciso saber quantificar.

A importância da quantificação pode ser explicitada quando se considera sua dimensão na área de estatística. Lopes e Meirelles (2005, p.1) citam a seguinte frase pronunciada pelo escritor $\mathrm{H}$. G. Wells: "O raciocínio estatístico será um dia tão necessário à cidadania eficiente como a capacidade de ler e escrever". E Lopes (2008), ao comentar sobre a inserção da estatística e da probabilidade no currículo da Matemática desde as séries iniciais da escola básica afirma que

o estudo desses temas torna-se indispensável ao cidadão nos dias de hoje e em tempos futuros, delegando ao ensino da matemática o compromisso de 
não só ensinar o domínio dos números, mas também a organização de dados, leitura de gráficos e análises estatísticas. (LOPES, 2008, p.58)

Ainda segundo a autora,

atualmente, as propostas curriculares de matemática, em todo o mundo, dedicam atenção especial a esses temas, enfatizando que o estudo dos mesmos é imprescindível para que as pessoas possam analisar índices de custo de vida, realizar sondagens, escolher amostras e tomar decisões em várias situações do cotidiano. (LOPES, 2008, p. 59)

Números, gráficos, tabelas, índices de custo de vida e outros são mapas que procuram representar algum aspecto da realidade, assim como os tradicionais mapas cartográficos utilizados por geógrafos. Depreende-se que estes artefatos (números, gráficos, tabelas, índices) ajudam a compreender a realidade, que certamente é de interesse de muitas ciências, incluindo-se a Geografia. Muitas técnicas de quantificação têm como base elementos do corpo de conhecimento da Estatística. E daí a importância da Estatística para a quantificação em Geografia.

Pereda (2006) analisa o ensino de estatística no contexto dos Parâmetros Curriculares Nacionais (PCN) do Ministério da Educação. Segundo a autora, os PCN propõem incluir já no Ensino Fundamental, elementos de estatística, probabilidade e análise combinatória no currículo de Matemática considerados dentro do bloco "tratamento da informação".

No Ensino Médio, os PCN apontam, dentre as habilidades a serem desenvolvidas, a capacidade de solucionar problemas através da sua identificação (compreender enunciados, formular questões) e desenvolver o raciocínio "tirando conclusões a partir de gráficos, figuras e esquemas". Também no Ensino Médio, deve-se trabalhar habilidades do educando para "compreender o caráter aleatório e não determinístico dos fenômenos naturais e sociais e utilizar instrumentos adequados para medidas, determinação de amostras e cálculo de probabilidade" (PEREDA, 2006, p.17).

Mas o ensino de métodos quantitativos (técnicas de quantificação) nos níveis fundamentais e médio será ainda bastante incompleto. Segundo Costa Neto (1977), um estudo estatístico envolve, direta ou indiretamente, tópicos de Estatística Descritiva, Cálculo de Probabilidades, Amostragem e Estatística Indutiva (Estatística Inferencial). Assim, a estatística que se ensinar nos níveis fundamental e médio certamente não será suficiente para 
abarcar todo o conjunto de métodos quantitativos, seja por insuficiência de tempo dispensado ao assunto, seja pelo relativo baixo grau de maturidade e abstração do educando em apreender conceitos que requerem, em diversos momentos, um grau de abstração mais refinado, só obtido ao longo de maior vivência, ainda não experimentada pelos educandos de baixa faixa etária, como é o caso de estudantes do Ensino Médio. O educando egresso do Ensino Médio possivelmente será capaz de apreender conceitos básicos da estatística descritiva e noções superficiais sobre distribuições de probabilidade.

Já no nível superior, com exceção dos cursos de graduação em Estatística, pode-se dizer que, em geral, os demais cursos de graduação exigem uma carga mínima de disciplinas envolvendo estatística. Desta forma, os alunos - incluindo-se aí os alunos do curso de Geografia - necessitam complementar de alguma maneira sua formação acadêmica com relação aos conceitos de estatística e probabilidade. Em geral, os cursos alocam uma única disciplina ligada à Estatística.

Certamente torna-se inviável a inserção de um leque extenso de várias disciplinas com foco em Estatística em cursos de graduação em Geografia. Se assim fosse exigido para melhoria da formação do geógrafo, também leques extensos de disciplinas da Economia e Sociologia entre outras, deveriam ser embutidas na matriz curricular dos cursos de Geografia que se tornaria extremamente extensa.

Mas o fato é que quando um geógrafo se propuser a utilizar técnicas de quantificação dentro do contexto de análise espacial de dados geográficos, verificar-se-á que o entendimento dos fundamentos estatísticos básicos é essencial. No mínimo o domínio efetivo - e não o conhecimento mecânico (“decoreba”) - dos conceitos relativos a estatísticas descritivas básicas, distribuições clássicas de probabilidade discreta e contínua, e testes estatísticos de hipótese para raciocínio inferencial deverão estar, de fato, internalizados pelo geógrafo. Mas é quase certo que, com pouco (ou nenhum) contato com a estatística em seu curso de graduação, o geógrafo formado - com raríssimas exceções - não terá base para realização eficaz da quantificação na análise espacial de dados geográficos.

Além de pouco (ou nenhum) conteúdo de estatística em nível de graduação, o geógrafo deparar-se-á com livros-texto básicos de estatística e outros recursos audiovisuais, como por exemplo, tutorias na Internet, cuja forma de ensino se dá predominantemente pela apresentação de fórmulas, macetes de aplicação das mesmas, e exercícios de fixação das mesmas que levam o aluno a apenas aplicar o cálculo correto para a obtenção do número. Por exemplo, o material aponta que a média aritmética é o resultado do somatório de $N$ elementos 
dividido pelo valor $N$. Em seguida, apresentam-se diversos exercícios em que o aluno treina o cálculo da média. Mas semanticamente, o que é, afinal, a média aritmética? Os livros/recursos audiovisuais, raramente se preocupam em explicar que, a média é uma espécie de númerosíntese, um número representante do grupo de dados.

Diversos livros são escritos onde em apenas uma ou duas páginas são explicados temas diversos como níveis de mensuração que as variáveis podem ter (nominal, ordinal, intervalar e razão), medidas de tendência central e de variabilidade, distribuições de probabilidade discretas e contínuas, regressão e correlação linear simples. Em geral, nestas duas páginas apresenta-se a citação do tema (variância, por exemplo) seguida da apresentação da fórmula e exemplos de cálculo. O objetivo aqui não é criticar negativamente o conteúdo destes livros, mas enfatizar que o modo com que se tenta abranger e apresentar os conteúdos de estatística não permite ao leitor a apreensão da semântica dos mesmos.

Sejam livros atuais ou mais antigos, com títulos similares a "estatística para economistas", "estatística para administradores", "estatística para ciências humanas e do comportamento", dentre outros apresentam, via de regra, a mesma estrutura: apresentar fórmulas (e gráficos) por meio de exemplos curtos e diretos de estatística descritiva e estatística inferencial direcionando o leitor a mecanicamante repetir a aplicação das fórmulas apresentadas nos exercícios propostos. E isso limita o leitor de captar a semântica, o verdadeiro sentido da técnica de mensuração utilizada. O leitor não entende, por exemplo, qual o real significado da mediana, moda, variância, quartil, distribuição de probabilidade, etc. Aprendeu, na maioria dos casos, apenas a decorar fórmulas.

Então, com pouca (ou nenhuma) disciplina ligada à quantificação cursada pelo aluno, em que se usou material audiovisual onde a ênfase foi muito mais para decorar fórmulas do que efetivamente entender seu significado, o graduando em Geografia tem diante de si um ambiente que, se não o desestimula, não produz estímulos para que se interesse por quantificação.

O livro de Druck et. al. (2004) “Análise Espacial de Dados Geográficos” foca nos temas referentes à análise de padrões pontuais, análise de superfícies e análise de áreas. E no prefácio do livro os autores comentam sobre técnicas estatísticas e estatística espacial:

a abordagem tradicional para o tratamento de dados sociais, econômicos e ambientais utiliza técnicas estatísticas bem estabelecidas como testes de hipóteses, análise de variância e modelos lineares. Estas, embora relevantes e úteis, não permitem considerar o espaço geográfico. Uma das motivações do 
livro que ora entregamos ao leitor é que 'onde' ocorrem os fenômenos é muito importante, e em alguns casos essencial à compreensão dos problemas. Assim, este livro apresenta um conjunto de técnicas que fazem uso explícito da localização dos fenômenos (DRUCK et. al., 2004, Prefácio).

Pela colocação dos autores, somente as técnicas estatísticas tradicionais não são suficientes para processar a variável localização geográfica que, por sua vez, requer seu tratamento por meio de técnicas (estatísticas) que fazem uso explícito da localização dos fenômenos. Mas se a formação acadêmica em geral oferece ao geógrafo pouca estatística tradicional, deixando-o praticamente sem base conceitual sobre o assunto, como compreender então as técnicas que têm como base a variável localização geográfica?

No livro "Geomática: Modelos e aplicações ambientais", o apresentador do livro comenta que

a análise e modelagem computacional de fenômenos geográficos são técnicas modernas com amplo campo de aplicação no monitoramento ambiental, especialmente úteis a gestores e tomadores de decisão no estabelecimento de políticas públicas relacionadas à questão socioambiental e ao uso e ocupação do solo. (MEIRELLES, 2007, Apresentação)

Apesar do enfoque ambiental, o apresentador comenta que o livro "aborda a questão da Geoinformação de forma ampla, compreendendo estudos nos campos de Geologia, Ecologia, Agronomia, Planejamento Urbano e Regional, Hidrologia, Engenharia Florestal e Socioeconomia" (MEIRELLES, 2007, Apresentação).

O livro aborda temas de modelagem computacional como técnicas de análise espacial, banco de dados geográficos, métodos geoestatísticos e modelagem dinâmica espacial. Já os editores do livro o apresentam destacando que

o conjunto dos capítulos percorre todo o leque possível de alternativas correntes em modelagem numérico-computacional aplicáveis em Geomática. Os exemplos mostrados no livro servem como rota para indicar novos rumos e tendências do que será rotineiro em Ciências da Informação Espacial em um futuro breve. (MEIRELLES, 2007, p. 19).

Em vista do que foi exposto, ressalta-se que há que se reforçar, durante o processo de formação acadêmica do geógrafo, ao menos os conceitos básicos de estatística tradicional e 
também espacial. Ações tomadas nesta direção certamente conduzem à formação de geógrafos com uma preparação - ao menos básica - para o entendimento conceitual da quantificação aplicada à Geografia, embutida nas análises espaciais de dados geográficos que irão ajudar a desvendar a forma e a estrutura das organizações espaciais.

\section{Questões e hipóteses de pesquisa}

As ferramentas de geotecnologia aí estão acessíveis a todos os usuários, permitindo, como nunca antes, realizar análises espaciais de dados geográficos em diversas instâncias das organizações espaciais, auxiliando na compreensão da forma e estrutura das mesmas. Mas as técnicas embutidas nas análises são de natureza matemática, heurística e principalmente estatística. Compreender semanticamente as técnicas de quantificação é importante para saber executar e interpretar os resultados oriundos da análise espacial implementada.

E o que se questiona, portanto, está ligado à formação do geógrafo com relação à sua preparação para uso e entendimento de quantificação em Geografia. Há oferta de disciplinas ou cursos de extensão ou outras formas de capacitação que trabalhem os conceitos estatísticos necessários ao uso e entendimento de técnicas quantitativas aplicadas à análise espacial? Assim, a pergunta de partida que se faz no escopo deste trabalho é a seguinte:

\section{- A formação acadêmica que o geógrafo recebe em seu curso de graduação o capacita a realizar quantificação na análise espacial de dados geográficos?}

Este questionamento surgiu por parte da minha experiência como professor há aproximadamente dez anos no Curso de Ciência da Computação de uma faculdade particular. Percebi repetidas vezes que conceitos matemáticos e estatísticos básicos, a maioria em nível de Ensino Fundamental e Médio não eram de domínio da maioria dos alunos. Daí a dificuldade que eu tinha em tratar os conteúdos das disciplinas em si (Teoria da Computação, Inteligência Artificial, Pesquisa Operacional, Estruturas de Dados), pois precisava dedicar tempo para cobrir deficiências de temas que o aluno egresso do Ensino Médio a priori não deveria apresentar e, não raro, tratar com extrema superficialidade o tema da disciplina devido estas deficiências dos alunos. 
Além disso, tive a oportunidade de trabalhar com Sistemas de Informações Geográficas (SIG) e interagir com alunos graduandos do curso de Geografia. De modo similar aos meus alunos em Ciência da Computação, percebia a dificuldade da maioria dos graduandos em Geografia não no uso da ferramenta em si (Arc-Info e Arc-View), por exemplo, na sequência de cliques do mouse para produzir sobreposição de mapas, mas sim na interpretação dos resultados obtidos que por vezes requeriam entendimento de conceitos matemáticos básicos, como por exemplo, uma simples proporção.

Uma forma de tentar responder, ou ao menos tentar se aproximar de alguma resposta à pergunta de partida se dá através da verificação dos conteúdos ministrados nas disciplinas ligadas à matemática e à estatística cursadas pelo geógrafo estudante, e os conteúdos necessários ao entendimento das técnicas de análise espacial de dados geográficos. Assim, a pergunta poderia ser reelaborada da seguinte forma:

\title{
- Os conteúdos ministrados nas disciplinas ligadas à matemática e à estatística cursadas durante a formação acadêmica do geógrafo fornecem subsídios para a compreensão das técnicas quantitativas de análise espacial de dados geográficos?
}

Particularmente, já em 1988, Rosa (1988) respondia esta pergunta ao afirmar que

\begin{abstract}
A ausência de uma formação básica em matemática e ciências da natureza compromete o perfil do bacharel de Geografia, uma vez que numerosos recursos técnicos colocados atualmente à disposição de pesquisas não podem ser operados sem aquela formação. (...) É pequeno o número de cursos de aperfeiçoamento, extensão, atualização oferecidos aos profissionais geógrafos. (ROSA, 1988, p. 81)
\end{abstract}

Um fato é que, independentemente da área de conhecimento, quanto mais recursos educacionais se encontrarem à disposição para o aprendizado, mais chances o educando tem de efetivamente apreender e compreender o conteúdo em questão. $\mathrm{O}$ aparato tecnológico à disposição da sociedade permite que na área educacional recursos multimídia possam ser utilizados. Pela Internet é possível a realização de tutoriais para ensino de conteúdos diversos, por meio de softwares que manipulam som e imagem. $\mathrm{O}$ assunto tratado pode ser apresentado de forma que vá além do caráter estático de textos e imagens dos meios impressos (livros, 
jornais, revistas), sendo apresentado de forma dinâmica na tela de algum computador (PC, tablet, smartphone, etc).

Então, independentemente da eficácia da formação do geógrafo em nível de graduação para realização de análise espacial de dados geográficos é possível colocar outra questão de pesquisa:

- O uso de software tutor para ensino de conceitos básicos de técnicas quantitativas de análise espacial de dados geográficos pode auxiliar na efetiva aprendizagem de tais conceitos?

Com base nas perguntas de partida, colocamos duas hipóteses em formato SE... ENTÃO, apresentadas abaixo.

\section{Hipótese 1:}

SE

a escolarização formal do geógrafo for insuficiente em conteúdos de técnicas quantitativas

ENTÃO a capacitação do geógrafo para realização de análises espaciais de dados geográficos será nula ou insuficiente

\section{Hipótese 2:}

SE

houver disponível um software tutor para ensino de técnicas de análises espaciais de dados geográficos

ENTÃO a capacitação do educando(geógrafo) para realização de análises espaciais de dados geográficos pode ser melhorada caso o mesmo faça uso do software como recurso auxiliar ao aprendizado

São estas as duas hipóteses que norteiam todo o presente trabalho. 


\section{Objetivo do trabalho}

\section{Objetivo geral}

Realizar uma investigação com relação à aprendizagem da quantificação no processo de formação do geógrafo em nível de graduação (habilitação em Licenciatura e Bacharelado) para atuação em atividades ligadas à análise espacial de dados geográficos.

\section{Objetivos específicos}

(1) Verificar os conteúdos das disciplinas ligadas à área de matemática e estatística da matriz curricular de cursos de graduação em Geografia relacionando-os com conceitos básicos das técnicas de análise espacial de dados geográficos.

(2) Investigar a familiaridade que o geógrafo em formação apresenta com relação aos conceitos básicos de matemática e estatística que servem de suporte ao entendimento de técnicas de análise espacial de dados geográficos.

(3) Propor e desenvolver um software tutor para ensino de conceitos básicos de algumas técnicas de análise espacial de dados geográficos como ferramenta complementar de ensino e verificar sua utilidade para auxiliar o aprendizado do assunto por parte do graduando em Geografia. 


\section{CAPÍTULO 1}

\section{FUNDAMENTAÇÃO TEÓRICA}

\subsection{INTRODUÇÃO}

$\mathrm{Na}$ Introdução foi realçada a importância da quantificação em Geografia. A quantificação é importante no processo de entendimento da forma, função, estrutura e processo das organizações espaciais, pois auxilia na caracterização da forma e estrutura no contexto da análise espacial de dados geográficos realizada pelo geógrafo, considerado como um analista das organizações espaciais. Mas afinal, o que seria a análise espacial de dados geográficos? Esta questão é tratada no item 1.2. Após a apresentação do que se trata, no item 1.3 são abordados alguns conceitos matemáticos e estatísticos que servem de base conceitual para as diversas técnicas quantitativas usadas em análise espacial.

É fato que a matemática ensinada nos ensinos Fundamental e Médio é o verdadeiro pilar conceitual que possibilita o aprendizado dos conceitos das técnicas quantitativas de análise espacial. Um aluno egresso do Ensino Médio com fraco embasamento matemático certamente terá dificuldades para lidar com conceitos estatísticos/matemáticos de quaisquer disciplinas ligadas a estas temáticas. No item 1.4 são analisados os Parâmetros Curriculares Nacionais (PCN), elaborados em 1997 pelo Ministério da Educação com o propósito de atualizar a educação brasileira diante de um cenário mundial cada vez mais globalizado. Procurou-se aqui avaliar a proposta de conteúdos ligados à Matemática contidos nos PCN que devem ser de domínio do aluno ao término do ciclo básico.

O item 1.5 tece considerações sobre a educação estatística e suas dimensões conceituais, pois a educação estatística, em última instância, é o processo condutor da apreensão de conceitos que irão propiciar ao geógrafo a realização de quantificação aplicada na análise espacial de dados geográficos. E finalmente, o item 1.6 aborda alguns aspectos teóricos sobre aprendizagem significativa e o uso de imagem como recurso que pode auxiliar na aprendizagem efetiva de conceitos. 


\subsection{A ANÁLISE ESPACIAL DE DADOS GEOGRÁFICOS}

A realidade é um contínuo processo de complexos fenômenos naturais e sociais que ocorrem concomitantemente apresentando graus variados de interconexões. E tais fenômenos ocorrem invariavelmente num determinado espaço. Vejamos alguns exemplos de fenômenos:

$\checkmark$ Distribuição de postos de vacinação pelos bairros de determinadas cidades para atender uma campanha de vacinação em massa.

Distribuição de estações pluviométricas numa determinada bacia hidrográfica para auxiliar o estudo do regime de chuvas na região da bacia.

Distribuição de antenas de recepção/emissão de sinais de aparelhos celulares numa determinada área urbana.

Verificação de pontos de ocorrência de acidentes ao longo de uma rodovia.

Verificação de pontos de ocorrência de determinada espécie vegetal na superfície de uma montanha.

$\checkmark$ População de faixa etária de 15 a 19 anos residente nos bairros de determinada cidade.

Porcentagem de eleitores dos setores censitários de um país que votaram no candidato X.

$\checkmark$ Produtividade em $\mathrm{kg} / \mathrm{ha}$ de determinada cultura em talhões pré-demarcados numa determinada fazenda agrícola.

$\checkmark$ A proporção de moradores praticantes de determinada religião por bairros de determinada cidade.

Expressões culturais diversas (dança, culinária, vestimenta, rito religioso, lazer, etc) de populações em determinadas localidades e/ou regiões de um país.

$\checkmark$ Amostras pontuais de solo de determinada área para realizar a estimativa do teor de alumínio por toda a superfície da área considerada.

Amostras pontuais de determinada praga em árvores de um pomar para realizar a estimativa da densidade populacional da praga em todo o pomar.

As rotas de furacões que periodicamente flagelam determinadas regiões de determinados 
países.

A logística de armazenamento e posterior escoamento para consumo interno/externo da produção agrícola de determinado país para um determinado período.

$\checkmark$ A dinâmica temporal de espalhamento da ocorrência de casos de determinada doença nos moradores dos bairros de determinada cidade.

$\checkmark$ A dinâmica temporal de aquisição de determinada tecnologia (computador, TV a cabo, por exemplo) pelos moradores dos bairros de determinada cidade.

Observando os exemplos acima, pode-se notar que o componente espacial, isto é, onde o fenômeno ocorre ou onde o fenômeno ocorre com maior/menor intensidade é um dos focos das atenções de análise. O estudo desses fenômenos focando a localização espacial denominase análise espacial de dados geográficos.

Analisando acerca da natureza do conhecimento geográfico dos fenômenos, Golledge (2002) faz a seguinte colocação:

So what comprises Geographic Thinking and Reasoning? By examining published geography literature over the past 50 years I have compiled a partial list of thinking and reasoning processes that should help to answer this question. The list includes:

- Comprehending scale transformations

- Being able to transform perceptions, representations and images from one dimension to another and reverse

- Comprehending superordinate and subordinate relations and frames of reference

- Comprehending problems of spatial alignment

- Comprehending distance effects

- Comprehending spatial association

- Comprehending orientation and direction

- Comprehending spatial classification 
- Comprehending clustering and dispersion

- Comprehending spatial change and spatial spread

- Comprehending non-spatial and spatial hierarchy

- Comprehending densities and density decay (population density gradientes in different cultural settings)

- Comprehending spatial shapes and patterns (geometry and topology)

- Comprehending locations and places

- Comprehending overlay and dissolve (spatial aggregation and disaggregation)

- Comprehending integration of geographic features represented as points, networks and regions

- Comprehending spatial closure (interpolation)

- Comprehending proximity and adjacency (nearest neighbor) and their effects (distance decay)

- Recognizing spatial forms (such as city spatial structures; relating traverses or cross-sections to three dimensional block diagrams or images) (GOLLEDGE, 2002, p.3-6)

Analisando-se os problemas abordados pelo pensamento geográfico levantado por Golledge (2002) observamos que os fenômenos exemplificados anteriormente teriam correspondência com ao menos algum processo de pensamento geográfico citado pelo autor.

Por exemplo, o fenômeno de expressões culturais diversas (dança, culinária, vestimenta, etc) pode ser enquadrado na categoria de pensamento geográfico "comprehending clustering and dispersion" e/ou "comprehending spatial change and spatial spread" e/ou "comprehending spatial association" se estudamos as expressões culturais no intuito de averiguar o espaço de manifestação do comportamento cultural em grupos (econômicos, étnicos, etc) e/ou estudamos como o comportamento cultural se espalha (ou se contrai) espacialmente.

Outro exemplo: a distribuição de postos de vacinação pelos bairros de determinadas 
cidades para a campanha de vacinação poderia ser enquadrada na categoria "comprehending clustering and dispersion".

Assim, a análise espacial de dados geográficos pode ser entendida como o "comprehending" (e "recognizing") exaustivamente citado por Golledge (2002). E a compreensão da realidade sócio-espacial, passa pelo desvelamento da forma e estrutura com o uso de quantificação, e se completa com o desvelamento da função das formas e dos processos que produzem as estruturas sócio-espaciais.

Para enfatizar o foco da localização geográfica na análise espacial, Assunção (2001) ressalta que

os dados utilizados em estatística espacial possuem um índice que faz referência a uma área geográfica, geralmente representada em um mapa bidimensional. (...) A característica fundamental de uma técnica de análise espacial é que a referência geográfica é utilizada explicitamente no modelo. Assim, uma análise de regressão linear simples usando como variável dependente as taxas de homicídio em Minas Gerais em 2000 e como variável independente o PIB per capita municipal em 1998 não é uma análise espacial mesmo que as unidades de observação (os municípios mineiros) tenham evidentemente uma localização espacial. A questão é que a localização espacial não foi utilizada em nenhum momento no processo de análise. (ASSUNÇÃO, 2001 p.3)

Na Figura 5 observa-se um esboço do processo de análise exemplificado por Assunção (2001) em que o autor ressalta a realização de uma análise não espacial

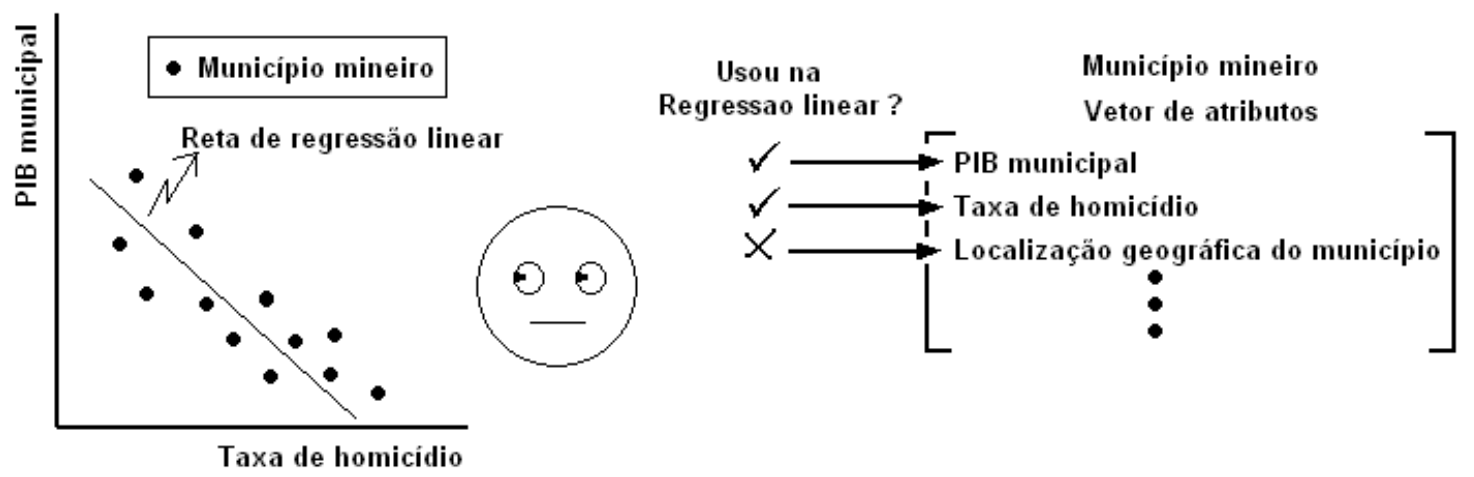

Figura 5 - Um esboço pictórico do exemplo de regressão linear citado por Assunção (2001). Fonte: Elaborado pelo autor. 
Para apresentar outro exemplo, suponha que tenha sido realizado um "provão" no contexto de um projeto educacional para alunos do Ensino Médio de cinco municípios (A, B, C, D e E). O que se quer saber é: (1) será que a nota média das provas dos participantes do "provão" é diferente entre os grupos de alunos que estudam no período matutino, vespertino e noturno? E também: (2) será que a nota média das provas dos participantes do "provão" é diferente entre os grupos de alunos em função dos cinco municípios onde moram/estudam os alunos?

Para tentar responder estas duas questões utilizou-se a técnica de análise de variância (ANOVA), uma para cada caso, cujo esboço conceitual é mostrado na Figura 6.

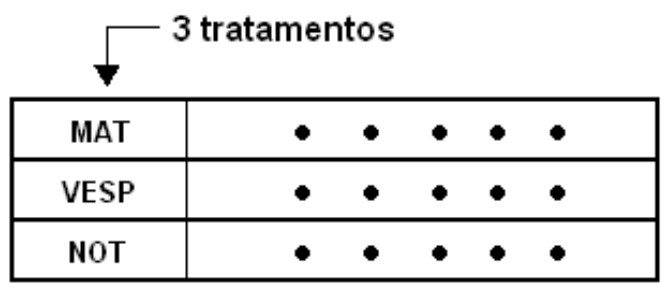

(1)

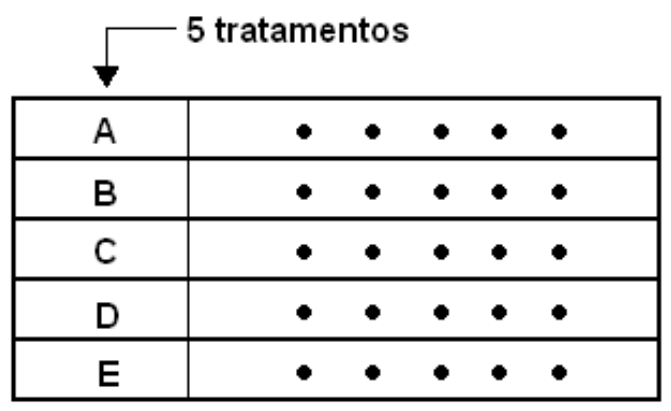

(2)

Figura 6 - Tabelas de dados de entrada para análise de variância (ANOVA) para (1) e (2).

Fonte: Elaborado pelo autor.

Desta forma, quando realizamos ANOVA para o caso (1), em que os tratamentos referem-se aos períodos matutino, vespertino e noturno, a análise não é espacial. Mas no caso (2) em que se averigua se a média da prova é diferente entre os grupos de alunos em função dos municípios em que moram/estudam, então a localização do fenômeno é o foco de interesse e talvez seja o elemento que melhor irá apontar aquela realidade. Este seria, assim, um exemplo de análise espacial.

Em termos de técnicas de análise espacial, segundo Druck et. al. (2004, p.23), a taxonomia mais comumente usada para caracterizar os problemas de análise espacial considera três tipos de dados: (1) eventos ou padrões pontuais; (2) superfícies contínuas e (3) áreas com contagem e taxas agregadas.

A título de verificação do uso desta taxonomia de caracterização de problemas de análise espacial, o livro de Taylor (1977) dedica o capítulo IV, intitulado "Point pattern 
analysis" e o capítulo V, intitulado "Areal association", indicando o tratamento de eventos pontuais e o tratamento de áreas com contagem e taxas agregadas respectivamente. Não foram tratadas no livro técnicas para dados de superfícies contínuas. Já o livro de Meirelles et. al. (2007) abrange com maior ênfase as técnicas para dados de superfícies contínuas e de áreas com contagem e taxas agregadas relacionando-as ao uso de geotecnologias.

A Figura 7 apresenta os três tipos de dados da taxonomia de caracterização citada por Druck et. al. (2004).

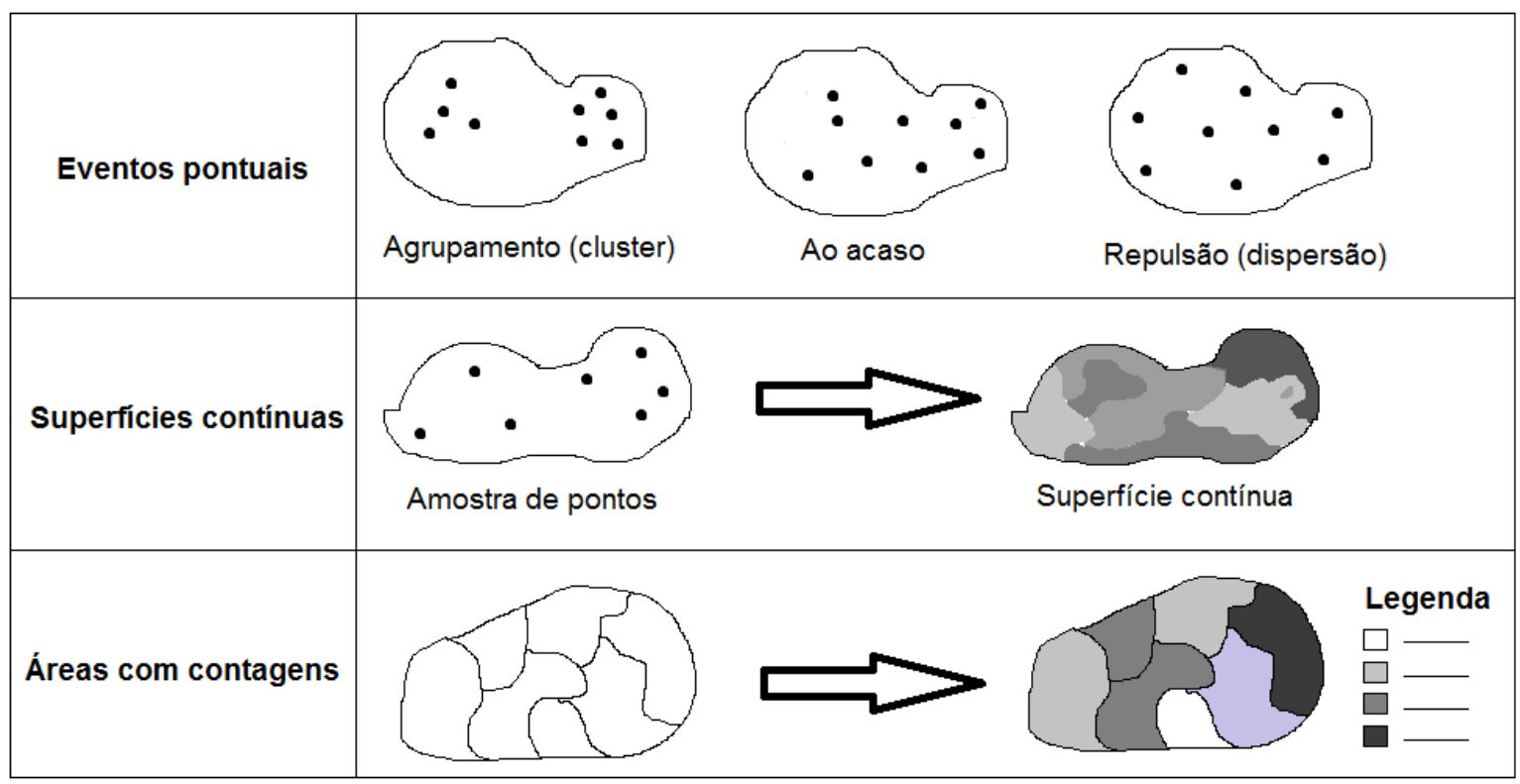

Figura 7 - Taxonomia usada para caracterizar os problemas de análise espacial segundo Druck et. al. (2004).

Fonte: Elaborado pelo autor.

Assunção (2001) cita ainda a existência de um quarto tipo de dados: os dados de interação espacial. Nestes dados existem pontos fixos que seriam conectados em pares e o que interessaria seria o estudo dos fluxos entre os pares. Os fluxos poderiam ser fluxos migratórios entre duas cidades (dois pontos fixos), fluxo de vôos, de mercadorias, de pacientes para hospitais, etc (ver Figura 8). Taylor(1977) aborda no capítulo VII, intitulado "applied spatial analysis" o tradicional modelo gravitacional para tais tipos de dados. Além disso, dedica uma parte do capítulo para os problemas locacionais, ressaltando que tais problemas são abordados por um subconjunto de técnicas da área de Pesquisa Operacional. 


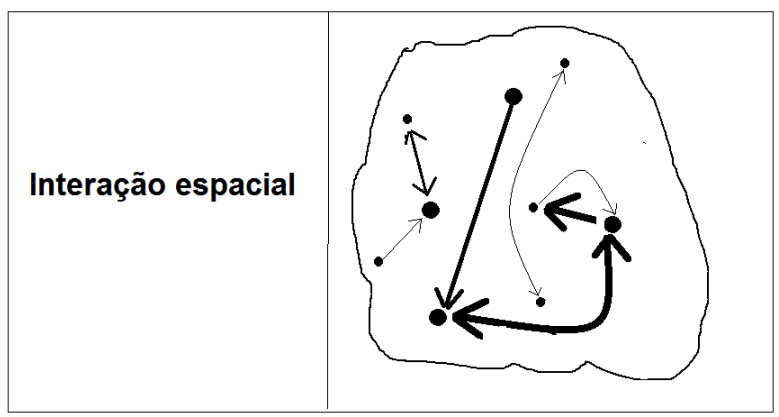

Figura 8 - Problemas de análise espacial abrangendo interação espacial

Fonte: Elaborado pelo autor.

Para citar alguns casos, os exemplos de fenômenos citados anteriormente de distribuição de postos de vacinação, de estações pluviométricas e de antenas de recepção/emissão de sinais para celulares são exemplos típicos de análise espacial de eventos pontuais. Aliás, nos três casos exemplificados se os padrões de distribuição forem identificados como sendo do tipo repulsão/dispersão, então significa que os fenômenos se apresentam da melhor forma possível com relação ao tema de interesse que representam, pois a dispersão significa, nos três casos, melhor oferta do evento em questão na área considerada.

As amostras pontuais de solo e de pragas dos exemplos citados para estimativa da intensidade dos fenômenos de interesse podem ser abordadas por técnicas de análise espaciais para delineamento de superfícies contínuas.

A distribuição da população de faixa etária 15-19 anos por bairros, a percentagem de eleitores do candidato $\mathrm{X}$ por setores censitários, as expressões culturais diversas por regiões e as dinâmicas temporais de espalhamento de doença e de aquisição de alguma tecnologia podem ser abordadas por técnicas de análise espaciais que processam contagens em áreas. Para esclarecer, as áreas com contagens são aquelas que se conhece o valor de ocorrência do fenômeno dentro dos limites da área, mas não se sabe exatamente onde ele ocorre. Por exemplo, o recenseamento aponta que em determinado bairro existem 3.456 moradores de faixa etária 15-19 anos. Então tem-se a informação do bairro (área em questão) mas não se sabe onde exatamente moram cada um dos 3.456 indivíduos.

Finalmente, as rotas de furacões e a logística de armazenamento e escoamento da produção agrícola podem ser tratadas sob o enfoque de técnicas voltadas para o processamento de dados com interações espaciais. 
À luz dos exemplos considerados percebe-se que a proposta utilizada para caracterização dos problemas de análise espacial é consistente e serve de guia para que se possa entender a natureza da análise espacial que se pretenda empreender.

\subsection{ALGUNS CONCEITOS BÁSICOS DE QUANTIFICAÇÃO EMBUTIDOS NAS TÉCNICAS DE ANÁLISE ESPACIAL}

As técnicas quantitativas utilizadas para as diversas instâncias de análise espacial baseiam-se em diversos conceitos matemáticos e estatísticos. O conhecimento e domínio de tais conceitos é fundamental para o usuário de fato entender os diversos detalhes da técnica que está sendo usada. Se não totalmente, ao menos boa parte dos conceitos deve ser assimilada pelo usuário, para entender os resultados obtidos com a aplicação da técnica. No que se segue são apresentados alguns conceitos embutidos em algumas técnicas de análise espacial (e não a descrição detalhada em si da técnica).

Inicialmente toma-se como base o livro de Taylor (1977), intitulado "Quantitative Methods in Geography”, para apontar conceitos abordados por este autor, e que são usados, direta ou indiretamente no processamento dos dados de eventos pontuais, de superfícies contínuas, de áreas com contagens e de interações espaciais.

Básico para qualquer trabalho de qualquer natureza que lide com um conjunto de dados é o cálculo de estatísticas descritivas. Taylor (1977) cita as mais comuns: média aritmética simples, variância, desvio padrão e coeficiente de variação. Para exemplificar, cita o uso do coeficiente de variação pelo economista J.G. Williamson para examinar desigualdades regionais entre países. Apresenta também o cálculo do centro médio espacial e da distância padrão, que é o correspondente espacial do desvio padrão, e mostra um exemplo prático de uso do centro médio espacial para avaliar o padrão de deslocamento da população norte americana ao longo do tempo.

As diversas técnicas de análise (espacial ou não) lidam com variáveis. É preciso conhecer e entender conceitualmente as escalas de mensuração das variáveis: escala nominal, ordinal, intervalar e de razão. O autor também aborda este conteúdo.

Em seguida, Taylor (1977) cita os três conceitos (primitivas) espaciais fundamentais apresentados originalmente por Nystuen (1963) : distância, direção (orientação) e posição relativa (conexão). Unwin (2010) acrescenta a este rol de primitivas a fronteira. De acordo com este autor, padrões espaciais, vizinhança, acessibilidade, circulação, etc, são derivados, 
de uma forma ou de outra, destas quatro primitivas. E estas primitivas possuem características definidas matematicamente através da distância euclideana, relações angulares, índices e taxas.

Em diversas situações do cotidiano de trabalho, o geógrafo irá lidar com um conjunto de dados e, diversas vezes terá acesso apenas a uma parte deste conjunto de dados, ou seja, terá acesso a uma amostra dos dados. Taylor (1977) enfatiza a importância para o geógrafo em saber trabalhar com amostras. Comenta sobre as técnicas de amostragem aleatória, estratificada e sistemática mostrando exemplos de amostragens de pontos de ocorrência de eventos em determinada área.

Taylor (1977) dedica o capítulo III do livro à apresentação de teoria de probabilidade e inferência estatística que serve ao geógrafo enquanto cientista social. Segundo o autor,

In carrying out empirical research, the geographer like any other scientist is confronted with a set of evidence to compare with some hypothesis that has been stated previously. The hypothesis may have been derived from geographic theory or it may be simply intuitive notion. The empirical evidence consists of measures of the concepts that occur in the hypothesis and for which data have been collected. The question that must be faced is, 'does this evidence support the hypothesis? '. (TAYLOR, 1977, p. 85)

Assim, o geógrafo é um cientista como os demais cientistas de outros ramos do conhecimento e, em algum momento do trabalho de análise do espaço será impelido a hipotetizar diante de evidências diversas que se manifestam nos fenômenos sócio-espaciais de seu interesse. Uma forma de abordar/analisar estes casos se dá pelo uso da Teoria de Probabilidade. No livro, o autor apresenta uma síntese, abordando os conceitos: (1) de análise combinatória (permutação combinação e arranjo); (2) os axiomas do cálculo de probabilidades; (3) distribuição binomial e (4) distribuição normal. Segue apresentando conceitos de estatística inferencial com foco sobre testes de hipótese, usando exemplos que envolvam o espaço, como no caso de realizar um teste de hipótese para verificar se a localização de chácaras produtoras de hortaliças baseiam-se na proximidade geográfica de centros consumidores e do tipo de solo. Finaliza o capítulo abordando a autocorrelação espacial.

O título do capítulo 4 do livro de Taylor é "Point pattern analysis". As técnicas apresentadas se enquadram na taxonomia de dados de eventos pontuais (ver Figura 7). $\mathrm{O}$ autor 
apresenta a técnica de análise de quadrantes, exemplificando um caso de ocorrência de pontos no espaço considerado via processo (distribuição) de Poisson e usa os testes de hipótese de Komolgorov-Smirnov e $\chi^{2}$ para averiguar a aleatoriedade do padrão de distribuição espacial dos pontos. Para o caso de padrões de dispersão, apresenta um exemplo com o modelo de distribuição de Dacey. E para o padrão de agregação, apresenta um exemplo com base na distribuição binomial negativa.

O autor também aborda a análise dos k vizinhos mais próximos (K-nearest neighbors) para análise de padrões de eventos pontuais, usando a denominada escala $\mathrm{R}$ que mede a similaridade do arranjo observado de pontos sobre a área de interesse em relação a um arranjo hipotético dos pontos nesta área com configuração aleatória.

Grattel et. al. (1996) comentam que a análise de quadrantes e $\mathrm{k}$ vizinhos mais próximos são insuficientes para lidar com problemas na área de epidemiologia e utilizam uma abordagem diferente. Esta abordagem diferente é tratada também por Druck et. al. (2004) no capítulo 2 do livro intitulado "Análise espacial de eventos". Os eventos pontuais são caracterizados pelos denominados "efeitos de primeira ordem" e "efeitos de segunda ordem". Segundo os autores,

os efeitos de primeira ordem, considerados globais ou de larga escala, correspondem a variações no valor médio do processo no espaço. Neste caso, estamos interessados na intensidade do processo, isto é, no número de eventos por unidade de área. Efeitos de segunda ordem, denominados locais ou de pequena escala, representam a dependência espacial no processo, proveniente da estrutura de correlação espacial. Para medir a dependência espacial, procuramos estimar o relacionamento entre pares de eventos (por unidade de área) no espaço, o que corresponde a uma aproximação do cálculo da covariância entre as variáveis aleatórias que representam cada evento (DRUCK et. al., 2004, p.33)

E ambos os autores citam o estimador de intensidade (Kernel estimaton), uma técnica exploratória para avaliar os efeitos de primeira ordem, e a função K, uma técnica para avaliar os efeitos de segunda ordem. Para o uso destas técnicas, é necessário assumir o processo como sendo estacionário e isotrópico. Estacionariedade refere-se ao fato de a região de estudo apresentar o mesmo valor esperado de eventos para qualquer ponto da região. Isotropia é a propriedade de a dependência espacial entre dois pontos distintos quaisquer da região de 
estudo depender apenas da distância entre as mesmas, e não depender da direção (norte-sul, leste-oeste, etc).

Com relação aos tipos de dados de superfícies contínuas (ver Figura 7), o livro de Taylor (1977) não aborda este tema. Druck et. al., (2004) tratam este tema no capítulo 3 (Análise espacial de superfícies). Nesta situação, os pontos formam uma amostra representativa do fenômeno sobre a área de estudo. Com base nestes pontos deseja-se gerar superfícies via interpolação dos dados da amostra. Segundo os autores, três tipos de modelo produzem a interpolação: (1) Modelos determinísticos de efeitos locais, (2) Modelos determinísticos de efeitos globais e (3) Modelos estatísticos de efeitos locais e globais (krigagem).

Os modelos determinísticos de efeito local usam funções simples que calculam um valor médio com base num subconjunto de pontos da amostra que sejam vizinhos locais (a uma distância pré-determinada) ou usam um estimador de intensidade tal qual usado na amostra de padrões de eventos pontuais. Os modelos determinísticos de efeito global produzem superfícies por ajuste polinomial por meio de um processo de regressão múltipla. $\mathrm{E}$ finalmente, os modelos estatísticos de efeitos locais e globais (krigagem) compreendem um conjunto de técnicas de estimação e predição de superfícies baseadas na modelagem da estrutura de correlação espacial. A hipótese implícita no procedimento geoestatístico é que o processo estudado é estacionário. Usa técnicas de análise descritiva de dados, análise da estrutura de correlação espacial e interpolação estatística.

Com relação à geoestatística, Bettini (2007) cita o que se espera de um leitor que deseje aprender os conceitos básicos de geoestatística:

\footnotetext{
Admitem-se conhecidos os conceitos de variável aleatória (VA), distribuições de probabilidade de VAs discretas e contínuas, uni e multivariadas, bem como seus modelos e parâmetros. São particularmente importantes as noções de momentos, quantis, covariância, correlação, dependência linear, amostragem, estatísticas e estimadores. Caso o leitor não esteja à vontade com esses termos, deverá consultar textos básicos de Estatística (BETTINI, 2007, p.193)
} 
Em outras palavras, pelas colocações de Bettini (2007), pode-se dizer que a geoestatística está apoiada em conceitos estatísticos e probabilísticos que demandam um razoável (para não dizer sólido) domínio por parte do usuário.

Com relação aos tipos de dados de áreas com contagens (ver Figura 7), o livro de Taylor (1977) aborda-os no capítulo V (“areal association”). Na verdade, já no capítulo III Taylor aborda a questão da autocorrelação espacial. No capítulo V, o objetivo é comparar dois ou mais mapas (da mesma área de estudo) simultaneamente. Nas palavras do autor, "the purpose of such map comparision is to find out which phenomena share common locations" (TAYLOR, 1977, p.173). Para comparação, usa o coeficiente de correspondência espacial, o recurso gráfico da curva de Lorenz, e índice de dissimilaridade $\left(\mathrm{D}_{\mathrm{A}}\right)$, calculado com base na curva de Lorenz. Em seguida, considera o uso de correlação linear simples, usando os coeficientes de correlação de Pearson e de Spearman. Complementa abordando análise de regressão tratando do coeficiente de correlação, do erro padrão e coeficiente de regressão. Segue a abordagem expandindo a ideia para análise de regressão múltipla contextualizando o uso de mapas de resíduos, onde apresenta um exemplo de mapa de resíduos para o caso de análise de relação entre população rural e precipitação média anual em Nebraska.

Percebe-se a importância de processamento de múltiplas variáveis quando o autor diz que "we do not live in a bivariate world, and we should not expect too much of analysis of bivariate relatons" (TAYLOR, 1977, p. 213). Apenas para reforçar a importância da quantificação voltada para os dados de análise de áreas com contagens podemos citar o livro de Johnston (1978) cujo título "Multivariate statistical analysis in Geography" aborda, por exemplo, técnicas multivariadas para a análise de variância, e a técnica de análise em componentes principais e análise fatorial.

No capítulo 5 do livro de Druck et. al., (2004), Câmara et. al. (2004), abordam a análise espacial dos tipos de dados de áreas com contagens. Citam a possibilidade de abordagem por modelos espaciais discretos ou contínuos. Para o modelo espacial discreto, a variável aleatória que descreve o número de ocorrência do evento na área segue uma distribuição de Poisson e, em alguns casos, a distribuição normal. Iniciam apresentando algumas técnicas exploratórias aplicadas aos dados espaciais através da visualização de valores extremos (outliers), percentis e desvio padrão nos mapas. Mostram o uso destes mapas exemplificando a distribuição espacial do indicador que mede a proporção de recém- 
natos que nascem em boas condições de saúde (Índice de APGAR) para os bairros do Rio de Janeiro, no ano de 1994.

Apresentam o uso do gráfico de médias e medianas para verificar, a nível exploratório, a presença ou não de estacionariedade de primeira e segunda ordem. Apresentam como exemplo o uso desta técnica aplicada a dois indicadores socioeconômicos do censo 1991 renda média do chefe da família e proporção de chefes de família com escolaridade igual ou superior ao segundo grau - para setores censitários da Ilha do Governador, no Rio de Janeiro.

Ainda a nível exploratório, abordam a técnica de autocorrelação espacial, a exemplo do que foi abordado por Taylor (1977) no capítulo III de seu livro. Citam o uso da média móvel espacial para explorar a variação da tendência espacial dos dados e em seguida apresentam e exemplificam os indicadores globais de autocorrelação espacial: índice global de Moran e índice de Geary. Exemplificam o índice global de Moran para o índice de exclusão/índice de inclusão social em São Paulo e o índice de Geary para mortalidade por homicídios no Rio de Janeiro. Ambos os valores dos índices são avaliados por testes estatísticos de hipótese específicos.

Os autores apresentam o variograma - também usado para tipos de dados de superfícies contínuas - como indicador de dependência espacial. Exemplificam o uso de variograma analisando a mortalidade por homicídios na região Sudeste. Como forma adicional de visualizar a dependência espacial, os autores apresentam o diagrama de espalhamento de Moran e o mapa de espalhamento de Moran, exemplificando estas técnicas através do já usado exemplo do índice de exclusão/índice de inclusão social em São Paulo. Finalizam a parte de técnicas exploratórias citando e exemplificando o uso de indicadores locais de autocorrelação espacial.

Para os casos em que os dados das áreas são taxas e que podem apresentar superestimação, os autores citam o uso de estimadores bayesianos para contornar este problema. Em seguida, são abordadas técnicas de regressão espacial. Como exemplo ilustrativo das técnicas estudou-se o relacionamento entre renda e longevidade na cidade de São Paulo, para os dados do Censo de 1991, onde comparou-se o modelo não espacial, o modelo autoregressivo (spatial lag) e o modelo em regimes espaciais.

Finalmente, os autores abordam o modelo de variação espacial contínua que visa dissolver os limites das áreas de contagens (ou taxas) em superfície contínua. Usam a técnica do estimador de intensidade (Kernel estimation) para interpolar dados de homicídio no Rio de Janeiro no triênio 1990-1992, e krigagem ordinária exemplificando a técnica 
para a distribuição da taxa de homicídios por 100 mil habitantes, para os 96 distritos de São Paulo em 1996.

Finalizando o capítulo, os autores fazem um interessante comentário ao afirmarem que "estudiosos de dados sócio-econômicos podem se beneficiar substancialmente das técnicas deste capítulo" (CÂMARA et. al., p. 148).

A quarta categoria de tipo de dado espacial, além dos dados de eventos pontuais, superfícies contínuas e áreas com contagens/taxas é, conforme dito anteriormente, aquela que lida com interação espacial (ver Figura 8). Conforme salientado anteriormente, Taylor(1977) aborda no capítulo VII, intitulado "applied spatial analysis" o tradicional modelo gravitacional para tais tipos de dados. Além disso, dedica uma parte do capítulo para os problemas locacionais, ressaltando que tais problemas são abordados por um subconjunto de técnicas da área de Pesquisa Operacional. A estrutura matemática para representação dos problemas locacionais é o grafo. Entender os principais aspectos de Teoria dos Grafos seria útil ao entendimento da resolução de problemas locacionais.

No livro de Druck et. al. (2004), Pedrosa e Câmara (2004) também abordam este tipo de dado no capítulo 6 intitulado "modelagem dinâmica e geoprocessamento". O foco da abordagem refere-se às dinâmicas espaciais e temporais, indo além da análise espacial estática. Citam as cadeias de Markov, modelo logístico de difusão, modelos de regressão e autômatos celulares, que lidam com a questão dinâmica espacial-temporal de fenômenos. Cadeias de Markov têm como base elementos da teoria de probabilidade, o modelo logístico de difusão tem como base o Cálculo Diferencial, os modelos de regressão têm como base os conceitos estatísticos de regressão e, finalmente, os autômatos celulares são estruturas de dados que assumem a forma matricial processadas por um conjunto previamente definido de regras de transição de estado de seus elementos.

Apenas para exemplificar, Almeida et. al. (2007) apresentam um estudo de caso da dinâmica espaço-temporal de uso do solo da cidade paulista de Bauru através da modelagem via autômatos celulares, concluindo ser a modelagem útil "para os casos de identificação dos principais vetores de expansão urbana e suas vocações (tendências de uso), permitindo ao poder público ordenar e direcionar (se for o caso) o crescimento urbano" (ALMEIDA et. al., 2007, p.492).

Em essência, neste tópico procurou-se identificar alguns conceitos (e técnicas) matemáticos e estatísticos que servem de base para a realização de quantificação em análises 
espaciais de dados geográficos. Pode-se dizer, em síntese, que o conhecimento básico para entendimento de técnicas quantitativas de análises espaciais se baseiam em três tipos de estatísticas: (1) estatística descritiva; (2) estatística inferencial e (3) estatística multivariada.

A estatística descritiva fornece o ferramental para a primeira abordagem do fenômeno espacial de interesse, assim como para o fenômeno não espacial. Isto significa entender, essencialmente, as medidas de tendência central e de dispersão. Entender variáveis aleatórias, seus níveis de mensuração e distribuições de probabilidade servem de suporte ao entendimento e uso de estatística inferencial, por meio de estimativas e testes de hipótese. E conforme apontado por Taylor (1977), não vivemos num mundo bivariado, mas sim multivariado. Os fenômenos espaciais normalmente requerem, assim como os fenômenos não espaciais, o processamento de três ou mais variáveis simultaneamente. E daí a importância do conhecimento de técnicas de análise multivariada, onde as múltiplas variáveis podem ser analisadas de forma descritiva e/ou inferencial.

No âmbito da realidade brasileira vale registrar que, historicamente, a geografia brasileira nos anos 1970 experimentou o processo de uma prática embasada na quantificação. Nomes como Orlando Valverde, Speridião Faissol, Fany Davidovich, Roberto Lobato Corrêa ligados ao Instituto Brasileiro de Geografia e Estatística (IBGE) e Antonio Christofoletti e Lúcia Helena de Oliveira Gerardi da Universidade Estadual Paulista (UNESP) de Rio Claro dentre outros são referências no pioneirismo da quantificação em Geografia no Brasil. Segundo Guedes (2013),

Na Geografia a estatística surge a partir dos anos 1950, associado à teoria geral dos sistemas, mas se apresentou mais forte a partir da década de 1970 com a chamada revolução da Geografia quantitativa. (...)No Brasil se destacam como baluartes desse período, o Curso de Geografia de Rio Claro (Universidade Estadual Paulista/UNESP) e o Instituto Brasileiro de Geografia e Estatística (IBGE). Na UNESP vários professores utilizaram com afinco essa abordagem, sendo por isso muito criticado por seus pares de outras instituições que não viam com bons olhos o uso dessa ferramenta. Nesse período foi lançado o periódico 'Boletim de Geografia Teorética' e o livro 'Quantificação em Geografia', até hoje um marco na literatura em nosso vernáculo escrito pelas professoras Lúcia Helena de Oliveira Gerardi e Bárbara Christine Nentwig Silva. No IBGE, o uso da quantificação era presença obrigatória nas discussões de trabalhos (para uma melhor 
averiguação veja os artigos Revista Brasileira de Geografia e EstatísticaRBG, nesse período), sendo inclusive lançado um livro na temática, mas quem se destacou foi o geógrafo Speridião Faissol, escrevendo vários artigos no período. (GUEDES, 2013, p. 158-159)

Finalmente, vale registrar e endossar o que foi colocado por Guedes (2013) sobre o pioneiro livro de Gerardi e Silva (1981) como sendo um marco da Geografia Quantitativa brasileira. O livro é um material de conteúdos versando sobre quantificação, apresentando aplicações no campo da Geografia, escrito em Língua Portuguesa e que certamente propiciou a difusão da cultura da quantificação, se não em toda, certamente em parte da geração de geógrafos brasileiros da década 1980.

\subsection{OS PCN E OS CONTEÚDOS DE MATEMÁTICA E ESTATÍSTICA}

Os conceitos básicos para entendimento e realização de análise espacial de dados geográficos, conforme afirmado anteriormente são, em última instância, de natureza estatística e, naturalmente, matemática, uma vez que a Estatística está assentada sobre conhecimentos matemáticos desde simples temas, como frações e proporções, até temas mais complexos, como por exemplo, cálculo diferencial e integral.

O graduando do curso de Geografia, assim como qualquer graduando de qualquer outro curso de nível superior, naturalmente é aluno egresso do Ensino Fundamental e Ensino Médio nesta ordem cronológica. E os conteúdos de Matemática ministrados no Ensino Fundamental e Ensino Médio são óbvia e naturalmente básicos e imprescindíveis para o aprendizado dos conceitos matemáticos que servem de suporte ao aprendizado de conceitos estatísticos.

Os conteúdos de Matemática dos ensinos Fundamental e Médio são importantes para a formação do indivíduo, não somente para sua formação profissional, mas principalmente para sua formação como cidadão. As tecnologias de informação e comunicação (TIC) cada vez mais proporcionam maior disseminação de dados brutos, informação e conhecimento. $\mathrm{O}$ indivíduo os tem diante de si em diversos formatos, dentre os quais, tabelas, gráficos, mapas, índices e resultados de estudos usando amostras. Entender estes formatos e tomar decisões passa a ser algo obrigatório para o exercício da cidadania nas sociedades pós-modernas. 
Os sistemas educacionais nas instâncias nacional, regional e local nas diversas partes do mundo vêm se adaptando a esta realidade. No caso do Brasil, pode-se apontar o ano de 1996 como um marco visando mudanças no setor educacional nacional. Segundo Brasil (1997a),

A nova Lei de Diretrizes e Bases da Educação Nacional (Lei Federal n. 9.394), aprovada em 20 de dezembro de 1996, consolida e amplia o dever do poder público para com a educação em geral e em particular para com o Ensino Fundamental. Assim, vê-se no art. 22 dessa lei que a educação básica, da qual o Ensino Fundamental é parte integrante, deve assegurar a todos "a formação comum indispensável para o exercício da cidadania e fornecer-lhes meios para progredir no trabalho e em estudos posteriores", fato que confere ao Ensino Fundamental, ao mesmo tempo, um caráter de terminalidade e de continuidade. Essa LDB reforça a necessidade de se propiciar a todos a formação básica comum, o que pressupõe a formulação de um conjunto de diretrizes capaz de nortear os currículos e seus conteúdos mínimos, incumbência que, nos termos do art. $9^{\circ}$, inciso IV, é remetida para a União. Para dar conta desse amplo objetivo, a LDB consolida a organização curricular de modo a conferir uma maior flexibilidade no trato dos componentes curriculares, reafirmando desse modo o princípio da base nacional comum (Parâmetros Curriculares Nacionais), a ser complementada por uma parte diversificada em cada sistema de ensino e escola na prática, repetindo o art. 210 da Constituição Federal. (BRASIL, 1997a, p. 14)

Os Parâmetros Curriculares Nacionais ( $\mathrm{PCN}$ ) tornam-se então uma espécie de referencial de conteúdos. No caso específico da Matemática, segundo Brasil (1997b),

é cada vez mais frequente a necessidade de se compreender as informações veiculadas, especialmente pelos meios de comunicação, para tomar decisões e fazer previsões que terão influência não apenas na vida pessoal, como na de toda a comunidade. Estar alfabetizado, neste final de século, supõe saber ler e interpretar dados apresentados de maneira organizada e construir representações, para formular e resolver problemas que impliquem o recolhimento de dados e a análise de informações. Essa característica da vida contemporânea traz 
ao currículo de Matemática uma demanda em abordar elementos da estatística, da combinatória e da probabilidade, desde os ciclos iniciais. (BRASIL, 1997b, p. 84)

Os PCN criaram uma delimitação de blocos de conteúdos para a Matemática. No Ensino Fundamental há os blocos de conteúdos de (1) números e operações; (2) espaço e forma; (3) grandezas e medidas e (4) tratamento da informação. É neste último bloco que os elementos de estatística, combinatória e probabilidade são abordados.

No contexto dos PCN as oito séries do Ensino Fundamental aparecem divididas em quatro Ciclos: $1^{\mathrm{o}}$ ciclo $\left(1^{\mathrm{a}}\right.$ e $2^{\mathrm{a}}$ séries $), 2^{\mathrm{o}}$ ciclo ( $3^{\mathrm{a}}$ e $4^{\mathrm{a}}$ séries $), 3^{\mathrm{o}}$ ciclo $\left(5^{\mathrm{a}}\right.$ e $6^{\mathrm{a}}$ séries $)$ e o $4^{\mathrm{o}}$ ciclo $\left(7^{\mathrm{a}}\right.$ e $8^{\mathrm{a}}$ séries). Atualmente, a $1^{\mathrm{a}}$ e $2^{\mathrm{a}}$ série correspondem ao $2^{\mathrm{o}}$ e $3^{\mathrm{o}}$ ano; a $3^{\mathrm{a}}$ e $4^{\mathrm{a}}$ série correspondem ao $4^{\mathrm{o}}$ e $5^{\mathrm{o}}$ ano; a $5^{\mathrm{a}}$ e $6^{\mathrm{a}}$ série correspondem ao $6^{\mathrm{o}}$ e $7^{\mathrm{o}}$ ano e a $7^{\mathrm{a}}$ e $8^{\mathrm{a}}$ série correspondem ao $8^{\circ}$ e $9^{\circ}$ ano respectivamente. E com relação ao Ensino Médio, os Parâmetros Curriculares Nacionais para o Ensino Médio (PCNEM) "apontam de que forma o aprendizado de Ciências e de Matemática, já iniciado no Ensino Fundamental, deve encontrar complementação e aprofundamento no Ensino Médio" (PARÂMETROS CURRICULARES NACIONAIS - ENSINO MÉDIO, 2013, p.6).

Segundo os PCNEM, com relação às competências e habilidades que se espera serem promovidas e desenvolvidas no Ensino Médio, dentre outras citadas assinala-se no Quadro 1 algumas relacionadas diretamente com o aprendizado em alguma instância de conhecimentos ligados ao bloco "tratamento da informação".

Quadro 1 - Alguns conhecimentos e habilidades a serem promovidos durante o Ensino Médio na área de ciências da natureza, matemática e suas tecnologias.

- Interpretar e utilizar diferentes formas de representação (tabelas, gráficos, expressões, ícones...)

- Identificar variáveis relevantes e selecionar os procedimentos necessários para a produção, análise e interpretação de resultados de processos e experimentos científicos e tecnológicos

- Identificar, analisar e aplicar conhecimentos sobre valores de variáveis, representados em gráficos, diagramas ou expressões algébricas, realizando previsão de tendências, extrapolações e interpolações e interpretações 
Quadro 1 - Alguns conhecimentos e habilidades a serem promovidos durante o Ensino Médio na área de ciências da natureza, matemática e suas tecnologias. - (Continuação)

- Analisar qualitativamente dados quantitativos representados gráfica ou algebricamente relacionados a contextos sócio-econômicos, científicos ou cotidianos

- Desenvolver modelos explicativos para sistemas tecnológicos e naturais

- Formular hipóteses e prever resultados

- Compreender o caráter aleatório e não determinístico dos fenômenos naturais e sociais e utilizar instrumentos adequados para medidas, determinação de amostras e cálculo de probabilidades

- Utilizar elementos e conhecimentos científicos e tecnológicos para diagnosticar e equacionar questões sociais e ambientais

- Utilizar instrumentos de medição e de cálculo

- Procurar e sistematizar informações relevantes para a compreensão da situação-problema Fonte: Parâmetros Curriculares Nacionais - Ensino Médio (2013, p.12).

Pagan (2010) apresenta um quadro demonstrativo destas habilidades por ciclo no Ensino Fundamental e por ano no Ensino Médio. Nos quadros 2 e 3 encontram-se as informações levantadas pela autora.

Analisando-se as informações dos quadros 2 e 3, pode-se notar, como afirma Pagan (2010), que "desde o primeiro ano da Escola Básica, a Estatística se faz presente, dentro do bloco Tratamento da Informação, sendo desenvolvida em todos os quatro ciclos do Ensino Fundamental, fazendo-se presente também no Ensino Médio" (PAGAN, 2010, p.99).

De acordo com PCN+ (2013), o Ensino Médio teria três temas estruturadores: (1) álgebra: números e funções; (2) geometria e medidas e (3) análise de dados. O tema "análise de dados" abrangeria as unidades temáticas: (a) estatística; (b) contagem e (c) probabilidade. Como sugestão de abordagem das unidades temáticas, o $1^{\circ}$ ano do Ensino Médio trataria de “estatística: descrição de dados; representações gráficas;”. No $2^{\circ}$ ano seria abordado “estatística: análise de dados" e "contagem". E finalmente, no $3^{\circ}$ ano abordar-se-ia "probabilidade". 
Quadro 2 - Habilidades estatísticas propostas nos PCN para o Ensino Fundamental.

\section{Ciclo I ( $2^{0}$ e $3^{0}$ ano $)$}

- Identificar o uso de tabelas e gráficos para facilitar a leitura e interpretação de informações e construir formas pessoais de registro para comunicar informações coletadas

Ciclo II ( $4^{\circ}$ e $5^{0}$ ano)

- Recolher dados e informações, elaborar formas para organizá-los e expressá-los, interpretar dados apresentados sob forma de tabelas e gráficos e valorizar essa linguagem como forma de comunicação.

- Demonstrar interesse para investigar, explorar e interpretar, em diferentes contextos do cotidiano e de outras áreas do conhecimento, os conceitos e procedimentos matemáticos abordados neste ciclo

\section{Ciclo III ( $6^{0}$ e $7^{\circ}$ ano $)$}

- Por meio da exploração de situações de aprendizagem, levar o aluno a coletar, organizar e analisar informações, construir e interpretar tabelas e gráficos, formular argumentos convincentes, tendo por base a análise de dados organizados em representações matemática diversas

\section{Ciclo IV ( $\left(^{\circ}\right.$ e $9^{\circ}$ ano $)$}

- Por meio da exploração de situações de aprendizagem que leve o aluno a construir tabelas de frequência e representar graficamente dados estatísticos, utilizando diferentes recursos, bem como elaborar conclusões a partir da leitura, análise, interpretação de informações apresentadas em tabelas e gráficos.

Fonte: Elaborado pelo autor com base no Quadro 4.1 apresentado em Pagan (2010, p. 99)

Quadro 3 - Habilidades estatísticas propostas nos PCN para o Ensino Médio.

$1^{0}$ e $2^{\circ}$ ano

- Identificar formas adequadas para descrever e representar dados numéricos e informações de natureza social, econômica, política, científico-tecnológica ou abstrata.

- Ler e interpretar dados e informações de caráter estatístico apresentados em diferentes linguagens e representações, na mídia ou em outros textos e meios de comunicação.

- Obter médias e avaliar desvios de conjuntos de dados ou Informações de diferentes naturezas.

- Compreender e emitir juízos sobre informações estatísticas de natureza social, econômica, política ou científica apresentadas em textos, notícias, propagandas, censos, pesquisas e outros meios.

- Dominar a linguagem de eventos, levantar hipóteses de equiprobabilidade, associar a estatística dos resultados observados e as frequências dos eventos correspondentes, e utilizar a estatística de tais frequiências para estimar a probabilidade de um evento dado.

Fonte: Elaborado pelo autor com base no Quadro 4.1 apresentado em Pagan (2010, p. 99) 
Em síntese, em face de uma nova realidade global, propostas para reformulação do sistema educacional brasileiro foram apresentadas e, há de se ressaltar que no bojo dessas propostas reconhece-se a importância da estatística para a formação do cidadão. As propostas incentivam o exercício de raciocínio estatístico durante todas as fases do Ensino Fundamental e Médio. Se o educando egresso do Ensino Médio de fato tiver tido um sólido contato e aprendizado de raciocínio estatístico, então é de se esperar que esteja de fato preparado para no ensino superior avançar nos estudos ligados às técnicas quantitativas e, particularmente, preparado para apreender e saber usar conceitos ligados à análise espacial de dados geográficos. A Figura 9 apresenta uma pirâmide representando os pilares de conhecimentos necessários para, em última instância, entender e saber utilizar análise espacial de dados geográficos onde se observa a importância dos pilares dos ensinos Fundamental e Médio.

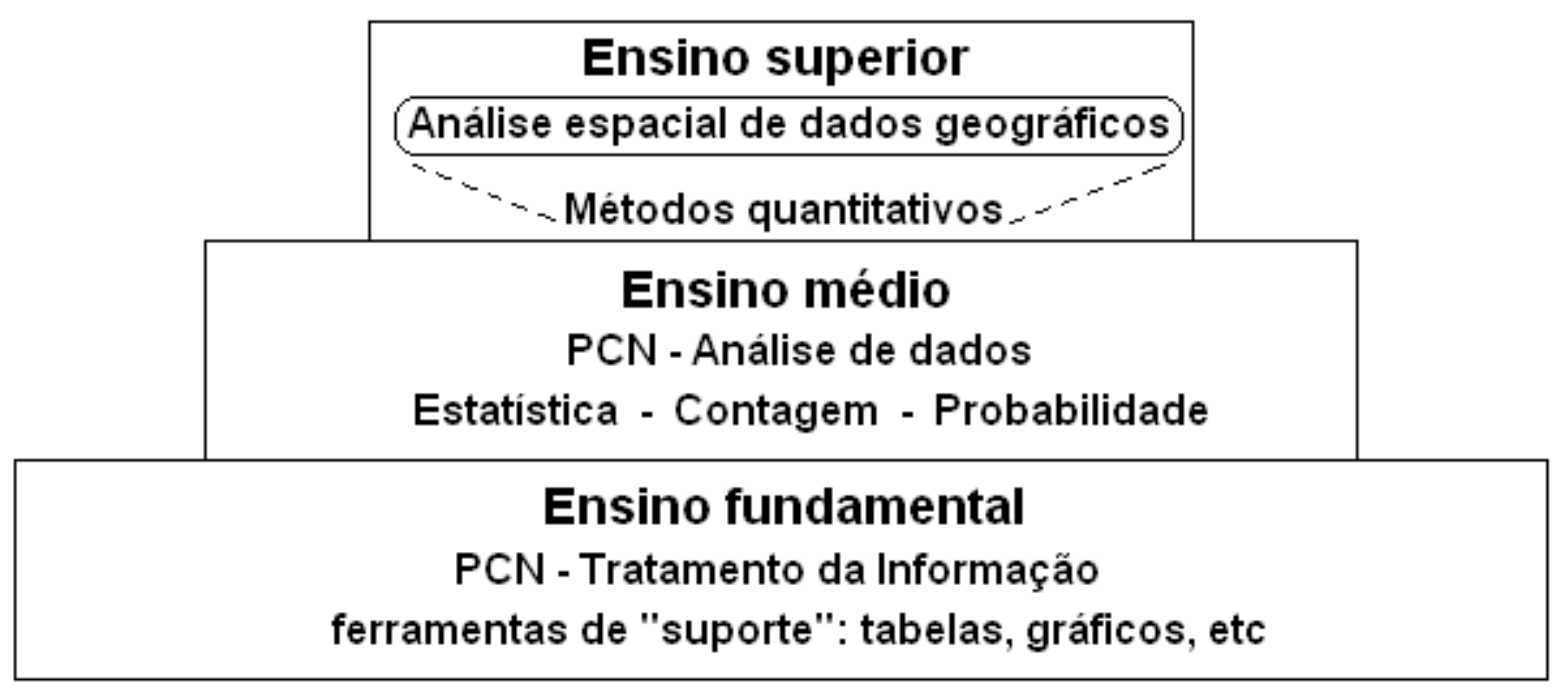

Figura 9 - Pirâmide de pilares de conhecimentos necessários para entendimento de técnicas quantitativas usadas em análise espacial de dados geográficos.

Fonte: Elaborado pelo autor.

Os PCN receberam elogios e críticas desde seu lançamento em 1997. Diversas críticas sobre os PCN para disciplinas específicas de História, Geografia, Língua Portuguesa, Língua Estrangeira e Educação Física podem ser encontradas na literatura. De modo geral, na época do lançamento dos PCN, diversos críticos "entendem os PCNs como uma imposição governamental e que a proposta, antes de ser educacional é neo-liberal, com o claro propósito de atender as exigências do capital internacional" (COSTA, G.C. Crítica da crítica dos PCNS: 
Uma concepção dialética. <http://groups-beta.google.com/group/digitalsource>. Acesso em: 20 abril 2013).

É certo que as críticas aos PCN com respeito ao caráter ideológico embutido em projetos educacionais conduzidos por qualquer governo são válidas. Particularmente, aos PCN de Matemática, foco de interesse deste trabalho, pode-se também admitir as críticas de caráter ideológico. Pode-se também admitir críticas às estratégias didáticas propostas e/ou utilizadas para transmissão dos conteúdos (como ensinar). Mas é difícil questionar a validade de se ensinar, nos Ensinos Fundamental e Médio, as linhas estruturantes de Matemática proposta pelos PCN: (1) álgebra: números e funções; (2) geometria e medidas e (3) análise de dados.

Ou seja, há espaço para se criticar o que ensinar ao aluno, proposto pelos PCN? Se sim, certamente significa incluir mais conteúdo. Se a crítica for pela retirada de conteúdos de matemática propostos, tais conteúdos retirados deverão então ser trabalhados no Ensino Superior. Assim, considera-se, no escopo deste trabalho, ser coerente a proposta dos PCN para o que ensinar em Matemática. Este conteúdo, conforme anteriormente comentado, é fundamental, é a base para aprendizagem das técnicas quantitativas aplicáveis à análise espacial de dados geográficos. Espera-se então, que o aluno egresso do Ensino Médio domine tais conteúdos, extremamente apropriados para seu aprimoramento educacional no Ensino Superior, e mesmo como cidadão consciente e atuante em sua realidade.

\subsection{SOBRE EDUCAÇÃO ESTATÍSTICA}

A estrutura de argumentação apresentada até este ponto do trabalho permite apontar que a formação do geógrafo em quantificação para realização eficaz de análise espacial de dados geográficos passa pela base de conhecimentos matemáticos e estatísticos que venha a adquirir durante sua formação escolar, contando o conhecimento que adquire desde as séries iniciais do Ensino Fundamental. Em outras palavras, pode-se dizer que o uso e entendimento de análise espacial de dados geográficos por parte do geógrafo (e de outros profissionais também) depende de seu grau de educação estatística.

A educação estatística começou a ficar evidenciada na estrutura da matriz curricular da escola básica, por volta da década de 1980. Segundo Borba et. al. (2011), 
Em 1980, em seu documento "Agenda para Ação", o National Council of Teachers of Mathematics sugeriu que se ampliasse o espectro de conteúdos, incluindo Estatística, Probabilidade e Combinatória, a serem trabalhados na escolarização básica nos Estados Unidos da América, desde os anos iniciais. Esse documento, portanto, foi um dos primeiros do continente americano a indicar a Estatística como tópico essencial do Ensino Básico. (BORBA et. al., 2011, p.1)

Segundo Pagan (2010), “o termo Educação Estatística é muito empregado por diversos autores, tem vários e divergentes significados" (PAGAN, 2010, p.43). Não somente o termo "educação estatística", mas também os termos "letramento estatístico" (ou "literacia estatística"), "pensamento estatístico" e "raciocínio estatístico", que surgem no desenrolar da temática ligada à educação estatística, são citados por diversos autores com significados nem sempre iguais entre si.

Para estruturar uma concepção teórica sobre educação estatística no contexto deste trabalho, toma-se por base as considerações de Campos (2007) que relata que diversos autores publicaram estudos que procuraram identificar alguns objetivos do ensino de Estatística. Segundo Campos (2007),

esses autores defendem que o planejamento da instrução deve pender para o desenvolvimento de três importantes competências, quais sejam a literacia, o raciocínio e o pensamento estatístico, sem as quais não seria possível aprender (ou apreender) os conceitos fundamentais dessa disciplina. (CAMPOS, 2007, p.49)

Assim, a educação estatística pode ser vista como sendo uma composição de três competências ou três dimensões: (1) literacia (letramento) estatístico, (2) pensamento estatístico e (3) raciocínio estatístico. Com relação ao letramento estatístico, Gal (2002) assim o define:

It is proposed here that in this context, the term "statistical literacy" refers broadly to two interrelated components, primarily (a) people's ability to interpret and critically evaluate statistical information, data-related arguments, or stochastic phenomena, which they may 
encounter in diverse contexts, and when relevant (b) their ability to discuss or communicate their reactions to such statistical information, such as their understanding of the meaning of the information, their opinions about the implications of this information, or their concerns regarding the acceptability of given conclusions. (GAL, 2002, p.2-3)

Em outras palavras, no contexto definido por Gal (2002), o letramento estatístico envolve (a) a leitura da informação estatística na forma de números, gráficos, tabelas, mapas e outros, (b) o real entendimento do que tal informação estatística representa dentro do contexto analisado e (c) a capacidade de explicar o cenário do contexto analisado. Indo além, o letramento estatístico permite inclusive o indivíduo entender o processo de geração de informação estatística e também avaliar a qualidade de tal processo que gerou tal informação.

Desta forma se, por exemplo, for veiculado pela mídia que determinada pesquisa de opinião apontou que determinado candidato (digamos, X) tem $90 \%$ das intenções de voto, um indivíduo letrado estatisticamente irá questionar: Como foi realizado o processo de amostragem das pessoas que participaram da pesquisa? Como foi colocada a pergunta sobre intenção de voto? Ou seja, o indivíduo consegue analisar criticamente a qualidade da informação estatística que tem diante de si, diferentemente de um indivíduo não letrado estatisticamente, que recebe a informação de forma passiva, acrítica.

Com relação ao pensamento estatístico, outra dimensão da educação estatística, Campos (2007) faz as seguintes colocações:

De acordo com Mallows (1998), podemos inicialmente imaginar o pensamento estatístico como sendo a capacidade de relacionar dados quantitativos com situações concretas, admitindo a presença da variabilidade e da incerteza, explicitando o que os dados podem dizer sobre o problema em foco. O pensamento estatístico ocorre quando os modelos matemáticos são associados à natureza contextual do problema em questão, ou seja, quando surge a identificação da situação analisada e se faz uma escolha adequada das ferramentas estatísticas necessárias para sua descrição e interpretação. (...) O pensador estatístico, segundo Chance (2002), é capaz de ir além do que lhe é ensinado no curso, questionando espontaneamente e investigando os resultados acerca dos dados envolvidos num contexto específico. (CAMPOS, 2007, p.53) 
Chance (2002) relata que diversos artigos utilizam o termo "pensamento estatístico" sem contudo defini-lo. Avaliando diversos artigos que tratam de pensamento estatístico, a autora aponta, dentre outros, que se verifica a "onipresença da variabilidade" e a "modelagem e mensuração da variabilidade". De fato, não é exagero dizer que a Estatística existe porquê existe variabilidade nos agrupamentos de dados. Por exemplo, tomando-se um conjunto de indivíduos e anotando-se a altura e o peso de cada um desses indivíduos, observar-se-á que existirão ao menos dois indivíduos com altura e/ou peso diferentes entre si. Isto é, há variação nos valores das variáveis.

Desta forma, o pensamento estatístico pode ser visto como a capacidade de realizar análises considerando-se que há variabilidade nos valores das variáveis da massa de dados do fenômeno de interesse e, por isso, existem incertezas de natureza probabilística nos resultados intermediários e/ou finais do processo analítico desenvolvido.

Finalmente, com relação ao raciocínio estatístico, Garfield(2002) apresenta uma definição direta para o termo:

\begin{abstract}
Statistical reasoning may be defined as the way people reason with statistical ideas and make sense of statistical information. This involves making interpretations based on sets of data, graphical representations, and statistical summaries. Much of statistical reasoning combines ideas about data and chance, which leads to making inferences and interpreting statistical results. Underlying this reasoning is a conceptual understanding of important ideas, such as distribution, center, spread, association, uncertainty, randomness, and sampling. (GARFIELD, 2002, http://www.amstat.org/publications/jse/v10n3/garfield.html)
\end{abstract}

O raciocínio estatístico pode então ser entendido como a quantificação intuitiva básica que o indivíduo utiliza em seu cotidiano diário. O uso dessa quantificação intuitiva básica ocorre de maneira de certa forma instintiva. Verri (2013) apresenta um interessante exemplo de raciocínio estatístico:

EXEMPLO de Raciocínio Estatístico: estamos numa fila no banco. Tem 1 guichê funcionando, com 13 pessoas na nossa frente. Como só temos 30 minutos antes de uma reunião com o chefe, ficaremos na fila ou vamos embora? A visão estatística nos permite analisar com segurança técnica. 
Podemos medir o tempo médio de 3 pessoas chamadas, em nossa frente (ficaram agora 10 pessoas). E medirmos no relógio o tempo médio delas das 3 primeiras pessoas. Achamos o tempo médio de 5 minutos (então, estas 3 pessoas, já nos levaram 15 minutos no total). Como ainda têm 10 pessoas na nossa frente, teremos a probabilidade de levarmos 50 minutos esperando a nossa vez, após os 15 minutos gastos no atendimento das 3 primeiras pessoas - total de 15 minutos. Logo, perdemos estes 15 minutos, dentro dos 30 minutos, antes da reunião com o chefe, quando entramos na fila, fazendo a amostragem de medição. Assim, temos 15 minutos possíveis de espera, mas a média de atendimento da nossa amostragem com 3 pessoas, foi de 5 minutos. Concluímos que vamos chegar atrasados a reunião com o chefe, onde: só temos 15 minutos finais, entretanto teremos que ficar na fila mais 50 minutos - de fila provável. E vamos chegar atrasados na reunião por 35 minutos se tentarmos o atendimento no caixa. ESTA É A ESSÊNCIA DO RACIOCÍNIO ESTATÍSTICO, em que tomamos uma DECISÃO estatística, baseada em observação do evento que amostramos e medimos. E para tudo que fazemos na vida, tomamos decisões parecidas, se formos racionais. (VERRI, Os fundamentos do raciocínio estatístico, http://www.clubedeautores.com.br/book/145189--

Os_Fundamentos_do_Raciocinio_Estatistico\#.Vhe87W7wpak, acesso em 26 jul 2013)

Para sintetizar, Chance (2002) pondera sobre as três competências:

it seems that a definition of "statistical thinking" includes "what a statistician does." These processes clearly involve, but move beyond, summarizing data, solving a particular problem, reasoning through a procedure, and explaining the conclusion. Perhaps what is unique to statistical thinking, beyond reasoning and literacy, is the ability to see the process as a whole (with iteration), including "why," to understand the relationship and meaning of variation in this process, to have the ability to explore data in ways beyond what has been prescribed in texts, and to generate new questions beyond those asked by the principal investigator. While literacy can be narrowly viewed as understanding and interpreting statistical information presented, for example in the media, and reasoning can be narrowly viewed as working through the tools and concepts learned 
in the course, the statistical thinker is able to move beyond what is taught in the course, to spontaneously question and investigate the issues and data involved in a specific context. (CHANCE, 2002, http:// http://www.amstat.org/publications/jse/v10n3/chance.html)

Neste contexto sintetizado por Chance (2002), podemos destacar que os três componentes da educação estatística são complementares. O letramento e raciocínio estatístico são habilidades fundamentais que, uma vez adquiridas, permitem o indivíduo entender criticamente aspectos de quantificação embutidos nas informações que cotidianamente recebe. Com a habilidade do pensamento estatístico consegue ir além, entendendo o "porquê “("why”) do processo formador da informação com quantificação. Ainda, um indivíduo com boa capacidade de letramento e raciocínio estatístico é um indivíduo que tem potencial para ser consumidor de informação estatística. Com a habilidade de pensamento estatístico, será também um indivíduo com potencial para ser produtor de informação estatística.

Todavia, repetindo e concordando com o que foi colocado por Pagan (2010, p.43), “o termo Educação Estatística é muito empregado por diversos autores, tem vários e divergentes significados". Mas, supondo o contrário, supondo que sejam estáveis as conceituações sobre letramento, pensamento e raciocínio estatístico, como fazer para mapear o relacionamento ente estas dimensões?

Campos (2007) cita que o relacionamento não se dá com a precedência de uma dimensão (ou capacidade como coloca o autor) sobre a outra, mas que há uma relação intrínseca entre elas. Cita ainda que "delMas (2002) propõe duas interpretações entre as três capacidades". Na primeira interpretação,

cada capacidade tem um domínio independente das demais, ao mesmo tempo em que existem interseções parciais entre dois domínios e uma parte de interseção das três capacidades. Se essa perspectiva está correta, é possível desenvolver uma capacidade independentemente das outras, ao mesmo tempo em que devem existir atividades que enfatizam as três capacidades ao mesmo tempo. (CAMPOS, 2007, p. 64)

Na segunda interpretação, "apresenta a Literacia como uma capacidade de abrangência geral, com o pensamento e o raciocínio incluídos em seu domínio. Um cidadão 
estatisticamente competente (ou seja, estatisticamente letrado), tem o pensamento e o raciocínio totalmente desenvolvidos" (CAMPOS, 2007, p. 64). A Figura 10 apresenta o esquema conceitual proposto por delMas (2002) para estes dois tipos de relacionamento entre as três capacidades.

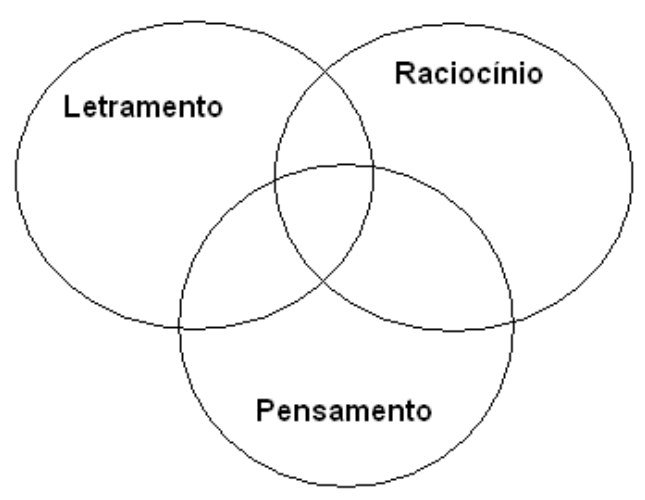

(A)

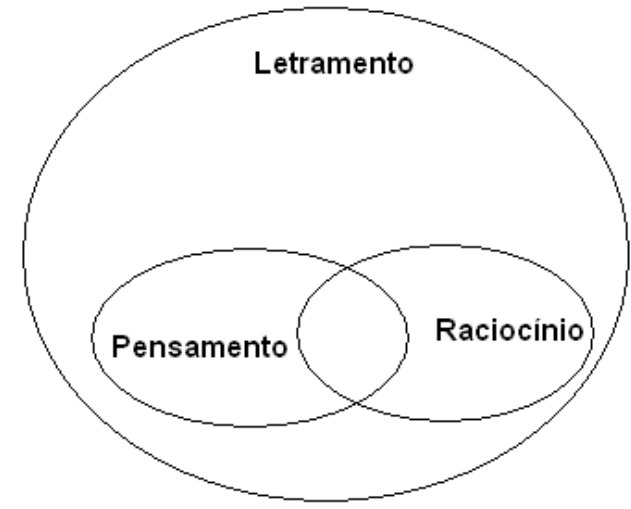

(B)

Figura 10 - Esquemas de relacionamento entre as três capacidades conforme delMas(2002). (A) primeira interpretação de relacionamento. (B) segunda interpretação.

Fonte: Elaborado pelo autor com base nas figuras em delMas (2002)

Campos (2007) apresenta uma terceira interpretação, que é uma ampliação do relacionamento esquematizado na Figura 10(A), e está apresentado na Figura 11.

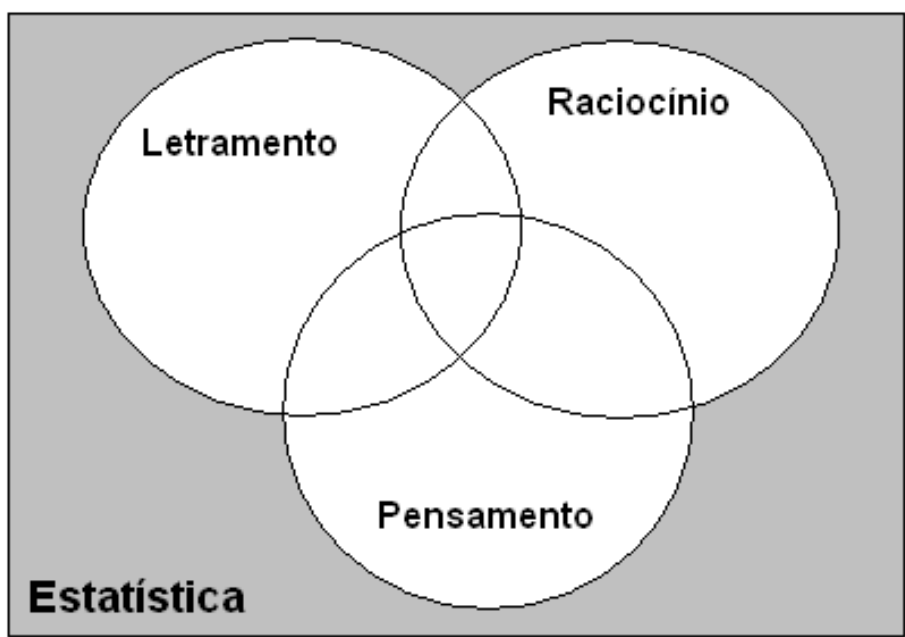

Figura 11 - Relacionamento entre as três capacidades proposto por Campos (2007, p. 65).

Fonte: Elaborado pelo autor com base em Campos (2007, p.65, Figura 2.3) 
Segundo o autor,

em complemento a essas interpretações, nós propomos um diagrama que utiliza a figura 1 como base, mas que admite a existência de um conjunto universo da Estatística em seu entorno. Nesse diagrama, teríamos domínios da Estatística que não desenvolvem nenhuma das três capacidades. Esses domínios seriam a parte da Estatística que lida, por exemplo, com o cálculo puro ou com o uso da tecnologia. (CAMPOS, 2007, p. 65)

\section{Segundo o autor, a área de cor cinzenta na Figura 11 representaria}

domínios da Estatística que não desenvolvem nenhuma das três capacidades. Esses domínios seriam a parte da Estatística que lida, por exemplo, com o cálculo puro ou com o uso da tecnologia. (...) seriam aspectos marginais da Estatística, tais como o conhecimento sobre as funções computacionais, ou seja, as sintaxes de comando de programas como o Excel. Também estariam inseridos nesse contexto as fórmulas de cálculo de arranjo, combinação e permutação, que em si não desenvolvem conceito algum de Estatística, mas que podem ser utilizadas no cálculo de certas probabilidades (observe que o conceito de probabilidade independe dessas fórmulas). Outro exemplo seriam as matrizes e os determinantes, usados na regressão com duas ou mais variáveis explicativas. Poderíamos também citar as derivadas parciais, usadas para a dedução das fórmulas do método dos mínimos quadrados. Se quiséssemos ir adiante, poderíamos ainda inserir nesse contexto os algoritmos das operações básicas de multiplicação, divisão, a raiz quadrada, potenciação e outros. Tais conteúdos, embora marginais, integram o campo conceitual da Estatística, fazem parte de seu conjunto Universo, porém, são sobretudo do domínio da Matemática. Entretanto, observamos que muitos professores gastam boa parte de seu tempo de aula explicando esses conteúdos, que supostamente seriam prioritários para a Estatística. Embora alguns possam discordar, entendemos que tais conteúdos podem, no domínio da Estatística, resolver-se mediante o auxílio da tecnologia (calculadoras, emuladores, computadores), visto que pouco (ou nada) contribuem para o desenvolvimento das três capacidades aqui ressaltadas como mais importantes. (CAMPOS, 2007, p.65,66) 
Deve-se salientar que esta proposta de Campos é bastante oportuna e condizente com a realidade da formação acadêmica do geógrafo (e de diversos outros profissionais) com relação à capacitação para apreensão de conceitos estatísticos que sirvam de suporte ao uso e entendimento de análise espacial de dados geográficos. Uma única disciplina ligada à estatística, oferecida em cursos de graduação em Geografia, muito provavelmente estaria transmitindo apenas os aspectos "marginais" da estatística. Os aspectos "marginais" (no contexto apontado acima por Campos) certamente não produzirão geógrafos consumidores de informação estatística.

Na prática, é comum a disciplina única de estatística ter como critério de avaliação, provas em que se tem que decorar as fórmulas para aplicá-las em problemas similares aos problemas de formatos "pré-moldados" apresentados durante as aulas. Parece então que o que se trabalha na disciplina única é a "estatística marginal".

Vale ressaltar que a "estatística marginal" tem seu valor, e Campos(2007) reconhece isso. Mas deve ser trabalhada após o entendimento conceitual que a circunda. Se, por exemplo, um aluno entende o conceito de média aritmética simples e suas propriedades, então se ele tem diante de si um grupo de dados cuja média é $X$ e a este grupo de dados for acrescentado um valor $Y$ menor que $X$, saberá que o novo valor da média será menor que o valor $X$. Uma vez que entenda de fato este conceito, pode então se debruçar sobre os aspectos "marginais" da média, no caso as fórmulas de cálculo da mesma.

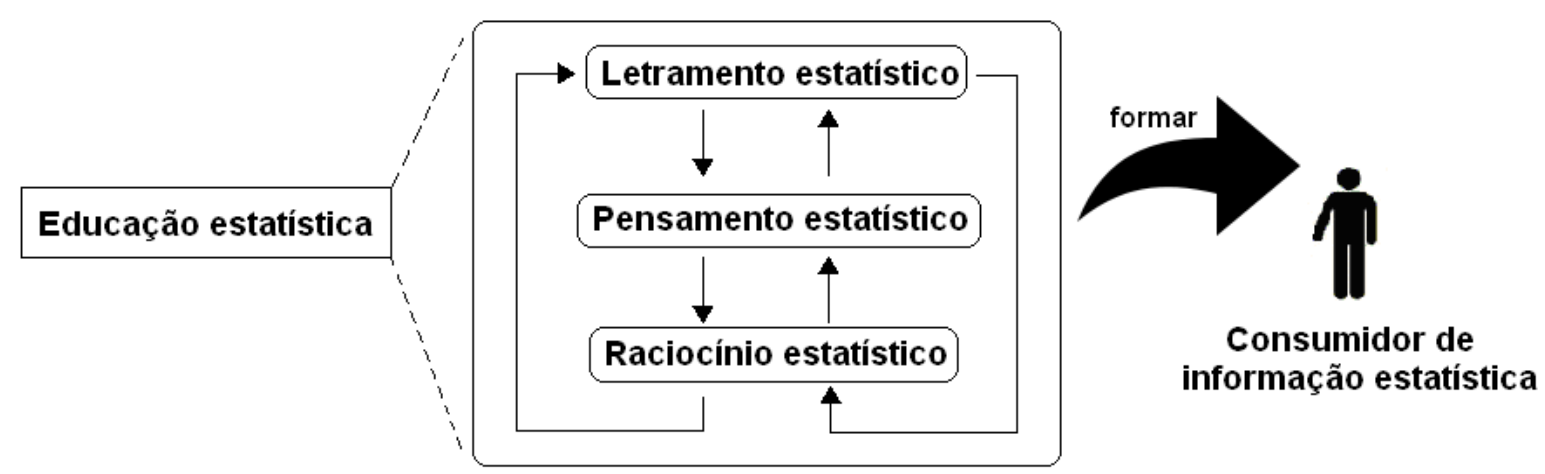

Figura 12 - O ápice da educação estatística: formar consumidor de informação estatística que também sabe produzir a mesma.

Fonte: Elaborado pelo autor.

Para finalizar a respeito das considerações sobre educação estatística apontadas anteriormente, é apresentado na Figura 12 um esquema conceitual que representaria, no 
escopo deste trabalho, o ápice da educação estatística, que é formar um consumidor de informação estatística, capaz também de ser produtor da mesma . O indivíduo que entende (“consome") a informação estatística que tem diante de si, certamente saberá (ou terá condições de saber) como ela foi produzida e mesmo se necessário, saberá produzi-la. É, portanto, um indivíduo completamente educado estatisticamente.

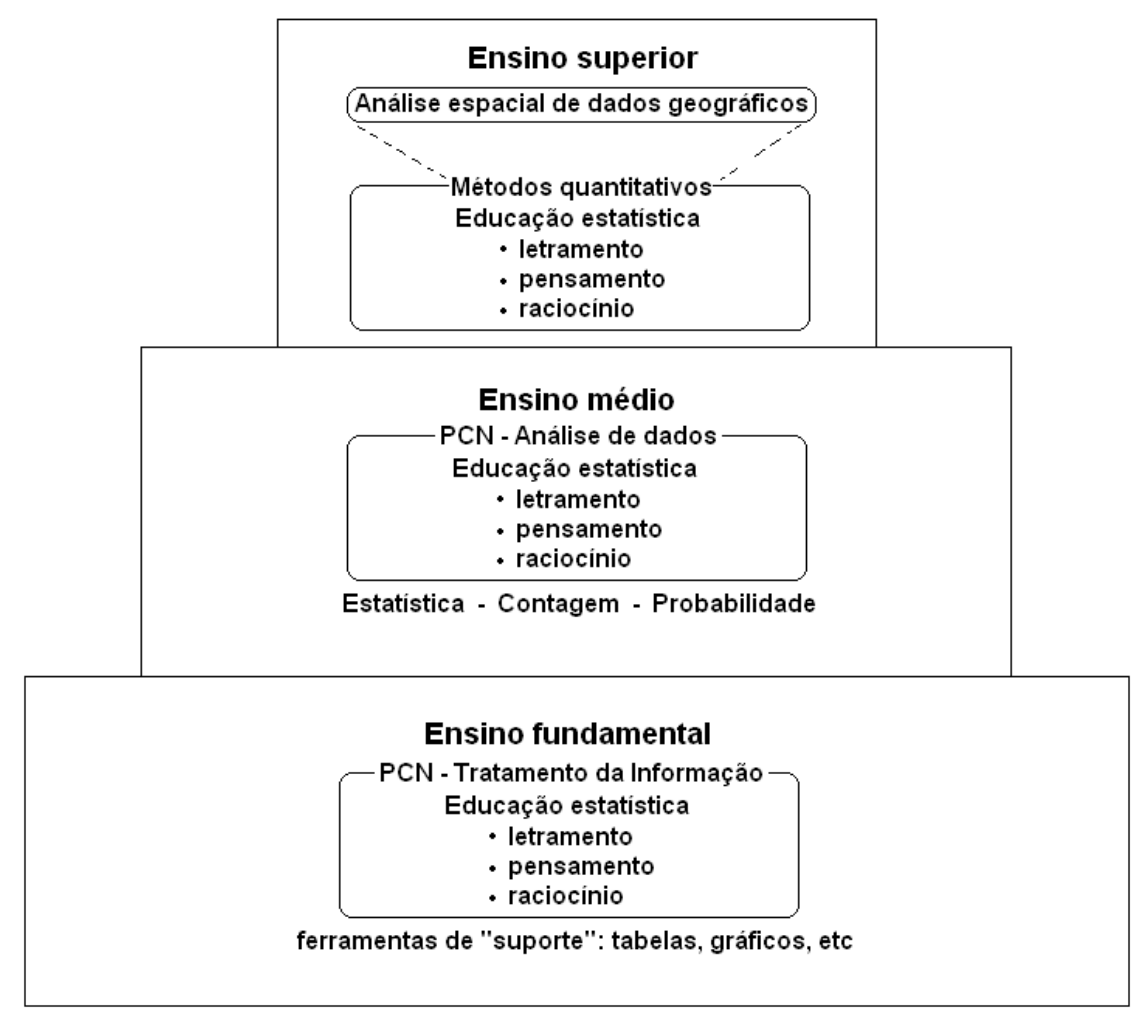

Figura 13 - Pirâmide de pilares de conhecimentos necessários para entendimento quantificação em análise espacial de dados geográficos (realçando a importância da educação estatística).

Fonte: Elaborado pelo autor.

Ao considerar os esforços das ações governamentais com vistas à melhoria da educação em geral, verifica-se que os PCN são produtos destas ações e seguramente aponta-se que, em última instância, a proposta dos PCN é a tentativa de construção de uma educação que propicie letramento, pensamento e raciocínio (não só na esfera estatística) ao educando. Desta forma, a pirâmide de pilares de conhecimentos necessários para entendimento de quantificação na análise espacial de dados geográficos apresentada na Figura 9 poderia ser redesenhada embutindo-se nela as dimensões da educação estatística. O resultado está apresentado na Figura 13. 
Na pirâmide da Figura 13 destaca-se a educação estatística. Como se observa, a educação estatística é um longo processo que se inicia (ou deveria ser iniciado) nas séries iniciais da escolarização formal do aluno do Ensino Fundamental. Vale dizer que o processo se inicia, mas não necessariamente termina após a conclusão do Ensino Superior. A educação estatística deve ser vista como um processo contínuo ao longo da vida profissional e da vivência como cidadão do indivíduo.

\subsection{APRENDIZAGEM SIGNIFICATIVA ATRAVÉS DE CONTEÚDO IMAGÉTICO}

$\mathrm{O}$ artefato tecnológico utilizado para ensino evoluiu significativamente nos últimos 40 anos. Quadro-negro, giz e livros impressos eram os artefatos tecnológicos das salas de aula nos anos 1970. Embora mais raro, havia também eventualmente a possibilidade de uso do gravador de fitas “K7”. Em meados dos anos 1980/1990 os retroprojetores, canetas apontadoras a laser, e os videocassetes tornam-se, às vezes, presença nas salas de aula.

Nos anos 2000 em diante, os computadores em diversas formas (desktops, smartphones, tables) aliados aos modernos projetores de imagem e áudio e à Internet são presença corriqueira em diversos ambientes, inclusive no ambiente escolar. Isto possibilita uma oportunidade ímpar para que, no âmbito do ensino, a transmissão do conhecimento via som e imagem ocorra de forma mais eficaz.

O som (apresentação oral do assunto por parte do professor) e a imagem desenhada no quadro negro do assunto apresentado nas salas de aula nos anos 1970 vão gradativamente se modificando, tornando-se meios com melhor qualidade advinda da natural evolução tecnológica dos equipamentos. A imagem estática que está no quadro-negro pode se tornar dinâmica, sendo projetada em movimento, acompanhada de sons com diferentes entonações que realçam os trechos do assunto apresentado em sala de aula.

Com o atual patamar tecnológico extremamente propício à produção e distribuição de som e imagem, a veiculação de conhecimento pode se tornar mais ampla e de melhor qualidade, proporcionando a real apreensão do conteúdo veiculado por parte do educando, desde que se saiba produzir som e imagem do assunto de interesse com a finalidade de transmissão de conteúdo com significado. Em essência, o contexto do "conteúdo com significado" representa a transmissão de som e imagem que proporcionem reflexão por parte do educando, e este processo de reflexão (instigado inicialmente pelo aparato de som e 
imagem das modernas tecnologias) resultará na efetiva apreensão do conhecimento que estiver em questão.

No escopo das teorias de aprendizagem, Oliveira e Chadwick (1982) comentam sobre a teoria de aprendizagem de David Ausubel. Segundo os autores,

essa teoria preocupa-se primordialmente com a aprendizagem de matérias escolares no que se refere à aquisição e retenção desses conhecimentos de maneira "significativa" (em oposição à matéria sem sentido, decorada ou aprendida mecanicamente) (...) O termo "significativo" (meaningful) opõese à aprendizagem de conteúdo sem sentido tal como memorização de paresassociados, de palavras ou sílabas sem sentido, etc". (OLIVEIRA e CHADWICK, 1982, p. 15)

O conceito de aprendizagem significativa foi proposto originalmente nos trabalhos sobre teoria de aprendizagem de David Paul Ausubel (1963, 1968). Sintetizando sua teoria de aprendizagem, o próprio Ausubel pondera que "se tivesse que reduzir toda a psicologia educacional a um só princípio, diria o seguinte: o fator isolado mais importante influenciando a aprendizagem é aquilo que o aprendiz já sabe. Determine isso e ensine-o de acordo" (AUSUBEL,1978, p. iv). Na teoria de Ausubel, segundo Tavares (2003),

existem três requisitos essenciais para a aprendizagem significativa: (1) a oferta de um novo conhecimento estruturado de maneira lógica; (2) a existência de conhecimentos na estrutura cognitiva que possibilite a sua conexão com o novo conhecimento; (3) a atitude explícita de apreender e conectar o seu conhecimento com aquele que pretende absorver. Esses conhecimentos prévios são também chamados de conceitos subsunçores ou conceitos âncora. Quando se dá a aprendizagem significativa, o aprendente transforma o significado lógico do material pedagógico em significado psicológico, à medida que esse conteúdo se insere de modo peculiar na sua estrutura cognitiva, e cada pessoa tem um modo específico de fazer essa inserção, o que torna essa atitude um processo idiossincrático. (TAVARES, 2003, p.56).

Moreira (1997) também enfatiza os principais aspectos da aprendizagem significativa de acordo com Ausubel. Segundo o autor, para Ausubel, 
aprendizagem significativa é o processo através do qual uma nova informação (um novo conhecimento) se relaciona de maneira não arbitrária e substantiva (não-literal) à estrutura cognitiva do aprendiz. É no curso da aprendizagem significativa que o significado lógico do material de aprendizagem se transforma em significado psicológico para o sujeito. (MOREIRA, 1997, p.19)

A não arbitrariedade significa que a nova informação (novo conhecimento) apresentada ao aprendiz relacionar-se-á não com qualquer aspecto de sua estrutura cognitiva, mas sim com conhecimentos previamente já estabelecidos na estrutura cognitiva do mesmo. Como aponta Tavares (2003), esses conhecimentos prévios são subsunçores, ou âncoras que possibilitam a conexão, a fixação da nova informação.

A substantividade (não literalidade) significa que o que fica retido na estrutura cognitiva do aprendiz é a "substância" do novo conhecimento (novas ideias), e não as palavras e/ou imagens e/ou sons que servem de simples meios de transmissão. Na Figura 14 é apresentado um esquema pictórico para representar a ideia de aprendizagem significativa do modelo ausubeliano.

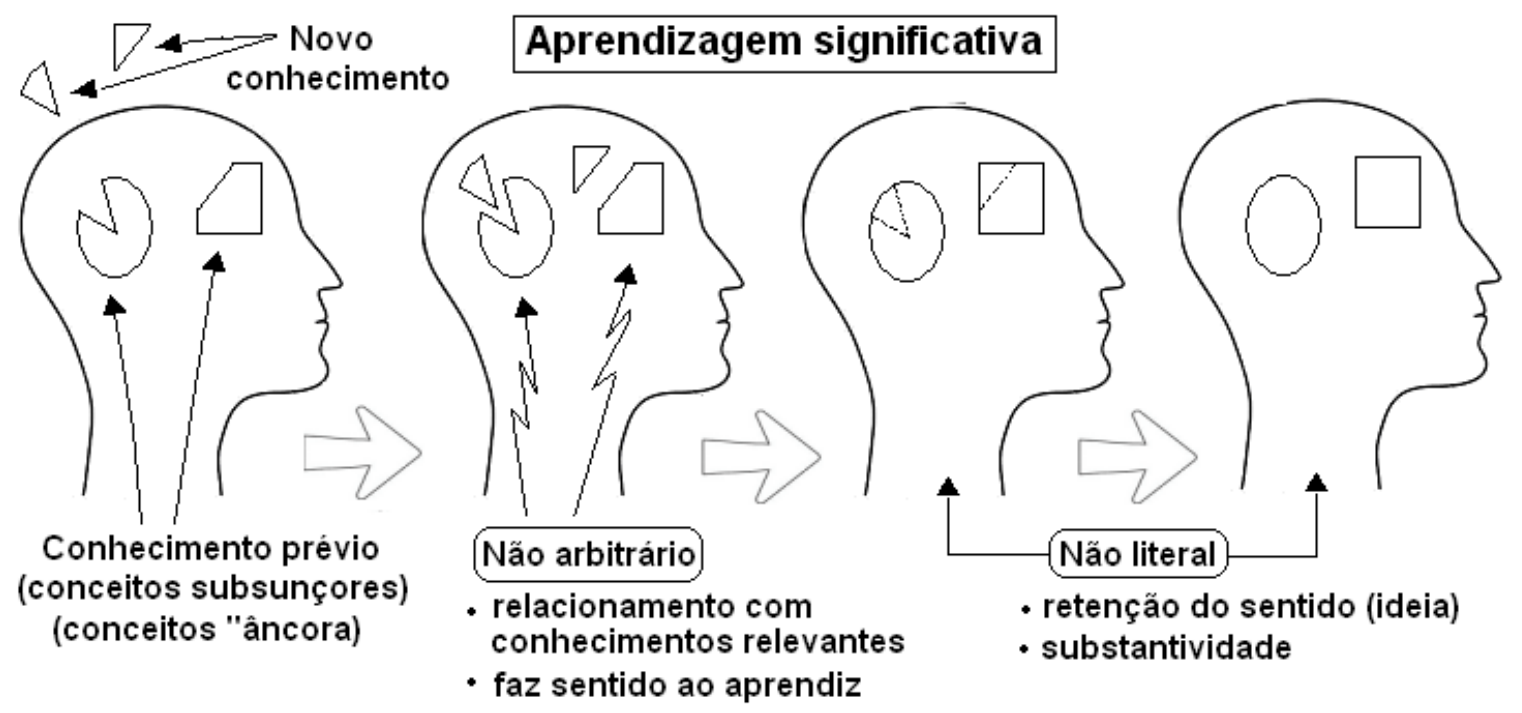

Figura 14 - Esquema pictórico para representar a ideia de aprendizagem significativa na teoria de Ausubel.

Fonte: Elaborado pelo autor.

É oportuno também considerar sobre a aprendizagem mecânica, oposta à aprendizagem significativa. Segundo Moreira (1997), 
quando o material de aprendizagem é relacionável à estrutura cognitiva somente de maneira arbitrária e literal que não resulta na aquisição de significados para o sujeito, a aprendizagem é dita mecânica ou automática. A diferença básica entre aprendizagem significativa e aprendizagem mecânica está na relacionabilidade à estrutura cognitiva: não arbitrária e substantiva versus arbitrária e literal. Não se trata, pois, de uma dicotomia, mas de um contínuo no qual elas ocupam os extremos. (MOREIRA, 1997, p.20)

Aprendizagem significativa e aprendizagem mecânica, podem então coexistir. De fato, Ausubel não descarta a possibilidade de aprendizagem mecânica. Segundo Tavares (2004),

\begin{abstract}
Ausubel sugere o uso da aprendizagem mecânica quando não existirem na estrutura cognitiva do aprendente ideias-âncora (subsunçor) que facilitam a conexão entre esta e a nova informação, quando não existirem ideias prévias que possibilitem essa ancoragem. Em uma dada circunstância, nos deparamos com a tarefa de aprender uma sequência de determinados conteúdos, sem ter tido a oportunidade de algum conhecimento próximo. Ele sugere que o conhecimento inicial seja memorizado e, a partir desse conhecimento absorvido, seja paulatinamente estruturado o conhecimento sobre o tópico considerado. (TAVARES, 2004, p.57)
\end{abstract}

Como o novo conhecimento a ser incorporado à estrutura cognitiva do aprendiz não encontra conceitos subsunçores (“âncoras”) prévios, ele será fixado de forma arbitrária e literal, cuja retenção em memória é bastante volátil, pois não tem sentido para o aprendiz. Este novo conhecimento é vulgarmente designado por "decoreba", que ocorre com frequência, por exemplo, quando o aprendiz estuda e decora fórmulas para aplicação em um exame escolar que irá realizar em breve. Na Figura 15 é apresentado um esquema pictórico para representar a ideia de aprendizagem mecânica, realçando o aspecto arbitrário e literal que o novo conhecimento tem para a estrutura cognitiva do aprendiz. 


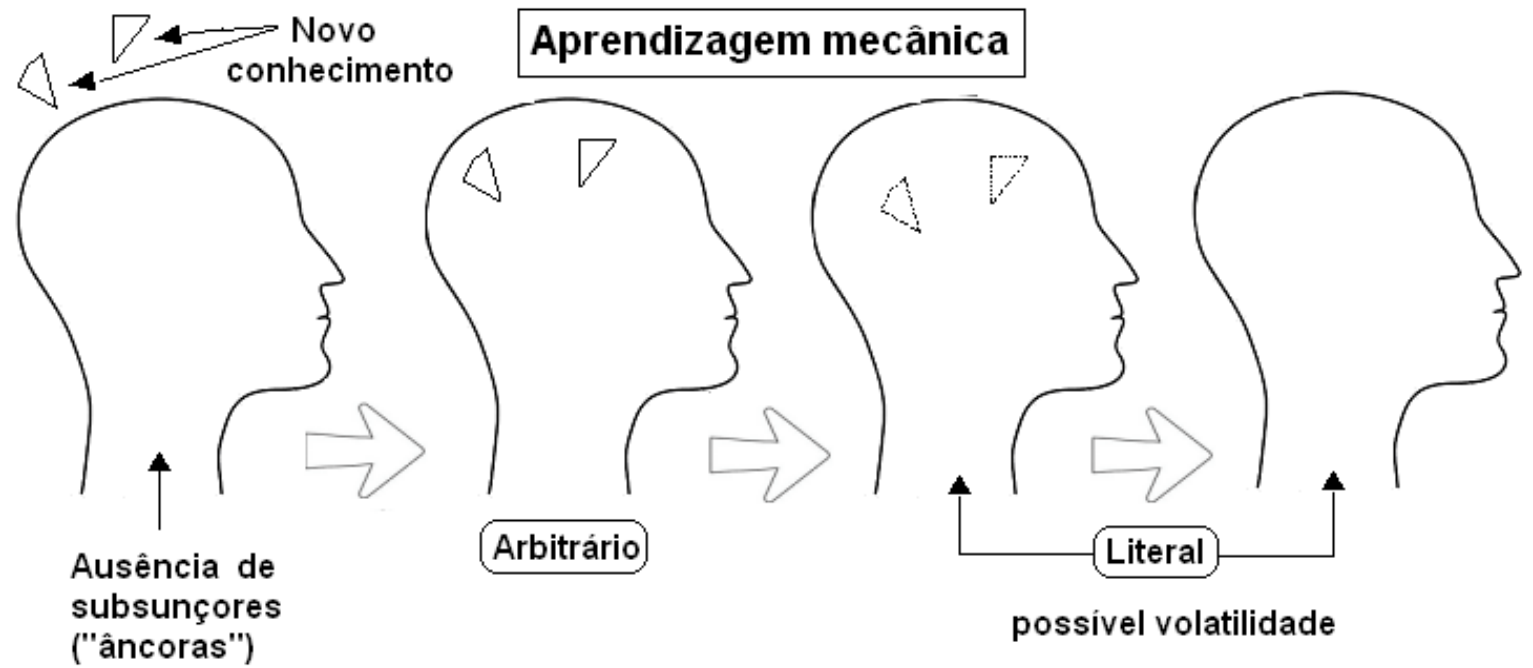

Figura 15 - Esquema pictórico para representar a ideia de aprendizagem mecânica.

Fonte: Elaborado pelo autor.

E a Figura 16 representa pictoricamente as aprendizagens mecânica e significativa que não são antagônicas, mas sim "um contínuo da qual elas fazem parte” (TAVARES, 2003).

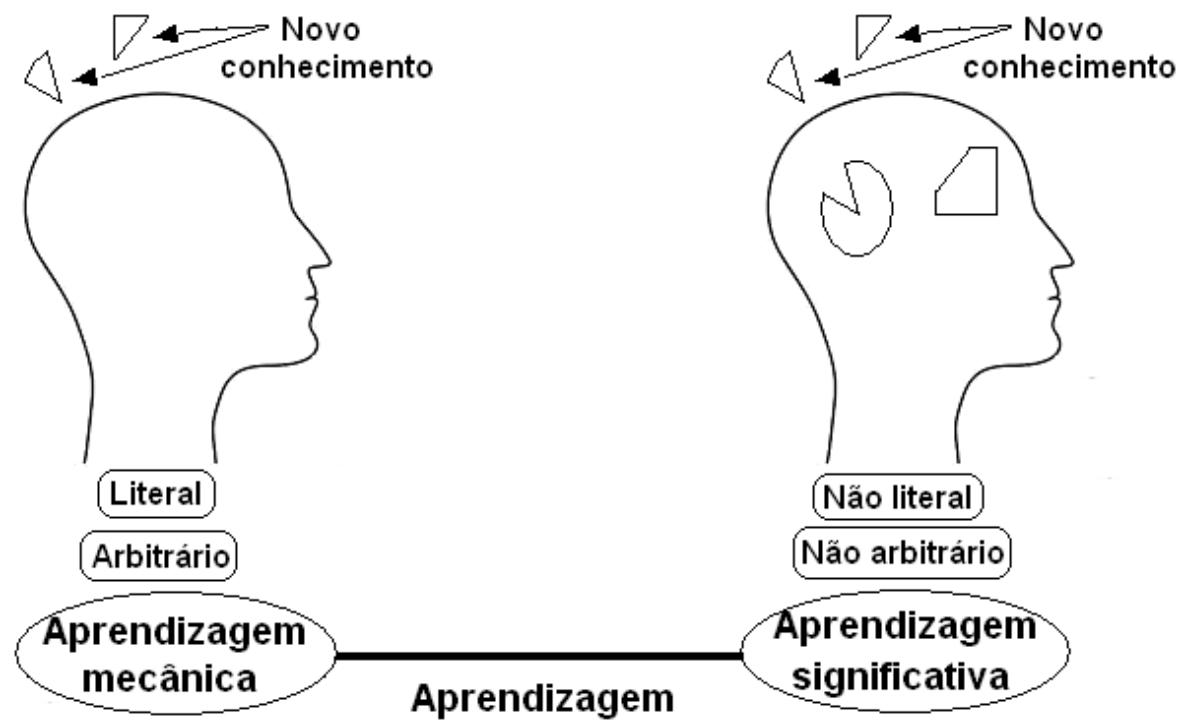

Figura 16 - Esquema pictórico para representar a ideia de contínuo das aprendizagens mecânica e significativa.

Fonte: Elaborado pelo autor.

Finalmente, com relação ao tema da aprendizagem significativa, deve-se ressaltar que também se leva em consideração na teoria ausubeliana de aprendizagem, conforme salienta Tavares (2004), "a atitude explícita de apreender e conectar o seu conhecimento com aquele 
que pretende absorver" (TAVARES, 2004, p. 56). Ou seja, para o êxito da empreitada da aprendizagem significativa é preciso que o aprendiz seja parte ativa do processo. O próprio autor comenta esta questão:

a aprendizagem significativa requer um esforço do aprendente em conectar de maneira não arbitrária e não literal o novo conhecimento com a estrutura cognitiva existente. É necessária uma atitude proativa, pois numa conexão uma determinada informação liga-se a um conhecimento de teor correspondente na estrutura cognitiva do aprendiz; e em uma conexão não literal a aprendizagem da informação não depende das palavras específicas que foram usadas na recepção da informação. Desse modo, podemos ter uma aprendizagem receptiva significativa em uma sala de aula convencional, onde se usam recursos tradicionais tais como giz e quadro-negro, quando existiram condições de o aprendente transformar significados lógicos de determinado conteúdo potencialmente significativo, em significados psicológicos, em conhecimento construído e estruturado idiossincraticamente. (TAVARES, 2004, p.56)

Em outras palavras, o aprendiz deve apresentar motivação ("uma atitude proativa") para a eficácia da aprendizagem significativa. Mas, segundo Oliveira e Chadwick (1982),

diferentemente de muitos autores que colocam a motivação como 'causa' da aprendizagem Ausubel diz (Ausubel, 1968, p.365-366): “a relação causal entre motivação e aprendizagem é mais recíproca do que unidirecional. Por esta razão, e também pelo fato de que motivação não é uma condição indispensável para aprendizagem, é desnecessário adiar atividades de aprendizagem até que interesses apropriados ou motivações sejam desenvolvidos. Frequentemente, a melhor maneira de ensinar a um estudante não motivado é ignorar seu estado motivacional por certo tempo, e concentrar-se em ensinar, tão efetivamente quanto possível. Alguma aprendizagem vai-se instaurar, apesar da falta de motivação. E, a partir da satisfação inicial por ter aprendido algo, espera-se que irá desenvolver a motivação para aprender mais". (OLIVEIRA e CHADWICK, 1982, p. 123) 
Pelo que se depreende das colocações, para Ausubel motivação não é pré-requisito para aprendizagem, mas, de fato, tem sua importância, pois ela será um fator (ainda que ocorra posteriormente) que irá efetivamente colaborar para a cristalização de conceitos subsunçores (conceitos "âncora") na estrutura cognitiva do aprendiz. Assim, não é incongruência considerar a motivação como tema importante para que ocorra a aprendizagem significativa.

Experiências diversas que não sejam centradas no tradicional ensino "giz e cuspe", onde o professor é o centro do processo ensino-aprendizagem estão sempre sendo propostas. Particularmente, existem tentativas de empreender um ensino com aprendizagem significativa, com foco na transmissão do conhecimento via imagem.

Sobre o uso de imagens, Coutinho et. al. (2010) comentam que

segundo Pozzer-Ardenghi e Roth (2005), as imagens são singularmente importantes para a construção do conhecimento científico. Elas constituem um meio amplamente aceito no diálogo científico, tendo um potencial particular para comunicar aspectos da natureza e para indicar o conteúdo de ideias. (POZZER-ARDENGHI e ROTH (2005) apud COUTINHO et. al., 2010, p.3)

O propósito do trabalho de Coutinho et. al. (2010) é analisar o valor didático de imagens presentes em quatro coleções de livros de Biologia para o Ensino Médio. O referencial teórico deste trabalho se baseia (1) no modelo de memória operacional e (2) na teoria da carga cognitiva (COUTINHO et. al., 2010, p.1). O trabalho consistiu, essencialmente, em considerar toda a informação dos livros que não se apresentassem em formato textual, como sendo imagem. Assim, figuras, esquemas, desenhos, fotos e diagramas são imagens. Os autores analisaram então todas as imagens dos livros selecionados e realizaram uma classificação da utilidade da imagem como recurso didático eficaz. Segundo os autores,

inicialmente, as imagens foram classificadas de acordo com quatro categorias: "decorativa", "representacional", "organizacional" e "explicativa" (Mayer, 2001, p. 76-77). Após, para a análise do valor didático das imagens, foram utilizados três princípios advindos da teoria cognitiva: coerência, sinalização e contigüidade. Posteriormente, as imagens foram 
categorizadas como "sem valor didático", "com carga cognitiva alta" aquelas de difícil leitura pelo aluno - e "com carga cognitiva baixa" aquelas de mais fácil leitura pelo aluno. Encontrou-se uma alta prevalência de imagens "sem valor didático" e "com carga cognitiva alta", em detrimento das imagens "com carga cognitiva baixa". Isto pode dificultar a organização e processamento das informações na memória operacional do leitor e prejudicar o processo de aprendizagem. (COUTINHO et. al., 2010, p.1)

Em essência, pelo que se depreende das colocações de Coutinho et. al. (2010) uma imagem que seja didaticamente eficaz é uma imagem com "carga cognitiva baixa", ou, em outras palavras, imagem com carga cognitiva baix potencializa a aprendizagem significativa.

Moimaz (2009) realizou um trabalho de ensino de História para alunos do $1^{\circ}$ e $2^{\circ}$ ano do Ensino Médio com foco na interpretação de pinturas, por parte dos alunos, para entendimento de determinado contexto histórico. Segundo a autora, "a partir da década de 1980, houve um repensar do ensino de História, sendo proposto o uso de diferentes linguagens culturais em sala de aula" (MOIMAZ, 2009, p. 5) E de acordo com a autora, a experiência de uso da imagem para aprendizagem significativa foi positiva:

a leitura das pinturas permite a construção do conhecimento histórico. $\mathrm{O}$ primeiro contato com a obra, a identificação do tema, a reflexão sobre os elementos apresentados, ou melhor, a consciência do que se vê, a interpretação do fato apresentado na obra e sua contextualização são operações fundamentais as quais possibilitam, concomitantemente, a leitura e compreensão da obra e a construção do conhecimento. Observamos os resultados positivos referentes ao uso da pintura histórica em sala de aula quando realizamos uma investigação com alunos do Ensino Médio. Esses alunos estudaram o tema "descobrimento do Brasil" por meio das pinturas históricas "Descoberta do Brasil" (1922) e "Índios a bordo da nau capitânia" (c. 1900) de Oscar Pereira da Silva, "Primeira Missa" (1861) de Victor Meirelles e "Elevação da Cruz" (1879) de Pedro Peres. A pintura estabelece uma narrativa. Ao produzirem mapas conceituais, os alunos construíram uma narrativa em torno do tema estudado, organizando as informações e os conceitos históricos e demonstrando compreender a história narrada nas 
pinturas, relacionando-a com as informações dispostas em outros textos, bem como dialogando com seus conhecimentos prévios. (MOIMAZ, 2009, p. 5)

Gibin e Ferreira (2013) avaliaram o uso de imagens como recurso auxiliar para o ensino de conceitos de Química. Argumentam favoravelmente ao uso de imagens no ensino da seguinte forma:

nas situações de ensino e aprendizagem, a introdução de imagens que somente embelezam o texto não proporciona melhorias na aprendizagem dessas informações. As ilustrações empregadas em um livro didático que repetem as informações contidas em texto produzem um efeito positivo sobre a aprendizagem. Em alguns casos, é possível utilizar as ilustrações para substituir, com eficiência, um texto escrito. A simples presença de uma imagem não facilita nem dificulta necessariamente $o$ processo de aprendizagem. O uso de ilustrações adequadas facilita a compreensão de textos e melhora a memorização, especialmente a de longo prazo. Muitas vezes, os leitores podem apresentar dificuldade para compreender as ilustrações complexas se não for fornecido nenhum subsídio no momento da leitura e, além disso, muitos geralmente fazem uma leitura superficial das imagens, pois não esperam que elas apresentem informações relevantes. As imagens provocam reações afetivas e são mais atraentes do que as palavras. Por fim, quando os estudantes são motivados a elaborarem suas próprias imagens mentais, a partir das imagens impressas, apresentam resultados mais positivos em relação à aprendizagem. (GIBIN e FERREIRA, 2013, p. 20)

Vale realçar a colocação dos autores quanto ao fato de que a simples presença da imagem não irá necessariamente facilitar ou dificultar a aprendizagem, mas o uso de imagens adequadas podem colaborar com a aprendizagem efetiva. No caso do trabalho dos autores, foi construído um banco de imagens por meio do uso de recursos computacionais como o programa de ilustração CorelDRAW 10 e eventualmente o editor de imagens Photoshop 6.0. As imagens produzidas abordavam representações de reações químicas, modelos atômicos, esquemas de separações de misturas, estados físicos da matéria e até mesmo gráficos e tabelas. E numa experiência de ensino em sala de aula sobre ácidos e bases usando imagens projetadas via retroprojetor, os autores relatam que 92,5\% dos 35 alunos de uma turma de 
Ensino Médio do $3^{\circ}$ ano afirmaram que tiveram uma compreensão boa ou muito boa sobre o assunto após esta aula.

Heckler et. al. (2007) desenvolveram, para o ensino de óptica no Ensino Médio, um aplicativo em linguagem $\mathrm{html}$, com 77 animações e utilizaram 13 simuladores (Java Applets) disponíveis na Internet sobre o assunto e utilizaram este material para ensino para 40 alunos de duas turmas do $3^{\circ}$ ano. Os autores ponderam que

o ensino de Física no Brasil ainda enfrenta várias dificuldades de aprendizagem e pouco interesse por boa parte dos alunos. Fazendo um paralelo entre a sociedade da informação e o ambiente de ensino tradicional, de um lado encontramos a evolução rápida dos computadores e das telecomunicações afetando todos os níveis da sociedade, da vida profissional à vida privada. Do outro, visualizamos uma escola onde o professor apresenta aulas em quadro negro e giz, visto pelos alunos como o dono da informação e senhor do conhecimento, mas desestimulando a criatividade e o envolvimento dos aprendizes. Para a maior parte dos alunos, a Física não passa de um conjunto de códigos e fórmulas matemáticas a serem memorizadas e de estudos de situação que, na maioria das vezes, estão totalmente alheias às suas experiências cotidianas. Em geral, estes alunos não fazem uma conexão entre a Física aprendida e o mundo ao seu redor. Entre as causas desse reconhecido fracasso no aprendizado de Física está a falta de uma metodologia moderna, tanto do ponto de vista pedagógico quanto tecnológico. (HECKLER et. al., 2007, p. 267)

Os autores disponibilizaram o material produzido para duas turmas do $3^{\circ}$ ano do Ensino Médio e, segundo os autores, ao serem questionados sobre a utilidade deste material interativo, $82 \%$ dos alunos responderam que foi importante para o entendimento do assunto estudado. E analisando as opiniões dos alunos, relataram que os materiais de fato proporcionaram um ambiente de estimulo, motivação e envolvimento no processo de ensino/aprendizagem, fazendo que os mesmos participassem ativamente da aquisição de informações e construção do conhecimento. Além disso, o material despertou maior interesse pelas aulas de Física na visão de $95 \%$ dos alunos.

Honda (2013) relata a experiência de ensino de forma marcantemente interdisciplinar de Matemática e Geografia abrangendo atividades de exploração de espaços geográficos representados sob o ponto de vista da Geografia pelo globo terrestre e por projeções 
cartográficas (em mapas), e sob o ponto de vista da Matemática representados por esferas, planos cartesianos, pontos e retas no contexto da Geometria Euclideana e Riemaniana. O espaço geográfico é representado por formas imagéticas em diferentes escalas e, aproveitando-se deste fato, a autora procurou proporcionar um ensino, para alunos do $6^{\circ}$ e $9^{\circ}$ anos do Ensino Fundamental, baseado em atividades concretas de manuseio de imagens (globo e mapas). O espaço geográfico representado nas imagens foi explorado de forma quantitativa (distância entre pontos, cálculo de áreas, projeções planas, etc). Diante do material imagético, os alunos trabalharam com coordenadas geográficas, coordenadas cartesianas, forma e medidas da Terra, sistemas de coordenadas e fusos horários. Segundo a autora, após as atividades os alunos demostraram, em geral, terem aprendido o que foi trabalhado nas atividades, o que segundo a autora é um indicativo positivo obtido pelo trabalho de forma interdisciplinar.

Neste contexto, o novo conhecimento a ser aprendido de forma significativa pelo aprendiz, pode então ter como meio de transmissão não somente o som (linguagem verbal) e a escrita, mas também a imagem. Mas como apontam Gibin e Ferreira (2013), não servem imagens que "somente embelezam o texto". Aliás, as imagens que somente embelezam o texto segundo estes autores seriam as imagens categorizadas como "decorativas" ou "representacionais" no trabalho de Coutinho et. al. (2010) que seriam sem valor didático.

É portanto preciso saber criteriosamente escolher a imagem que irá proporcionar reflexão (não literalidade) na estrutura cognitiva do aprendiz, ou seja, a imagem que transmite sentido lógico passível de ser transformado em sentido psicológico para o mesmo.

Cecatto (2013) comenta sobre o uso da imagem além de seu possível aspecto meramente ilustrativo:

em nosso século, as imagens ocupam lugar exponencial, perpassando pela sociedade e adentrando os espaços educacionais. Consoante Circe Bittencourt (2009: 360), o uso de imagens para fins de pesquisa e ensino tem se destacado e ao mesmo tempo exigido dos professores tratamento metodológico adequado a fim de que sua utilização não se limite ao aspecto ilustrativo para chamar a atenção dos estudantes (AUMONT, 1993; BARBOSA, 2009; BORGES, 2003; CHARTIER, 1993; JOLY, 1996; KORNIS, 1992; NAPOLITANO, 2006; PAIVA, 2006; PESAVENTO, 2008; SANTAELLA e NÖTH, 2008) (...) A utilização de iconografias requer compreender o contexto de produção, as intencionalidades de quem a produziu, a fim de utilizá-la como fonte de pesquisa e ensino, para não 
cometer anacronismos, e assim, ultrapassar os aspectos ilustrativos. Nesse sentido, independente da imagem que nos é apresentada, saber elaborar a leitura do material visual considerando as especificidades das imagens, permitirá ampliar a capacidade informativa. Esta não exclui a linguagem escrita e vice versa, pois ambas se complementam, compartilham e trocam mensagens e significados (CECATTO, 2013, p.2-3)

O uso de imagens para ensino de técnicas de quantificação diversas pode ser um recurso que favoreça a aprendizagem significativa, desde que a imagem utilizada vá além do caráter de ilustração e "embelezamento" do texto que a acompanha. Isto deve ser levado em consideração, pois atualmente diversos softwares são usados para ensinar técnicas quantitativas e o apelo que se faz é que as imagens produzidas pelo software irão contribuir para o efetivo aprendizado do usuário. Por exemplo, não raro encontram-se tutoriais com o objetivo de ensinar estatística através do uso de planilha eletrônica, ou mesmo tutoriais que ensinam o manuseio de um software de processamento de imagens, ou o manuseio de um software de SIG.

O problema é que há um risco potencial de tais tutoriais servirem apenas ao aprendizado mecânico, onde se aprendem digitações de fórmulas em planilhas e cliques de mouse que realizam determinadas operações tais como construção de gráficos diversos (histogramas, gráficos de barras, gráficos de setores, etc), testes estatísticos de hipótese, sobreposições de mapas temáticos diversos, realces em imagens de satélites, etc. Usar as imagens destes tutoriais significa usar apenas seus aspectos "ilustrativos". Significa, conforme aponta Campos (2007, p. 65), lidar "com o cálculo puro ou com o uso da tecnologia". Seria, enfim, lidar com os "aspectos marginais da Estatística" que contribuem pouco ou quase nada com o letramento, pensamento e/ou raciocínio estatístico do aprendiz.

Na Figura 17 observa-se o detalhe de um software que, se for usado como tutorial que orienta como realizar regressão linear simples, na verdade apenas ensina mecanicamente o que clicar para gerar a reta de regressão. Nada ensina sobre os conceitos de regressão em si. Então, como tutorial, o software só tem serventia para ensinar "aspectos marginais" do assunto. 


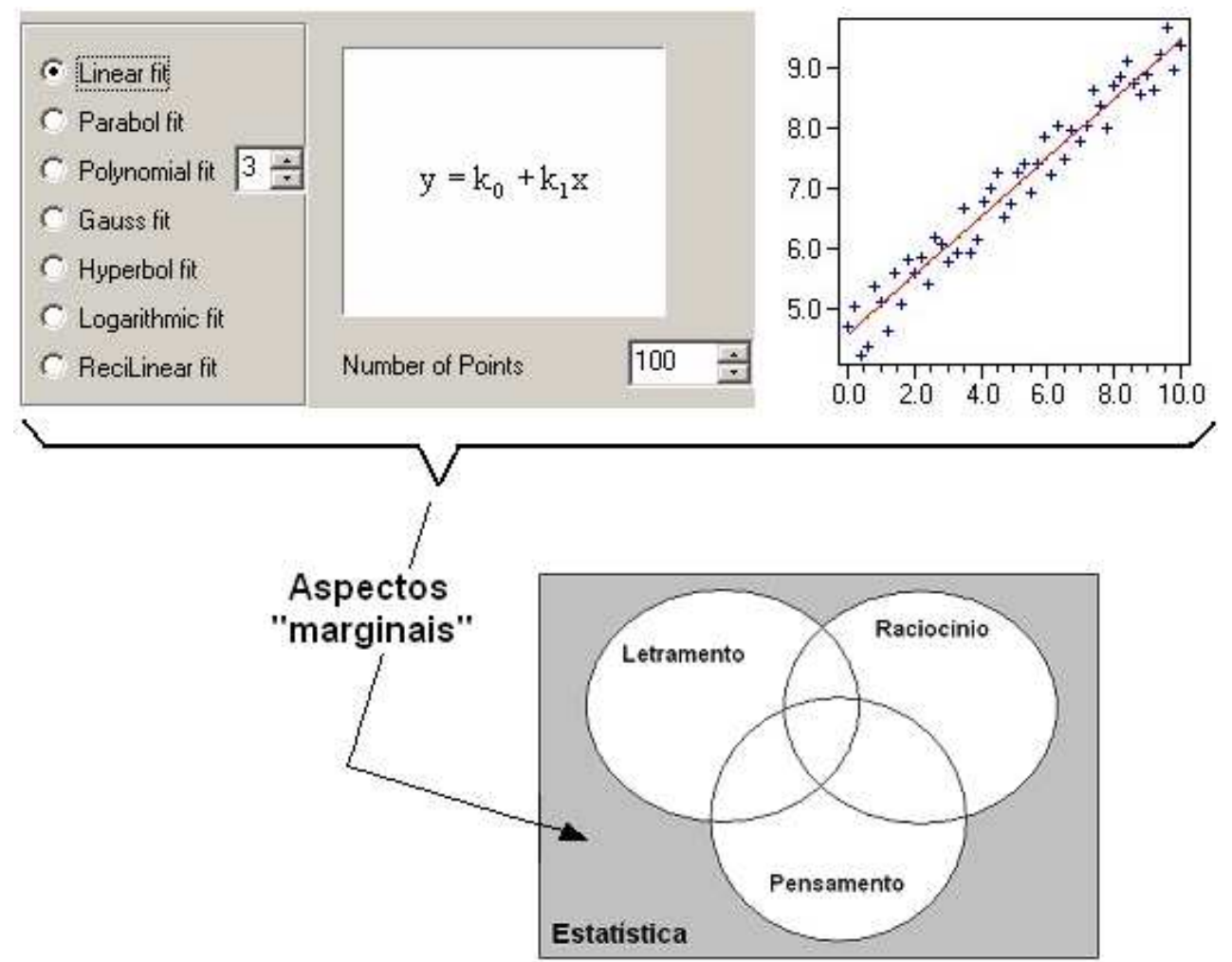

Figura 17 - Interface de um software que se for usado para ensino, transmite apenas os "aspectos marginais" da Estatística.

Fonte: Elaborado pelo autor.

O que se espera então da construção de softwares que usem imagens para ensino de técnicas de quantificação visando aprendizagem significativa, é a criação de imagens que ultrapassem o aspecto meramente ilustrativo e se tornem, de fato, imagens que veiculem informação para o aprendiz, imagens que carreguem sentido lógico e se transformem em sentido psicológico em sua estrutura cognitiva.

Conforme pondera Cecatto (2013), a linguagem imagética não exclui a linguagem escrita e vice versa, ao contrário, "ambas se complementam, compartilham e trocam mensagens e significados" (CECATTO, 2013, p.3). E Coutinho et. al. (2010) comentam sobre o princípio da contiguidade espacial, considerado básico para que uma imagem tenha valor didático. Segundo este princípio, a imagem e o texto sobre o assunto de interesse devem estar o mais próximo possível no meio de veiculação. Por exemplo, se o texto e a imagem (que não embeleza o texto) de determinado tema aparecem na mesma página do livro (ou outro meio) lado a lado, então esta contiguidade espacial da imagem e do texto tem maior potencial de proporcionar aprendizagem significativa. 
Então, considerando-se o princípio de contiguidade espacial, podemos ter, na mesma página de um livro, ou na mesma tela de um software, uma imagem (figura, desenho, foto, diagrama, gráfico, esquema), um texto escrito e, se for o caso, símbolos (fórmulas da Matemática, da Física, da Química, da Cartografia, etc). E caso o meio seja um software, o som pode complementar o material, além de a imagem, o texto escrito e os símbolos eventualmente serem apresentados de forma dinâmica (imagem animada).

Assim, no escopo deste trabalho, um conteúdo imagético (uma imagem) deve ser entendido como a utilização da imagem como usualmente é entendida, mas também, um conteúdo imagético pode se constituir, ao mesmo tempo, de imagem, de texto escrito e símbolos, animados ou não, e com uso do som. Esta colocação é pertinente uma vez que, neste trabalho, o software desenvolvido com o intuito de proporcionar aprendizagem significativa de conceitos relativos à quantificação baseia-se totalmente na produção de telas compostas por imagem, texto escrito e símbolos em contiguidade espacial, constituindo-se assim no conteúdo imagético que, espera-se, tenha valor didático, ou seja, proporcione aprendizagem significativa do conteúdo veiculado ao usuário que interage com a tela do software. 


\section{CAPÍTULO 2}

\section{MATERIAIS E MÉTODOS}

\subsection{INTRODUÇÃO}

Observando-se as duas hipóteses de pesquisa deste trabalho, apresentadas na Introdução (pág. 19), pode-se perceber que, para ambas as hipóteses dispostas em regras em formato SE...ENTÃO..., caso seus antecedentes sejam verdadeiros os consequentes das regras são delineados de forma subjetiva.

Afinal, como definir precisamente uma capacitação nula ou insuficiente caso o geógrafo tenha tido insuficiência de conteúdos de técnicas quantitativas em sua escolarização formal? E como definir precisamente a melhora da capacitação do geógrafo para realização de análises espaciais de dados geográficos caso haja disponível um software tutor para ensino de técnicas de análises espaciais de dados geográficos?

Assim, neste contexto, a opção metodológica escolhida para pesquisa de investigação das duas hipóteses deste trabalho foi a da pesquisa qualitativa. Segundo Godoy,

hoje em dia a pesquisa qualitativa ocupa um reconhecido lugar entre as várias possibilidades de se estudar os fenômenos que envolvem os seres humanos e suas intrincadas relações sociais, estabelecidas em diversos ambientes. (GODOY, 1995, p.21)

Segundo a autora, existem três tipos de pesquisa qualitativa: (1) pesquisa documental, (2) estudo de caso e (3) etnografia. E sobre a etnografia a autora comenta que

é comum associarmos a pesquisa etnográfica com a antropologia, onde ela tem sido tradicionalmente empregada em estudos com populações primitivas e minorias culturais. Hoje ela é utilizada também na exploração de temáticas associadas a outras áreas do conhecimento, como, por exemplo, a educação, a psicologia social e a administração de empresas. $\mathrm{Na}$ administração de empresas, os estudos de cultura organizacional, conforme propostos e desenvolvidos por VanMaanen, ilustram essa possibilidade. (...) Um 
etnógrafo pode centrar seu trabalho sobre uma tribo indígena com pouco contato com a civilização, uma comunidade de alemães no Estado de Santa Catarina, ou determinada ocupação dentro de uma fábrica. O trabalho de campo é o coração da pesquisa etnográfica, pois sem um contato intenso e prolongado com a cultura ou grupo em estudo será impossível ao pesquisador descobrir como seu sistema de significados culturais está organizado, como se desenvolveu e influencia o comportamento grupal. (GODOY, 1995, p. 27-28)

Desta forma, a pesquisa qualitativa deste trabalho pode ser enquadrada como sendo de tipo etnográfica, onde o grupo social de interesse a ser estudado são os graduandos de cursos de Geografia do País e o fenômeno de interesse deste grupo a ser investigado refere-se a sua formação para atuar com quantificação aplicada em análise espacial de dados geográficos.

Ainda com relação à aplicação de pesquisa qualitativa, Godoy (1995) aponta que "considerando que a abordagem qualitativa, enquanto exercício de pesquisa, não se apresenta como uma proposta rigidamente estruturada, ela permite que a imaginação e a criatividade levem os investigadores a propor trabalhos que explorem novos enfoques" (GODOY, 1995, p. 23). Assim, neste trabalho, para analisar (1) se a formação acadêmica do geógrafo o capacita a realizar quantificação na análise espacial de dados geográficos e (2) se a existência de um software tutor para ensino de conceitos básicos de técnicas quantitativas de análise espacial de dados geográficos poderia auxiliar na efetiva aprendizagem de tais conceitos, foram realizadas diversas atividades de coleta de dados que pudessem fornecer subsídios a estas questões.

Procedeu-se a um levantamento da matriz curricular de alguns cursos de graduação de Geografia no País para observar as disciplinas oferecidas ligadas ao ensino de quantificação. Além disso, foi planejado o desenvolvimento de um software tutor para ensino de alguns conceitos de quantificação usados na análise espacial de dados geográficos.

Com base na teoria de aprendizagem significativa de Ausubel, na premissa de que o aprendiz só aprende com base naquilo que já sabe, ou seja, só aprende um novo conhecimento se possuir previamente conceitos subsunçores (conceitos "âncora"), considerou-se, no escopo deste trabalho, ser importante conhecer a bagagem de conhecimentos de Matemática e Estatística que o graduando de Geografia adquiriu durante sua vida escolar no Ensino Fundamental e Ensino Médio, pois é este conhecimento que serve de base ("âncora”) para o 
aluno aprender quantificação aplicada à Geografia (para análise espacial de dados geográficos) durante sua formação acadêmica no Ensino Superior.

Uma vez detectados o nível de conhecimentos básicos de matemática e estatística do graduando em Geografia obtidos nos ensinos Fundamental e Médio, foi definido o tipo de conteúdo a ser embutido no software tutor. Para que o conteúdo não ficasse extenso, foi definido que o conteúdo, em princípio, seria ou análise espacial de padrões de eventos pontuais ou então análise espacial de padrões de área com contagens. A proposta do software, independentemente do assunto, foi apresenta-lo primordialmente via imagens que, espera-se, ultrapassem o aspecto "ilustrativo" e sejam, de fato, veiculadoras de sentido lógico que se transformem em sentido psicológico na estrutura cognitiva do aprendiz.

Para averiguar o conhecimento básico do graduando em Geografia em quantificação foi elaborada uma apostila com conceitos básicos de Estatística Descritiva e usada como material de ensino em uma turma de alunos do curso de Geografia, para sondagem inicial da familiaridade dos mesmos com conceitos matemáticos. Posteriormente, foi também elaborado um questionário para mapeamento da familiaridade do aluno com conceitos matemáticos básicos. O software tutor desenvolvido foi denominado EDH. Em paralelo à construção do $\mathrm{EDH}$, foram realizadas, em duas oportunidades (agosto/2013 e março/2015), nas turmas da disciplina Climatologia Geral do curso de Geografia da UnB, a intervenção nas aulas com o propósito de apresentar alguns conceitos básicos de quantificação (média, variância, desvio padrão e coeficiente de variação), usando o software EDH. Além disso, o software EDH foi utilizado uma vez como material didático na disciplina Tópicos Especiais em Geografia no curso de Mestrado/Doutorado em Geografia na UnB (março/2014), com o propósito de ser avaliado pelos alunos que cursaram a disciplina.

Finalmente, posteriormente à construção do EDH foi oferecido um curso de extensão onde foi utilizado como material didático o referido software. Os participantes do curso faziam a leitura das lições embutidas no EDH e em seguida respondiam a um questionário (teste) sobre os conceitos tratados nas lições. O questionário serviu de base para avaliação da eficácia do software como recurso que proporcionasse melhorias no ensino de técnicas de quantificação, ou seja, se teria utilidade no âmbito de uma aprendizagem significativa.

No escopo desta pesquisa, todos os questionários aplicados junto aos alunos foram avaliados de forma subjetiva, dada a natureza qualitativa da mesma. Assim, os questionários de avaliação de familiaridade do aluno com conceitos matemáticos e os questionários 
aplicados no curso de extensão e aulas em turmas do curso de Geografia não foram mensurados quantitativamente (com notas de 0 a 10, por exemplo), mas sim qualitativamente.

Na Figura 18 abaixo é apresentado um fluxograma das atividades de coleta de dados realizadas no escopo deste trabalho. E nos tópicos 2.2 a 2.9 a seguir são apresentados os detalhes das nove atividades apresentadas na Figura 18.
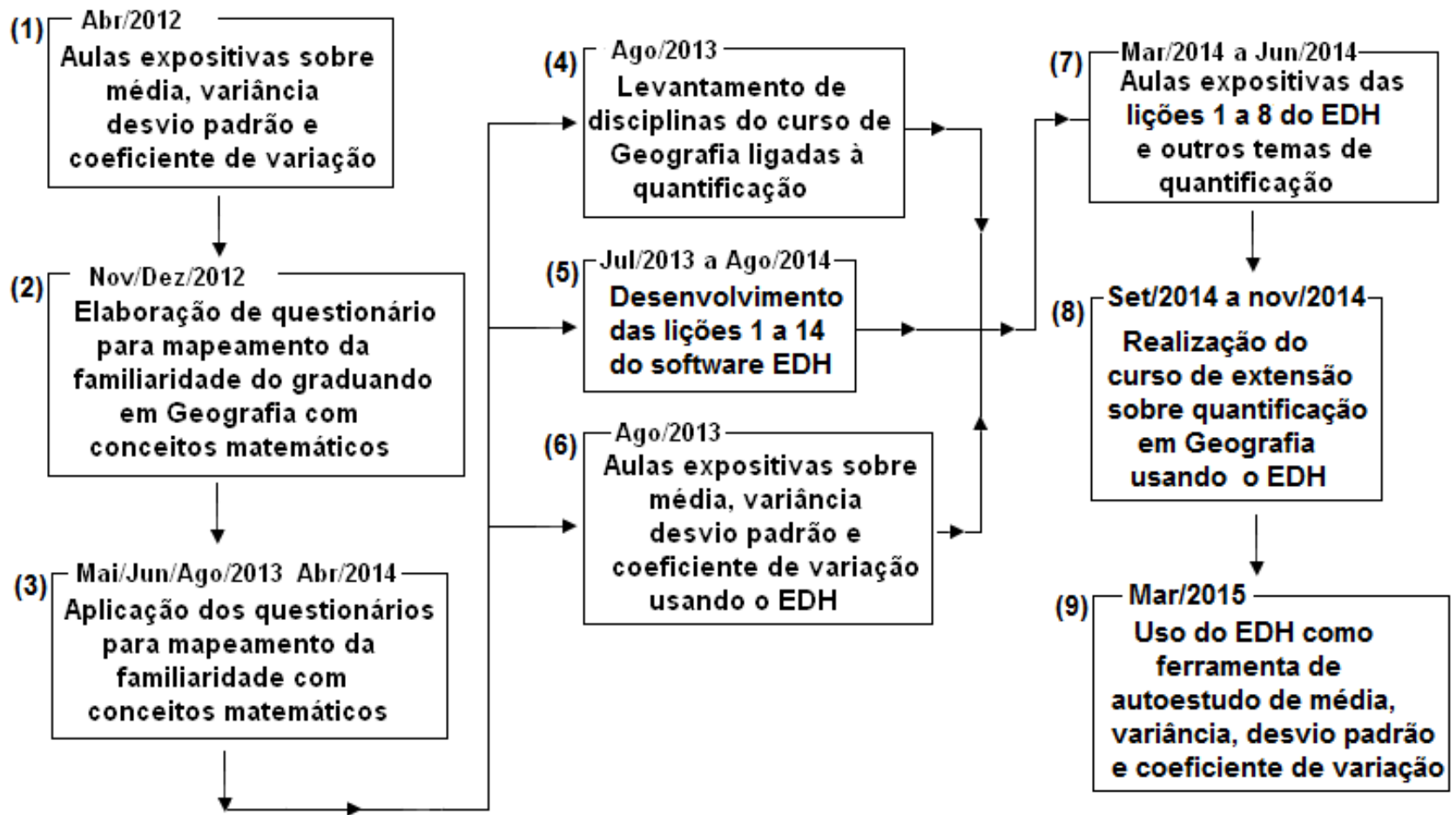

Figura 18 - Fluxograma de atividades de coleta de dados realizadas no escopo deste trabalho.

Fonte: Elaborado pelo autor.

\subsection{AULAS EXPOSITIVAS REALIZADAS EM ABRIL/2012}

No início do primeiro semestre letivo de 2012 na UnB, para investigar inicialmente o nível de familiaridade de conceitos matemáticos do graduando do curso de Geografia, preparei uma apostila com aproximadamente 70 páginas para ensino de conceitos básicos de média aritmética, variância, desvio padrão e coeficiente de variação e planejei o ensino em sala de aula destes assuntos usando o referido material. Os conceitos quantitativos de média, variância, desvio padrão e coeficiente de variação, são conceitos básicos da Estatística Descritiva e relativamente de fácil compreensão desde que o aprendiz apresente conhecimentos matemáticos básicos ministrados no Ensino Fundamental. Por isso este assunto foi escolhido. 
A orientadora deste trabalho, Profa. Ercília Torres Steinke, neste período letivo lecionou a disciplina "Climatologia Geral", que é disciplina obrigatória no curso de Geografia da UnB e, pelo fluxo do curso, é cursada pelo aluno logo no primeiro semestre do curso, ou seja, quando o aluno é calouro e, muito provavelmente, é recém egresso do Ensino Médio.

Então, para que eu pudesse realizar a investigação pretendida, a professora Ercília cedeu oito horas-aula da referida disciplina para que eu ministrasse as aulas envolvendo os conceitos de quantificação que eu havia preparado na apostila. A apostila elaborada serviu posteriormente como base para elaboração das lições iniciais do software tutor EDH. A composição da apostila - de modo a propiciar aprendizagem significativa - visava representar os conceitos primordialmente por meio de imagens. Para exemplificar, na Figura 19 é apresentado um trecho da apostila tratando do conceito de média aritmética, onde o que se espera é que o aprendiz fixe a ideia de média com a imagem apresentada. Na Figura 20 o trecho da apostila prepara a apresentação do conceito de desvio padrão, que é apresentado em seguida na apostila (ver Figura 21). Finalmente, na Figura 22 observa-se trecho da apostila que procura motivar o geógrafo aprendiz para usar as ferramentas de quantificação apresentadas, pois são úteis ao trabalho geográfico. Nota-se nas figuras, que a ideia chave do conceito apresentado está centrada na imagem, sendo complementada pela linguagem escrita, colocada da forma mais sucinta possível.

Suponha que a Turma B de um determinado colégio possui 26 alunos cujos pesos em $\mathrm{Kg}$ foram aferidos durante uma aula de Educação Física.

- Pergunta:

$\checkmark$ Como podemos "avaliar" o grupo de alunos em relação ao peso? Ou, de outra forma...

$\checkmark$ Como podemos "sintetizar" o "padrão" do grupo em relação ao peso ?

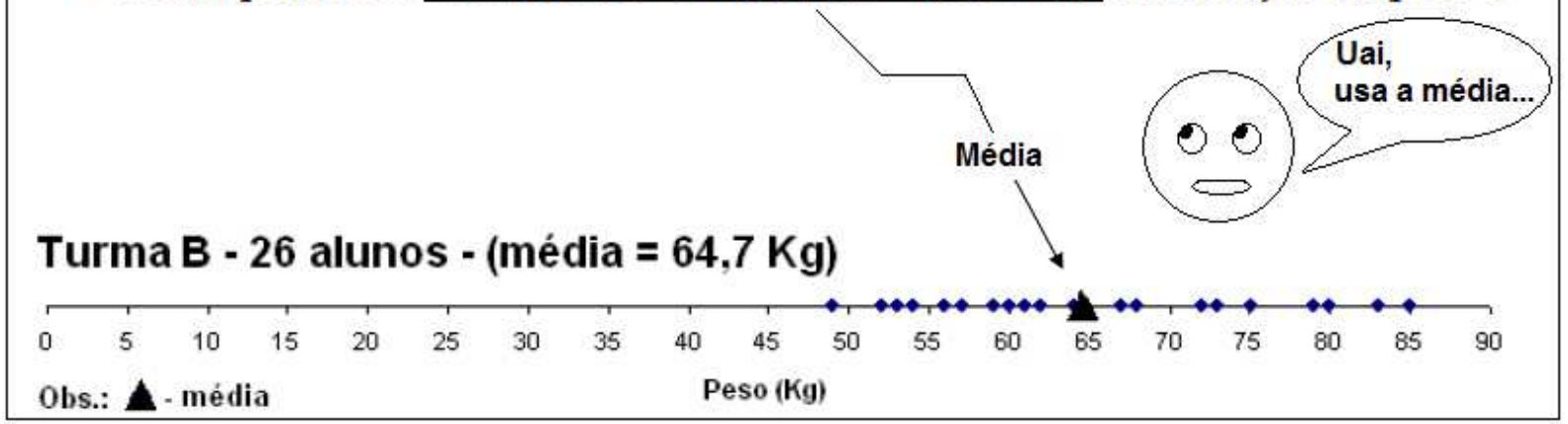

Figura 19 - Trecho da apostila preparada para ensino de alguns conceitos quantitativos usada em abril/2012. A imagem tenta auxiliar o aprendiz a fixar o conceito de média aritmética.

Fonte: Elaborado pelo autor. 


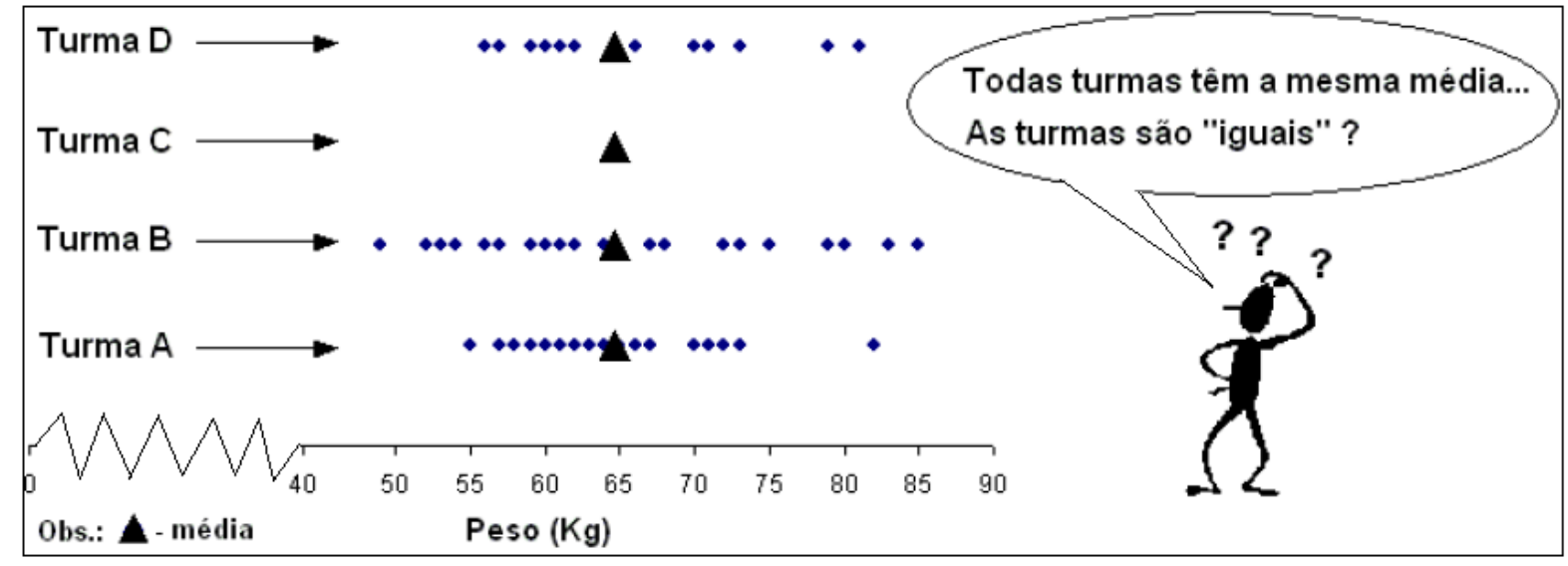

Figura 20 - Trecho da apostila preparada para ensino de alguns conceitos quantitativos usada em abril/2012. A imagem prepara a apresentação do conceito de desvio padrão, apresentado em seguida.

Fonte: Elaborado pelo autor.

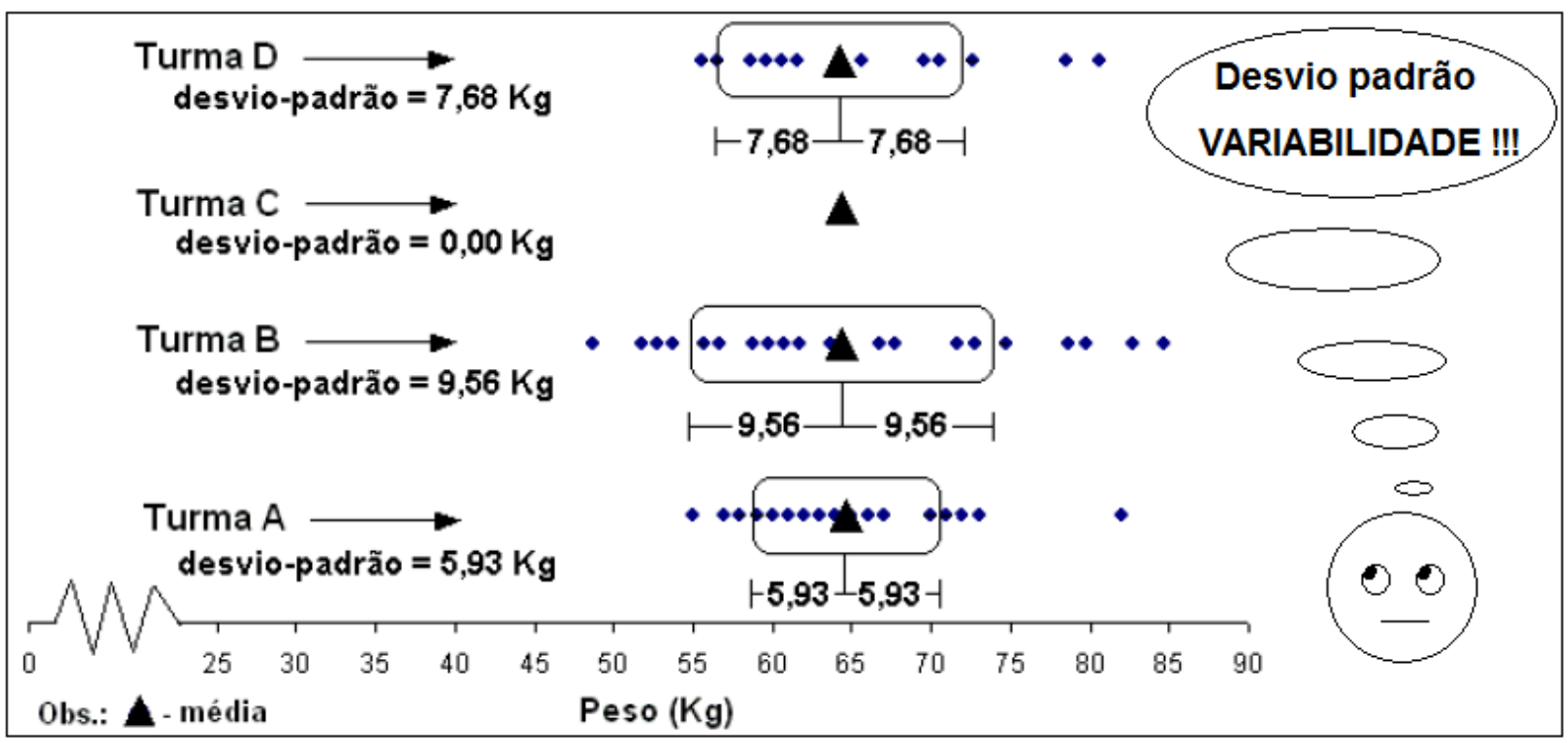

Figura 21 - Trecho da apostila preparada para ensino de alguns conceitos quantitativos usada em abril/2012. A imagem apresenta o conceito de desvio padrão.

Fonte: Elaborado pelo autor. 


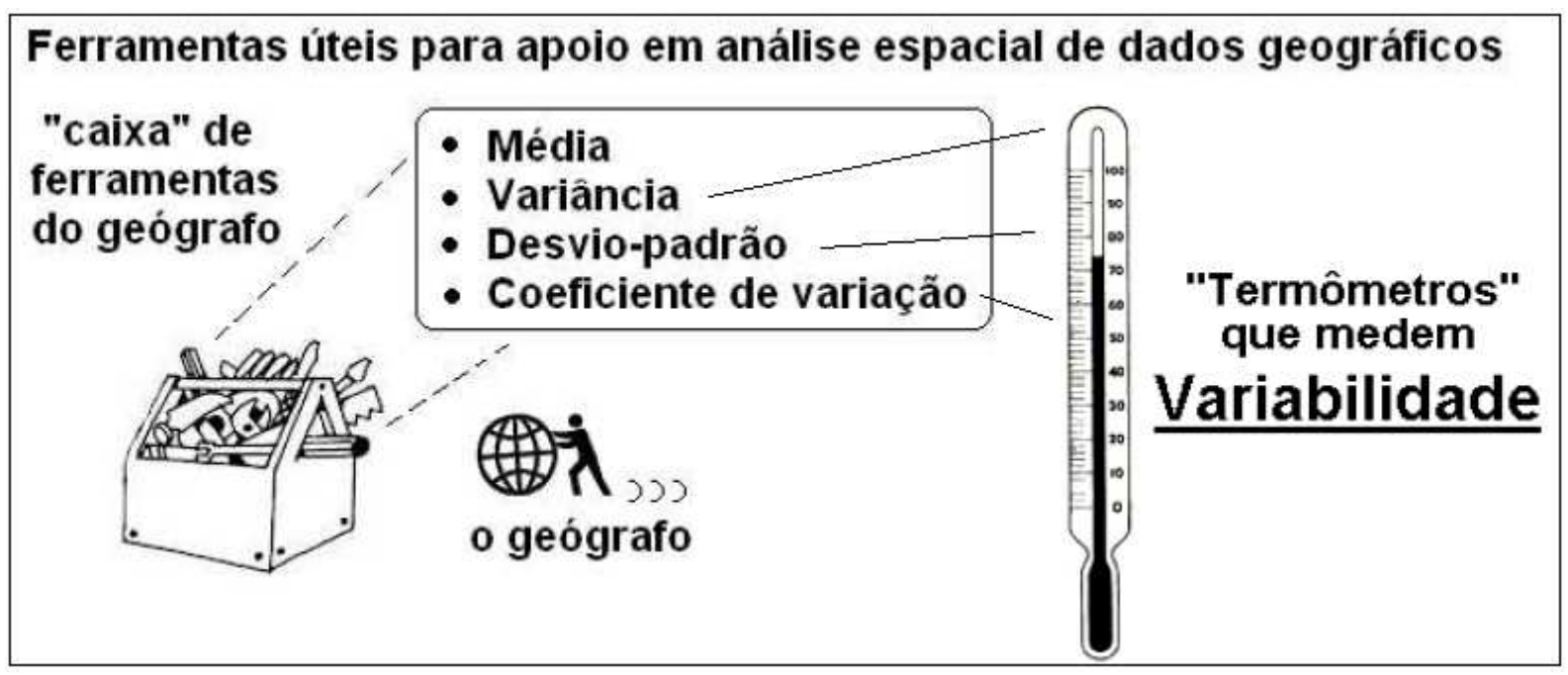

Figura 22 - Trecho da apostila preparada para ensino de alguns conceitos quantitativos usada em abril/2012. Imagem para motivação para uso das ferramentas de quantificação.

Fonte: Elaborado pelo autor.

A turma de Climatologia Geral deste período tinha aproximadamente 30 alunos matriculados. Nos quatro encontros presenciais em sala de aula (oito horas-aula), ocorridos em duas semanas de abril de 2012, utilizei a apostila projetando-a no quadro. As aulas foram mais centradas nas minhas explicações sobre os assuntos, mas eu apresentava o assunto sempre com base na apostila que, em sala de aula servia de apoio. Enfatizava aos alunos a necessidade deles lerem o material posteriormente em ambiente extra-classe.

De modo geral, poucos alunos demonstravam algum interesse pelo assunto, mesmo sabendo que o assunto seria cobrado na primeira prova da disciplina. Os poucos alunos que se manifestavam durante as aulas questionando o assunto apresentavam dúvidas de conceitos matemáticos em nível de Ensino Fundamental. A ideia de fração (proporção) pareceu não estar internalizada pelos alunos em geral. Por exemplo, alguns alunos manifestaram dificuldade em entender o coeficiente de variação, que em essência é ou uma fração própria ou uma fração imprópria. Em outras palavras o conceito de fração/proporção não pareceu ser um conceito subsunçor (conceito "âncora") para alguns alunos.

Na primeira prova de Climatologia Geral foi cobrada uma questão que tratava do assunto que foi ministrado nas aulas. A professora Ercília me relatou posteriormente que os alunos não foram bem na questão do assunto que ministrei. Neste momento inicial do trabalho, a preocupação maior era mapear, de forma exploratória, a familiaridade do aluno com conceitos matemáticos básicos. A experiência em sala de aula com a turma e o resultado não satisfatório na questão do assunto na primeira prova me levaram a elaborar um 
questionário que tentasse mapear de forma mais consistente a familiaridade do graduando do curso de Geografia com conceitos matemáticos básicos. A ideia seria tentar aplicar o questionário não somente ao aluno calouro do curso de Geografia, mas também aos demais alunos.

Em síntese, a experiência de elaboração da apostila e as aulas ministradas na turma de Climatologia Geral em abril de 2012 foram importantes para dar um direcionamento ao trabalho, servindo de base para a definição do conteúdo constituinte do software tutor EDH.

\subsection{ELABORAÇÃO E APLICAÇÃO DE UM QUESTIONÁRIO PARA MAPEAMENTO DA FAMILIARIDADE DE CONCEITOS MATEMÁTICOS POR PARTE DO ALUNO GRADUANDO EM GEOGRAFIA}

A experiência em abril de 2012 com as aulas expositivas sobre média, variância, desvio padrão e coeficiente de variação levaram, conforme já relatado, a elaborar um questionário para mapear de forma mais consistente a familiaridade do graduando do curso de Geografia com conceitos matemáticos básicos. A impressão inicial que ficou com a experiência de 2012 foi que o aluno (em geral) poderia não apresentar domínio dos conceitos matemáticos básicos necessários ao aprendizado de técnicas quantitativas usadas na análise espacial de dados geográficos.

O conteúdo das questões do questionário foi baseado em conteúdos matemáticos que os alunos egressos do Ensino Médio deveriam a priori conhecer, segundo os Parâmetros Curriculares Nacionais para o Ensino Fundamental (PCN) e para o Ensino Médio (PCNEM). As questões não exigiam, portanto, que os alunos tivessem qualquer conhecimento matemático/estatístico tratado a partir do Ensino Superior. Assim, no contexto deste trabalho, a familiaridade do aluno com relação a conceitos matemáticos refere-se ao domínio que o aluno tem sobre conteúdos de Matemática abordados nos ensinos Fundamental e Médio.

A elaboração dos questionários ocorreu em novembro e dezembro de 2012. Foram elaboradas sete questões de múltipla escolha, cada questão com cinco alternativas e uma única correta. A proposta foi aplicar os questionários durante o tempo de aula dos alunos de Geografia utilizando um tempo médio de aplicação de 50 minutos, e por isso a escolha da quantidade de sete questões de modo que o aluno pudesse dedicar um tempo médio de sete minutos para cada questão. 
Já foi mencionado no item 1.4 do Capítulo 1, mas, para melhor entendimento dos quadros 4 e 5 abaixo apresentados, repete-se que, segundo os PARÂMETROS CURRICULARES NACIONAIS - ENSINO MÉDIO (2013, p.6), com relação às competências e habilidades que se espera serem promovidas e desenvolvidas no Ensino Médio, dentre outras pode-se citar: (a) Interpretar e utilizar diferentes formas de representação (tabelas, gráficos, expressões, ícones...); (b) Identificar variáveis relevantes e selecionar os procedimentos necessários para a produção, análise e interpretação de resultados de processos e experimentos científicos e tecnológicos; (c) Identificar, analisar e aplicar conhecimentos sobre valores de variáveis, representados em gráficos, diagramas ou expressões algébricas, realizando previsão de tendências, extrapolações e interpolações e interpretações; (d) Analisar qualitativamente dados quantitativos representados gráfica ou algebricamente relacionados a contextos sócio-econômicos, científicos ou cotidianos; (e) Desenvolver modelos explicativos para sistemas tecnológicos e naturais; (f) Formular hipóteses e prever resultados; (g) Compreender o caráter aleatório e não determinístico dos fenômenos naturais e sociais e utilizar instrumentos adequados para medidas, determinação de amostras e cálculo de probabilidades; (h) Utilizar elementos e conhecimentos científicos e tecnológicos para diagnosticar e equacionar questões sociais e ambientais; (i) Utilizar instrumentos de medição e de cálculo e (j) Procurar e sistematizar informações relevantes para a compreensão da situação-problema.

Ainda, de acordo com PCN+ (2013, p. 4), o Ensino Médio apresenta três temas estruturadores: (1) álgebra: números e funções; (2) geometria e medidas e (3) análise de dados. Os conteúdos das questões elaboradas para o questionário se alinharam a estas propostas. No Quadro 4 observam-se alguns conhecimentos e habilidades citados pelos PCNEM que seriam necessários para resolução das questões do questionário. E no Quadro 5 observam-se as áreas temáticas dos PCNEM em que cada questão do questionário elaborado se enquadraria. 
Quadro 4 - Alguns conhecimentos e habilidades necessários para resolução das questões do questionário

\begin{tabular}{|l|c|}
\hline $\begin{array}{l}\text { Alguns conhecimentos e habilidades a serem promovidos durante o } \\
\text { Ensino Médio na área de ciências da natureza, matemática e suas } \\
\text { tecnologias segundo os PCNEM }\end{array}$ & $\begin{array}{c}\text { Questão do } \\
\text { Questionário }\end{array}$ \\
\hline $\begin{array}{l}\text { Interpretar e utilizar diferentes formas de representação (tabelas, } \\
\text { gráficos, expressões, ícones...) }\end{array}$ & $1,2,4,5,7$ \\
\hline $\begin{array}{l}\text { Analisar qualitativamente dados quantitativos representados gráfica } \\
\text { ou algebricamente relacionados a contextos sócio-econômicos, } \\
\text { científicos ou cotidianos }\end{array}$ & 7 \\
\hline $\begin{array}{l}\text { Compreender o caráter aleatório e não determinístico dos fenômenos } \\
\text { naturais e sociais e utilizar instrumentos adequados para medidas, } \\
\text { determinação de amostras e cálculo de probabilidades }\end{array}$ & 3 \\
\hline $\begin{array}{l}\text { Procurar e sistematizar informações relevantes para a compreensão da } \\
\text { situação-problema }\end{array}$ & $1,2,3,4$, \\
\hline
\end{tabular}

Quadro 5 - Temas estruturadores para matemática no Ensino Médio segundo os PCNEM e associação das questões do questionário com os temas

\begin{tabular}{|l|c|}
\hline $\begin{array}{c}\text { Temas estruturadores para matemática no Ensino Médio } \\
\text { segundo os PCNEM }\end{array}$ & $\begin{array}{c}\text { Questão do } \\
\text { Questionário }\end{array}$ \\
\hline Tema 1: álgebra e funções - variação de grandezas & $1,2,4,5,6,7$ \\
\hline Tema 1: álgebra e funções - trigonometria & - \\
\hline Tema 2: geometria e medidas - geometria plana & 5 \\
\hline Tema 2: geometria e medidas - geometria espacial & 1,5 \\
\hline Tema 2: geometria e medidas - métrica & 7 \\
\hline Tema 2: geometria e medidas - geometria analítica & 1,2 \\
\hline Tema 3: análise de dados - estatística & 2,3 \\
\hline Tema 3: análise de dados - contagem & 3 \\
\hline Tema 3: análise de dados - probabilidade & \\
\hline
\end{tabular}

Os respondentes do questionário não se identificavam pelo nome. Informavam apenas sexo e idade e também a seguinte pergunta: “você gosta de matemática e/ou estatística?" que 
apresentava quatro categorias qualitativas de resposta: detesto, gosto um pouco, gosto e gosto muito.

Com a finalidade de aumentar a amostra de questionários respondidos e para que fossem obtidas impressões de outras realidades fora do curso de Geografia da UnB, foram consultados vários professores de diversas Instituições Federais de Ensino Superior (IFES) com cursos de Geografia (licenciatura e/ou bacharelado) no Brasil, para verificar a possibilidade de aplicação dos questionários. Infelizmente ocorreram casos de professores que não retornaram o contato, de modo que, ao final, foi possível aplicar 384 questionários para os alunos de cursos de graduação em Geografia em mais cinco instituições públicas de Ensino Superior e uma faculdade particular. As seis instituições que se prontificaram em aplicar o questionário foram: Universidade Federal da Grande Dourados (UFGD), Universidade Federal de Tocantins (UFT), Universidade Federal de Goiás (UFG), Universidade Federal de Santa Maria (UFSM), Universidade Estadual de Ponta Grossa (UEPG) e Centro Universitário de Brasília (UNICEUB).

Os questionários foram aplicados em diversas turmas de diversas disciplinas do curso de Geografia em maio/2013, junho/2013, agosto/2013 e abril/2014. Para aplicar o questionário, era acertado previamente com o professor da disciplina um dia e horário para aplicação (no início ou no fim da aula).

Aos alunos das turmas era informado o propósito do questionário (mapeamento de familiaridade com conceitos matemáticos), o fato de o questionário não estar associado com qualquer tipo de avaliação da disciplina e que os mesmos não seriam identificados nos questionários e, por isso, que respondessem com base em seu real conhecimento do assunto, podendo inclusive deixar a questão em branco caso não soubessem respondê-la. $O$ aluno que já tinha respondido o questionário em alguma turma visitada anteriormente, não o respondia novamente. Na Figura 23 observa-se a capa do questionário, onde foi feito o registro dos dados básicos do colaborador e assinaladas as respostas das sete questões. 


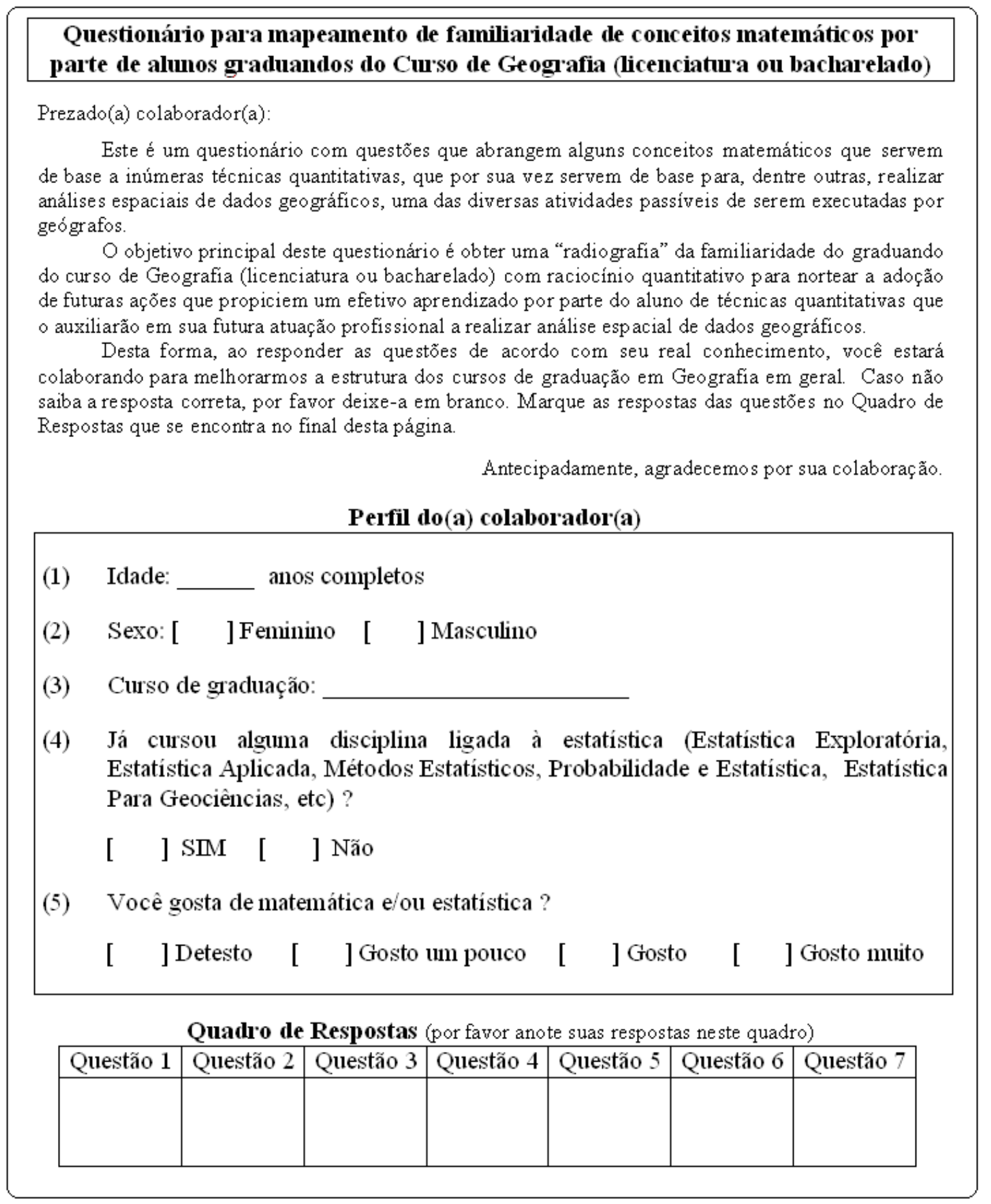

Figura 23 - Capa do questionário para mapeamento da familiaridade de conceitos matemáticos por parte do graduando em Geografia. Aplicado em maio/junho/agosto 2013 e abril/2014

Fonte: Elaborado pelo autor.

Foi elaborado um programa no ambiente de programação e banco de dados do software ACCESS, para serem digitadas as respostas dos questionários. Na Figura 24 
observa-se um exemplo da tela para digitação dos dados no banco de dados com valores de um questionário digitados.

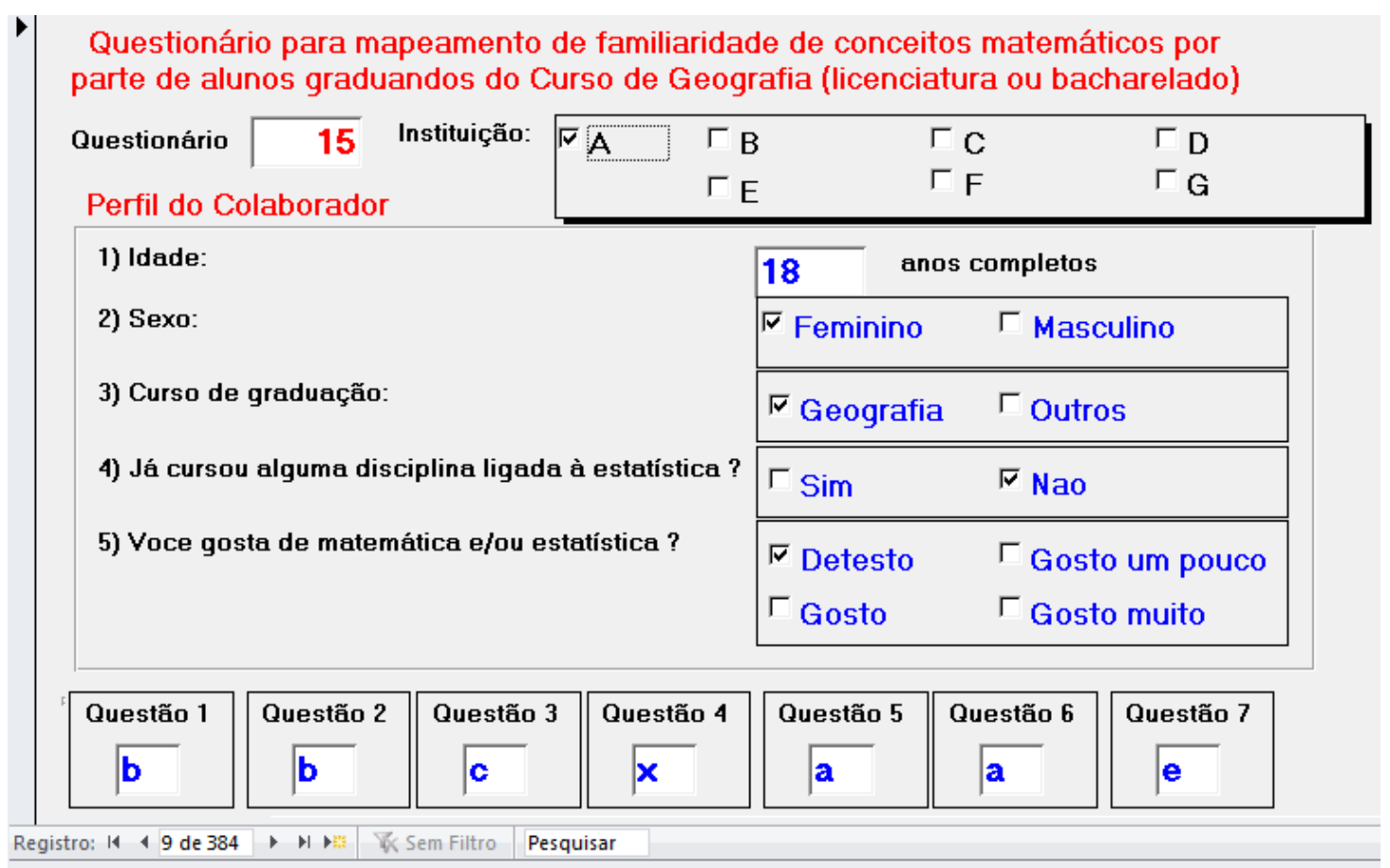

Figura 24 - Tela para digitação dos dados dos questionários aplicados com valores de um questionário digitados.

Fonte: Elaborado pelo autor.

Os resultados e discussões da análise dos dados dos questionários estão apresentados adiante no Capítulo 3. Mas o conteúdo do software tutor a ser desenvolvido, conforme afirmado anteriormente, em princípio, seria ou análise espacial de padrões de eventos pontuais ou então análise espacial de padrões de área com contagens. Mas para qualquer um destes dois temas, o pré-requisito para uma aprendizagem significativa seria o aluno ter um razoável domínio (familiaridade) de conceitos matemáticos tratados nos níveis de Ensino Fundamental e Médio, que foram o objeto de avaliação no questionário.

Contudo, os primeiros resultados dos questionários aplicados indicaram que os alunos apresentavam dificuldades com os conceitos matemáticos básicos. Em outras palavras, no escopo da teoria de aprendizagem de Ausubel, os alunos, a priori, não apresentaram subsunçores ("âncoras") destes conceitos matemáticos de modo a fixarem os conceitos de análise espacial de padrões de eventos pontuais e de análise espacial de padrões de área com contagens. 
Então o desenvolvimento do software EDH foi projetado para conter conceitos básicos de Estatística Descritiva. Não era o propósito inicial, mas, pelos resultados iniciais dos questionários ficou claro que seria a melhor opção. De qualquer forma, mesmo mudando a opção de conteúdo do software EDH, as investigações deste trabalho continuaram válidas, ou seja, verificar se a formação escolar do geógrafo o capacita para usar quantificação em análise espacial de dados geográficos e se um software tutor pode auxiliar o aprendizado significativo de técnicas quantitativas.

\subsection{DESENVOLVIMENTO DAS LIÇÕES 1 A 14 DO SOFTWARE EDH}

Conforme citado anteriormente, a aplicação dos 384 questionários ocorreram nos meses de maio/2013, junho/2013, agosto/2013 e abril/2014. Contudo, em meados de junho/2013 já havia disponível uma boa quantidade de questionários respondida e, numa avaliação de dados preliminar, os resultados dos questionários aplicados já apontavam a dificuldade do aluno com conceitos matemáticos básicos. Desta forma, foi nesta época (junho/2013) que decidi desenvolver o software tutor EDH contendo conceitos básicos de Estatística Descritiva ao invés de quantificação para análise de padrões pontuais ou padrões de áreas com contagens.

O software levou aproximadamente um ano para ficar pronto. Foi por mim desenvolvido entre julho de 2013 e agosto de 2014. Foi desenvolvido para poder ser consultado via Internet, através do uso de algum navegador (browser). Foi escrito usando-se a linguagem HTML 5 e javascript, e é composto por aproximadamente 1.700 arquivos de imagens em formatos PNG e GIF, uma vez que o propósito do software é tentar proporcionar aprendizagem significativa primordialmente através de conteúdo imagético de conceitos relativos à quantificação.

Dentre as aproximadamente 1.700 imagens componentes do software, muitas são sequências que formam imagens dinâmicas (GIFs animados). E o que se desejou na elaboração das imagens - de forma artesanal diga-se de passagem - foi produzir imagens que fossem além do aspecto "meramente ilustrativo" e se tornassem, de fato, conversoras de sentido lógico do conhecimento transmitido para sentido psicológico na estrutura cognitiva do aprendiz. A parte mais árdua nesta tarefa é concretizar em um conteúdo imagético (dinâmico ou não) o aspecto abstrato do tema da quantificação, e de modo que o conteúdo imagético 
apresentasse carga cognitiva baixa, isto é, aquele conteúdo que seja de fácil leitura por parte do aprendiz. O sucesso em fazer um conteúdo imagético ser bom para a aprendizagem significativa depende quase que exclusivamente desta concretização.

O software foi batizado de EDH, que significa "Estatística em Doses Homeopáticas", numa alusão ao remédios homeopáticos, tradicionalmente ministrados em pequenas doses por um tempo maior que os remédios alopáticos, mas que ao final produzem efeito benéfico no organismo do paciente.

Os assuntos escolhidos a serem apresentados "em doses homeopáticas", com ênfase na transmissão de conhecimento via conteúdo imagético foram: (1) ideias básicas sobre objeto, variável, população e amostra; (2) média, variância, desvio padrão e coeficiente de variação; (3) centro médio espacial e distância padrão; (4) medidas de posição (separatrizes) e (5) curva de Lorenz e índice de Gini. Os assuntos podem ser inseridos na categoria de elementos de Estatística Descritiva, sendo conceitos mais simples de serem apreendidos, eventualmente até por alunos que apresentem deficiência de conhecimentos matemáticos básicos (como fração/proporção, por exemplo).

Os assuntos foram estruturados no software EDH em 14 lições. A proposta do EDH é ter uma interface mais simples possível, de modo que o usuário navegue pelas páginas eletrônicas da forma mais linear possível (tela "para frente" e "para trás" evitando entrar em sub-telas), como se estivesse folheando um livro impresso. Além disso, a simplicidade das telas tem o importante propósito de forçar o usuário a se fixar no conteúdo da aprendizagem, minimizando a possibilidade de se distrair com outros arranjos visuais alheios ao assunto em questão, algo bastante típico em diversos tutoriais que abundam na Internet. Em outras palavras, a simplicidade das telas serve para eliminar, ou ao menos suprimir, imagens que sejam categorizadas como "decorativas" ou "representacionais" segundo Coutinho et. al. (2010) que seriam sem valor didático.

Nota-se na Figura 25 a simplicidade da interface já na tela de menu principal do EDH. Dispõe-se apenas das opções "Lições", "Atividades" e "Serviços" e a tela de menu das 14 lições apresenta, da mesma forma, uma interface simples, conforme se observa na Figura 26: 


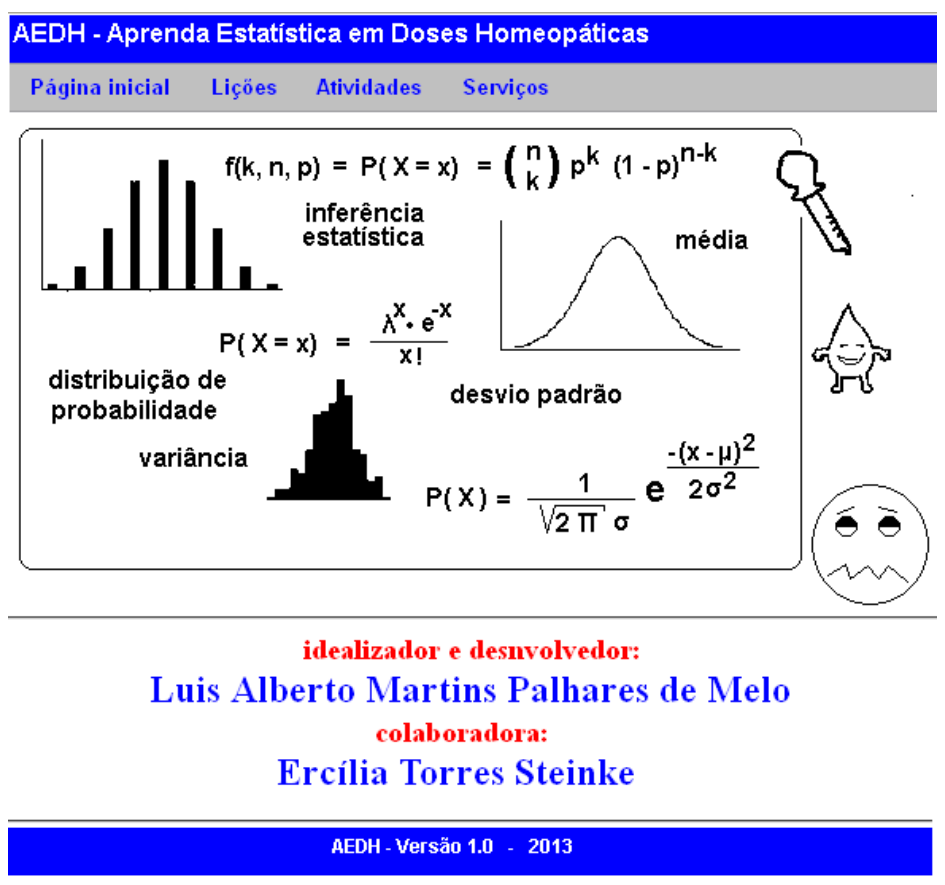

Figura 25 - Tela de menu principal do software EDH.

Fonte: Elaborado pelo autor.

\begin{tabular}{|c|c|c|}
\hline \multicolumn{3}{|l|}{ Retornar à Página inicial } \\
\hline \multicolumn{3}{|c|}{ AEDH - Lista de Lições } \\
\hline Lição 1 - Para aprender... & Lição 2 - Aos geógrafos... & Lição 3 - Tudo é objeto \\
\hline Lição 4 - População & Lição 5 - Variável: atributo do objeto & Lição 6 - População e Amostra \\
\hline Lição 7 -Média aritmética simples & Lição 8 - Variância e desvio padrão & Lição 9 - Estatística espacial - centro médio espacial \\
\hline Lição 10 - Estatística espacial - distância padrão & Lição 11 - Proporção... porcentagem... do "bolo" & Lição 12 - Medidas de posição (separatrizes) e box plot \\
\hline Lição 13 - Sobre coeficientes, índices, taxas... & Lição 14 - Curva de Lorenz e Coeficiente de Gini & \\
\hline
\end{tabular}

Figura 26 - Tela de menu da lista de lições do software EDH.

Fonte: Elaborado pelo autor.

A navegação "para a frente" e "para trás" pode ser vista no exemplo de tela mostrado na Figura 27. 


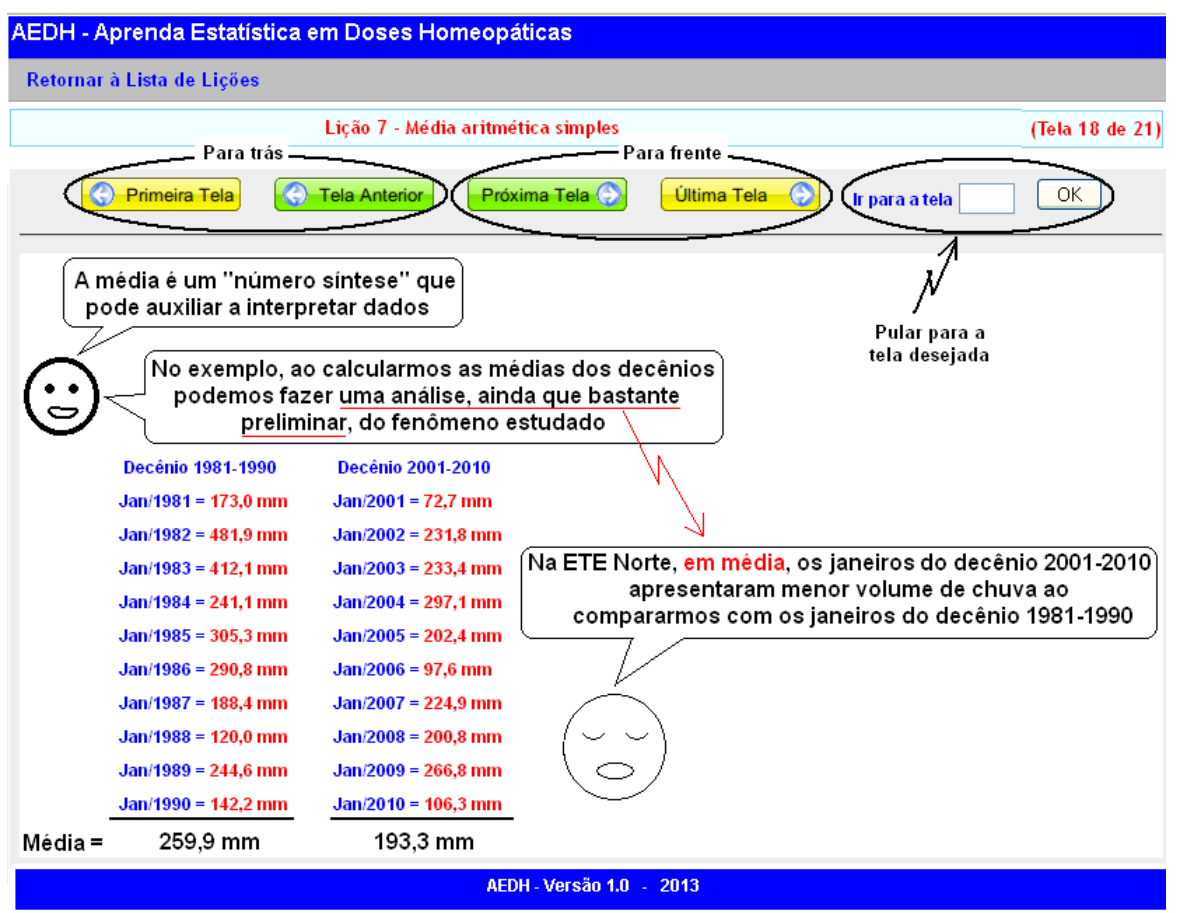

Figura 27 - Exemplo de página realçando a interface de navegação "para frente" e "para trás". Fonte: Elaborado pelo autor.

Para exemplificar alguns conteúdos de páginas, são apresentadas nas figuras 28 a 31 algumas páginas (telas) da lição 8, que trata dos conceitos de variância, desvio padrão e coeficiente de variação, e é composta por 45 páginas (telas), algumas das quais com imagens dinâmicas e também exigindo interação por parte do usuário.

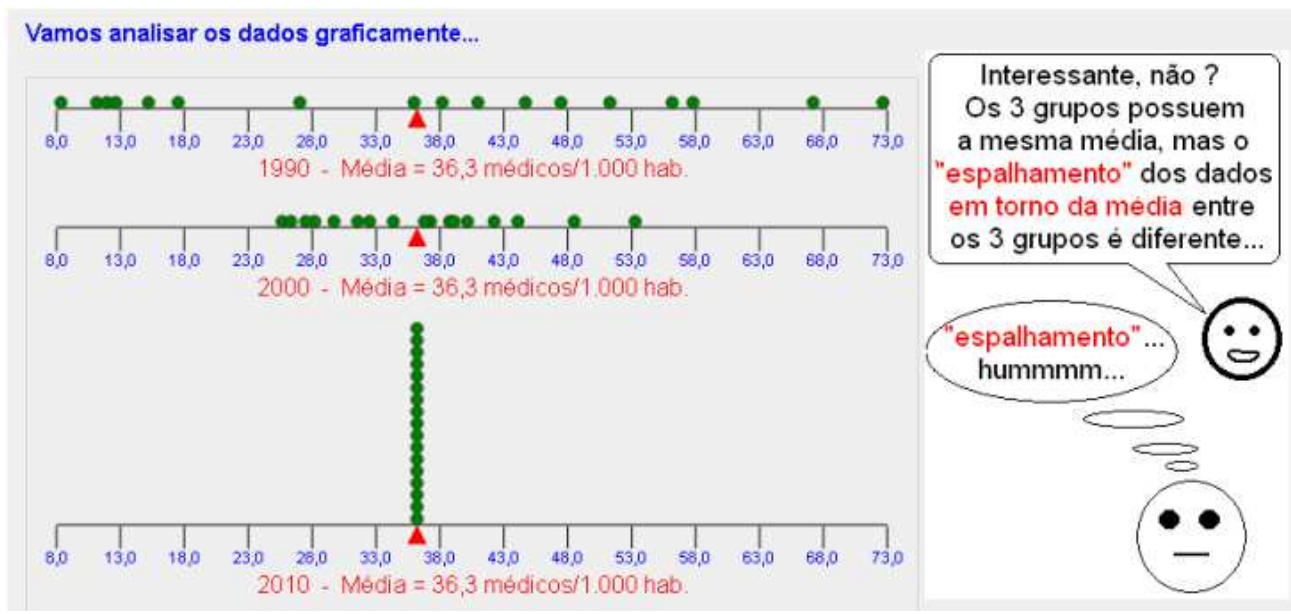

Figura 28 - "Aproximação" aos conceitos de variância e desvio padrão. A imagem de dados (representados por bolinhas) espalhados. E a palavra espalhamento sendo destacada.

Fonte: Elaborado pelo autor. 
Na Figura 28 observa-se uma situação em que irá fazer surgir o conceito de variância. Primeiro trabalha-se a ideia de espalhamento. Depois, trabalha-se com a interação do usuário para se efetuar o cálculo da variância e do desvio padrão. As figuras 29 e 30 mostram estas etapas

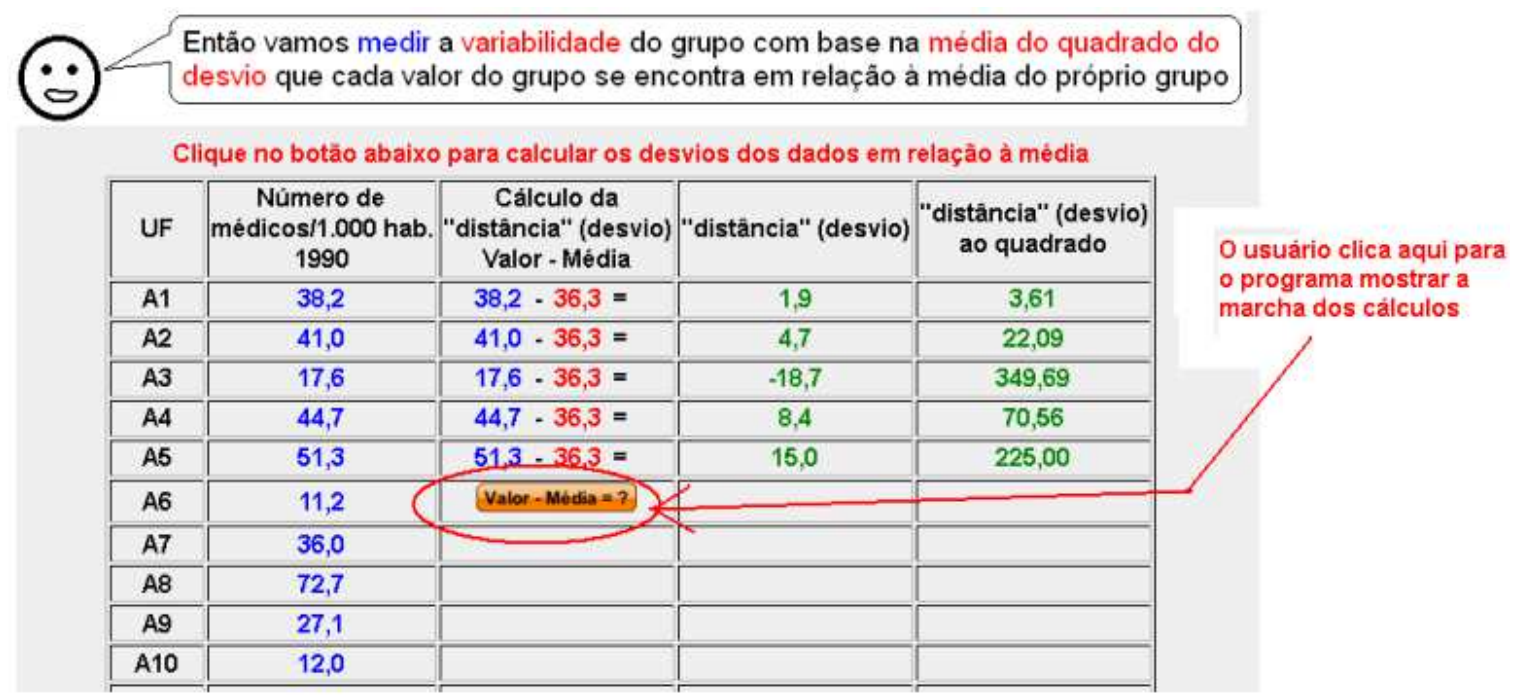

Figura 29 - Interação do usuário como tentativa de entendimento dos cálculos.

Fonte: Elaborado pelo autor.

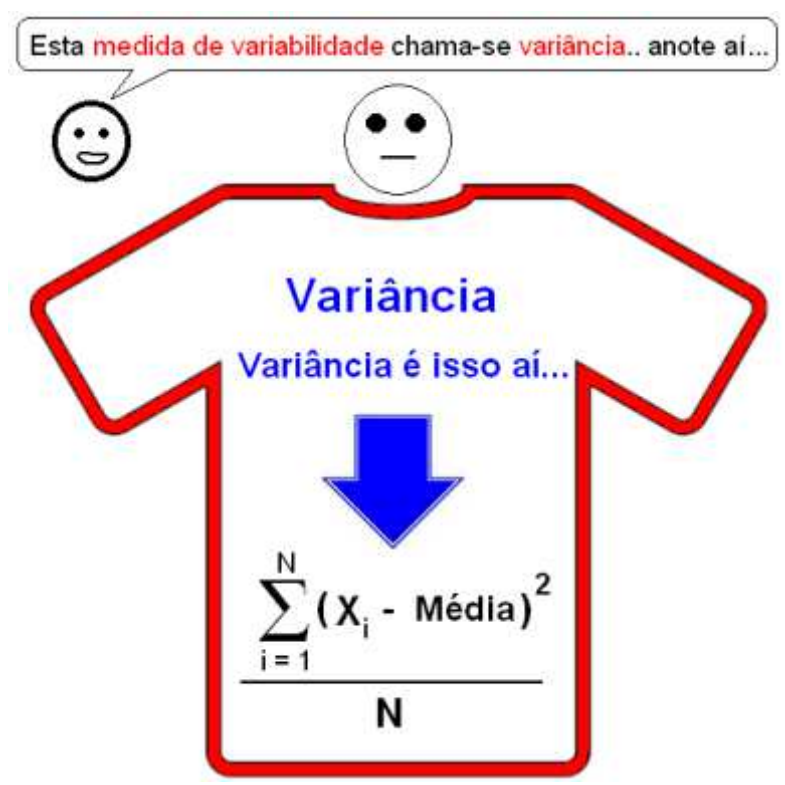

Figura 30 - A abordagem da fórmula de cálculo da variância

Fonte: Elaborado pelo autor. 
Ao final, procede-se a interpretação (análise) dos dados à luz dos conceitos de variabilidade. A Figura 31 mostra o ápice do entendimento conceitual, quando o usuário efetua a análise dos dados usando variância e desvio padrão.

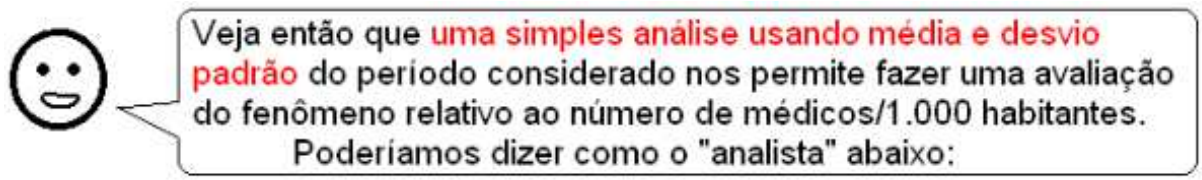

- No pais ALFA, durante os 20 anos de 1990-2010, politicas públicas ou outros fatores atuaram de modo que produziram uma distribuição bastante homogênea de médicos pelas 17 UFs do pais...

- Se 36 médicos/1.000 habitantes é suficiente ou não para propiciar qualidade na saúde, isso é outro estudo que deve ser realizado. Mas é fato que houve uma perfeita distribuição (homogeneizaçâo) de recursos humanos (no caso médicos) pelas UFs
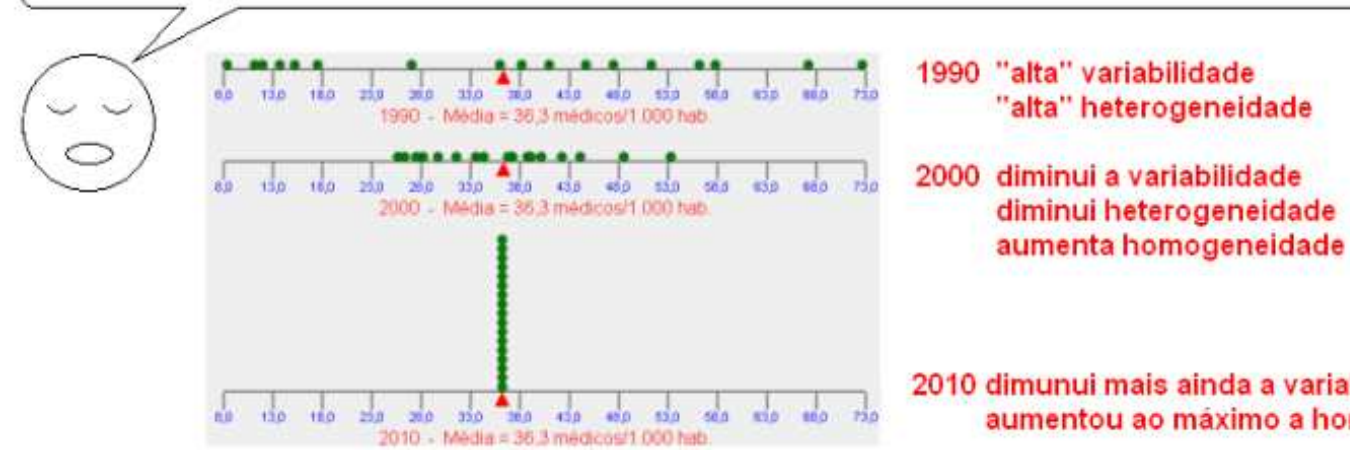

1990 "alta" variabilidade "alta" heterogeneidade

2000 diminui a variabilidade diminui heterogeneidade aumenta homogeneidade

2010 dimunui mais ainda a variabilidade aumentou ao máximo a homogeneidade

Figura 31 - A análise de dados após o entendimento do conceito de variância e desvio padrão. Fonte: Elaborado pelo autor.

Para exemplificar uma parte do EDH com apresentação de imagem dinâmica, na Figura 32 é apresentada uma página da lição 9, sobre o centro médio espacial ponderado em que apresenta o ponto de centro médio espacial dinamicamente mudando de posição espacial conforme o avanço temporal dos anos de 2008 a 2012. 


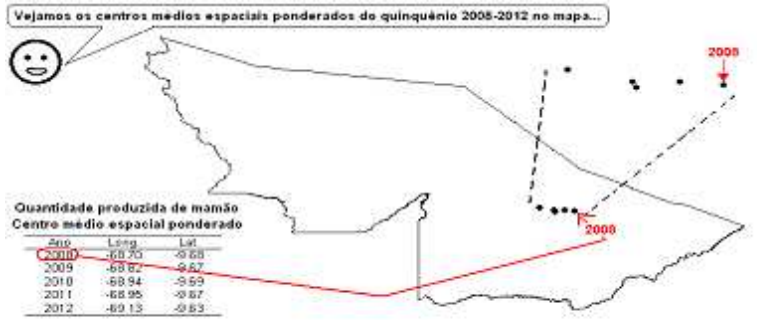

(A)

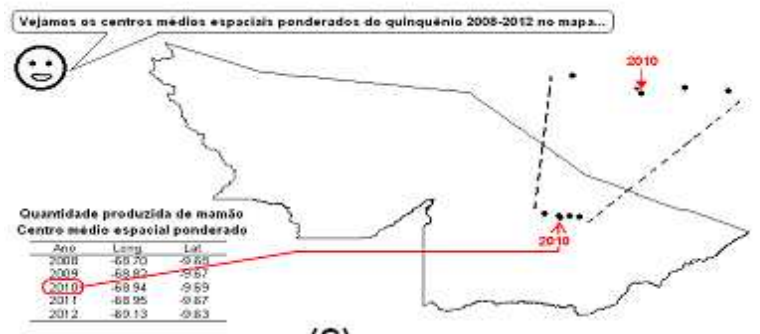

(C)

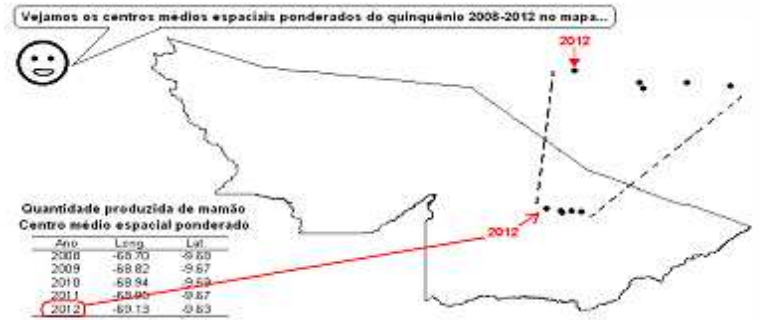

(E)

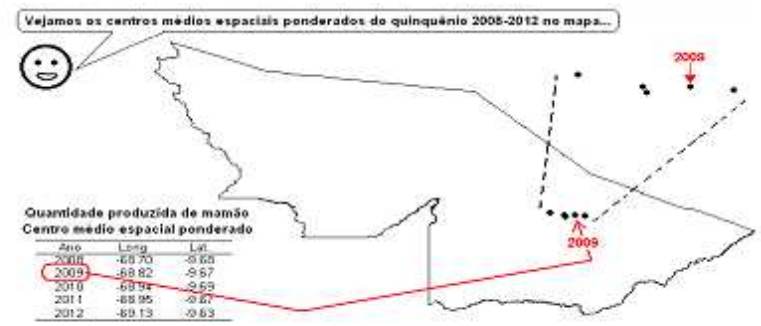

(B)

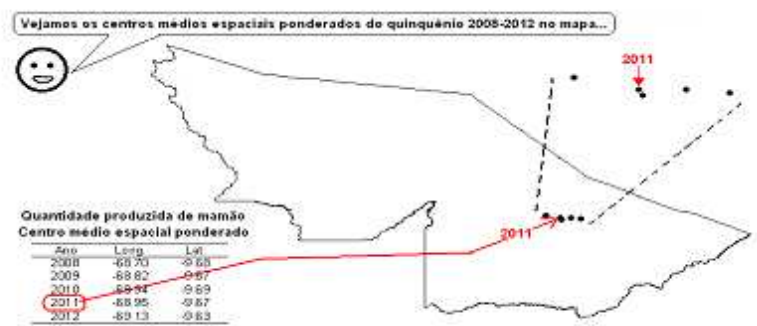

(D)

Figura 32 - Exemplo de imagem dinâmica (GIF animado) da lição 9 do software EDH. As imagens (A), (B), (C), (D) e (E) se sucedem na tela causando impressão de movimento do centro médio espacial ponderado dos anos de 2008 a 2012

Fonte: Elaborado pelo autor.

Para reforçar o aprendizado das lições do software EDH, foram desenvolvidas atividades propostas para o usuário com o objetivo de fixação de conteúdos. A última página (tela) de cada lição é uma página que convida o aprendiz a realizar as atividades propostas. Fica a mensagem ao leitor, lembrando-o que é ele quem quer aprender. Na Figura 33 observase a última página da lição 12 referente às separatrizes lembrando o leitor a estar motivado para o aprendizado. 


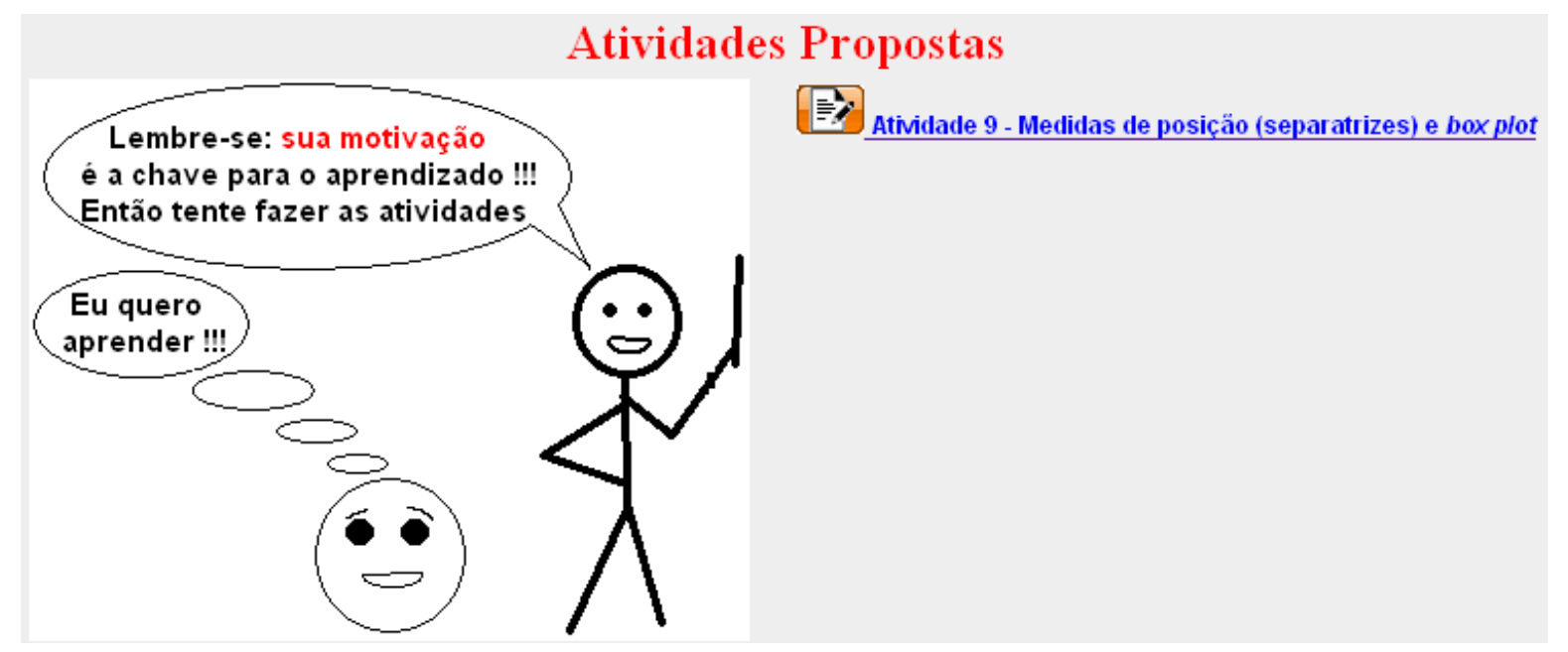

Figura 33 - Última tela da lição 12 estimulando o leitor a realizar atividades propostas referentes ao tema da lição.

Fonte: Elaborado pelo autor.

Ainda que no escopo da teoria de aprendizagem de Ausubel se considere que a relação entre motivação e aprendizagem seja mais reciproca do que causal, logo na lição 1 do software EDH chama-se a atenção do usuário para a motivação que ele deve ter para efetivamente aprender. As Figuras 34 e 35 mostram a sequência de duas telas apresentadas no EDH enfatizando a motivação como importante comportamento esperado do aprendiz para que o mesmo alcance a aprendizagem significativa dos assuntos tratados no software.

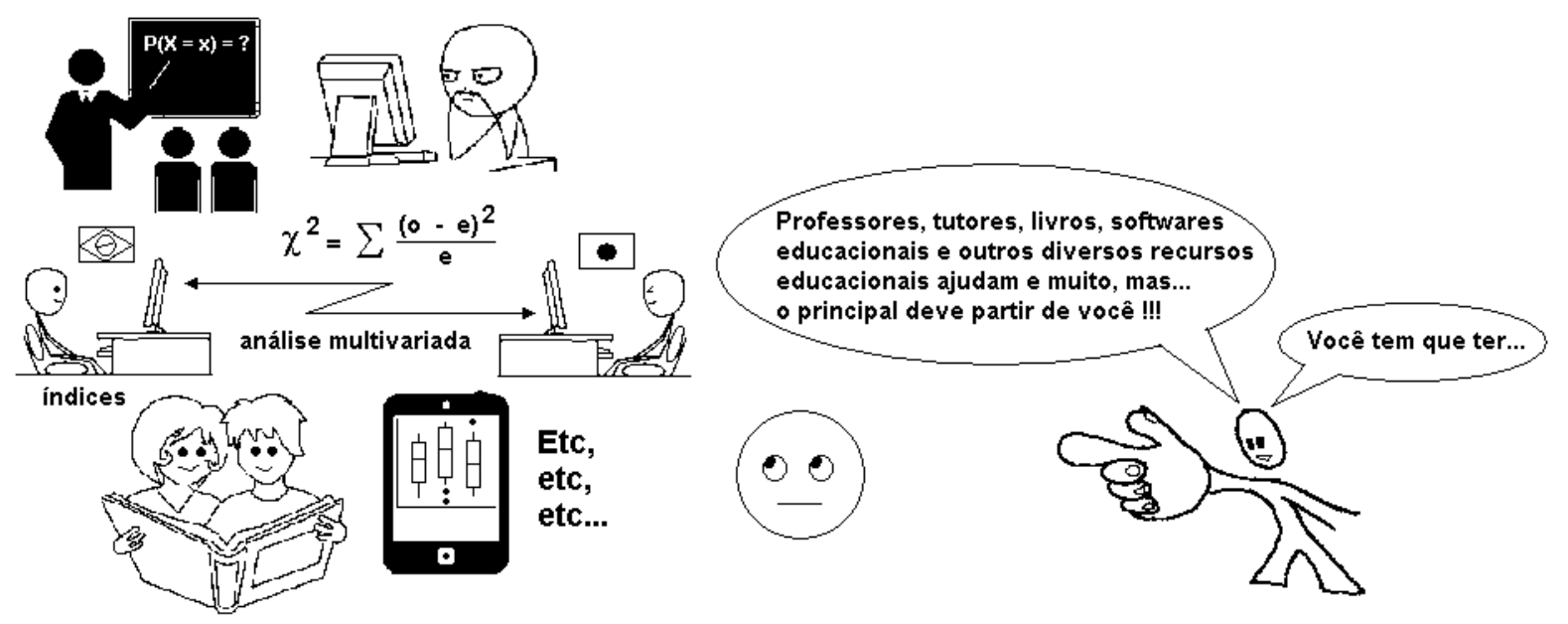

Figura 34 - Primeira tela da lição 1 do EDH para realçar a importância da motivação como fator de aprendizagem.

Fonte: Elaborado pelo autor. 


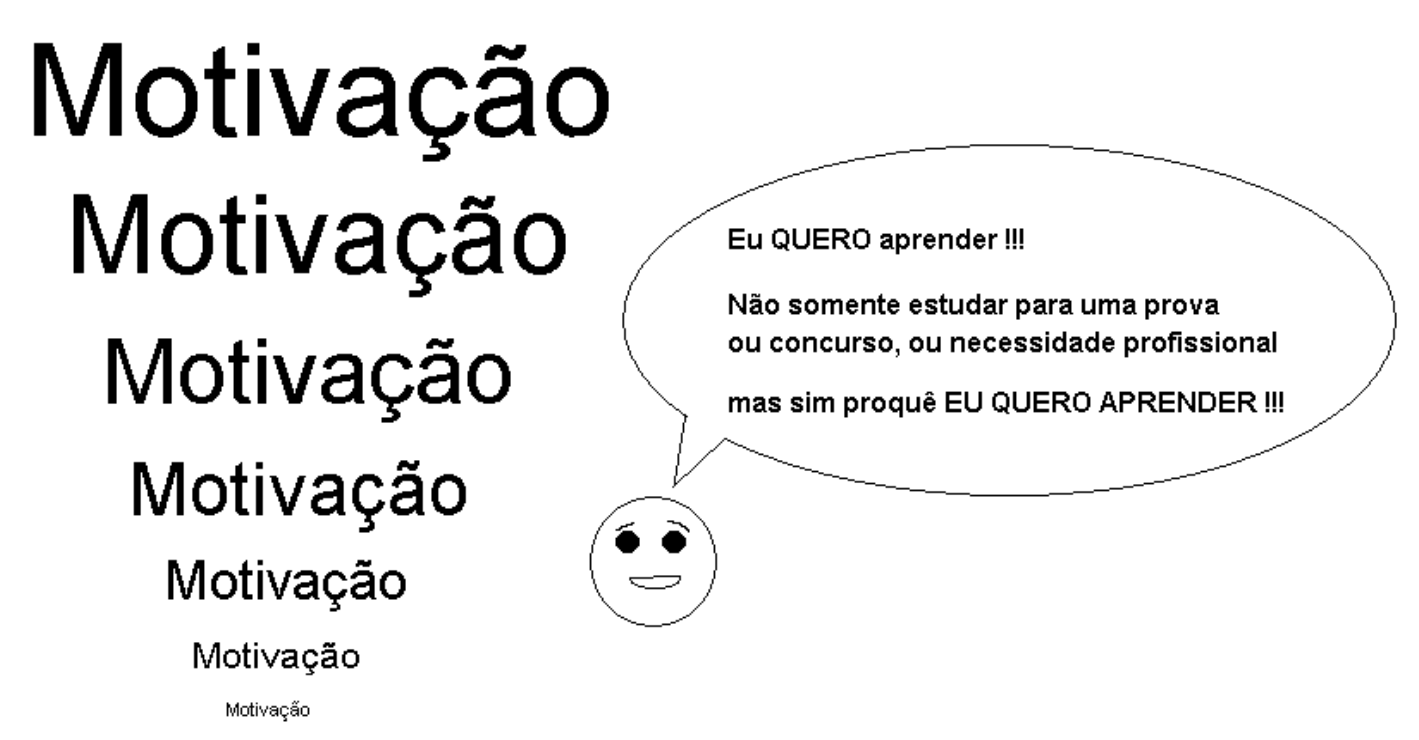

Figura 35 - Segunda tela da lição 1 do EDH para realçar a importância da motivação como fator de aprendizagem.

Fonte: Elaborado pelo autor.

A ideia das atividades é a mesma para o conteúdo das lições, ou seja, espera-se que as imagens contidas nas atividades colaborem com a aprendizagem significativa de conteúdos. A título de ilustração, a Figura 36 apresenta uma tela de atividades referente ao assunto da lição 12 (separatrizes). Nesta tela, ao clicar o botão "Certo" ou o botão "Errado" o programa apresenta uma explicação e informa se a resposta do usuário está certa ou não. Na Figura 37 é apresentada a explicação do item (2), que foi marcado pelo usuário como correto, mas na verdade não está correto.

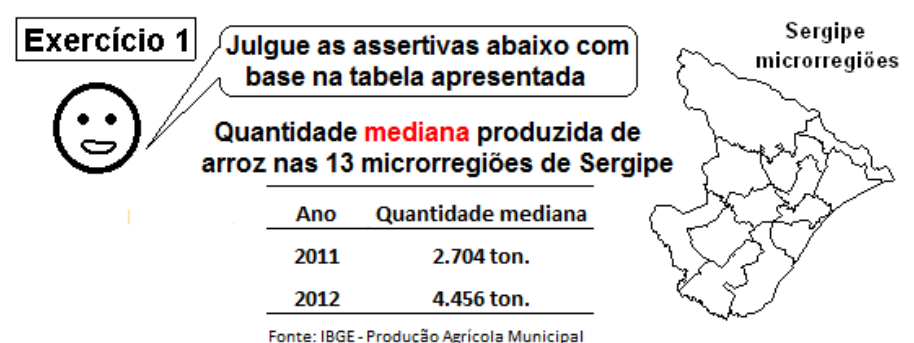

\begin{tabular}{|c|c|c|}
\hline $\begin{array}{l}\text { (1) Para } 2011 \text { é possivel afirmar que exatamente } 6 \text { microrregiões } \\
\text { sergipanas produziram, cada uma, mais de } 2.704 \text { toneladas }\end{array}$ & Eerta Enado & $\checkmark$ Resposta certa \\
\hline $\begin{array}{l}\text { (2) O valor mediano de } 4.456 \text { toneladas produzidas de arroz } \\
\text { em } 2012 \text { comparado ao valor mediano de } 2.704 \text { toneladas } \\
\text { em } 2011 \text { permite afirmar que a produção total de arroz } \\
\text { em Sergipe aumentou de } 2011 \text { para } 2012\end{array}$ & Eerta Errado & X Resposta Errada \\
\hline
\end{tabular}

Figura 36 - Assertivas dos itens (1) e (2) do Exercício 1 assinaladas como correta pelo usuário. Contudo, o item (2) é errado e o software EDH informa ao usuário.

Fonte: Elaborado pelo autor. 


\section{Item (2)}

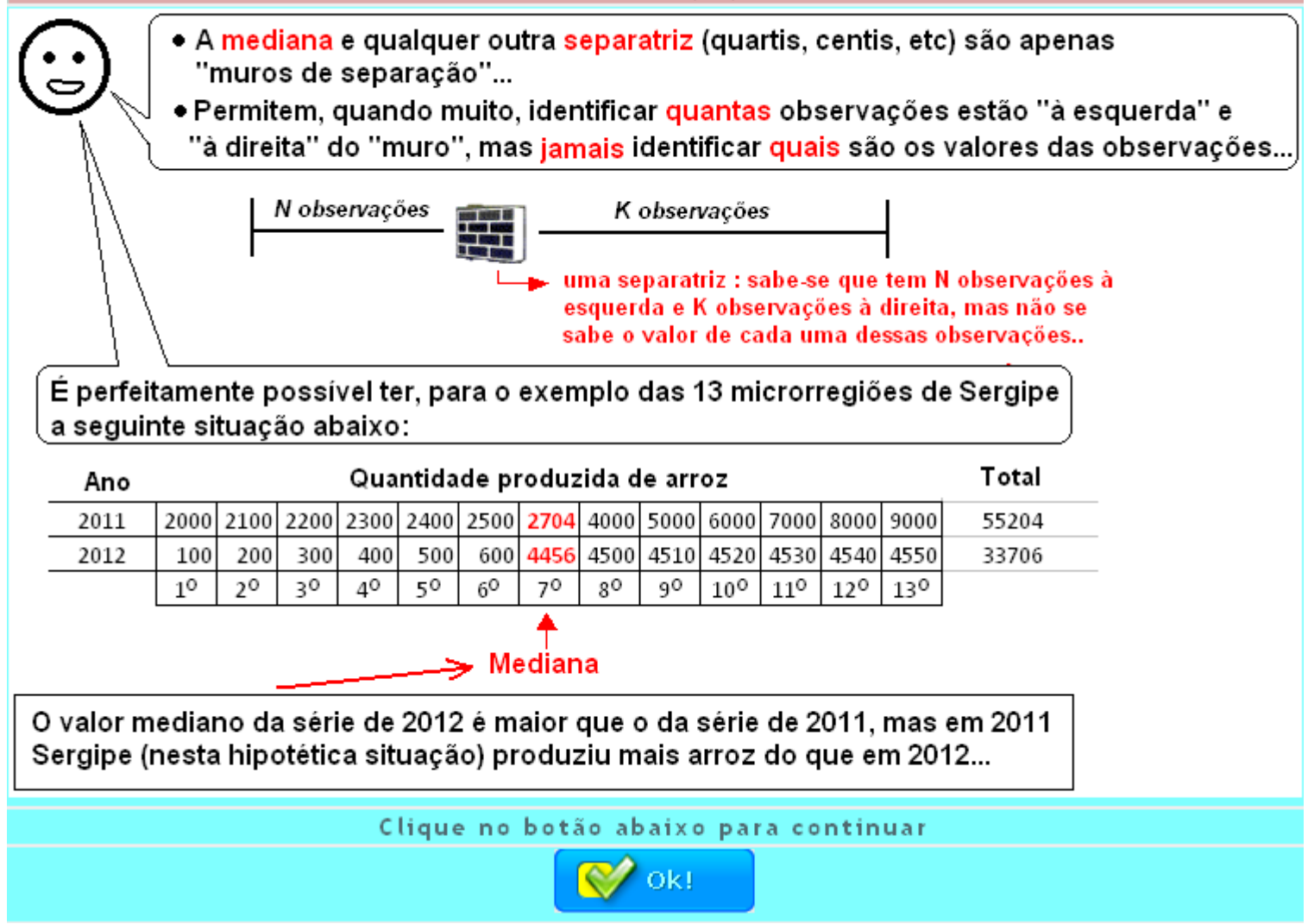

Figura 37 - Explicação do resultado do item (2)

Fonte: Elaborado pelo autor.

Para finalizar, vale ressaltar que a parte mais árdua do trabalho de construção do EDH foi conseguir concretizar em conteúdo imagético (dinâmico ou não) o aspecto abstrato do tema da quantificação em questão. Os conteúdos das lições foram, portanto, desenvolvidos de forma "artesanal". Para cada tema apresentado, o mais importante foi conhecer bem seus aspectos conceituais, principalmente sua estrutura abstrata, e pensar alguma situação que se materializasse na forma de imagem a abstração conceitual do tema de quantificação em questão. Neste contexto, a arte suplanta a técnica para a elaboração dos conteúdos das páginas. Objetivou-se, assim, que o conteúdo imagético do EDH pudesse proporcionar aprendizagem significativa ao aprendiz que, também em alguma intensidade, teria algum ganho em termos de letramento, pensamento e raciocínio estatístico. 


\subsection{LEVANTAMENTO DE DISCIPLINAS DO CURSO DE GEOGRAFIA LIGADAS À QUANTIFICAÇÃO}

Em paralelo ao desenvolvimento do software EDH, e com o intuito de averiguar se a formação acadêmica recebida pelo geógrafo durante seu curso de graduação o capacita a realizar quantificação para análise espacial de dados geográficos, foi realizado um levantamento da matriz curricular de cursos de Geografia de algumas universidades do País.

No item 1.3 do Capítulo 1, foram apresentados alguns conceitos básicos de quantificação que são básicos para o entendimento de análise espacial de dados geográficos. Em essência pode-se dizer que é necessário um conhecimento básico de três estatísticas: estatística descritiva; estatística inferencial e estatística multivariada. Outros conhecimentos como cálculo diferencial e integral ou algoritmos heurísticos por exemplo, podem ser considerados conhecimentos desejáveis, mas num primeiro momento pode-se prescindir o seu entendimento. As matrizes curriculares analisadas e comentários estão apresentados no Capítulo 3 a seguir.

\subsection{AULAS EXPOSITIVAS REALIZADAS EM AGOSTO/2013 SOBRE MÉDIA, VARIÂNCIA, DESVIO PADRÃO E COEFICIENTE DE VARIAÇÃO USANDO O SOFTWARE EDH}

Ao final de julho de 2013 e início de agosto de 2013, o software EDH já contava com as lições e atividades referentes aos conceitos de objetos, variáveis, população, amostra, média, variância, desvio padrão e coeficiente de variação, implementados nas lições 1 a 8 do software. Então foi planejada e executada a apresentação do assunto das lições 1 a 8 na forma de aulas expositivas, a exemplo do que ocorrera em abril de 2012, mas desta vez acontecendo em agosto de 2013 e sendo utilizado como material de apoio o EDH.

Novamente as aulas foram ministradas para os alunos da disciplina Climatologia Geral, cuja professora no período, a exemplo de 2012, também era a professora Ercília, orientadora deste trabalho. Foram designadas oito horas-aula (quatro encontros presenciais) da disciplina para as aulas versando sobre os mesmos temas de abril de 2012, ou seja, média, variância, desvio padrão e coeficiente de variação. Diferentemente de abril de 2012, quando usei como material didático uma apostila por mim elaborada, desta vez o material usado foi o 
software EDH, disponibilizado para os alunos. Os alunos foram avaliados em prova sobre estes conteúdos, que valeram $10 \%$ da nota total da primeira prova de Climatologia Geral.

Nos quatro encontros, apresentei os conceitos usando como material de apoio unicamente o EDH. A dinâmica das aulas se baseava em aula expositiva em que eu apresentava e explorava o assunto (sempre usando o EDH) e em seguida apresentava exercícios de fixação, sempre lembrando aos alunos a similaridade dos conceitos embutidos nos exercícios trabalhados em sala com o que seria cobrado na prova. Enfatizava aos alunos que não seria cobrada a "decoreba" da fórmula da variância, desvio padrão e coeficiente de variação, mas sim sua interpretação. Enfatizei também reiteradas vezes que os alunos deveriam manusear o EDH para obter embasamento para responder a questão da prova. A prova foi aplicada com 10 questões com respostas dicotômicas (resposta possível: certo ou errado). Os resultados e discussões sobre este conteúdo estão disponíveis no Capítulo 3 a seguir.

Vale ressaltar que estas aulas foram uma forma de preparação para o curso de extensão que viria a ser ministrado entre setembro e novembro de 2014, usando o EDH como ferramenta central do curso, e a experiência com a turma diante do EDH como material didático foi extremamente positiva pelo fato de, em sala de aula, ao projetar as imagens do $\mathrm{EDH}$ eu percebia um pouco do nível de familiaridade com conceitos matemáticos destes alunos que participavam da aula questionando os assuntos do EDH projetados no quadro.

\subsection{AULAS EXPOSITIVAS REALIZADAS EM MARÇO/2014 A JUNHO/2014 DAS LIÇÕES 1 A 8 DO EDH E OUTROS TEMAS DE QUANTIFICAÇÃO}

Com o propósito de continuar testando o software EDH, que se encontrava em desenvolvimento, para o primeiro semestre letivo de 2014, juntamente com a professora Ercília Torres Steinke, foi proposta a oferta da disciplina Tópicos Especiais em Geografia, nos cursos de Mestrado e Doutorado em Geografia da UnB com o tema "Quantificação em Geografia”. A ideia seria novamente utilizar o software EDH como material didático para ensino das lições 1 a 8 e mais as lições novas que fossem sendo desenvolvidas no ambiente do $\mathrm{EDH}$, além de apostilas sobre os demais assuntos que seriam embutidos adiante no EDH e 
que não estariam em tempo hábil inseridos no EDH para ser utilizado já no primeiro período letivo de 2014.

Ao final do período, os conteúdos ministrados na disciplina pertenciam ao escopo de quantificação descritiva e foram os seguintes: (1) objetos e variáveis; (2) média; (3) variância e desvio padrão; (4) coeficiente de variação; (5) curva de Lorenz e coeficiente de Gini; (6) separatrizes e box plot; (7) centro médio espacial; (8) distância padrão; (9) coeficientes de especialização, localização e redistribuição e (10) índice global de Moran.

Todos os dez conteúdos citados acima foram ministrados durante a disciplina e a dinâmica de apresentação e interação dos alunos com os conceitos foram fundamentais para a definição do conteúdo final de lições do EDH. Dos dez temas acima citados, apenas o coeficiente de redistribuição e o índice global de Moran não foram incorporados ao EDH.

Os resultados e discussão da dinâmica das aulas de Tópicos Especiais em Geografia Quantificação em Geografia que ministrei no primeiro semestre de 2014 estão apresentados adiante no Capítulo 3.

\subsection{REALIZAÇÃO DE CURSO DE EXTENSÃO SOBRE QUANTIFICAÇÃO EM GEOGRAFIA DE SETEMBRO/2014 A NOVEMBRO/2014 USANDO EDH}

Por volta do final de agosto de 2014 e início de setembro do mesmo ano, o software EDH estava implementado com as 14 lições contendo os temas que foram delimitados durante o primeiro semestre de 2014, com a experiência de aulas de quantificação em Geografia ministradas na disciplina Tópicos Especiais em Geografia - Quantificação em Geografia.

Para testar o uso do software EDH como ferramenta que contribui (ou não) de forma a melhorar a capacitação do graduando em Geografia em técnicas quantitativas para aplicação em análise espacial de dados geográficos, foi planejada a realização de um curso de extensão sobre quantificação em Geografia sobre os temas das 14 lições do software EDH. O curso de extensão foi realizado na UnB entre setembro de 2014 e novembro de 2014. A escolha da localidade de aplicação do curso de extensão (na UnB, em Brasília) deveu-se pela maior facilidade de acompanhamento do desenrolar do curso por minha parte.

O foco do curso foi avaliar o software EDH como ferramenta de autoestudo. Diferentemente do uso do EDH com a turma de Climatologia Geral em agosto de 2013 e com a turma de Tópicos Especiais em Geografia em março a junho de 2014, neste curso de extensão, eu não fiz qualquer intervenção para auxiliar no ensino dos assuntos apresentados 
no curso. O participante do curso deveria estudar o assunto (a lição) exclusivamente usando o EDH por conta própria, ou eventualmente debatendo com outros participantes, e nos encontros presenciais respondia um questionário (um teste) sobre o assunto. Os resultados e discussão da dinâmica deste curso de extensão estão apresentados adiante no Capítulo 3.

\subsection{USO DO EDH COMO MATERIAL DE AUTOESTUDO SOBRE MÉDIA, VARIÂNCIA, DESVIO PADRÃO E COEFICIENTE DE CORRELAÇÃO EM MARÇO DE 2015}

Para finalizar as coletas de dados deste trabalho, para o primeiro semestre de 2015 planejou-se a avaliação do uso do EDH como ferramenta de autoestudo dos assuntos das lições 1 a 8, ou seja, média, variância, desvio padrão e coeficiente de correlação com a turma de alunos da disciplina Climatologia Geral da UnB. Novamente, pelo fato da professora desta disciplina ser a orientadora deste trabalho, a acessibilidade a esta turma foi facilitada. A ideia de aprendizagem foi a mesma que a estratégia usada no curso de extensão, ou seja, nenhuma intervenção de ensino da minha parte. $\mathrm{O}$ aluno deveria realizar o autoestudo do assunto por conta própria, usando o EDH como material didático e após três semanas de autoestudo foi aplicado um teste versando sobre os conteúdos lidos no EDH. Antes do teste final, no primeiro dia de aula, foi aplicado um questionário para mapeamento da familiaridade do aluno com conceitos matemáticos, a exemplo dos 384 questionários aplicados em 2013/2014. Os resultados e discussão do desempenho dos alunos nos testes estão apresentados adiante no Capítulo 3. 


\section{CAPÍTULO 3}

\section{RESULTADOS E DISCUSSÕES}

\subsection{INTRODUÇÃO}

Neste capítulo 3 são apresentados os resultados e discussões obtidos das diversas atividades realizadas no escopo deste trabalho, sendo apresentados nos tópicos 3.2 a 3.11 a seguir.

\subsection{OS 384 QUESTIONÁRIOS PARA MAPEAMENTO DA FAMILIARIDADE DE CONCEITOS MATEMÁTICOS POR PARTE DO ALUNO GRADUANDO EM GEOGRAFIA}

Conforme comentado no item 2.3, em novembro e dezembro de 2012 foi elaborado um questionário para mapear a familiaridade do graduando do curso de Geografia com conceitos matemáticos básicos. Foram elaboradas sete questões de múltipla escolha, cada questão com cinco alternativas e uma única correta. A proposta foi aplicar os questionários durante o tempo de aula dos alunos de Geografia utilizando um tempo médio de aplicação de 50 minutos, e por isso a escolha da quantidade de sete questões de modo que o aluno pudesse dedicar um tempo médio de sete minutos para cada questão.

O conteúdo das questões foi baseado em conteúdos matemáticos que os alunos egressos do Ensino Médio deveriam a priori conhecer, segundo os Parâmetros Curriculares Nacionais para o Ensino Fundamental (PCN) e para o Ensino Médio (PCNEM). As questões não exigiam, portanto, que os alunos tivessem qualquer conhecimento matemático/estatístico tratado a partir do Ensino Superior.

Após a aplicação dos questionários foram geradas algumas estatísticas descritivas que permitiram ter uma primeira aproximação para detecção da familiaridade dos alunos com conceitos matemáticos básicos.

Inicialmente analisou-se os resultados da questão 6 do questionário, que está ligada à lógica proposicional (ou cálculo proposicional) e é um exemplo da denominada "Regra de De Morgan": a negação de ( $p E q$ ) é (não-p OU não-q). Eventualmente pode ser tratada 
diretamente no Ensino Médio quando forem abordadas apresentações ou revisões de Teoria dos Conjuntos. Ainda que eventualmente não seja abordada formalmente no Ensino Médio, a questão foi selecionada, pois este tipo de raciocínio lógico é usado por todos nós, consciente ou inconscientemente em nossos cotidianos. Usamos e processamos, consciente ou inconscientemente, assertivas com os conectivos E, OU EXCLUDENTE, OU NÃO EXCLUDENTE e NÃO. A Figura 38 apresenta o enunciado da questão 6 com a resolução e resposta.

\section{Questăo 6 Seja a seguinte afirmaçăo:}

"A geografia é viuva do espaço e geometrias năo são geografias".

Assinale a alternativa que representa a negaçăo da afirmaçăo acima.

(A) A geografia não é viưva do espaço e geometrias são geografias

(B) Se a geografia năo è viưva do espaço, entăo geonetrias năo săo geografias

(C) Se geometrias são geografias, então a geografia não é viưva do espaço

(D) A geografia não é viúva do espaço ou geometrias são geografias

(E) Se a geografia não é viưva do espaço, então geometrias sấo geografias

\section{Resolução}

A frase tem duas afirmativas ligadas pelo conectivo $E$ $\underline{\text { a geografia è viúva do espaço } E \text { geometrias não são geografias }}$

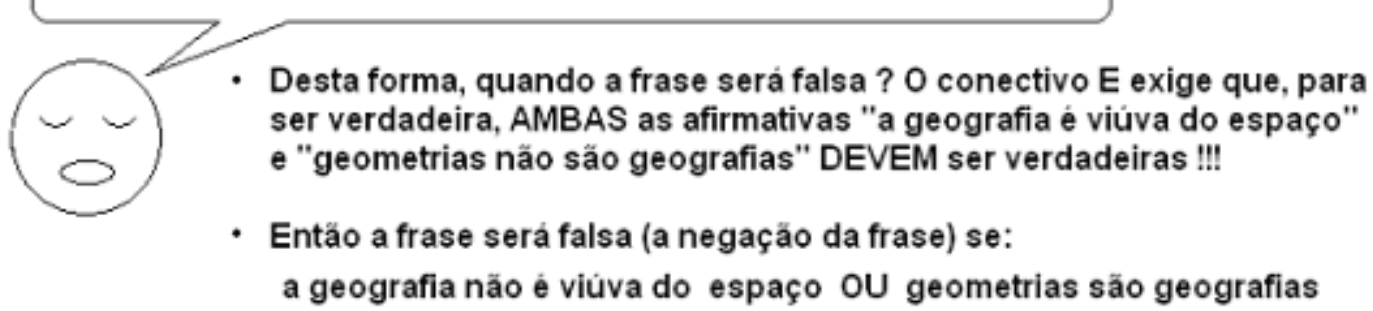

\section{Resposta: D}

Figura 38 - A questão 6 do questionário com resolução e resposta.

Fonte: Elaborado pelo autor.

Dos 384 respondentes, para a questão 6 apenas 36 a acertaram, ou seja, 9,38\% do total. Como a Regra de De Morgan pode não ter sido abordada durante o Ensino Médio, esta questão foi desconsiderada das estatísticas descritivas. Desta forma, considerou-se o questionário contendo seis questões. Doravante, as estatísticas apresentadas referem-se ao universo de seis questões: questão 1, 2, 3, 4, 5 e 7. 
Usando o software $\mathrm{R}$ foram calculadas algumas estatísticas descritivas básicas para a variável total de questões certas. O resultado está apresentado na Figura 39.

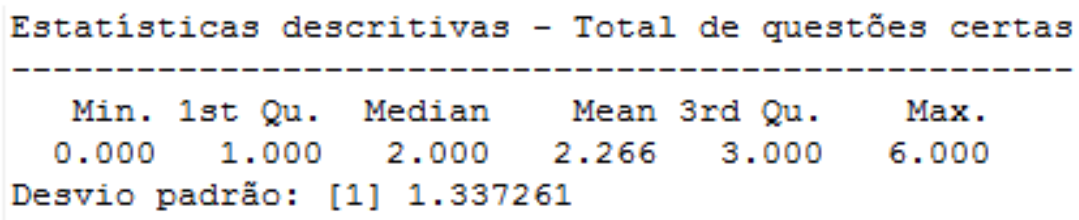

Figura 39 - Estatísticas descritivas para a variável total de questões certas.

Fonte: Elaborado pelo autor.

Conforme se observa, a média de acertos foi 2,266 questões com desvio padrão de 1,34 questões. $\mathrm{O}$ valor de terceiro quartil (Q3) foi 3,0. Isto significa que 75\% dos alunos (288 alunos dos 384) acertaram, no máximo, três das seis questões consideradas. O valor mediano (Md) foi 2,0. Isto significa que 50\% dos alunos (192 alunos dos 384) acertaram, no máximo, duas das seis questões consideradas.

Tabela 1 - Frequência absoluta e relativa de respondentes em relação ao total de questões respondidas corretamente

\begin{tabular}{ccc}
\hline $\begin{array}{c}\text { Total de questões } \\
\text { respondidas corretamente }\end{array}$ & $\begin{array}{c}\text { Total de respondentes } \\
\text { (frequência absoluta) }\end{array}$ & $\begin{array}{c}\text { Total de respondentes } \\
\text { (frequência relativa - \%) }\end{array}$ \\
\hline 0 & 32 & 8,33 \\
1 & 87 & 22,66 \\
2 & 106 & 27,60 \\
3 & 90 & 23,44 \\
4 & 47 & 12,24 \\
5 & 19 & 4,95 \\
6 & 3 & 0,78 \\
\hline Total & 384 & 100,00 \\
\hline
\end{tabular}

A Tabela 1 apresenta a quantidade absoluta e relativa de respondentes em relação ao total de questões respondidas corretamente. Observa-se que $159(41,41 \%)$ dos respondentes acertaram metade ou mais da metade das questões, isto é, acertaram três ou mais questões. E apenas $69(17,97 \%)$ dos respondentes acertaram quatro ou mais questões. 
Com relação à afetividade por matemática/estatística, na Figura 40 observa-se a distribuição de frequência da variável gosta de matemática/estatística.

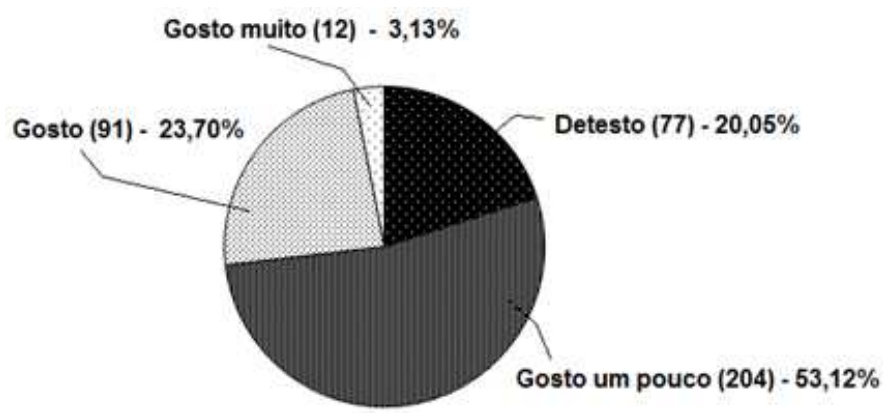

Figura 40 - Distribuição de frequência da variável gosta de matemática/estatística Fonte: Elaborado pelo autor.

Pouco mais da metade $(53,12 \%)$ dos respondentes afirmou "gostar um pouco" de matemática/estatística. Qualitativamente esta categoria pode ser considerada como intermediária entre as categorias "detestar" e "gostar". É possível que alguns respondentes de fato "não gostem" (ao invés de "detestarem") pois, subjetivamente podem ter interpretado que "detestar" talvez fosse um termo muito forte para caracterizar sua não apreciação por matemática/estatística. É possível então que o percentual de 53,12\% de respondentes que afirmaram gostar um pouco de matemática/estatística possa ser um pouco menor, pois alguns destes respondentes marcariam "não gosto" caso esta opção de resposta existisse. A priori, pode-se supor que quanto maior o gosto por matemática/estatística, maior o número de acertos que o respondente deve ter. Na Tabela 2 observam-se as frequências do número de acertos pelas quatro categorias qualitativas da variável gosta de matemática/estatística.

Tabela 2 - Distribuição de frequência do total de questões respondidas corretamente com base na variável gosta de matemáticalestatística

Total de questões respondidas corretamente

$\begin{array}{lllllllll}\text { Gosta de } & 0 & 1 & 2 & 3 & 4 & 5 & 6 & \text { Total }\end{array}$

matemática/estatística

\begin{tabular}{lcccccccc}
\hline Detesto & 8 & 25 & 21 & 15 & 8 & 0 & 0 & 77 \\
Gosto um pouco & 19 & 48 & 59 & 42 & 21 & 13 & 2 & 204 \\
Gosto & 5 & 12 & 20 & 31 & 16 & 6 & 1 & 91 \\
Gosto muito & 0 & 2 & 6 & 2 & 2 & 0 & 0 & 12
\end{tabular}


Para averiguar se há a possibilidade de associação entre as variáveis gosta de matemática/estatística e total de questões respondidas corretamente a variável quantitativa discreta total de questões respondidas corretamente foi transformada em variável ordinal da seguinte forma: zero ou um acertos considera-se um valor baixo de acertos. Dois ou três acertos considera-se um valor médio de acertos. E quatro, cinco ou seis acertos considera-se um valor alto. Além disso, os valores categóricos gosto e gosto muito foram unificados numa mesma categoria. Então a distribuição de frequências apresentada na Tabela 2 rearranjada fica conforme apresentado na Tabela 3.

Tabela 3 - Distribuição de frequência de questões respondidas corretamente conforme as categorias baixo, médio e alto com base na variável gosta de matemática/estatística

\begin{tabular}{lcccc}
\hline \multicolumn{1}{c}{ Gosta de } & Baixo & Médio & Alto & Total \\
matemática/estatística & (0 a 1 & (2 a 3 acertos) & (4 a 6 acertos) & \\
& acertos $)$ & & & \\
\hline Detesto & 33 & 36 & 8 & 77 \\
Gosto um pouco & 67 & 101 & 36 & 204 \\
Gosto - Gosto muito & 19 & 59 & 25 & 103 \\
\hline \multicolumn{1}{c}{ Total } & 119 & 196 & 69 & 384 \\
\hline
\end{tabular}

As variáveis gosta de matemática/estatística e desempenho no questionário são de natureza ordinal. Foi então calculada, com base na Tabela 3, no ambiente de software R a medida Gamma de Goodman e Kruskall $\gamma$, adequada para variáveis ordinais. O intervalo da medida $\gamma$ é $-1 \leq \gamma \leq 1$. Se $\gamma=0$ as variáveis não apresentam associação. $\gamma=1$ significa perfeita associação positiva, isto é, quanto maior a intensidade de uma variável ordinal também é maior a intensidade da outra variável. $\gamma=-1$ significa perfeita associação negativa, isto é, quanto maior a intensidade de uma variável ordinal menor é a intensidade da outra variável.

Para a amostra de 384 respondentes foi obtido o valor $\gamma=-0,06$ e intervalo de confiança ao nível de $95 \%$ para a estatística calculada ficou entre -0,118 e -0,001. Isto quer dizer que se fossem obtidas 100 amostras de 384 respondentes, em 95 amostras $\gamma$ assumiria um valor entre $-0,118$ e $-0,001$. 
O teste de significância para $\gamma$ onde $\mathrm{H}_{0}$ significa que não há associação entre o gosto por Matemática/Estatística e o desempenho no questionário $(\gamma=0)$, e a hipótese alternativa $\mathrm{H}_{1}$ que aceita a associação entre as variáveis $(\gamma \neq 0)$ resultou no p-valor de $2,10 \%$ o que indica que o teste foi significativo ao nível 2,10\%. Rejeitou-se assim a hipótese $\mathrm{H}_{0}$ em favor de $\mathrm{H}_{1}$, ou seja, aceitou-se $\gamma \neq 0$. Mas o valor amostral de $\gamma$ é muito próximo de zero e supondo-se que este valor amostral seja um bom estimador do verdadeiro valor de $\gamma$, isso sinaliza ausência de associação entre as variáveis consideradas. Assim, não necessariamente maior gosto por Matemática/Estatística significaria melhor desempenho no questionário.

Outra avaliação de associação de variáveis foi feita entre as variáveis sexo e desempenho no questionário. A Tabela 4 é a tabela de contingência dessas variáveis.

Tabela 4 - Distribuição de frequência de questões respondidas corretamente conforme as categorias baixo, médio e alto com base na variável sexo

\section{Desempenho no questionário}

$\begin{array}{ccccc}\text { Sexo } & \text { Baixo } & \text { Médio } & \text { Alto } & \text { Total } \\ & \text { (0 a } 1 \text { acertos }) & \text { (2 a } 3 \text { acertos }) & \text { (4 a } 6 \text { acertos }) & \end{array}$

\begin{tabular}{ccccc}
\hline Feminino & 50 & 82 & 18 & 150 \\
Masculino & 69 & 114 & 51 & 234 \\
\hline \multicolumn{1}{c}{ Total } & 119 & 196 & 69 & 384 \\
\hline
\end{tabular}

A variável sexo é uma variável nominal e, por isso, a estatística gamma de Goodman e Kruskall $\gamma$ não é adequada para averiguação de sua associação com a variável desempenho no questionário. Foi então calculada a estatística $\mathrm{V}$ de Cramer, que é baseada na estatística $\chi^{2}$, no ambiente de software $\mathrm{R}$ com os dados da Tabela 4.

Foi obtido $\chi^{2}=5.9505$. $\mathrm{O}$ teste de significância para $\chi^{2}$ foi o seguinte: hipótese $\mathrm{H}_{0}=$ as variáveis sexo e desempenho no questionário são independentes, isto é, $\chi^{2}=0$. A hipótese alternativa $H_{1}$ aceita a associação entre as mesmas $\left(\chi^{2} \neq 0\right)$. Para $\chi^{2}=5.9505$ com dois graus de liberdade o p-valor vale 5,104\%. O teste seria então significativo ao nível de 5,104\% o que permitiria aceitarmos $\mathrm{H}_{1}$, ou seja, admitir que há associação entre as variáveis. A medida de Cramer encontrada foi $\mathrm{V}=0,1244828$. Quanto mais perto de 0 , maior a evidência de que as variáveis apresentam uma associação fraca. Para $\mathrm{V}=0$ significa que as variáveis não apresentam associação entre si. O valor 0,1244828 é próximo de zero, o que sinaliza uma 
fraca associação entre as vaiáveis consideradas, ou seja, o desempenho no questionário não estaria associado com o sexo do indivíduo.

Dando continuidade às estatísticas descritivas, foram averiguados o percentual de acertos, erros e não resolução (resposta em branco) das seis questões consideradas. A Tabela 5 e a Figura 41 apresentam os resultados obtidos.

Tabela 5 - Frequência absoluta e relativa de respostas certas, erradas e em branco das questões 1, 2, 3, 4, 5 e 7 dos 384 questionários respondidos

\begin{tabular}{cccc}
\hline Questão & Certas & $\begin{array}{c}\text { Respostas } \\
\text { Erradas }\end{array}$ & Em branco \\
\hline 1 & $275(71,62 \%)$ & $100(26,04 \%)$ & $9(2,34 \%)$ \\
2 & $220(57,29 \%)$ & $156(40,63 \%)$ & $8(2,08 \%)$ \\
3 & $89(23,18 \%)$ & $194(50,52 \%)$ & $101(23,30 \%)$ \\
4 & $69(17,97 \%)$ & $289(75,26 \%)$ & $26(6,77 \%)$ \\
5 & $47(12,24 \%)$ & $259(67,45 \%)$ & $78(20,31 \%)$ \\
7 & $170(44,27 \%)$ & $162(42,19 \%)$ & $52(13,54 \%)$ \\
\hline
\end{tabular}

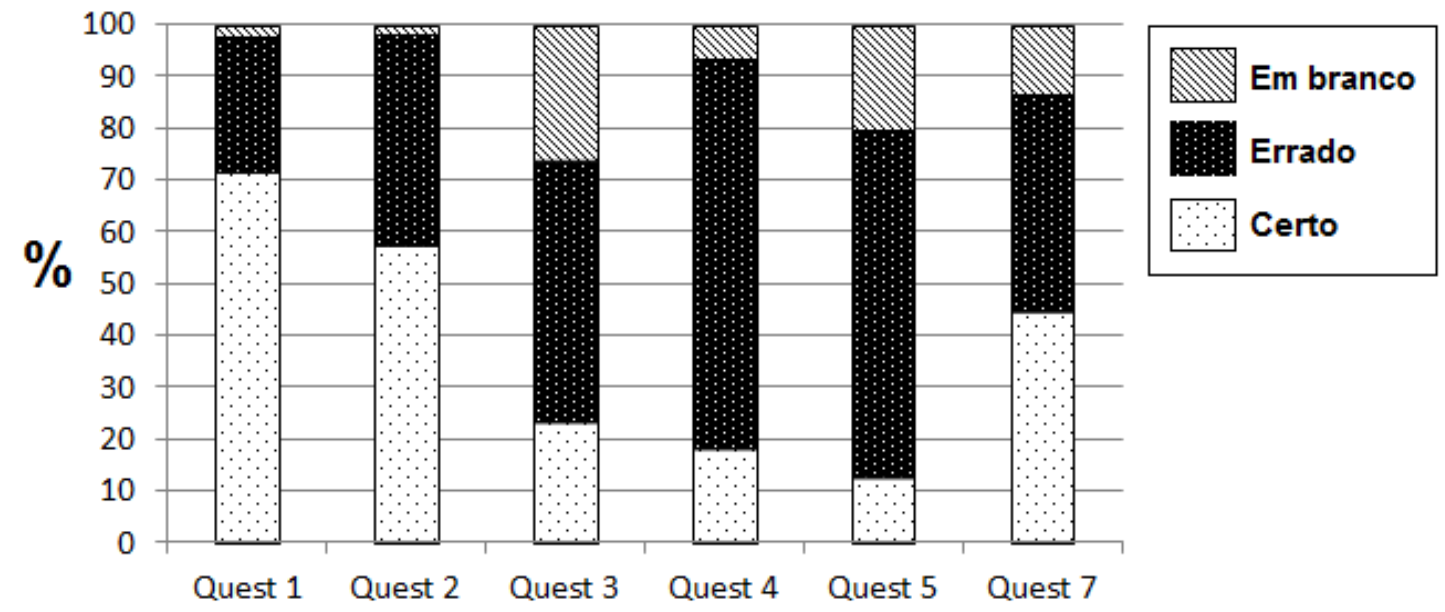

Figura 41 - Percentual de acertos, erros e não resolução das questões 1, 2, 3, 4, 5 e 7 pelos 384 respondentes.

Fonte: Elaborado pelo autor.

Observando-se a Tabela 5 e a Figura 41 nota-se que a questão 1 foi a que apresentou melhor percentual de acertos considerando-se os 384 questionários respondidos. As questões 
2 e 7 apresentaram um razoável percentual de acertos e as questões 3, 4 e 5 apresentaram baixo percentual de acertos. A seguir são apresentadas as questões.

\subsubsection{Questão 1 do questionário}

Nas Figura 42 e 43 observa-se o enunciado e resolução da questão 1 respectivamente.

Onestẵo 1 Situaçăo hipotètica: o gráfico de barras abaixo apresenta a quantidade total produzida de cinco culturas (arroz, tomate, soja, café e batata) dos paises A e B em determinado ano.

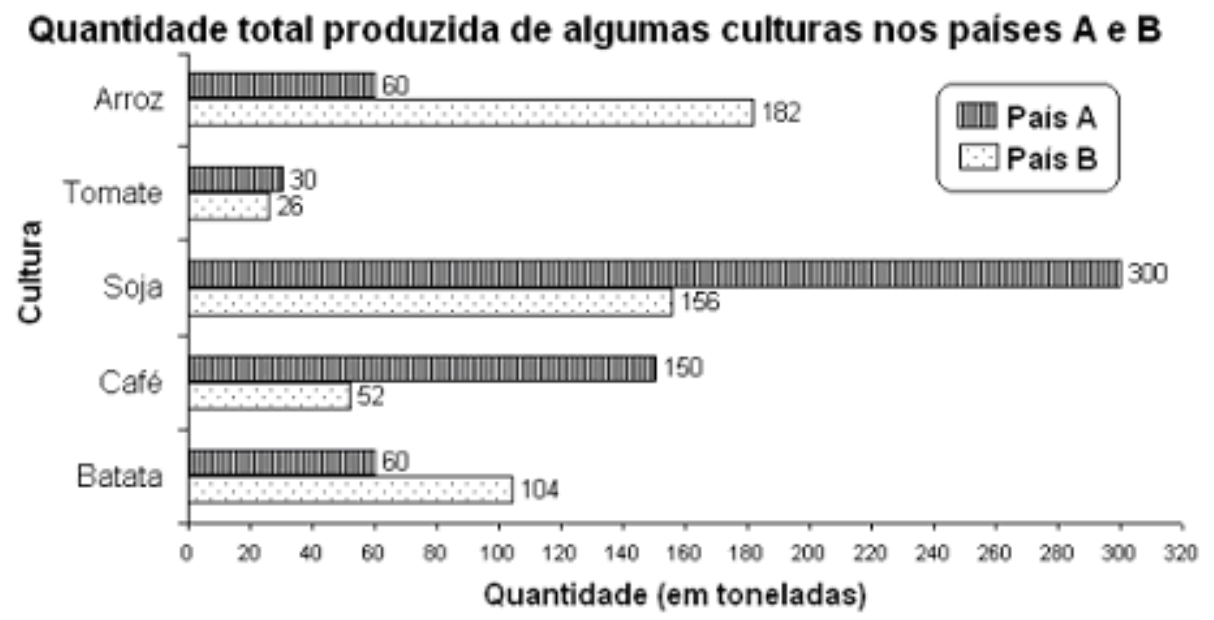

Assinale abaixo o grafico de setores (tambèm conhecido como "grafico de pizza") que representa corretamente a produçăo total em percentagem das cinco culturas no pais $\mathrm{A}$.

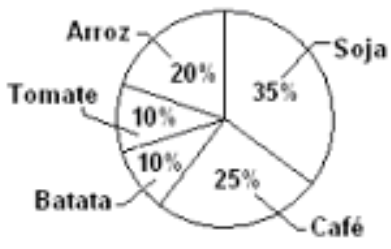

(A)

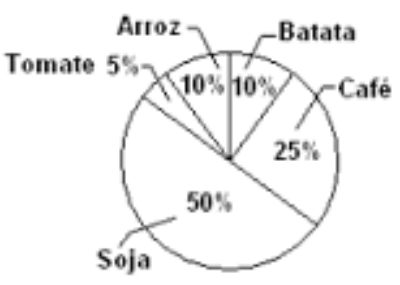

(B)

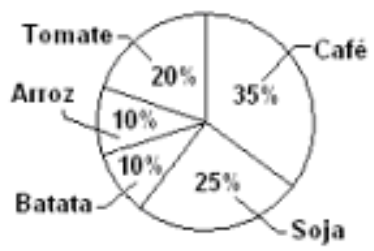

(C)

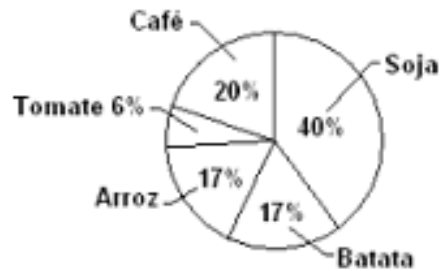

(D)

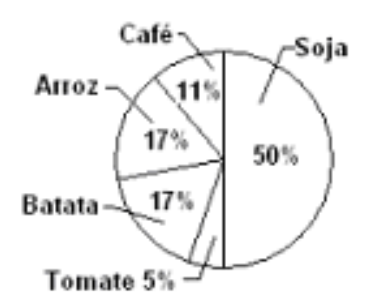

(E)

Figura 42 - A questão 1 do questionário.

Fonte: Elaborado pelo autor. 


\section{Resolução}

$1^{\circ}$ passo: somar a quantidade total produzida pelo pais $\mathrm{A}$ :

Arroz $=60 \mathrm{~kg}+$ Tomate $=30 \mathrm{~kg}+$ Soja $=300 \mathrm{~kg}+$ Cafe $=150 \mathrm{~kg}+$ Batata $=60 \mathrm{~kg} \Longrightarrow$

$\Longrightarrow$ Total Pais $A=600 \mathrm{~kg}$

$2^{\circ}$ passo: calcular a proporçào de cada produto

Arroz $=\frac{60 \mathrm{~kg}}{600 \mathrm{~kg}}=\frac{1}{10}=0,10=10 \%$

Tomate $=\frac{30 \mathrm{~kg}}{600 \mathrm{~kg}}=\frac{1}{20}=0,05=5 \%$

Soja $=\frac{300 \mathrm{~kg}}{600 \mathrm{~kg}}=\frac{1}{2}=0,50=50 \%$

Cafe $=\frac{150 \mathrm{~kg}}{600 \mathrm{~kg}}=\frac{1}{4}=0,25=25 \%$

Batata $=\frac{60 \mathrm{~kg}}{600 \mathrm{~kg}}=\frac{1}{10}=0,10=10 \%$

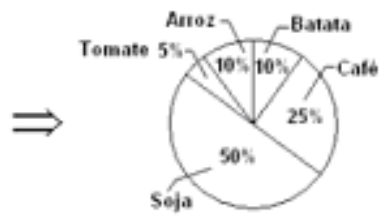

Resposta: B

Figura 43 - Resolução e resposta da questão 1 do questionário.

Fonte: Elaborado pelo autor.

A questão 1 requer interpretação de dados quantitativos por meio de informação visual (gráfico). Exigia do respondente o conhecimento das noções inerentes à proporção e a transformação da informação dada em valores absolutos em um gráfico de barras para informação em valores relativos (proporção) em um gráfico de setores. A elevada proporção de acertos $(71,62 \%)$ da questão 1 pode ser um indício que o respondente de fato consegue processar a informação visual representando-a em formas diferentes (gráfico de barras e gráfico de setores) e sabe mapear quantidades absolutas para quantidades relativas.

\subsubsection{Questão 2 do questionário}

Na Figura 44 observa-se o enunciado, resolução e resposta da questão 2. 
Qmestắ 2 Situaçăo lipotética: o IBGE fez um levantamento em um total de 500 municipios para verificar quantos mnnicipios sho prodntores de arroz, de feijaso, ou de ambos. Verificou-se que 120 municipios năo produzem nem arroz nem feijăo, 80 municipios produzem arroz e feijăo, $\mathrm{e}$ 100 municipios produzem somente feijäo. Qual a percentagem de municipios que produzem somente arroz?

(A) entre $10 \%$ e $25 \%$ dos 500 municipios

(B) entre $30 \%$ e $45 \%$ dos 500 municipios

(C) entre $50 \%$ e $75 \%$ dos 500 municipios

(D) entre $80 \%$ e $90 \%$ dos 500 municipios

(E) mais de $90 \%$ dos 500 municipios

$X+80+100+120=500 \Longrightarrow X=200$

Resolução Somente arroz

200 municipios produzem somente arroz

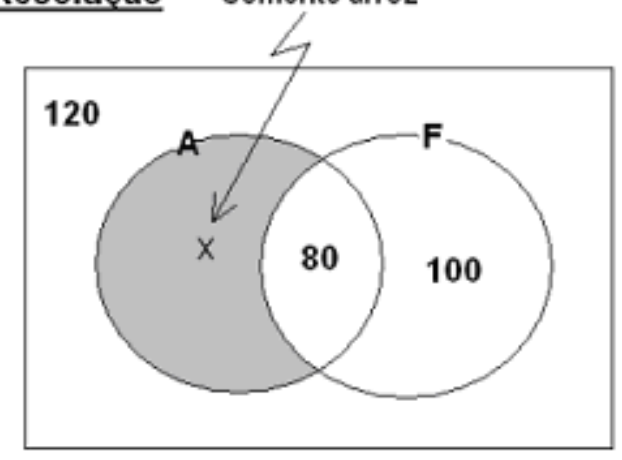

Em termos de proporçăo temos: $\frac{200}{500}=0,4=40 \%$ dos municipios

Resposta: B

Figura 44 - A questão 2 do questionário, resolução e resposta.

Fonte: Elaborado pelo autor.

$\mathrm{Na}$ questão 2, a temática envolve noções de teoria dos conjuntos exigindo o conhecimento/aplicação das noções de união, interseção e complemento (exclusão - não pertence) para efetuar contagens em duas categorias (conjuntos). Além disso, exigia, como na questão 1, o entendimento de quantidades relativas (proporções). A modesta proporção de $57,29 \%$ de acertos na questão 2 pode ser um indício de que o respondente apresente alguma dificuldade com as noções básicas de teoria de conjuntos, pois o cálculo de proporção parece ser de entendimento do aluno, haja visto o bom desempenho na questão 1, onde $71,62 \%$ dos respondentes calcularam proporção corretamente. Em outras palavras, os que não acertaram a questão 2 podem não ter conseguido representar o esboço conceitual do problema em termos de conjuntos e daí não conseguiram chegar à etapa de cálculo do percentual de municípios que produzem somente arroz.

\subsubsection{Questão 3 do questionário}

Na Figura 45 observa-se o enunciado, resolução e resposta da questão 3. A questão 3 envolve problema de análise combinatória, importante para entender os conceitos de 
distribuições de probabilidade (binomial, poisson, normal, etc). Apenas 89 respondentes $(23,18 \%)$ acertaram a questão. Chama a atenção que 101 respondentes $(23,30 \%)$ deixaram a questão em branco, admitindo assim desconhecimento do assunto. Se de fato a baixa proporção de acertos $(23,18 \%)$ da amostra for a mais próxima possível da realidade, significa que o aluno graduando em Geografia egresso do Ensino Médio desconhece estes conceitos, dificultando o entendimento da modelagem de fenômenos (naturais e sociais) não determinísticos quando forem tratados durante o curso de graduação em Geografia.

Questăo 3 Situaçăo hipotética: em um determinado projeto governamental é necessảio que se escolha un grupo contendo três midades federativas para implantaçăo da fase experimental do projeto. As unidades federativas que podem ser escollidas para o grupo săo: Amazonas, Pará, Mato Grosso, Sergipe, Goiás, Paraná, Espirito Santo e Tocantins. Foram anotados em pedaços de papel todos os possiveis gupos de três uidades federativas que se pode obter a partir dos oito estados disponiveis. Cada pedaço de papel contendo um possivel grupo foi depositado numa urna para que se fosse realizado o sorteio de um único pedaço de papel que apontaria entăo o grupo com os nomes das três unidades federativas onde se realizaria a fase experimental do projeto. Admitindo que durante o sorteio todos os possiveis gupos tenham igual probabilidade de serem selecionados da urna, qual a probabilidade de o estado do Amazonas pertencer ao grupo sorteado? Observaçäo: a obtençäo da quantidade total de grupos com $p$ elementos obtidos a partir de $n$ possiveis elementos se dá pela fórmula da combinaçăo: $\mathrm{C}_{n, y}=n ! /\left((n-p) !{ }^{\star} p !\right)$.
(A) entre $1 / 56$ e $12 / 56$
Resolução
$1^{\circ}$ passo:
Total possivel de grupos com 3 estados:
(B) entre $13 / 56$ e $18 / 56$
(C) entre $19 / 56$ e $25 / 56$
(D) entre $26 / 56$ e $37 / 56$
(E) mais de $37 / 56$
$2{ }^{\circ}$ passo: Supondo que um elemento do grupo è o Amazonas:

$$
C_{8,3}=\frac{8 !}{(8-3) ! 3 !}=56
$$

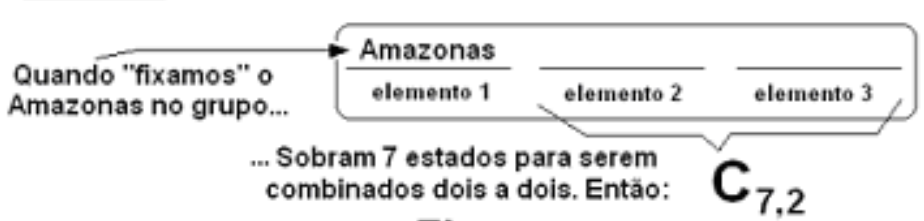
$3^{\circ}$ passo:

$$
C_{7,2}=\frac{7 !}{(7-2) ! 2 !}=21
$$

Em 56 grupos de 3 estados possiveis, em 21 grupos o Amazonas fará parte.

Entäo a probabilidade de o grupo sorteado conter o Amazonas é:

$$
\mathbf{P}=\frac{\mathbf{C}_{7,2}}{\mathbf{C}_{8,3}}=\frac{21}{56} / / \quad \text { Resposta: C }
$$

Figura 45 - A questão 3 do questionário, resolução e resposta.

Fonte: Elaborado pelo autor. 


\subsubsection{Questão 4 do questionário}

Na Figura 46 observa-se o enunciado da questão 4 e na Figura 47 a resolução e resposta da mesma.

Apenas 17,97\% acertaram a questão 4, ou seja, 69 respondentes. A questão, cujos dados a serem manipulados apresentavam-se em formato tabular, envolvia a aplicação de simples operações aritméticas de soma, subtração e divisão, e entendimento e aplicação dos conceitos de média aritmética simples e proporção/percentagem. Registra-se que dos 384 respondentes, $159(41,40 \%)$ assinalaram - incorretamente - como resposta correta a letra A da questão. Isto sinaliza que substancial parcela da amostra parece desconhecer o conceito de média aritmética simples.

Vale por fim ressaltar que informações apresentadas em formato tabular são extremamente comuns em todos os ramos do conhecimento, inclusive nas informações do cotidiano divulgadas na televisão, Internet, revistas, etc. A leitura e entendimento da informação assim disposta é, portanto, fundamental. 
Questäo 4 Situaçăo hipotética: a tabela abaixo apresenta o número de casos de dengue registrados nos mnnicipios A e B nos anos de 2004 a 2010. Assinale a alternativa correta.

Número de casos de dengue registrados nos municipios A e B no periodo de 2004 a 2010

\begin{tabular}{ccc}
\hline Ano & Municipio A & Municipio B \\
\hline 2004 & 118 & 202 \\
2005 & 155 & 193 \\
2006 & 163 & 197 \\
2007 & $?$ & 288 \\
2000 & $?$ & 271 \\
2009 & 172 & 241 \\
2010 & 120 & 218 \\
\hline Total de casos (2004 a 2010) & 1330 & 1610 \\
\hline Obs.: ? - número conhecido mas nāo \\
apresentado na tabela
\end{tabular}

(A) quanto ao núuero médio de casos de dengue no periodo 2004-2010, no municipio B ocorreram em média 230 casos por ano. Mas näo é possivel calcular o numero médio de casos de dengue para o mesmo periodo para o municipio $\mathrm{A}$ a partir das informaçoes da tabela.

(B) Se no ano de 2011 o municipio $\mathrm{A}$ apresentou uma reduçăo de $30 \%$ de casos em relaçăo ao ano de 2010 , entäo em 2011 ocorreram entre 90 e 100 casos em A.

(C) Suponha que o municipio $\mathrm{B}$ adote açőes que permitem a rednçăo em $50 \%$ do unimero de casos ano após ano a partir de 2010. Desta forma, em 2011 ocorreriam metade dos casos ocorridos em 2010. Fin 2012 ocorreriam metade dos casos de 2011 e assin sucessivamente. Nestas condiçőes, em 2014 ocorreriam menos de 10 casos no mnnicipio $B$.

(D) $\dot{E}$ possivel afurmar com certeza que no municipio $\mathrm{A}$, no periodo de 2004 a 2009 , ocorren, ano após ano, un aumento no número de casos registrados.

(E) $\mathrm{O}$ municipio $\mathrm{A}$ apresenton 43 casos a mais de dengne que o municipio $\mathrm{B}$, considerando-se apenas os anos de 2007 e 2008

Figura 46 - A questão 4 do questionário.

Fonte: Elaborado pelo autor. 


\section{Resolução}

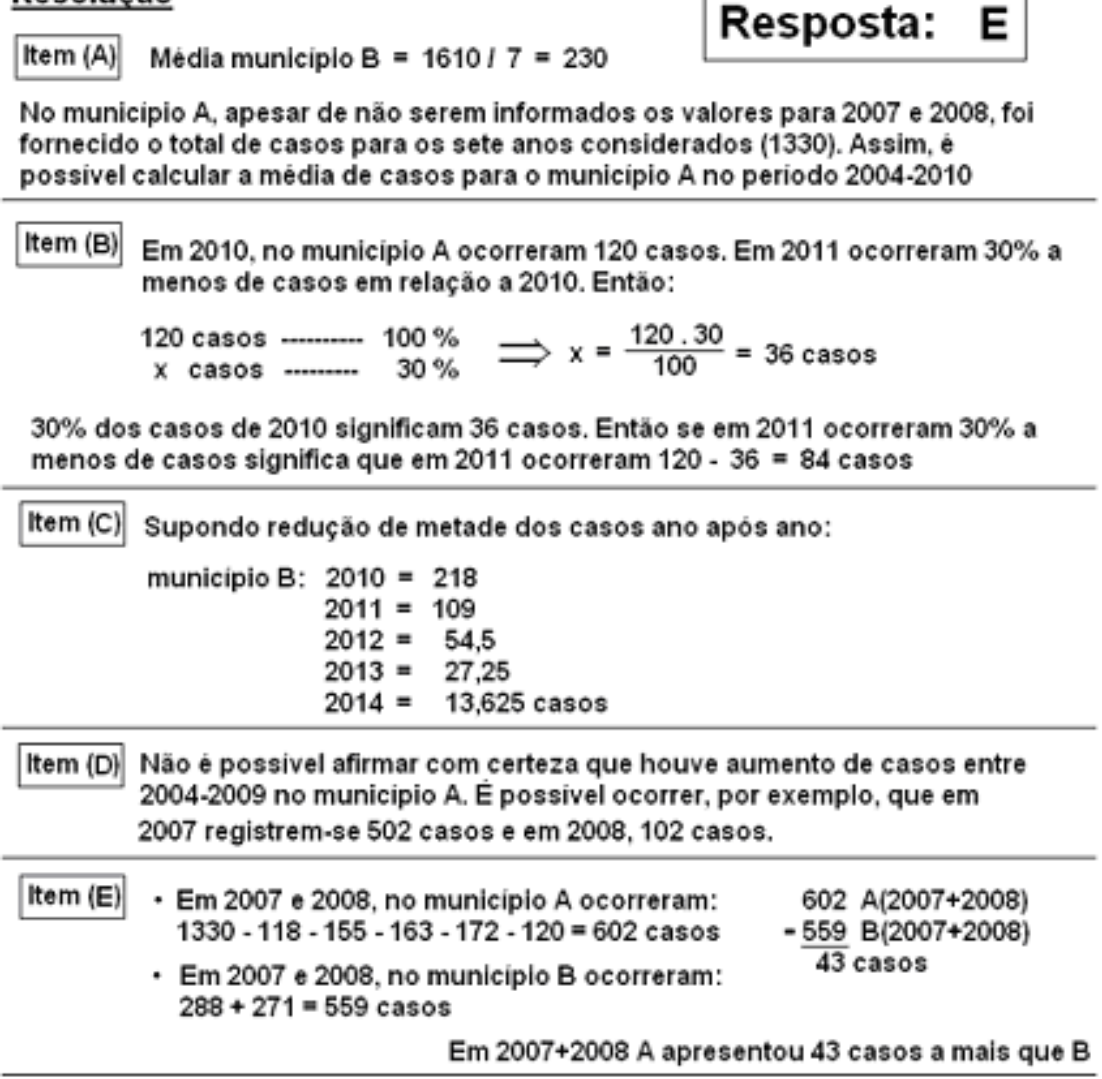

Figura 47 - Resolução e resposta da questão 4 do questionário.

Fonte: Elaborado pelo autor.

\subsubsection{Questão 5 do questionário}

Na Figura 48 observa-se o enunciado, resolução e resposta da questão 5. Apenas 47 respondentes $(12,24 \%)$ acertaram a questão 5. Foi a questão com menor quantidade de acertos. Cobrou-se nesta questão a matemática do cotidiano que lida com escala, que tem forte ligação com o trabalho do geógrafo em seu trabalho de análise do espaço geográfico. Se de fato a baixa proporção de acertos $(12,24 \%)$ de respondentes da amostra for a mais próxima possível da realidade, significa que o aluno desconhece estes conceitos e apresentará dificuldades nas disciplinas de Geografia que tenham suporte de conceitos cartográficos. 
Questắo 5 Situaçăo lipotética: os Mapas 1 e 2 abaixo apresentados representam a mesma regiäo, porém encontr am-se em escalas distintas. Existem quatro pontos fixos na regiäo, $\mathrm{A}, \mathrm{B}, \mathrm{C}$ e $\mathrm{D}$, que săo vértices de un retângulo imaginário conforme mostrado nos Mapas 1 e 2. Sabe-se que a escala do Mapa 1 è de $1 \mathrm{~cm}=2.000$ metros e que no Mapa 1 a distância do segmento de reta $\mathrm{AD}$ $=\mathrm{BC}=2 \mathrm{~cm}$. No Mapa 2 a distância do seguento de reta $\mathrm{AB}=\mathrm{CD}=0,75 \mathrm{~cm}$. Sabe-se ainda que a área real do quadrilatero $\mathrm{ABCD}$ è de $24 \mathrm{Km}^{2}$. Assinale a alternativa correta.

(A) A escala do Mapa $2 \mathrm{e}: 1 \mathrm{~cm}=800.000 \mathrm{~cm}$

(B) A escala do Mapa 2 é: $1 \mathrm{~cm}=750.000 \mathrm{~cm}$

(C) A escala do Mapa 2 é: $1 \mathrm{cma}=2.400 .000 \mathrm{~cm}$

(D) A escala do Mapa 2 è: $1 \mathrm{~cm}=6.000 \mathrm{~m}$

(E) A escala do Mapa 2 è: $1 \mathrm{~cm}=1.500 .000 \mathrm{~cm}$

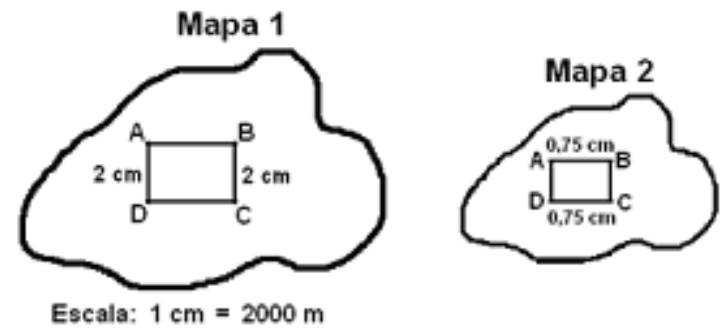

Resolução $1^{\circ}$ passo: No Mapa 1 temos que:

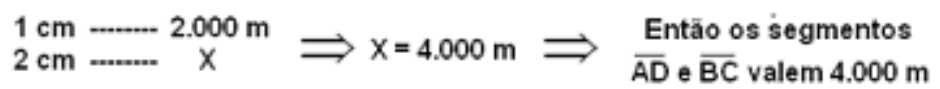

$2{ }^{\circ}$ passo: $A$ área do quadrilätero $A B C D$ vale $24 \mathrm{Km}^{2}$

$A$ área de $A B C D$, que è um retângulo vale $\overline{\mathrm{AD}} \times \overline{\mathrm{AB}}$. Então:

$\overline{\mathrm{AD}} \times \overline{\mathrm{AB}}=24 \mathrm{~km}^{2} \Longrightarrow 4.000 \mathrm{~m} \times \overline{\mathrm{AB}}=24.000 .000 \mathrm{~m}^{2} \Rightarrow \overline{\mathrm{AB}}=6.000 \mathrm{~m}$

$3^{\circ}$ passo: No Mapa 2 temos que $\overline{\mathrm{AB}}=0,75 \mathrm{~cm}$. Como $\overline{\mathrm{AB}}=6.000 \mathrm{~m}$ então:

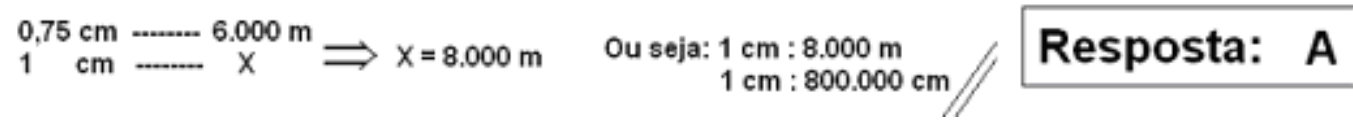

Figura 48 - A questão 5 do questionário, resolução e resposta.

Fonte: Elaborado pelo autor.

\subsubsection{Questão 7 do questionário}

Na Figura 49 observa-se o enunciado, resolução e resposta da questão 7. A questão 7 apresentou um razoável percentual de acertos de 44,27\%. Porém, pela importância do conceito - relacionar proporcionalidade direta ou inversa entre duas grandezas - chama mais a atenção que 55,73 \% dos respondentes não tenham acertado. A análise dos resultados da questão 7 deixa uma dúvida: será que os respondentes que não acertaram, não entendem o conceito de proporcionalidade direta/inversa entre duas variáveis, e/ou não conseguem reconhecer e expressar estas proporcionalidades em formato visual de gráfico? Seja qual for a reposta, a ideia de proporcionalidade direta e inversa - tema da questão 7 é muito utilizada nos discursos do cotidiano, em noticiários, etc, e é fundamental em quantificação em Geografia. 
Questão 7 Situação hipotética: os graficos I a IV abaixo apresentam a relaçăo entre duas variáveis quantitativas para um grupo de oito paises, onde cada pais é representado por um ponto nos gráficos. Assinale a alternativa correta.

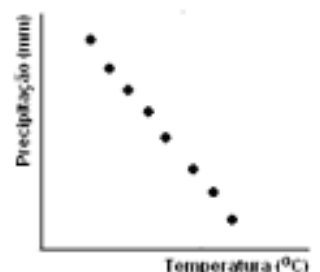

(I)

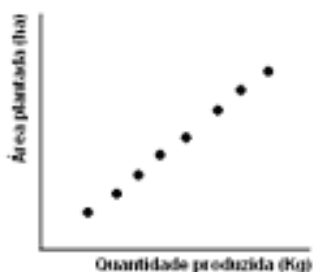

(II)

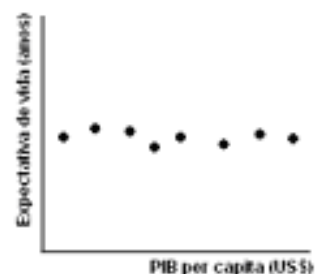

(III)

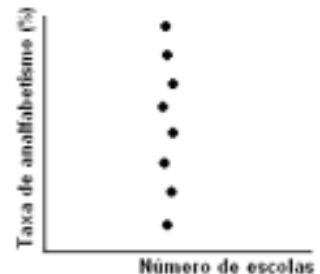

(IV)

(A) Para o grupo dos oito paises, as variàveis do gráfico I säo diretamente proporcionais entre si e as variáveis do gráfico $I$ sắo inversamente proporcionais entre si

(B) Para o grupo dos oito paises, as variàveis do grafico III são diretamente proporcionais entre si e as variàveis do gráfico IV săo inversamente proporcionais entre si

(C) Para o grupo dos oito paises, as variáveis do grafico I são diretamente proporcionais entre si e as variaveis do grafico IV săo inversamente proporcionais entre si

(D) Para o grupo dos oito paises, as variaveis do grafico II säo diretamente proporcionais entre si e as variáveis do gráfico I săo inversamente proporcionais entre si

(E) Para o grupo dos oito paises, as variáveis do gráfico IV săo diretanente proporcionais entre si $e$ as variaveis do gráfico III săo inversamente proporcionais entre si

\section{Resolução}

\section{Resposta: D}

- No grafico (I) as variáveis säo inversamente proporcionais entre si. Amentando a temperatura, diminui a precipitaçăo

- No gráfico (II) as variáveis são diretamente proporcionais entre si. Aumentando a quantidade produzida, aumenta a área plantada

- No grpafico (III) näo há proporcionalidade. Independentemente de maior ou menor PIB per capita, a expectativa de vida não varia

- No grafico (IV) nāo há proporcionalidade. Independentemente de maior ou menor taxa de analfabetismo, o número de escolas näo varia

Figura 49 - A questão 7 do questionário, resolução e resposta.

Fonte: Elaborado pelo autor.

\subsubsection{Considerações sobre os resultados obtidos}

O número médio de 2,266 questões respondidas corretamente entre as seis questões consideradas para os 384 respondentes e o valor do terceiro quartil de três questões, isto é, 288 dos 384 respondentes acertarem no máximo três das seis questões, fornecem indícios para possivelmente afirmar que, a priori, em geral há pouca familiaridade dos graduandos de Geografia - ao menos no universo das instituições onde se aplicou o questionário - com conceitos básicos de Matemática que são essenciais para realização de atividades que requeiram aplicação de quantificação em Geografia. 
Os conceitos matemáticos embutidos nas questões do questionário envolviam, com exceção das noções de análise combinatória da questão 3, simples conhecimentos usados, não somente em atividades específicas de diversos ramos do saber (Geografia, Física, Biologia, Engenharia, etc), mas principalmente, no cotidiano das pessoas: um cidadão precisa aplicar conceitos de proporção e média aritmética, por exemplo, no comércio ao comprar e/ou vender bens e serviços.

Se fosse usado um termo para designar o pré-requisito necessário para resolução das seis questões consideradas do questionário, este termo seria "fração". Em essência, as seis questões propostas, em maior ou menor intensidade necessitam que o respondente tenha um entendimento sólido deste conceito que, de alguma forma, é necessário para a resolução correta das questões. O desempenho do grupo de 384 respondentes no questionário pode sinalizar que o graduando em Geografia, em geral, não apresenta, ou apresenta de forma tênue este conceito subsunçor em sua estrutura cognitiva. Como este conceito é de fundamental importância para a quantificação, pode-se supor que o aluno terá dificuldades para uma aprendizagem significativa de conceitos mais elaborados de quantificação e, assim, apresentará dificuldades em aplicar quantificação em análise espacial de dados geográficos.

As questões 1, 2 e 7 foram as que apresentaram maior percentual de acertos por parte dos respondentes. Numa primeira análise talvez seja possível apontar um cenário onde o conceito subsunçor que possibilite a resolução correta destas questões seja o mesmo. Em outro cenário, é plausível supor que apenas as questões 1 e 2 requeiram o mesmo conceito subsunçor para correta resolução. Na Tabela 6 é apresentado o total de respondentes que acertaram ao menos as questões 1,2 e 7 e o total de respondentes que acertaram ao menos as questões 1 e 2 e erraram a 7, correspondendo aos dois cenários considerados.

Tabela 6 - Total de respondentes do questionário que acertaram ao menos as questões 1,2 e 7 ou que acertaram ao menos as questões 1 e 2

Acertou questões

\begin{tabular}{cc} 
Cenário 1 & Cenário 2 \\
\hline Ao menos 1, 2 e 7 & Ao menos 1 e 2 e \\
& erraram a 7 \\
$95(24,73 \%)$ & $170(44,27 \%)$ \\
\hline
\end{tabular}


Se for considerado que o conceito de fração/proporção é o mesmo conceito subsunçor para responder as questões 1, 2 e 7, então observa-se na Tabela 6 que apenas 24,73\% dos respondentes apresentaria, a priori este conceito. Caso seja considerado que o conceito de fração/proporção é o mesmo conceito subsunçor apenas para responder as questões 1 e 2 então 44,27\% apresentaria esta característica. De qualquer forma, é uma baixa quantidade de respondentes em ambos os cenários, mais uma vez considerando-se que estes conceitos a priori foram trabalhados com os alunos em nível de Ensino Fundamental e Ensino Médio.

Assim, se a amostra de 384 respondentes de cursos de Geografia for de fato representativa da realidade dos graduandos de Geografia do País, então a pouca familiaridade dos graduandos de Geografia com conceitos básicos de Matemática pode acarretar deficiências na capacitação do graduando para o efetivo aprendizado de técnicas diversas de quantificação aplicada à Geografia. Em geral, a matriz curricular dos cursos de graduação em Geografia é composta de apenas uma única disciplina ligada à quantificação, e recebe diversas denominações dependendo da instituição (Estatística Aplicada, Noções de Estatística, Estatística Para Geociências, etc). Contudo, se o aluno chega ao Ensino Superior com pouca familiaridade de conceitos matemáticos básicos tratados no Ensino Básico, muito provavelmente terá dificuldades na disciplina da matriz curricular que trata, de alguma forma, a quantificação em Geografia.

Os resultados deste questionário serviram para direcionar o conteúdo de assuntos ligados à quantificação que deveriam ser inseridos no software EDH. O planejamento inicial era desenvolver o EDH com lições que lidassem com análise espacial de áreas com contagens contínuas ou análise de padrões espaciais de pontos. Contudo, foram escolhidos conceitos básicos de quantificação que podem ser considerados como conceitos ligados ao escopo da Estatística Descritiva e são eles, já citados no item 3.7: (1) objetos e variáveis; (2) média; (3) variância e desvio padrão; (4) coeficiente de variação; (5) curva de Lorenz e coeficiente de Gini; (6) separatrizes e box plot; (7) centro médio espacial e (8) distância padrão.

Para finalizar, vale como sugestão, com o propósito de se certificar com maior confiabilidade sobre a familiaridade de conceitos matemáticos básicos por parte dos graduandos em Geografia, que seja feita uma investigação, como a que foi apresentada, coordenada em instância nacional para aplicação de um questionário e avaliação dos resultados, com um maior numero de instituições de ensino superior, maior número de respondentes e maior cobertura geográfica, para melhor investigar este aspecto do futuro profissional de Geografia do País. 


\subsection{LEVANTAMENTO DE DISCIPLINAS DO CURSO DE GEOGRAFIA LIGADAS À QUANTIFICAÇÃO}

Conforme comentado no item 2.5, com o intuito de averiguar se a formação acadêmica recebida pelo geógrafo durante seu curso de graduação o capacita a realizar quantificação para análise espacial de dados geográficos, foi realizado um levantamento da matriz curricular de cursos de Geografia de algumas universidades do País. Este levantamento consistiu em verificar a ementa das disciplinas ligadas de alguma forma à quantificação, da matriz curricular dos cursos de Geografia consultando-se a Internet.

Foram verificadas a grade curricular de 16 cursos de graduação de bacharelado em Geografia no Brasil, para constatar se há oferta de disciplinas ao graduando de Geografia com conteúdos ligados às três estatísticas (estatística descritiva, inferencial e/ou multivariada), pois são os conceitos destas disciplinas realmente básicos para entendimento e execução da análise espacial de dados geográficos. Ressalta-se que poderiam também ser escolhidos cursos de graduação em nível de licenciatura, pois, conforme já foi colocado anteriormente neste trabalho, a quantificação é também importante para o geógrafo com habilitação em licenciatura.

Foram escolhidas três universidades públicas da Região Sul, seis da Região Sudeste, três da Região Centro Oeste, uma da Região Norte e três da Região Nordeste. Com este critério, tentou-se ter ao menos uma instituição de cada uma das cinco regiões do Brasil. Dentre as 16 universidades escolhidas, constatou-se, por acesso ao site das universidades na Internet, que na Universidade de São Paulo (USP), Universidade Federal de Santa Catarina (UFSC) e Universidade Federal do Ceará (UFC) não há disciplina obrigatória ligada à quantificação, havendo optativa. Na Universidade Federal de Minas Gerais (UFMG), Universidade Federal do Rio de Janeiro (UFRJ) e Universidade Federal de Alagoas (UFAL) há a obrigatoriedade de duas disciplinas e, nas demais dez universidades há a obrigatoriedade de um única disciplina.

Para tomar como parâmetro de referência de comparação de conteúdos, foi analisada a ementa e o programa da disciplina "Estatística Aplicada" do curso de bacharelado em Geografia da Universidade de Brasília (UnB). Esta é a única disciplina, de caráter obrigatório, da matriz curricular do curso que seria ligada direta ou indiretamente à análise espacial. Vale ressaltar que disciplinas como "Sistemas de Informação Geográfica" ou "Sensoriamento Remoto" não contam pois, seriam disciplinas que não têm como propósito ensinar 
quantificação, mas sim usar algumas técnicas de quantificação, pressupondo portanto conhecimento prévio do aluno sobre o tema. No Quadro 6 é apresentada a ementa e o programa da disciplina.

Quadro 6 - Ementa e programa da disciplina "Estatística Aplicada" da UnB

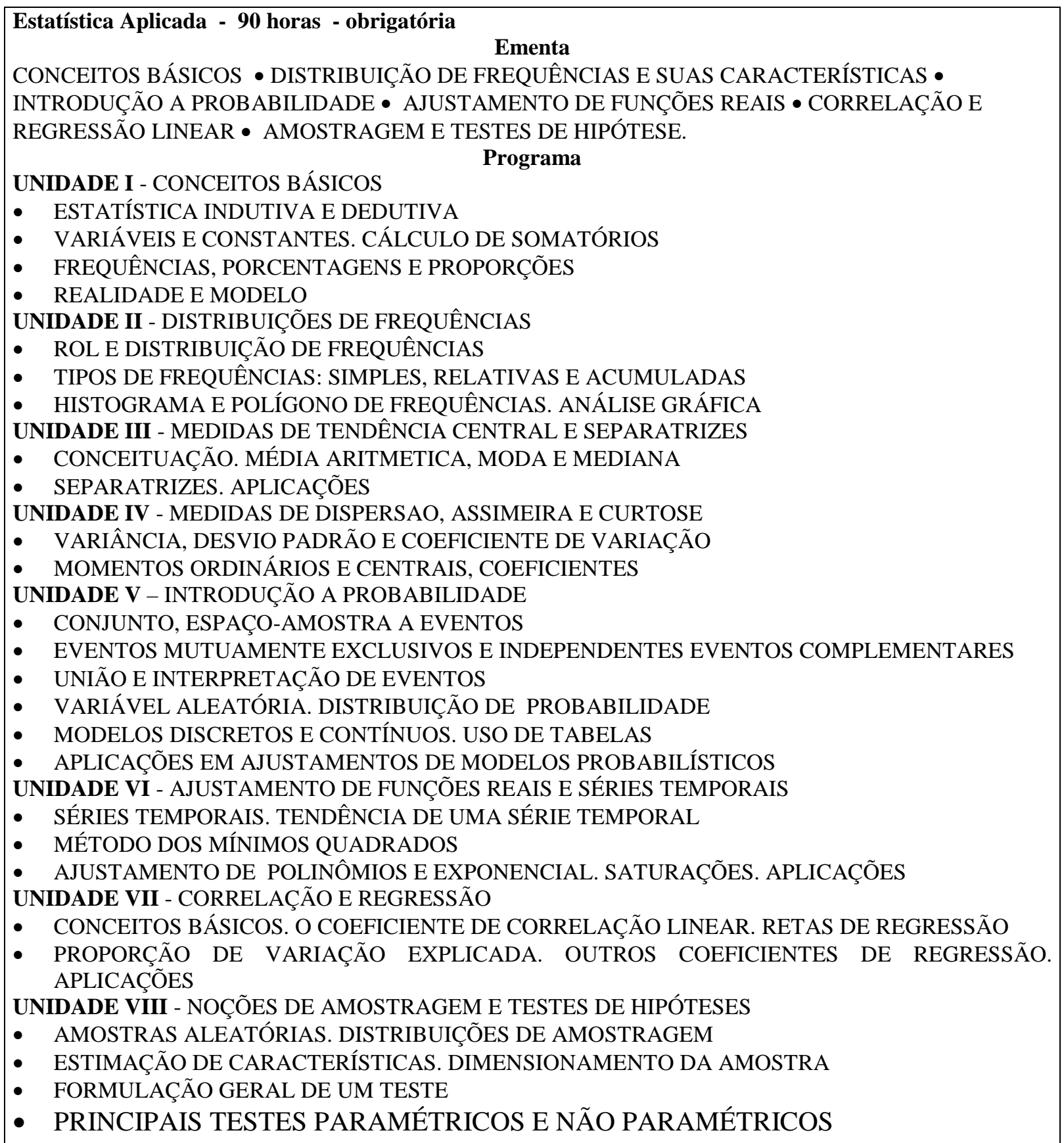

Fonte: Universidade de Brasília (2013a).

Observando a ementa e o programa da disciplina, pode-se dizer que das três estatísticas básicas, apenas a estatística multivariada não está contemplada no conteúdo. A 
estatística descritiva estaria abordada nas Unidades II, III e IV, e a estatística inferencial nas Unidades V e VIII, podendo ser usada na abordagem dos temas das Unidades VI e VII. A carga horária de 90 horas indica que as aulas são ministradas três vezes por semana. Isto significa maior tempo dedicado para a disciplina, quando comparada com a grande maioria das demais disciplinas obrigatórias do curso. Sinaliza a carga horária de 90 horas, de alguma forma, o reconhecimento de um conteúdo mais extenso da disciplina.

Apesar de abranger conceitos de estatística descritiva e inferencial, o que se questiona é se, de fato, é suficiente esta única disciplina para o geógrafo apreender os conceitos ministrados e trabalhados nas aulas da disciplina. Para fins de comparação, pode-se considerar algumas disciplinas da matriz curricular do curso de Estatística da própria Universidade de Brasília (UNIVERSIDADE DE BRASÍLIA, 2013b) que estão diretamente envolvidas com os conceitos das três estatísticas. São consideradas as seguintes disciplinas: (1) Estatística Exploratória; (2) Métodos Estatísticos; (3) Introdução à Probabilidade; (4) Métodos Estatísticos 1; (5) Cálculo de Probabilidade 1; (6) Cálculo de Probabilidade 2; (7) Inferência Estatística; (8) Técnicas de Amostragem e (9) Análise de Regressão Linear.

Há ainda outras disciplinas que poderiam ser citadas como, por exemplo, Análise de Séries Temporais ou Análise de Dados Categorizados, mas o rol das nove disciplinas citadas abarcam satisfatoriamente os conteúdos básicos das três estatísticas. Muito do que é apresentado no conteúdo das nove disciplinas citadas está voltado para a parte teórica (teoremas e demonstrações, por exemplo), transformando-se por vezes em conteúdo extremamente abstrato com forte base matemática.

Para o geógrafo, interessa a parte prática (aplicada) e, por isso, uma única disciplina compacta e direta de conteúdos práticos diretamente aplicáveis é proposta na matriz curricular do curso de Geografia na Universidade de Brasília. Ainda assim, é possível questionar se esta disciplina única compacta fornecerá subsídios para o entendimento e uso de uma quantificação efetivamente aplicada à análise espacial.

No caso do aluno de graduação em Estatística o que de fato ocorre é o aprendizado em espiral, onde o assunto é tratado repetidas vezes pelas diversas disciplinas. Por exemplo, conceitos de estatística descritiva estarão sendo apresentados em Estatística Exploratória e revistos, em maior ou menor intensidade, em Métodos Estatísticos 1. As chances de efetivamente aprender por espiral os conceitos são maiores. Já o aluno de Geografia tem diante de si uma única disciplina compacta e está forçado a aprender não em espiral, mas de forma linear de uma só vez. 
Outro problema que pode ocorrer referente à oferta de apenas uma única disciplina ligada aos conceitos de análise espacial de dados geográficos refere-se ao processo ensinoaprendizagem da disciplina. Como são muitos conceitos para serem apreendidos, muito provavelmente a dinâmica das aulas se resumirá à apresentação do assunto (variância, por exemplo) que culmina na apresentação de uma fórmula (que muito provavelmente deverá ser decorada para a prova) e rápidos exemplos de "como fazer os cálculos" ou "como construir os gráficos". Ao final da disciplina o aluno teoricamente teve contato com diversos conceitos básicos para análise espacial, mas efetivamente não apreendeu nenhum conceito. A aprendizagem, muito provavelmente se dará de forma mecânica, sem que o sentido lógico do conteúdo se transforme em sentido psicológico na estrutura cognitiva do aprendiz. Em outras palavras, muito provavelmente o aluno não irá adquirir letramento, pensamento e nem raciocínio estatístico. Se defrontará corriqueiramente durante as aulas apenas com "aspectos marginais da Estatística".

Então, à luz destas colocações, o que se afirma é que uma única disciplina muito provavelmente será insuficiente para que o graduando em Geografia consiga apreender os conceitos das três estatísticas, salvo casos em que o aluno tenha algum embasamento prévio de temas que facilitem o seu aprendizado nesta disciplina única. Evidentemente não é o caso de inserir na matriz curricular de Geografia nove ou mais disciplinas do curso de Estatística. Se assim fosse o caso, outras disciplinas de outras áreas como a Sociologia e Economia deveriam também ser inseridas, o que tornaria a formação acadêmica do geógrafo interminável.

Mas alguma solução para ir além da disciplina única deve ser buscada. Já nos anos 1970, Johnston (1978) apontava que

The use of statistics in geographical research has increased rapdily during the last two or three decades. Most students being trained in geography at tertiary educational institutions receive some instruction in statistical methods; all are given things to read, particularly research reports in journals, in which statistical procedures form a basic part of the reasoning. And yet relatively few geographers students have strong background in school mathematics, and even fewer continue with mathematical studies in paralell with their geography. (JOHNSTON, 1978, p. XV) 
Em última instância, o autor apontava para a necessidade de os geógrafos, em sua formação acadêmica no Ensino Superior, dedicarem atenção ao embasamento matemático e estatístico, dada a necessidade de realizar e entender a quantificação de fenômenos do espaço geográfico. E ao incentivar os "estudos matemáticos em paralelo com sua Geografia“ deixa implícito que cursar apenas uma disciplina ligada à estatística/matemática é pouco para efetivamente apreender conceitos.

Continuando a verificação de matriz curricular, nos Quadros 7 a 21 são apresentadas as disciplinas e as ementas de alguns cursos de bacharelado em Geografia. As ementas das disciplinas da Universidade do Rio de Janeiro, Universidade Federal do Amazonas, Universidade Federal da Bahia e Universidade Federal do Ceará não foram encontradas disponibilizadas na Internet.

Quadro 7 - Disciplina "Estatística Básica I" - UFRGS

\section{Universidade Federal do Rio Grande do Sul (UFRGS)}

Bacharelado em Geografia - Disciplina ligada indiretamente à análise espacial

Estatística Básica I - 60 horas - Obrigatória

Ementa:

- Descrição estatística.

- Noções de Probabilidade.

- Técnicas de amostragem.

- Distribuições amostrais.

- Estimação.

- Testes Estatísticos.

- Análise de Correlação

Fonte: Universidade Federal do Rio Grande do Sul (2013) 
Quadro 8 - Disciplina “Análise Estatística em Geociências” - UFSC

\section{Universidade Federal de Snata Catarina (UFSC)}

Bacharelado em Geografia - Disciplina ligada indiretamente à análise espacial

Análise Estatística em Geociências - 108 horas - Optativa

Ementa:

- Conceitos e métodos para aquisição, tratamento e interpretação de dados quantitativos.

- Mensuração, organização e descrição estatística de dados.

- Distribuições de frequiências.

- Medidas de tendência central e dispersão.

- Inferência estatística

- Testes paramétricos e não paramétricos.

- Correlação e análise de regressão

Fonte: Universidade Federal de Santa Catarina (2013)

Quadro 9 - Disciplina “Análise Estatística em Geociências” - UFPR

\section{Universidade Federal do Paraná (UFPR)}

Bacharelado em Geografia - Disciplina ligada indiretamente à análise espacial

Estatística II - 60 horas - Obrigatória

Ementa:

- Estatística: Representação Tabular e Gráfica

- Distribuições de Frequências

- Elementos de Probabilidade

- Distribuições Discretas de Probabilidades

- Distribuições Contínuas de Probabilidades

- Noções de Amostragem

- Estimativa de Parâmetros

- Teoria das Pequenas Amostras

- Testes de Hipóteses

- Análise da Variância

- Ajustamento de Curvas

- Regressão e Correlação

- Séries Temporais

- Controle Estatístico de Qualidade

Fonte: Universidade Federal do Paraná (2013) 
Quadro 10 - Disciplinas "Complementos de Matemática I" e "Estatistica" - UFRJ Universidade Federal do Rio de Janeiro (UFRJ)

Bacharelado em Geografia - Disciplina ligada indiretamente à análise espacial

Complementos de Matemática I - 60 horas - Obrigatória

Ementa:

Estatistica - 68 horas - Obrigatória

Ementa:

Fonte: Universidade Federal do Rio de Janeiro (2013)

Quadro 11 - Disciplina "Noções de Estatística" - USP

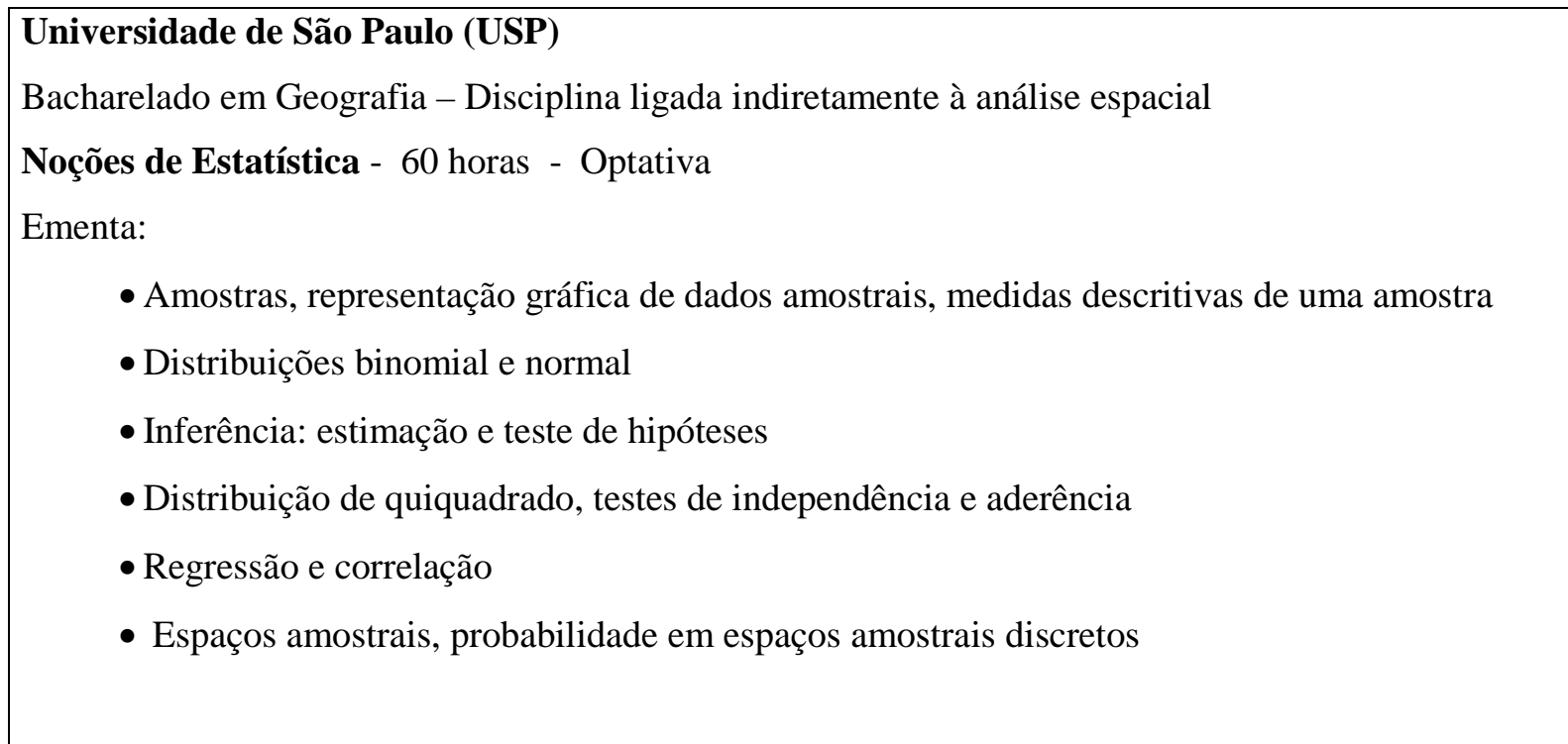

Fonte: Universidade de São Paulo (2013) 
Quadro 12 - Disciplina "Estatística Aplicada à Geografia" - UNESP (Campus Ourinhos) Universidade Estadual Paulista - Campus Ourinhos (UNESP)

Bacharelado em Geografia - Disciplina ligada indiretamente à análise espacial

Estatística aplicada à Geografia - 60 horas - Obrigatória

Ementa:

- Geografia, método científico e quantificação

- Amostragem

- Níveis de mensuração

- Estatística espacial

- Correlação e regressão linear simples

- Similaridade e classificação

- Algumas técnicas selecionadas de quantificação

Fonte: Universidade Estadual Paulista - Campus Ourinhos (2013)

Quadro 13 - Disciplina "Estatística Aplicada à Geografia" - UNESP

(Campus Presidente Prudente)

\section{Universidade Estadual Paulista - Campus Presidente Prudente (UNESP)}

Bacharelado em Geografia - Disciplina ligada indiretamente à análise espacial

Estatística aplicada à Geografia - 60 horas - Obrigatória

Ementa:

- Geografia, Método Científico e Quantificação.

- Técnicas de Amostragem

- Séries Estatísticas

- Descrição Tabular e Gráfica

- Características Numéricas de um Conjunto de Dados

- Introdução à Análise de Regressão e Correlação.

- Números Índices

- Introdução à Análise espacial

Fonte: Universidade Estadual Paulista - Campus Presidente Prudente (2013) 
Quadro 14 - Disciplina “Geoestatística" - UFU

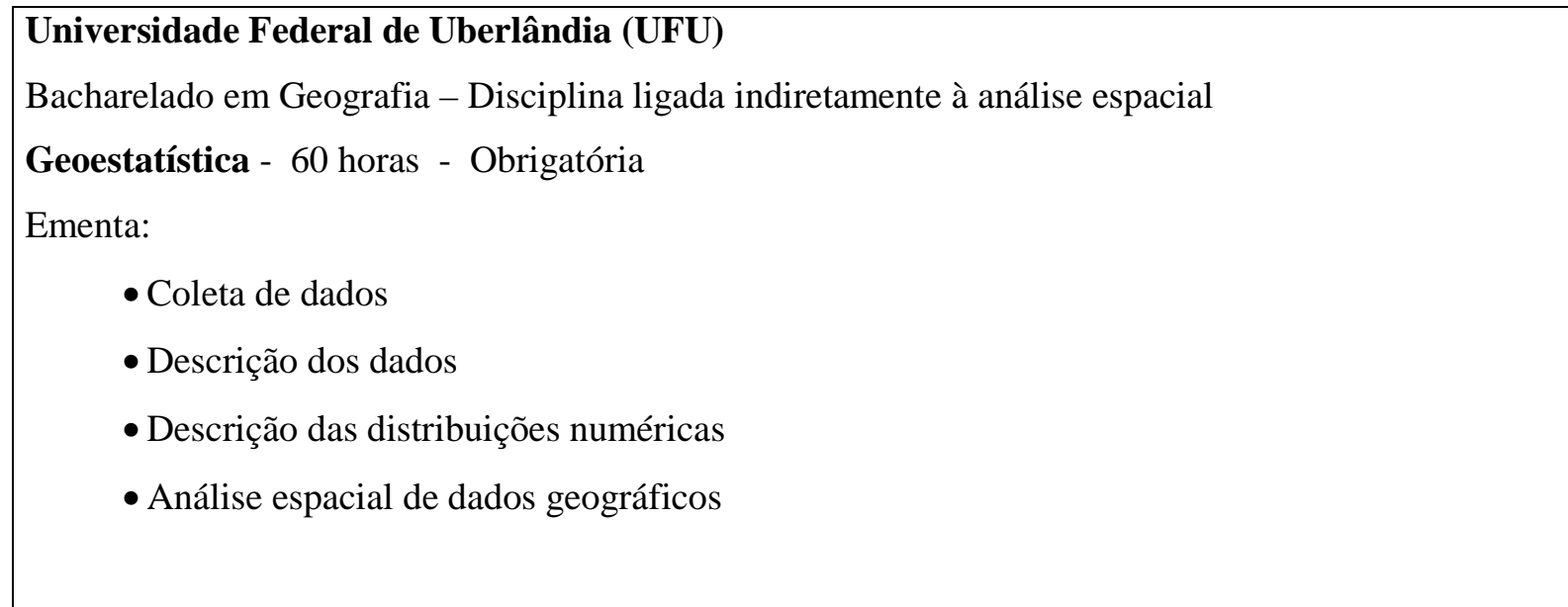

Fonte: Universidade Federal de Uberlândia (2013)

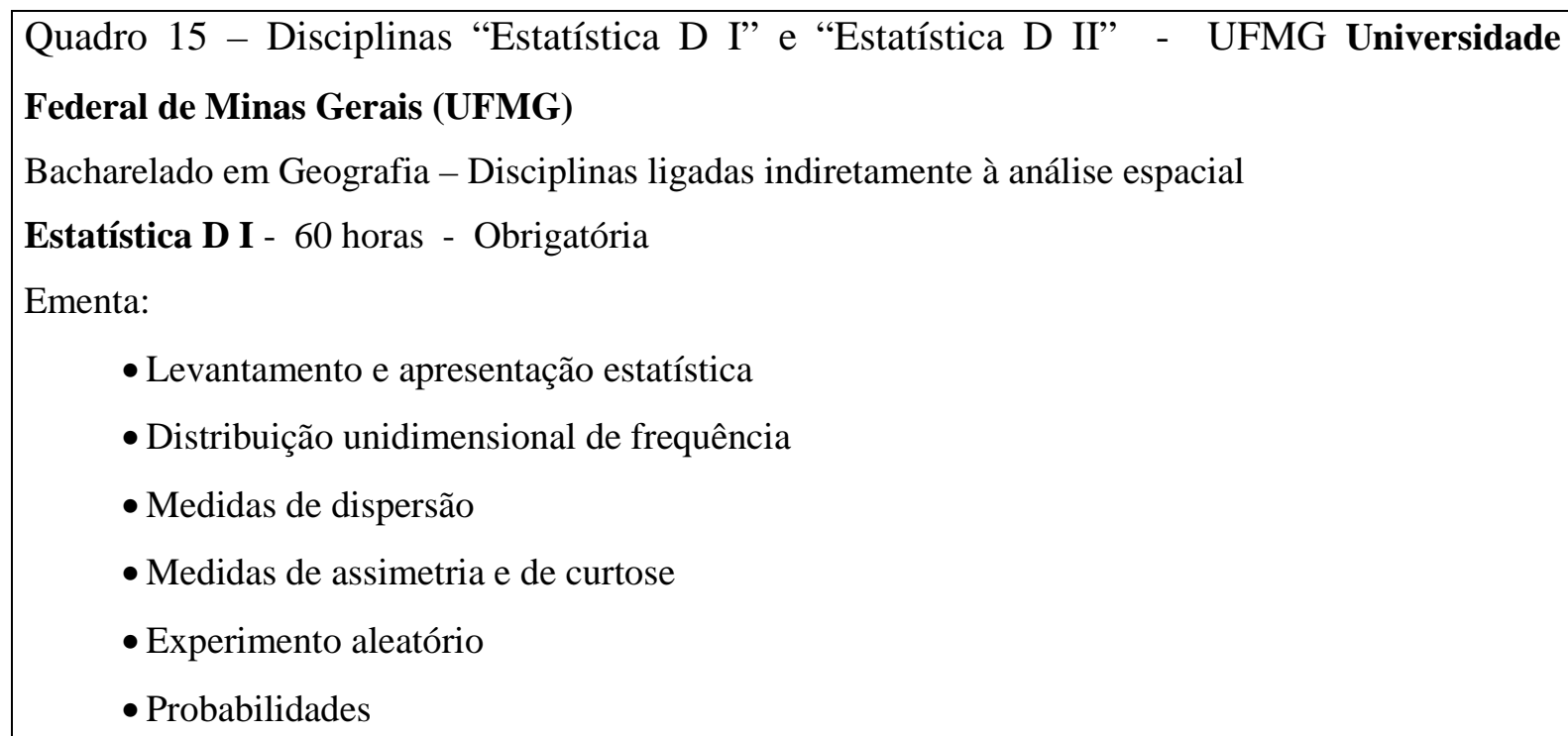

Estatística D II - 60 horas - Obrigatória

Ementa:

- Modelos probabilísticos

- Distribuição por amostragem e noções de inferência

- Ajustamento estatístico

- Regressão e Correlação

- Séries cronológicas

- Números índices

- Análise de grupamento

Fonte: Universidade Federal de Minas Gerais (2013) 
Quadro 16 - Disciplina "Estatística Aplicada à Geografia" - UFG

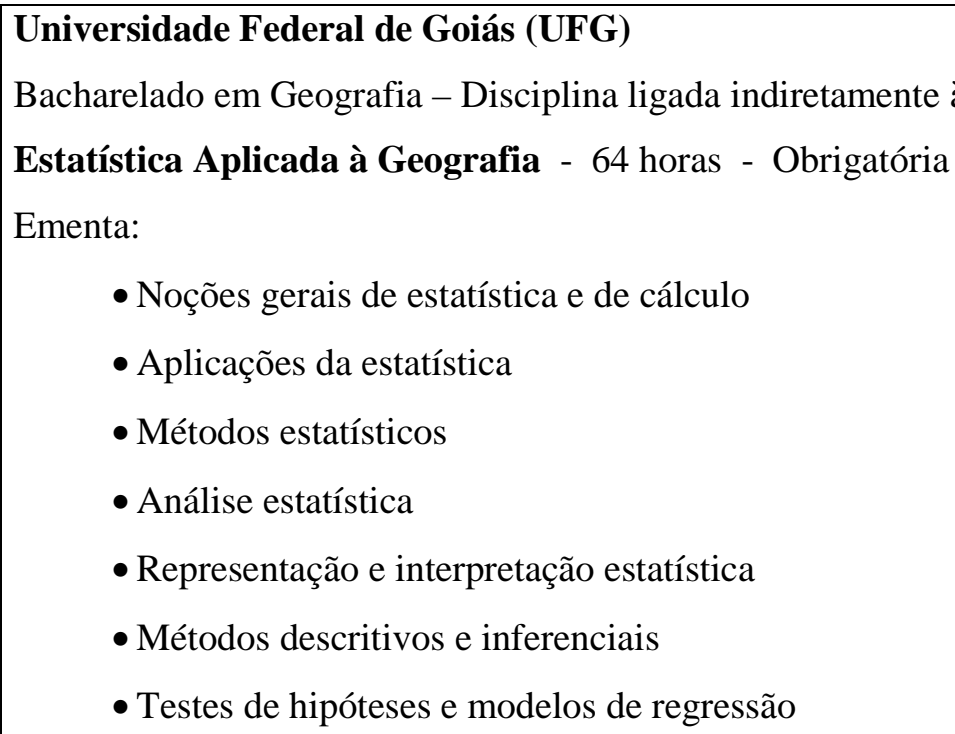

- Noções gerais de estatística e de cálculo

- Aplicações da estatística

- Métodos estatísticos

- Análise estatística

- Representação e interpretação estatística

- Métodos descritivos e inferenciais

- Testes de hipóteses e modelos de regressão

Fonte: Universidade Federal de Goiás (2013)

Quadro 17 - Disciplina “Estatística Geral I" - UFMT

\section{Univerdade Federal de Mato Grosso (UFMT)}

Bacharelado em Geografia - Disciplina ligada indiretamente à análise espacial

Estatística Geral I - 64 horas - Obrigatória

Ementa:

- Conceitos básicos de estatística

- Métodos de amostragem

- Estatística descritiva

- Indicadores sociais

- Noções de probabilidade

- Noções de inferência estatística

- Regressão e correlação

Fonte: Universidade Federal de Mato Grosso (2013) 
Quadro 18 - Disciplina "Introdução à Estatística" - UFAM

\section{Universidade Federal do Amazonas (UFAM)}

Bacharelado em Geografia - Disciplina ligada indiretamente à análise espacial

Introdução à Estatística - 60 horas - Obrigatória

Ementa:

Fonte: Universidade Federal do Amazonas (2013)

Quadro 19 - Disciplina "Modelos Estatísticos em Geociências” - UFC

\section{Universidade Federal do Ceará (UFC)}

Bacaharelado em Geografia - Disciplina ligada indiretamente à análise espacial

Modelos Estatísticos em Geociências - 64 horas - Optativa

Ementa:

Fonte: Universidade Federal do Ceará (2013)

Quadro 20 - Disciplinas “Complementos de Matemática I" e "Estatistica I B” - UFBA

\section{Universidade Federal da Bahia (UFBA)}

Bacharelado em Geografia - Disciplina ligada indiretamente à análise espacial

Complementos de Matemática I - 102 horas - Obrigatória

Ementa:

Estatistica I B - 68 horas - Obrigatória

Ementa:

Fonte: Universidade Federal da Bahia (2013) 
Quadro 21 - Disciplinas "Quantificação em Geografia " e "Geoestatística” - UFAL

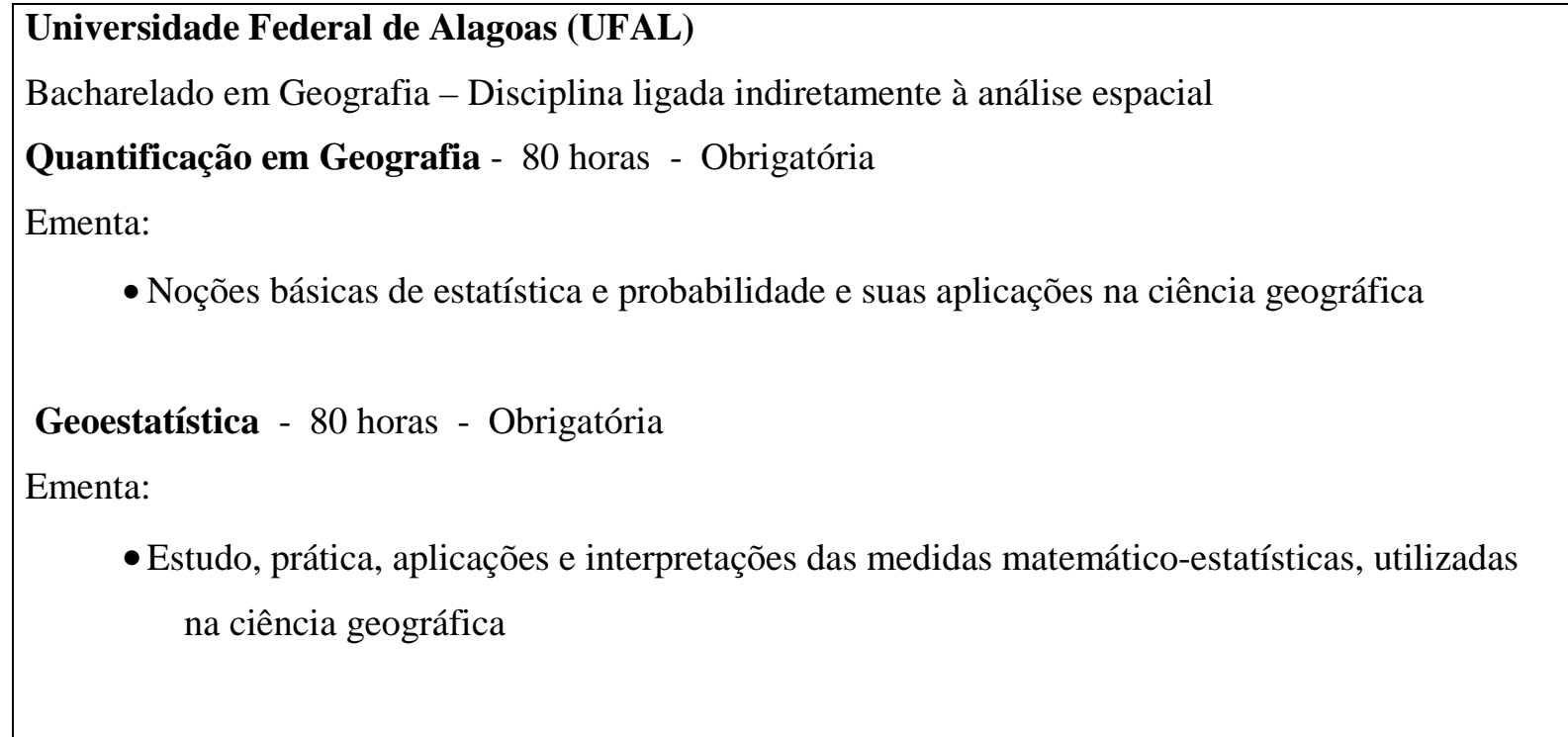

Fonte: Universidade Federal de Alagoas (2013)

Observando as ementas das disciplinas apresentadas nos Quadros 7 a 21, nota-se que, em geral, apresentam similaridade entre si e com a ementa da disciplina "Estatística Aplicada" da Universidade de Brasília (ver Quadro 6). Pela observação das ementas, pode-se dizer que são abordados tópicos de estatística descritiva e inferencial. Algumas ementas ressaltam mais alguns temas de estatística descritiva enquanto outras ementas ressaltam mais estatística inferencial. Mas pode-se afirmar que, em essência, os conceitos das "duas estatísticas" são trabalhados da forma linear, a exemplo do que foi comentado para o caso do curso de bacharelado em Geografia da Universidade de Brasília.

Vale também dizer que, a exemplo da Universidade de Brasília, para os cursos de Geografia das universidades citadas nos Quadros 7 a 21 a matriz curricular oferece ao aluno uma única disciplina compacta de conteúdos práticos diretamente aplicáveis de estatística descritiva e inferencial. E pode-se dizer que isso vale também para as universidades com duas disciplinas obrigatórias, pois as ementas dessas disciplinas evidenciam o caráter compacto dos temas que abordam.

Partindo-se das colocações de Johnston (1978) de que são poucos os estudantes de Geografia que continuam os estudos de matemática em paralelo com os estudos de disciplinas da Geografia, e considerando-se que seja importante um embasamento estatístico (e matemático) para realizar quantificação em análise espacial de dados geográficos, então, os geógrafos egressos das universidades citadas muito provavelmente terão dificuldades para realização e entendimento de resultados obtidos destas análises, pelo pouco contato com os 
temas de estatística e matemática. A aprendizagem dos conteúdos de quantificação não será significativa, sendo esquecida pela falta de continuidade dos estudos ligados à quantificação.

Deve-se então pensar a implementação de ações, ainda durante a formação acadêmica do aluno, para realizar estudos de matemática/estatística em paralelo com as disciplinas ligadas diretamente à Geografia. Espera-se com isso capacitar o futuro geógrafo para efetivamente saber realizar quantificação aplicada em análise espacial de dados geográficos.

\subsection{AVALIAÇÃO DO USO DO EDH EM AGOSTO/2013 NA TURMA DE CLIMATOLOGIA GERAL}

No início de agosto de 2013, ministrei aos alunos da disciplina de Climatologia Geral da UnB quatro aulas expositivas sobre o assunto das lições 1 a 8 do EDH e foram sempre lembrados a estudarem o assunto via EDH, pois seriam cobrados sobre este assunto em uma questão na primeira prova da disciplina. A questão valia $10 \%$ da nota da prova.

Vale relatar que durante as aulas ministradas, percebi que haviam alunos que apresentavam dúvidas sobre simples conceitos. As dúvidas mais marcantes foram: (1) representação de frações e proporções. Alguns alunos que se manifestaram durante a aula desconheciam que, por exemplo, 0,6 é o mesmo que 0,60 e é o mesmo que 60/100. (2) No ensino do cálculo da média aritmética, o símbolo $\sum$ referente ao somatório era desconhecido por parte de alguns alunos. Suponho que outros que não se manifestaram também apresentavam estas dúvidas. A detecção destes problemas me fez refazer posteriormente às aulas ministradas - a lição 7 do software EDH que trata de média aritmética. Inclui seis páginas (telas) em que tentei usar conteúdo imagético para o ensino efetivo do conceito de somatório. Nas Figuras 50 e 51 observam-se duas destas seis telas inclusas, com o propósito de ensinar o significado do símbolo $\sum$ para os próximos usuários do EDH. 


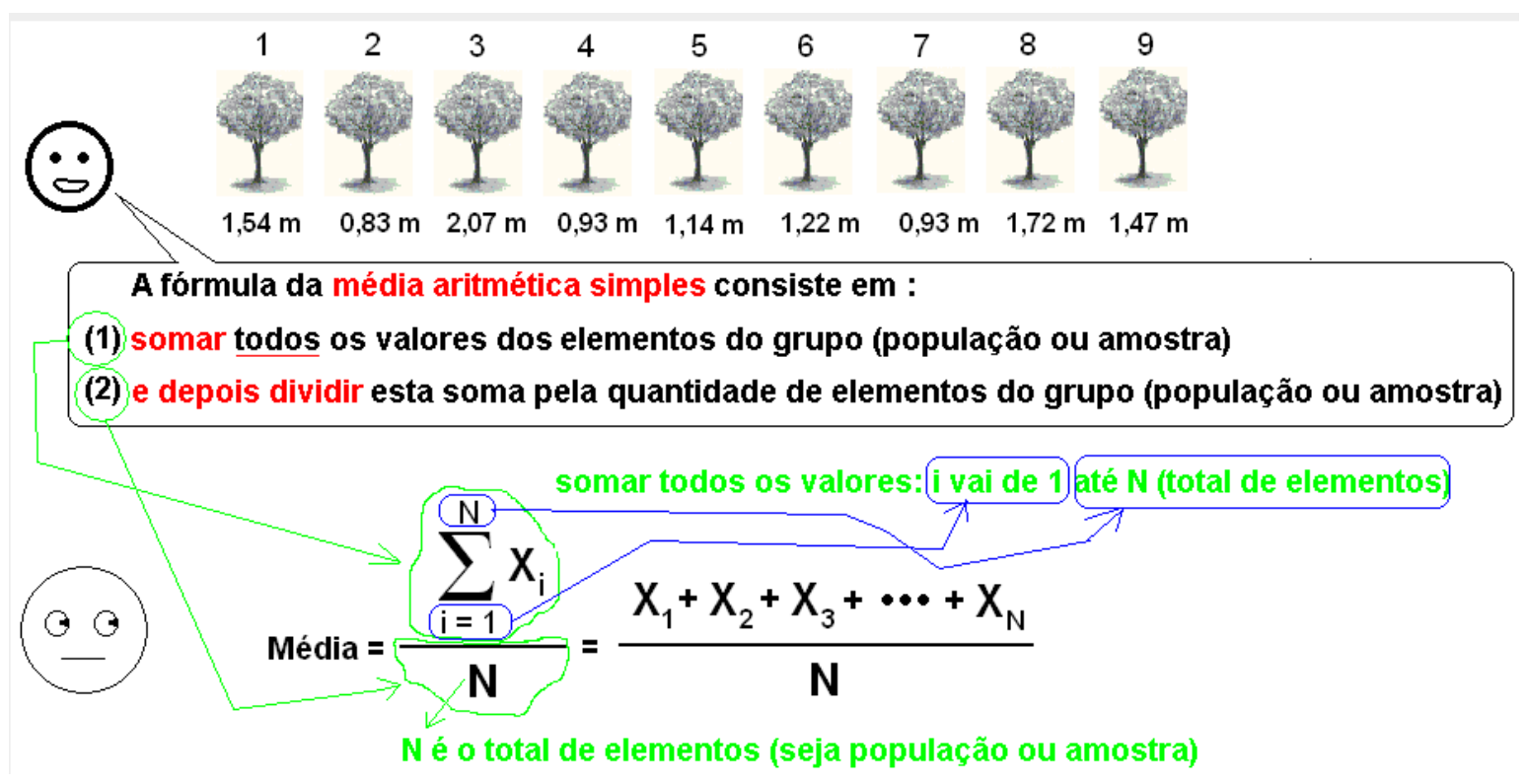

Figura 50 - Tela inclusa na lição 7 para ensinar a ideia de somatório

Fonte: Elaborado pelo autor.

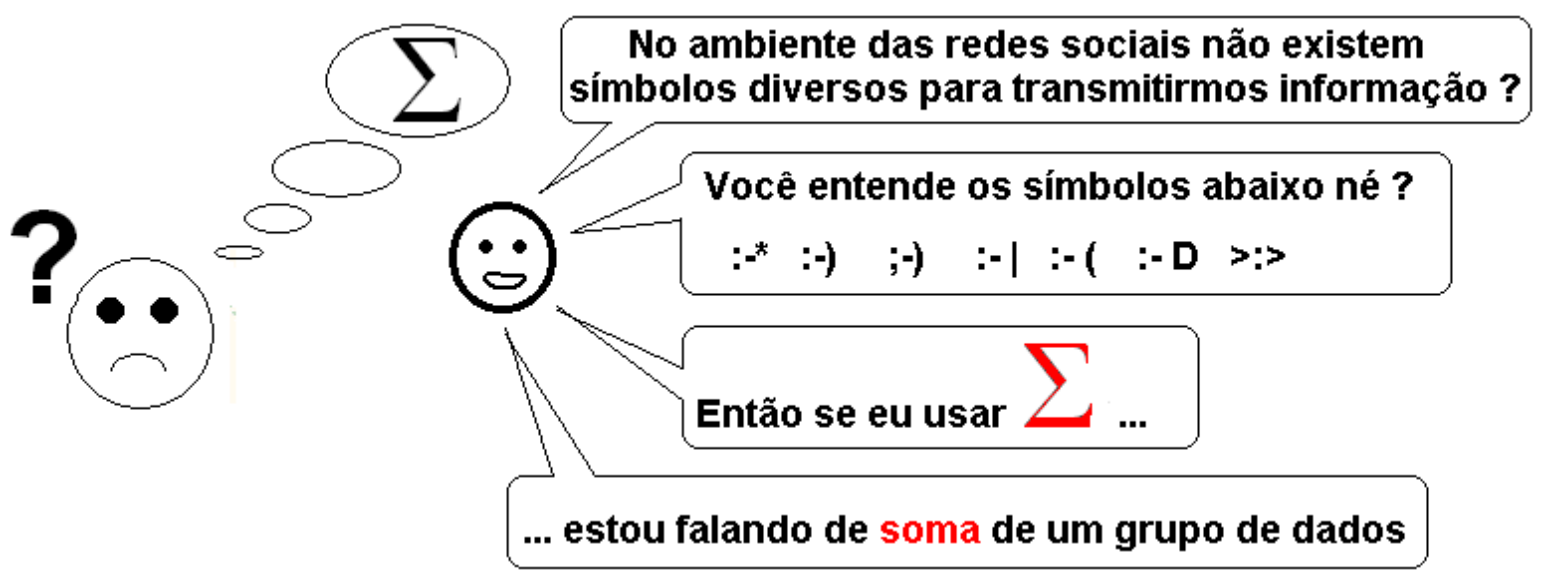

Figura 51 - Tela inclusa na lição 7 para ensinar a ideia de somatório

Fonte: Elaborado pelo autor.

Além destas seis telas, no início de 2014 inclui a lição 11 intitulada "proporção... porcentagem... do 'bolo' " visando ensinar, via imagens, o conceito de proporção.

Com relação à prova, na semana seguinte a apresentação da $4^{\mathrm{a}}$ aula, foi aplicada juntamente com as demais questões de climatologia e foi realizada por 29 alunos. A questão do assunto de quantificação contava com dez itens dicotômicos (resposta 'certo' ou 'errado'). 
$\mathrm{Na}$ prova, um item marcado erradamente anularia um item marcado corretamente, para minimizar a marcação por "chute". Na Tabela 7 encontram-se as marcações e o total de acertos (sem descontar os erros) dos 29 alunos e na Figura 52 observam-se os dez itens da questão com as respostas.

Deve-se ressaltar que os itens exigiam muito mais o entendimento conceitual de média, desvio padrão e coeficiente de variação, do que a "decoreba" das fórmulas. Os itens da questão expressam, em linguagem escrita, os assuntos apresentados primordialmente em conteúdo imagético no EDH.

Tabela 7 - Marcações e total de acertos dos 29 alunos para os itens envolvendo conceitos de média, variância, desvio padrão e coeficiente de variação

\begin{tabular}{|c|c|c|c|c|c|c|c|c|c|c|c|}
\hline Aluno & I1 & $\mathrm{I} 2$ & I3 & I4 & I5 & I6 & I7 & I8 & I9 & $\mathrm{I} 10$ & ACERTOS \\
\hline 3 & $E$ & $E$ & $\mathrm{C}$ & $\mathrm{C}$ & $E$ & $E$ & $\mathrm{C}$ & $\mathrm{E}$ & $\mathrm{C}$ & $\mathrm{E}$ & 10 \\
\hline 4 & $\mathrm{E}$ & $\mathrm{E}$ & $\mathrm{C}$ & $\mathrm{C}$ & $\mathrm{E}$ & $\mathrm{E}$ & $\mathrm{C}$ & E & $\mathrm{C}$ & $\mathrm{E}$ & 10 \\
\hline 29 & E & $\mathrm{E}$ & $\mathrm{C}$ & $\mathrm{C}$ & $\mathrm{E}$ & $\mathrm{E}$ & $\mathrm{C}$ & E & C & E & 10 \\
\hline 25 & $\mathrm{E}$ & $\mathrm{E}$ & $\mathrm{C}$ & $\mathrm{C}$ & $\mathrm{E}$ & $\mathrm{E}$ & C & $\mathrm{E}$ & C & C & 9 \\
\hline 14 & X & $\mathrm{E}$ & $\mathrm{C}$ & $\mathrm{C}$ & $\mathrm{E}$ & $\mathrm{E}$ & $\mathrm{C}$ & C & C & E & 8 \\
\hline 24 & $\mathrm{X}$ & $\mathrm{E}$ & $\mathrm{E}$ & $\mathrm{C}$ & $\mathrm{E}$ & $\mathrm{E}$ & $\mathrm{C}$ & $\mathrm{E}$ & $\mathrm{C}$ & $\mathrm{E}$ & 8 \\
\hline 23 & $\mathrm{E}$ & $\mathrm{E}$ & $\mathrm{C}$ & $\mathrm{C}$ & $\mathrm{C}$ & $\mathrm{E}$ & $\mathrm{C}$ & E & E & $\mathrm{E}$ & 8 \\
\hline 13 & E & $\mathrm{E}$ & $\mathrm{E}$ & $\mathrm{C}$ & $\mathrm{E}$ & $\mathrm{E}$ & $\mathrm{C}$ & E & E & $\mathrm{E}$ & 8 \\
\hline 7 & $\mathrm{C}$ & $\mathrm{E}$ & $\mathrm{E}$ & $\mathrm{C}$ & $\mathrm{C}$ & $\mathrm{E}$ & $\mathrm{C}$ & E & $\mathrm{C}$ & E & 7 \\
\hline 9 & $\mathrm{C}$ & $\mathrm{E}$ & $X$ & $\mathrm{C}$ & $X$ & $\mathrm{E}$ & $\mathrm{C}$ & E & $\mathrm{C}$ & $\mathrm{E}$ & 7 \\
\hline 12 & $\mathrm{C}$ & $\mathrm{E}$ & $\mathrm{C}$ & $\mathrm{C}$ & $\mathrm{C}$ & $\mathrm{E}$ & $\mathrm{C}$ & E & E & E & 7 \\
\hline 15 & E & $\mathrm{E}$ & $\mathrm{C}$ & $\mathrm{E}$ & $\mathrm{C}$ & $\mathrm{E}$ & $\mathrm{C}$ & $\mathrm{C}$ & $\mathrm{C}$ & E & 7 \\
\hline 22 & $\mathrm{C}$ & $\mathrm{E}$ & $\mathrm{C}$ & $\mathrm{E}$ & $\mathrm{E}$ & $\mathrm{E}$ & $\mathrm{C}$ & E & $\mathrm{C}$ & $\mathrm{C}$ & 7 \\
\hline 5 & E & $\mathrm{E}$ & $X$ & $\mathrm{C}$ & $\mathrm{C}$ & $\mathrm{E}$ & $\mathrm{C}$ & E & $X$ & $X$ & 6 \\
\hline 2 & E & $\mathrm{E}$ & $X$ & $\mathrm{C}$ & $X$ & $X$ & $\mathrm{C}$ & $\mathrm{C}$ & $X$ & E & 5 \\
\hline 28 & E & $\mathrm{E}$ & $\mathrm{E}$ & $\mathrm{C}$ & $\mathrm{C}$ & $\mathrm{C}$ & $\mathrm{C}$ & E & E & $\mathrm{C}$ & 5 \\
\hline 16 & $\mathrm{E}$ & $\mathrm{C}$ & $\mathrm{E}$ & $\mathrm{E}$ & $\mathrm{E}$ & $\mathrm{E}$ & $\mathrm{C}$ & $\mathrm{C}$ & $\mathrm{E}$ & $\mathrm{E}$ & 5 \\
\hline 10 & E & $\mathrm{E}$ & $X$ & $\mathrm{C}$ & $X$ & $\mathrm{C}$ & $\mathrm{C}$ & E & X & X & 5 \\
\hline 17 & $\mathrm{C}$ & $\mathrm{C}$ & $\mathrm{C}$ & $\mathrm{C}$ & $\mathrm{E}$ & $\mathrm{C}$ & $\mathrm{C}$ & $\mathrm{C}$ & E & $\mathrm{E}$ & 5 \\
\hline 11 & $\mathrm{C}$ & $\mathrm{C}$ & $\mathrm{E}$ & $\mathrm{C}$ & $\mathrm{E}$ & $\mathrm{E}$ & $\mathrm{C}$ & $\mathrm{C}$ & E & E & 5 \\
\hline 21 & $\mathrm{X}$ & $\mathrm{E}$ & $X$ & $\mathrm{C}$ & $\mathrm{E}$ & $\mathrm{C}$ & $\mathrm{C}$ & E & $\mathrm{X}$ & $X$ & 5 \\
\hline 1 & E & $\mathrm{C}$ & $\mathrm{E}$ & $\mathrm{C}$ & $\mathrm{E}$ & $\mathrm{C}$ & $\mathrm{C}$ & E & $E$ & $\mathrm{C}$ & 5 \\
\hline 19 & $\mathrm{E}$ & $\mathrm{E}$ & $\mathrm{E}$ & $\mathrm{C}$ & $\mathrm{C}$ & $\mathrm{E}$ & $\mathrm{E}$ & $\mathrm{C}$ & $\mathrm{E}$ & $\mathrm{E}$ & 5 \\
\hline 18 & $\mathrm{E}$ & $\mathrm{C}$ & $\mathrm{E}$ & $\mathrm{C}$ & $\mathrm{C}$ & $\mathrm{E}$ & $\mathrm{C}$ & $\mathrm{C}$ & E & E & 5 \\
\hline 8 & $\mathrm{C}$ & $\mathrm{E}$ & $\mathrm{E}$ & $\mathrm{C}$ & $\mathrm{C}$ & $\mathrm{E}$ & $\mathrm{C}$ & $\mathrm{C}$ & $\mathrm{C}$ & $\mathrm{C}$ & 5 \\
\hline 6 & $\mathrm{E}$ & $\mathrm{E}$ & $X$ & $\mathrm{E}$ & $\mathrm{E}$ & $X$ & $\mathrm{E}$ & $\mathrm{E}$ & $X$ & $X$ & 4 \\
\hline 27 & $X$ & $\mathrm{E}$ & $\mathrm{E}$ & $\mathrm{C}$ & $\mathrm{C}$ & $\mathrm{C}$ & $\mathrm{C}$ & E & $X$ & $X$ & 4 \\
\hline 20 & X & $\mathrm{C}$ & $X$ & $\mathrm{E}$ & $\mathrm{C}$ & $\mathrm{C}$ & X & X & X & X & 0 \\
\hline 26 & $X$ & X & $X$ & $X$ & $X$ & $X$ & X & $X$ & X & $X$ & 0 \\
\hline
\end{tabular}




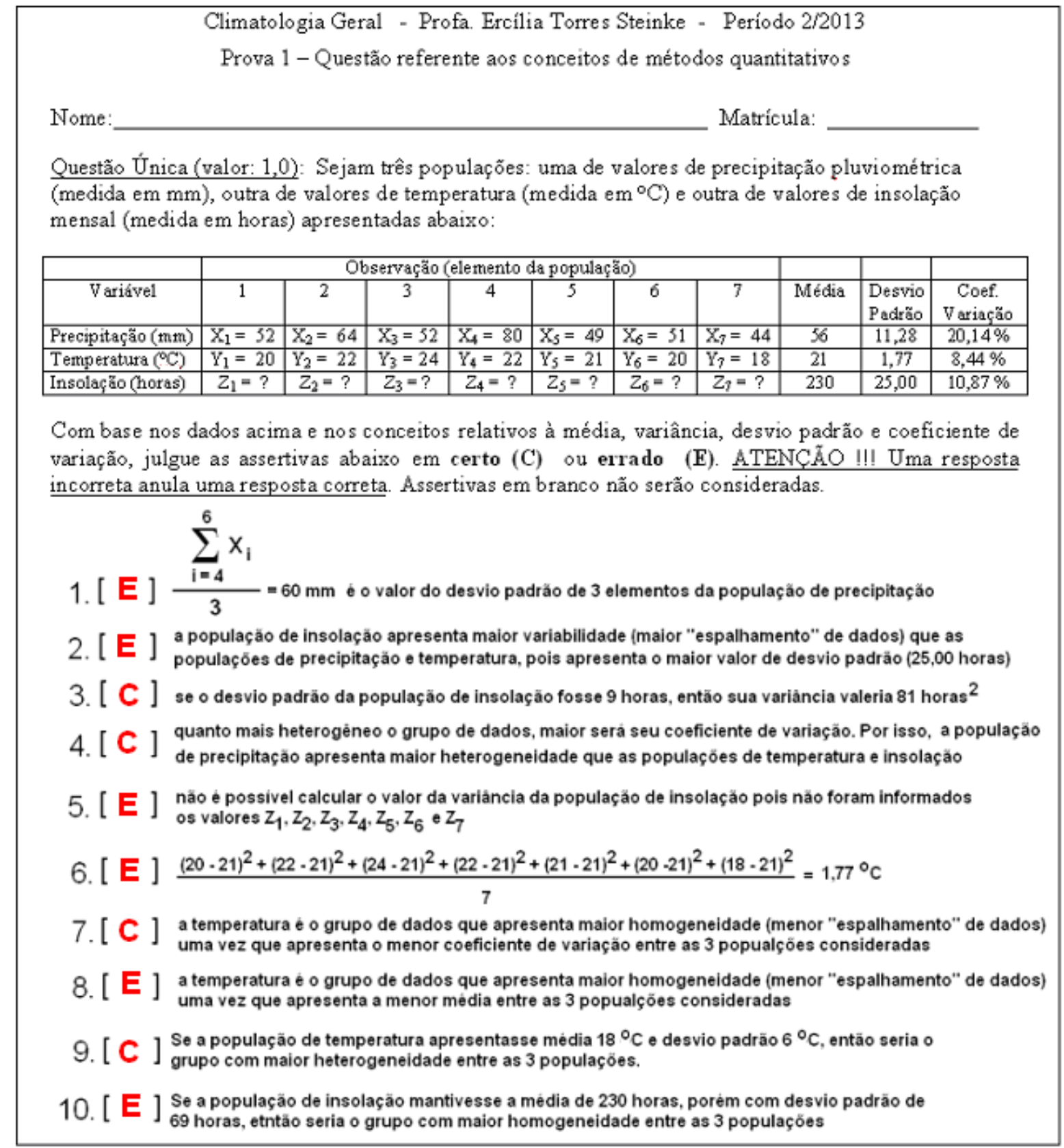

Figura 52 - Questão referente a conceitos de média, variância, desvio padrão e coeficiente de variação da primeira prova da disciplina Climatologia Geral na UnB no período 2/2013.

Fonte: Elaborado pelo autor.

O número médio de itens respondidos corretamente foi 6,03 com desvio padrão 2,46 e coeficiente de variação 40,71\%. Observa-se da Tabela 7 que 25 alunos acertaram cinco ou mais itens, o que pode indicar um razoável padrão de acertos. Se for considerado que um número razoável de acertos seja sete ou mais para aceitar que o aluno entendeu o conteúdo, 
pode-se verificar na Tabela 7 que 13 alunos obtiveram esta quantidade de acertos, o que corresponde a $44,82 \%$ da turma.

É claro que é possível que os acertos tenham sido obtidos pelo "chute", mesmo sob pena de perda de outro item da questão, caso o "chute" fosse incorreto. Para analisar se houve "chute" ou se o aluno de fato interpretou e entendeu o item, foi feita uma verificação das respostas dadas pelos alunos entre os itens cujo conteúdo e raciocínio são muito similares. Se de fato o aluno entende o conceito, então é de se esperar que o aluno acerte os itens que tratem do mesmo tema e exijam raciocínio similar para resolução.

Os itens 1, 2 e 6 tratam do desvio padrão (e variância indiretamente), porém o raciocínio para resolução é diferente em cada item. Desta forma, considerou-se que o aluno respondeu estes itens de forma independente um do outro.

Os itens 3 e 5 tratam de variância de forma mais direta. Bastaria saber que a variância é o desvio padrão elevado ao quadrado. Se o aluno soubesse isto, muito provavelmente marcaria as respostas corretas: C para o item 3 e E para o item 5. A Tabela 8 mostra as marcações dos alunos para os itens 3 e 5.

Tabela 8 - Marcações dos 29 alunos nos itens 3 e 5

\begin{tabular}{ccc}
\hline $\begin{array}{c}\text { Item 3 } \\
\text { (resposta: C) }\end{array}$ & $\begin{array}{c}\text { Item 5 } \\
\text { (resposta: } \mathbf{E})\end{array}$ & $\begin{array}{c}\text { Total de } \\
\text { respondentes }\end{array}$ \\
\hline C & C & 3 \\
C & E & 7 \\
E & C & 6 \\
E & E & 5 \\
X & C & 2 \\
X & E & 2 \\
X & X & 4 \\
\hline
\end{tabular}

Obs.: C - Certo; E - Errado; X - em branco

Observa-se da Tabela 8 que apenas sete dos 29 alunos acertaram os itens 3 e 5, o que representa um percentual de $24,13 \%$. Assim, inicialmente, a priori supõe-se que apenas $25 \%$ estavam entendendo a ideia numérica da relação entre variância e desvio padrão.

Os itens 4, 7 e 8 tratavam do coeficiente de variação. Noções conceituais de maior/menor heterogeneidade/homogeneidade de grupos de dados. Se o aluno soubesse esses 
conceitos muito provavelmente marcaria as respostas corretas: $\mathrm{C}$ para o item 4, C para o item 7 e E para o item 8. A Tabela 9 mostra as marcações dos alunos para os itens 4, 7 e 8.

Tabela 9 - Marcações dos 29 alunos nos itens 4, 7 e 8

\begin{tabular}{cccc}
\hline $\begin{array}{c}\text { Item 4 } \\
\text { (resposta: C) }\end{array}$ & $\begin{array}{c}\text { Item 7 } \\
\text { (resposta: C) }\end{array}$ & $\begin{array}{c}\text { Item 8 } \\
\text { (resposta: E) }\end{array}$ & $\begin{array}{c}\text { Total de } \\
\text { respondentes }\end{array}$ \\
\hline C & C & C & 6 \\
C & C & E & 16 \\
C & E & C & 1 \\
E & C & C & 2 \\
E & C & E & 1 \\
E & E & E & 1 \\
E & X & X & 1 \\
X & X & X & 1 \\
\hline
\end{tabular}

Obs.: C - Certo; E - Errado; X - em branco

Observa-se da Tabela 9 que apenas 16 dos 29 alunos acertaram os itens 4, 7 e 8, o que representa um percentual de $55,17 \%$. Assim, inicialmente, a priori supõe-se que metade dos alunos entenderam os conceitos de heterogeneidade/homegeneidade medidos pelo coeficiente de variação.

Finalmente, os itens 9 e 10 lidavam com heterogeneidade/homegeneidade analisados por meio dedo coeficiente de variação. Mas nestes itens o aluno deveria saber também a relação matemática onde o coeficiente de variação é o valor do desvio padrão dividido pela média. Se o aluno soubesse esses conceitos muito provavelmente marcaria as respostas corretas: C para o item 9 e E para o item 10. A Tabela 10 mostra as marcações dos alunos para os itens 9 e 10.

Tabela 10 - Marcações dos 29 alunos nos itens 9 e 10

\begin{tabular}{ccc}
\hline $\begin{array}{c}\text { Item 9 } \\
\text { (resposta: C) }\end{array}$ & $\begin{array}{c}\text { Item 10 } \\
\text { (resposta: E) }\end{array}$ & $\begin{array}{c}\text { Total de } \\
\text { respondentes }\end{array}$ \\
\hline C & C & 3 \\
C & E & 8 \\
E & C & 2 \\
E & E & 8 \\
X & E & 1 \\
X & X & 7 \\
\hline
\end{tabular}

Obs.: C - Certo; E - Errado; X - em branco 
Observa-se da Tabela 10 que apenas oito dos 29 alunos acertaram os itens 9 e 10 , o que representa um percentual de 27,56\%. Assim, inicialmente, a priori supõe-se que aproximadamente $25 \%$ dos alunos estavam entendendo a ideia numérica do coeficiente de variação.

Com base nos valores das tabelas 8,9 e 10 foi elaborada a Tabela 11 sintetizando os resultados obtidos.

Tabela 11 - Síntese dos principais resultados obtidos

\begin{tabular}{cccc}
\hline $\begin{array}{c}\text { Alunos que } \\
\text { acertaram sete ou } \\
\text { mais itens }\end{array}$ & $\begin{array}{c}\text { Alunos que } \\
\text { acertaram os } \\
\text { Itens 3 e 5 } \\
\text { (conceito de } \\
\text { desvio padrão) }\end{array}$ & $\begin{array}{c}\text { Alunos que } \\
\text { acertaram os } \\
\text { Itens 4, 7 e 8 } \\
\text { (conceito de } \\
\text { coeficiente de } \\
\text { variação) }\end{array}$ & $\begin{array}{c}\text { Alunos que } \\
\text { acertaram os } \\
\text { Itens 9 e 10 } \\
\text { (conceito de } \\
\text { coeficiente de } \\
\text { variação) }\end{array}$ \\
\hline 13 & 7 & 16 & 8 \\
$(44,82 \%)$ & $(24,13 \%)$ & $(55,19 \%)$ & $(27,56 \%)$ \\
\hline
\end{tabular}

Em síntese, observando-se o percentual de itens similares respondidos corretamente (itens 3 e 5, itens 4, 7 e 8 e itens 9 e 10) chamou a atenção o baixo resultado de aproveitamento obtido pelo grupo de alunos. Diante deste quadro pode-se questionar sobre a validade ou não do EDH. Mas a impressão geral que tive em sala de aula foi desinteresse pelo assunto por parte da maioria dos alunos. É possível que houvesse interesse pelo assunto por parte dos alunos, mas minha didática em sala de aula e/ou o próprio material podem não ter agradado aos alunos e isso tenha causado o mau desempenho na prova.

Mas, outros fatores podem ter influenciado o rendimento do aluno, como por exemplo o fato de não ter estudado o suficiente a parte relativa aos temas tratados no EDH para a prova e dado mais atenção aos outros assuntos (ligados diretamente à climatologia), ou mesmo não ter estudado nada para a prova ou, ainda, o aluno podia não apresentar interesse pelo assunto e como o tema valeria apenas $10 \%$ da prova o aluno não dedicou atenção ao assunto.

$\mathrm{Na}$ quarto e último encontro antes da prova, com a presença de 27 alunos em sala, informei à turma que continuava desenvolvendo o EDH e futuramente iria montar um "curso de extensão" para ensino de alguns métodos quantitativos usando o EDH. Perguntei então aos alunos se eles teriam interesse em realizar o "curso de extensão". Apenas oito dos 27 alunos levantaram a mão informando ter interesse, ou seja, apenas aproximadamente $30 \%$ dos 
alunos. E vale destacar que durante os quatro encontros, sempre enfatizei o universo atual das geotecnologias como importante ferramenta de trabalho do geógrafo, e a importância que a quantificação teria em seu dia a dia profissional. Em outras palavras, pode ser que haja de fato pouca afetividade pelo graduando em Geografia com disciplinas que envolvem quantificação.

A ideia do EDH é ser uma ferramenta que funcione como tutor do aluno proporcionando uma aprendizagem significativa. Nesta etapa do trabalho, o EDH foi usado, conforme já assinalado, com um instrutor em atitude mais ativa e o aluno em atitude mais passiva, pois foi o instrutor quem folheou as páginas do EDH enfatizando os aspectos a serem assimilados, ou seja, foi o instrutor quem conduziu o uso do EDH. A ideia é que o EDH seja usado como ferramenta de autoestudo por parte do aluno. Mas, nesta etapa do trabalho, o propósito era, de fato, sondar a aceptividade do aluno ao assunto (quantificação) e ao uso da ferramenta (EDH). E como já comentado, a impressão que tive foi um desinteresse do aluno pelo assunto e, pelas dúvidas levantadas em sala de aula, sua pouca familiaridade com conceitos matemáticos.

\subsection{AVALIAÇÃO DO USO DO EDH EM MARÇO/2014 E OUTROS TEMAS DE QUANTIFICAÇÃO}

No primeiro semestre letivo de 2014 foi a ofertada a disciplina Tópicos Especiais em Geografia, para os cursos de Mestrado e Doutorado em Geografia da UnB com o tema "Quantificação em Geografia". A turma era composta por sete alunos, todos graduados em Geografia. Os tópicos ministrados no curso foram: (1) objetos e variáveis; (2) média; (3) variância e desvio padrão; (4) coeficiente de variação; (5) curva de Lorenz e coeficiente de Gini; (6) separatrizes e box plot; (7) centro médio espacial; (8) distância padrão; (9) coeficientes de especialização, localização e redistribuição e (10) índice global de Moran.

O material didático usado para abordagem dos assuntos (1) a (4) foi o EDH. As lições 1 a 8 do EDH abrangem estes assuntos. Os demais assuntos estavam em paralelo sendo implementados no EDH, com exceção dos assuntos (9) e (10) que não foram incorporados. Então, durante os meses de março a junho de 2014 eu estava desenvolvendo as lições no $\mathrm{EDH}$, mas em paralelo montava apostilas com "imagens" dos assuntos (5) a (10) para uso com os alunos na disciplina. Estas apostilas, usadas em sala de aula, foram importantes para a estruturação das lições 9 a 14 do EDH, pois o uso em sala juntamente com a participação dos 
alunos permitiu identificar algumas de suas dúvidas e dificuldades e, assim, pude tentar montar conteúdo imagético nas lições do EDH visando sanar tais dificuldades.

Para exemplificar, durante o curso foi elaborada uma apostila para ensinar o coeficiente de Gini, tema incorporado posteriormente ao EDH, na lição 14. Na Figura 53 é apresentada uma página da apostila que mostra, de forma estática, uma etapa para o cálculo do coeficiente de Gini. Esta imagem estática inspirou o desenvolvimento de imagens dinâmicas para ensino do cálculo e foi inserido no EDH.

\section{Vamos calcular a área $\beta$ :}

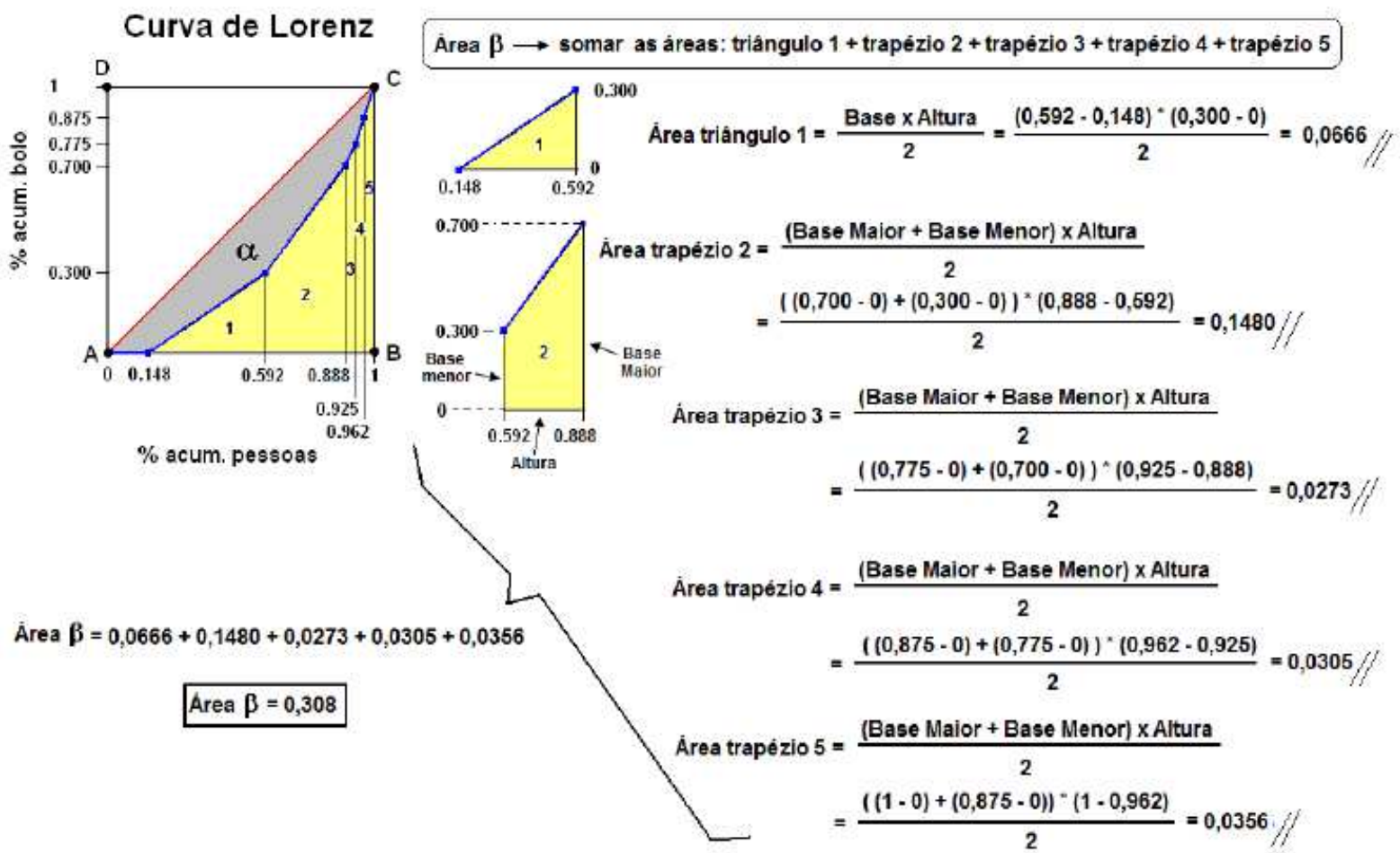

Figura 53 - Uma imagem estática da apostila apresentado uma etapa do cálculo do coeficiente de Gini.

Fonte: Elaborado pelo autor.

Na Figura 54 verifica-se uma cena da imagem dinâmica. 


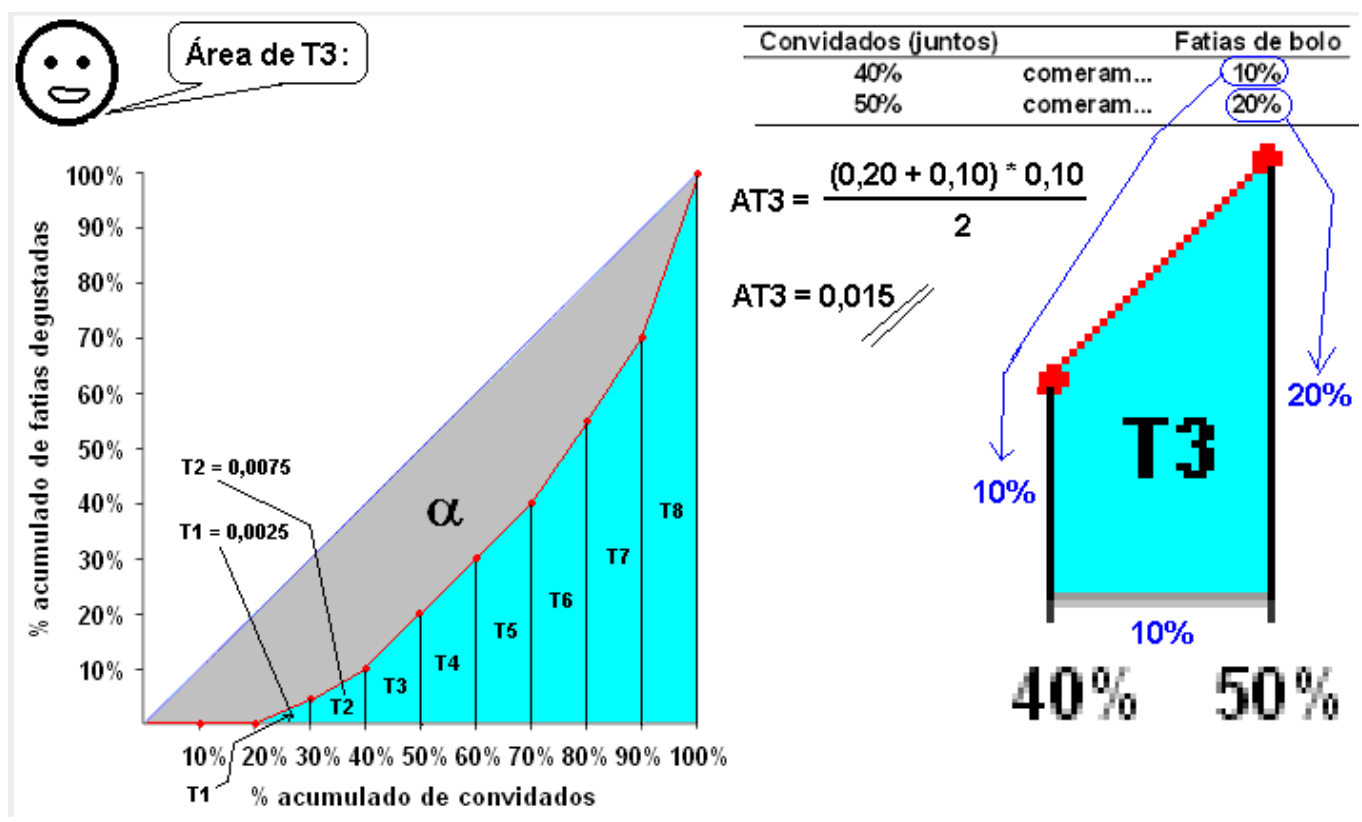

Figura 54 - Uma cena de uma imagem dinâmica do EDH apresentado uma etapa do cálculo do coeficiente de Gini.

Fonte: Elaborado pelo autor.

Além da utilidade para auxiliar a elaboração das lições 9 a 14 do EDH, nesta etapa do trabalho foi avaliado o uso do software EDH para auxílio no ensino dos conceitos de média, variância, desvio padrão e coeficiente de variação, ou seja, com base nas lições 1 a 8. Aos sete alunos foi solicitado o manuseio do EDH para responder os mesmos dez itens apresentados aos alunos de Climatologia Geral em agosto de 2013 (ver Figura 52).

Diferentemente dos alunos de agosto de 2013, foi solicitado o estudo do assunto pelo EDH para resolução dos itens da questão, mas a resolução não teria qualquer valor de avaliação na disciplina. Ficou claro para estes sete alunos que o objetivo era proporcionar feedback sobre o EDH no escopo deste trabalho. Dos sete alunos, cinco realizaram a resolução. Além da resolução, foi solicitado aos alunos que respondessem suas condições de preparação para resolução dos itens da questão. Estas condições foram denominadas de "mapeamento da dinâmica de aprendizagem". Nas figuras 55 a 57 observam-se os itens do mapeamento da dinâmica de aprendizagem que os alunos preencheram. 


\section{MAPEAMENTO DA SUA DINÂMICA DE APRENDIZAGEM RESPONDA ABAIXO APÓS RESPONDER AS QUESTÕES PROPOSTAS}

Leitura de material para responder as questões

\begin{tabular}{|ll|l|l|}
\hline[ & ] & Não li nenhum material: nem o do software EDH, nem qualquer outro material. \\
\hline[ & ] & Li somente o material do software EDH. \\
\hline[ & ] & Li somente outro material diferente do software EDH. \\
\hline[ & ] & Li o material do software EDH e também outro material diferente do software EDH. \\
\hline
\end{tabular}

\section{Eu lembrava e/ou conhecia e/ou entendia o assunto}

\begin{tabular}{|ll|l|}
\hline [ & ] & $\begin{array}{l}\text { Como assinalei antes, não li nenhum material, mas eu lembrava das noções conceituais de } \\
\text { média, variância, desvio padrão e coeficiente de variação que estudei em outra oportunidade. }\end{array}$ \\
\hline [ & ] & $\begin{array}{l}\text { Antes mesmo da leitura, eu lembrava/entendia as noções conceituais de média, variância, } \\
\text { desvio padrão e coeficiente de variação que estudei em outra oportunidade. }\end{array}$ \\
\hline [ & ] & $\begin{array}{l}\text { Durante e depois da leitura, eu lembrei das noções conceituais de média, variância, desvio } \\
\text { padrão e coeficiente de variação que estudei em outra oportunidade. }\end{array}$ \\
\hline
\end{tabular}

Eu não conhecia ou não entendia o assunto antes da leitura

\begin{tabular}{|ll|l|}
\hline[ & [ & $\begin{array}{l}\text { Antes da leitura, eu não conhecia as noções conceituais de média, variância, desvio padrão e } \\
\text { coeficiente de variação pois jamais as estudei em outra oportunidade. }\end{array}$ \\
\hline[ & [ & $\begin{array}{l}\text { Antes da leitura, eu não entendia as noções conceituais de média, variância, desvio padrão e } \\
\text { coeficiente de variação mesmo quando as estudei em outra oportunidade. }\end{array}$ \\
\hline
\end{tabular}

Figura 55 - Primeira parte dos itens para mapeamento da dinâmica de aprendizagem do respondente.

Fonte: Elaborado pelo autor. 


\section{Eu entendi o assunto durante e/ou após a leitura}

\begin{tabular}{|ll|l|}
\hline[ & {[} & $\begin{array}{l}\text { Foi durante e/ou após a leitura que eu entendi as noções conceituais de média, variância, } \\
\text { desvio padrão e coeficiente de variação, pois antes da leitura, apesar de ter estudado, eu não } \\
\text { entendia tais noções conceituais }\end{array}$ \\
\hline$[\quad$ & ] & $\begin{array}{l}\text { Foi durante e/ou após a leitura que eu entendi as noções conceituais de média, variância, } \\
\text { desvio padrão e coeficiente de variação, pois antes da leitura, apesar de ter estudado, eu não } \\
\text { entendia tais noções conceituais. }\end{array}$ \\
\hline
\end{tabular}

\section{Não entendi o assunto mesmo após a leitura}

[ ] $\begin{aligned} & \text { Mesmo após minha leitura, continuei a não entender as noções conceituais de média, } \\ & \text { variância, desvio padrão e coeficiente de variação. Minhas respostas às questões foram } \\ & \text { baseada no "chute". }\end{aligned}$

\section{Com relaç̃o ao uso do software EDH (se você fez a leitura do material)}

\begin{tabular}{|ll|l|}
\hline[ & {[} & $\begin{array}{l}\text { Não tentei usar efetivamente o EDH para entender os conceitos, por isso não me considero } \\
\text { apto a fazer alguma avaliação sobre o EDH. }\end{array}$ \\
\hline [ & ] & $\begin{array}{l}\text { Para entendimento das noções conceituais de média, variância, desvio padrão e coeficiente } \\
\text { de variação o EDH não foi útil. Ao contrário, acredito que me confundiu mais ainda sobre os } \\
\text { conceitos que tentou apresentar. }\end{array}$ \\
\hline[ & {[} & $\begin{array}{l}\text { Para entendimento das noções conceituais de média, variância, desvio padrão e coeficiente } \\
\text { de variação o EDH foi útil. Acredito que o material ajudou na fixação dos conceitos. }\end{array}$ \\
\hline [ & ] & $\begin{array}{l}\text { Para entendimento das noções conceituais de média, variância, desvio padrão e coeficiente } \\
\text { de variação o EDH foi útil. Mas outro material que li sobre o assunto aborda de forma } \\
\text { melhor que o EDH. }\end{array}$ \\
\hline [ & ] & $\begin{array}{l}\text { Para entendimento das noções conceituais de média, variância, desvio padrão e coeficiente } \\
\text { de variação o EDH foi útil. E o EDH aborda o assunto melhor que outro material que li } \\
\text { sobre o assunto. }\end{array}$ \\
\hline
\end{tabular}

Figura 56 - Segunda parte dos itens para mapeamento da dinâmica de aprendizagem do respondente.

Fonte: Elaborado pelo autor. 


\section{O uso do software EDH (se você fez a leitura do material)}

Caso tenha usado o EDH, por favor relate brevemente os pontos positivos (interface estática e interativa, exemplos para abordagem, atividades propostas, etc)

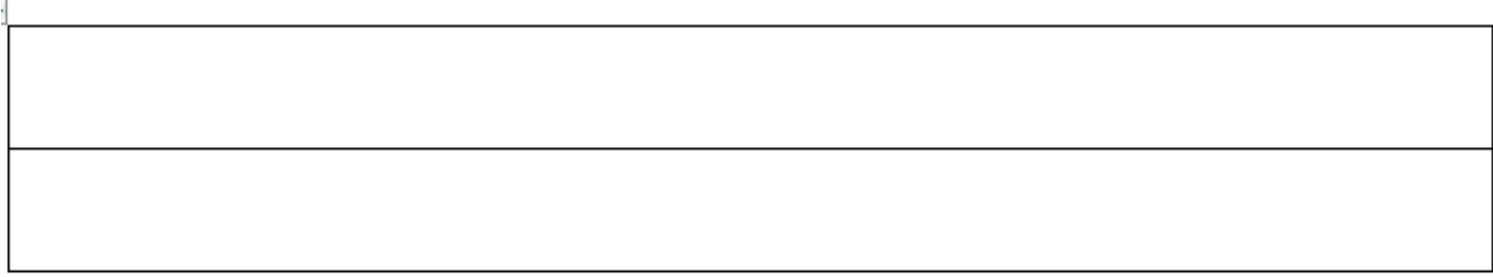

Caso tenha usado o EDH, por favor relate brevemente os pontos negativos (interface estática e interativa, exemplos para abordagem, atividades propostas, etc)

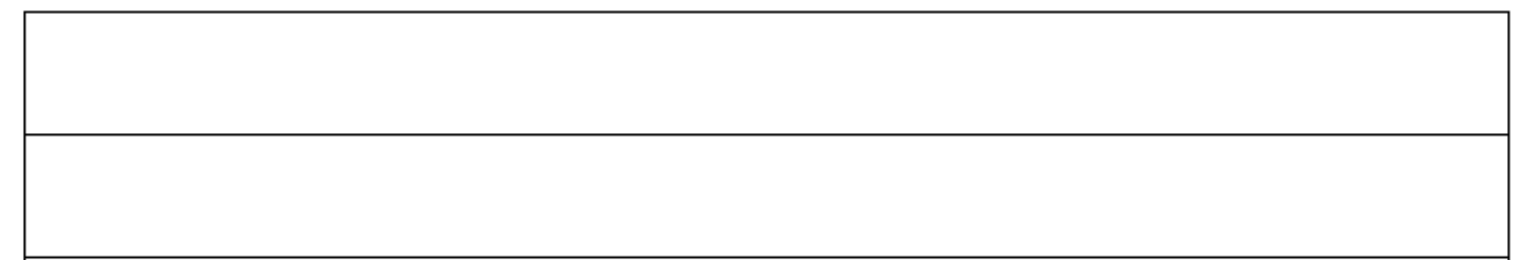

Figura 57 - Terceira parte dos itens para mapeamento da dinâmica de aprendizagem do respondente.

Fonte: Elaborado pelo autor.

A seguir, nos quadros 22 a 26 são apresentadas as respostas o mapeamento da dinâmica de aprendizagem dos cinco respondentes. 
Quadro 22 - Respostas e condições do RESPONDENTE 1

\begin{tabular}{|c|c|}
\hline \multicolumn{2}{|c|}{ Respondente 1} \\
\hline Você gosta de matemática e/ou estatística? & Gosto um pouco \\
\hline Marcações dos 10 itens: & {$[\mathrm{E}][\mathrm{E}][\mathrm{C}][\mathrm{C}][\mathrm{x}][\mathrm{E}][\mathrm{C}][\mathrm{x}][\mathrm{C}][\mathrm{E}]$} \\
\hline Total de itens corretos: & 8 \\
\hline Itens 3 e 5 & {$[\mathrm{C}][\mathrm{x}]$ - um item correto } \\
\hline Itens 4,7 e 8 & {$[\mathrm{C}][\mathrm{C}][\mathrm{x}]-$ dois itens corretos } \\
\hline Itens 9 e 10 & {$[\mathrm{C}][\mathrm{E}]-$ dois itens corretos } \\
\hline \multicolumn{2}{|c|}{ Condições (mapeamento) para resolução dos itens } \\
\hline $\begin{array}{l}\text { - Li somente o material do software E } \\
\text { - Durante e depois da leitura, eu len } \\
\text { desvio padrão e coeficiente de varia } \\
\text { - Foi durante elou após a leitura qu } \\
\text { desvio padrão e coeficiente de v } \\
\text { estudado, eu não conhecia tais noçô } \\
\text { Para entendimento das notações } \\
\text { coeficiente de variação, o EDH foi } \\
\text { dos conceitos. }\end{array}$ & $\begin{array}{l}\text { oções conceituais de média, variância, } \\
\text { studei em outra oportunidade. } \\
\text { di as noções conceituais de variância, } \\
\text { pois antes da leitura, apesar de ter } \\
\text { uais. } \\
\text { dito que o material ajudou na fixação }\end{array}$ \\
\hline \multicolumn{2}{|c|}{ Pontos positivos do EDH } \\
\hline \multicolumn{2}{|c|}{$\begin{array}{l}\text { "A facilidade de instalação e operação do software. A disponibilidade de aulas seguidas por } \\
\text { exercícios práticos facilitou a compreensão do assunto proposto". }\end{array}$} \\
\hline \multicolumn{2}{|c|}{ Pontos negativos do EDH } \\
\hline $\begin{array}{l}\text { “Algumas das atividades poderiam ser obi } \\
\text { curso ao concluí-las. Poderia ser inserida } \\
\text { apresentados na lição e suas fórmulas". }\end{array}$ & $\begin{array}{l}\text { modo que o aluno só avançasse no } \\
\text { em cada lição com todos os conceitos }\end{array}$ \\
\hline
\end{tabular}


Quadro 23 - Respostas e condições do RESPONDENTE 2

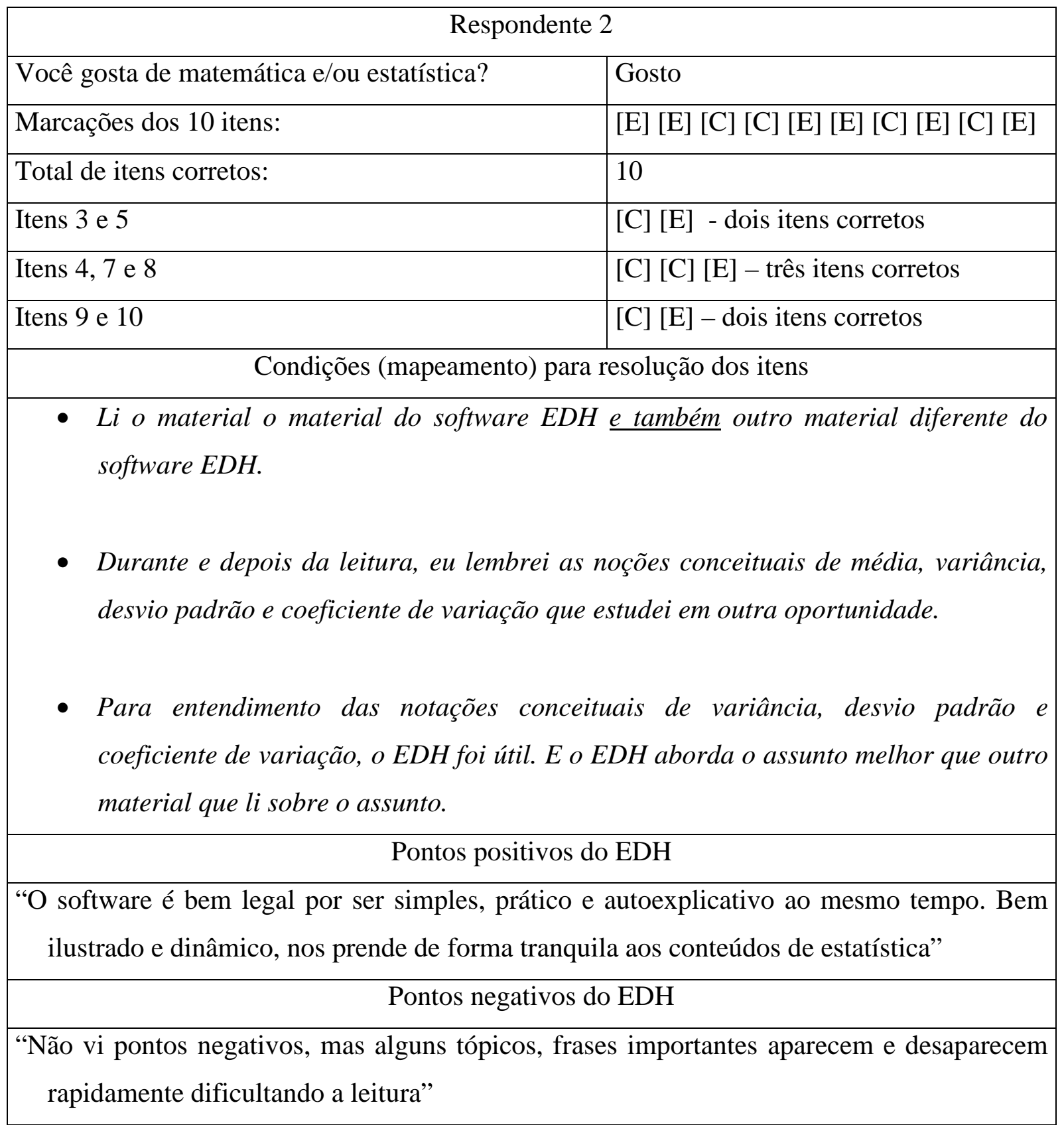


Quadro 24 - Respostas e condições do RESPONDENTE 3

\begin{tabular}{|c|c|}
\hline \multicolumn{2}{|c|}{ Respondente 3} \\
\hline Você gosta de matemática e/ou estatística? & Gosto um pouco \\
\hline Marcações dos 10 itens: & {$[\mathrm{E}][\mathrm{E}][\mathrm{C}][\mathrm{C}][\mathrm{E}][\mathrm{E}][\mathrm{C}][\mathrm{E}][\mathrm{C}][\mathrm{E}]$} \\
\hline Total de itens corretos: & 10 \\
\hline Itens 3 e 5 & {$[\mathrm{C}][\mathrm{E}]$ - dois itens corretos } \\
\hline Itens 4,7 e 8 & {$[\mathrm{C}][\mathrm{C}][\mathrm{E}]-$ três itens corretos } \\
\hline Itens 9 e 10 & {$[\mathrm{C}][\mathrm{E}]-$ dois itens corretos } \\
\hline \multicolumn{2}{|c|}{ Condições (mapeamento) para resolução dos itens } \\
\hline $\begin{array}{l}\text { - Li somente o material do software } E \\
\text { - Antes da leitura, eu não conhecia a } \\
\text { padrão e coeficiente de variação, po } \\
\text { - Para entendimento das notações } \\
\text { coeficiente de variação, o EDH foi } \\
\text { dos conceitos. }\end{array}$ & $\begin{array}{l}\text { conceituais de média, variância, desvio } \\
\text { as estudei em outra oportunidade } \\
\text { ıais de variância, desvio padrão e } \\
\text { edito que o material ajudou na fixação }\end{array}$ \\
\hline \multicolumn{2}{|c|}{ Pontos positivos do EDH } \\
\hline \multicolumn{2}{|c|}{$\begin{array}{l}\text { "Interface boa, interatividade ótima, exemplos ótimos, atividades ótimas. Gostei muito da } \\
\text { didática. A abordagem é adequada, permite o esclarecimento de dúvidas no decorrer da } \\
\text { leitura. Os exercícios são ótimos para a fixação. O conteúdo que vi com calma em } \\
\text { 29/03/2014 ainda está claro em minha mente" }\end{array}$} \\
\hline \multicolumn{2}{|c|}{ Pontos negativos do EDH } \\
\hline $\begin{array}{l}\text { "Acredito que o menu de lições e atividade } \\
\text { toda a execução do material, facilitar } \\
\text { interessante também a possibilidade de a } \\
\text { assim a consulta a outras partes do mater }\end{array}$ & $\begin{array}{l}\text { permanecer, de forma resumida, durante } \\
\text { egação. Com o menu aparente, seria } \\
\text { s, telas, exercícios de forma simultânea, } \\
\text { e as lições é facilitada" }\end{array}$ \\
\hline
\end{tabular}


Quadro 25 - Respostas e condições do RESPONDENTE 4

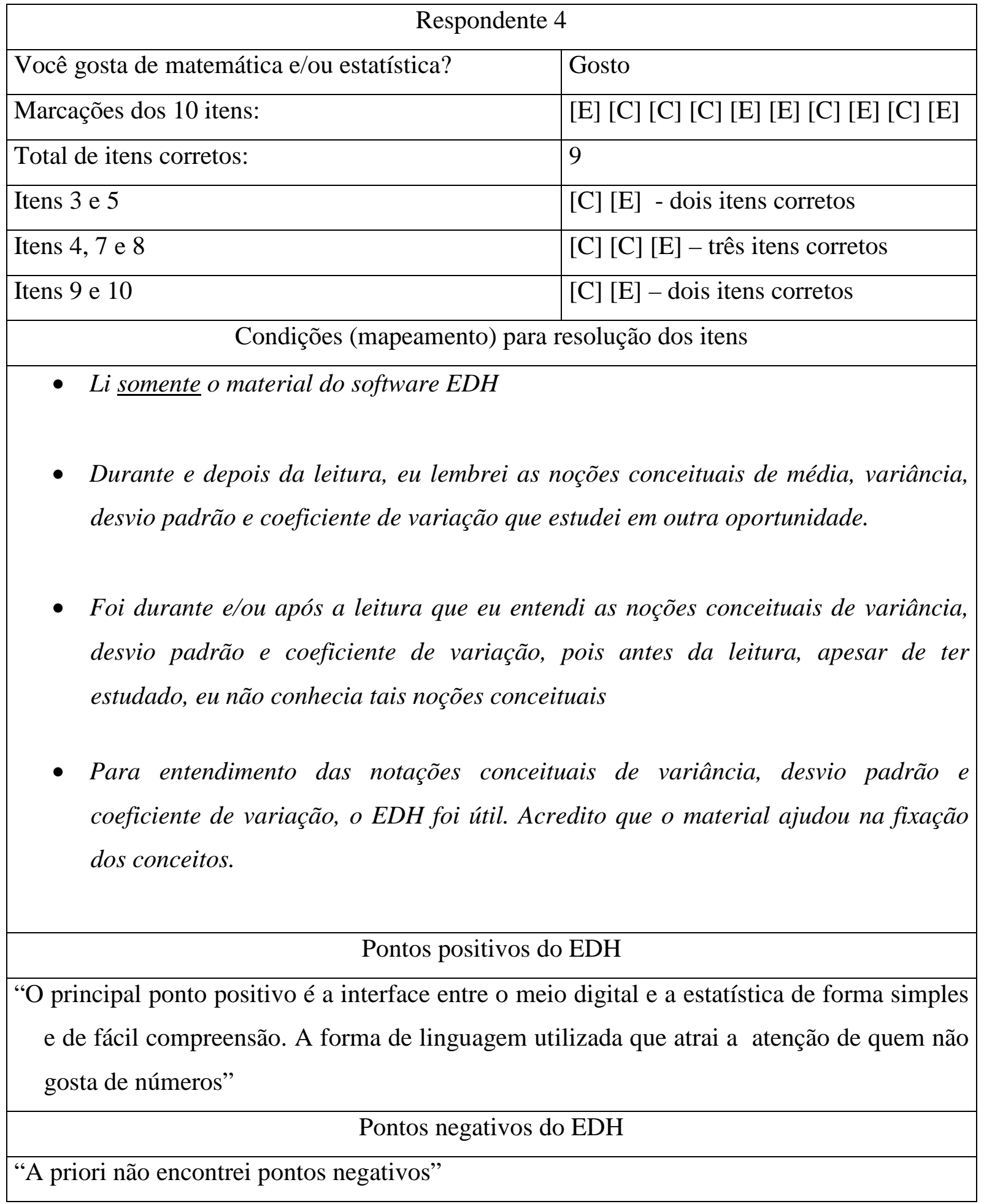


Quadro 26 - Respostas e condições do RESPONDENTE 5

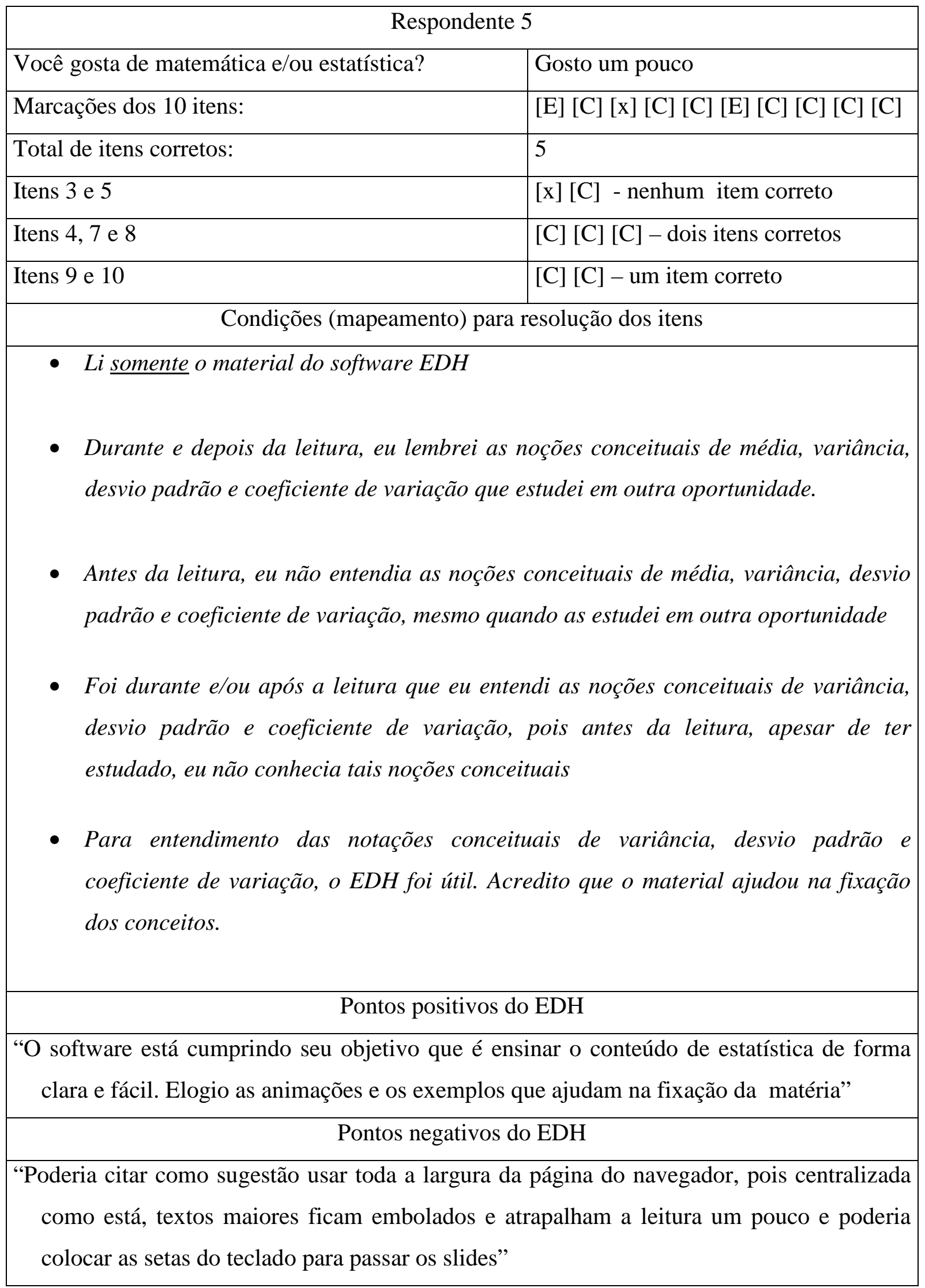


Conforme se observa nos quadros 22 a 26, com exceção do respondente 5, os demais responderam os itens do questionário de modo satisfatório para se considerar, a priori, que podem ter tido uma aprendizagem significativa dos conceitos avaliados.

Todos afirmaram ter lido o material do EDH e confirmaram que o EDH ajudou na fixação de conteúdos. O respondente 3 foi o único a afirmar que jamais havia estudado o assunto anteriormente e os demais afirmaram que já haviam estudado mas, com o uso do EDH relataram ter de fato entendido as noções conceituais do assunto.

Com relação aos pontos positivos, todos os cinco respondentes teceram considerações bastante favoráveis ao EDH. Podemos destacar os termos citados:

- “aulas seguidas por exercícios práticos facilitou a compreensão" (respondente 1); "simples, prático e autoexplicativo" e "bem ilustrado e dinâmico" (respondente 2);

- “a abordagem é adequada, permite o esclarecimento de dúvidas no decorrer da leitura. Os exercícios são ótimos para a fixação" (respondente 3);

- "a forma de linguagem utilizada que atrai a atenção de quem não gosta de números" (respondente 4)

- "Elogio as animações" (respondente 5)

De fato, o que se espera do EDH parece ter se confirmado nos relatos dos cinco respondentes. Em essência, a abordagem de conceitos de quantificação via conteúdo imagético pode ser uma forma de proporcionar aprendizagem significativa e, a médio e longo prazo, contribuir para o raciocínio, pensamento e letramento estatístico.

Com relação aos pontos negativos do EDH, os respondentes relatam, em geral, algum aspecto da interface do software:

- 'poderia ser inserida uma 'tela' em cada lição com todos os conceitos apresentados na lição e suas fórmulas" (respondente 1)

- "alguns tópicos, frases importantes aparecem e desaparecem rapidamente dificultando a leitura" (respondente 2)

- "o menu de lições e atividades poderia permanecer, de forma resumida, durante toda a execução do material, facilitaria a navegação" (respondente 3)

- "usar toda a largura da página do navegador, pois centralizada como está, textos maiores ficam embolados" (respondente 5) 
Estes pontos, apontados como negativos, podem ser resolvidos de forma relativamente simples. Em particular, com relação à citação de "textos embolados" em páginas centralizadas, a ideia seria tentar desdobrar ao máximo a página em duas ou mais pois, realmente, a ideia para se alcançar aprendizagem significativa é ter páginas (telas) "leves", com o mínimo de informação textual e imagens, de modo que o conteúdo imagético tenha como característica uma carga cognitiva baixa. Contudo, há casos em que é necessário, para a real compreensão do tema tratado, que um conteúdo mais denso de imagens e textos esteja na mesma página.

Conforme dito anteriormente, os tópicos (5) curva de Lorenz e coeficente de Gini; (6) separatrizes e box plot; (7) centro médio espacial; (8) distância padrão; (9) coeficientes de especialização, localização e redistribuição e (10) índice global de Moran foram trabalhados na disciplina em forma de apostila, pois estavam sendo desenvolvidos para o EDH em paralelo à disciplina. $\mathrm{O}$ que pude perceber, acontecendo com os sete alunos, foi a não familiaridade de alguns conceitos matemáticos básicos. Contudo, durante as aulas eu explicava e, a priori, os alunos entendiam. A seguir, são citadas algumas das dúvidas surgidas.

(1) Fórmula da área de quadrado e triângulo. Ao abordar o cálculo do coeficiente de Gini, em dado momento é necessário calcular a área de $\alpha$ conforme mostrado na Figura 58 abaixo. Os alunos não se lembravam das fórmulas das áreas do quadrado e do triângulo. Além disso, apresentaram certa dificuldade para interpretar e entender a partir da figura, o cálculo da variável G. Contudo, a partir de minhas intervenções, consegui fazer os alunos entenderem todo o contexto.

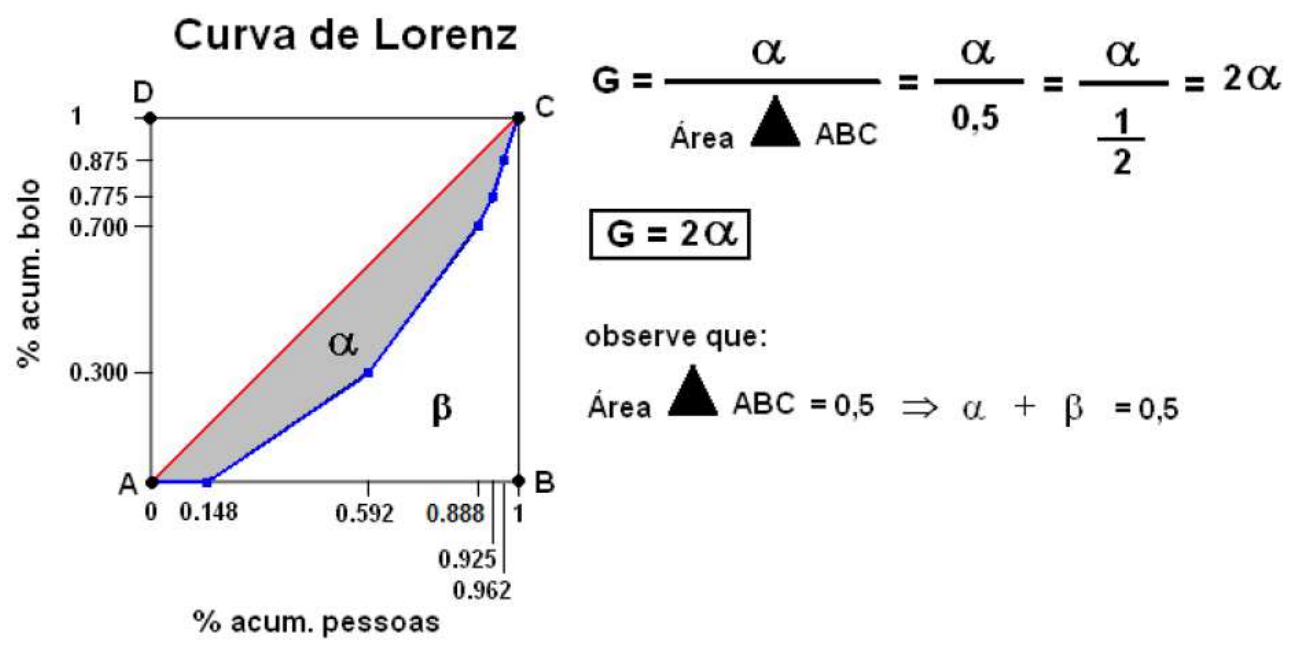

Figura 58 - Figura apresentando contexto pictórico para cálculo de G.

Fonte: Elaborado pelo autor. 
(2) Média aritmética ponderada. O conceito não estava claro para alguns alunos ao ser apresentada de forma direta a fórmula para média ponderada. Com explicação, os alunos entenderam. Na Figura 59 observa-se o contexto em que foi usada a média ponderada.

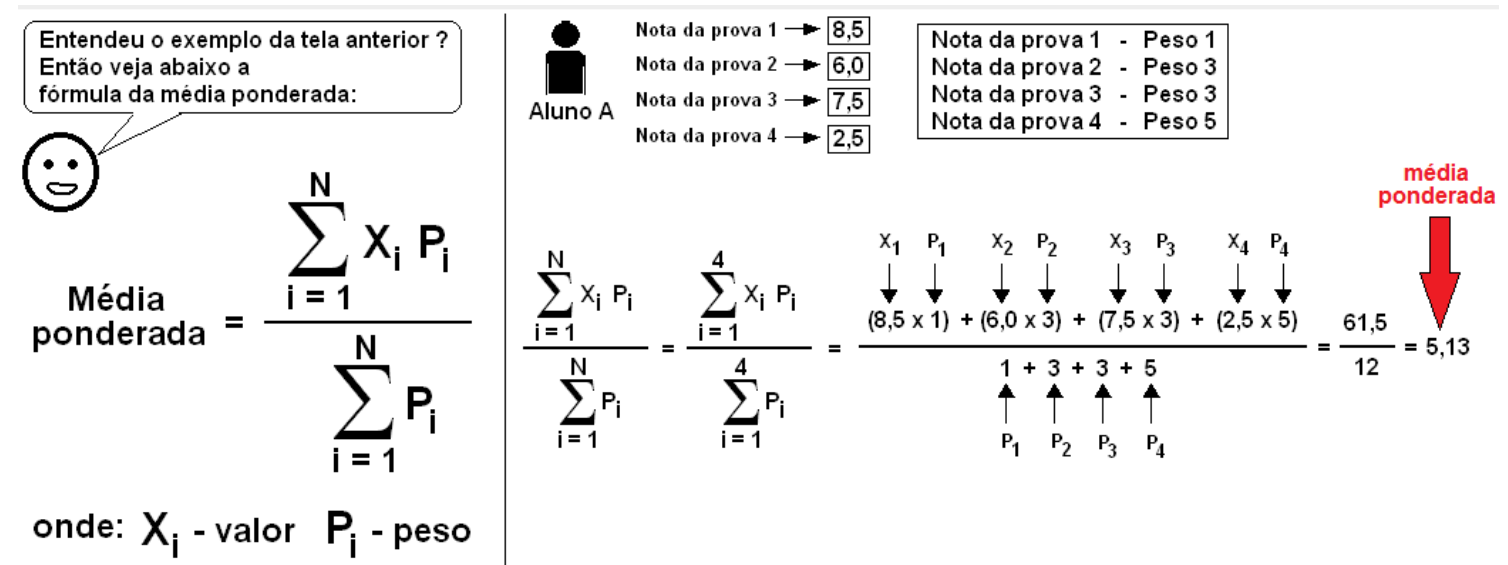

Figura 59 - Figura apresentando contexto pictórico de uso da média aritmética ponderada.

Fonte: Elaborado pelo autor.

(3) Estrutura matricial (tabela) e cálculos de coeficientes e/ou índices com dados da tabela. Foi preciso fazer a apresentação de forma bem detalhada do material para entendimento dos alunos sobre o assunto. Nas figuras 60 e 61 observa-se a contextualização da estrutura matricial e o cálculo de um coeficiente, no caso, o coeficiente de localização. Pude perceber que os alunos não estavam à vontade com o processamento de dados em formato matricial. Mas, conforme dito acima, com a explicação bem detalhada foi possível o entendimento do assunto. A maior dificuldade por parte dos alunos foi a visualização dos índices das fórmulas, como no exemplo da Figura 61, onde os índices $g$, e $h$ servem para simbolizar colunas, e o índice $r$ serve para simbolizar linhas da estrutura matricial. 
Análise de Estruturas Espaciais

(texto base: Estatística Econômica e Social - Jorge de Souza - Ed. Campus 1977)

Considere um espaço geográfico (país, região, município, distrito, etc) dividido em $n$ "áreas" $\mathbf{E}_{1}, \mathbf{E}_{2}, \mathbf{E}_{3}, \ldots \mathbf{E}_{\mathbf{n}}$

- Considere um conjunto de $\boldsymbol{m}$ atividades (culturas agrícolas, escolas, hospitais, indústrias, precipitação, doenças, nascimentos, etc) $\mathbf{A}_{\mathbf{1}}, \mathbf{A}_{\mathbf{2}}, \mathbf{A}_{\mathbf{3}}, \ldots \mathbf{A}_{\mathbf{m}}$

O que se deseja investigar é a distribuição dessas $\underline{m}$ atividades nos $n$ espaços geográficos.

Deseja-se avaliar aspectos de especialização, concentração e localização sob o ponto de vista estático e dinâmico.

$m$ atividades sobre $n$ espaços geográficos

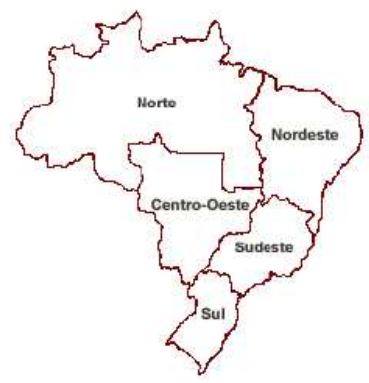

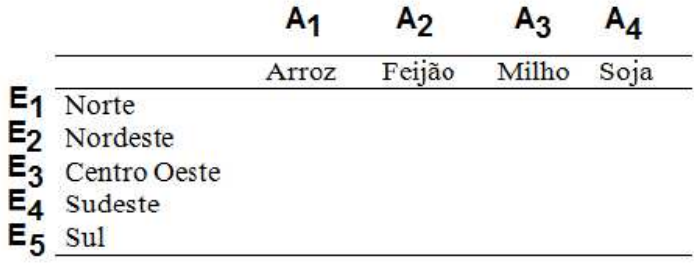

Figura 60 - Contextualização de uso de uma estrutura matricial.

Fonte: Elaborado pelo autor.

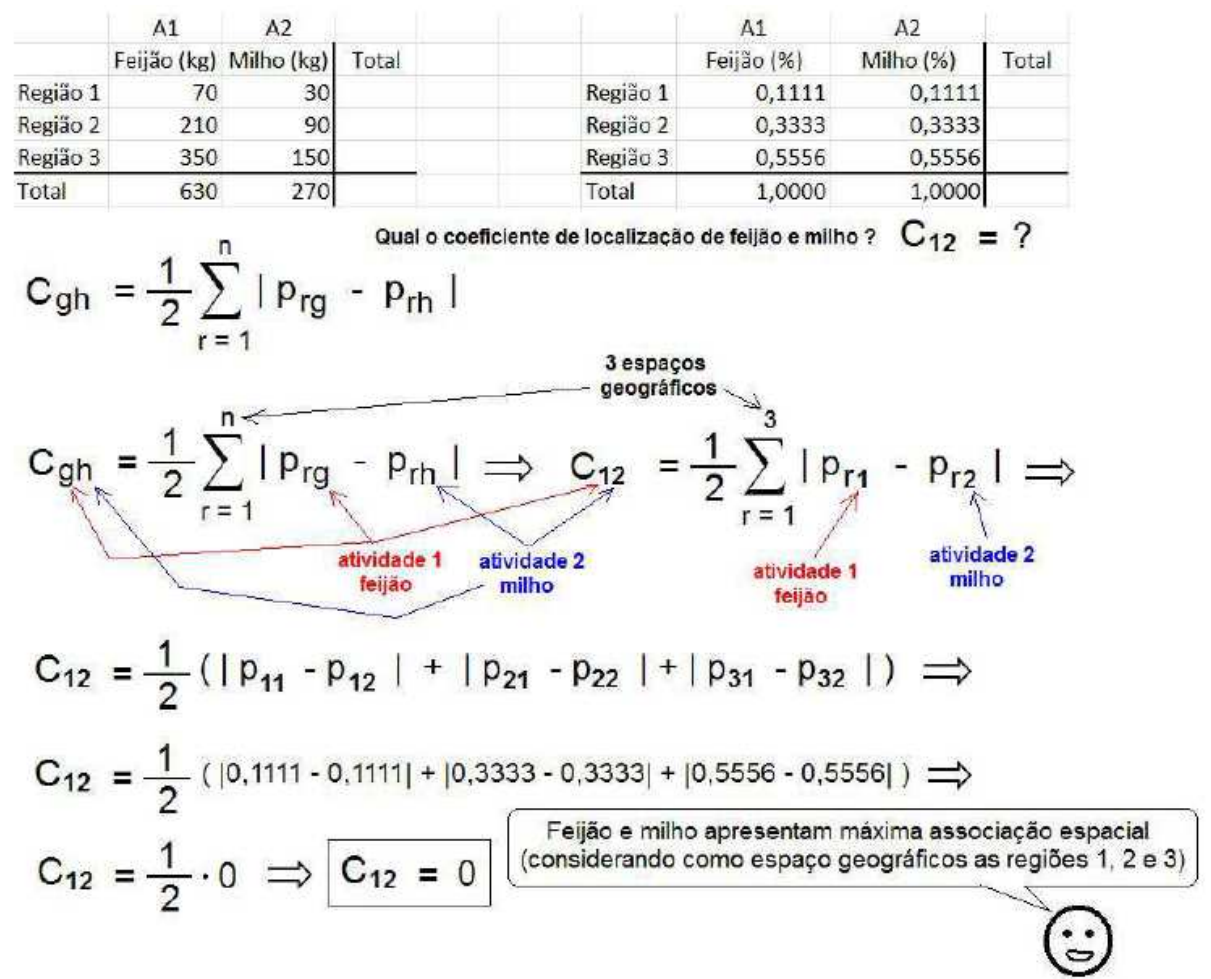

Figura 61 - Exemplo de cálculo do coeficiente de localização para feijão e milho, com base em dados dispostos em estrutura matricial.

Fonte: Elaborado pelo autor. 
Para avaliação dos tópicos (5) a (10), os alunos fizeram apresentação de um extenso trabalho onde basicamente implementaram em planilha eletrônica diversos quantificadores para dados diversos de unidades da federação obtidos junto ao IBGE (dados de produção agrícola, demográficos, de saúde, etc). Os quantificadores eram provenientes dos tópicos (5) a (10) como, por exemplo, os já citados coeficiente de Gini e coeficiente de localização.

Para finalizar, vale ressaltar, mais uma vez, que os resultados obtidos nestas atividades na disciplina foram de extrema valia para o propósito do projeto. Com o uso do EDH pude perceber que há a possibilidade de o mesmo vir a ser uma ferramenta que proporcione aprendizagem significativa de conceitos de quantificação. E com as demais aulas pude perceber um pouco sobre a familiaridade de conceitos matemáticos e dúvidas que eventualmente um graduando em Geografia possa vir a ter. Isso foi bastante útil no desenvolvimento das lições 9 a 14 do EDH que implementei ao longo dos meses de março a julho de 2014, quando obtive uma versão do EDH pronta para ser testada no curso de extensão planejado para o segundo semestre de 2014.

\subsection{O CURSO DE EXTENSÃO SOBRE QUANTIFICAÇÃO EM GEOGRAFIA DE SETEMBRO/2014 A NOVEMBRO/2014 USANDO EDH}

Por volta do final de agosto de 2014 o software EDH estava implementado com as 14 lições contendo os temas que foram delimitados durante o primeiro semestre de 2014, com a experiência de aulas de quantificação em Geografia ministradas na disciplina Tópicos Especiais em Geografia - Quantificação em Geografia.

$\mathrm{O}$ EDH finalmente poderia ser testado como ferramenta de autoestudo. Para testar o uso do software EDH como ferramenta que contribui (ou não) de forma a melhorar a capacitação do graduando em Geografia em técnicas quantitativas para aplicação em análise espacial de dados geográficos, foi planejada a realização de um curso de extensão sobre quantificação em Geografia sobre os temas das 14 lições do software EDH. O curso de extensão foi realizado na UnB sob a organização do Decanato de Extensão, entre setembro de 2014 e novembro de 2014. O foco do curso foi avaliar o software EDH como ferramenta de autoestudo capaz de proporcionar, via conteúdo imagético, aprendizagem significativa de alguns conceitos de quantificação. 
Diferentemente do uso do EDH com a turma de Climatologia Geral em agosto de 2013 e com a turma de Tópicos Especiais em Geografia em março a junho de 2014, neste curso de extensão, eu não fiz qualquer intervenção para auxiliar no ensino dos assuntos apresentados no curso. O participante do curso deveria estudar o assunto (a lição) do EDH por conta própria, ou eventualmente debatendo com outros participantes, e nos encontros presenciais respondia um questionário (um teste) sobre o assunto estudado.

O principal aspecto a ser considerado na montagem do curso de extensão foi a forma de seleção dos participantes. Como incentivar os alunos a realizarem o curso? A pergunta que fiz no segundo semestre de 2013 para os alunos de Climatologia Geral sobre o interesse em participar de um curso de extensão e a resposta positiva de apenas 30\% me deixou apreensivo com relação à adesão de alunos ao curso de extensão.

Se o interesse por um curso de extensão versando sobre quantificação a priori fosse mesmo baixo entre os graduandos de Geografia, poderia ocorrer de eventualmente aparecerem poucos ou mesmo nenhum aluno para realização do curso e o teste de uso do EDH não poderia ser realizado. Assim, a primeira medida decidida para incentivar a participação no curso foi a ausência de taxa de inscrição, ou seja, o curso seria gratuito.

$\mathrm{Na} U$ UnB, é possível disponibilizar certificados de participação para aqueles que concluírem o curso de extensão atendendo os requisitos mínimos definidos para o curso em questão. Pensei inicialmente em considerar como "prova" (teste) os exercícios que os alunos deveriam realizar após lerem as lições do EDH. Assim, o aluno só receberia o certificado somente se obtivesse suficiência na resolução dos testes das lições.

Mas meu receio de afastar o interesse dos alunos me fez desistir da ideia, pois os alunos poderiam desistir do curso, uma vez que seriam aplicados diversos testes para averiguação de entendimento dos conceitos das lições do EDH e, assim, o aluno muito provavelmente se sentiria "estressado" de tantas "provas".

Por outro lado, sem nenhum tipo de coerção, ou melhor, sem nenhuma contrapartida por parte do aluno para engajamento no curso, poderia ocorrer o caso do aluno se inscrever no curso somente com a intenção de receber o certificado para incrementar ou mesmo "iniciar" seu curriculum. De fato, isto infelizmente ocorreu. E o problema é que o aluno que se inscreveu somente com este propósito não serviu como elemento para avaliação do software $\mathrm{EDH}$.

A única forma de coerção para o aluno receber o certificado de participação foi exigir o comparecimento do aluno em no mínimo $75 \%$ dos encontros presenciais para responder ao 
questionário (teste) aplicado sobre o assunto da lição do EDH. E este questionário não seria avaliado como prova, mas sim como mera ferramenta aferidora da utilidade (ou não) do EDH para o propósito de aprendizagem significativa no contexto deste trabalho. Assim, poderia ocorrer o caso do aluno ir aos $75 \%$ de encontros presenciais e deixar o questionário totalmente em branco, ou resolvê-lo na base do "chute", pois nada garantiria nem o obrigaria a ter lido o material para responder o questionário. E isto, de fato, infelizmente ocorreu.

Em suma, o curso de extensão foi gratuito, e foi exigido, para obtenção de certificado de participação apenas a presença em sala de aula em $75 \%$ dos encontros presenciais para responder, de forma totalmente livre por parte do aluno, o questionário referente ao assunto da lição. E as análises da utilidade do EDH ficaram restritas ao material produzido pelos poucos alunos que efetivamente se engajaram no curso, motivados a aprender os assuntos das lições do EDH.

No primeiro encontro presencial, os participantes responderam um questionário de mapeamento de familiaridade de alguns conceitos de matemática básicos, similar ao questionário aplicado em 2013 para 384 respondentes. Desta vez, ao invés de sete, eram cinco questões. Este questionário inicial serviu para mapear o perfil do participante com relação aos seus conhecimentos matemáticos básicos.

$\mathrm{O}$ encontro presencial ocorria uma vez por semana. Havia alunos que compareciam às quartas-feiras no final da tarde e outros alunos compareciam no fim de tarde das sextas-feiras. A dinâmica do curso ocorreu da seguinte forma: no primeiro encontro, além de ter sido aplicado o questionário de mapeamento, foi informado ao aluno para estudar determinadas lições do EDH e na semana seguinte seria aplicado o questionário (teste) sobre os conceitos das lições indicadas para leitura, além do preenchimento, por parte do aluno, do mapeamento de sua dinâmica de aprendizagem. Na semana seguinte o aluno comparecia para realizar o questionário e ser informado das próximas lições a serem lidas para a outra semana seguinte. E assim sucessivamente até o oitavo encontro, quando teriam sido estudadas pelos participantes todas as lições.

Em suma, a dinâmica do curso estava complemente centrada na interação do participante com o software EDH. Durante as oito semanas, os participantes procederam ao autoestudo sem que nenhuma vez sequer eu tenha auxiliado no entendimento de conceitos, ao contrário do que eu havia feito nas experiências anteriores. Eu simplesmente comparecia aos encontros para aplicar os questionários da semana. Os resultados obtidos ao final do curso 
estão apresentados a seguir. Na Tabela 12 estão citados os questionários(testes) aplicados nos oito encontros.

Tabela 12- Lições do EDH abordadas e assuntos dos questionários aplicados

\begin{tabular}{|c|c|c|}
\hline $\begin{array}{l}\text { Encontro } \\
\text { (semana) }\end{array}$ & $\begin{array}{l}\text { Lições do } \\
\text { software } \\
\text { EDH }\end{array}$ & Assunto do questionário \\
\hline 1 & - & $\begin{array}{l}\text { Questionário para mapeamento da familiaridade de conceitos } \\
\text { matemáticos em nível de Ensino Fundamental e médio dos } \\
\text { participantes do curso }\end{array}$ \\
\hline 2 & $3,4,5$ e 6 & Objeto, variável, população e amostra \\
\hline 3 & 7 & Média aritmética simples \\
\hline 4 & 8 & Variância e desvio padrão \\
\hline 5 & 9 & Estatística espacial - centro médio espacial \\
\hline 6 & 10 & Estatística espacial - distância padrão \\
\hline 7 & $11 \mathrm{e} 12$ & Medidas de posição (separatrizes) e box plot \\
\hline 8 & 13 e 14 & Curva de Lorenz e Coeficiente de Gini \\
\hline
\end{tabular}

Inscreveram-se para o curso 50 participantes, o limite máximo permitido pelo Decanato de Extensão, mas, ao fim do período do curso de extensão, apenas 19 tiveram a participação suficiente para garantir a obtenção de certificado de participação $(75 \%$ de comparecimento aos encontros). Dos 50 participantes, dez desistiram antes de começar o curso, pois não compareceram em nenhum encontro. No primeiro encontro, quando foi aplicado o questionário para mapeamento da familiaridade de conceitos matemáticos em nível de Ensino Fundamental e Médio dos participantes do curso, compareceram 38 participantes. O $39^{\circ}$ participante compareceu apenas no segundo encontro e o $40^{\circ}$, apenas no terceiro encontro.

Ao longo dos encontros seguintes, participantes deixavam de comparecer e, por isso, ao final da oitava semana, apenas 19 concluíram com percentual de participação mínimo exigido para obtenção de certificado. Para avaliar a eficácia do software com base no desempenho dos 40 participantes, os mesmos foram designados por P1, P2, P3 e assim sucessivamente até P40. Na Tabela 13 apresenta-se o mapa de indicação de resolução dos questionários pelos 40 participantes. 
Tabela 13 - Mapa de indicação de resolução do questionário

\begin{tabular}{|c|c|c|c|c|c|c|c|c|}
\hline & \multicolumn{8}{|c|}{ Encontro/Semana } \\
\hline $\begin{array}{c}\text { Particip } \\
.\end{array}$ & $\begin{array}{c}1 \\
\text { (quest. } \\
\text { Famil.) }\end{array}$ & $\begin{array}{c}2 \\
\text { (obj. } \\
\text { pop.am.) }\end{array}$ & $\begin{array}{c}3 \\
\text { (média) }\end{array}$ & $\begin{array}{c}4 \\
\text { (var. } \\
\text { dv.pad) }\end{array}$ & $\begin{array}{c}5 \\
\text { (centro } \\
\text { méd.) }\end{array}$ & $\begin{array}{c}6 \\
\text { (dist. } \\
\text { Padrão) }\end{array}$ & $\begin{array}{c}7 \\
\text { (separa- } \\
\text { trizes) }\end{array}$ & $\begin{array}{c}8 \\
\text { (gini/ } \\
\text { Lorenz) }\end{array}$ \\
\hline $\mathrm{P} 1$ & $\mathrm{X}$ & $\mathrm{X}$ & $\mathrm{X}$ & $\mathrm{X}$ & $\mathrm{X}$ & $\mathrm{X}$ & $\mathrm{X}$ & $\mathrm{X}$ \\
\hline $\mathrm{P} 2$ & $\mathrm{X}$ & $\mathrm{X}$ & $\mathrm{X}$ & $\mathrm{X}$ & $\mathrm{X}$ & $\mathrm{X}$ & $\mathrm{X}$ & - \\
\hline $\mathrm{P} 3$ & $\mathrm{X}$ & $\mathrm{X}$ & $\mathrm{X}$ & $\mathrm{X}$ & $\mathrm{X}$ & $\mathrm{X}$ & $\mathrm{X}$ & - \\
\hline P4 & $\mathrm{X}$ & $\mathrm{X}$ & $\mathrm{X}$ & $\mathrm{X}$ & $\mathrm{x}$ & $\mathrm{x}$ & $\mathrm{x}$ & $\mathrm{x}$ \\
\hline P5 & $\mathrm{X}$ & $\mathrm{X}$ & $\mathrm{X}$ & $\mathrm{X}$ & $\mathrm{X}$ & $\mathrm{X}$ & $\mathrm{X}$ & $\mathrm{X}$ \\
\hline P6 & $\mathrm{X}$ & $\mathrm{X}$ & $\mathrm{X}$ & $\mathrm{X}$ & $\mathrm{X}$ & $\mathrm{X}$ & $\mathrm{X}$ & - \\
\hline P7 & $\mathrm{X}$ & $\mathrm{X}$ & $\mathrm{X}$ & $\mathrm{X}$ & $\mathrm{X}$ & $\mathrm{X}$ & $\mathrm{X}$ & $\mathrm{X}$ \\
\hline P8 & $\mathrm{X}$ & $\mathrm{X}$ & $\mathrm{X}$ & $\mathrm{X}$ & $\mathrm{X}$ & $\mathrm{X}$ & $\mathrm{X}$ & - \\
\hline P9 & $\mathrm{X}$ & $\mathrm{X}$ & $\mathrm{X}$ & $\mathrm{X}$ & $\mathrm{X}$ & $\mathrm{X}$ & $\mathrm{X}$ & - \\
\hline $\mathrm{P} 10$ & $\mathrm{X}$ & $\mathrm{X}$ & $\mathrm{X}$ & $\mathrm{X}$ & $\mathrm{X}$ & $\mathrm{X}$ & $\mathrm{X}$ & - \\
\hline P11 & $\mathrm{X}$ & $\mathrm{X}$ & $\mathrm{X}$ & $\mathrm{X}$ & $\mathrm{X}$ & - & $\mathrm{X}$ & - \\
\hline $\mathrm{P} 12$ & $\mathrm{X}$ & $\mathrm{X}$ & $\mathrm{X}$ & $\mathrm{X}$ & $\mathrm{X}$ & $\mathrm{X}$ & $\mathrm{X}$ & - \\
\hline $\mathrm{P} 13$ & $\mathrm{X}$ & $\mathrm{X}$ & $\mathrm{X}$ & $\mathrm{X}$ & $\mathrm{X}$ & $\mathrm{X}$ & $\mathrm{X}$ & - \\
\hline P14 & $\mathrm{X}$ & $\mathrm{X}$ & $\mathrm{X}$ & $X$ & $\mathrm{X}$ & - & $X$ & - \\
\hline P15 & $X$ & $X$ & $\mathrm{X}$ & $\mathrm{X}$ & $X$ & - & $\mathrm{X}$ & - \\
\hline P16 & $X$ & $X$ & $\mathrm{X}$ & $X$ & $X$ & - & - & $\mathrm{X}$ \\
\hline P17 & $\mathrm{X}$ & $\mathrm{X}$ & $\mathrm{X}$ & $\mathrm{X}$ & $X$ & $X$ & - & - \\
\hline P18 & $X$ & $X$ & $X$ & $X$ & $X$ & $X$ & - & - \\
\hline P19 & $X$ & $X$ & $X$ & $X$ & $X$ & $X$ & - & - \\
\hline P20 & $X$ & $X$ & $X$ & - & - & - & - & - \\
\hline $\mathrm{P} 21$ & $X$ & $X$ & $X$ & - & - & - & - & - \\
\hline P22 & $X$ & $X$ & $X$ & - & - & - & - & - \\
\hline $\mathrm{P} 23$ & $X$ & $X$ & $X$ & - & - & - & - & - \\
\hline P24 & $X$ & $X$ & - & - & - & - & - & - \\
\hline $\mathrm{P} 25$ & $X$ & $X$ & - & - & - & - & - & - \\
\hline P26 & $X$ & $X$ & - & - & - & - & - & - \\
\hline P27 & $X$ & $X$ & - & - & - & - & - & - \\
\hline P28 & $X$ & $X$ & - & - & - & - & - & - \\
\hline P29 & $X$ & $X$ & - & - & - & - & - & - \\
\hline
\end{tabular}


Tabela 13 (continuação) - Mapa de indicação de resolução do questionário

\begin{tabular}{|c|c|c|c|c|c|c|c|c|}
\hline & \multicolumn{8}{|c|}{ Encontro/Semana } \\
\hline Particip & $\begin{array}{c}1 \\
\text { (quest. } \\
\text { Famil.) }\end{array}$ & $\begin{array}{c}2 \\
\text { (obj. } \\
\text { pop.am.) }\end{array}$ & $\begin{array}{c}3 \\
\text { (média) }\end{array}$ & $\begin{array}{c}4 \\
\text { (var. } \\
\text { dv.pad) }\end{array}$ & $\begin{array}{c}5 \\
\text { (centro } \\
\text { méd.) }\end{array}$ & $\begin{array}{c}6 \\
\text { (dist. } \\
\text { Padrão) }\end{array}$ & $\begin{array}{c}7 \\
\text { (separa- } \\
\text { trizes) }\end{array}$ & $\begin{array}{c}8 \\
\text { (gini/ } \\
\text { Lorenz) }\end{array}$ \\
\hline P30 & $\mathrm{X}$ & $\mathrm{X}$ & - & - & - & - & - & - \\
\hline P31 & $X$ & $X$ & - & - & - & - & - & - \\
\hline P32 & $\mathrm{X}$ & - & $\mathrm{X}$ & - & - & - & - & - \\
\hline P33 & $X$ & - & - & - & - & - & - & - \\
\hline P34 & $X$ & - & - & - & - & - & - & - \\
\hline P35 & $X$ & - & - & - & - & - & - & - \\
\hline P36 & $\mathrm{X}$ & - & - & - & - & - & - & - \\
\hline P37 & $\mathrm{X}$ & - & - & - & - & - & - & - \\
\hline P38 & $\mathrm{X}$ & - & - & - & - & - & - & - \\
\hline P39 & - & $X$ & - & - & - & - & - & - \\
\hline P40 & - & - & $X$ & - & - & - & - & - \\
\hline
\end{tabular}

Obs.: X : o participante respondeu o questionário - : o participante não respondeu o questionário

\subsubsection{Primeiro encontro - questionário de mapeamento da familiaridade de conceitos matemáticos básicos (questionário 1)}

Conforme citado anteriormente, o questionário 1 foi aplicado no primeiro encontro com o objetivo de verificar a familiaridade que o participante possuía com conceitos básicos de matemática. Todos os conceitos das questões do questionário foram (ou deveriam ser) abordados nos ensinos Fundamental e Médio.

Para designar qualitativamente a familiaridade prévia dos participantes com relação ao conhecimento de conceitos matemáticos básicos, foi adotada como premissa que quanto mais questões o participante acertasse, maior deveria ser sua familiaridade com conceitos matemáticos básicos. Foram definidas quatro categorias qualitativas a saber: nula, insuficiente, razoável e boa. A relação entre a quantidade de questões respondidas corretamente e a designação qualitativa do participante são apresentadas na Tabela 14. 
Tabela 14 - Designações qualitativas para a familiaridade com conceitos matemáticos básicos em nível de Ensino Médio

\begin{tabular}{cc}
\hline $\begin{array}{c}\text { Número de questões } \\
\text { respondidas corretamente }\end{array}$ & $\begin{array}{c}\text { Designação qualitativa da } \\
\text { familiaridade com } \\
\text { conceitos matemáticos }\end{array}$ \\
\hline 0 & Nula \\
1 a 2 & Insuficiente \\
3 & Razoável \\
4 a 5 & Boa \\
\hline
\end{tabular}

O questionário de mapeamento de familiaridade, continha cinco questões, versando sobre interpretação de dados em formato tabular, noções básicas de probabilidade, proporcionalidade em escalas, taxa e contagem/proporção. Em essência, apesar das questões apresentarem "roupagens" diferentes entre si, o conceito principal das questões envolve o entendimento por parte de respondente do conceito de proporção. Por este fato é que se considerou que a designação qualitativa depende apenas do número de questões corretas, e não quais foram as questões respondidas corretamente.

Assim, por exemplo, um respondente que acertou apenas a questão 1 e 2 é considerado ter familiaridade insuficiente de conceitos matemáticos (de acordo com a Tabela 14), o mesmo ocorrendo com outro respondente que tenha acertado apenas as questões 3 e 5 , pois ambos acertaram apenas duas questões entre as cinco do questionário. Afinal, supõe-se que em essência é o conceito de proporção que está embutido em todas as questões propostas.

Após aplicação do questionário, foi realizada a designação qualitativa de cada participante com relação à familiaridade de conceitos matemáticos, apresentada na Tabela 15. 
Tabela 15 - Familiaridade com conceitos matemáticos dos 40 participantes

\begin{tabular}{|c|c|l|c|c|l|}
\hline Participante & $\begin{array}{c}\text { Qtde. } \\
\text { questões } \\
\text { certas }\end{array}$ & $\begin{array}{c}\text { Familiaridade } \\
\text { conceitos } \\
\text { matemáticos }\end{array}$ & Participante & $\begin{array}{c}\text { Qtde. } \\
\text { questões } \\
\text { certas }\end{array}$ & $\begin{array}{c}\text { Familiaridade } \\
\text { conceitos } \\
\text { matemáticos }\end{array}$ \\
\hline P1 & 4 & Boa & P20 & 3 & Razoável \\
P2 & 2 & Insuficiente & P21 & 1 & Insuficiente \\
P3 & 4 & Boa & P22 & 4 & Boa \\
P4 & 3 & Razoável & P23 & 0 & Nula \\
P5 & 2 & Insuficiente & P24 & 1 & Insuficiente \\
P6 & 3 & Razoável & P25 & 1 & Insuficiente \\
P7 & 1 & Insuficiente & P26 & 2 & Insuficiente \\
P8 & 3 & Razoável & P27 & 3 & Razoável \\
P9 & 5 & Boa & P28 & 0 & Nula \\
P10 & 4 & Boa & P29 & 4 & Boa \\
P11 & 2 & Insuficiente & P30 & 1 & Insuficiente \\
P12 & 3 & Razoável & P31 & 3 & Razoável \\
P13 & 0 & Nula & P32 & 3 & Razoável \\
P14 & 1 & Insuficiente & P33 & 4 & Boa \\
P15 & 2 & Insuficiente & P34 & 5 & Boa \\
P16 & 2 & Insuficiente & P35 & 2 & Insuficiente \\
P17 & 1 & Insuficiente & P36 & 0 & Nula \\
P18 & 2 & Insuficiente & P37 & 0 & Nula \\
P19 & 3 & Razoável & P38 & 0 & Nula \\
P20 & 3 & Razoável & P39 & - & \\
P21 & 1 & Insuficiente & P40 & - & \\
\hline P39 & 1 & & & & -
\end{tabular}

Obs: P39 e P40 não responderam o questionário

Na Figura 62 é apresentada a distribuição de frequência da variável familiaridade de conceitos matemáticos. Observa-se que apenas 21,05\% dos participantes acertaram quatro ou cinco questões, ou seja, apenas oito. E vale ressaltar que desses oito participantes, P33 e P34 eram alunos do curso de Estatística e P9, do curso de Economia. Assim, dos 38 respondentes do questionário, cinco alunos entre 35 eram alunos do curso de Geografia. Então, apenas 1/7 dos alunos de Geografia foram considerados como apresentando boa familiaridade com conceitos matemáticos, ou seja, apenas $14,28 \%$.

E se for considerar conjuntamente as categorias qualitativas boa e razoável, apenas $44,73 \%$ dos respondentes se enquadrariam em uma destas categorias. A priori, poderia se supor que esses $44,73 \%$ apresentariam conceitos subsunçores em sua estrutura cognitiva que facilitariam o aprendizado dos conteúdos das lições do EDH ou, a priori, teriam menos dificuldades durante o curso. 


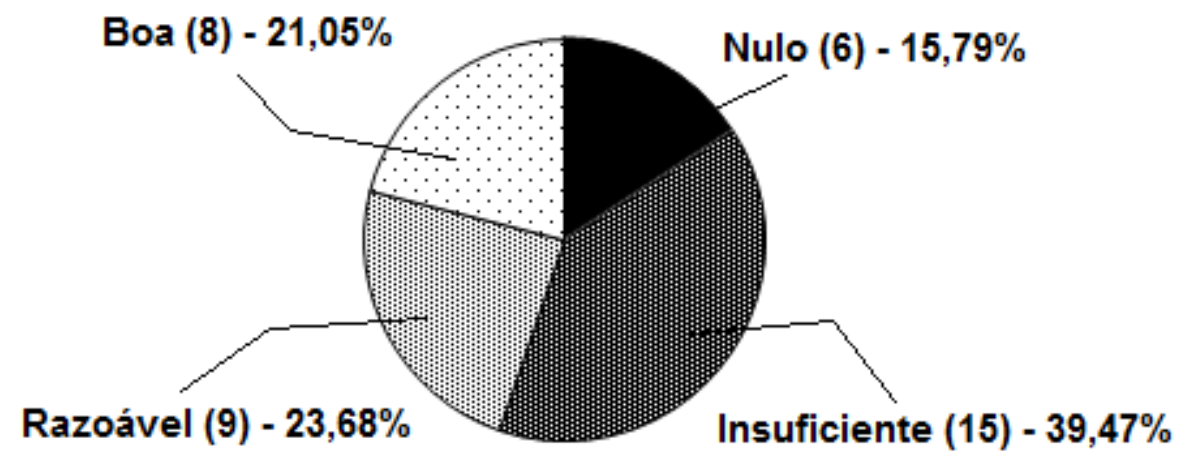

Figura 62 - Distribuição de frequência da variável familiaridade de conceitos matemáticos. Fonte: Elaborado pelo autor.

Embora no escopo do curso de extensão o questionário de familiaridade de conceitos matemáticos tenha sido usado primordialmente para categorizar o participante em uma das classes boa, razoável, insuficiente e nula, foi verificada a performance dos respondentes no questionário. Na Tabela 16 e Figura 63 estão apresentados os percentuais de acertos, erros e não resolução (resposta em branco) das cinco questões.

Tabela 16 - Frequência absoluta e relativa de respostas certas, erradas e em branco das questões 1 a 5 dos 38 questionários respondidos

\begin{tabular}{cccc}
\hline Questão & Certas & $\begin{array}{c}\text { Respostas } \\
\text { Erradas }\end{array}$ & Em branco \\
\hline 1 & $23(60,53 \%)$ & $13(34,21 \%)$ & $2(5,26 \%)$ \\
2 & $18(47,37 \%)$ & $13(34,21 \%)$ & $7(18,42 \%)$ \\
3 & $10(26,32 \%)$ & $6(15,79 \%)$ & $22(57,89 \%)$ \\
4 & $17(44,74 \%)$ & $18(47,37 \%)$ & $3(7,89 \%)$ \\
5 & $16(42,11 \%)$ & $8(21,05 \%)$ & $14(36,84 \%)$ \\
\hline
\end{tabular}




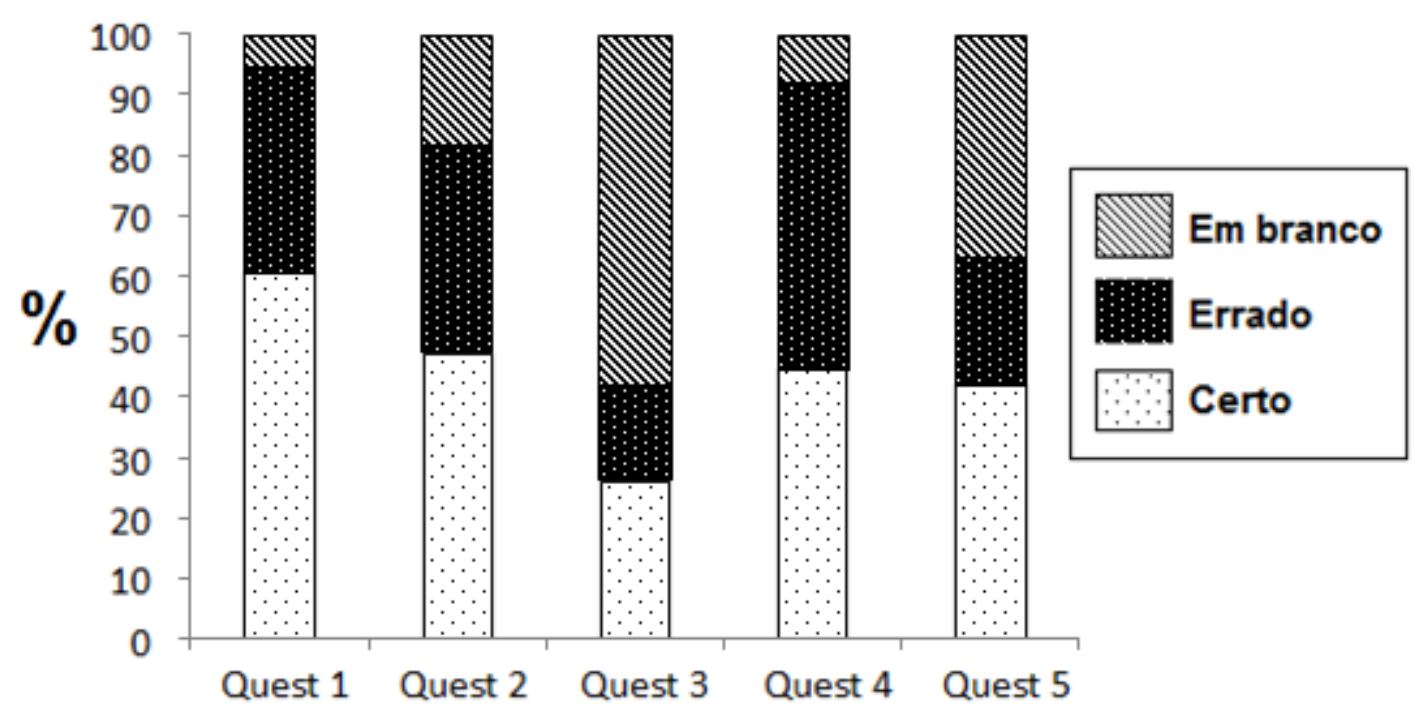

Figura 63 - Percentual de acertos, erros e não resolução das questões 1 a 5 pelos 38 respondentes.

Fonte: Elaborado pelo autor.

Da Tabela 16 e Figura 63 observa-se que a Questão 1 foi a que apresentou maior quantidade de acertos $(60,53 \%)$ e a Questão 3, menor quantidade de acertos $(26,32 \%)$. A Questão 3 foi a mesma aplicada no questionário de mapeamento de familiaridade em 2013 e abril de 2014, mudando-se apenas seus valores, e sendo a questão de número cinco naquele questionário. Chama a atenção por ser um tipo de questão que lida com escala, que por sua vez tem forte ligação com o trabalho do geógrafo em seu trabalho de análise do espaço geográfico. Nos apêndices 1 a 6 encontram-se as cinco questões do questionário com respectivas respostas e resoluções.

\subsubsection{Segundo encontro - questionário sobre conceitos de objeto, variável, população e amostra (assunto das lições 3 a 6 do EDH) (questionário 2)}

As lições 3, 4, 5 e 6 do software EDH foram objeto de análise no questionário 2 do curso de extensão. Em síntese, para se trabalhar com quantificação deve-se ter em mente que, conceitualmente, tudo é objeto. E todo objeto tem atributos. Quando se quer quantificar, toma-se um grupo (um conjunto) de objetos e escolhe-se um determinado atributo dos objetos para análise. Este grupo (conjunto) de atributos (também denominados variáveis) é a população de interesse e as técnicas quantitativas são aplicadas a este grupo ou a parte do grupo. 
A lição 3 intitulada "Tudo é objeto" é composta de 11 telas. Nas Figuras 64 e 65 observam-se imagens de duas das 11 telas que tentam transmitir os conceitos de objeto e atributo do objeto.

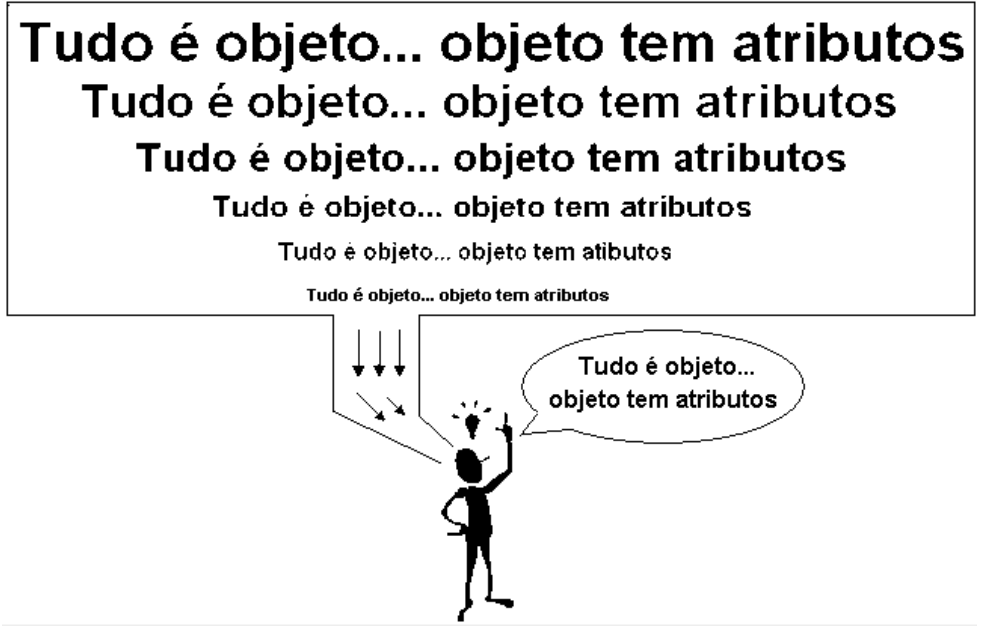

Figura 64 - uma tela da lição 3 - objeto e atributos

Fonte: Elaborado pelo autor.

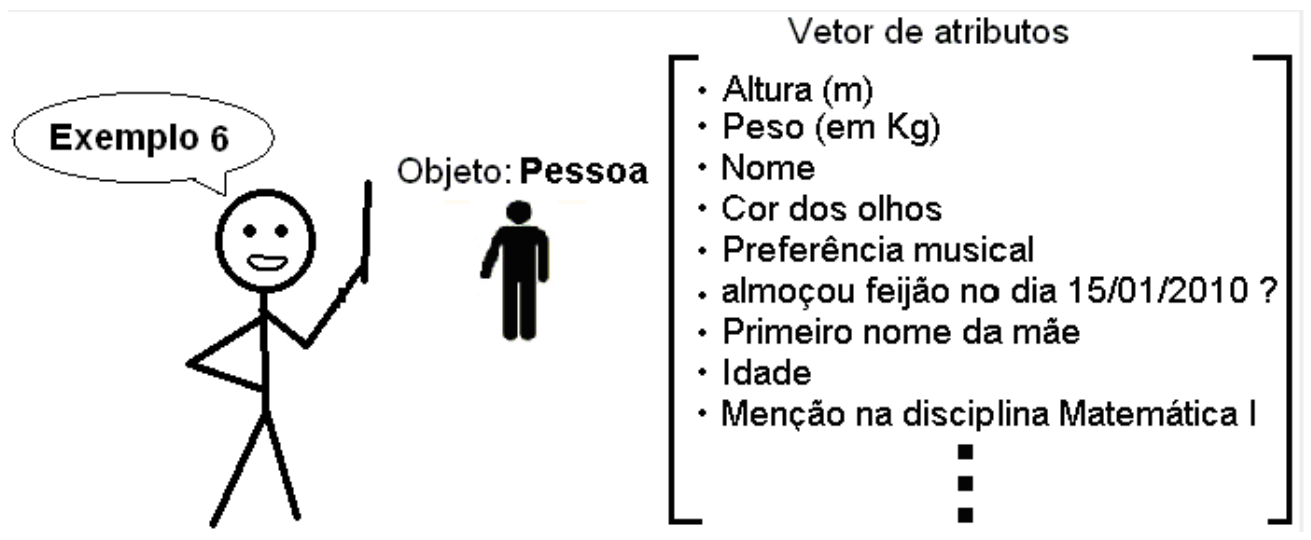

Figura 65 - uma tela da lição 3 - exemplo de objeto e atributos do objeto

Fonte: Elaborado pelo autor.

Na lição 4, intitulada "População", procura-se caracterizar o grupo (conjunto) de atributos. Foram montadas 21 telas para esta lição. Na Figura 66 é apresentada uma tela em que visualmente se tenta transmitir ao leitor o relacionamento entre o objeto, os atributos de objetos e um grupo (população - conjunto) de atributos do objeto, e na Figura 67, a síntese da lição 4. 


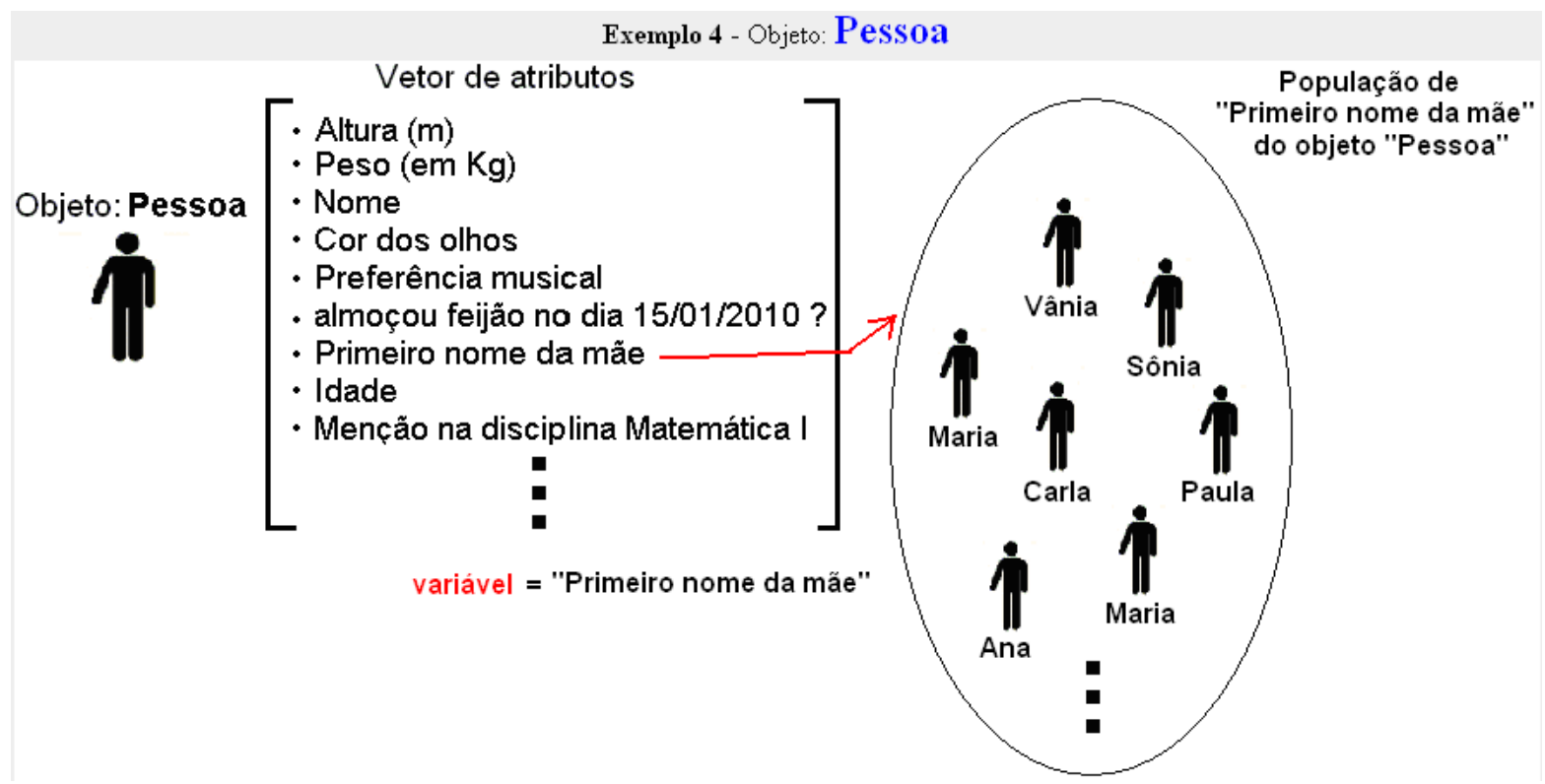

Figura 66 - uma tela da lição 4 - exemplo de relacionamento entre o objeto, os atributos de objetos e um grupo (população - conjunto) de atributos do objeto.

Fonte: Elaborado pelo autor.

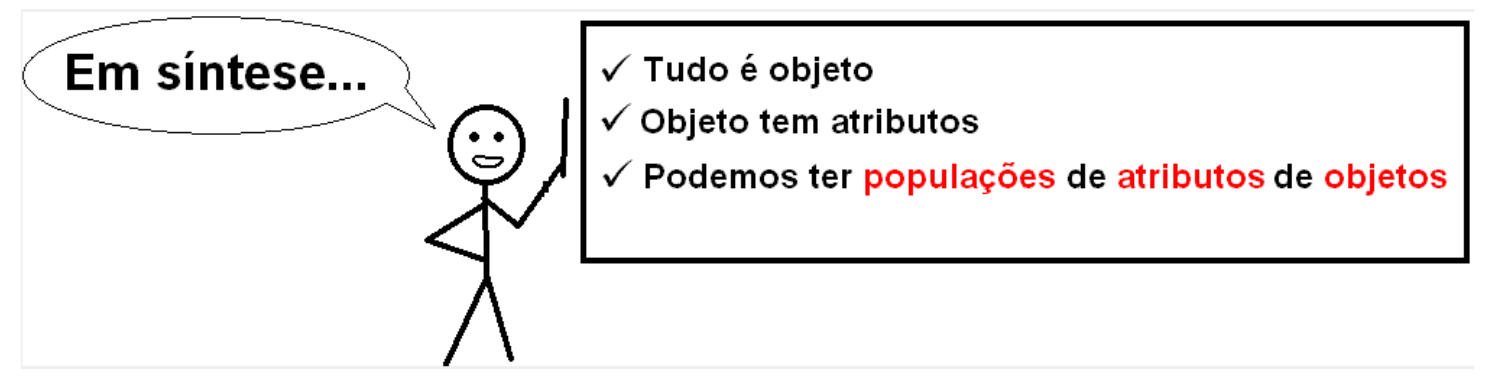

Figura 67 - Síntese da lição 4.

Fonte: Elaborado pelo autor.

Na lição 5, intitulada "Variável: atributo do objeto" ressalta-se que os atributos do objeto são as variáveis de interesse. Na Figura 68 observa-se a tela da lição 5 onde a intenção é o entendimento intuitivo do conceito de variável por parte do leitor. Nas Figuras 69 e 70 observam-se telas exemplificadoras. As telas têm o propósito primordial de apresentar um conteúdo imagético que ajude a fixar o conceito. Na Figura 71 observa-se a síntese da lição 5. 


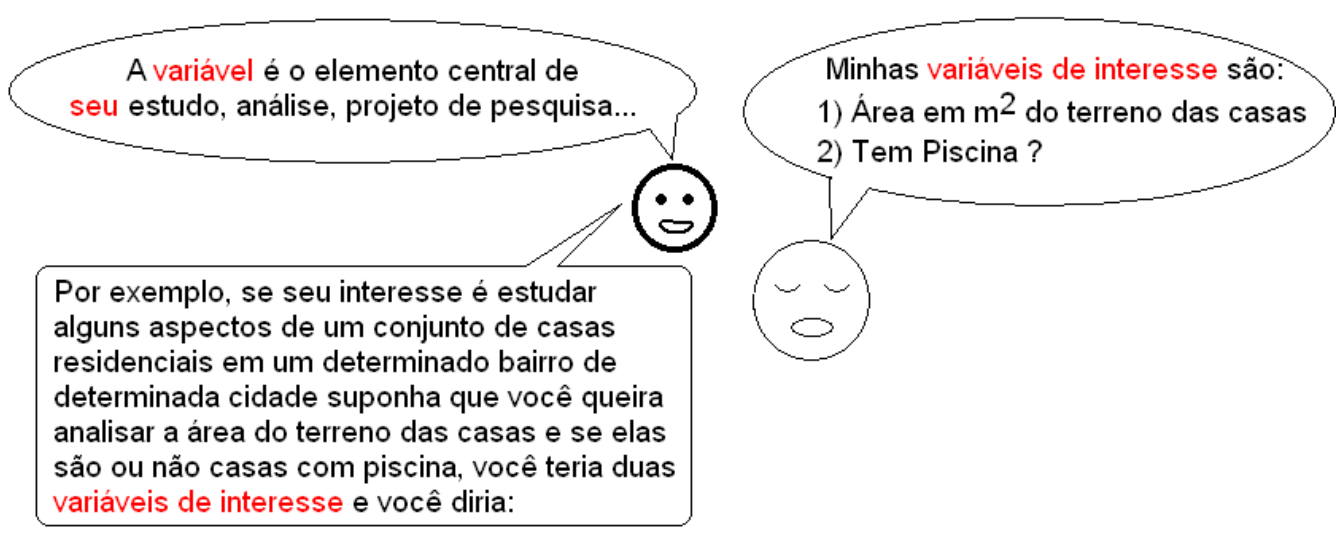

Figura 68 - Uma tela para propiciar o entendimento intuitivo do conceito de variável.

Fonte: Elaborado pelo autor.

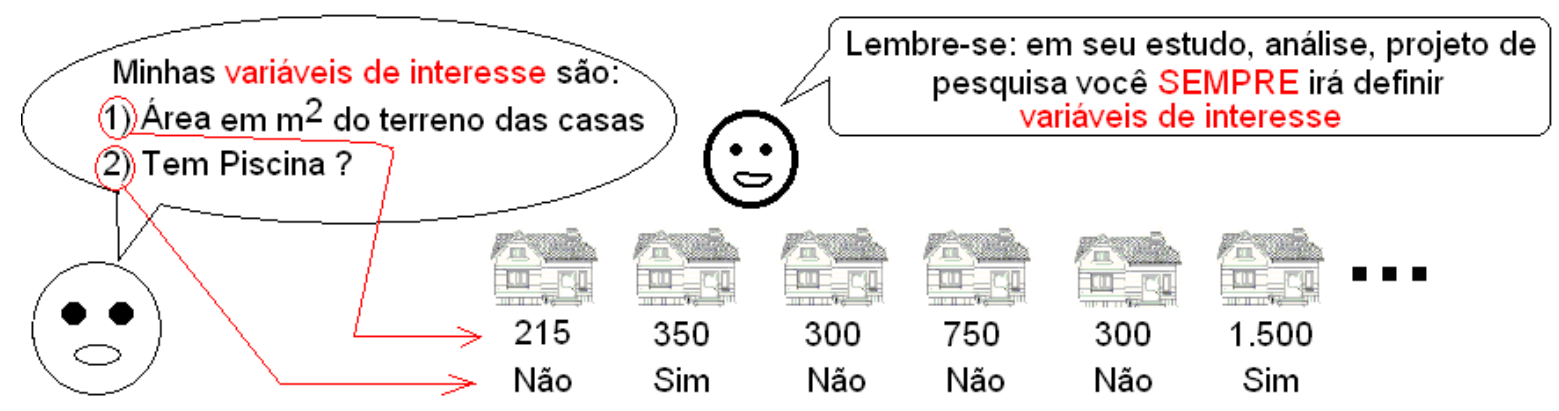

Figura 69 - Uma tela com exemplo para tentar concretizar o conceito de variável.

Fonte: Elaborado pelo autor.

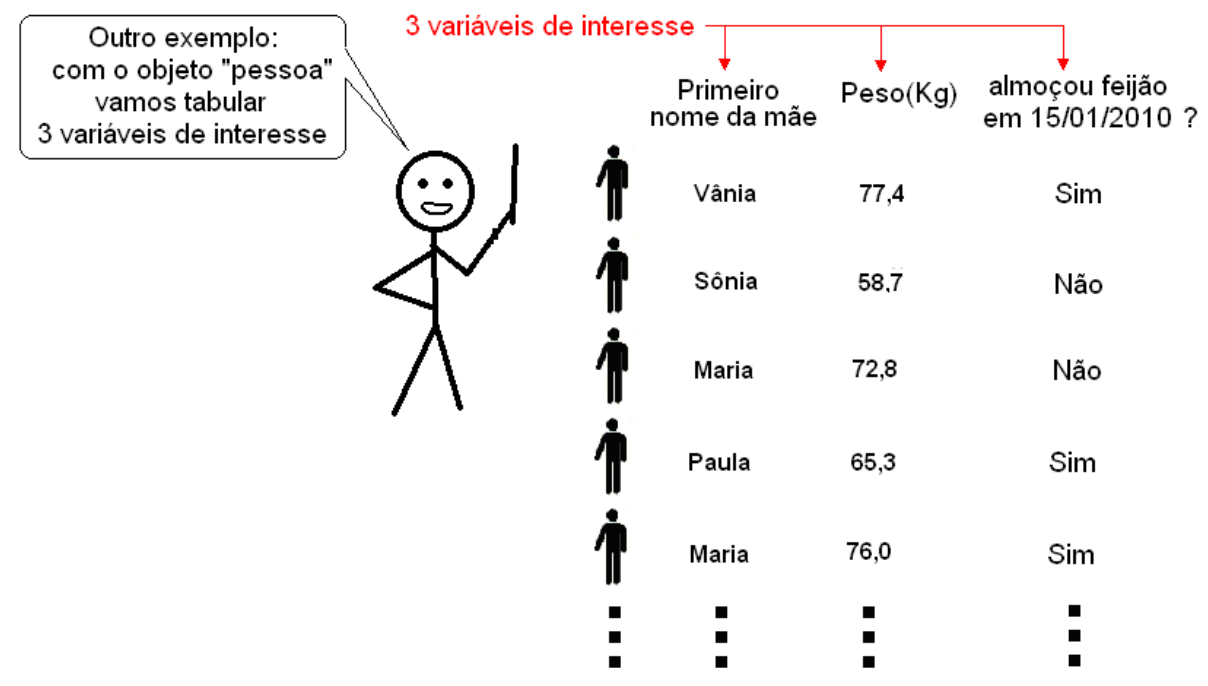

Figura 70 - Outra tela com exemplo para tentar concretizar o conceito de variável. 
Fonte: Elaborado pelo autor.

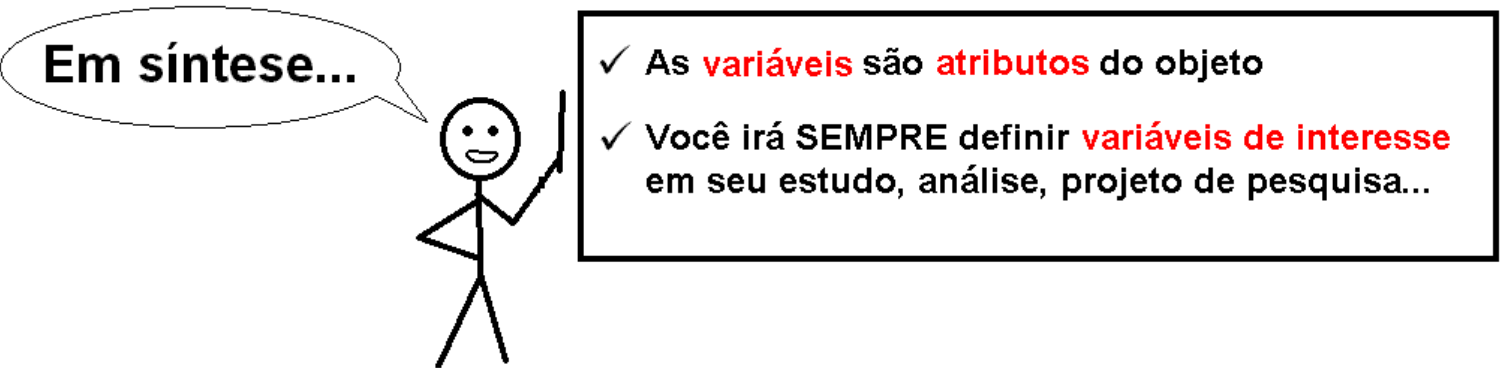

Figura 71 - Síntese da lição 5.

Fonte: Elaborado pelo autor.

Finalmente, completando o conteúdo de assuntos avaliados no questionário 2, a lição 6 intitulada "População e amostra" visa solidificar o entendimento de população e, adicionalmente apresenta a ideia de amostra. A lição 6 possui 18 telas e nas Figuras 72 e 73 observam-se telas com imagens que devem auxiliar no entendimento dos conceitos abordados.

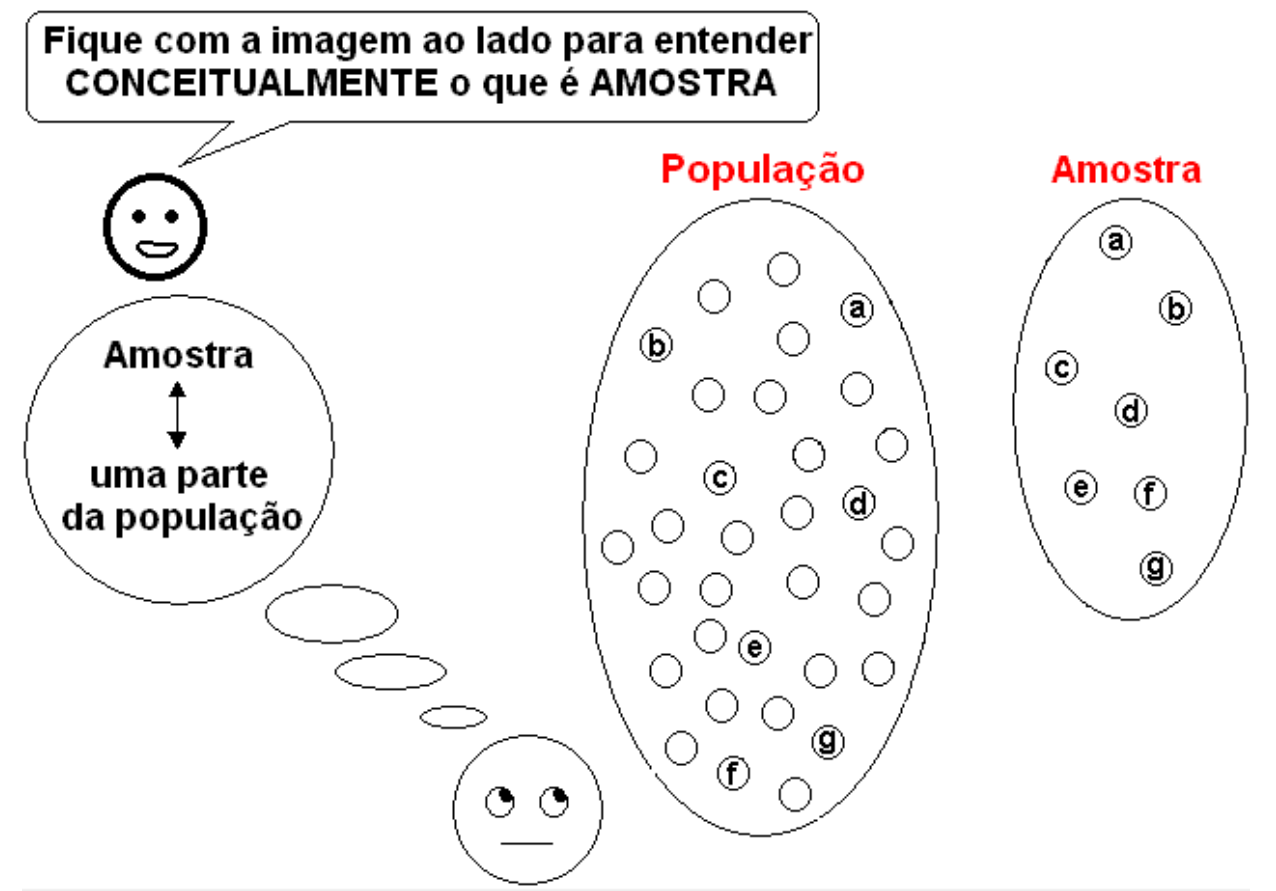

Figura 72 - Conceito de população e amostra apresentado de forma visual .

Fonte: Elaborado pelo autor. 


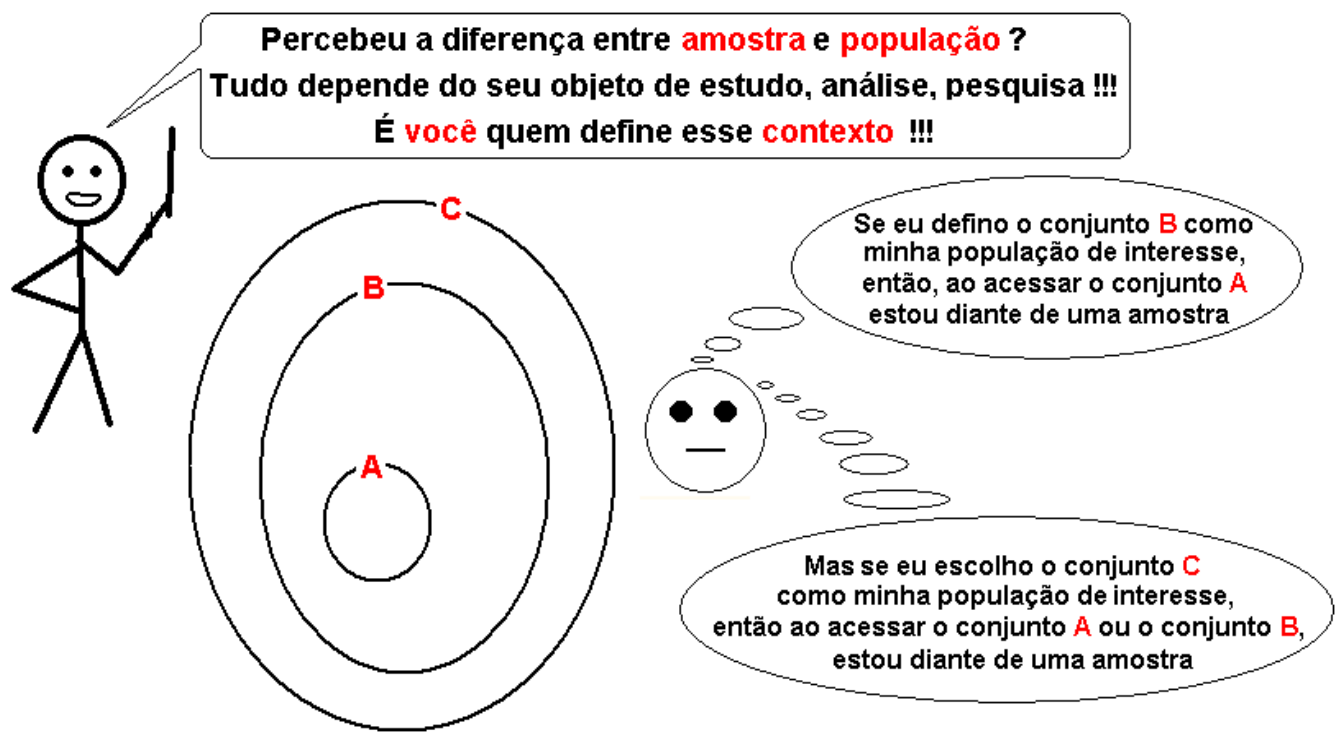

Figura 73 - Conceito de população e amostra apresentado de forma visual

Fonte: Elaborado pelo autor.

\subsubsection{Respostas dos participantes ao questionário 2 - objetos, variáveis, população e amostra}

O questionário 2 encontra-se no Apêndice 7. Nas Tabelas 17 e 18 encontram-se as correções dos itens das questões 1,2 e 3 dos participantes. Os itens das três questões deste questionário são, todos, abertos, isto é, o participante respondeu-os de forma descritiva. Foram analisadas todas as respostas e atribuiu-se as seguintes correções: "C", "E" e "X" que significam, respectivamente, "resposta correta", "resposta errada" e "não respondeu"

O questionário, na verdade, é um teste. No escopo deste trabalho foram consideradas três categorias possíveis de desempenho do respondente ao questionário: (1) satisfatório, (2) parcialmente satisfatório e (3) não satisfatório, representados, respectivamente pelas letras $S$, $\mathrm{P}$ e N. A designação $\mathrm{S} / \mathrm{P} / \mathrm{N}$ de desempenho no questionário foi feita de forma qualitativa, considerando-se a quantidade de itens respondidos corretamente e, em alguns casos, dependendo de quais foram os itens respondidos corretamente. A coluna "Desempenho" apresentada nas tabelas 17 e 18 indica o desempenho do participante nos itens do questionário. 
Tabela 17 - Respostas dos participantes P1, P9, P10, P11, P13, P14, P27 e P28

\begin{tabular}{|c|c|c|c|c|c|c|c|c|c|c|c|c|c|c|}
\hline & \multicolumn{14}{|c|}{$\begin{array}{l}\text { Dinâmica de interação do participante com o software EDH } \\
\text { (Declarado pelo próprio participante) }\end{array}$} \\
\hline & $\begin{array}{ll}\text { - } & \mathrm{L} \\
\text { - } & \mathrm{D} \\
& \text { al } \\
- & \mathrm{P} \\
& \mathrm{E} \\
& \mathrm{c}\end{array}$ & $\begin{array}{l}\text { some } \\
\text { urante } \\
\text { nostra } \\
\text { ara en } \\
\text { DH f } \\
\text { nceit }\end{array}$ & e var & $\begin{array}{l}\text { mater } \\
\text { epois } \\
\text { iável } \\
\text { mento } \\
\text { 1. Ac } \\
\text { mordi }\end{array}$ & $\begin{array}{l}\text { ial do } \\
\text { da lei } \\
\text { que eu } \\
\text { das } r \\
\text { redito } \\
\text { alment }\end{array}$ & $\begin{array}{l}\text { softw } \\
\text { itura e } \\
\text { estud } \\
\text { noções } \\
\text { que } \\
\text { te via }\end{array}$ & $\begin{array}{l}\text { are ED } \\
\text { eu lem } \\
\text { lei em } \\
\text { s cono } \\
\text { a abo } \\
\text { image }\end{array}$ & $\begin{array}{l}\text { DH } \\
\text { nbrei } \\
\text { outra } \\
\text { ceituai } \\
\text { rdage } \\
\text { ns aju }\end{array}$ & $\begin{array}{l}\text { das no } \\
\text { oport } \\
\text { s de } 1\end{array}$ & $\begin{array}{l} \\
\text { oções } \\
\text { unidac } \\
\text { popul } \\
\text { assur } \\
\text { a fixac }\end{array}$ & $\begin{array}{l}\text { conc } \\
\text { de } \\
\text { ação, } \\
\text { nto te } \\
\text { ção do }\end{array}$ & eituais & $\begin{array}{l} \\
\text { s de } \mathrm{p} \\
\text { tra e } \\
\text { o apre } \\
\text { teúdos }\end{array}$ & $\begin{array}{l}\text { opulação, } \\
\text { variável o } \\
\text { esentar os }\end{array}$ \\
\hline Part. & $\begin{array}{c}\text { Item } \\
1.1\end{array}$ & $\begin{array}{c}\text { Item } \\
1.2\end{array}$ & $\begin{array}{c}\text { Item } \\
1.3\end{array}$ & $\begin{array}{c}\text { Item } \\
1.4\end{array}$ & $\begin{array}{c}\text { Item } \\
2.1\end{array}$ & $\begin{array}{c}\text { Item } \\
2.2\end{array}$ & $\begin{array}{c}\text { Item } \\
2.3\end{array}$ & $\begin{array}{c}\text { Item } \\
2.4\end{array}$ & \begin{tabular}{c|} 
Item \\
3.1
\end{tabular} & $\begin{array}{c}\text { Item } \\
3.2\end{array}$ & $\begin{array}{c}\text { Item } \\
3.3\end{array}$ & $\begin{array}{c}\text { Item } \\
3.4\end{array}$ & $\begin{array}{c}\text { Item } \\
3.5\end{array}$ & $\begin{array}{c}\text { Desem- } \\
\text { penho }\end{array}$ \\
\hline $\mathrm{P} 1$ & $\bar{C}$ & $\bar{C}$ & $\bar{C}$ & $\mathrm{C}$ & $\mathrm{C}$ & $\mathrm{C}$ & $\bar{C}$ & $\bar{C}$ & - & $\mathrm{C}$ & $\mathrm{C}$ & $\mathrm{C}$ & - & $\mathrm{S}$ \\
\hline P9 & $\mathrm{C}$ & $\mathrm{C}$ & $\mathrm{C}$ & $\mathrm{C}$ & $\mathrm{C}$ & $\mathrm{C}$ & $\mathrm{C}$ & $\mathrm{C}$ & - & $\mathrm{C}$ & $\mathrm{C}$ & $\mathrm{C}$ & - & $S$ \\
\hline P10 & E & E & $\mathrm{E}$ & $\mathrm{C}$ & $\mathrm{C}$ & $\mathrm{C}$ & $\mathrm{C}$ & E & - & $\mathrm{C}$ & $\mathrm{C}$ & $\mathrm{C}$ & - & $\mathrm{P}$ \\
\hline P11 & E & E & $\mathrm{C}$ & $\mathrm{E}$ & $\mathrm{C}$ & $\mathrm{E}$ & $\mathrm{E}$ & $\mathrm{C}$ & - & $\mathrm{C}$ & $\mathrm{E}$ & $\mathrm{E}$ & - & $\mathrm{N}$ \\
\hline P13 & $\mathrm{C}$ & $\mathrm{C}$ & $\mathrm{E}$ & $X$ & $\mathrm{E}$ & $\mathrm{E}$ & $\mathrm{E}$ & $\mathrm{E}$ & - & $\mathrm{C}$ & $\mathrm{C}$ & $\mathrm{C}$ & - & $\mathrm{N}$ \\
\hline P14 & $\mathrm{C}$ & $\mathrm{C}$ & $\mathrm{C}$ & $\mathrm{C}$ & $\mathrm{C}$ & $\mathrm{C}$ & $\mathrm{C}$ & $\mathrm{C}$ & - & $\mathrm{C}$ & $\mathrm{C}$ & $\mathrm{C}$ & - & $S$ \\
\hline $\mathrm{P} 28$ & $\mathrm{C}$ & $\mathrm{C}$ & $\mathrm{C}$ & $\mathrm{C}$ & $\mathrm{C}$ & $\mathrm{C}$ & $\mathrm{C}$ & $\mathrm{C}$ & - & $\mathrm{C}$ & $\mathrm{C}$ & $\mathrm{C}$ & - & $S$ \\
\hline P29 & C & C & $\mathrm{C}$ & $\mathrm{C}$ & $\mathrm{C}$ & $\mathrm{C}$ & $\mathrm{C}$ & $\mathrm{C}$ & - & $\mathrm{C}$ & $\mathrm{C}$ & $\mathrm{C}$ & - & $S$ \\
\hline
\end{tabular}

Tabela 18 - Respostas dos participantes P3, P4, P5, P8, P15, P16, P17, P18, P19 e P20

\begin{tabular}{|c|c|c|c|c|c|c|c|c|c|c|c|c|c|c|}
\hline & \multicolumn{14}{|c|}{$\begin{array}{c}\text { Dinâmica de interação do participante com o software EDH } \\
\text { (Declarado pelo próprio participante) }\end{array}$} \\
\hline & $\begin{array}{ll} & \mathrm{L} \\
\text { - } & \mathrm{D} \\
& \mathrm{ar} \\
- & \mathrm{P} \\
\mathrm{E} \\
\mathrm{cc}\end{array}$ & $\begin{array}{l}\text { i parci } \\
\text { urante } \\
\text { nostra } \\
\text { ara en } \\
\text { DH f } \\
\text { onceit }\end{array}$ & $\begin{array}{l}\text { almen } \\
\text { e de } \\
\text { e var } \\
\text { tendir } \\
\text { oi úti } \\
\text { os prin }\end{array}$ & $\begin{array}{l}\text { te o n } \\
\text { epois } \\
\text { iável } \\
\text { mento } \\
\text { 1. Ac } \\
\text { mordi }\end{array}$ & $\begin{array}{l}\text { gateria } \\
\text { da lei } \\
\text { que eu } \\
\text { das } 1 \\
\text { edito } \\
\text { lment }\end{array}$ & $\begin{array}{l}\text { al do } s \\
\text { itura } \\
\text { estud } \\
\text { noçõe } \\
\text { que }\end{array}$ & $\begin{array}{l}\text { oftwar } \\
\text { eu lem } \\
\text { lei em } \\
\text { s cono } \\
\text { a abo } \\
\text { image }\end{array}$ & $\begin{array}{l}\text { re ED } \\
\text { nbrei } \\
\text { outra } \\
\text { ceituai } \\
\text { rdage }\end{array}$ & $\begin{array}{l}\text { H. } \\
\text { das } n \\
\text { oport } \\
\text { is de } \\
\text { m do } \\
\text { dou } n\end{array}$ & $\begin{array}{l} \\
\text { oções } \\
\text { unidad } \\
\text { popula } \\
\text { assur }\end{array}$ & $\begin{array}{l}\text { conce } \\
\text { de } \\
\text { ação, } \\
\text { nto te } \\
\text { ção do }\end{array}$ & eituais & $\begin{array}{l}\mathrm{s} \text { de } \\
\text { tra e } \\
\text { o apre } \\
\text { teúdos }\end{array}$ & $\begin{array}{l}\text { opulação, } \\
\text { variável o } \\
\text { esentar os }\end{array}$ \\
\hline Part. & $\begin{array}{c}\text { Item } \\
1.1 \\
\end{array}$ & $\begin{array}{c}\text { Item } \\
1.2 \\
\end{array}$ & $\begin{array}{c}1 \\
\text { Item } \\
1.3 \\
\end{array}$ & $\begin{array}{c}\text { Item } \\
1.4\end{array}$ & $\begin{array}{c}\text { Item } \\
2.1 \\
\end{array}$ & $\begin{array}{c}\text { Item } \\
2.2 \\
\end{array}$ & \begin{tabular}{|c|} 
Item \\
2.3 \\
\end{tabular} & $\begin{array}{c}\text { Item } \\
2.4 \\
\end{array}$ & $\begin{array}{c}\text { Item } \\
3.1 \\
\end{array}$ & $\begin{array}{c}\text { Item } \\
3.2 \\
\end{array}$ & $\begin{array}{c}\text { Item } \\
3.3 \\
\end{array}$ & $\begin{array}{c}\text { Item } \\
3.4\end{array}$ & $\begin{array}{c}\text { Item } \\
3.5 \\
\end{array}$ & \begin{tabular}{|c|}
$\begin{array}{c}\text { Desem- } \\
\text { penho }\end{array}$ \\
\end{tabular} \\
\hline P3 & $E$ & $E$ & $\mathrm{C}$ & $\mathrm{E}$ & $\mathrm{C}$ & $E$ & $\mathrm{C}$ & $\mathrm{C}$ & - & $\mathrm{C}$ & $\mathrm{C}$ & $\mathrm{C}$ & - & $\mathrm{P}$ \\
\hline P4 & $\mathrm{E}$ & $\mathrm{E}$ & $\mathrm{E}$ & $X$ & $\mathrm{C}$ & $\mathrm{E}$ & $X$ & $X$ & - & $X$ & $X$ & $X$ & - & $\mathrm{N}$ \\
\hline P5 & $\mathrm{C}$ & $\mathrm{C}$ & $\mathrm{C}$ & $\mathrm{C}$ & $\mathrm{C}$ & $\mathrm{C}$ & $\mathrm{C}$ & $\mathrm{C}$ & - & $\mathrm{C}$ & $\mathrm{C}$ & $\mathrm{C}$ & - & 3 \\
\hline P8 & $\mathrm{C}$ & $\mathrm{C}$ & $\mathrm{C}$ & $\mathrm{C}$ & $\mathrm{C}$ & $\mathrm{C}$ & $\mathrm{C}$ & $\mathrm{C}$ & - & $\mathrm{C}$ & $\mathrm{C}$ & $\mathrm{C}$ & - & $S$ \\
\hline P15 & $\mathrm{C}$ & $\mathrm{C}$ & $\mathrm{C}$ & $\mathrm{C}$ & $\mathrm{E}$ & $X$ & $X$ & E & - & $X$ & $X$ & $X$ & - & $\mathrm{P}$ \\
\hline P16 & $\mathrm{C}$ & $\mathrm{C}$ & $\mathrm{C}$ & $\mathrm{C}$ & $\mathrm{C}$ & $\mathrm{C}$ & $\mathrm{C}$ & $\mathrm{C}$ & - & $\mathrm{C}$ & $\mathrm{C}$ & $\mathrm{C}$ & - & S \\
\hline P17 & $\mathrm{E}$ & $\mathrm{E}$ & $\mathrm{C}$ & $\mathrm{C}$ & $\mathrm{C}$ & $\mathrm{E}$ & $\mathrm{E}$ & $\mathrm{E}$ & - & $\mathrm{C}$ & $\mathrm{C}$ & $\mathrm{C}$ & - & $\mathrm{N}$ \\
\hline P18 & $\mathrm{C}$ & $\mathrm{C}$ & $\mathrm{C}$ & $\mathrm{C}$ & $\mathrm{C}$ & $\mathrm{C}$ & $\mathrm{E}$ & $\mathrm{C}$ & - & $\mathrm{C}$ & $\mathrm{C}$ & $\mathrm{C}$ & - & $S$ \\
\hline P19 & E & $\mathrm{E}$ & $X$ & $X$ & $\mathrm{C}$ & $\mathrm{C}$ & E & $\mathrm{E}$ & - & $\mathrm{C}$ & $\mathrm{C}$ & $\mathrm{C}$ & - & $\mathrm{N}$ \\
\hline $\mathrm{P} 20$ & $\mathrm{C}$ & $\mathrm{C}$ & $\mathrm{C}$ & $\mathrm{E}$ & $\mathrm{C}$ & $\mathrm{C}$ & $\mathrm{C}$ & $\mathrm{E}$ & - & $\mathrm{C}$ & $\mathrm{C}$ & $\mathrm{C}$ & - & $\mathrm{P}$ \\
\hline
\end{tabular}


Os seguintes participantes afirmaram não ter lido o material do EDH: P2, P6, P7, P12, P21, P22, P23, P24, P25, P26, P29, P30, P31, P32 e P39. Como o objetivo do trabalho é verificar a utilidade do EDH como ferramenta para o efetivo aprendizado do assunto apresentado, não foram analisadas as respostas dadas por estes participantes.

Na Tabela 19 são transcritos comentários positivos feitos pelos participantes sobre o $\mathrm{EDH}$, e na Tabela 20 os pontos negativos.

Tabela 19 - Pontos positivos do software EDH citados pelos participantes que responderam o questionário 2

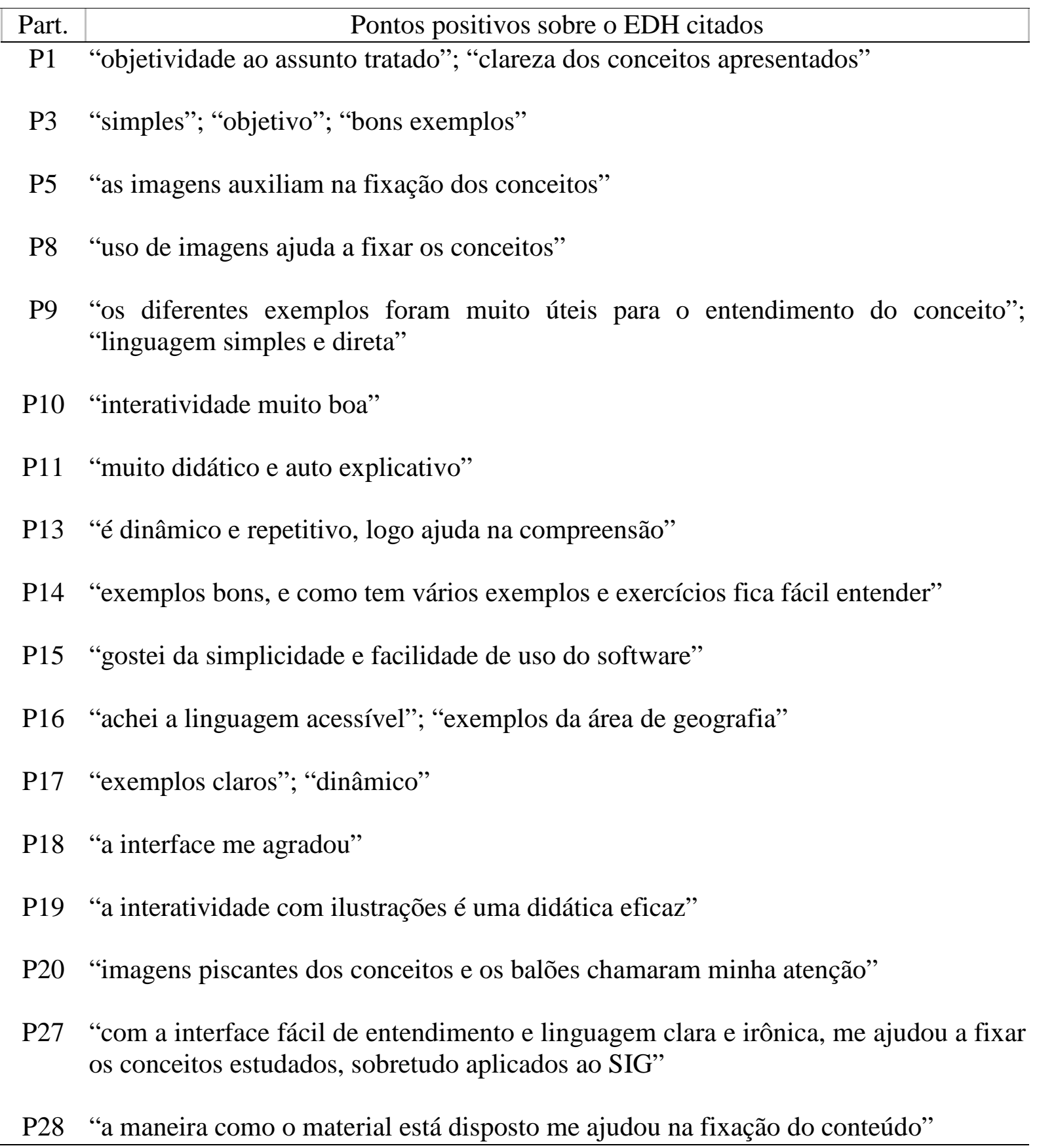


Tabela 20 - Pontos negativos do software EDH citados pelos participantes que responderam o questionário 2

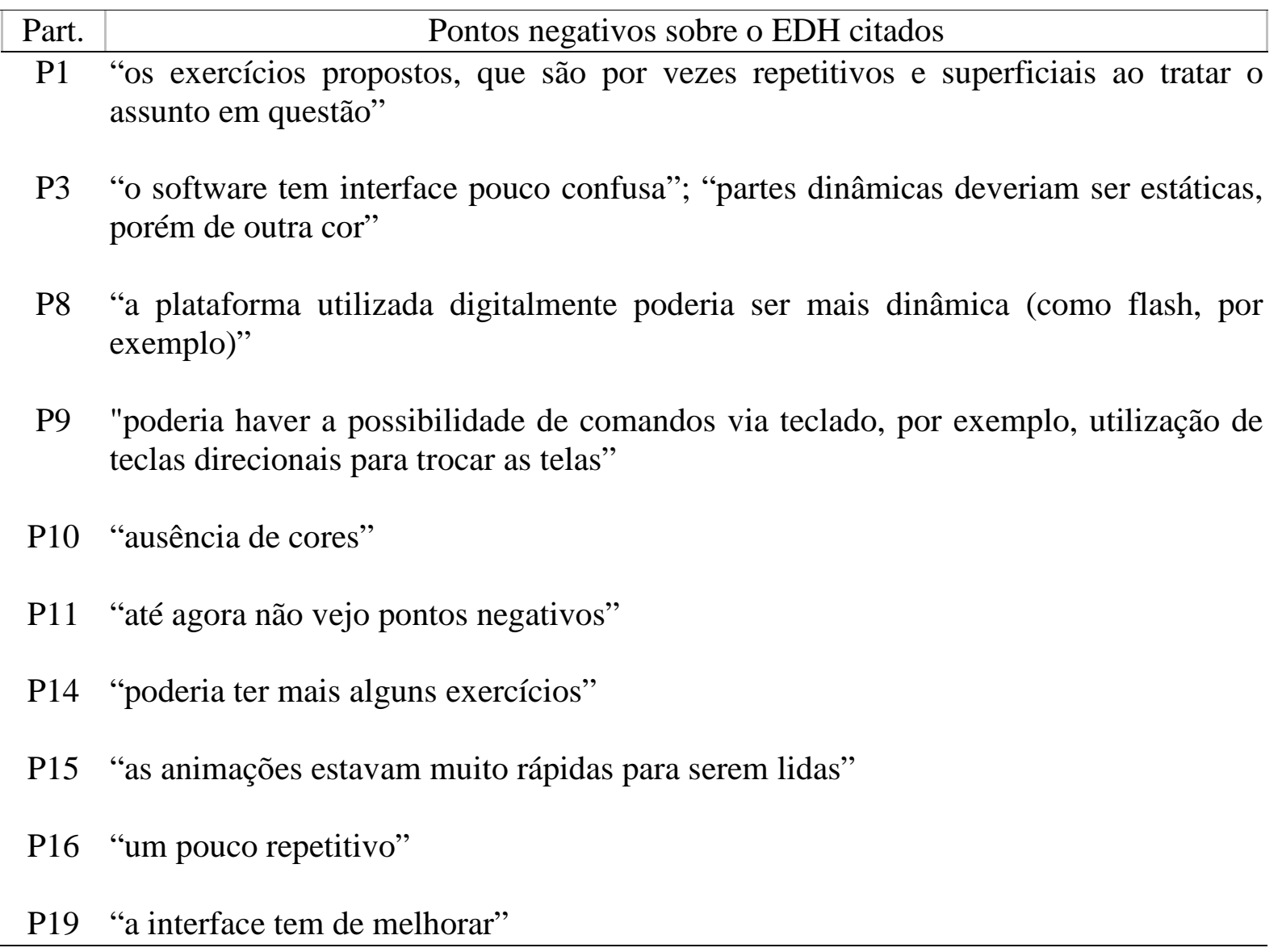

Os pontos positivos do EDH citados pelos respondentes em geral concordam com os objetivos propostos pelo uso do software, que é ser uma ferramenta que transmite conteúdos de forma bastante direta e objetiva, usando conteúdo imagético sempre que possível para representar o conteúdo transmitido.

Com relação aos pontos negativos apontados, em geral tem a ver com a interface do software, considerada "pobre" de uma maneira geral. Ressalta-se que a proposta do software é de fato ter a interface (o "painel de controle") o mais rudimentar possível, pois o que se deseja é canalizar a atenção do leitor para o conteúdo apresentado, e uma interface mais "rica" pode chamar mais a atenção do que o conteúdo. Uma interface mias "rica" aumenta o risco de imagens decorativas e/ou representacionais que somente "embelezam" o texto, ou seja aumenta-se o risco de produção de conteúdo imagético sem valor didático. Dai o propósito do EDH de uma interface "pobre".

O participante $\mathrm{P} 1$ apontou como ponto negativo que os exercícios propostos são "repetitivos e superficiais". Mas a superficialidade, e principalmente, a repetitividade dos 
exercícios são propostas do $\mathrm{EDH}$, pois espera-se que isso ajude a fixação do conteúdo apresentado, propiciando o real aprendizado do mesmo. Assim, o que parece ser ponto negativo indicado pelo participante é, na verdade, ponto positivo do software, pois o que ficou enfadonho para o participante, assim ficou porque muito provavelmente ele realmente apreendeu o conceito apresentado via $\mathrm{EDH}$, ou seja, o objetivo do $\mathrm{EDH}$ foi atingido ao proporcionar aprendizagem significativa ao usuário.

\subsubsection{Terceiro encontro - questionário sobre conceitos de média aritmética simples (assunto da lição 7 do EDH) (questionário 3)}

A lição 7 do software EDH, versando sobre média aritmética simples, foi objeto de análise no questionário 3 do curso de extensão. A média aritmética simples é um "número síntese" representativo de um grupo (população ou amostra) de dados numéricos. A lição 7 é composta de 21 telas onde em essência apresenta-se o somatório de um grupo de $n$ valores, ressaltando o uso da letra grega $\sum$ para representar somatório e a caracterização da média como a divisão do somatório $\left(\sum\right)$ pelos $n$ valores. Nas Figuras 74 e 75 observam-se telas da lição apresentando este conceito.

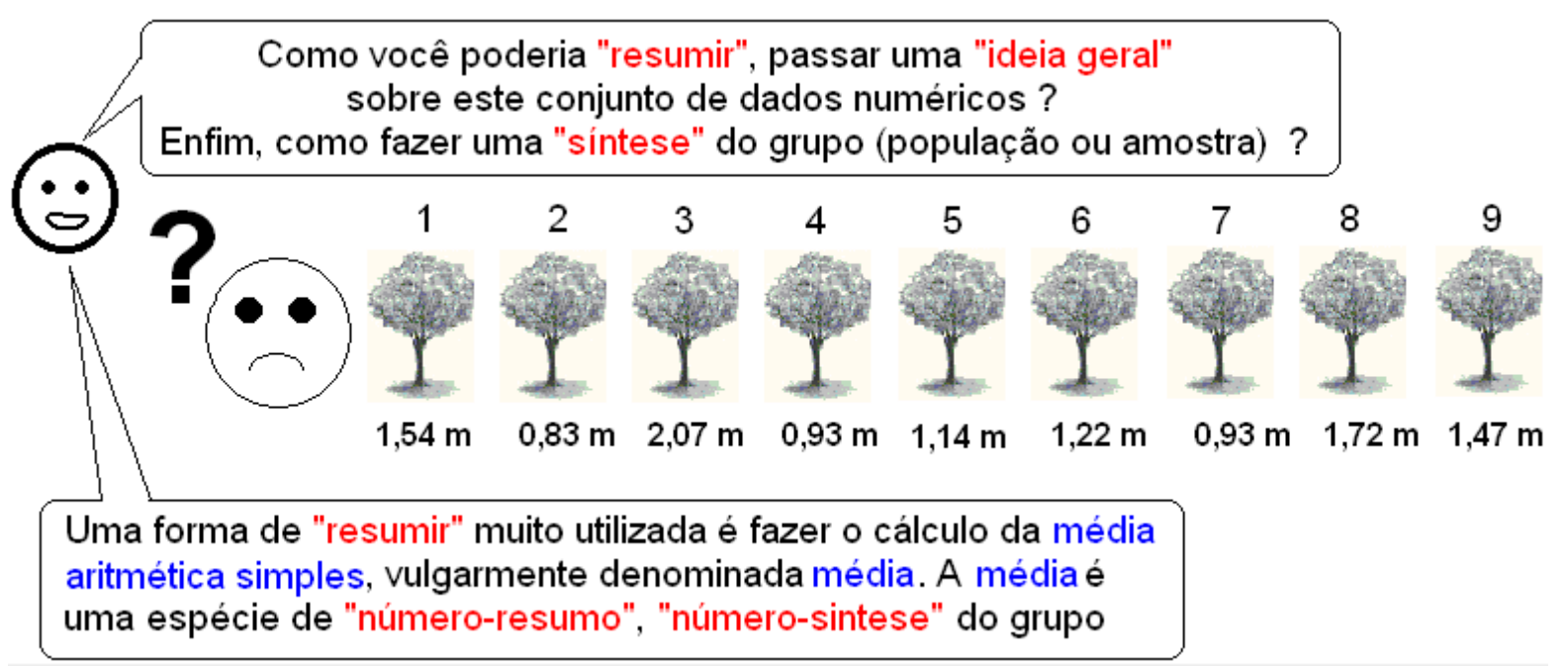

Figura 74 - Conceito de média aritmética como "número síntese"

Fonte: Elaborado pelo autor. 


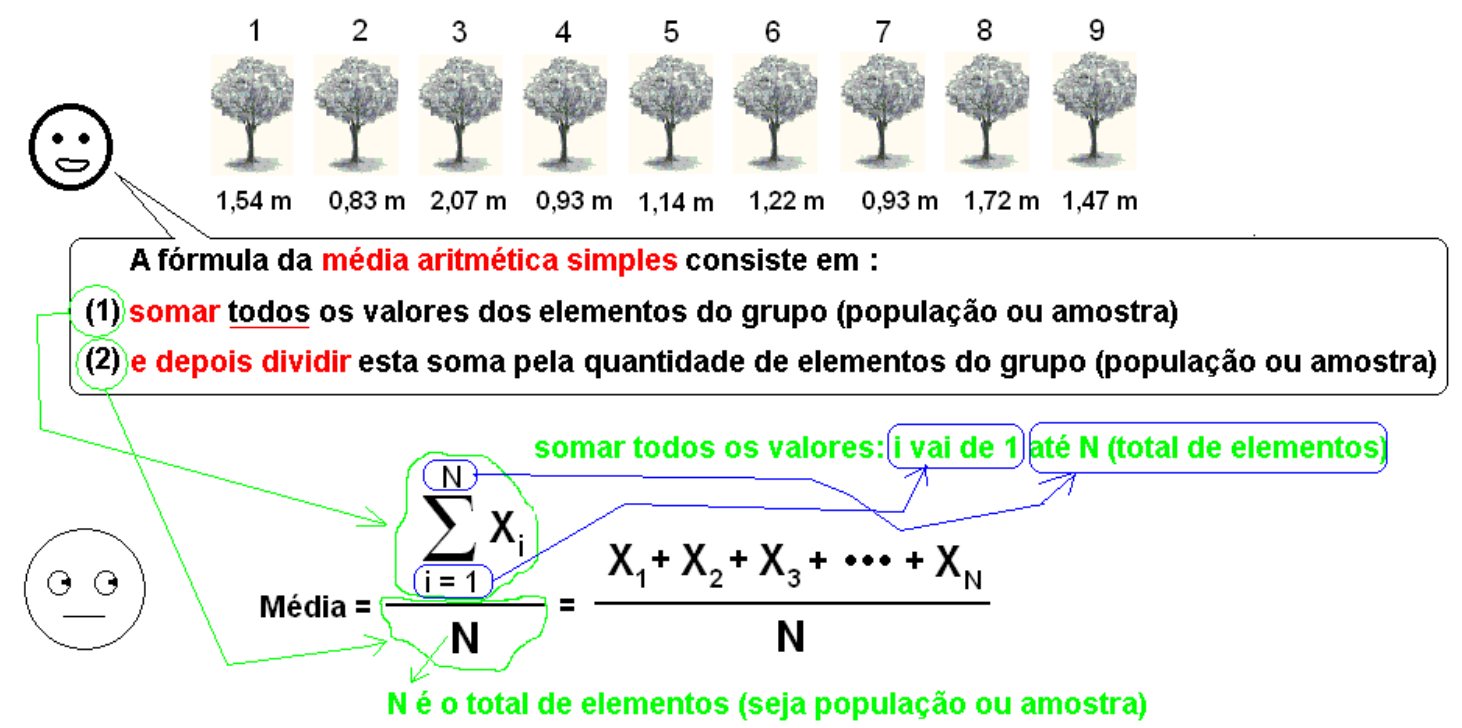

Figura 75 - Conceito de média aritmética como "número síntese".

Fonte: Elaborado pelo autor.

Depois de apresentados os conceitos, outras telas são apresentadas com conteúdo dinâmico para representar a soma do grupo de valores e finalizando com o cálculo da média aritmética. As Figuras 76 a 80 apresentam um exemplo de tela do EDH em que há movimento (dinâmica). Cada uma das figuras é um "quadro" componente do movimento da imagem. O usuário interage com o software via cliques de mouse, para calcular a média.

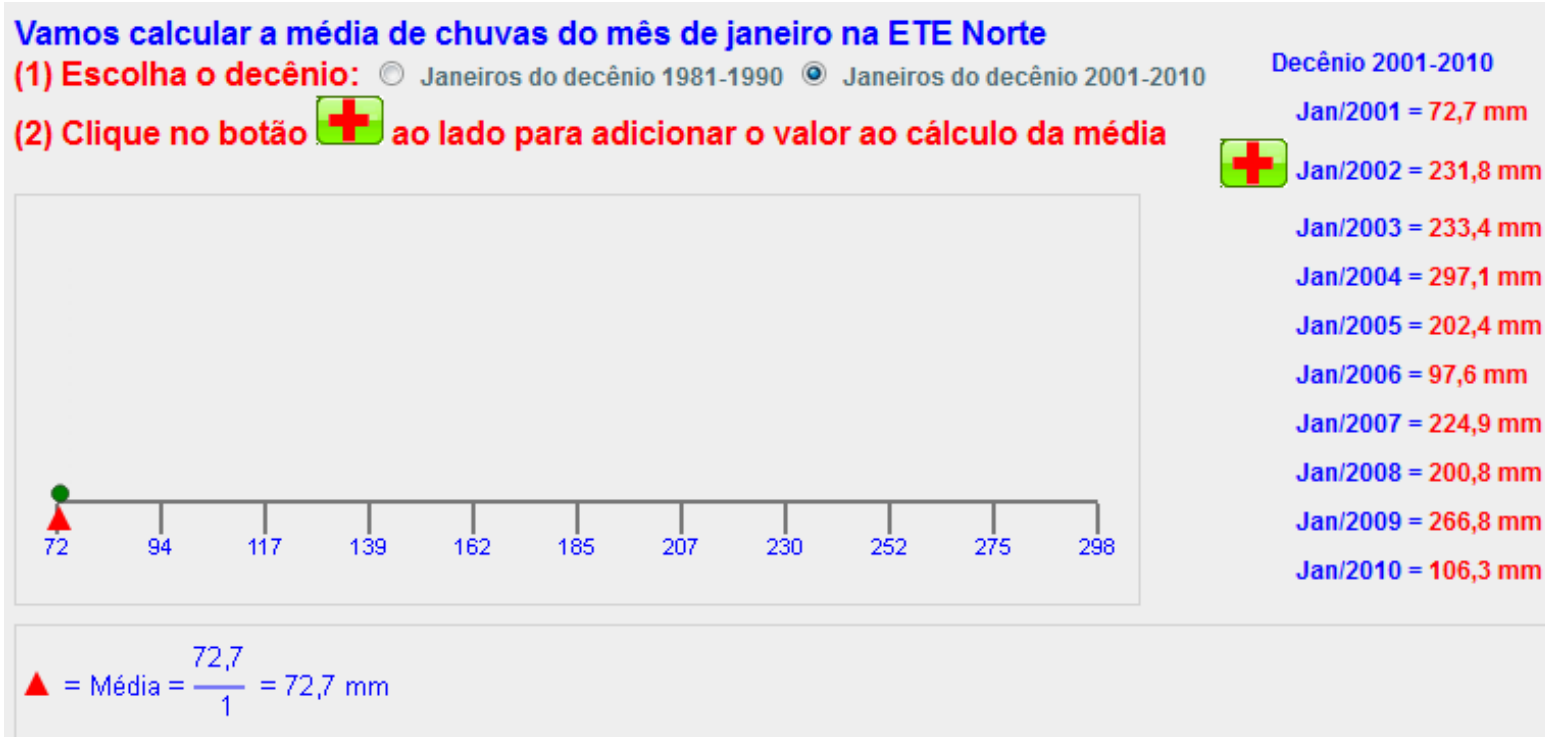

Figura 76 - A média calculada com o primeiro valor da série $(72,7 \mathrm{~mm})$.

Fonte: Elaborado pelo autor. 
Vamos calcular a média de chuvas do mês de janeiro na ETE Norte

(1) Escolha o decênio: $\bigcirc$ Janeiros do decênio 1981-1990 C Janeiros do decênio 2001-2010

Decênio 2001-2010

(2) Clique no botão ao lado para adicionar o valor ao cálculo da média

Jan $/ 2001=72,7 \mathrm{~mm}$

Jan $/ 2002=231,8 \mathrm{~mm}$

Jan $/ 2003=233,4 \mathrm{~mm}$

Jan $/ 2004=297,1 \mathrm{~mm}$

Jan $/ 2005=202,4 \mathrm{~mm}$

Jan $/ 2006=97,6 \mathrm{~mm}$

Jan $/ 2007=224,9 \mathrm{~mm}$

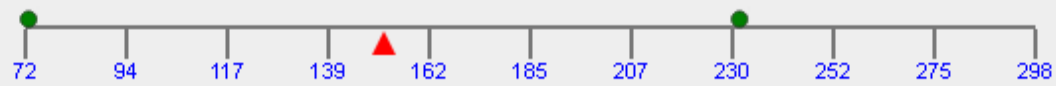

Jan $/ 2008=200,8 \mathrm{~mm}$

Jan $/ 2009=266,8 \mathrm{~mm}$

$\operatorname{Jan} / 2010=106,3 \mathrm{~mm}$

$\boldsymbol{\Delta}=$ Média $=\frac{72,7+231,8}{2}=152,2 \mathrm{~mm}$

Figura 77 - A média calculada com os dois primeiros valores $(72,7$ e 231,8 mm).

Fonte: Elaborado pelo autor.

\section{Vamos calcular a média de chuvas do mês de janeiro na ETE Norte}

(1) Escolha o decênio: Janeiros do decênio 1981-1990 Janeiros do decênio 2001-2010

Decênio 2001-2010

(2) Clique no botão ao lado para adicionar o valor ao cálculo da média

Jan $/ 2001=72,7 \mathrm{~mm}$

Jan $/ 2002=231,8 \mathrm{~mm}$

Jan $/ 2003=233,4 \mathrm{~mm}$

Jan/2004 = 297,1 mm

Jan $/ 2005=202,4 \mathrm{~mm}$

Jan $/ 2006=97,6 \mathrm{~mm}$

Jan $/ 2007=224,9 \mathrm{~mm}$

Jan $/ 2008=200,8 \mathrm{~mm}$

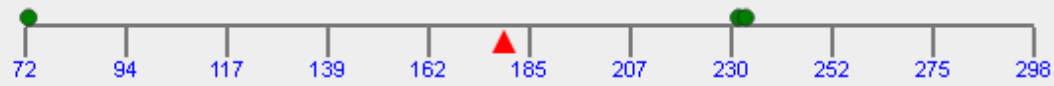

Jan $/ 2009=266,8 \mathrm{~mm}$

Jan $/ 2010=106,3 \mathrm{~mm}$

$\boldsymbol{\Delta}=$ Média $=\frac{72,7+231,8+233,4}{3}=179,2 \mathrm{~mm}$

Figura 78 - A média dos três primeiros valores $(72,7 ; 231,8 ; 233,4$ mm).

Fonte: Elaborado pelo autor. 


\section{Vamos calcular a média de chuvas do mês de janeiro na ETE Norte}

(1) Escolha o decênio: $\bigcirc$ Janeiros do decênio 1981-1990 @ Janeiros do decênio 2001-2010

(2) Clique no botão ao lado para adicionar o valor ao cálculo da média

Figura 79 - A média dos quatro primeiros valores $(72,7 ; 231,8 ; 233,4 ; 297,1 \mathrm{~mm})$.

Fonte: Elaborado pelo autor.

\section{Vamos calcular a média de chuvas do mês de janeiro na ETE Norte}

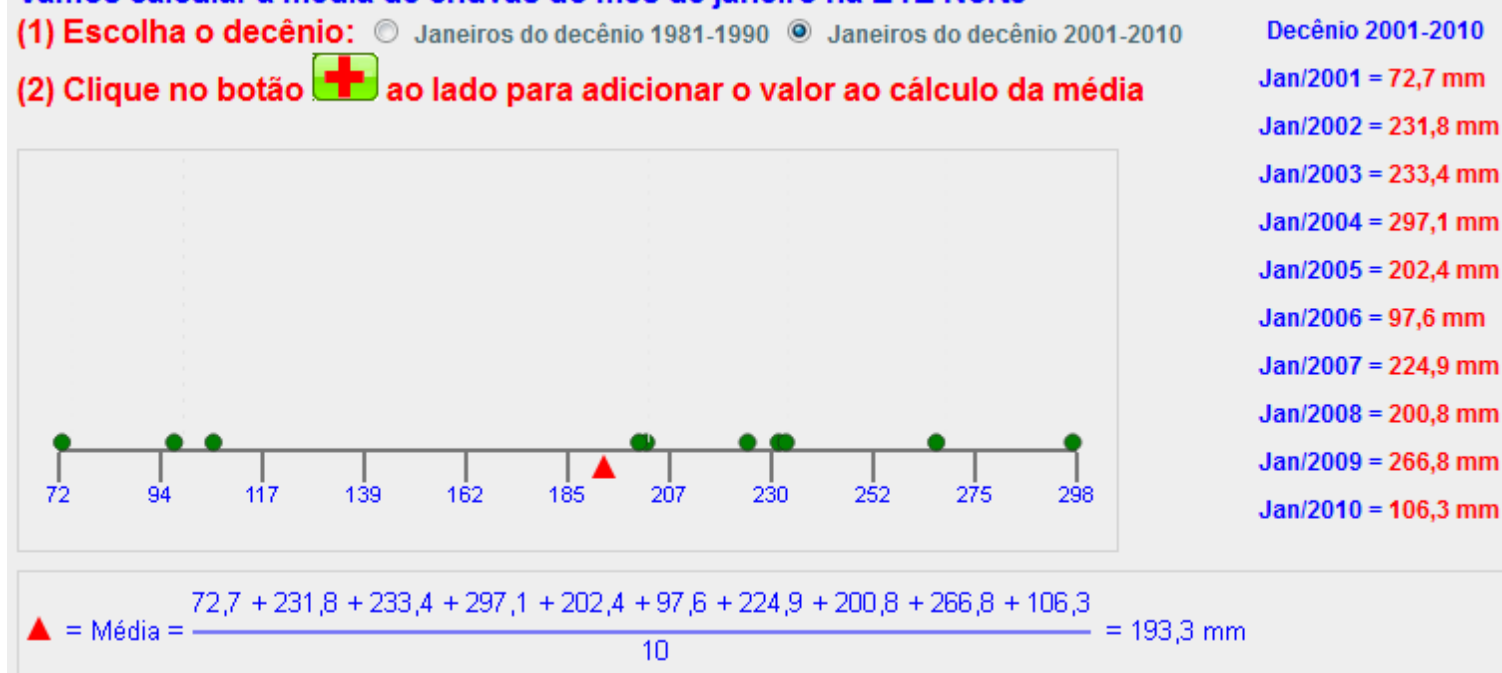

Figura 80 - A média do grupo de valores.

Fonte: Elaborado pelo autor. 


\subsubsection{Respostas dos participantes ao questionário 3 - média aritmética simples}

O questionário 3 encontra-se no Apêndice 8. Nas tabelas 21 a 24 encontram-se as correções dos itens das questões 1 e 2. Os itens das duas questões deste questionário são, todos, de resposta dicotômica, isto é, o item está certo ou errado. Foram computados o total de itens respondidos corretamente pelo participante. A avaliação do desempenho foi realizada de forma similar à realizada para o questionário 2, ou seja, foram avaliados, qualitativamente, os itens certos e errados do respondente e classificado seu desempenho em satisfatório (S), parcialmente satisfatório $(\mathrm{P})$ ou não satisfatório $(\mathrm{N})$.

Tabela 21 - Respostas dos participantes P1, P4, P5, P6, P7, P8, P10, P11, P13, P17, P18, P21, $\mathrm{P} 23$ e $\mathrm{P} 40$

\begin{tabular}{|c|c|c|c|c|c|c|c|c|c|c|c|c|c|c|c|c|c|c|}
\hline & \multicolumn{18}{|c|}{$\begin{array}{l}\text { Dinâmica de interação do participante com o software EDH } \\
\text { (Declarado pelo próprio participante) }\end{array}$} \\
\hline & \multicolumn{18}{|c|}{$\begin{array}{l}\text { - Li somente o material do software EDH } \\
\text { - Durante e depois da leitura, eu lembrei das noções conceituais de média aritmética } \\
\text { simples que estudei em outra oportunidade. } \\
\text { - Para entendimento das noções conceituais de média aritmética simples o EDH foi } \\
\text { útil. Acredito que a abordagem do assunto tentando apresentar os conceitos } \\
\text { primordialmente via imagens ajudou na fixação dos conteúdos. } \\
\text { - A apresentação sobre o somatório, representado por } \sum \text {, pelo software EDH foi } \\
\text { útil. Entendi conceitos sobre o somatório que antes estavam obscuros para mim. }\end{array}$} \\
\hline . Part. & \multicolumn{9}{|c|}{ Questão 1} & \multicolumn{8}{|c|}{ Questão 2} & $\begin{array}{l}\text { Desem- } \\
\text { penho }\end{array}$ \\
\hline P1 & + & & & & & & & & & & & & & & & & & $\sigma$ \\
\hline $\mathrm{P} 4$ & & & & + & + & + & + & + & & & $\mathrm{X}$ & + & + & + & + & $X$ & & \\
\hline P5 & + & + & & & & & & + & & & & + & $X$ & + & + & $X$ & & $\mathbf{F}$ \\
\hline P6 & + & + & + & + & + & + & $X$ & $X$ & & & $X$ & + & + & + & + & + & & \\
\hline P7 & + & & + & & & & & + & & & & + & + & + & $X$ & + & & 5 \\
\hline P8 & + & + & + & + & + & + & + & + & & & $\mathrm{x}$ & + & + & + & + & + & & \\
\hline P10 & + & & & & & & & + & & & + & & + & + & + & + & & \\
\hline P11 & $X$ & + & & $X$ & + & $X$ & & $X$ & $X$ & + & + & + & $X$ & + & + & + & + & $P$ \\
\hline $\mathrm{P} 13$ & + & & & $X$ & $X$ & $X$ & & + & & & $X$ & + & + & + & $X$ & $X$ & + & \\
\hline P17 & $X$ & $X$ & $X$ & $X$ & & & & $X$ & $X$ & & $X$ & + & + & $X$ & $X$ & $X$ & $X$ & $\mathbf{N}$ \\
\hline P18 & + & + & + & $X$ & + & $X$ & $X$ & $X$ & $X$ & & + & + & + & + & $X$ & + & + & $\Gamma$ \\
\hline $\mathrm{P} 21$ & $X$ & + & + & + & + & + & & + & & + & + & + & + & + & + & + & + & $S$ \\
\hline P23 & + & + & + & + & + & + & & + & & & + & + & + & + & $X$ & + & + & $S$ \\
\hline P40 & + & & & & & & & & + & & $X$ & & + & + & + & + & + & $S$ \\
\hline
\end{tabular}

Obs.: + - acertou o item $\mathrm{X}$ - errou o item 
Tabela 22 - Respostas dos participantes P2, P9, P16 e P22

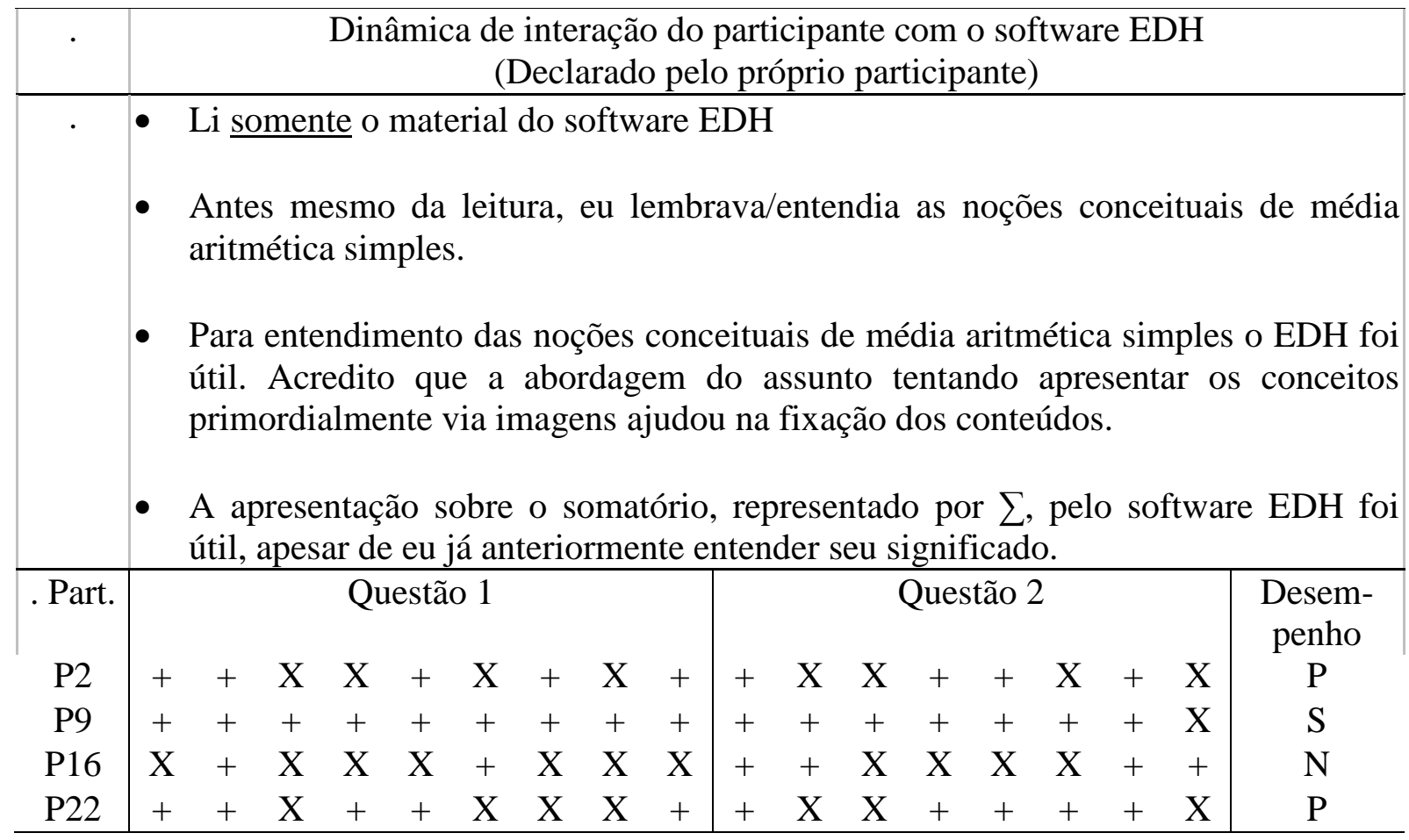

Obs.: + - acertou o item $\mathrm{X}$ - errou o item

Tabela 23 - Respostas dos participantes P12, P14

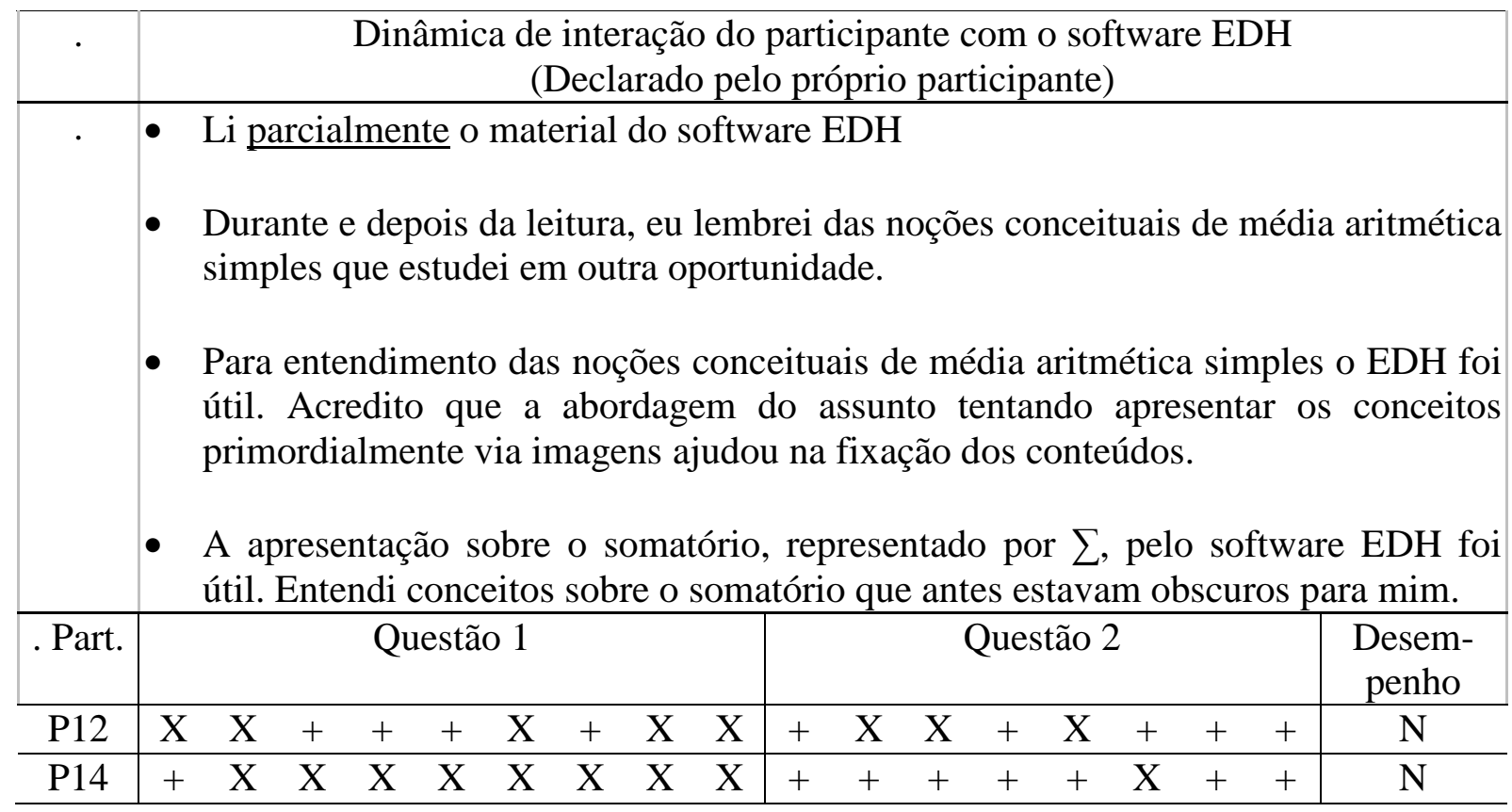

Obs.: + - acertou o item $\mathrm{X}$ - errou o item 
Tabela 24 - Respostas do participante P19

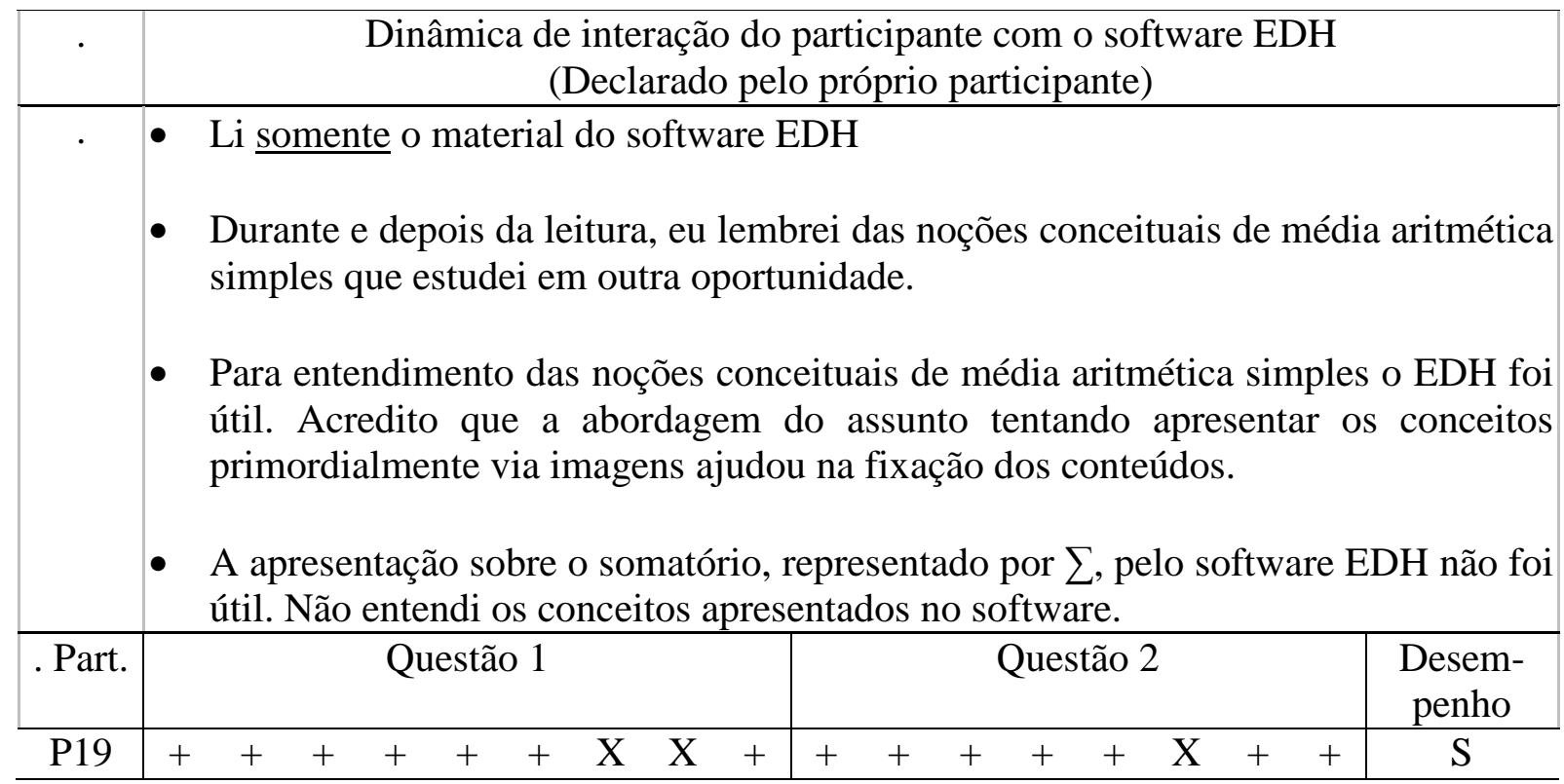

Obs.: + - acertou o item $\mathrm{X}$ - errou o item

Os participantes P12 e P14, citados na tabela 23 afirmaram ter lido parcialmente a lição do EDH. Mas pelo padrão de respostas da questão 2, que lidava com o raciocínio de média aritmética, pode-se supor que, na verdade, não leram a lição do EDH e responderam com o conhecimento que tinham sobre média. O padrão de respostas dado pelos participantes na questão 1, que lidava com o entendimento de somatório - representado pelo símbolo $\sum$ parece indicar que os mesmos não entendem ainda a simbologia de somatório e, por isso, apresentaram um desempenho não satisfatório. Desta forma considerou-se que o EDH pode não ter sido útil por aparentemente não ter sido utilizado pelos participantes.

O participante P3 declarou ter lido parcialmente o EDH, mas antes mesmo da leitura parcial assinalou que lembrava das noções conceituais de média aritmética simples. Só que assinalou também que mesmo após a leitura (parcial) continuou não entendendo as noções conceituais de média aritmética e as respostas às questões foram baseadas no "chute". Assim, este questionário foi descartado da análise. O descarte de análise de questionário também ocorreu para o participante P20, pois o mesmo estava "colando" as respostas de outro participante, o que invalidou a análise deste questionário respondido por P20.

Os participantes P15 e P32 afirmaram não ter lido o material do EDH. Como o objetivo do trabalho é verificar a utilidade do EDH como ferramenta para o efetivo aprendizado do assunto apresentado, não foram analisadas as respostas dadas por estes participantes no questionário 3. 
O participante P19 afirmou ter lido a lição 7 do EDH e que o mesmo foi útil para entendimento dos conceitos de média aritmética simples. Porém, o EDH não foi útil para entendimento de somatório. P19 apresentou um desempenho satisfatório na resolução do questionário e, por isso, ao afirmar que o EDH não foi útil para ensinar a noção de somatório, pode-se considerar que talvez o conteúdo imagético montado para tal finalidade não tenha sido suficiente para transmissão do conteúdo de forma adequada à fixação para o participante.

Na Tabela 25 são transcritos comentários positivos feitos pelos participantes sobre o EDH, e na Tabela 26 os pontos negativos.

Tabela 25 - Pontos positivos do software EDH citados pelos participantes que responderam o questionário 3

P4 “animações claras e 'passo a passo' que ajudaram bastante na fixação dos conceitos acerca de média aritmética simples. Por exemplo, a explicação sobre o símbolo $\sum$ foi de extrema importância para o restante da atividade"

P5 "A explicação sobre cada símbolo foi muito esclarecedora, foi possível entender particularidades antes utilizadas e não totalmente entendidas. Ex.: $\sum$ "

P6 "Aborda de forma direta e clara os conceitos, mas eu creio que ele seja mais útil para quem já tenha lido sobre. Ele ajuda a relembrar de forma rápida e prática"

P7 "Material bastante detalhado, facilitando sua compreensão".

P8 "As imagens para explicação do somatório foram muito úteis"

P9 "Uso de GIFS animados foi muito útil."; "Linguagem direta"

P10 "Gráficos bons"; "Fácil para aprendizagem, uso e compreensão"

P11 "Bons exemplos"; "Bem didático"

P12 "Método inovador com o uso de imagens, simplifica e auxilia na compreensão"

P14 "Bem didático e fixa bem os conceitos"

P16 "Achei a animação de médias pluviométricas excelente"

P17 "Didático"; "De fácil aprendizagem"
} 
Tabela 25 - Pontos positivos do software EDH citados pelos participantes que responderam o questionário 3 (continuação)

\begin{tabular}{ll}
\hline Part. & Pontos positivos sobre o EDH citados \\
\hline P18 "Os exemplos apresentados foram úteis" \\
P19 "A interatividade e a simplicidade é um ponto positivo. As atividades também" \\
P22 "Dinâmico. Linguagem simples" \\
P23 "Bastante didático" \\
P40 "Os exercícios ajudaram a fixar o conteúdo" \\
\hline
\end{tabular}

Tabela 26 - Pontos negativos do software EDH citados pelos participantes que responderam o questionário 3

\begin{tabular}{|c|c|}
\hline Part. & Pontos negativos sobre o EDH citados \\
\hline P1 & "Poucos exercícios" \\
\hline $\mathrm{P} 2$ & "A interface é um pouco feia, mas cumpre seus propósitos" \\
\hline P8 & "Deveria ter mais exercícios para entendimento do somatório" \\
\hline P9 & $\begin{array}{l}\text { "(Deveria) apresentar as variações da média dados o acréscimo de uma constante } \\
\text { em todos os números ou um multiplicador" }\end{array}$ \\
\hline P13 & "Ainda tenho dificuldades para entender o símbolo $\sum "$ \\
\hline P19 & $\begin{array}{l}\text { "É muito grosseiro, deveria melhorar na aparência e apresenta alguns erros de } \\
\text { português" }\end{array}$ \\
\hline $\mathrm{P} 21$ & "Um pouco confuso nos quadros, talvez muita informação em um quadro só" \\
\hline $\mathrm{P} 22$ & $\begin{array}{l}\text { "Precisa trabalhar a estética, o visual do EDH está ultrapassado e isso gera uma } \\
\text { falta de "respeito' por parte do aluno" }\end{array}$ \\
\hline $\mathrm{P} 23$ & $\begin{array}{l}\text { "A parte explicativa estava ótima, porém a lição, com as setas fora de ordem e } \\
\text { tortas estava um pouco confusa" }\end{array}$ \\
\hline P40 & "Os desenhos não são muito claros" \\
\hline
\end{tabular}




\subsubsection{Quarto encontro - questionário sobre conceitos de variância, desvio padrão e coeficiente de variação (assunto da lição 8 do EDH) (questionário 4)}

A lição 8 do software EDH, versando sobre variância e desvio padrão, foi objeto de análise no questionário 4 do curso de extensão. O objetivo principal da lição é enfatizar que a variância (e o desvio padrão consequentemente) é uma medida do "espalhamento" dos valores das observações em torno da média aritmética. A lição 8 é composta de 49 telas e nas figuras 81 e 82 observam-se telas da lição que apresentam o conceito de variância como "espalhamento" de valores em torno da média.

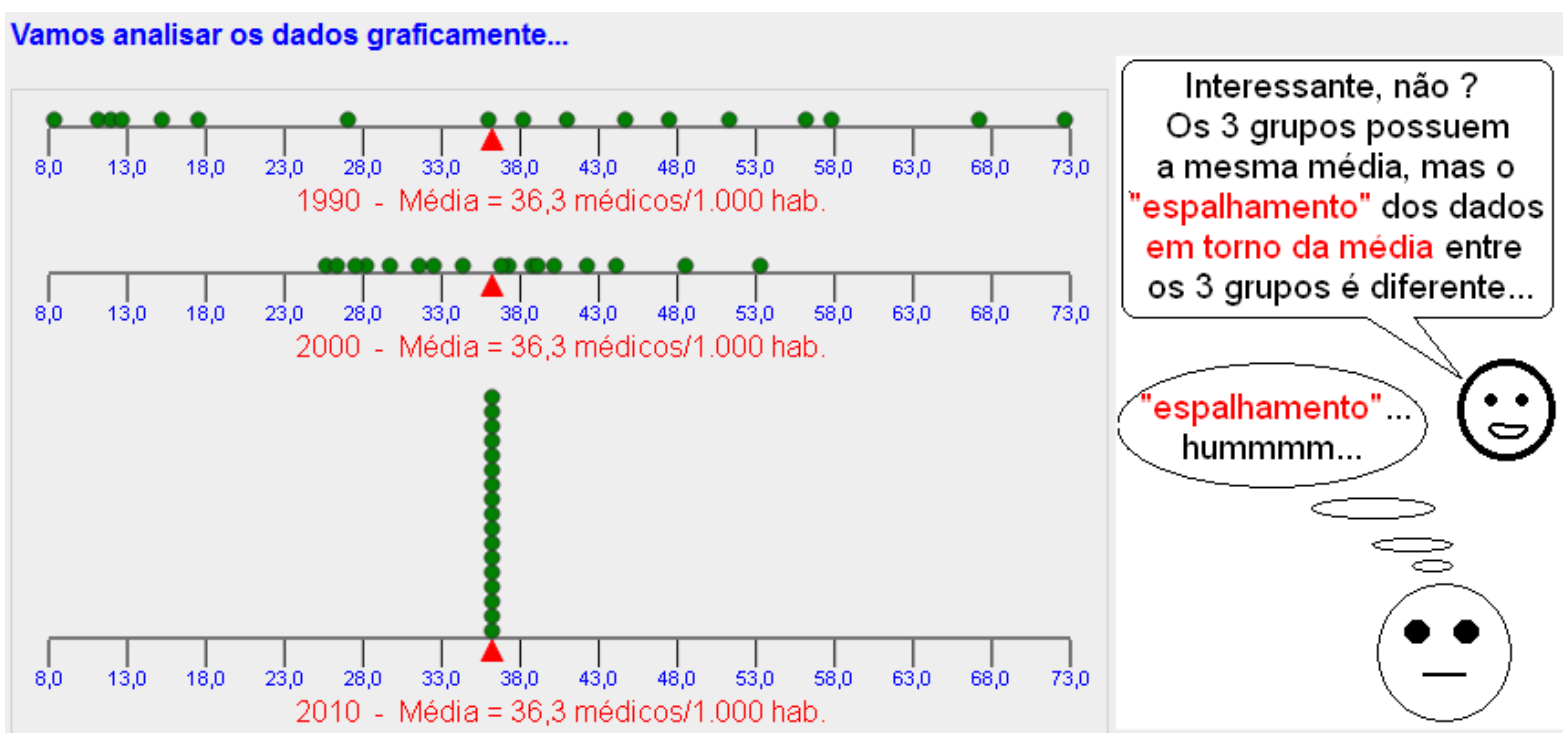

Figura 81 - Uma tela apresentando o conceito de variância como "espalhamento de dados".

Fonte: Elaborado pelo autor. 


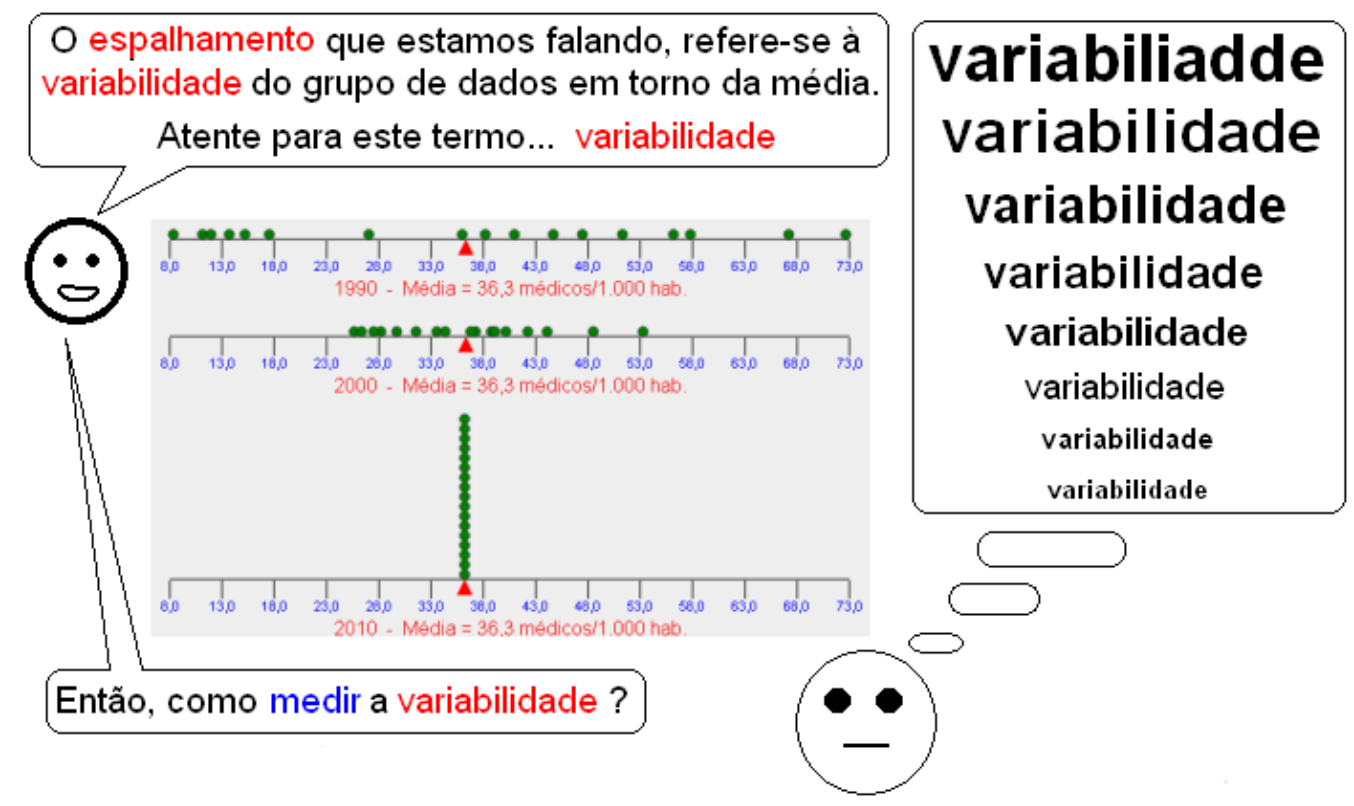

Figura 82 - Outra tela apresentando o conceito de variância como "espalhamento de dados".

Fonte: Elaborado pelo autor.

Outras telas são apresentadas com conteúdo dinâmico e interativo para auxiliar a fixação dos conteúdos da lição. A Figura 83 apresenta um exemplo de tela do EDH em que há interação e a Figura 84 um exemplo de movimento (dinâmica). O usuário interage com o software via cliques de mouse.

\begin{tabular}{|c|c|c|c|c|}
\hline \multirow{2}{*}{\multicolumn{5}{|c|}{ Clique no botão abaixo para calcular a "distância" (desvio) dos dados em relação à média }} \\
\hline & & & & \\
\hline UF & $\begin{array}{c}\text { Número de } \\
\text { médicos/1.000 hab. } \\
1990\end{array}$ & \begin{tabular}{|c|} 
Cálculo da \\
"distância" (desvio) \\
Valor - Média \\
\end{tabular} & "distância" (desvio) & "mapa" dos desvios \\
\hline A1 & 38,2 & $38,2-36,3=$ & 1,9 & $\underset{8,0}{\underbrace{}_{13,0}}$ \\
\hline A2 & 41,0 & $41,0-36,3=$ & 4,7 & 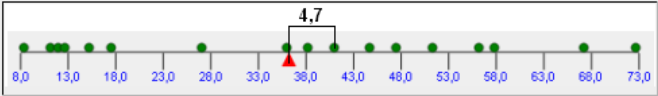 \\
\hline A3 & 17,6 & $17,6-36,3=$ & $-18,7$ & 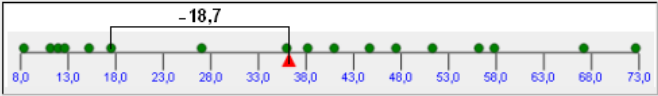 \\
\hline A4 & 44,7 & Valor - Média $=$ ? & & \\
\hline
\end{tabular}

Figura 83 - Tela interativa para calcular a distância (desvio) do valor observado para a média. À medida em que o usuário clica o botão "Valor - Média = ?" o programa EDH mostra o valor do desvio e um "mapa" do desvio calculado mostrando a média (o triângulo vermelho) e a observação (a bolinha verde).

Fonte: Elaborado pelo autor. 


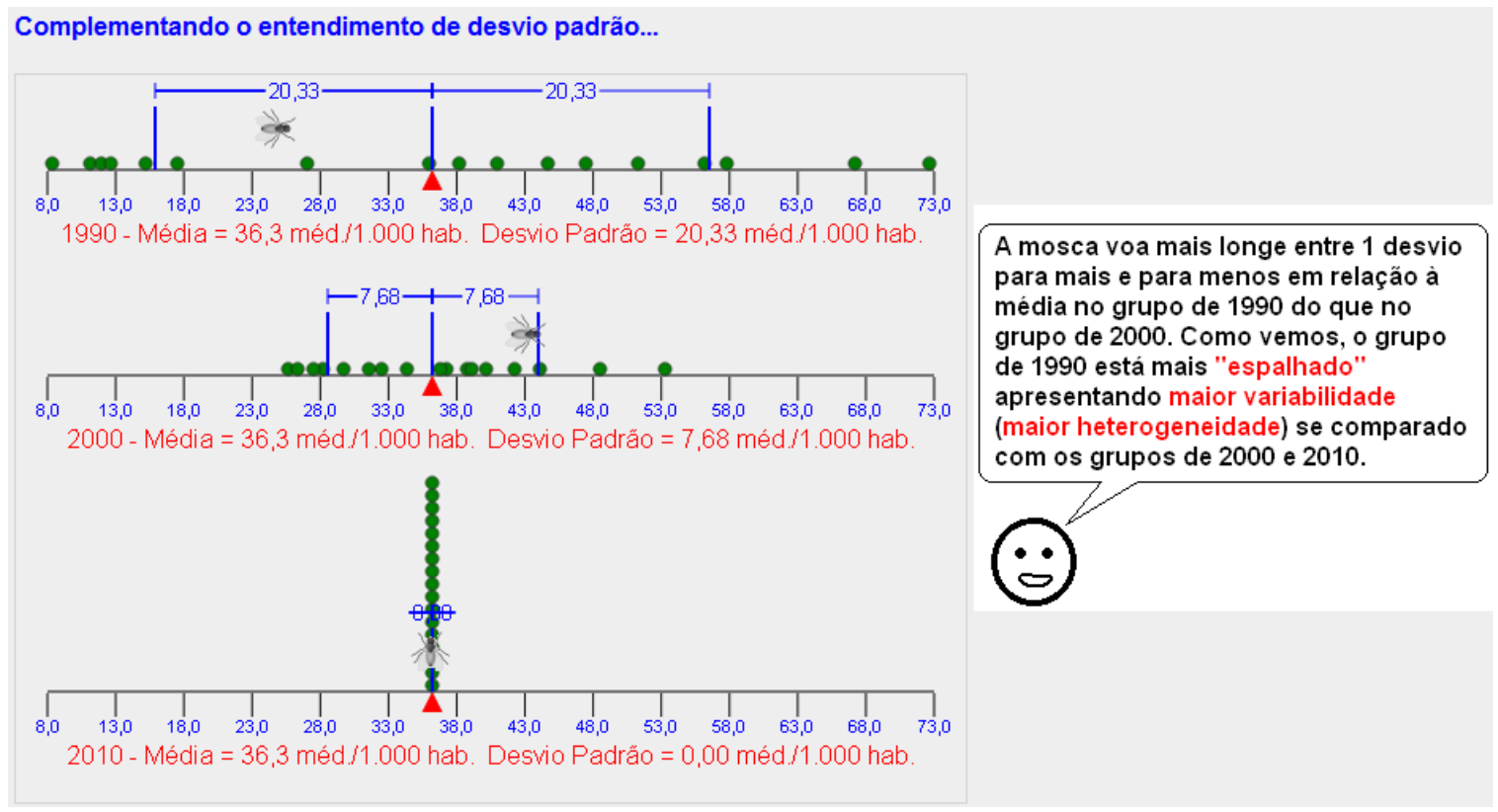

Figura 84 - Tela com a imagem dinâmica de moscas voando nos limites do desvio padrão de três grupos de dados.

Fonte: Elaborado pelo autor.

Finalmente, a tela da Figura 85 mostra a fórmula de cálculo da variância e desvio padrão para um grupo de dados que seja considerado uma população, e a tela da Figura 86 mostra uma imagem que resume a ideia de "espalhamento" (variância/desvio padrão) de dados.

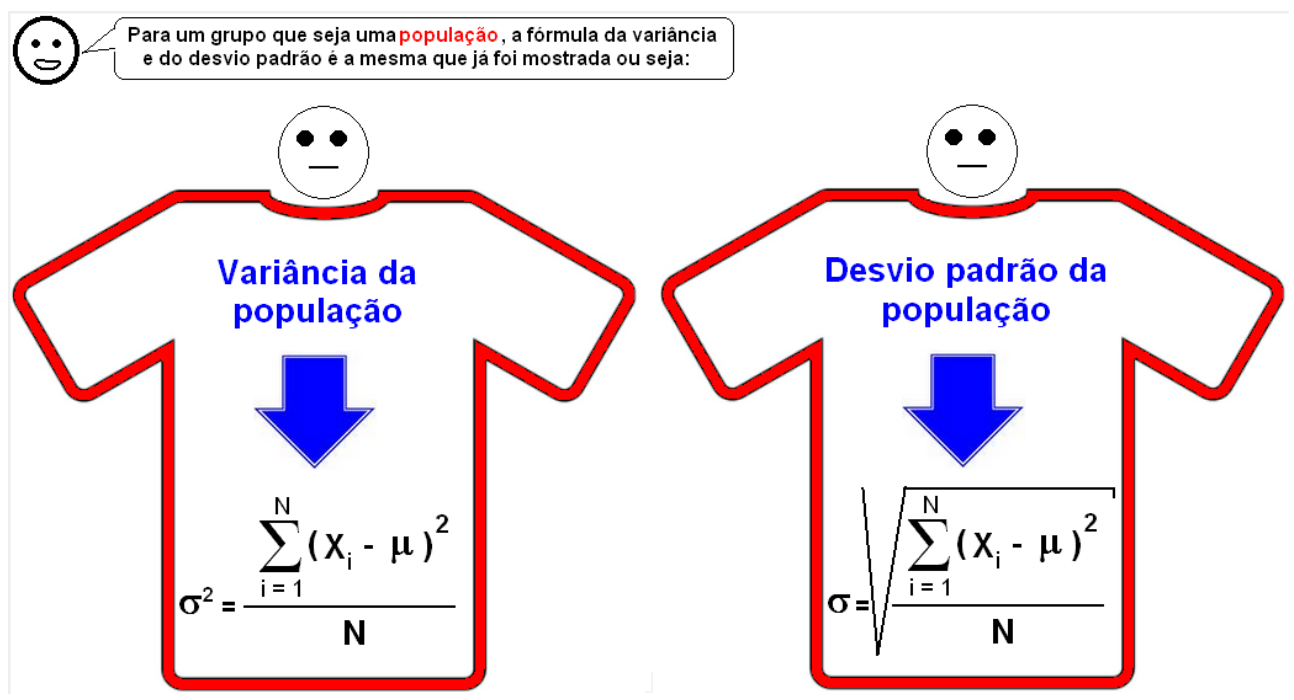

Figura 85 - Fórmula de cálculo da variância e desvio padrão para população.

Fonte: Elaborado pelo autor. 
- Para finalizar as ideias desta lição, vale a pena chamar sua atenção para a ideia chave desta lição: espalhamento dos dados em torno da média.

- Em linhas gerais, variância, desvio padrão e coeficiente de variação são "ferramentas" que tentam mensurar, digamos assim, o "grau" de espalhamento da massa de dados em torno da média... Tente SEMPRE lembrar desta ideia !!!!!

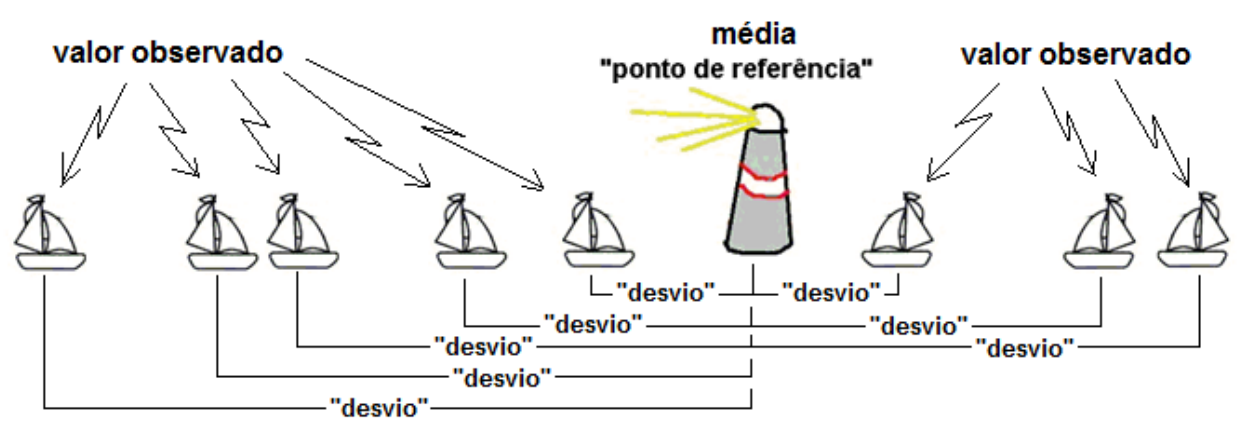

- A média é como se fosse o "ponto de referência" - o farol

- um valor observado é um barquinho

- o "desvio" é a distância do valor observado até a média

- os valores observados são a amostra (ou a população, conforme o caso)

Figura 86 - Tela com imagem para explicar o "espalhamento de dados".

Fonte: Elaborado pelo autor.

\subsubsection{Respostas dos participantes ao questionário 4 - variância, desvio padrão e coeficiente de variação}

O questionário 4 encontra-se no Apêndice 9. Nas Tabelas 27 a 31 encontram-se as correções dos itens das questões 1 e 2 e o item 08 do mapeamento da dinâmica de aprendizagem do respondente. Os itens das duas questões deste questionário são, todos, de resposta dicotômica, isto é, o item está certo ou errado. No item 08 o respondente era solicitado a escrever as fórmulas da variância e desvio padrão. Foram computados o total de itens respondidos corretamente pelo participante. A avaliação do desempenho foi realizada de forma similar à realizada para o questionário 2, ou seja, foram avaliados, qualitativamente, os itens certos e errados do respondente e classificado seu desempenho em satisfatório (S), parcialmente satisfatório $(\mathrm{P})$ ou não satisfatório $(\mathrm{N})$. 
Tabela 27 - Respostas dos participantes P1, P7, P10, P17 e P19

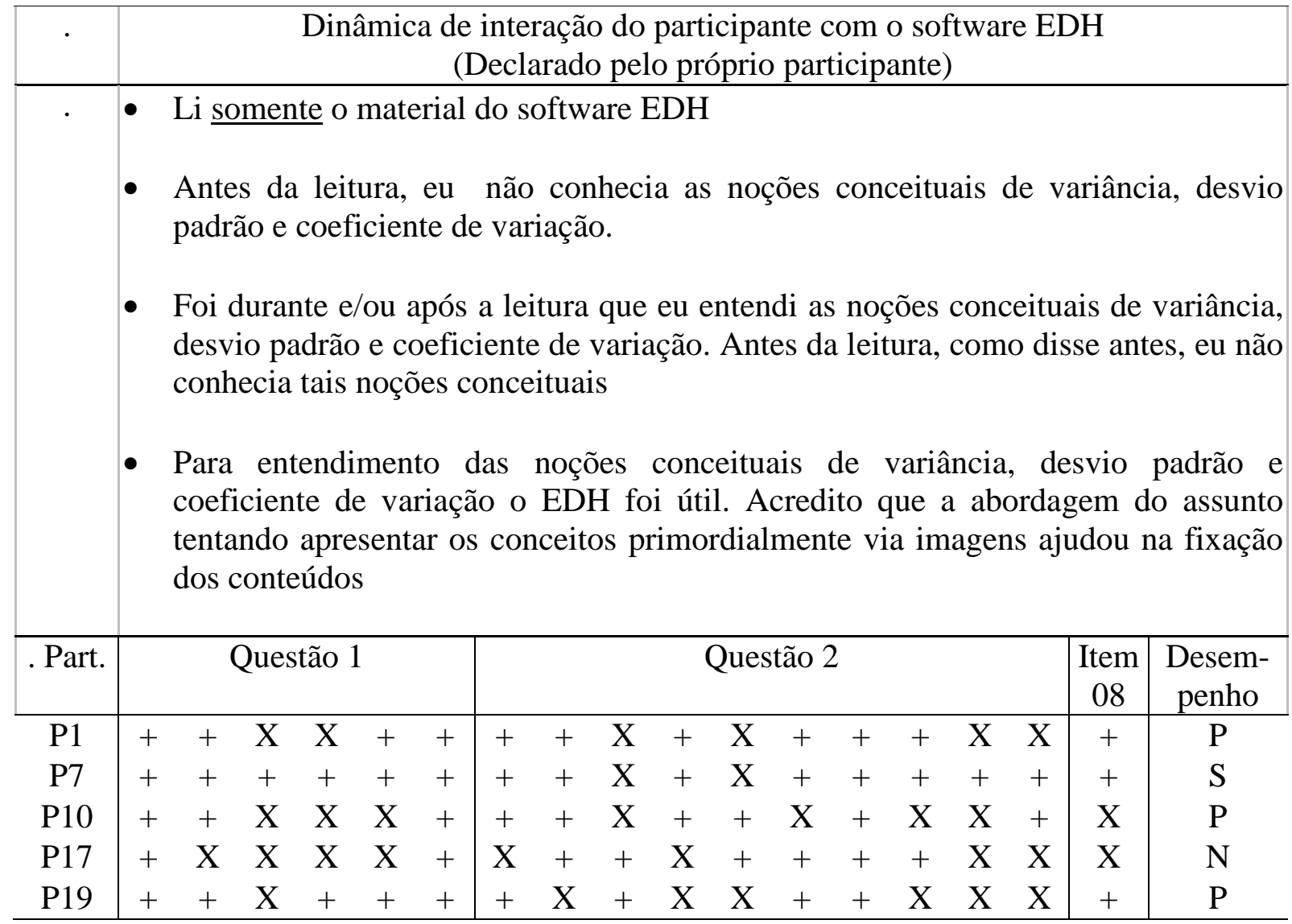

Obs.: + - acertou o item $\mathrm{X}$ - errou o item

Tabela 28 - Respostas dos participantes P3, P4, P5, P8 e P9

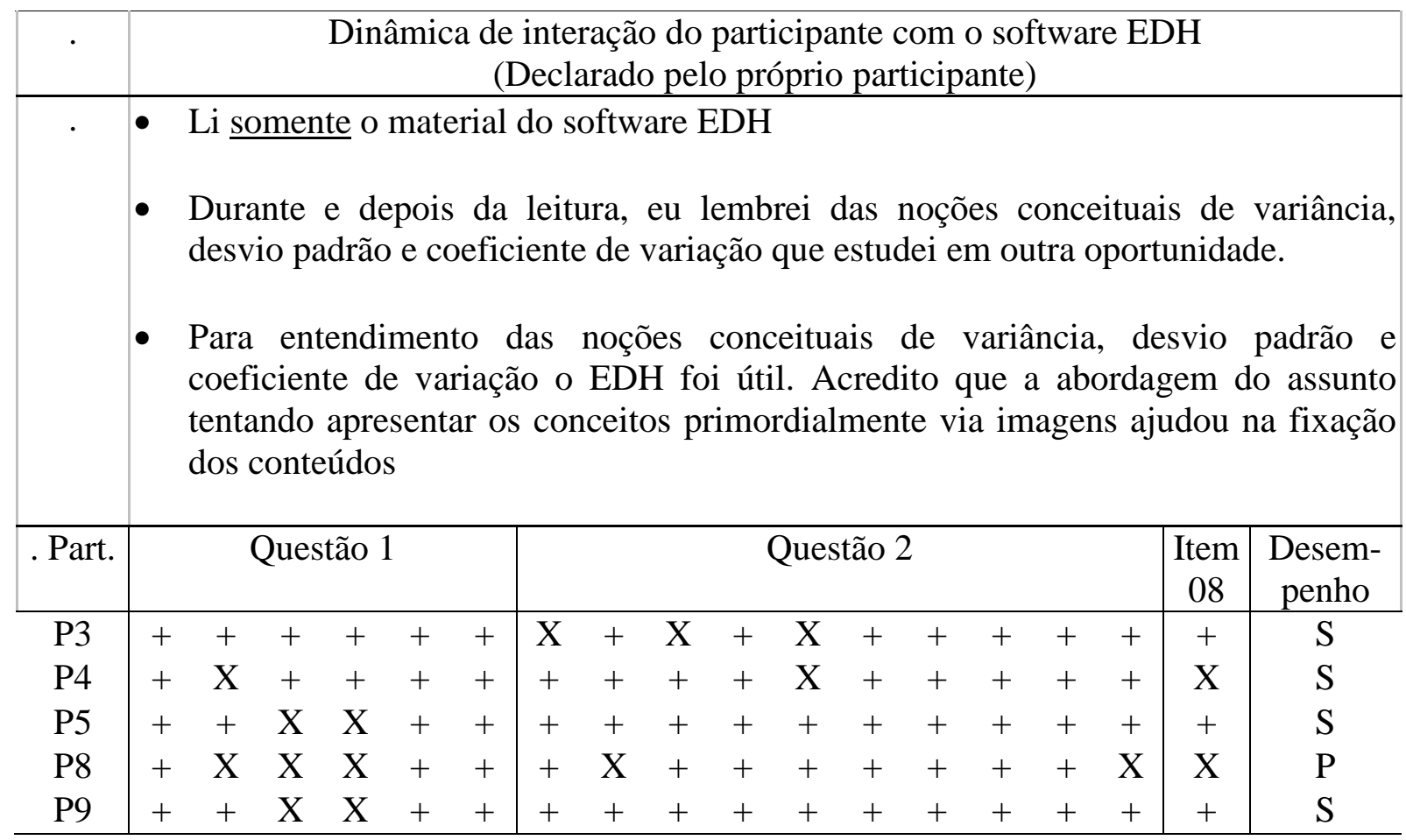

Obs.: + - acertou o item $\mathrm{X}$ - errou o item 
Tabela 29 - Respostas dos participantes P6 e P16

\begin{tabular}{|c|c|c|c|c|}
\hline & \multicolumn{4}{|c|}{$\begin{array}{l}\text { Dinâmica de interação do participante com o software EDH } \\
\text { (Declarado pelo próprio participante) }\end{array}$} \\
\hline & $\begin{array}{l}\text { - Li somente o material c } \\
\text { - Foi durante e/ou após } \\
\text { desvio padrão e coefí } \\
\text { estudado, eu não enten } \\
\text { - Para entendimento d } \\
\text { coeficiente de variaçã } \\
\text { tentando apresentar os } \\
\text { dos conteúdos }\end{array}$ & $\begin{array}{l}\text { lo software EDH } \\
\text { leitura que eu entendi as noções conceitu } \\
\text { ciente de variação, pois antes da leitura } \\
\text { dia tais noções conceituais. } \\
\text { as noções conceituais de variância, de } \\
\text { conteitos primordialmente via imagens aj } \\
\text { conceito útil. Acredito que a aborda }\end{array}$ & jio & $\begin{array}{l}\text { ariância, } \\
\text { de ter } \\
\text { adrão e } \\
\text { assunto } \\
\text { fixação }\end{array}$ \\
\hline . Part. & Questão 1 & Questão 2 & \begin{tabular}{|c|} 
Item \\
08
\end{tabular} & $\begin{array}{c}\text { Desem- } \\
\text { penho }\end{array}$ \\
\hline $\begin{array}{c}\text { P6 } \\
\text { P16 }\end{array}$ & $\begin{array}{l}+X X X+X \\
+X+X+X\end{array}$ & $\begin{array}{llllllllll}X & X & X & + & + & X & + & + & + & X \\
+ & + & + & + & + & + & + & + & + & +\end{array}$ & $\begin{array}{l}\mathrm{X} \\
+\end{array}$ & $\begin{array}{l}\mathrm{N} \\
\mathrm{S}\end{array}$ \\
\hline
\end{tabular}

Obs.: + - acertou o item $\mathrm{X}$ - errou o item

Tabela 30 - Respostas dos participantes P12 e P18

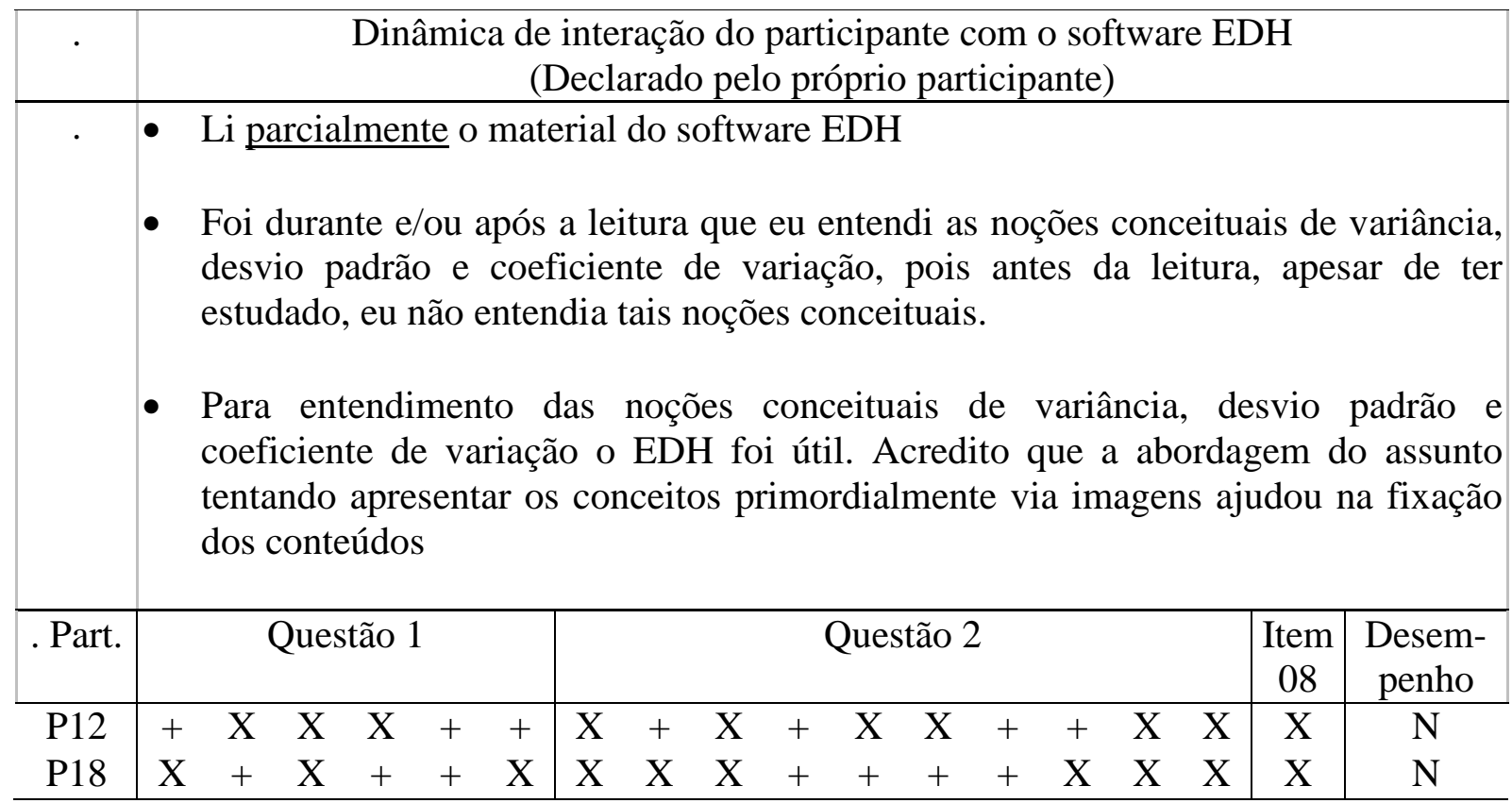

Obs.: + - acertou o item $\mathrm{X}$ - errou o item 
Tabela 31 - Respostas do participante P11

\begin{tabular}{|c|c|c|c|c|}
\hline & \multicolumn{4}{|c|}{$\begin{array}{l}\text { Dinâmica de interação do participante com o software EDH } \\
\text { (Declarado pelo próprio participante) }\end{array}$} \\
\hline & \multicolumn{4}{|c|}{$\begin{array}{l}\text { - Li parcialmente o material do software EDH } \\
\text { - Foi durante e/ou após a leitura que eu entendi as noções conceituais de variância, } \\
\text { desvio padrão e coeficiente de variação, pois antes da leitura, apesar de ter } \\
\text { estudado, eu não entendia tais noções conceituais. } \\
\text { - Para entendimento das noções conceituais de variância, desvio padrão e } \\
\text { coeficiente de variação o EDH foi útil. Mas outro material que li sobre o assunto } \\
\text { aborda de forma melhor que o EDH }\end{array}$} \\
\hline Part. & estão 1 & $\mathrm{Qu}$ & \begin{tabular}{|c|} 
Item \\
08 \\
\end{tabular} & \\
\hline$P 11$ & $X \quad X$ & $X \quad X$ & & \\
\hline
\end{tabular}

Obs.: + - acertou o item $\mathrm{X}$ - errou o item

Os participantes P2, P13 e P15 alegaram ter lido parcialmente a lição 8 do EDH e suas respostas foram baseadas no "chute". E o participante P14 declarou não ter lido o EDH. Desta forma os questionários destes participantes não foram considerados.

$\mathrm{Na}$ Tabela 32 são transcritos comentários positivos feitos pelos participantes sobre o EDH, e na Tabela 33 os pontos negativos.

Tabela 32 - Pontos positivos do software EDH citados pelos participantes que responderam o questionário 4

\begin{tabular}{|c|c|}
\hline Part. & Pontos positivos sobre o EDH citados \\
\hline P1 "O uso de imagens animadas e o uso das setas para indicar onde deve ser usado nas \\
fórmulas ajuda para o entendimento do conteúdo" \\
P3 "Explica os processos"; "Bons exemplos"; "Atividades objetivas" \\
P4 "Conceitos bem explicados e exemplificados por meio de "atividades guias' que \\
permitiram um maior entendimento e fixação" \\
P5 "O passo a passo das fórmulas são muito úteis para fixação do conteúdo" \\
P7 "O conteúdo abordado de maneira interativa facilita seu entendimento" \\
P8 “As imagens foram fundamentais para entendimento desse (complexo) conteúdo.
\end{tabular}


Tabela 32 - Pontos positivos do software EDH citados pelos participantes que responderam o questionário 4 (continuação)

\begin{tabular}{c|c|}
\hline Part. & \multicolumn{1}{c|}{ Pontos positivos sobre o EDH citados } \\
\hline P9 & $\begin{array}{l}\text { "Explicação do coeficiente de variação"; "O porquê de se elevar os desvios ao } \\
\text { quadrado" }\end{array}$ \\
P10 "As figuras em escala, melhor interpretação" & "os exemplos apresentados pelo EDH foram eficientes" \\
P18 & P19 "Ajudou muito a entender, pois tem uma linguagem simples" \\
\hline
\end{tabular}

Tabela 33 - Pontos negativos do software EDH citados pelos participantes que responderam o questionário 4

\begin{tabular}{cc}
\hline Part. & Pontos negativos sobre o EDH citados \\
\hline P1 "Poderia ter mais alguns exercícios"
\end{tabular}

P4 "O único ponto negativo foi o número de páginas digitais que encontrei na lição (49), pois ainda não havia me deparado com tamanha extensão. Porém, a motivação em conjunto com a eficiência e segurança do EDH fizeram com que eu continuasse"

P5 "Eu assimilei fácil por já entender um pouco, acredito que para pessoas que nunca tiveram contato, variância, coeficiente de variação e desvio padrão deveriam ser lições distintas com mais atividades"

P7 "Achei a primeira atividade um pouco confusa. Não entendi muito bem"

P8 "Poderiam haver mais exemplos de cada conceito utilizando outros tipos de dados. Poderia haver também uma melhor abordagem da fórmula"

P9 "Falta explicar o porquê da fórmula de cálculo de amostras ter divisão por N-1 ao invés de N"

P11 "Achei o assunto complicado, mas nada contra o software"

P16 "Muito texto" 


\subsubsection{Quinto encontro - questionário sobre conceitos de centro médio espacial (assunto da lição 9 do EDH) (questionário 5)}

A lição 9 do software EDH, versando sobre centro médio espacial, foi objeto de análise no questionário 5 do curso de extensão. $\mathrm{O}$ centro médio espacial é um ponto espacial representativo de um grupo (população ou amostra) de fenômenos/eventos pontuais ocorrentes sobre um determinado espaço geográfico considerado. A lição 9 é composta de 31 telas onde em essência apresenta-se a ideia de centro médio espacial (ponderado ou não) e sua forma de cálculo. Nas Figuras 87 a 90 observam-se algumas telas da lição apresentando este conceito.

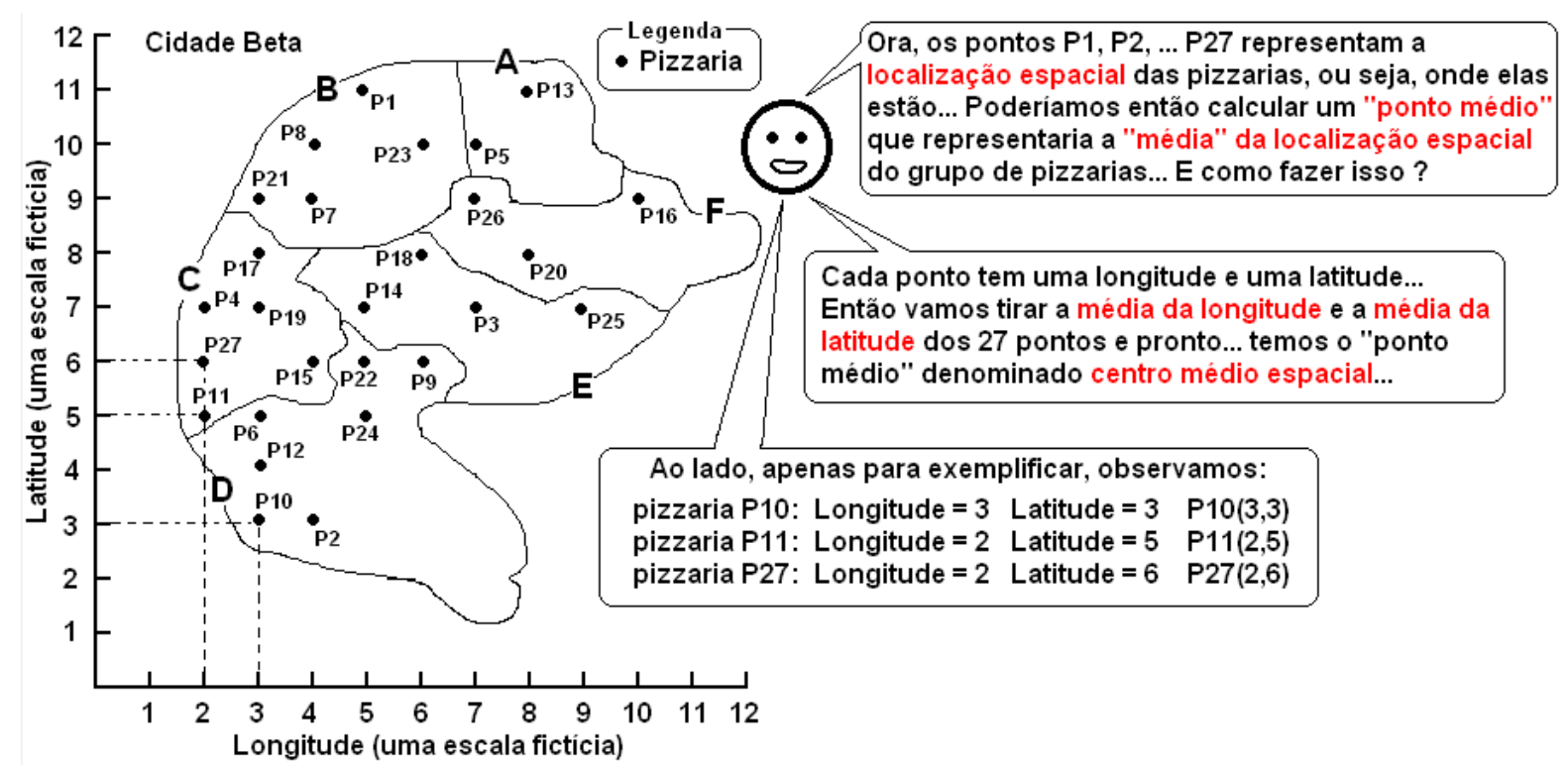

Figura 87 - Abordagem para apresentação do conceito de centro médio espacial

Fonte: Elaborado pelo autor. 
Olhando o mapa com o número médio de clientes por fim de semana nas 27 pizzarias, podemos pensar em ter um "ponto" que seja um "espaço-sintese" que leve em consideração não somente a localização da pizzaria, mas também o "peso" da influência da quantidade de clientes. Podemos calcular o centro médio espacial ponderado que vai apontar um "espaço-sintese" que leve em consideração a quantidade de clientes.
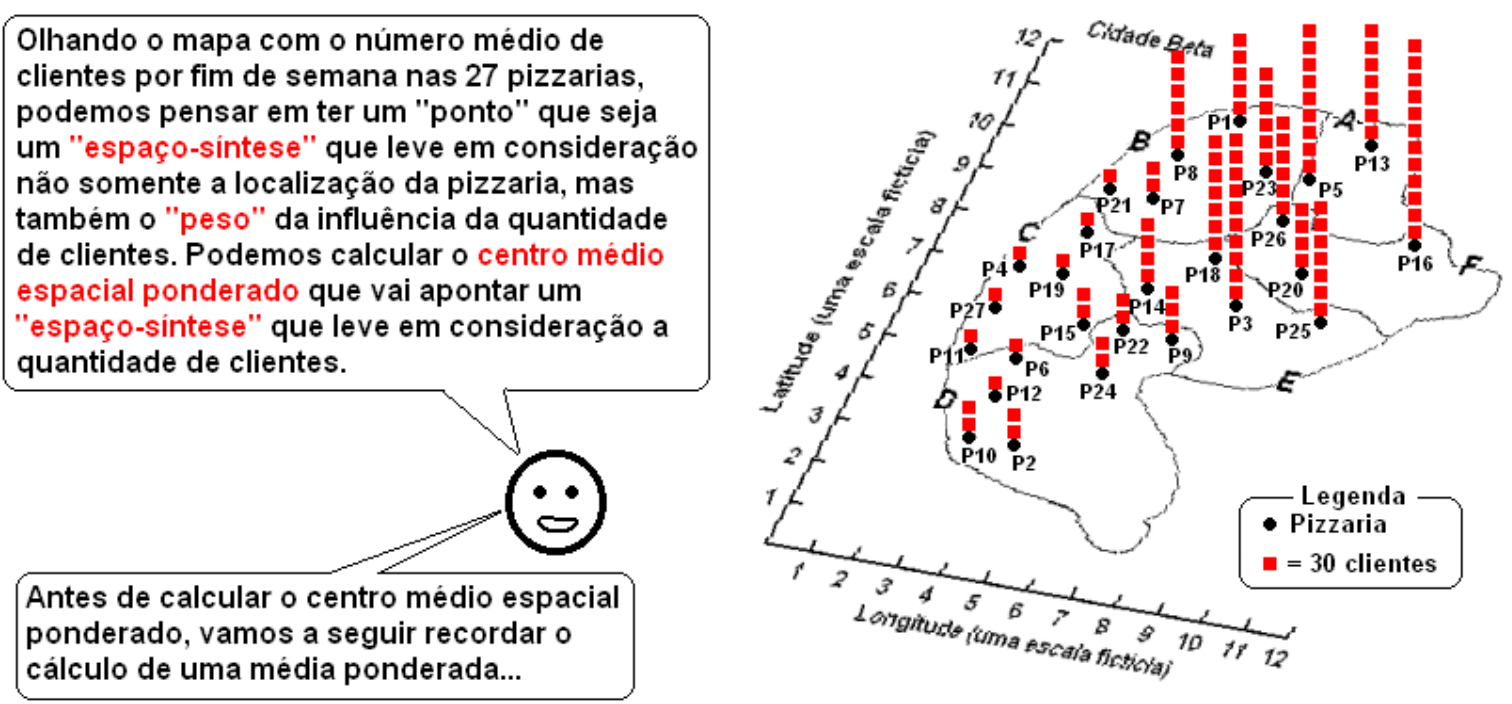

Figura 88 - Abordagem para apresentação do conceito de centro médio espacial ponderado Fonte: Elaborado pelo autor.

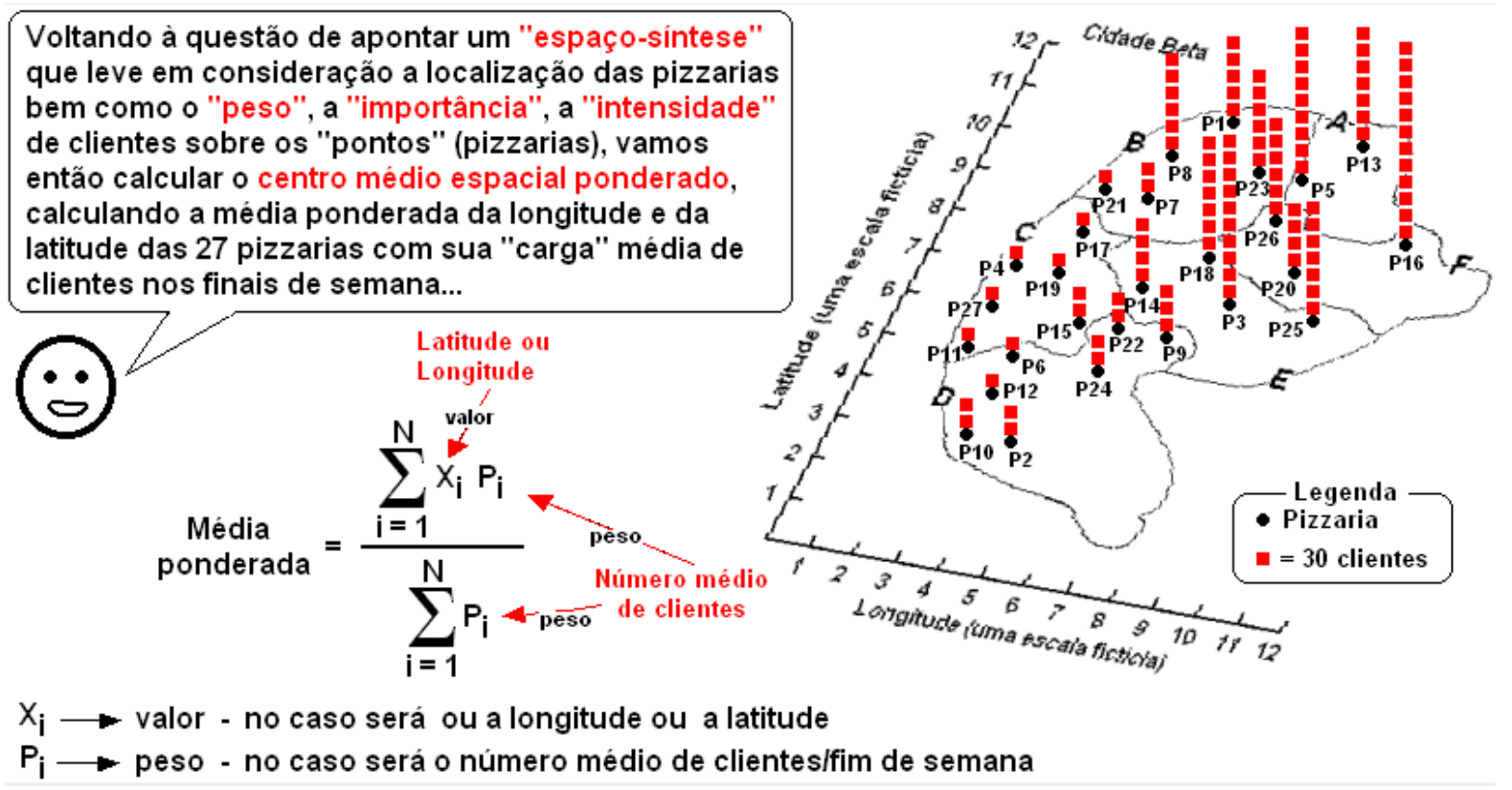

Figura 89 - Abordagem para apresentação do conceito de centro médio espacial ponderado

Fonte: Elaborado pelo autor. 

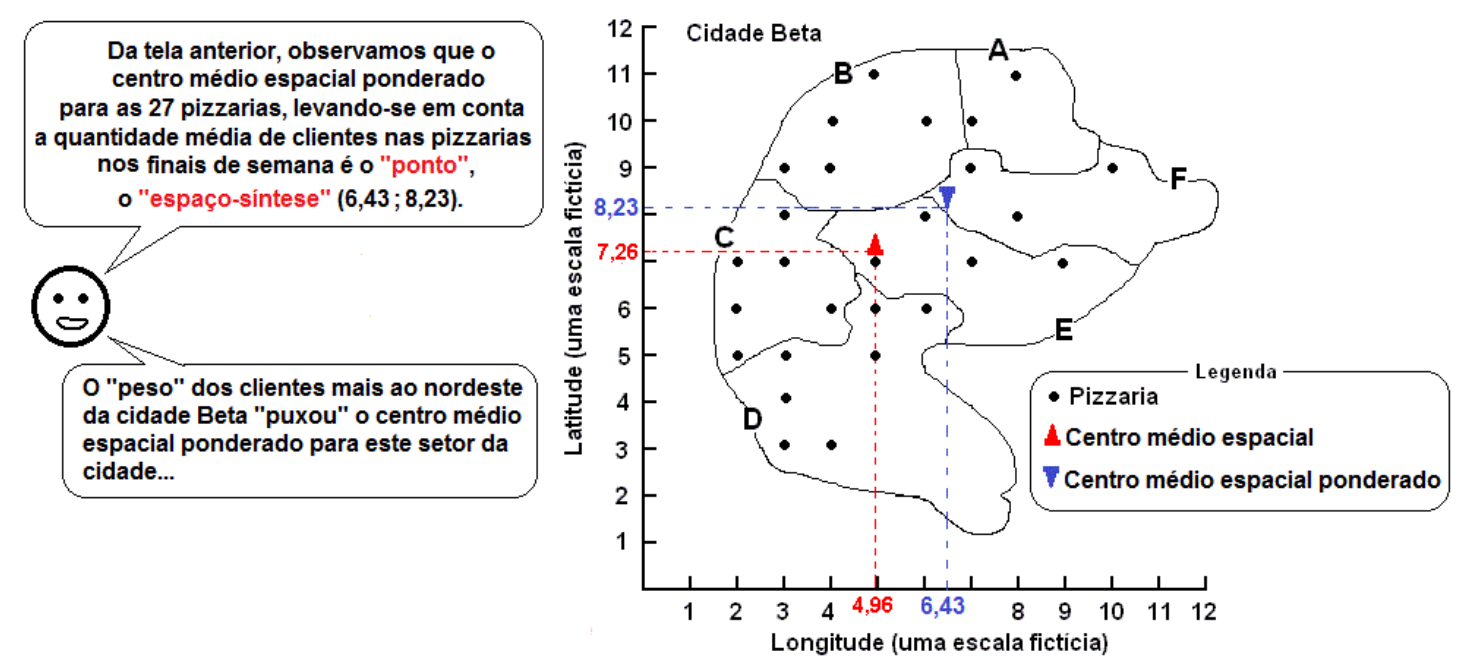

Figura 90 - Tela mostrando o centro médio espacial e o centro médio espacial ponderado Fonte: Elaborado pelo autor.

\subsubsection{Respostas dos participantes ao questionário 5 - estatística espacial - centro médio espacial}

O questionário 5 encontra-se no Apêndice 10. Nas Tabelas 34 a 37 encontram-se as correções dos itens da questão 1 e o item 08 do mapeamento da dinâmica de aprendizagem do respondente. Os itens da questão 1 são, todos, de resposta dicotômica, isto é, o item está certo ou errado. No item 08 o respondente era solicitado a escrever a fórmula do centro médio espacial ponderado. Foram computados o total de itens respondidos corretamente pelo participante. A avaliação do desempenho foi realizada de forma similar à realizada para o questionário 2, ou seja, foram avaliados, qualitativamente, os itens certos e errados do respondente e classificado seu desempenho em satisfatório $(\mathrm{S})$, parcialmente satisfatório $(\mathrm{P})$ ou não satisfatório $(\mathrm{N})$. 
Tabela 34 - Respostas dos participantes P1, P2, P4, P5, P7, P10, P13, P16 e P17

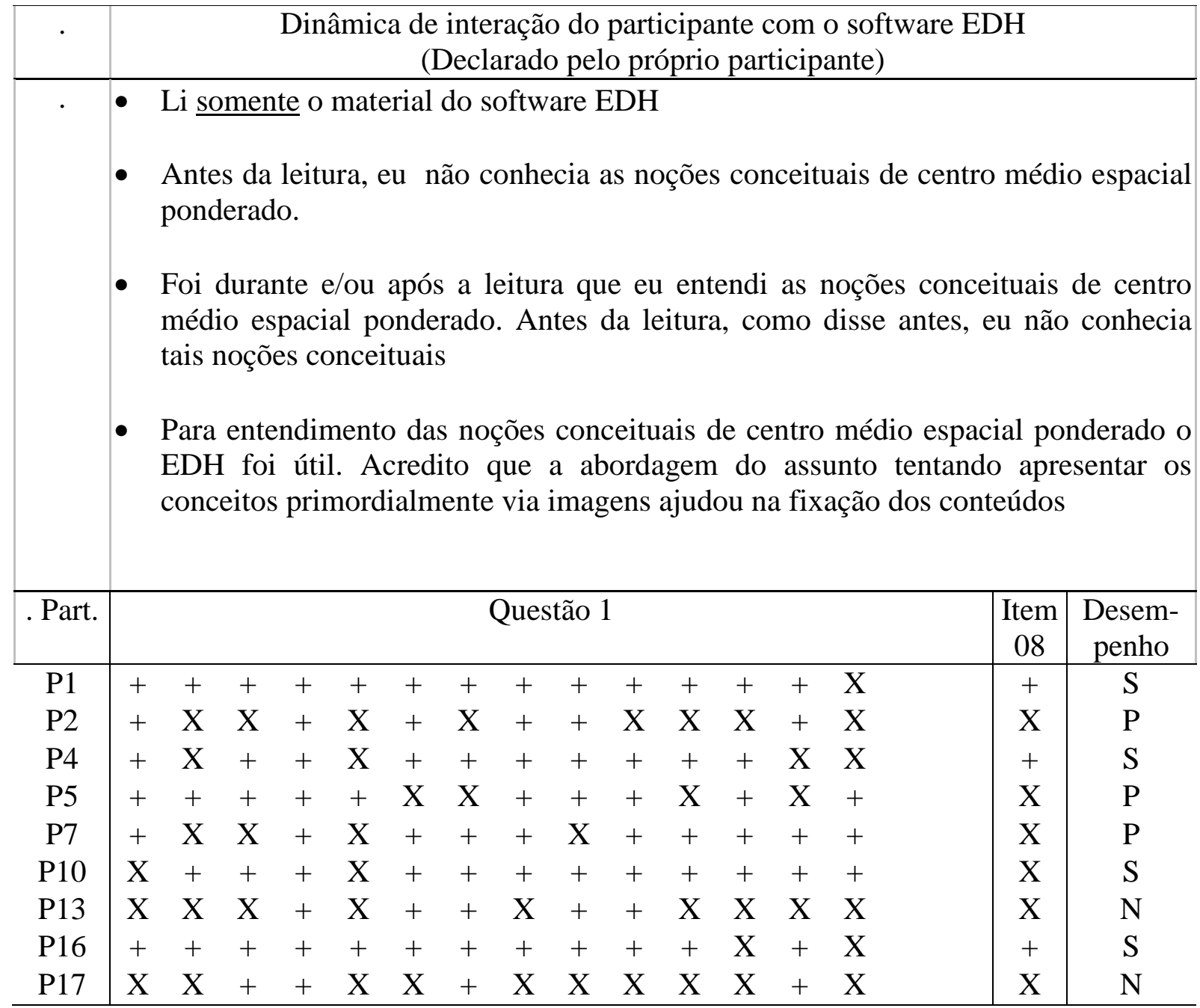

Obs.: + - acertou o item $\mathrm{X}$ - errou o item 
Tabela 35 - Respostas dos participantes P3, P11, P12, P18

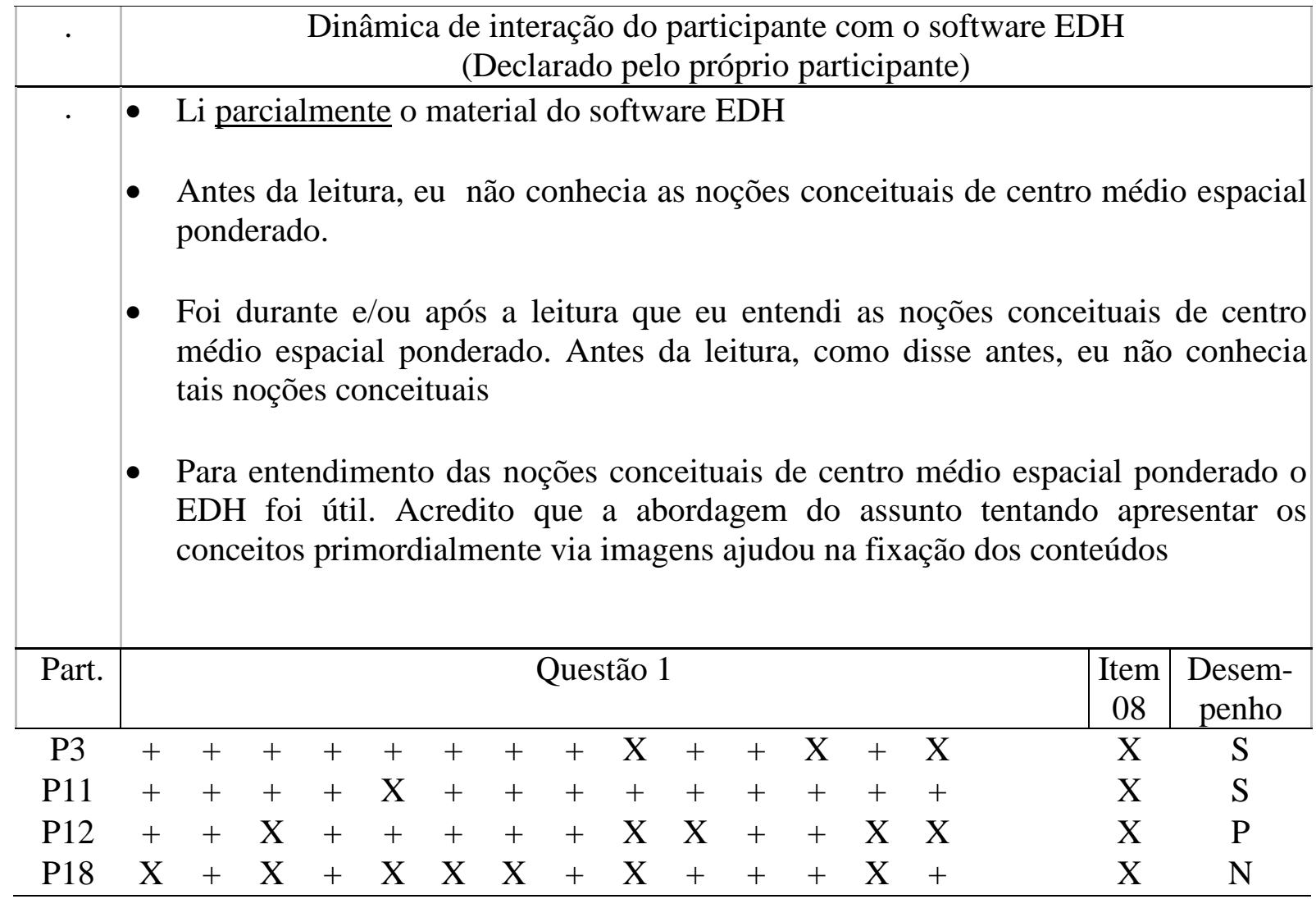

Obs.: + - acertou o item $\mathrm{X}$ - errou o item

Tabela 36 - Respostas do participante P6

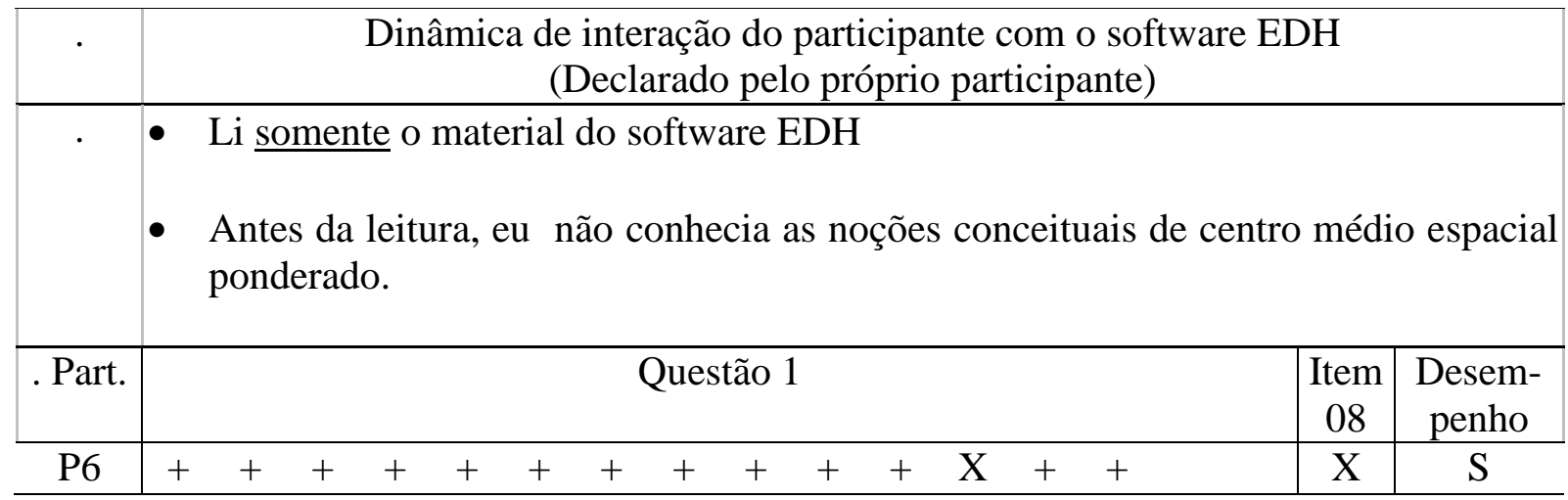

Obs.: + - acertou o item $\mathrm{X}$ - errou o item 
Tabela 37 - Respostas dos participantes P8 e P9

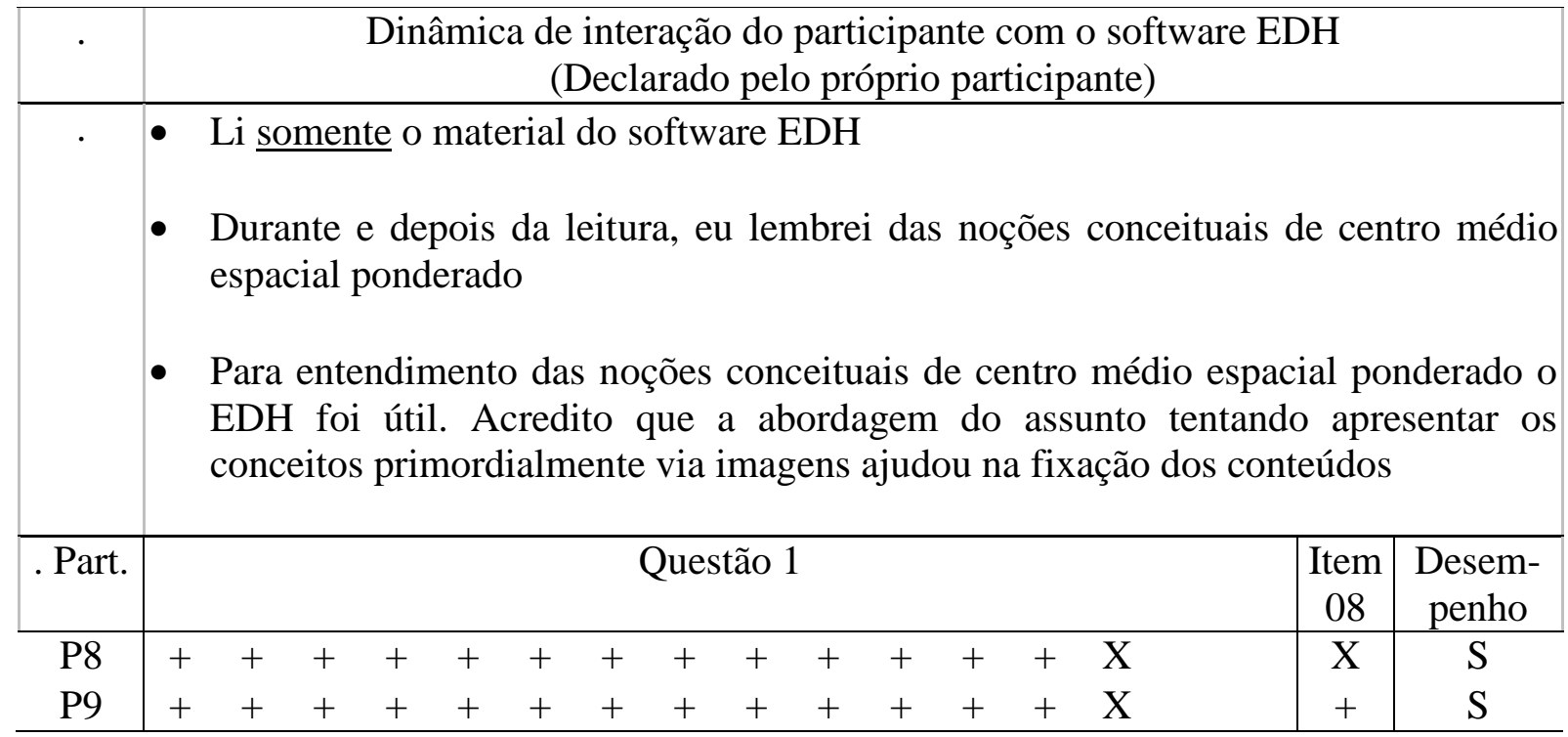

Obs.: + - acertou o item $\mathrm{X}$ - errou o item

O participante P15 alegou ter lido parcialmente a lição 9 do EDH e suas respostas foram baseadas no "chute". P15 estava "colando" as respostas de outro participante. Os participantes P14 e P19 declararam não ter lido o EDH. Desta forma os questionários destes participantes não foram considerados.

Na Tabela 38 são transcritos comentários positivos feitos pelos participantes sobre o $\mathrm{EDH}$, e na Tabela 39 os pontos negativos.

Tabela 38 - Pontos positivos do software EDH citados pelos participantes que responderam o questionário 5

\footnotetext{
Part. Pontos positivos sobre o EDH citados

P1 "A interatividade e o uso de imagens dinâmicas e o uso de exemplos"

P4 "Exemplos interativos como o das pizzarias (para entender o centro médio espacial")

P5 "A dinâmica das imagens interativas facilitam a assimilação. Os exercícios são de grande ajuda. A quantidade maior de exercícios em relação às lições anteriores facilita o entendimento. A diversidade de exemplos também. Ex.: sexo das pessoas, produção de mamão, quantidade de pizzarias"

P8 “A explicação minuciosamente detalhada dos cálculos de centro médio espacial e do ponderado e também dos bons exemplos da aplicação na Geografiaajudou sobremaneira no seu estudo"
} 
Tabela 38 - Pontos positivos do software EDH citados pelos participantes que responderam o questionário 5 (continuação)

P9 "O exemplo de deslocamento da produção de mamão"; "Nas atividades, o exercício com base nos dados do IBGE"

P10 "Os mapas interagindo com os conceitos, fórmulas e tabelas"

P11 "Didático e ilustrativo"

P12 "O uso de tabela dinâmica, bastando clicar no OK para ser resolvida"

P16 "As animações me ajudaram bastante"

Tabela 39 - Pontos negativos do software EDH citados pelos participantes que responderam o questionário 5

\begin{tabular}{c|c|}
\hline Part. & \multicolumn{1}{c|}{ Pontos negativos sobre o EDH citados } \\
\hline P1 "Poucos exercícios para fixação dos conteúdos" & "Exercícios sem gabarito" \\
P7 "Tive dificuldade no entendimento das atividades, achei um pouco confuso" & "Gostaria de um tutorial para aplicar os conceitos em um SIG qualquer" \\
P9 "Achei o assunto complicado, mas nada contra o software" \\
P11 "A explicação e metodologia do software é muito boa, até aqui não tinha encontrado \\
P12 dificuldades, porém dessa vez a fixação foi mais difícil, acredito que pela própria \\
dificuldade da matéria" \\
P16 "Os exemplos são meio longos, não sei se é necessário usar tantos números nos \\
primeiros. Fica um pouco cansativo"
\end{tabular}

\subsubsection{Sexto encontro - questionário sobre conceitos de distância padrão (assunto da lição 10 do EDH) (questionário 6)}

A lição 10 do software EDH, versando sobre distância padrão, foi objeto de análise no questionário 6 do curso de extensão. A distância padrão é o equivalente espacial do desvio padrão de um grupo de dados. Equivale ao raio de uma circunferência com centro no centro médio espacial (ponderado ou não) de um determinado conjunto de pontos alocados em 
determinado espaço geográfico. A lição 10 é composta de 45 telas que abordam os aspectos conceituais da distância padrão e sua forma de cálculo. Nas Figuras 91 a 95 observam-se algumas telas da lição apresentando este conceito.

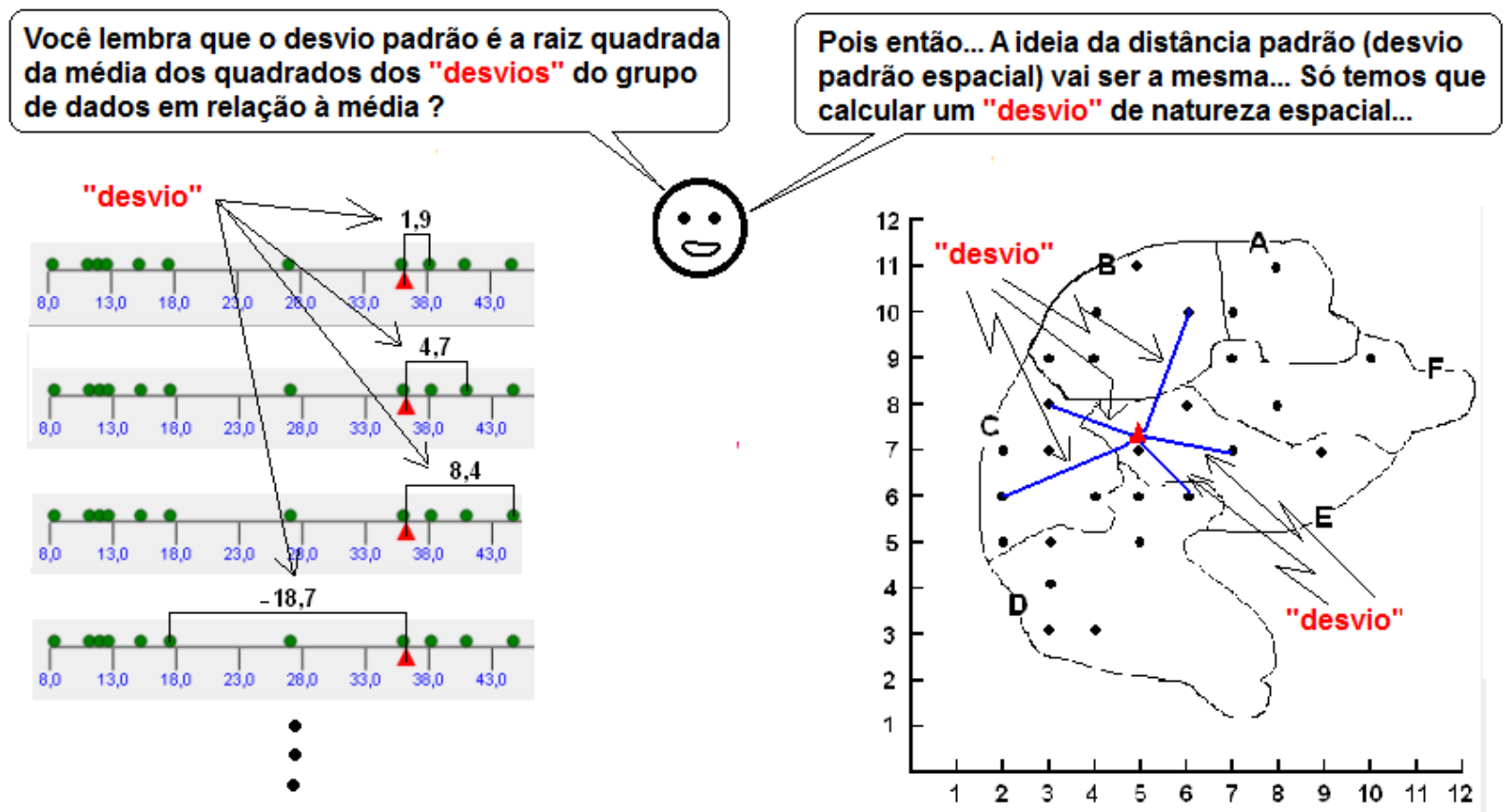

Figura 91 - Tela para abordagem ao conceito de distância padrão.

Fonte: Elaborado pelo autor.
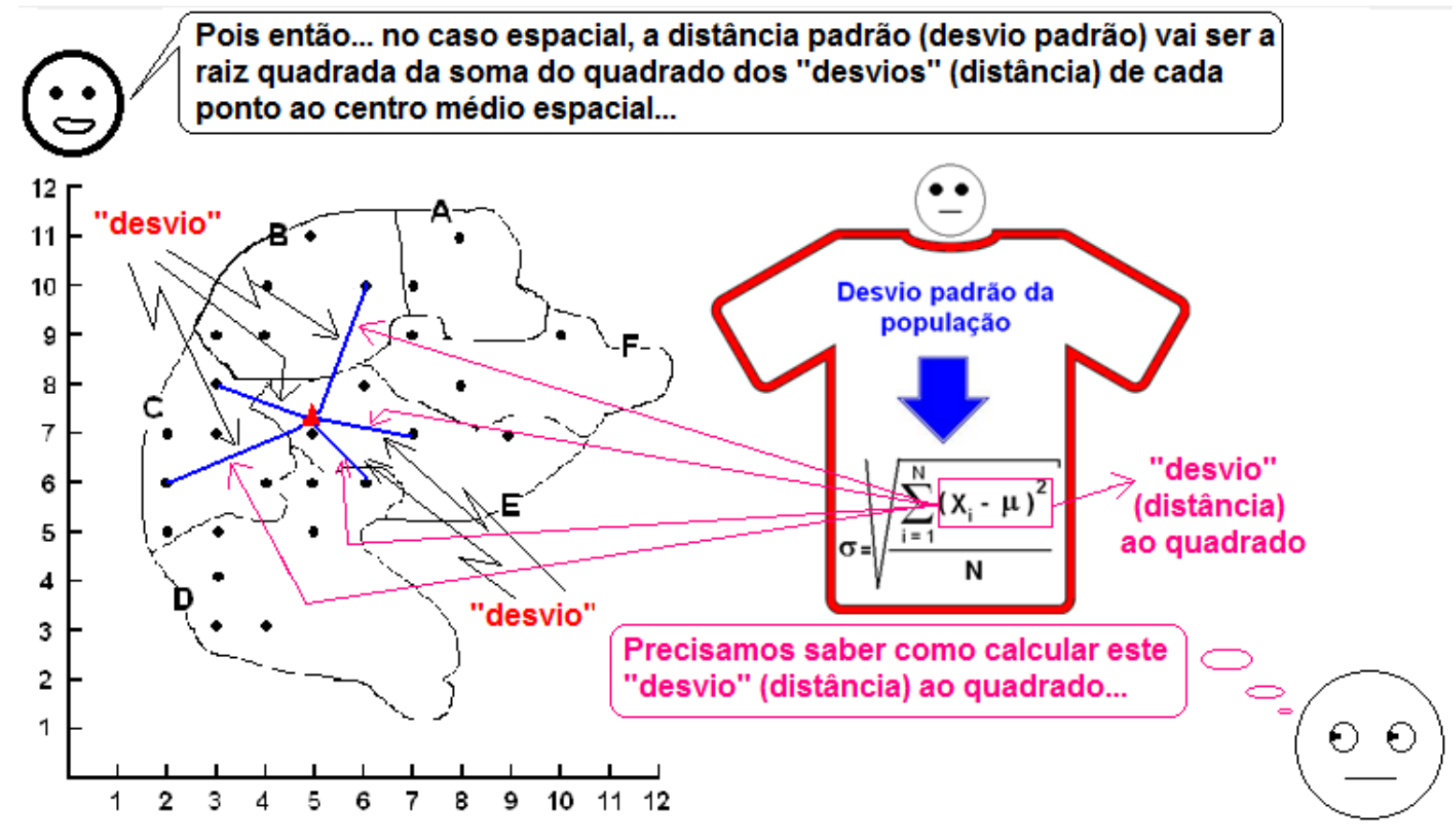

Figura 92 - Tela para abordagem ao cálculo da distância padrão.

Fonte: Elaborado pelo autor. 
Vamos calcular a distância padrão através de um exemplo:

(3) Clique no botão Quadrado dist. para calcular o quadrado da distância de cada um dos 7 pontos até a média

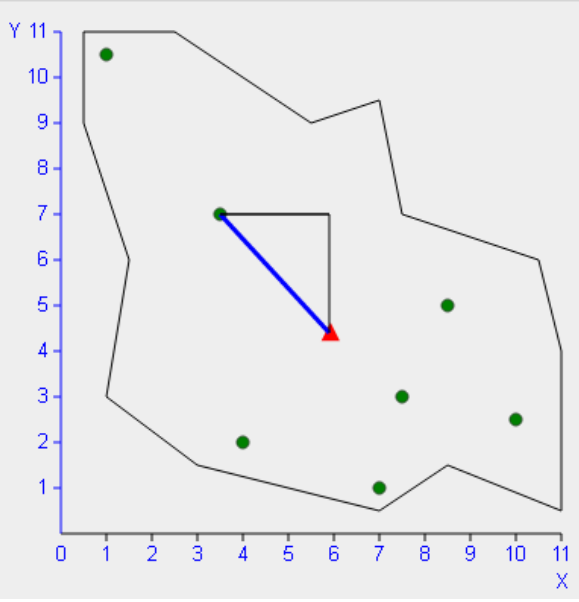

Dados do exemplo

\begin{tabular}{|c|c|c|c|c|c|}
\hline \multicolumn{6}{|c|}{ Dados do exemplo } \\
\hline & Ponto & $\mathrm{X}_{\mathrm{k}}$ & $\mathbf{Y}_{\mathrm{k}}$ & $\left(X_{k} ; Y_{k}\right)$ & \begin{tabular}{|c} 
distância \\
ao quadrado \\
$\mathrm{d}^{2}$
\end{tabular} \\
\hline & $P_{1}$ & $\overline{7,5}$ & 3,0 & $\left(X_{1} ; Y_{1}\right)=(7,5 ; 3,0)$ & 4,52 \\
\hline & $P_{2}$ & 7,0 & 1,0 & $\left(X_{2} ; Y_{2}\right)=(7,0 ; 1,0)$ & 12,77 \\
\hline & $P_{3}$ & 3,5 & 7,0 & $\left(X_{3} ; Y_{3}\right)=(3,5 ; 7,0)$ & 12,52 \\
\hline \multirow[t]{4}{*}{ Quadrado dist. } & $\mathrm{P}_{4}$ & 4,0 & 2,0 & $\left(X_{4} ; Y_{4}\right)=(4,0 ; 2,0)$ & \\
\hline & $P_{5}$ & 1,0 & 10,5 & $\left(X_{5} ; Y_{5}\right)=(1,0 ; 10,5)$ & \\
\hline & $P_{6}$ & $\overline{8,5}$ & 5,0 & $\left(X_{6} ; Y_{6}\right)=(8,5 ; 5,0)$ & \\
\hline & $P_{7}$ & 10,0 & 2,5 & $\left(X_{7} ; Y_{7}\right)=(10,0 ; 2,5)$ & \\
\hline Centro médio: & $\mathrm{C}_{\mathrm{m}}$ & 5,9 & 4,4 & $\left(X_{m} ; Y_{m}\right)=(5,9 ; 4,4)$ & \\
\hline
\end{tabular}

Figura 93 - Tela onde o usuário interage clicando no botão "Quadrado dist." para calcular a distância padrão.

Fonte: Elaborado pelo autor.

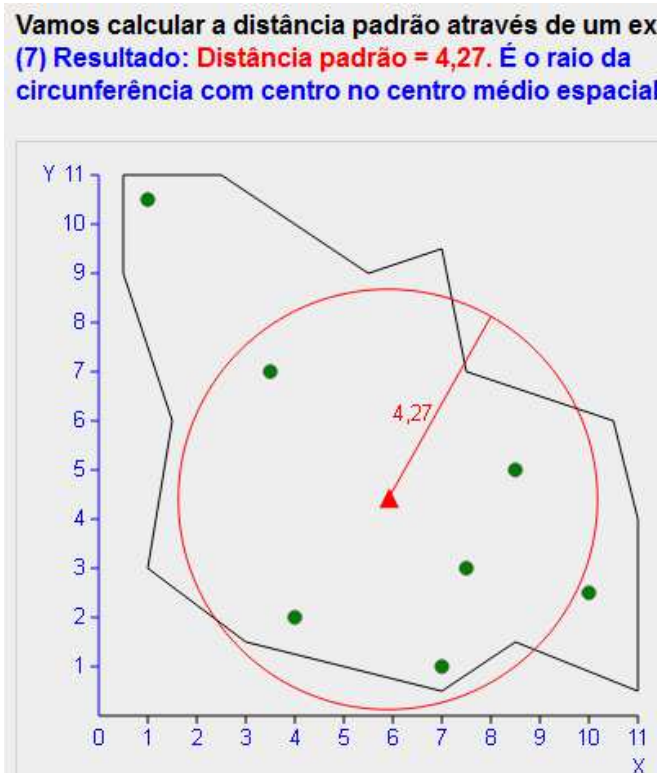

\begin{tabular}{|c|c|c|c|c|c|}
\hline \multicolumn{6}{|c|}{ Dados do exemplo } \\
\hline & Ponto & $x_{k}$ & $\mathbf{Y}_{\mathrm{k}}$ & $\left(X_{k} ; Y_{k}\right)$ & $\begin{array}{c}\text { distância } \\
\text { ao quadrado } \\
d^{2}\end{array}$ \\
\hline & $P_{1}$ & $\overline{7,5}$ & 3,0 & $\left(X_{1} ; Y_{1}\right)=(7,5 ; 3,0)$ & 4,52 \\
\hline & $P_{2}$ & 7,0 & $\overline{1,0}$ & $\left(X_{2} ; Y_{2}\right)=(7,0 ; 1,0)$ & 12,77 \\
\hline & $P_{3}$ & 3,5 & 7,0 & $\left(X_{3} ; Y_{3}\right)=(3,5 ; 7,0)$ & 12,52 \\
\hline & $\mathrm{P}_{4}$ & 4,0 & 2,0 & $\left(\mathrm{X}_{4} ; \mathrm{Y}_{4}\right)=(4,0 ; 2,0)$ & 9,37 \\
\hline & $P_{5}$ & 1,0 & 10,5 & $\left(X_{5} ; Y_{5}\right)=(1,0 ; 10,5)$ & 61,22 \\
\hline & $P_{6}$ & 8,5 & 5,0 & $\left(X_{6} ; Y_{6}\right)=(8,5 ; 5,0)$ & 7,11 \\
\hline & $P_{7}$ & 10,0 & $\overline{2,5}$ & $\left(X_{7} ; Y_{7}\right)=(10,0 ; 2,5)$ & 20,42 \\
\hline Centro médio: & $\mathrm{C}_{\mathrm{m}}$ & 5,9 & 4,4 & $\left(X_{m} ; Y_{m}\right)=(5,9 ; 4,4)$ & \\
\hline $\begin{array}{c}\text { Distância } \\
\text { padrão: }\end{array}$ & & & $i=$ & $=1$ & 4,27 \\
\hline & & & & 7 & \\
\hline
\end{tabular}

Figura 94 - Tela mostrando o resultado do cálculo da distância padrão.

Fonte: Elaborado pelo autor. 


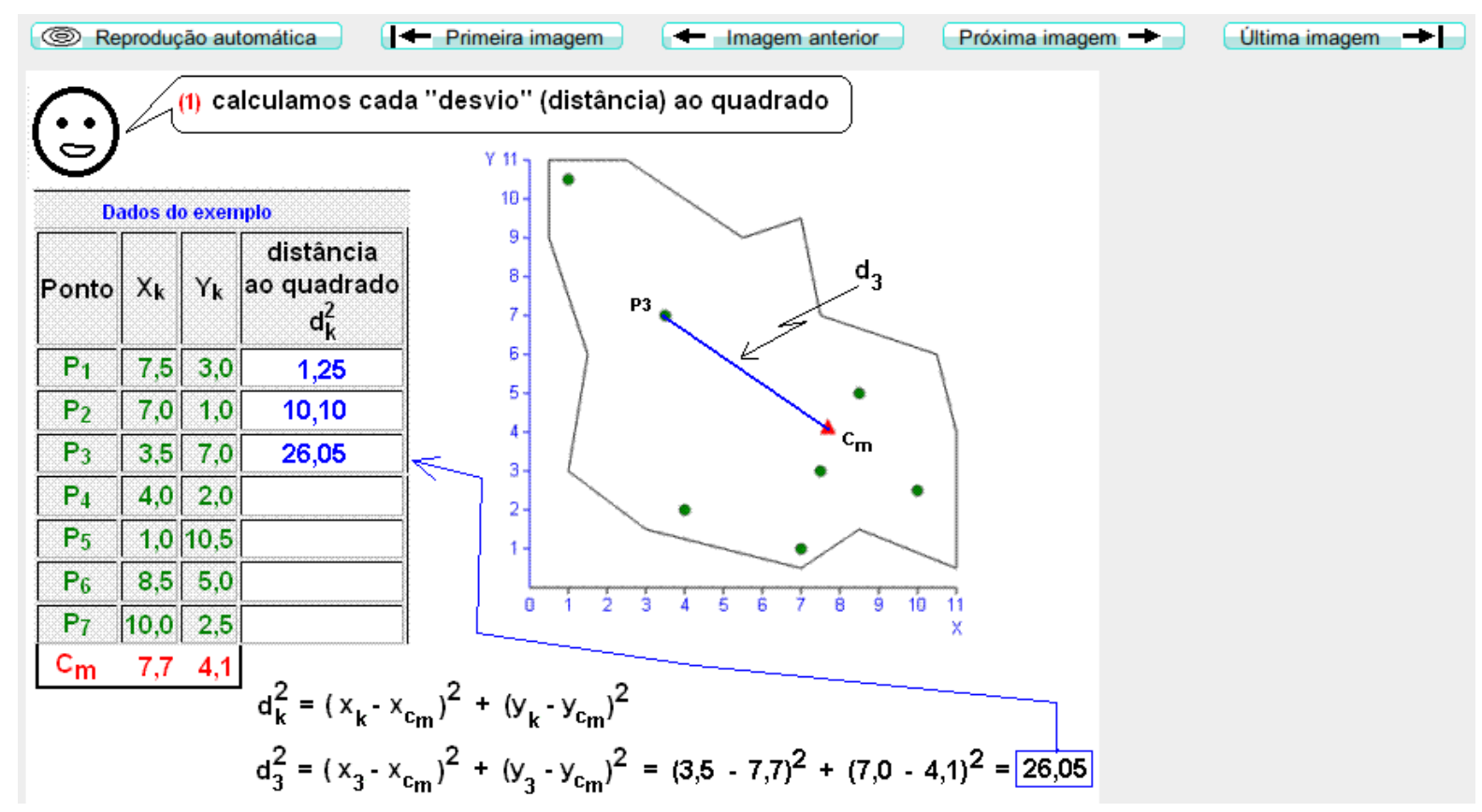

Figura 95 - Tela dinâmica calculando a distância padrão ponderada.

Fonte: Elaborado pelo autor.

\subsubsection{Respostas dos participantes ao questionário 6 - estatística espacial - distância padrão}

O questionário 6 encontra-se no Apêndice 11. Nas tabelas 40 a 42 encontram-se as correções dos itens da questão 1, questão 2 e o item 08 do mapeamento da dinâmica de aprendizagem do respondente. Os itens da questão 1 são, todos, de resposta dicotômica, isto é, o item está certo ou errado. A questão 2 exige como resposta valores calculados. No item 08 o respondente era solicitado a escrever a fórmula da distância padrão. Foram computados o total de itens respondidos corretamente pelo participante. A avaliação do desempenho foi realizada de forma similar à realizada para o questionário 2, ou seja, foram avaliados, qualitativamente, os itens certos e errados do respondente e classificado seu desempenho em satisfatório (S), parcialmente satisfatório $(\mathrm{P})$ ou não satisfatório $(\mathrm{N})$. 
Tabela 40 - Respostas dos participantes P1, P5, P7, P9 e P10

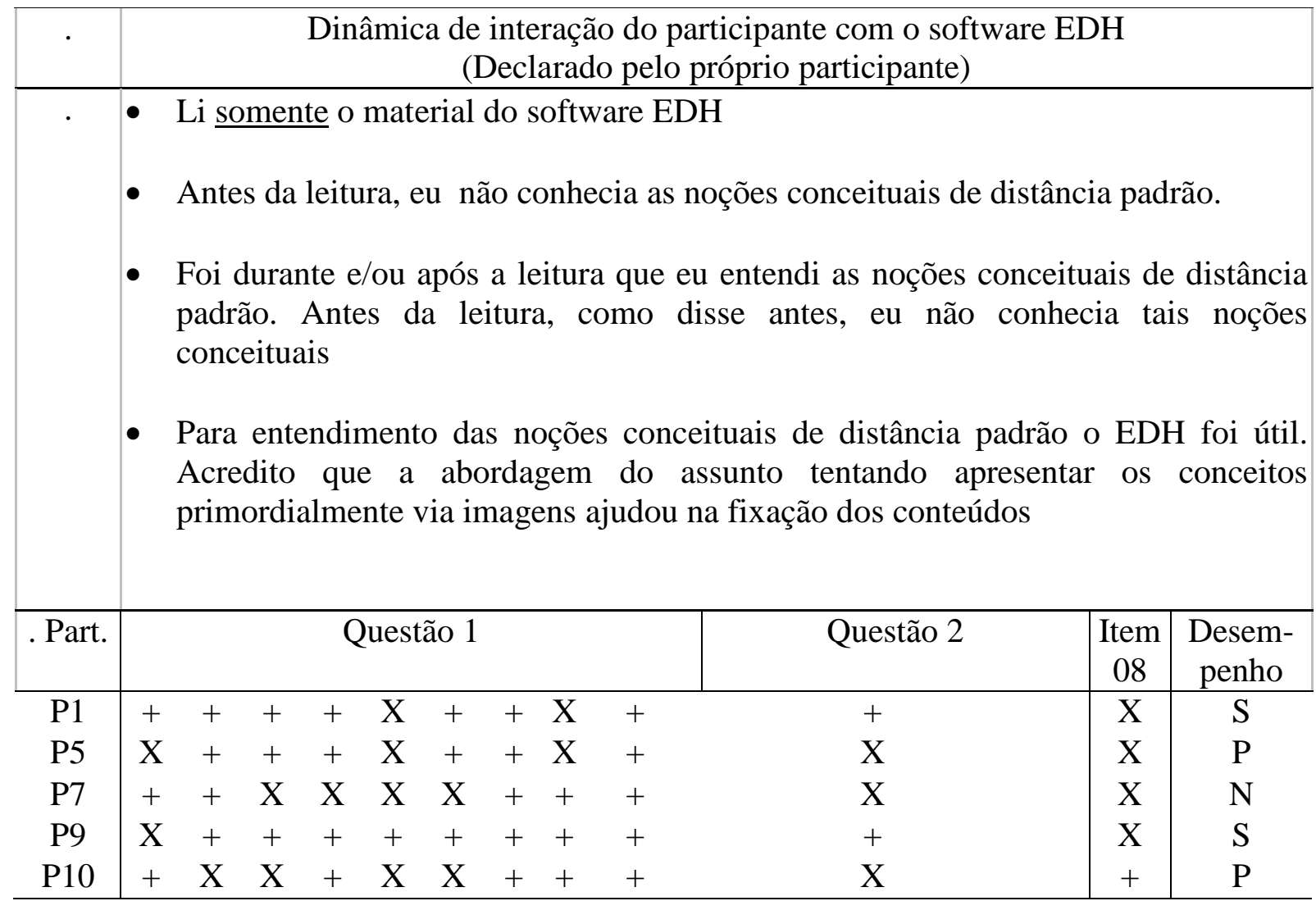

Obs.: + - acertou o item $\mathrm{X}$ - errou o item

Tabela 41 - Respostas do participante P8

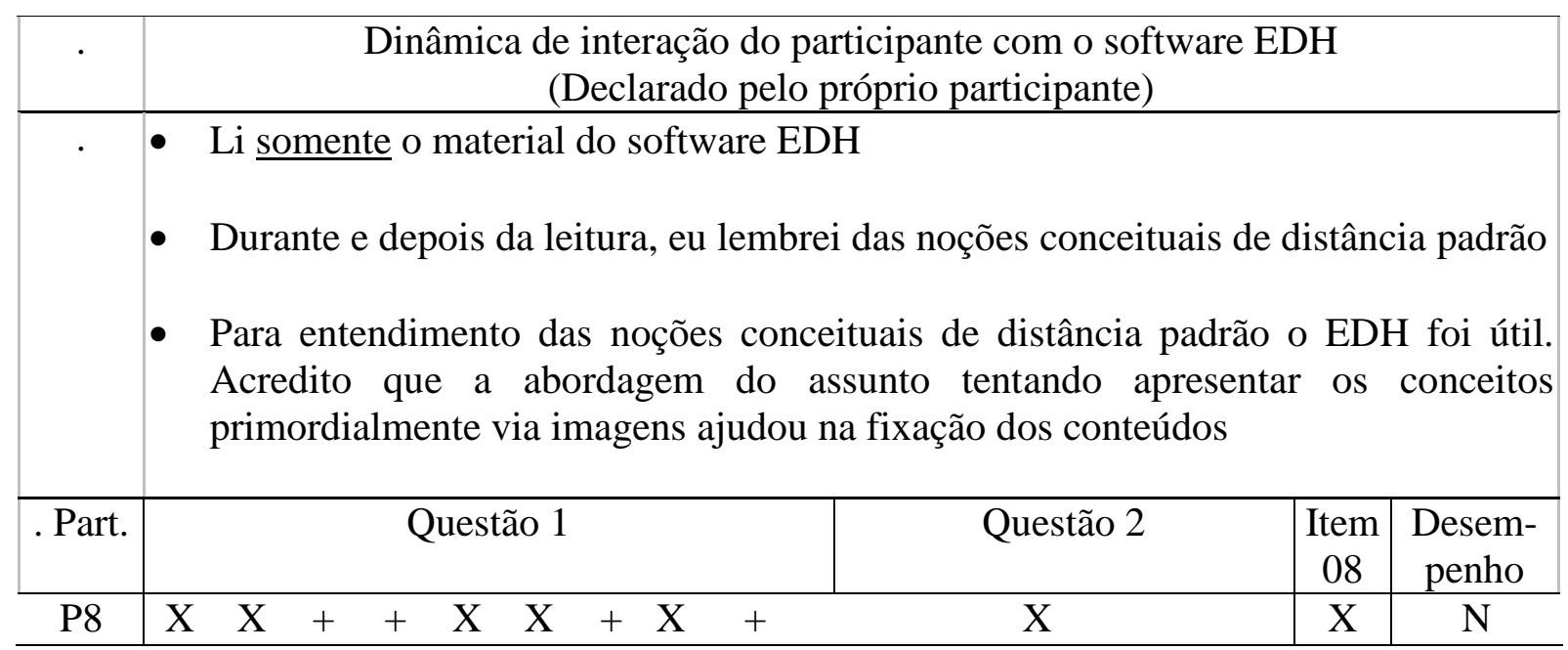

Obs.: + - acertou o item $\mathrm{X}$ - errou o item 
Tabela 42 - Respostas dos participantes P3 e P4

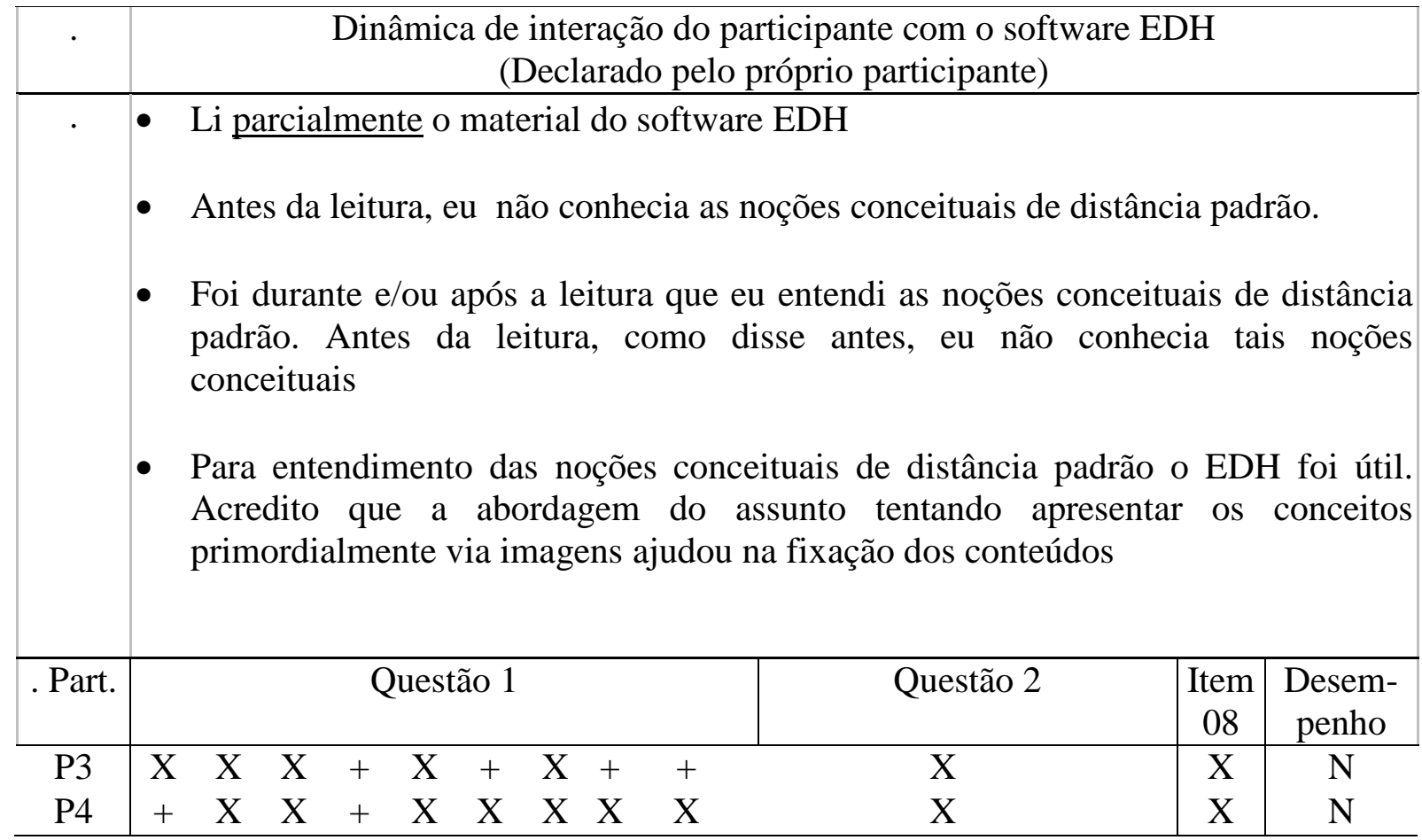

Obs.: + - acertou o item $\mathrm{X}$ - errou o item

Os participantes P2, P6 e P13 declararam não terem lido o material. Os participantes P12, P17, P18 e P19 declararam ter respondido aos itens com base no "chute". Desta forma foram desconsiderados os questionários destes participantes. E os participantes P11, P14, P15, P16 não compareceram para responder o questionário.

Na Tabela 43 são transcritos comentários positivos feitos pelos participantes sobre o $\mathrm{EDH}$, e na Tabela 44 os pontos negativos.

Tabela 43 - Pontos positivos do software EDH citados pelos participantes que responderam o questionário 6

\begin{tabular}{|c|c|}
\hline Part. & Pontos positivos sobre o EDH citados \\
\hline P1 & $\begin{array}{l}\text { "Uso de mapas com as respectivas representações e o uso de imagens para ilustrar os } \\
\text { exemplos" }\end{array}$ \\
\hline $\mathrm{P} 4$ & $\begin{array}{l}\text { "Os exemplos com 'shoppings' aproximaram e ilustraram para melhor fixação do } \\
\text { conteúdo" }\end{array}$ \\
\hline P5 & "A forma de abordagem dinâmica ajuda muito na fixação" \\
\hline P8 & "O uso de imagens" \\
\hline $\mathrm{P} 10$ & "A interatividade gráfica e imagética" \\
\hline
\end{tabular}


Tabela 44 - Pontos negativos do software EDH citados pelos participantes que responderam o questionário 6

\begin{tabular}{l} 
Part. \\
\hline P1 "Poucos exercícios para fixação conceitual" \\
P5 "A sequência de muitos slides $40 \ldots 50 \ldots$ dificulta um pouco, poderia ser dividido em \\
\\
2 lições" \\
P8 "As imagens poderiam apresentar mais exemplos" \\
P9 "Devido a grande quantidade de seções, gostaria de um slide resumo com as \\
fórmulas e definições principais" \\
P10 "Mais exercícios"
\end{tabular}

\subsubsection{Sétimo encontro - questionário sobre conceitos de medidas de posição (separatrizes) e box plot (assunto da lição 12 do EDH) (questionário 7)}

A lição 12 do software EDH, versando sobre medidas de posição e box plot, foi objeto de análise no questionário 7 do curso de extensão. As medidas de posição podem ser vistas como valores que auxiliam a caracterização descritiva de um conjunto de dados numéricos. $\mathrm{E}$ o box plot seria uma espécie de "mapa" que realça em particular três valores de separatriz: a mediana, o primeiro e terceiro quartis. A lição 12 é composta de 72 telas. Nas Figuras 96 a 99 observam-se algumas telas da lição abordando as separatrizes e o box plot.

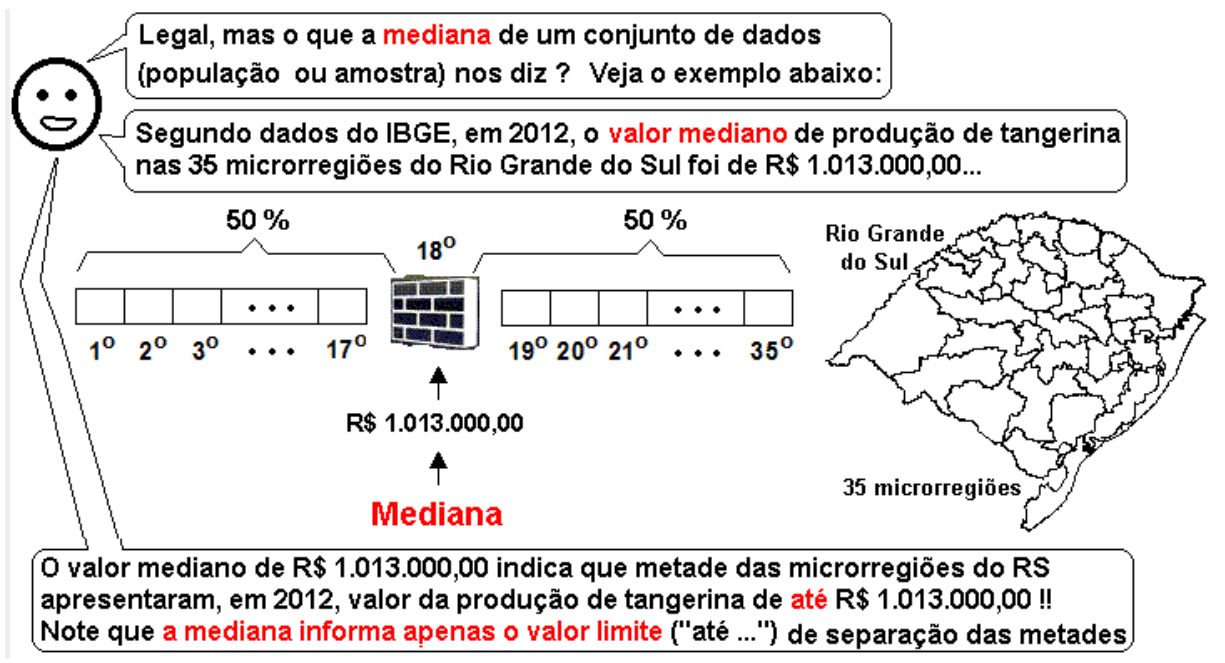

Figura 96 - Tela exemplificando a mediana.

Fonte: Elaborado pelo autor. 


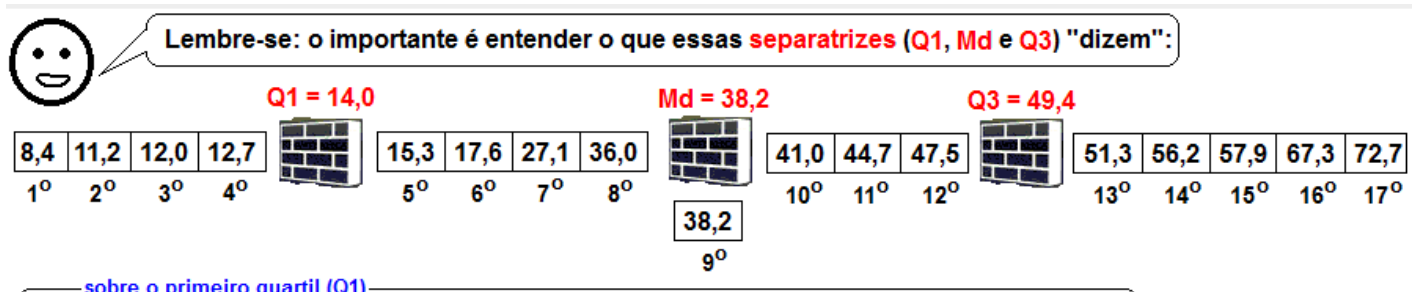

$$
\text { sobre o primeiro quartil (Q1) }
$$

$25 \%$ das Ufs apresentam uma média de até 14,0 médicos/1000 habitantes ou, dito de outra forma, $75 \%$ das Ufs apresentam uma média igual ou superior a 14,0 médicos $/ 1000$ habitantes

sobre a mediana $(\mathrm{Md})$

$50 \%$ das Ufs apresentam uma média de até 38,2 médicos $/ 1000$ habitantes ou, dito de outra

forma, $50 \%$ das UFs apresentam uma média igual ou superior a 38,2 médicos $/ 1000$ habitantes

sobre o terceiro quartil (Q3)

$75 \%$ das Ufs apresentam uma média de até 49,4 médicos/1000 habitantes ou, dito de outra

forma, $25 \%$ das Ufs apresentam uma média igual ou superior a 49,4 médicos $/ 1000$ habitantes

Figura 97 - Tela abordando a mediana, primeiro e terceiro quartis.

Fonte: Elaborado pelo autor.

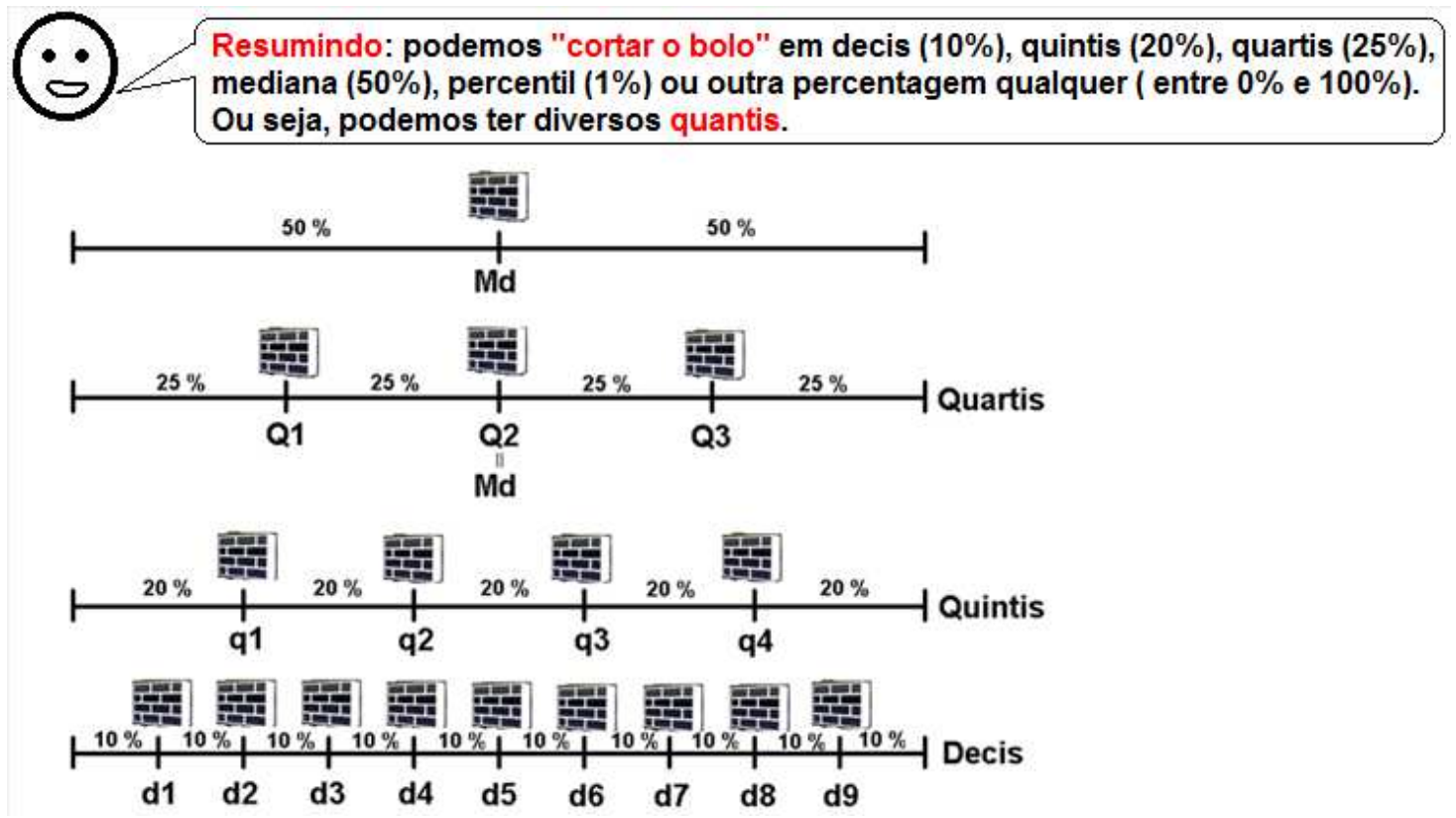

Figura 98 - Tela abordando diversos quantis (separatrizes).

Fonte: Elaborado pelo autor. 

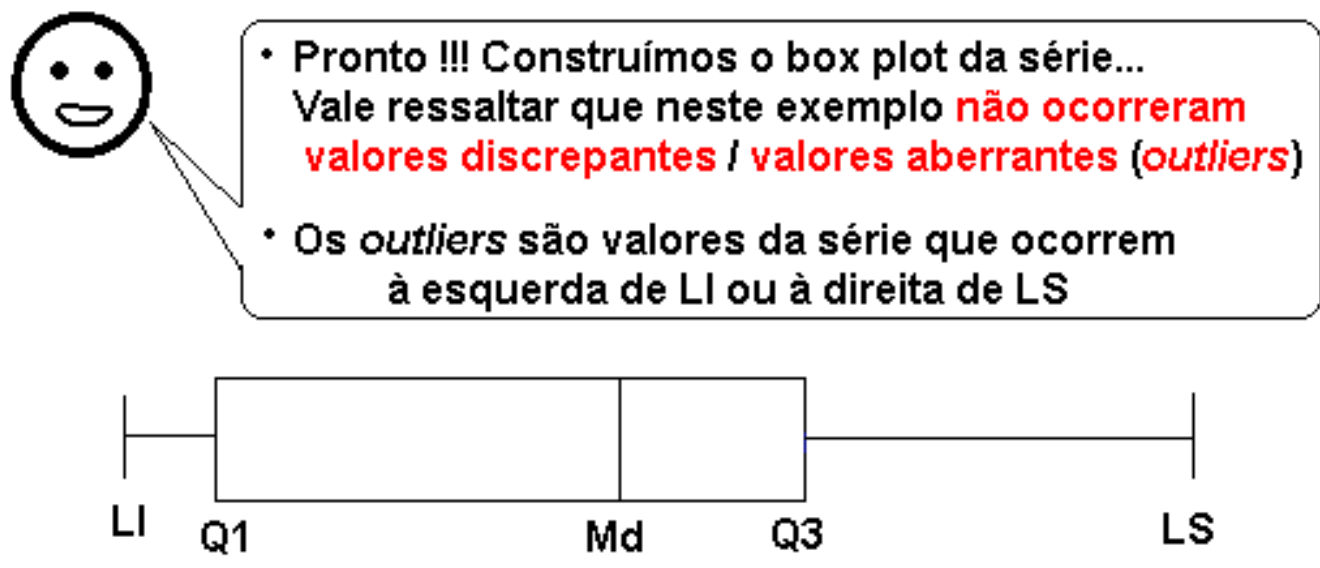

Série de dados ordenada

\begin{tabular}{|l|l|l|l|l|l|l|l|l|l|l|l|l|l|l|l|l|}
\hline 8,4 & 11,2 & 12,0 & 12,7 & 15,3 & 17,6 & 27,1 & 36,0 & 38,2 & 41,0 & 44,7 & 47,5 & 51,3 & 56,2 & 57,9 & 67,3 & 72,7 \\
\hline
\end{tabular}

Figura 99 - Tela mostrando o resultado da construção do box plot para um grupo de dados.

Fonte: Elaborado pelo autor.

3.6.7.1 Respostas dos participantes ao questionário 7 - medidas de posição (separatrizes) e box plot

O questionário 7 encontra-se no Apêndice 12. Nas tabelas 45 a 47 encontram-se as correções dos itens da questão 1 e questão 2. A questão 1 exige como resposta valores calculados. Os itens da questão 2 são, todos, de resposta dicotômica, isto é, o item está certo ou errado. Foram computados o total de itens respondidos corretamente pelo participante. A avaliação do desempenho foi realizada de forma similar à realizada para o questionário 2, ou seja, foram avaliados, qualitativamente, os itens certos e errados do respondente e classificado seu desempenho em satisfatório $(\mathrm{S})$, parcialmente satisfatório $(\mathrm{P})$ ou não satisfatório $(\mathrm{N})$. 
Tabela 45 - Respostas dos participantes P1, P4, P5, P7, P9 e P10

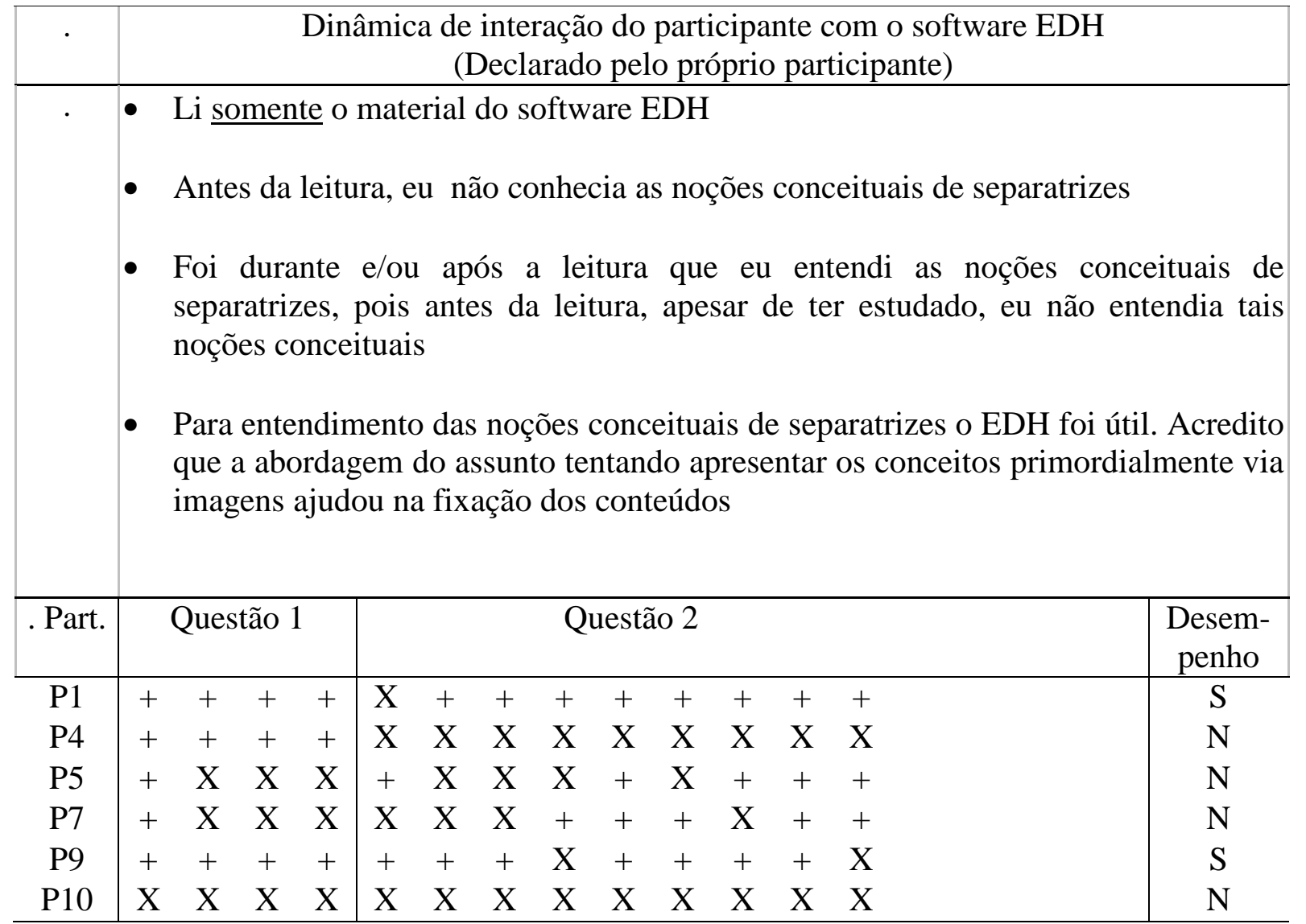

Obs.: + - acertou o item $\mathrm{X}$ - errou o item

Tabela 46 - Respostas do participante P8

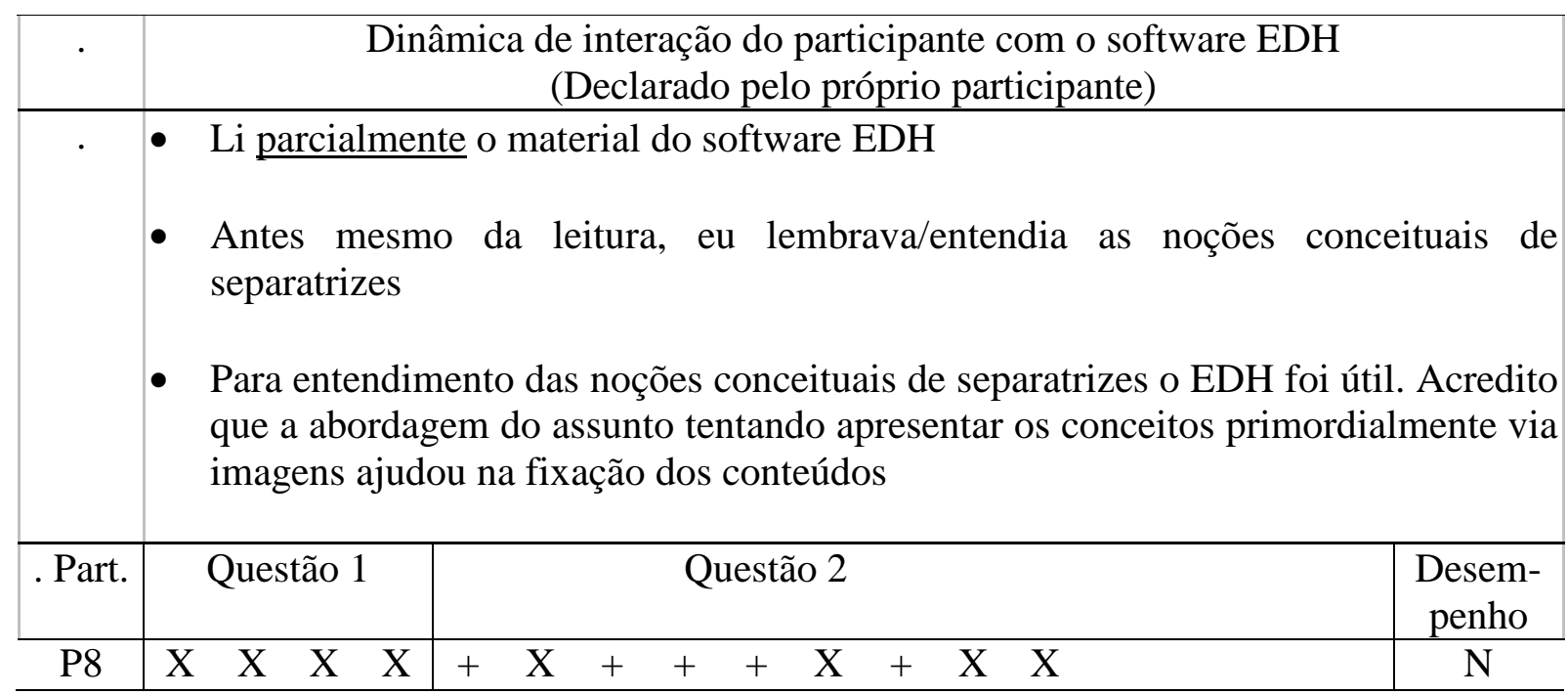

Obs.: + - acertou o item $\mathrm{X}$ - errou o item 
Tabela 47 - Respostas dos participantes P3, P11, P12 e P14

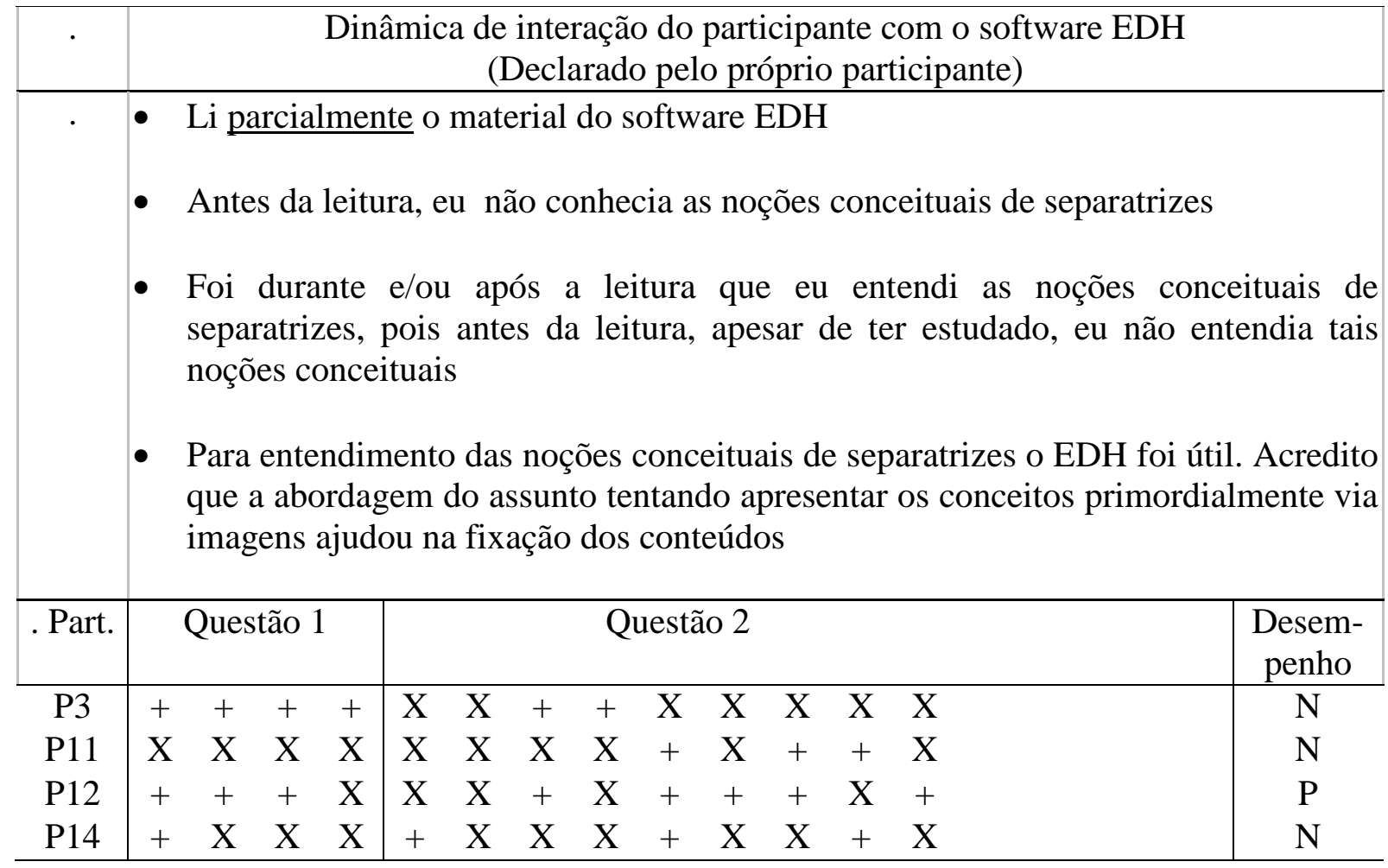

Obs.: + - acertou o item $\mathrm{X}$ - errou o item

Os participantes P2 e P6 declararam não terem lido o material. Os participantes P13 e P15 declararam ter respondido aos itens com base no "chute". Desta forma foram desconsiderados os questionários destes participantes. E os participantes P16, P17, P18 e P19 não compareceram para responder o questionário.

$\mathrm{Na}$ Tabela 48 são transcritos comentários positivos feitos pelos participantes sobre o EDH, e na Tabela 49 os pontos negativos. 
Tabela 48 - Pontos positivos do software EDH citados pelos participantes que responderam o questionário 7

\begin{tabular}{cl}
\hline Part. & \multicolumn{1}{c}{ Pontos positivos sobre o EDH citados } \\
\hline P1 "O uso de imagens dinâmicas “ \\
P3 "Opção de passar imagem por imagem nos GIFs" \\
P4 "Os conceitos de separatrizes apresentados de forma clara, interativa e \\
$\begin{array}{l}\text { exemplificada"; "O uso de imagens, como a de um muro ajudaram no entendimento } \\
\text { e fixação de conceitos" }\end{array}$ \\
P5 "As imagens e dinamicidade do software" \\
P8 "O uso de esquemas explicativos detalhando todas as etapas do cálculo de \\
separatrizes" \\
P9 "Divisão dos quantis com os muros"
\end{tabular}

Tabela 49 - Pontos negativos do software EDH citados pelos participantes que responderam o questionário 7

\begin{tabular}{c|c|}
\hline Part. & Pontos negativos sobre o EDH citados \\
\hline P1 "A velocidade muito rápida da reprodução de imagens" \\
P3 "Não focar intervalo quartílico junto com os quartis" \\
P5 "A interface do software precisa ser aprimorada para despertar mais interesse" \\
\hline
\end{tabular}

\subsubsection{Oitavo encontro - questionário sobre conceitos de curva de Lorenz e coeficiente de Gini (assunto da lição 14 do EDH) (questionário 8)}

A lição 14 do software EDH, versando sobre curva de Lorenz e coeficiente de Gini, foi objeto de análise no questionário 8 do curso de extensão. A curva de Lorenz é um gráfico que auxilia a visualização do grau de concentração de determinada quantidade de recursos em um grupo de entidades previamente identificadas. E o coeficiente de Gini seria uma espécie de "termômetro" que mede o grau de concentração. A lição 14 é composta de 72 telas. Nas figuras 100 a 105 observam-se algumas telas da lição abordando a curva de Lorenz e o coeficiente de Gini. 

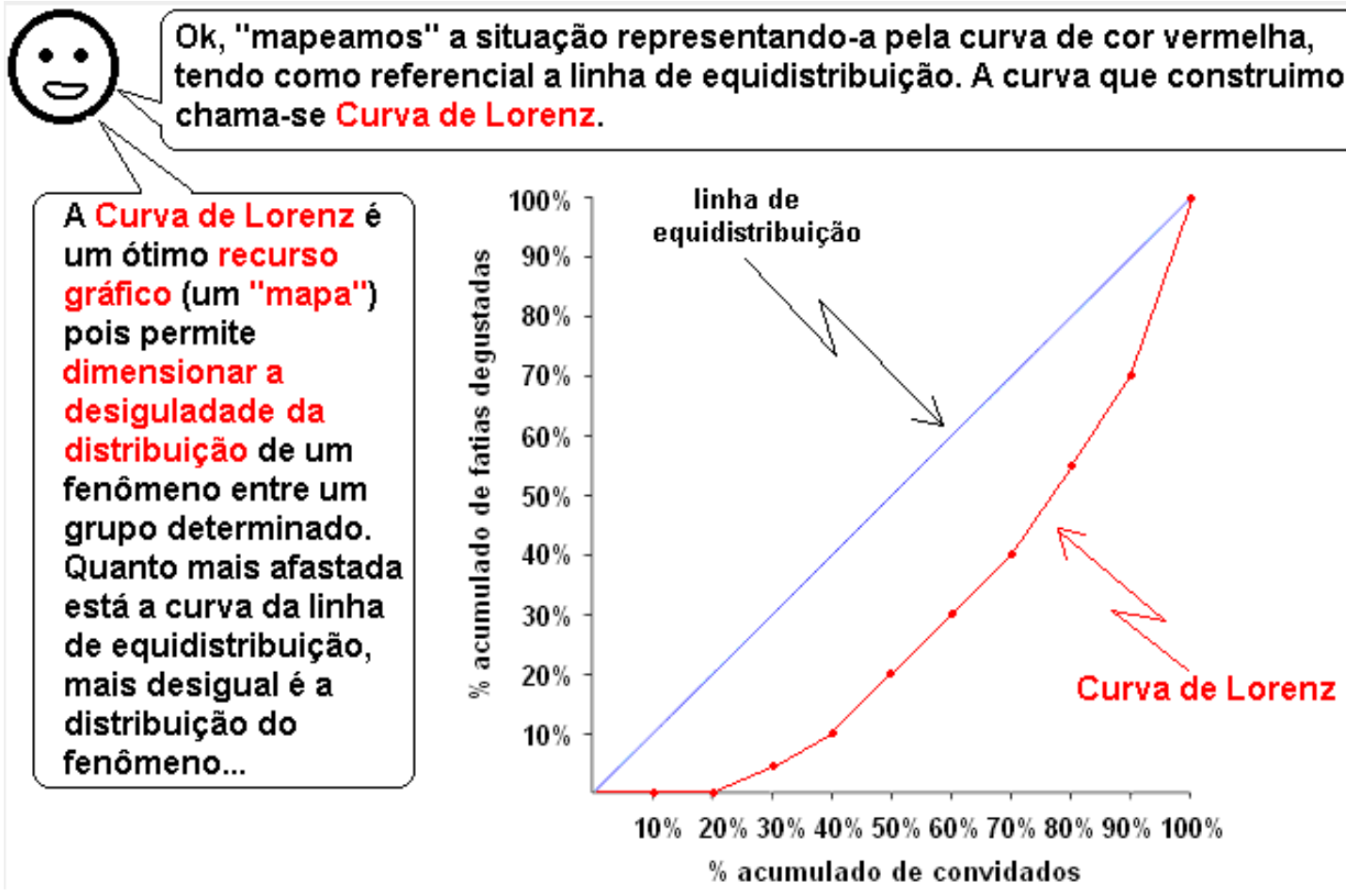

Figura 100 - Tela abordando a utilidade da curva de Lorenz.

Fonte: Elaborado pelo autor.

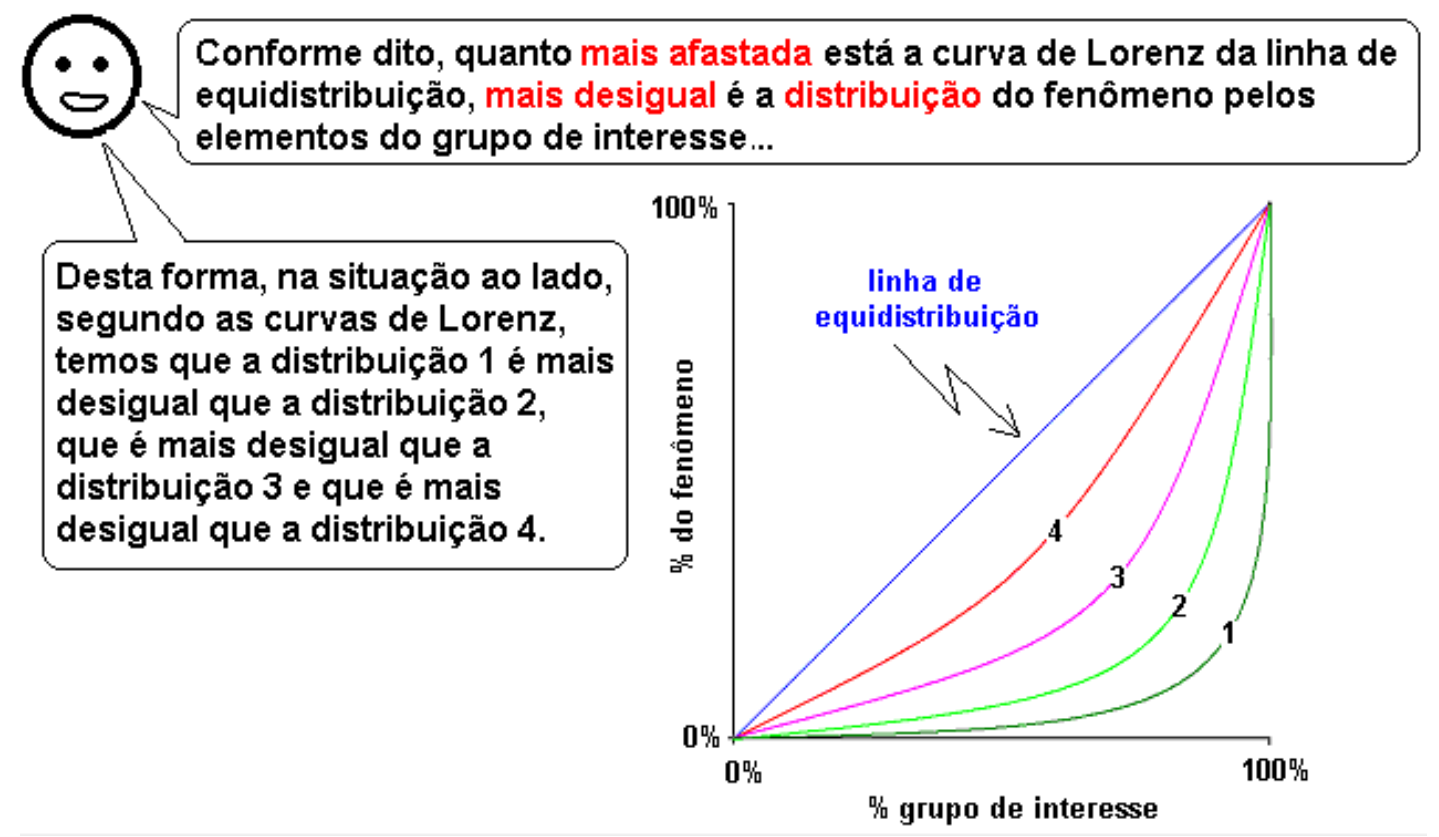

Figura 101 - Tela abordando a utilidade da curva de Lorenz.

Fonte: Elaborado pelo autor. 

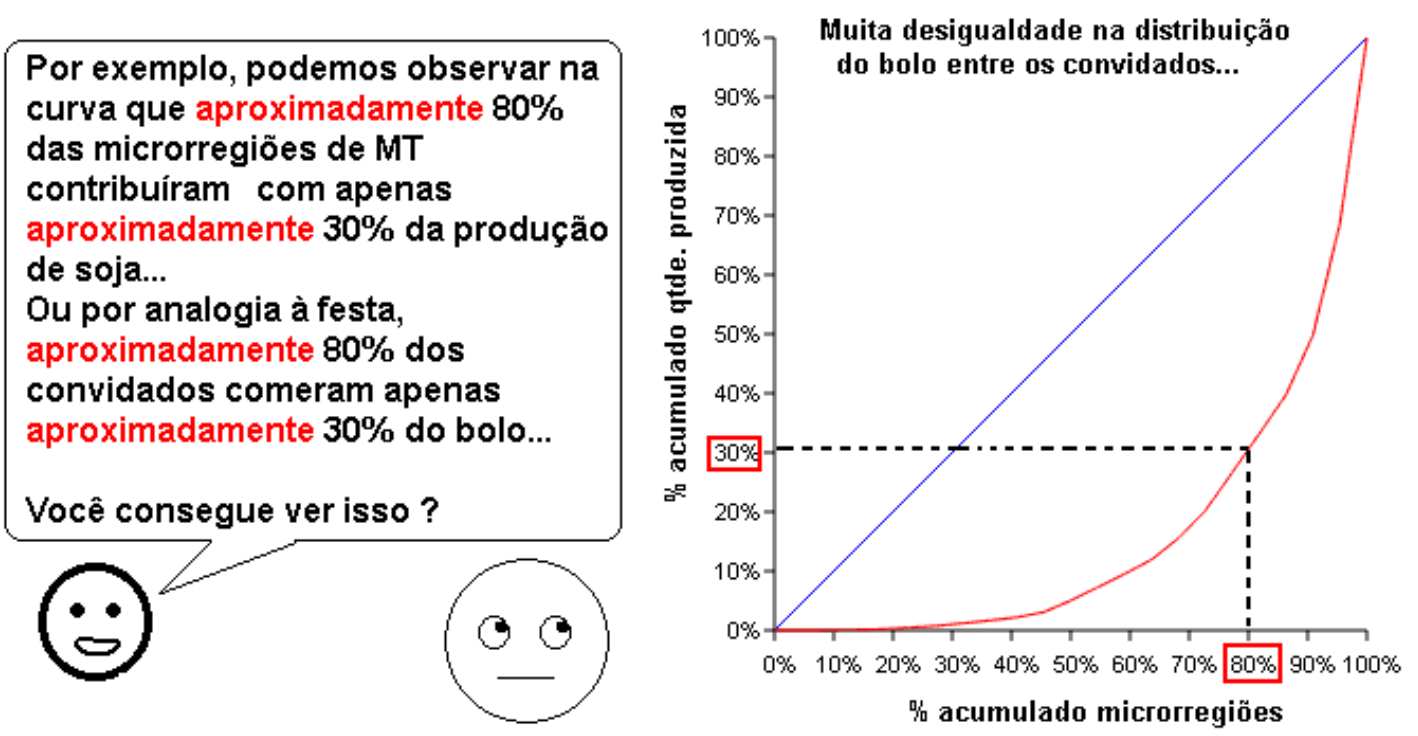

Figura 102 - Tela abordando a "leitura" de informações na curva de Lorenz.

Fonte: Elaborado pelo autor.

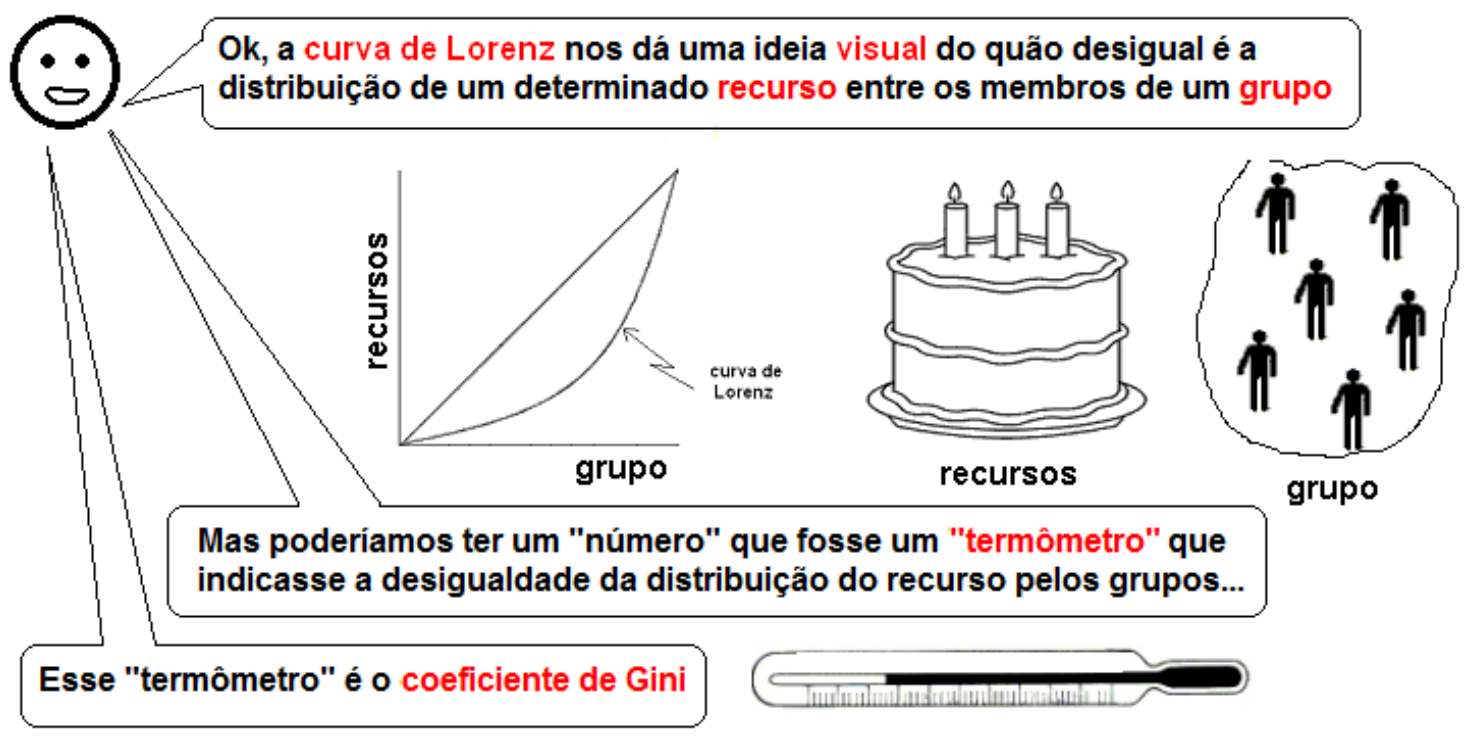

Figura 103 - Tela abordando a ligação conceitual entre a curva de Lorenz e o coeficiente de Gini.

Fonte: Elaborado pelo autor. 


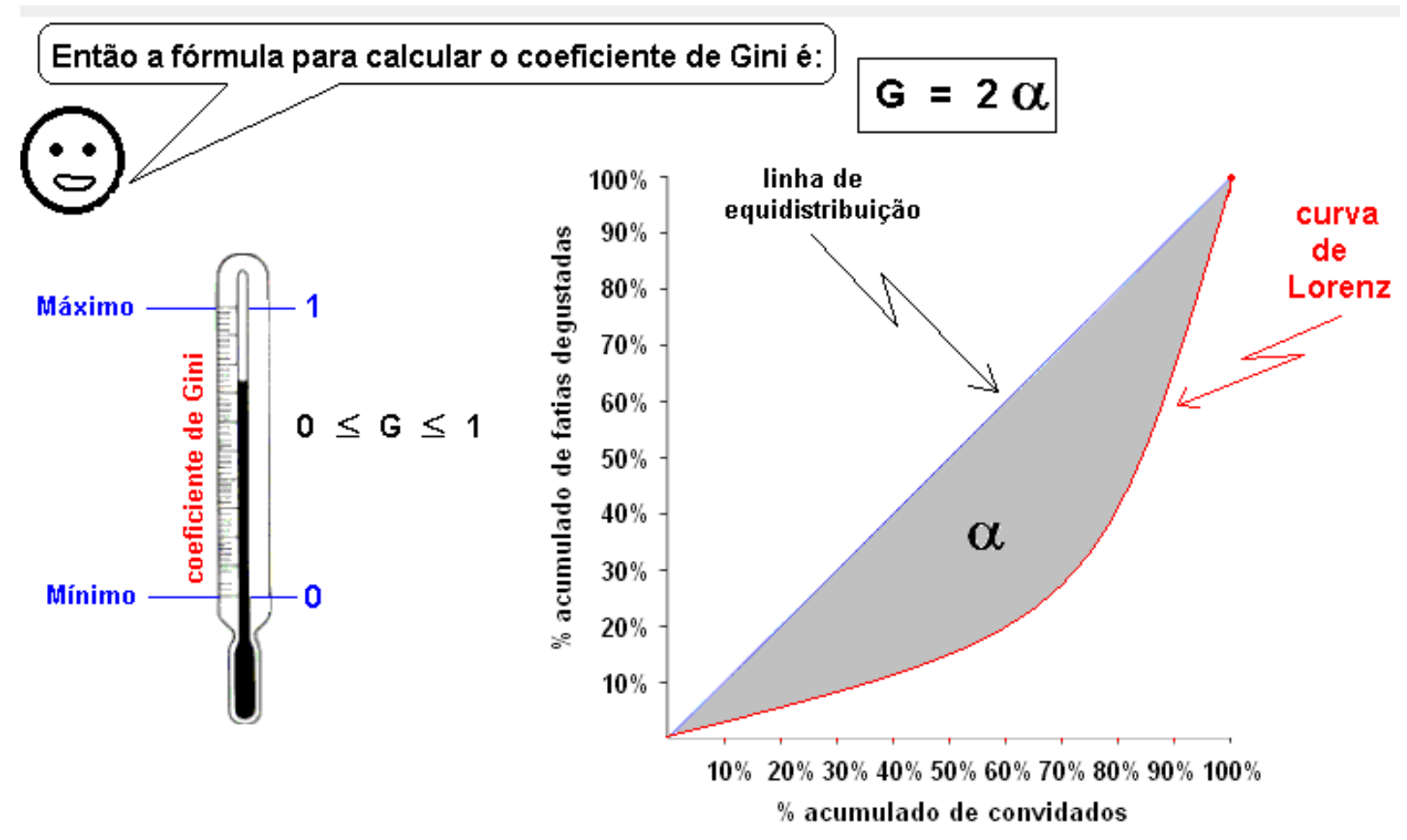

Figura 104 - Tela abordando a ligação conceitual entre a curva de Lorenz e o coeficiente de Gini.

Fonte: Elaborado pelo autor.

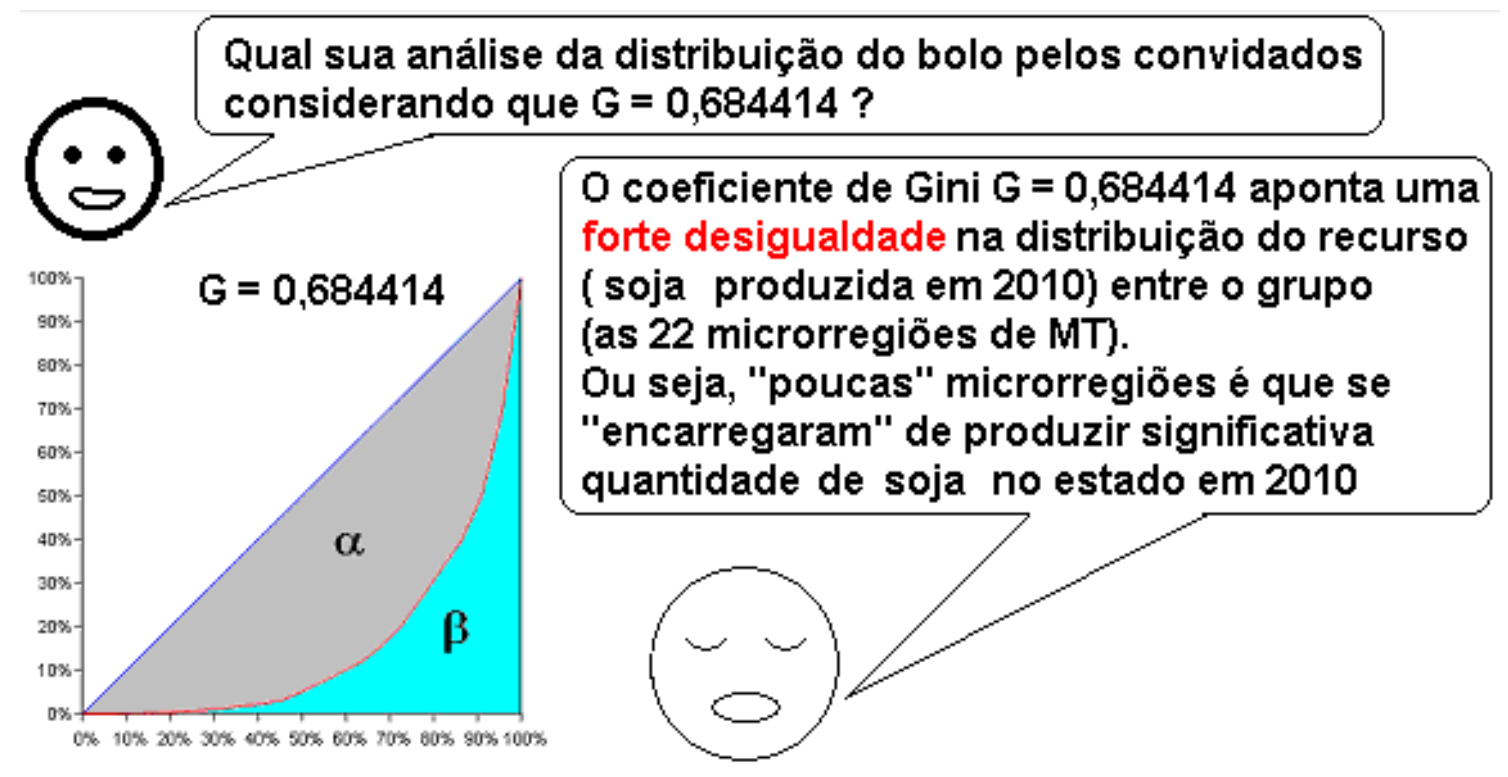

Figura 105 - Tela exemplificando uma análise com base na curva de Lorenz e coeficiente de Gini.

Fonte: Elaborado pelo autor. 


\subsubsection{Respostas dos participantes ao questionário 8 - curva de Lorenz e coeficiente de}

Gini

O questionário 8 encontra-se no Apêndice 13. Na Tabela 50 encontram-se as correções dos itens da questão 1 e questão 2. Os itens da questão 1 são, todos, de resposta dicotômica, isto é, o item está certo ou errado. A questão 2 exige como resposta valores calculados. Foram computados o total de itens respondidos corretamente pelo participante. A avaliação do desempenho foi realizada de forma similar á realizada para o questionário 2, ou seja, foram avaliados, qualitativamente, os itens certos e errados do respondente e classificado seu desempenho em satisfatório $(\mathrm{S})$, parcialmente satisfatório $(\mathrm{P})$ ou não satisfatório $(\mathrm{N})$.

Tabela 50 - Respostas dos participantes P1, P4, P5, P7 e P16

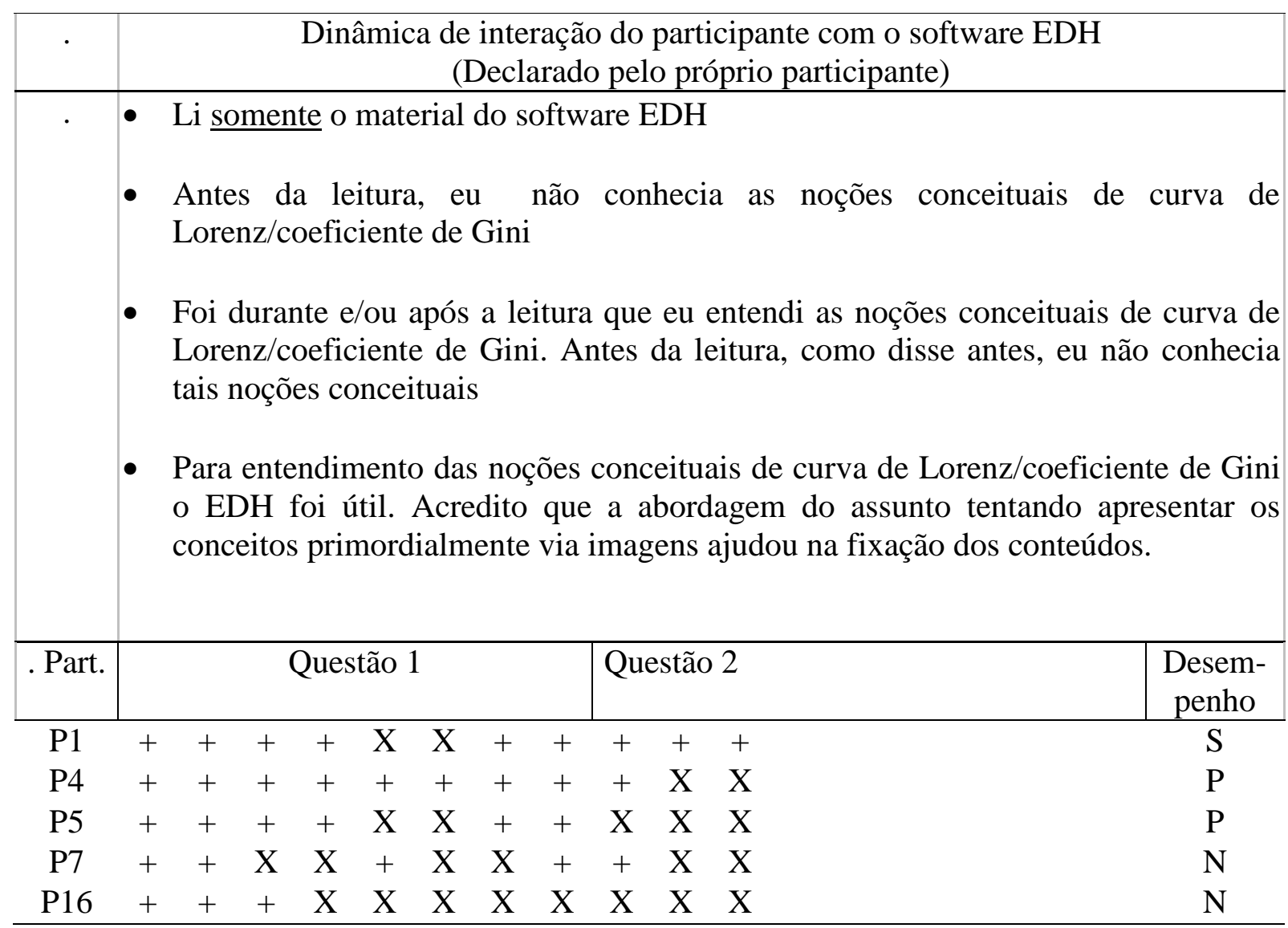

Os demais participantes entre os 19 que concluíram com o mínimo de $75 \%$ de presença não compareceram para responder o questionário.

Na Tabela 51 são transcritos comentários positivos feitos pelos participantes sobre o EDH, e na Tabela 52 os pontos negativos. 
Tabela 51 - Pontos positivos do software EDH citados pelos participantes que responderam o questionário 8

\begin{tabular}{c|c|}
\hline Part. & Pontos positivos sobre o EDH citados \\
\hline P1 "O uso de imagens dinâmicas e desenhos ilustrativos" & \\
P4 "Exemplos interativos, imagens que ajudaram na fixação do conteúdo, como a do \\
bolo dividido pelos convidados" \\
P5 "Tem menos slides com mais explicações" \\
P16 "A linguagem foi bem mais palatável (birita, etc)"; "gostei muito das animações" \\
\hline
\end{tabular}

Tabela 52 - Pontos negativos do software EDH citados pelos participantes que responderam o questionário 8

\begin{tabular}{c|c|}
\hline Part. & Pontos negativos sobre o EDH citados \\
\hline P1 "A quantidade de exercícios que é insuficiente para a prática do assunto abordado" & "Os cálculos se apresentam de forma confusa. Complicam um pouco" \\
P5 & \\
P16 "Achei a parte dos trapézios meio confusa, talvez usar um exemplo menor ajude" \\
\hline
\end{tabular}

\subsection{SÍNTESE DOS RESULTADOS DO CURSO DE EXTENSÃO SOBRE QUANTIFICAÇÃO EM GEOGRAFIA DE SETEMBRO/2014 A NOVEMBRO/2014 USANDO EDH}

A avaliação qualitativa sobre a utilidade do software EDH para auxiliar na aprendizagem significativa de técnicas de quantificação foi feita com base no desempenho dos 19 participantes que chegaram ao final do curso habilitados a receberem certificado de participação por comparecerem a no mínimo $75 \%$ dos encontros. A Tabela 53 apresenta o mapa de desempenho dos 19 participantes nos oito questionários respondidos, incluindo-se o primeiro questionário relativo à familiaridade de conceitos matemáticos. Esta tabela é uma síntese do desempenho dos participantes nos questionários e que foram apresentados em diversas tabelas apresentadas no tópico 3.6. 
Tabela 53 - Mapa de desempenho dos 19 participantes que concluíram o curso de extensão

\begin{tabular}{|c|c|c|c|c|c|c|c|c|c|}
\hline \multirow[b]{2}{*}{ Part. } & \multicolumn{9}{|c|}{ Encontro/Semana/Questionário } \\
\hline & 1 & 2 & 3 & 4 & 5 & 6 & 7 & 8 & \\
\hline & Familiar. & objeto/ & Média & Var. & Centro & Distância & Separat. & coef. & Desem- \\
\hline & Conceitos & var.iável & & Desv. & médio & padrão & Box plot & Gini & penho \\
\hline & Matemáticos & popul. & & Padrão & espacial & & & Lorenz & Geral \\
\hline & & amostra & & & & & & & \\
\hline P1 & Boa & $\mathrm{S}$ & $\mathrm{S}$ & $\mathrm{P}$ & $\mathrm{S}$ & $\mathrm{S}$ & $\mathrm{S}$ & $\mathrm{S}$ & $\mathbf{S}$ \\
\hline & & leu & leu & leu & leu & leu & leu & leu & \\
\hline $\mathbf{P 2}$ & Insuficiente & $\mathrm{X}$ & $\mathrm{P}$ & $\mathrm{x}$ & $\mathrm{P}$ & $\mathrm{x}$ & $X$ & $\mathrm{X}$ & $\mathbf{P}$ \\
\hline & & & leu & & leu & & & & \\
\hline P3 & Boa & $\mathrm{P}$ & $\mathrm{x}$ & $\mathrm{S}$ & $\mathrm{S}$ & $\mathrm{N}$ & $\mathrm{N}$ & $\mathrm{x}$ & $\mathbf{P}$ \\
\hline & & leu parc. & & leu & leu parc. & leu parc. & leu parc. & & \\
\hline P4 & Razoável & $\mathrm{N}$ & $\mathrm{S}$ & $\mathrm{S}$ & S & $\mathrm{N}$ & $\mathrm{N}$ & $\mathrm{P}$ & $\mathbf{S}$ \\
\hline & & leu parc. & leu & leu & leu & leu parc. & leu & leu & \\
\hline P5 & Insuficiente & S & $\mathrm{P}$ & $\mathrm{S}$ & $\mathrm{P}$ & $\mathrm{P}$ & $\mathrm{N}$ & $\mathrm{P}$ & $\mathbf{P}$ \\
\hline & & leu parc. & leu & leu & leu & leu & leu & leu & \\
\hline P6 & Razoável & $\mathrm{X}$ & $\mathrm{S}$ & $\mathrm{N}$ & $\mathrm{S}$ & $\mathrm{x}$ & $\mathrm{x}$ & $\mathrm{x}$ & $\mathbf{P}$ \\
\hline & & & leu & leu & leu & & & & \\
\hline P7 & Insuficiente & $\mathrm{x}$ & $\mathrm{S}$ & $\mathrm{S}$ & $\mathrm{P}$ & $\mathrm{N}$ & $\mathrm{N}$ & $\mathrm{N}$ & $\mathbf{P}$ \\
\hline & & & leu & leu & leu & leu & leu & leu & \\
\hline P8 & Razoável & $\mathrm{S}$ & $\mathrm{S}$ & $\mathrm{P}$ & $\mathrm{S}$ & $\mathrm{N}$ & $\mathrm{N}$ & $\mathrm{x}$ & $\mathbf{P}$ \\
\hline & & leu parc. & leu & leu & leu & leu & leu parc. & & \\
\hline P9 & Boa & S & $S$ & S & S & S & S & $\mathrm{x}$ & $\mathbf{S}$ \\
\hline & & leu & leu & leu & leu & leu & leu & & \\
\hline P10 & Boa & $\mathrm{P}$ & $\mathrm{S}$ & $\mathrm{P}$ & $\mathrm{S}$ & $\mathrm{P}$ & $\mathrm{N}$ & $\mathrm{x}$ & $\mathbf{P}$ \\
\hline & & leu & leu & leu & leu & leu & leu & & \\
\hline P11 & Insuficiente & $\mathrm{N}$ & $\mathrm{P}$ & $\mathrm{N}$ & S & $\mathrm{x}$ & $\mathrm{N}$ & $\mathrm{x}$ & $\mathbf{N}$ \\
\hline & & leu & leu & leu parc. & leu parc. & & leu parc. & & \\
\hline P12 & Razoável & $\mathrm{x}$ & $\mathrm{N}$ & $\mathrm{N}$ & $\mathrm{P}$ & $\mathrm{x}$ & $\mathrm{N}$ & $\mathrm{x}$ & $\mathbf{N}$ \\
\hline & & & leu & leu parc. & leu parc. & & leu parc. & & \\
\hline P13 & Nula & $\mathrm{N}$ & $\mathrm{N}$ & $\mathrm{x}$ & $\mathrm{N}$ & $\mathrm{x}$ & $\mathrm{x}$ & $\mathrm{x}$ & $\mathbf{N}$ \\
\hline & & leu & leu & & leu & & & & \\
\hline P14 & Insuficiente & $\mathrm{S}$ & $\mathrm{N}$ & $\mathrm{x}$ & $\mathrm{x}$ & $\mathrm{x}$ & $\mathrm{N}$ & $\mathrm{x}$ & $\mathbf{N}$ \\
\hline & & leu & leu & & & & leu parc. & & \\
\hline P15 & Insuficiente & $\mathrm{P}$ & $\mathrm{x}$ & $\mathrm{x}$ & $\mathrm{x}$ & $\mathrm{x}$ & $\mathrm{x}$ & $\mathrm{x}$ & $\mathbf{N}$ \\
\hline P16 & Insuficiente & $\begin{array}{l}\text { leu parc. } \\
\mathrm{S} \\
\text { leu parc. }\end{array}$ & $\begin{array}{c}\mathrm{N} \\
\text { leu }\end{array}$ & $\underset{\text { leu }}{S}$ & $\underset{\mathrm{leu}}{\mathrm{S}}$ & $\mathrm{x}$ & $\mathrm{x}$ & $\begin{array}{c}\mathrm{N} \\
\text { leu }\end{array}$ & $\mathbf{P}$ \\
\hline P17 & Insuficiente & $\mathrm{N}$ & $\mathrm{N}$ & $\mathrm{N}$ & $\mathrm{N}$ & $\mathrm{x}$ & $\mathrm{x}$ & $\mathrm{x}$ & $\mathbf{N}$ \\
\hline & & leu parc. & leu & leu & leu & & & & \\
\hline P18 & Insuficiente & $\mathrm{S}$ & $\mathrm{P}$ & $\mathrm{N}$ & $\mathrm{N}$ & $\mathrm{x}$ & $\mathrm{x}$ & $\mathrm{x}$ & $\mathbf{N}$ \\
\hline P19 & Razoável & $\begin{array}{c}\text { leu parc. } \\
\mathrm{N} \\
\text { leu parc. }\end{array}$ & $\begin{array}{c}\text { leu } \\
\text { S } \\
\text { leu }\end{array}$ & $\begin{array}{c}\text { leu parc. } \\
\mathrm{P} \\
\text { leu }\end{array}$ & $\begin{array}{c}\text { leu parc. } \\
\qquad x\end{array}$ & $\mathrm{x}$ & $\mathrm{x}$ & $\mathrm{X}$ & $\mathbf{N}$ \\
\hline
\end{tabular}

Na Tabela 53, a coluna 1 (familiar. conceitos matemáticos) contém o valor categórico (Boa, Razoável, Insuficiente ou Nula) dado à variável familiaridade de conceitos matemáticos, relativa ao desempenho no questionário da primeira semana de encontro. Nas colunas 2 a 8 são apresentados os valores $\mathrm{S}$ (satisfatório), $\mathrm{P}$ (parcialmente satisfatório) ou $\mathrm{N}$ (não satisfatório) indicando o desempenho do participante nos questionários 2 a 8 
respectivamente. Abaixo dos valores $\mathrm{S}, \mathrm{P}$ e N, encontra-se o termo "leu" ou o termo "leu parc." significando, respectivamente, que o participante declarou ter lido o material do EDH, ou então ter lido parcialmente o material do EDH. Nas mesmas colunas 2 a 8, a marcação da letra xis (x) indica que o participante ou faltou ao encontro, ou declarou ter respondido o questionário na base do "chute", sendo então descartada a análise do questionário.

$\mathrm{Na}$ última coluna encontra-se a atribuição qualitativa do desempenho geral do participante em função de seu desempenho apresentado no conjunto de questionários respondidos. Os valores $\mathrm{S}, \mathrm{P}$ e $\mathrm{N}$ têm o mesmo significado atribuído ao desempenho nos questionários, ou seja, significam, respectivamente, satisfatório, parcialmente satisfatório e não satisfatório. Assim, com base nesta coluna de desempenho geral são feitas algumas considerações sobre a utilidade do EDH como ferramenta de apoio à aprendizagem significativa.

Inicialmente deve-se ressaltar a natureza qualitativa da avaliação de desempenho aqui considerada. Há por isso, naturalmente, subjetividade na interpretação e atribuição do desempenho dos participantes considerando-os com desempenho geral satisfatório (S), parcialmente satisfatório $(\mathrm{P})$ ou não satisfatório $(\mathrm{N})$.

Começando a análise pela performance do participante P15, este foi o exemplo típico de participante completamente desinteressado, que realizou o curso com o propósito único de obtenção do certificado de participação. Realizava os questionários sempre "colando" explicitamente as respostas do participante sentando ao seu lado, mesmo sendo avisado em sala de aula reiteradas vezes de que o escopo da resolução do questionário servia apenas aos propósitos de avaliação da utilidade do EDH e era importante sua resolução individual. O resultado de $\mathrm{P} 15$ foi desconsiderado.

Os participantes P13 e P17 apresentaram desempenho geral não satisfatório. P17 informalmente relatou que apresentava "extrema dificuldade" (sic) com matemática e que ao ler as lições do EDH já apresentava dificuldades para entendimento do assunto. E P13 relatou que "desde meu Ensino Médio tinha dificuldade com matemática". E as respostas dos questionários de P13 e P17 parecem apontar a dificuldade com conceitos matemáticos. Neste caso, é notório, no contexto do modelo de aprendizagem significativa de Ausubel, que P13 e P17 não apresentam conceitos subsunçores para aprendizagem significativa do assunto contido no EDH.

O participante P2 apresentou desempenho geral parcialmente satisfatório. Como se observa na Tabela 53, afirmou ter lido somente o material do terceiro e quinto encontro, 
apresentando um desempenho parcialmente satisfatório nos mesmos. De fato, ao comparecer aos encontros, informalmente relatava ter lido "o começo da lição" (sic) e então respondia aos questionários.

Provavelmente estava interessado na obtenção do certificado de participação mas, nos momentos dos questionários da $3^{\mathrm{a}}$ e $5^{\mathrm{a}}$ lições mostrou que realmente havia lido um pouco destas lições, o que refletiu nas suas respostas. Pude então perceber que o pouco contato que fez com o material do EDH foi de alguma forma positivo. Ou seja, para P2, o EDH pareceu ter efeito potencial positivo para uma aprendizagem significativa e, por isso, seu desempenho geral foi considerado parcialmente satisfatório.

O participante P3 apresentou boa familiaridade de conceitos matemáticos no questionário do primeiro encontro mas apresentou desempenho geral parcialmente satisfatório. Conversando informalmente com P3, o mesmo relatava de suas dificuldades com as disciplinas que estava cursando no semestre e que "o semestre está pesado" (sic). Declarou ter lido por completo somente o material do $4^{\mathrm{o}}$ encontro e os demais que leu, fez apenas leitura parcial. Teceu comentários ao EDH nos questionários do $4^{\circ}$ e $5^{\circ}$ encontro, e seus comentários parecem corroborar que, de fato, o que foi lido no EDH tenha sido em alguma intensidade absorvido.

Os participantes P5 e P7 apresentaram padrão de desempenho similares. Apresentaram insuficiência na familiaridade de conceitos matemáticos no questionário do primeiro encontro mas apresentaram desempenho geral parcialmente satisfatório. Em geral, P5 e P7 declararam ter lido quase todas as lições. A maioria de seus desempenhos nos questionários foi classificada como parcialmente satisfatório, mas, pelos diversos comentários positivos e negativos sobre o EDH, nota-se que, de fato, utilizaram o EDH como ferramenta de aprendizado e, algum conhecimento transmitido pelo EDH foi apreendido por P5 e P7. Em conversas informais, P5 e P7 relataram a preocupação e importância de se qualificarem profissionalmente e, assim, muito provavelmente estavam com motivação para, de fato, adquirirem novos conhecimentos.

O participante P6 apresentou razoável familiaridade de conceitos matemáticos no questionário do primeiro encontro e desempenho geral parcialmente satisfatório. Conversando informalmente com P6, o mesmo relatou sua preocupação maior com as disciplinas do curso de Geografia, e que estava quase se formando ("faltam dois semestres para eu me formar"). 
Muito provavelmente continuou no curso de extensão com o propósito de obter o certificado de participação. Pude perceber que P6 leu efetivamente a lição 3, sobre média, quando emitiu o único comentário, de natureza positiva do EDH no caso, sobre o EDH: "Aborda de forma direta e clara os conceitos, mas eu creio que ele seja mais útil para quem já tenha lido sobre. Ele ajuda a relembrar de forma rápida e prática”. Nos demais questionários não emitiu comentários.

P6 já havia cursando anteriormente a disciplina Estatística Aplicada, daí seu comentário sobre o material ajudar a relembrar de forma rápida e prática. Para P6, muito provavelmente faltou motivação para realizar o curso. Pareceu ter o potencial (conceitos subsunçores) para aprender o assunto e, se usasse o EDH de forma mais efetiva certamente obteria uma aprendizagem significativa dos assuntos.

O participante P8 por sua vez, assim com P6, apresentou razoável familiaridade de conceitos matemáticos no questionário do primeiro encontro e desempenho geral parcialmente satisfatório. P8 relatou não gostar de matemática, mas estava fazendo o curso para "aprender um pouco" (sic). De fato, assim como P6, P8 parece ter conceitos subsunçores propícios ao aprendizado do material do EDH. Porém, diferentemente de P6, P8 utilizou o EDH com mais intensidade, pois em quase todas as lições que leu, fez comentários positivos e negativos sobre o EDH, mostrando que de fato interagiu com o software. Assim como P6, P8 pareceu ter o potencial para aprender o assunto e é possível supor que de fato a interação com o EDH o fez aprender de forma significativa.

O participante P10 foi um dos quatro entre os 19 participantes que apresentou boa familiaridade de conceitos matemáticos no questionário do primeiro encontro, mas seu desempenho geral foi parcialmente satisfatório. Em conversa informal, P10 relatou reconhecer a importância da quantificação em Geografia, mas afirmou ter "dificuldades com o assunto" (sic). P10 afirmou ter lido todas as lições para as quais respondeu o questionário, mas é possível que tenha na verdade lido apenas parcialmente o material. Ainda assim, como P6 e P8, pareceu ter o potencial para aprender o assunto.

O participante P16 apresentou insuficiente familiaridade de conceitos matemáticos no questionário do primeiro encontro e desempenho geral parcialmente satisfatório. P16 foi o típico participante que estava bastante motivado no início, mas claramente se desmotivou na metade do curso. Pode-se perceber que realizou a leitura da lição 2 e lição 4 pois colocou como comentários negativos do EDH: "um pouco repetitivo" e "muito texto". Ao comparecer para realização do quarto encontro, me perguntou quantos questionários ainda teria que 
responder. Ao responder que havia mais quatro questionários, P16 disse: "ahhhh, não é possível" (sic).

Contudo, ainda que P16 tenha se desmotivado na metade do curso e tenha tido desempenho insuficiente na resolução do questionário 1, pude perceber que quando estava motivado e interagiu com o software, de fato obteve aprendizagem significativa, pois no momento em que encontrou a repetitividade do assunto significou que captou a ideia do mesmo e emitiu comentário "negativo" acerca da repetitividade presente no software.

Os participantes P11, P12, P14, P18 e P19 foram caracterizados com desempenho geral não satisfatório. P11 e P19 apresentaram desempenho razoável no questionário de mapeamento de familiaridade de conceitos matemáticos enquanto que os demais apresentaram desempenho insuficiente. Em geral, estes participantes afirmaram ter lido parcialmente algumas das lições, e isto pode ter influenciado para terem apresentado desempenho não satisfatório. É possível que pouco antes do horário dos encontros semanais tenham efetivamente começado a leitura e, assim, não tenha havido tempo hábil para assimilação do assunto da lição parcialmente lida. É possível também que sequer tenham lido a lição, mas assinalado que leram parcialmente.

Por exemplo, P11 me relatou que o assunto do curso era interessante pois em seu trabalho usava SIG e realmente sentia a falta de algum embasamento em quantificação. Mas sempre chegava atrasado aos encontros para responder os questionários e chegou a relatar informalmente que "vim lendo a lição no ônibus do trabalho até aqui (UnB)" (sic).

O participante P19 em diversas conversas informais relatou que estava cheio de atividades: dois estágios, quatro disciplinas e uma viagem de campo de duas semanas durante o período do curso de extensão. Em conversas informais, percebi que o pouco que P19 leu de material do EDH, realmente entendeu e debateu o assunto. Provavelmente, se P19 se dedicasse ao curso, teria um bom aproveitamento.

Além disso, a insuficiência no desempenho no questionário de mapeamento de familiaridade de conceitos matemáticos talvez possa de fato espelhar a ausência ou pouca presença de conceitos subsunçores necessários à aprendizagem significativa do assunto. Mas observa-se que em alguns casos este grupo de participantes assinalou pontos positivos e/ou negativos sobre o EDH, indicando terem, de fato, realizado alguma manipulação do material.

Finalmente, os participantes P1, P4 e P9 foram os melhores participantes do curso de extensão, apresentando desempenho satisfatório. P1 e P9 apresentaram bom desempenho no questionário de familiaridade de conceitos matemáticos. Apesar de P4 ter apresentado 
razoável desempenho neste questionário, apresentou a mesma atitude proativa que P1 e P9 durante o curso.

Os três participantes demonstraram motivação para aprender. Após os questionários conversavam sobre o assunto da lição, e perspectivas de aplicação de quantificação em Geografia. P9 é aluno do curso de Economia e relatou que em seu trabalho de conclusão de curso pretendia usar indicadores espaciais para avaliação de cenários microeconômicos. Daí seu interesse e efetiva interação com o EDH e dedicação ao curso. Não realizou o último questionário, mas relatou que teve problemas particulares no dia e se ofereceu para realizar em outra oportunidade o questionário, mesmo sabendo que já tinha garantido o certificado de participação.

P4 apresentou desempenho não satisfatório nos questionários das lições 2, 6 e 7, mas relatou que não teve tempo suficiente para se dedicar ao EDH nestes momentos por estar envolvido em atividades (provas, trabalhos) das disciplinas que estava cursando no semestre. Mas realmente pude perceber seu engajamento nos momentos em que utilizou o EDH, que certamente contribuiu positivamente para apreensão de conteúdos.

O melhor participante do curso sem dúvida foi P1. É o típico aluno com perfil para aprendizagem significativa de quantificação aplicada em Geografia. Muito motivado e, a priori, com domínio de conceitos básicos de matemática (conceitos subsunçores). Realmente se dedicou ao curso, usando o EDH.

Fazendo um balanço geral do curso de extensão, ainda que apenas três entre 19 participantes tenham tido desempenho geral considerado satisfatório, a experiência de uso do EDH como ferramenta de apoio ao ensino se mostrou uma proposta válida, considerando-se o contexto de ocorrência do curso e a realidade dos participantes que em síntese eram:

(1) Os participantes de certa forma foram submetidos a uma sequência estressante de questionários semanais em que se exigia a leitura impreterível de material do EDH toda semana durante sete semanas seguidas.

(2) Os participantes eram alunos que, além do curso de extensão, tinham sua carga horária de disciplinas do curso, com cobranças de leituras de textos, provas e trabalhos e, eventualmente faziam estágio ou trabalhavam. 
(3) Considerando-se o grupo, em geral pode-se dizer que apresentou relativa insuficiência de conceitos subsunçores para aprendizagem dos conceitos de quantificação propostos na lições do EDH. Tal insuficiência certamente foi um obstáculo a mais no processo de aprendizagem.

\subsection{A UTILIDADE DO EDH COMO FERRAMENTA DE AUXÍLIO NO ENSINO DE QUANTIFICAÇÃO APLICADA EM GEOGRAFIA}

Para analisar a utilidade do EDH como ferramenta de auxílio no ensino de quantificação foram avaliados os pontos positivos e negativos citados pelos participantes do curso nos questionários respondidos. O padrão de comentários na maioria dos casos permite mostrar que, de fato, o participante interagiu com o EDH e conseguiu obter algum aprendizado, seja pelo entendimento, seja pela dúvida do conteúdo em questão.

Ao todo, os participantes do curso de extensão e os cinco alunos que usaram o EDH na disciplina Tópicos Especiais em Geografia(no primeiro semestre de 2014) emitiram 71 pontos positivos e 39 pontos negativos sobre o software. No quadro 27 está apresentado um resumo das ideias centrais dos comentários positivos e negativos emitidos. Assim, cada um dos comentários dos participantes está relacionado a um destes temas.

Quadro 27 - Ideias centrais dos pontos positivos e pontos negativos sobre o EDH citados pelos usuários do EDH

\begin{tabular}{|l|ll|}
\hline \multicolumn{2}{|c|}{ Pontos positivos do EDH } & \multicolumn{1}{c|}{ Pontos negativos do EDH } \\
\hline$\checkmark$ Imagens e conceitos & $\checkmark$ & Interface "pobre" (visual "ultrapassado") \\
$\checkmark$ Diferentes exemplos & $\checkmark$ & Mais exercícios de fixação \\
$\checkmark$ Linguagem simples e direta & $\checkmark$ & Muitas páginas \\
$\checkmark$ Interatividade & $\checkmark$ & Exemplos longos \\
$\checkmark$ Autoexplicativo & $\checkmark$ & Repetitividade de assuntos e/ou exercícios \\
$\checkmark$ Animações claras e 'passo a passo' & & \\
$\checkmark$ Lições com exercícios de fixação & & \\
\hline
\end{tabular}

Já foram abordados anteriormente os comentários sobre os pontos positivos e negativos sobre o EDH dos cinco alunos da disciplina de Tópicos Especiais em Geografia. 
Em essência, a impressão destes alunos foi a mesma dos participantes do curso de extensão. Já foi abordado também no tópico 3.6.2 (sobre o questionário 2) sobre pontos positivos e negativos do $\mathrm{EDH}$, que refletem, essencialmente, a mesma opinião dos participantes de pontos positivos e negativos de todas as lições do EDH.

Os pontos positivos (e alguns negativos) apontados pelos participantes são exatamente o que se esperava do EDH: (1) a abordagem de conceitos de quantificação via imagem (estática e/ou dinâmica), com uma linguagem simples com poucas ou mínimas frases escritas num 'balão' representando a fala de um tutor; (2) a interatividade com o software (cliques para cálculos diversos) propiciando uma forma de instrução programada, e (3) os exercícios de fixação propostos via conteúdo imagético.

Como pontos negativos citados pelos participantes, muitas críticas foram feitas a interface do EDH, rotulada de "pobre", "sem cores" e "ultrapassada". E, ressalta-se aqui mais uma vez que, ao contrário, o propósito da interface foi de fato ser a mais simples possível. Se uma interface simples pode ser sinônimo de "pobre", "sem cores", "ultrapassada", então, de fato, é o que foi desejado para o $\mathrm{EDH}$.

Repetindo o que já foi comentado, uma interface mias "rica" aumenta o risco de imagens decorativas e/ou representacionais que somente "embelezam" o texto, ou seja aumenta-se o risco de produção de conteúdo imagético sem valor didático. A "pobreza" da tela força o usuário a refletir apenas sobre o conceito apresentado. Ao contrário, uma tela "rica", em diversos tons de diversas cores ou com outros aparatos visuais e/ou textuais, podem desviar a atenção do conteúdo e dificultar o alcance da aprendizagem significativa.

Outros pontos negativos citados foram os exemplos longos e repetitividade de assuntos e/ou exercícios. Novamente, estas características são explicitamente desejadas para o EDH. O exemplo longo tem o propósito de mostrar passo a passo o assunto. Quando o participante se sente de alguma forma incomodado com o passo a passo, isso significa que ele já entende, ou acaba de entender, via interação com o EDH, os próximos passos do tema explorado. E quando percebe a repetitividade de assunto, significa que entendeu a ideia central do tema.

Por exemplo, o usuário do EDH entendeu o conceito de variância e, assim, o passo a passo mostrado para seu cálculo e diversos exemplos de situações de cálculo de variância (variância de dados pluviométricos, de quantidade produzida de feijão, de peso de recém nascidos, etc) torna-se enfadonho. Mas é esse o objetivo do EDH: tornar o assunto trivial para o usuário. Portanto, exemplos que se tornam longos e lições com repetitividade aos olhos do 
usuário são pontos positivos do $\mathrm{EDH}$, pois sinalizam a ocorrência de aprendizagem significativa do tema em questão.

Foram citados como pontos negativos ainda, lições com muito texto. Infelizmente, existem assuntos que vão requerer mais páginas eletrônicas do que outras. Assim, a quantidade de páginas dependerá muito da complexidade de conceitos inerentes ao assunto que se deseja ensinar. E a disponibilidade de poucos exercícios, pode ser resolvida propondose mais exercícios para as lições.

Como resultado final, o curso de extensão permitiu apontar que há indícios principalmente ao se analisar o padrão de pontos fortes e pontos fracos do software apontados pelos usuários - para considerar o software EDH como ferramenta útil para proporcionar aprendizagem significativa e, a médio e longo prazo, contribuir para o raciocínio, pensamento e letramento estatístico do educando.

\subsection{MAPEAMENTO DA IMPORTÂNCIA DADA PELO GRADUANDO EM GEOGRAFIA PARA A QUESTÃO DE QUANTIFICAÇÃO EM GEOGRAFIA}

No primeiro encontro do curso de extensão, foi aplicado o questionário para mapeamento da familiaridade de conceitos matemáticos por parte do graduando. Conforme apontado, neste encontro 38 dos 50 participantes inscritos comparecerem e responderam o questionário. Porém, após duas semanas, quando da aplicação do questionário 3, 19 dos 38 participantes haviam desistido, além de dez inscritos que nunca compareceram ao curso.

Além disso, no segundo semestre de 2013 ocorreu o fato de apenas 30\% dos alunos da turma de Climatologia Geral terem manifestado interesse em realizar o curso de extensão em quantificação. Diante destas circunstâncias, em outubro de 2014, $\operatorname{logo}$ após o $3^{\circ}$ encontro do curso de extensão, decidi elaborar um questionário para mapear a importância que o graduando de Geografia creditava à quantificação. Foi então elaborado um questionário para identificar a opinião dos alunos sobre o assunto. Diferentemente dos outros questionários, este foi um questionário para ser respondido rapidamente, pois não haviam cálculos a serem realizados, somente a coleta da impressão dos alunos sobre a questão da quantificação em Geografia. 
O questionário foi elaborado para ser aplicado na UnB, dada a facilidade de aplicação neste local, e foi realizado em novembro de 2014, contando com 134 respondentes. Destes, 120 eram alunos da Geografia. Nas figuras 106 e 107 observam-se os itens do questionário.

\section{Questionário para mapeamento da importância dada pelos alunos do Curso de Geografia} para a questão de quantificação em Geografia
(1) Idade: anos completos
(2) Sexo: [ ] Feminino [ ] Masculino
(3) Curso de graduação: Semestre: (ex.: $1^{\circ}$ semestre, $2^{\circ}$ semestre, $\ldots$ )

(4) Você gosta de matemática e/ou estatística ?

[ ] Detesto [ ] Gosto um pouco [ ] Gosto [ ] Gosto muito

(5) Sobre a relevância de métodos quantitativos (estatística) para a formação profissional do geógrafo você acredita ser:

[ ] Sem qualquer importância [ ] Pouco importante [ ] Importante [ ] Muito importante

] Sem importância para a linha da geografia humana, mas importante para a linha da geografia física

] Ainda não tenho base para opinar sobre a relevância de métodos quantitativos na formação do geógrafo

(6) Você já cursou a disciplina "Estatística Aplicada" ? [ ～Sim ～～～Não

Figura 106 - Primeira parte do questionário para mapear a importância dada pelos graduandos de Geografia para a questão de quantificação em Geografia.

Fonte: Elaborado pelo autor. 
Se você respondeu "Sim" ao item (6), por favor responda aos itens (7) a (14) abaixo:

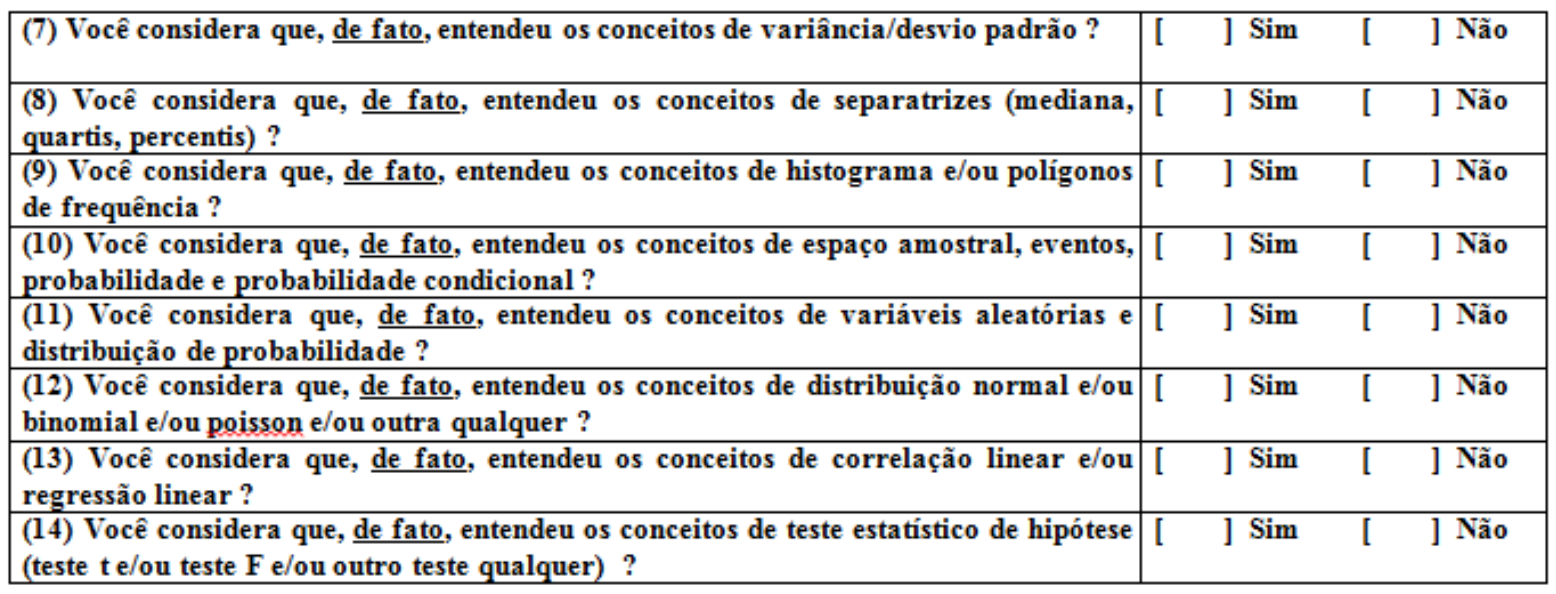

Caso considere ter tido ponto(s) positivo(s) para sua formação acadêmica/profissional ao cursar Estatística Aplicada, por favor cite-os resumidamente nas linhas abaixo

Caso considere ter tido ponto(s) negativo(s) para sua formação acadêmica/profissional ao cursar Estatística Aplicada, por favor cite-os resumidamente nas linhas abaixo

*** FIM - MUTTO OBRIGADO POR COLABORAR !!! ***

Figura 107 - Segunda parte do questionário para mapear a importância dada pelos graduandos de Geografia para a questão de quantificação em Geografia.

Fonte: Elaborado pelo autor.

Após a aplicação dos questionários foram geradas algumas estatísticas descritivas que permitiram ter uma primeira aproximação sobre a importância dada pelos alunos ao tema. Foram consideradas nestas estatísticas apenas os 120 questionários dos alunos graduandos de Geografia. Vale ressaltar que é possível que alunos que responderam este questionário responderam também em 2013 o questionário de mapeamento da familiaridade de conceitos matemáticos.

Com relação à afetividade por matemática/estatística, na Figura 108 observa-se a distribuição de frequência da variável gosta de matemática/estatística. 


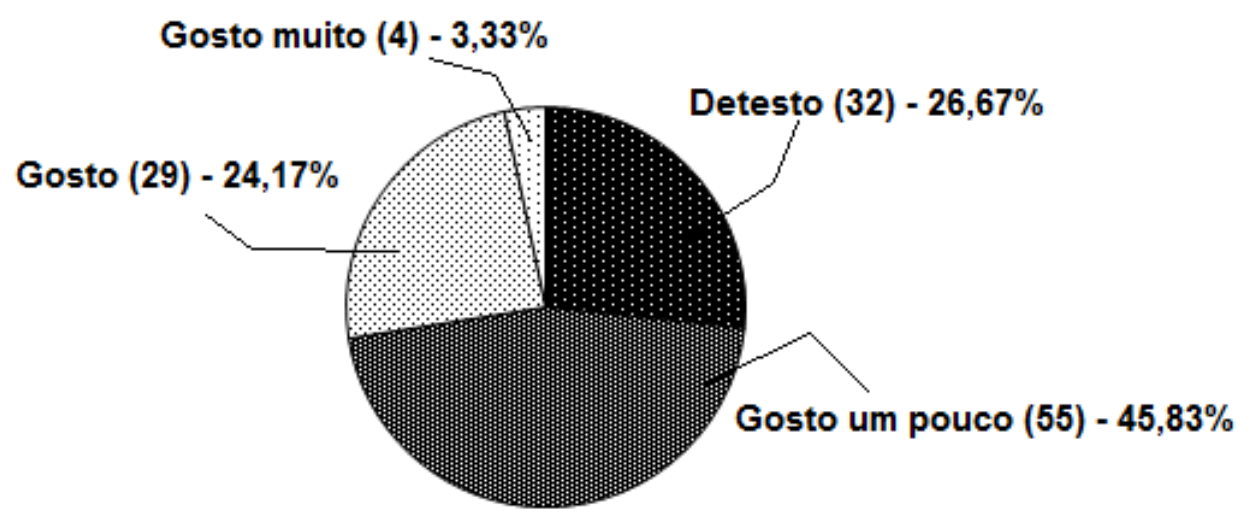

Figura 108 - Distribuição de frequência da variável gosta de matemática/estatística.

Fonte: Elaborado pelo autor.

A proporção de afetividade por matemática/estatística se manteve muito próxima àquela verificada no questionário de mapeamento de familiaridade de conceitos matemáticos de 2013. Talvez efetivamente seja válida a hipótese de que poucos graduandos em Geografia gostem realmente de Matemática.

Outra avaliação realizada foi para verificação de associação ou não entre as variáveis sexo e gosta de matemáticalestatística. A Tabela 54 é a tabela de contingência dessas variáveis. Os valores gosto e gosto muito da variável gosta de matemáticalestatística foram agrupados para fins de realização do teste qui-quadrado. Foi calculada a estatística $\mathrm{V}$ de Cramer, que é baseada na estatística $\chi^{2}$, no ambiente de software $\mathrm{R}$ com os dados da Tabela 54.

Tabela 54 - Distribuição de frequência de afetividade por matemática/estatística conforme as categorias detesto, gosto um pouco e gosto/gosto muito com base na variável sexo

Gosta de matemática/estatística

\begin{tabular}{|c|c|c|c|}
\hline Sexo & Detesto & $\begin{array}{c}\text { Gosto um } \\
\text { pouco }\end{array}$ & $\begin{array}{c}\text { Gosto/gosto } \\
\text { muito }\end{array}$ \\
\hline
\end{tabular}

\begin{tabular}{ccccc}
\hline Feminino & 20 & 19 & 12 & 51 \\
Masculino & 12 & 36 & 21 & 69 \\
\hline Total & 32 & 55 & 33 & 120 \\
\hline
\end{tabular}

Foi obtido $\chi^{2}=7.1704$. O teste de significância para $\chi^{2}$ foi o seguinte: hipótese $\mathrm{H}_{0}=$ as variáveis sexo e gosta de matemáticalestatística são independentes, isto é, $\chi^{2}=0$. A hipótese alternativa $\mathrm{H}_{1}$ aceita a associação entre as mesmas $\left(\chi^{2} \neq 0\right)$. Para $\chi^{2}=7.1704$ com dois graus 
de liberdade o p-valor vale 2,773\%. O teste seria então significativo ao nível de 2,773\% o que permitiria aceitarmos $\mathrm{H}_{1}$, ou seja, admitir que há associação entre as variáveis. A medida de Cramer encontrada foi $\mathrm{V}=0,24444$. Quanto mais perto de 0 , maior a evidência de que as variáveis apresentam uma associação fraca. Para $\mathrm{V}=0$ significa que as variáveis não apresentam associação entre si. O valor 0,24444 está um pouco afastado de zero, o que sinaliza uma fraca ou talvez uma levemente moderada associação entre as variáveis consideradas, ou seja, o gosto por matemática/estatística poderia estar associado ao sexo do indivíduo.

Com relação à relevância de métodos quantitativos para a Geografia, a opinião dos 120 respondentes está apresentada na Figura 109.

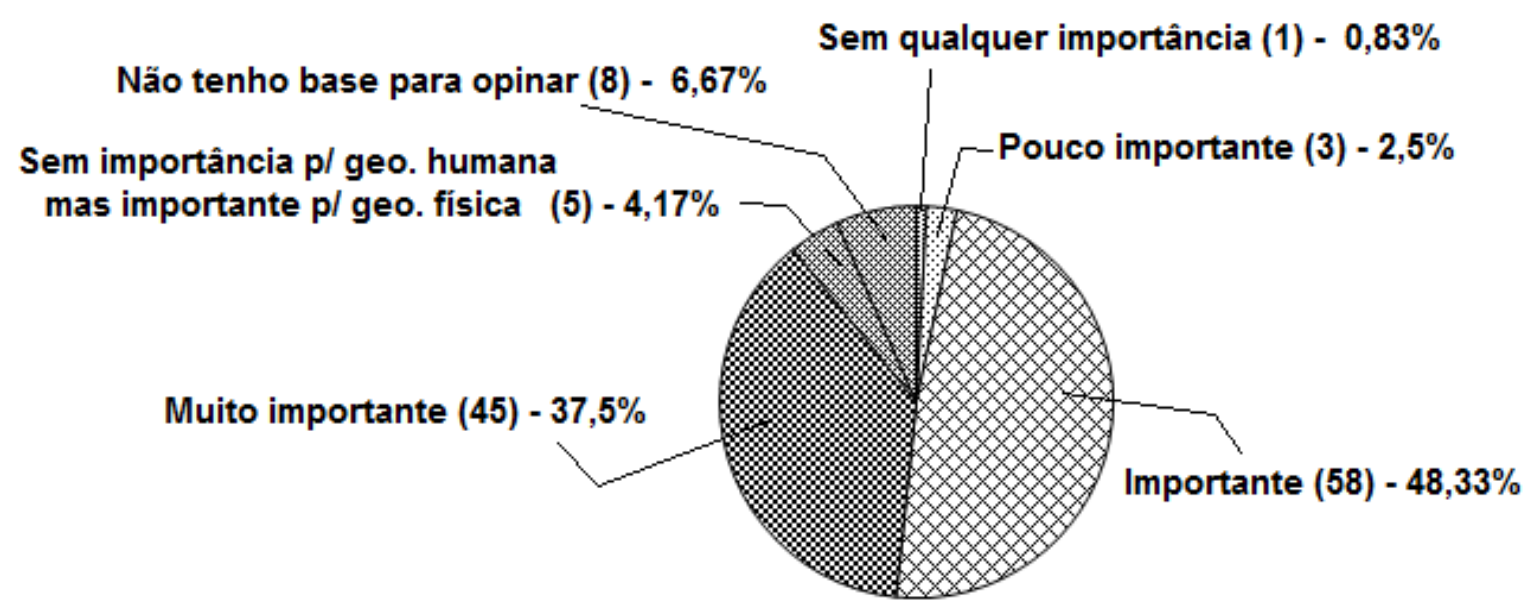

Figura 109 - Distribuição de frequência da variável relevância de métodos quantitativos Fonte: Elaborado pelo autor.

Observa-se na Figura 109 que 85,83\% dos respondentes, ou seja, 103 respondentes afirmaram ser importante e/ou muito importante os métodos quantitativos para a formação profissional do geógrafo. Apenas quatro respondentes não consideram importante e cinco respondentes acham relevante apenas para a área de Geografia Física. E chama a atenção que desses 103 respondentes que reconhecem a importância da quantificação, 70 afirmaram detestar ou gostar um pouco de matemática/estatística, ou seja, aproximadamente $68 \%$ dos 103 respondentes reconhecem a relevância da quantificação, mas não gostam efetivamente de matemática/estatística.

Dos 120 respondentes que cursavam geografia, 62 já haviam cursado a disciplina única obrigatória do curso de Geografia relacionada à quantificação: Estatística Aplicada. Nos itens (7) a (14) do questionário (ver Figura 107) os alunos que haviam cursado Estatística 
Aplicada informaram se consideravam ter, de fato, entendido ou não determinados conceitos relativos à disciplina. Na Figura 110 observam-se os conceitos considerados e a quantidade de respondentes que disseram ter e não ter entendido os conceitos.

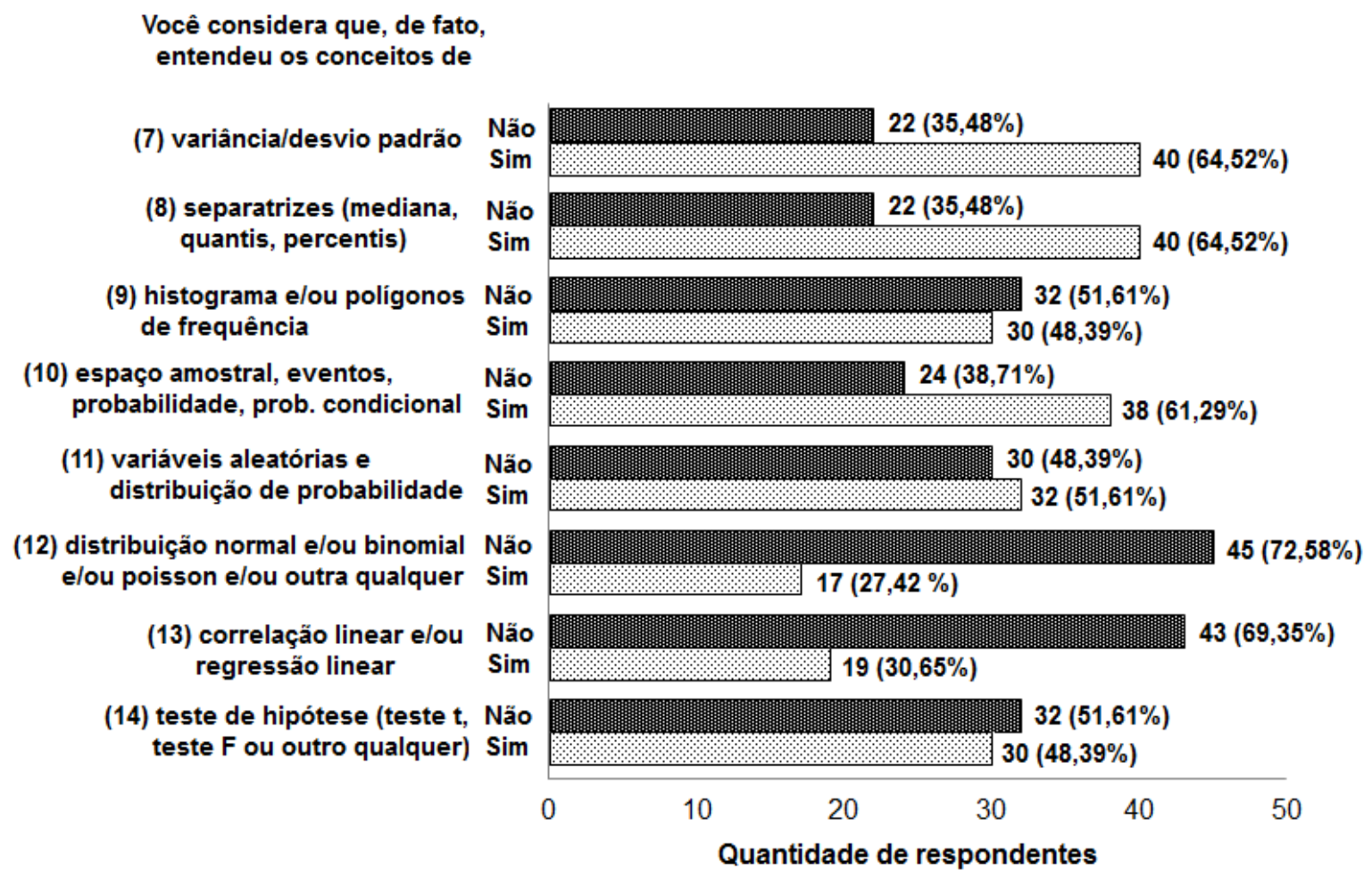

Figura 110 - Respostas dos 62 respondentes do curso de Geografia que já haviam cursado a disciplina Estatística Aplicada sobre o aprendizado de fato de alguns conceitos que foram ou deveriam ter sido ministrados na disciplina.

Fonte: Elaborado pelo autor.

Conforme se observa na Figura 110, dos 62 respondentes dos itens (7) a (14) do questionário, 64,52\%, a maioria portanto, afirmou ter entendido os conceitos de variância e desvio padrão, assim como igualmente a mesma proporção afirmou ter entendido os conceitos de separatrizes e 61,29\% afirmaram entender, de fato, os conceitos de espaço amostral, eventos, probabilidade e probabilidade condicional.

A amostra de respondentes deste questionário foi formada somente por alunos da UnB e, se esta proporção de maioria de alunos - aproximadamente $60 \%$ - que afirma realmente (de fato) ter entendido os conceitos perguntados nos itens (7), (8) e (10) for real, seria esperado que uma questão envolvendo algum dos conceitos citados em (7), (8) e (10) fosse corretamente respondida por aproximadamente $60 \%$ dos graduandos de Geografia da UnB que o respondessem. 
Não se sabe no escopo deste trabalho quais alunos da UnB além de responderem este questionário, responderam também o questionário de mapeamento de familiaridade de conceitos matemáticos aplicado em 2013. Não é possível fazer alguma avaliação mais precisa sobre este resultado, portanto.

Todavia, o questionário de 2013 foi respondido por 384 graduandos de Geografia de seis instituições públicas uma faculdade particular. Mas dos 384 respondentes, 211 eram alunos da UnB. Neste questionário, a Questão 3 tratava de um cálculo de probabilidade relativamente simples (ver Figura 45). Destes 211 alunos da UnB, apenas 52 acertaram esta questão envolvendo conceito de probabilidade, ou seja, 24,64\%. E neste questionário, para o item (10) 61,29\% dos graduandos de Geografia da UnB afirmaram ter entendido o conceito de probabilidade.

Se aproximadamente $60 \%$ dos graduandos de Geografia da UnB entendem de fato os conceitos de probabilidade, então no questionário de 2013 talvez deveria ocorrer proporção de acertos da Questão 3 entre os alunos da UnB por volta de $60 \%$ e não $24,64 \%$ como ocorreu. Há discrepância entre as proporções destas amostras. Mas, conforme dito, não há possibilidade de melhor avaliação, pois não se tem controle sobre os indivíduos das duas amostras. Contudo, a discrepância suscita dúvidas sobre o real entendimento por parte do aluno sobre o conceito de probabilidade. Tal questionamento talvez possa ser feito também sobre os outros conceitos em que a maioria declarou de fato entender.

Neste questionário foi solicitado aos alunos que cursaram Estatística Aplicada relatar os pontos positivos e pontos negativos que a disciplina proporcionou ou poderia proporcionar na formação acadêmica/profissional. Dos 62 alunos que cursaram Estatística Aplicada, foram citados 40 pontos positivos e 27 pontos negativos. Os pontos positivos e negativos citados estão apresentados nos apêndices 14 e 15 respectivamente.

No quadro 28 está apresentado um resumo das ideias centrais dos comentários positivos e negativos emitidos. Assim, cada um dos comentários dos participantes está relacionado a um destes temas. 
Quadro 28 - Ideias centrais dos pontos positivos e pontos negativos sobre a disciplina "Estatística Aplicada"

\begin{tabular}{|ll|}
\hline \multicolumn{1}{|c|}{ Pontos positivos da disciplina Estatística Aplicada } \\
\hline$\checkmark$ & Aplicar em SIG \\
$\checkmark$ & Compreender melhor Geografia Biológica \\
$\checkmark$ & Aprender coletar e interpretar dados \\
$\checkmark$ & Para leitura de gráficos e tabelas \\
$\checkmark$ & Hoje todas as ciências utilizam dados numéricos como forma de interpretação \\
& $\quad$ Pontos negativos da disciplina Estatística Aplicada \\
$\checkmark$ & Detalhes matemátice de reprovação dos alunos da Geografia \\
$\checkmark$ & Unb foca em Geografia Humana \\
$\checkmark$ & Como a disciplina é dada se torna monótona \\
$\checkmark$ & Poderia haver uma turma específica para a Geografia \\
$\checkmark$ & Conteúdo passado rapidamente (professor 'cospe' a matéria) \\
$\checkmark$ & Limitação no aprofundamento por falta de base do Ensino Médio \\
$\checkmark$ & Usar exemplos mais específicos da nossa área de atuação \\
$\checkmark$ & Só existe essa matéria obrigatória de cálculo. Poderia ter mais algumas \\
$\checkmark$ & Alunos da Geografia dão pouca importância sendo que é essencial \\
&
\end{tabular}

Em geral, os alunos citam a disciplina positivamente pelos benefícios que a mesma proporcionou a eles para realização do processamento de dados inicial, ou seja, estatística descritiva básica (coleta/tabulação de dados, representação gráfica e interpretação básica).

Mas os pontos negativos chamam mais a atenção. São apontadas fragilidades do processo de capacitação em quantificação. Surge a visão da divisão da Geografia nas dimensões humana e física, sendo a primeira privilegiada na UnB. E o fato da disciplina única de quantificação é notada. Nesta disciplina única o conteúdo é passado rapidamente sendo “cuspida" pelo professor, o que permite subentender que o conteúdo não será assimilado. Há a solicitação de aluno que pede mais carga de disciplina lidando com quantificação no curso.

Aponta-se ainda uma "mea-culpa" do aluno que admite não ter base matemática mesmo sendo egresso do Ensino Médio que, a priori, iria proporcionar tal base. Finalmente 
deve-se ressaltar que há crítica que deve ser tomada como sugestão de haver disciplina de quantificação específica para a Geografia, e sugestão/solicitação de se apresentarem exemplos de quantificação relativos especificamente à Geografia.

Pode-se notar que, em essência, a proposta do software EDH é ser uma ferramenta de auxílio no ensino da temática da quantificação privilegiando exemplos da Geografia. O EDH permite que o conteúdo seja analisado pelo usuário no seu próprio ritmo de aprendizagem, minimizando a eventual "cuspida" de matéria por parte do professor. Em suma, pode-se dizer que a ideia do EDH talvez possa ser válida para auxiliar a minimizar as dificuldades que o aluno da Geografia enfrenta ao cursar a disciplina única de quantificação.

Para finalizar, o questionário aplicado mostrou que, em geral, a amostra entrevistada de alunos da Geografia, não é tão entusiasta da quantificação, mas reconhece sua importância no trabalho geográfico. E nas críticas citadas à disciplina única cursada, apontam possíveis entraves ao aprendizado significativo em quantificação que surgem na sua formação acadêmica.

\subsection{O USO DO EDH COMO FERRAMENTA DE AUTOESTUDO DE MÉDIA, VARIÂNCIA, DESVIO PADRÃO E COEFICIENTE DE VARIAÇÃO}

O curso de extensão, conforme já comentado, não apresentava qualquer tipo de cobrança de aprendizado dos conceitos de quantificação embutidos no EDH. Em essência, a motivação e/ou o senso de responsabilidade do próprio aluno foram os elementos que podem ter, juntamente com o próprio EDH, desencadeado alguma instância de aprendizagem significativa no participante do curso. Conforme anteriormente relatado, houve casos de participantes somente comparecendo aos encontros do curso para garantir a presença mínima de $75 \%$ e receber o certificado, e participantes que alegavam "ler parcialmente" ou mesmo "não ler" a lição, fato que prejudicou a avaliação da utilidade do EDH.

Desta forma, para o primeiro semestre de 2015, juntamente com a professora Ercília foi planejada uma ação para uso do EDH por parte de alunos da Geografia, onde haveria uma cobrança, uma forma relativamente coercitiva para uso do EDH por parte do aluno. A ação ocorreu da forma descrita a seguir.

A professora Ercília lecionaria a disciplina Climatologia Geral no primeiro semestre de 2015. A avaliação dos alunos desta disciplina se daria mediante a aplicação de três provas, 
cada prova com valor máximo de dez pontos. Então foi proposto o seguinte: a primeira avaliação passaria a contar não mais com dez, mas sim com 13 pontos. Os três pontos a mais da primeira avaliação ficariam assim distribuídos: 1,5 ponto para um teste de avaliação de conhecimentos matemáticos básicos (teste 1) e 1,5 ponto para um teste de conhecimentos sobre média, variância, desvio padrão e coeficiente de variação com base nas lições 1 a 8 do software EDH (teste 2).

Como a disciplina Climatologia Geral é disciplina do primeiro período da grade curricular do curso de Geografia, a grande maioria da turma era composta de calouros, recém egressos do Ensino Médio. Assim, o primeiro teste seria um bom termômetro de aferição da familiaridade de conceitos matemáticos básicos. Logo no primeiro dia de aula da disciplina, os alunos foram "forçados" a resolverem este teste.

Foi explicado aos alunos que o teste 1 estava computado como 1,5 ponto extra. Caso o aluno não o realizasse ou tirasse nota zero não estaria sendo prejudicado, pois os dez pontos da primeira prova com assunto exclusivamente de Climatologia Geral estaria preservado. Mas os alunos foram estimulados a responderem os testes, pois eles poderiam servir de pontos de eventual recuperação caso a nota na primeira prova fosse baixa.

Neste primeiro dia também foi informado aos alunos acessarem determinado site da Internet para fazerem download do EDH e estudarem, por conta própria, os assuntos das lições 1 a 8 do software, pois o teste 2 com valor de 1,5 ponto seria aplicado na oitava aula de Climatologia Geral, ou seja, três semanas após o primeiro teste.

Esta forma de cobrança dos alunos na verdade não foi totalmente coercitiva pois, o aluno realmente não seria prejudicado caso não desejasse ler o material sobre quantificação do EDH. Desta forma poderia ficar sem realizar os testes 1 e 2 sem prejudicar sua avaliação na disciplina. O estímulo ficou por conta de um possível reforço na pontuação da prova 1 que poderia ser obtido com os testes 1 e 2 . Assim, esta estratégia realmente serviu de maior estímulo aos alunos frente ao EDH se comparado aos participantes do curso de extensão.

\subsubsection{O teste 1 aplicado na turma de Climatologia Geral do semestre letivo 1/2015}

O teste 1 de verificação de familiaridade de conceitos matemáticos básicos aplicado foi o mesmo teste que foi aplicado aos participantes do curso de extensão. As mesmas cinco questões que estão apresentadas nos apêndices 1 a 6 compunham o teste 1 , sendo acrescida 
uma questão, a questão 6, para verificar se o aluno entendia o conceito de variância. Esta questão 6 está apresentada na Figura 111.

Questão 6 As notas da prova de matemática dos quatro alunos da turma $A$ são: $5,7,10$ e 10 . As notas da prova de matemática dos quatro alunos da turma $B$ são: 7, 7, 8 e 10. Responda:

(6.1) Qual a variância das notas de matemática na turma $A$ ? Responda a caneta o valor dentro do retângulo ao lado

(6.2) Qual a variância das notas de matemática na turma $B$ ? Responda a caneta o valor dentro do retângulo ao lado

(6.3) Qual a turma que apresenta maior heterogeneidade nas notas da prova de matemática ? A ou $B$ ? Responda a caneta o valor dentro do retângulo ao lado

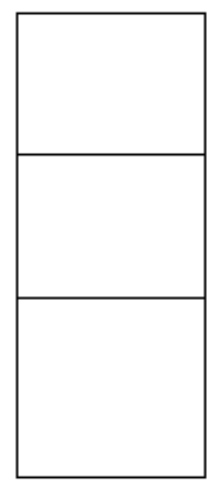

Figura 111 - A questão 6 do teste 1 de mapeamento de familiaridade de conceitos matemáticos básicos.

Fonte: Elaborado pelo autor.

O teste 1 foi realizado por 28 alunos. A questão 6 foi respondida corretamente por apenas um participante. A questão 6 que tratava sobre o conceito de variância serviu para sondar o conhecimento do grupo de alunos com respeito ao material do EDH ainda a ser trabalhado pelos alunos, ou seja, as lições 1 a 8. Como apenas um participante respondeu corretamente, concluiu-se que o grupo não conhecia o assunto e iria assim utilizar o EDH como ferramenta para aprendizado de algo desconhecido.

Com relação à afetividade por matemática/estatística, no teste 1 foi perguntado aos alunos o gosto por matemática/estatística com os valores qualitativos de resposta detesto, gosto um pouco, gosto e gosto muito, igual aos valores dos questionários aplicados anteriormente. Na Figura 112 observa-se a distribuição de frequência da variável gosta de matemática/estatística resultado do teste 1. 


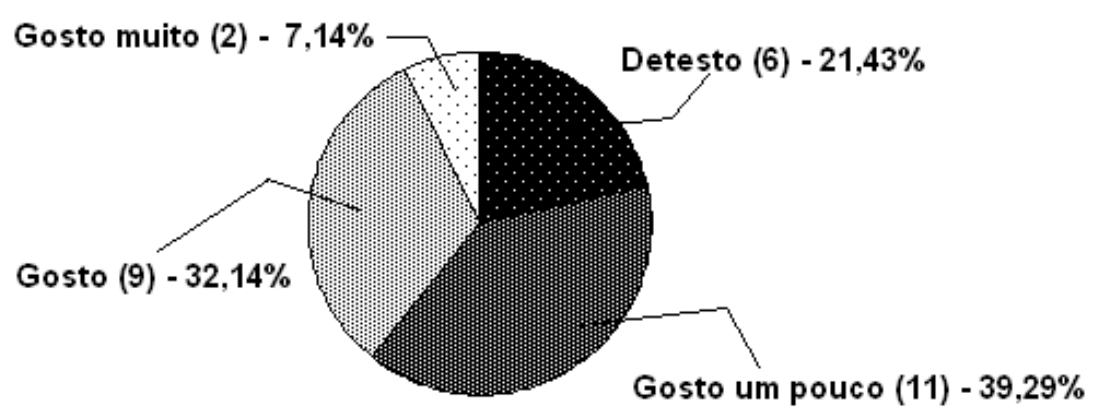

Figura 112 - Distribuição de frequência da variável gosta de matemática/estatística.

Fonte: Elaborado pelo autor.

Na Figura 112, observa-se desta amostra de 28 respondentes que houve um aumento do percentual de respondentes que afirmaram "gostar" ou "gostar muito" de matemática/estatística se comparado ao mesmo percentual dos 384 respondentes que também declararam "gostar" ou "gostar muito" de matemática no questionário de mapeamento de familiaridade de conceitos matemáticos de 2013. Em 2013 o percentual da amostra era de $26,83 \%$ e na turma de Climatologia Geral este percentual foi de 39,28\%.

Com relação às questões 1 a 5 do teste 1 , o procedimento de designação qualitativa da familiaridade prévia dos participantes com relação ao conhecimento de conceitos matemáticos básicos foi igual ao adotado para os participantes do curso de extensão e está apresentado na Tabela 14.

Tabela 55 - Familiaridade com conceitos matemáticos dos 28 alunos

\begin{tabular}{|c|c|l|c|c|l|}
\hline Aluno & $\begin{array}{c}\text { Qtde. } \\
\text { questões } \\
\text { certas }\end{array}$ & $\begin{array}{c}\text { Familiaridade } \\
\text { conceitos } \\
\text { matemáticos }\end{array}$ & Aluno & $\begin{array}{c}\text { Qtde. } \\
\text { questões } \\
\text { certas }\end{array}$ & $\begin{array}{c}\text { Familiaridade } \\
\text { conceitos } \\
\text { matemáticos }\end{array}$ \\
\hline A1 & 0 & Nula & A15 & 0 & Nula \\
A2 & 2 & Insuficiente & A16 & 2 & Insuficiente \\
A3 & 0 & Nula & A17 & 1 & Insuficiente \\
A4 & 3 & Razoável & A18 & 1 & Insuficiente \\
A5 & 4 & Boa & A19 & 2 & Insuficiente \\
A6 & 1 & Insuficiente & A20 & 0 & Nula \\
A7 & 1 & Insuficiente & A21 & 4 & Boa \\
A8 & 2 & Insuficiente & A22 & 0 & Nula \\
A9 & 1 & Insuficiente & A23 & 5 & Boa \\
A10 & 0 & Nula & A24 & 3 & Razoável \\
A11 & 5 & Boa & A25 & 4 & Boa \\
A12 & 3 & Razoável & A26 & 0 & Nula \\
A13 & 1 & Insuficiente & A27 & 1 & Insuficiente \\
A14 & 5 & Boa & A28 & 4 & Boa \\
\hline
\end{tabular}


Na Tabela 55 está apresentada a designação qualitativa de familiaridade de conceitos matemáticos básicos dos 28 alunos que realizaram o teste 1 .

Na Figura 113 é apresentada a distribuição de frequência da variável familiaridade de conceitos matemáticos. Comparando-se com a mesma distribuição de frequência do grupo de 38 participantes do curso de extensão, nota-se que o percentual de alunos classificados como apresentando boa familiaridade de conceitos matemáticos aumentou um pouco (25\%) mas, ainda assim a proporção de alunos com boa performance é baixa.

E se considerar conjuntamente as categorias qualitativas boa e razoável, apenas $35,71 \%$ dos alunos se enquadrariam em uma destas categorias. A priori, poderia se supor que esses $35,71 \%$ apresentariam conceitos subsunçores em sua estrutura cognitiva que facilitariam o aprendizado dos conteúdos das lições do EDH.

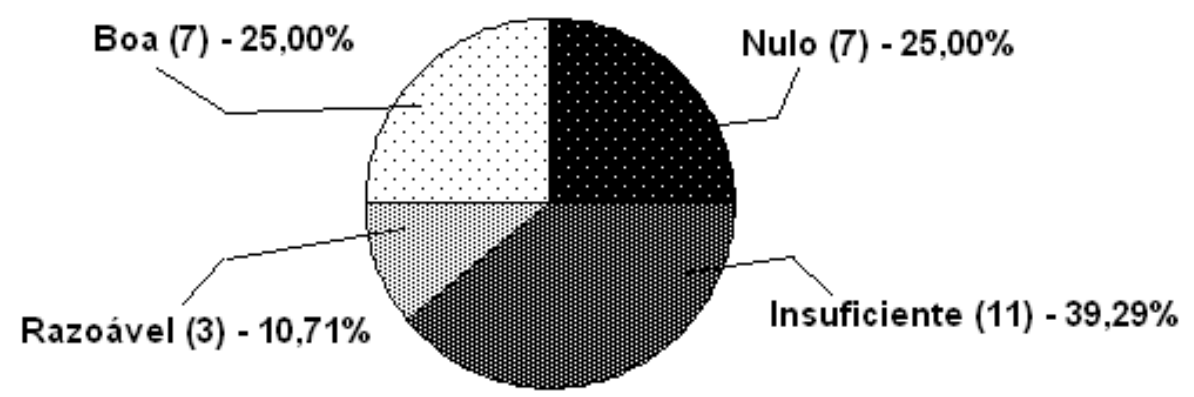

Figura 113 - Distribuição de frequência da variável familiaridade de conceitos matemáticos. Fonte: Elaborado pelo autor.

Para verificar se o fato do aluno gostar ou gostar muito de matemática pode ter influenciado ou não no desempenho no teste 1 , foi realizado o teste estatístico não paramétrico de Fischer. Por exigência do teste de Fischer, a afetividade do aluno por matemática foi agrupada em duas categorias: gosta (alunos que declararam gosto e gosto muito) ou não gosta (alunos que declararam gosto um pouco e detesto). E a performance de familiaridade do aluno no teste 1 ficou agrupada também em duas categorias: satisfatória (alunos com razoável e boa performance) ou não satisfatória (alunos com insuficiente e nula performance). A Tabela 56 apresenta estes agrupamentos qualitativos 
Tabela 56 - Agrupamento das variáveis gosta de matemáticalestatística

e familiaridade de conceitos matemáticos em duas categorias qualitativas para uso no teste de Fischer

\section{Familiaridade}

Matemática no Gosta de matemática

Teste 1

\begin{tabular}{cccc}
\hline & Gosto & Não gosto & Total \\
Satisfatória & 6 & 4 & 10 \\
Não satisfatória & 5 & 13 & 18 \\
Total & 11 & 17 & 28 \\
\hline
\end{tabular}

O teste de Fischer determina se os dois grupos de familiaridade (satisfatória e não satisfatória) diferem na proporção em que se enquadram com relação à afetividade por matemática/estatística (gosto e não gosto). A hipótese nula do teste é $\mathrm{H}_{0}=$ os dois grupos de familiaridade não diferem com relação ao gosto por matemática e a hipótese alternativa é $\mathrm{H}_{1}=$ os grupos diferem com relação ao gosto por matemática. Foi executado o teste no ambiente de software $\mathrm{R}$ e o $\mathrm{p}$-valor encontrado foi $\mathrm{p}=0,1027=10,27 \%$. Ou seja o teste seria significativo (aceitar $\mathrm{H}_{1}$ ) ao nível de 10,27\%. Então foi aceita a hipótese $\mathrm{H}_{0}$, ou seja, a familiaridade dos grupos não se distingue pelo gosto ou não por matemática.

Continuando a avaliação do teste 1, foi verificada a performance dos alunos no questionário. Na Tabela 57 e Figura 114 estão apresentados os percentuais de acertos e erros das cinco questões.

Tabela 57 - Frequência absoluta e relativa de respostas certas e erradas das questões 1 a 5 dos 28 questionários respondidos

\begin{tabular}{ccc}
\hline \multirow{2}{*}{ Questão } & Certas & Erradas \\
\hline 1 & $12(42,86 \%)$ & $16(57,14 \%)$ \\
2 & $8(28,57 \%)$ & $20(71,43 \%)$ \\
3 & $9(32,14 \%)$ & $19(67,86 \%)$ \\
4 & $13(46,43 \%)$ & $15(53,57 \%)$ \\
5 & $13(46,43 \%)$ & $15(53,57 \%)$ \\
\hline
\end{tabular}




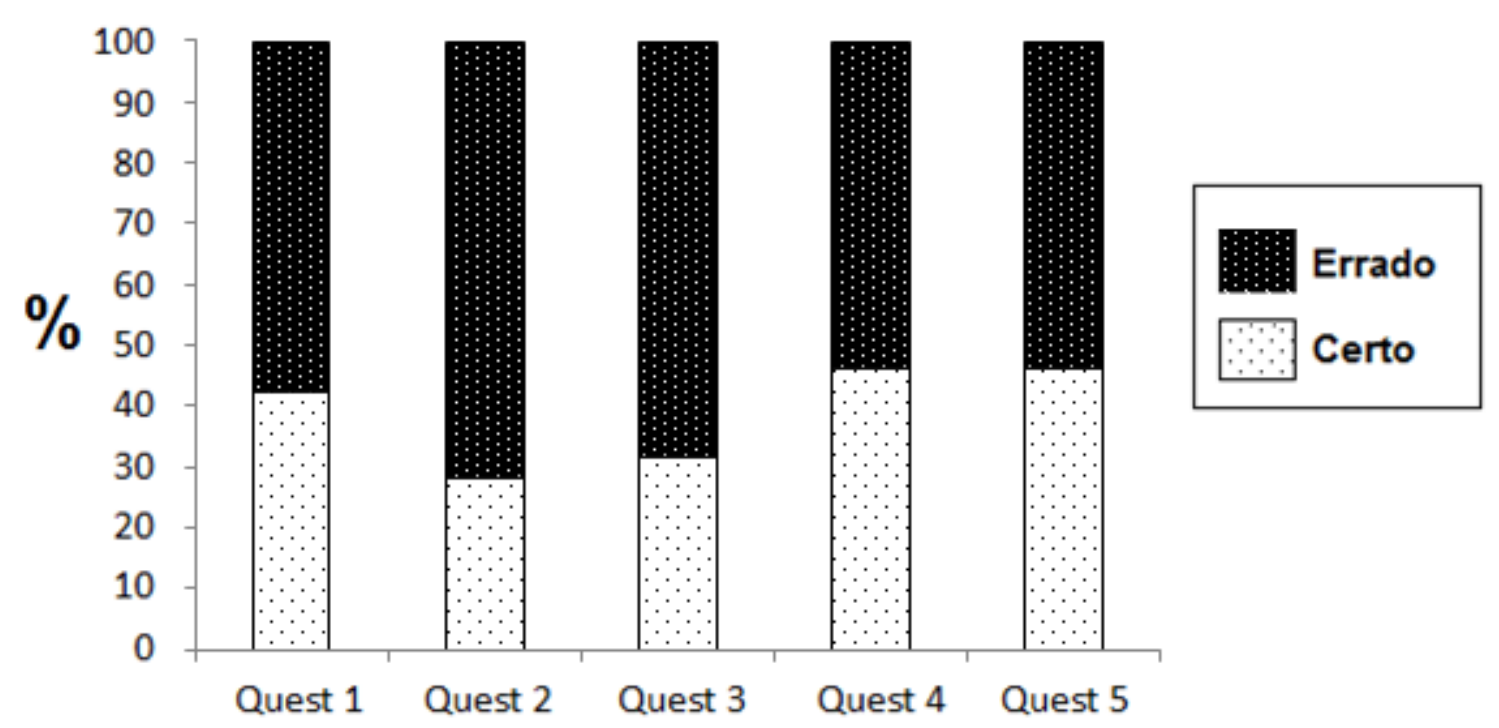

Figura 114 - Percentual de acertos e erros das questões 1 a 5 pelos 28 respondentes. Fonte: Elaborado pelo autor.

Nestas questões, nenhum aluno deixou a resposta em branco, pois valiam ponto extra e não havia qualquer penalidade caso o aluno errasse a questão. Da Tabela 57 e Figura 114 observa-se que as questões 4 e 5 foram as que apresentaram maior quantidade de acertos $(46,43 \%)$ mas, ainda assim, próximo da metade de alunos respondentes. A Questão 2, que lidava com o conceito de probabilidade, apresentou menor quantidade de acertos $(28,57 \%)$. A Questão 3 também apresentou baixo percentual de acertos $(32,14 \%)$ e foi a mesma aplicada no questionário de mapeamento de familiaridade em 2013 e abril de 2014, mudando-se apenas seus valores, e a mesma aplicada no questionário de mapeamento de familiaridade de conceitos matemáticos do curso de extensão. Chama a atenção por ser um tipo de questão que lida com escala, que por sua vez tem forte ligação com o trabalho do geógrafo em seu trabalho de análise do espaço geográfico.

Sintetizando a análise do desempenho global da turma no teste 1, ficou caracterizado que o grupo apresentou limitada familiaridade de conceitos matemáticos básicos.

\subsubsection{O teste 2 aplicado na turma de Climatologia Geral do semestre letivo 1/2015}

O teste 2 aplicado aos alunos da turma de Climatologia Geral do primeiro semestre letivo de 2015 abrangeu conceitos de média, variância, desvio padrão e coeficiente de variação. Conforme já comentado, os alunos acessaram o software EDH e estudaram as lições 
1 a 8, versando sobre os referidos temas. A questão 6 do teste 1 serviu para averiguar se os alunos tinham noção de variância e, somente um aluno dentre os 28 respondentes do teste 1 acertou o cálculo de variância. Assim, o assunto do EDH certamente era desconhecido pelo grupo de alunos.

O teste 2 consistia de 32 itens, todos de resposta dicotômica (certo ou errado) distribuídos em quatro questões e encontra-se no Apêndice 16. Os dez primeiros itens (questão 1) consistiam dos dez itens aplicados no questionário aplicado aos cinco alunos da disciplina de Tópicos Especiais em Geografia(semestre letivo 1/2014), no teste dos alunos da disciplina de Climatologia Geral do semestre letivo 2/2013 e também era a questão 2 do questionário do quarto encontro do curso de extensão (versando sobre variância, desvio padrão e coeficiente de variação).

A questão 2 consistia de nove itens e era o mesmo conjunto de itens da questão 1 do questionário do terceiro encontro do curso de extensão versando sobre média (ver Apêndice 8). A questão 3 consistia de seis itens e era o mesmo conjunto de itens da questão 1 do questionário do quarto encontro do curso de extensão versando sobre variância, desvio padrão e coeficiente de variação (ver Apêndice 9). Finalmente, a questão 4 do teste 2 era composta de sete itens e era a mesma que a questão 2 do questionário do terceiro encontro do curso de extensão versando sobre média (ver Apêndice 8).

Diferentemente do teste 1 , no teste 2 foi informado aos alunos que uma resposta errada anularia uma resposta certa do teste do aluno. O objetivo era minimizar o acerto de itens na base do "chute". Compareceram 32 alunos para a resolução do teste 2. O desempenho no teste 2 foi considerado de forma qualitativa, de modo idêntico às avaliações dos questionários do curso de extensão, ou seja, o desempenho no teste 2 pelo aluno foi considerado satisfatório $(\mathrm{S})$, parcialmente satisfatório $(\mathrm{P})$ ou não satisfatório $(\mathrm{N})$.

Na Tabela 58 encontra-se registrada a designação de familiaridade de conceitos matemáticos do aluno no teste 1 , o total de itens certos, errados e em branco dos alunos no teste 2 , bem como a avaliação qualitativa de desempenho dos mesmos no teste $2(\mathrm{~S}, \mathrm{P}$ ou $\mathrm{N})$. A designação da avaliação qualitativa da performance do aluno no teste 2 foi feita de forma subjetiva, levando-se em conta a quantidade de questões erradas, certas e em branco. Por exemplo, o aluno A13 foi considerado como tendo desempenho não satisfatório (N). Isto porque apesar de ter acertado mais itens do que errou (11 certos contra cinco errados), deixou muitos itens em branco (16), o que parece indicar a tendência de não saber o assunto, ou saber muito pouco. Já o aluno A16 acertou significativamente mais itens do que errou (14 certos 
contra três errados), mas deixou quase metade dos itens em branco. Então teve um desempenho considerado parcialmente satisfatório $(\mathrm{P})$.

Tabela 58 - Desempenho no teste 1 e total de itens certos, errados, em branco e desempenho dos alunos no teste 2

\begin{tabular}{|c|c|c|c|c|c|}
\hline Aluno & $\begin{array}{c}\text { Teste } 1 \\
\text { familiaridade } \mathrm{c} / \\
\text { matemática }\end{array}$ & $\begin{array}{c}\text { Teste } 2 \\
\text { Total de } \\
\text { Itens } \\
\text { errados } \\
\end{array}$ & $\begin{array}{c}\text { Teste } 2 \\
\text { Total de } \\
\text { Itens } \\
\text { Em branco }\end{array}$ & $\begin{array}{c}\text { Teste } 2 \\
\text { Total de } \\
\text { Itens } \\
\text { certos } \\
\end{array}$ & $\begin{array}{c}\text { Desempenho } \\
\text { no teste } 2\end{array}$ \\
\hline A1 & Nula & 0 & 32 & 0 & $\mathrm{~N}$ \\
\hline $\mathrm{A} 2$ & Insuficiente & 6 & 12 & 14 & $\mathrm{P}$ \\
\hline A3 & Nula & 14 & 9 & 9 & $\mathrm{~N}$ \\
\hline A4 & Razoável & 9 & 5 & 18 & $\mathrm{P}$ \\
\hline A5 & Boa & 5 & 1 & 26 & $S$ \\
\hline A6 & Insuficiente & 5 & 14 & 13 & $\mathrm{~N}$ \\
\hline A7 & Insuficiente & 11 & 0 & 21 & $\mathrm{P}$ \\
\hline A8 & Insuficiente & --- & --- & --- & --- \\
\hline A9 & Insuficiente & 19 & 0 & 13 & $\mathrm{~N}$ \\
\hline A10 & Nula & 15 & 2 & 15 & $\mathrm{~N}$ \\
\hline A11 & Boa & 7 & 19 & 6 & $\mathrm{~N}$ \\
\hline A12 & Razoável & 2 & 20 & 10 & $\mathrm{P}$ \\
\hline A13 & Insuficiente & 5 & 16 & 11 & $\mathrm{~N}$ \\
\hline A14 & Boa & 7 & 14 & 11 & $\mathrm{~N}$ \\
\hline A15 & Nula & 2 & 27 & 3 & $\mathrm{~N}$ \\
\hline A16 & Insuficiente & 3 & 15 & 14 & $\mathrm{P}$ \\
\hline A17 & Insuficiente & 13 & 0 & 19 & $\mathrm{~N}$ \\
\hline A18 & Insuficiente & 8 & 11 & 13 & $\mathrm{~N}$ \\
\hline A19 & Insuficiente & 8 & 4 & 20 & $\mathrm{P}$ \\
\hline A20 & Nula & 13 & 16 & 3 & $\mathrm{~N}$ \\
\hline A 21 & Boa & 2 & 12 & 18 & $\mathrm{~S}$ \\
\hline A22 & Nula & --- & --- & --- & --- \\
\hline A23 & Boa & 8 & 0 & 24 & $\mathrm{~S}$ \\
\hline A24 & Razoável & 12 & 0 & 20 & $\mathrm{P}$ \\
\hline A 25 & Boa & 9 & 0 & 23 & $\mathrm{~S}$ \\
\hline A26 & Nula & 11 & 7 & 14 & $\mathrm{~N}$ \\
\hline A 27 & Insuficiente & --- & --- & --- & --- \\
\hline A28 & Boa & 4 & 0 & 28 & $\mathrm{~S}$ \\
\hline A29 & --- & 9 & 11 & 12 & $\mathrm{~N}$ \\
\hline A30 & --- & 5 & 17 & 10 & $\mathrm{~N}$ \\
\hline A31 & --- & 12 & 10 & 10 & $\mathrm{~N}$ \\
\hline A32 & --- & 12 & 7 & 13 & $\mathrm{~N}$ \\
\hline A33 & --- & 12 & 12 & 8 & $\mathrm{~N}$ \\
\hline A34 & --- & 4 & 4 & 24 & $\mathrm{~S}$ \\
\hline A35 & --- & 8 & 14 & 10 & $\mathrm{~N}$ \\
\hline
\end{tabular}


Da Tabela 58 e Figura 115 observa-se que, dos 32 alunos, apenas seis foram classificados como tendo desempenho satisfatório no teste 2, ou seja, apenas 18,80\%. Chama a atenção que todos os alunos com familiaridade matemática nula no teste 1 apresentaram desempenho não satisfatório $(\mathrm{N})$ no teste 2. E dos sete alunos com boa familiaridade no teste 1, cinco apresentaram desempenho satisfatório $(\mathrm{S})$ e dois não satisfatório $(\mathrm{N})$. Além disso somente alunos com boa familiaridade no teste 1 obtiveram desempenho satisfatório, com exceção do aluno A34 que apresentou também desempenho satisfatório, mas não realizou o teste 1 .

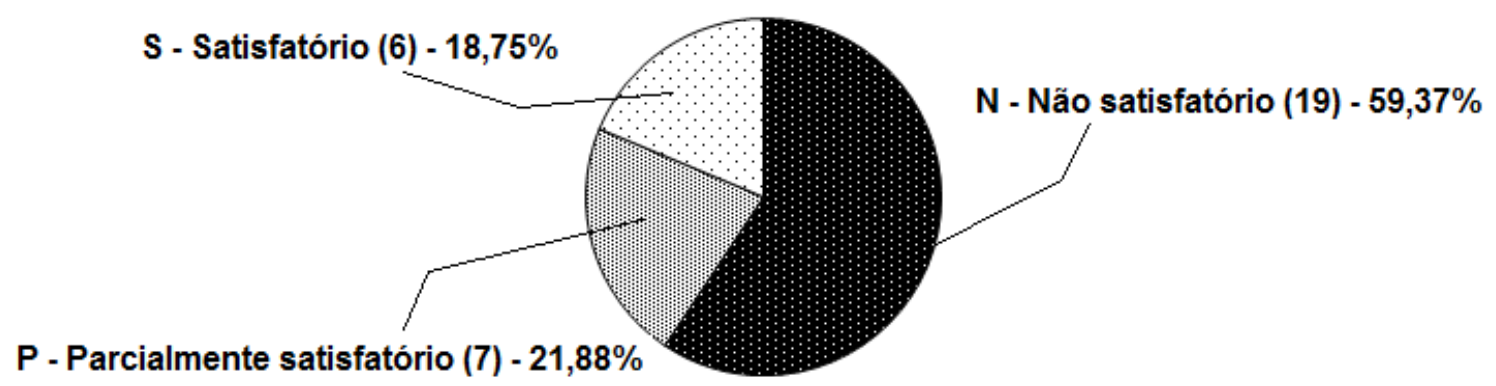

Figura 115 - Desempenho dos 32 alunos que realizaram o teste 2.

Fonte: Elaborado pelo autor.

Para testar a hipótese de que o desempenho satisfatório no teste 2 é influenciado pela boa familiaridade matemática, foi realizado o teste estatístico não paramétrico de Fischer. Por exigência do teste de Fischer, a familiaridade do aluno com matemática foi agrupada em duas categorias: apresenta (alunos que foram classificados com familiaridade razoável e boa no teste 1) ou não apresenta (alunos que foram classificados com familiaridade insuficiente ou nula no teste 1). E o desempenho no teste 2 ficou agrupado também em duas categorias: adequado (alunos com desempenho considerado satisfatório) ou não adequado (alunos com desempenho considerado parcialmente satisfatório e não satisfatório). A Tabela 59 apresenta estes agrupamentos qualitativos. Foram considerados somente alunos que realizaram ambos os testes 1 e 2 , ou seja, 25 alunos.

O teste de Fischer determina se os dois grupos de desempenho no teste 2 (adequado e não adequado) diferem na proporção em que se enquadram com relação à familiaridade com matemática do teste 1 (apresenta e não apresenta). A hipótese nula do teste é $\mathrm{H}_{0}=$ os dois grupos de desempenho no teste 2 não diferem com relação à familiaridade com matemática detectada no teste 1 e a hipótese alternativa é $\mathrm{H}_{1}=$ os grupos diferem com relação ao desempenho no teste 2. Foi executado o teste no ambiente de software R e o p-valor 
encontrado foi $\mathrm{p}=0,004743=0,47 \%$. Ou seja o teste seria significativo (aceitar $\mathrm{H}_{1}$ ) ao nível de $0,47 \%$. Então foi rejeitada a hipótese $\mathrm{H}_{0}$ e aceita a hipótese $\mathrm{H}_{1}$, ou seja, a familiaridade de conceitos matemáticos distingue o desempenho do aluno no teste 2 .

Tabela 59 - Agrupamento das variáveis familiaridade matemática e desempenho no teste 2 em duas categorias qualitativas para uso no teste de Fischer

\begin{tabular}{cccc}
\hline $\begin{array}{c}\text { Familiaridade } \\
\text { Matemática no } \\
\text { Teste 1 }\end{array}$ & Desempenho no teste 2 & \\
\hline & Adequado & Não adequado & Total \\
Apresenta & 5 & 5 & 10 \\
Não apresenta & 0 & 15 & 15 \\
Total & 5 & 20 & 25 \\
\hline
\end{tabular}

Considerando este cenário como aceitável, corrobora-se a ideia de conceitos subsunçores da teoria de aprendizagem de Ausubel. A questão 6 do teste 1 indicou que os alunos não conheciam o conceito de variância (e desvio padrão). Realizaram o teste 2 e muito provavelmente estudaram o assunto usando o $\mathrm{EDH}$, conforme recomendado. $\mathrm{E}$ os alunos com familiaridade matemática aceitável, ou seja, com conceitos subsunçores adequados, conseguiram, utilizando o EDH, adquirir algum conhecimento significativo sobre média, variância, desvio padrão e coeficiente de variação, que permitu apresentar bom desempenho no teste 2 que versava sobre estes temas.

É possível que o aluno tenha usado outro material para estudo mas, como foi informado para a turma que o teste 2 teria como base o $\mathrm{EDH}$, muito provavelmente os alunos que realmente estudaram, o fizeram usando o EDH e não outro material. Assim, os indivíduos com conceitos subsunçores adequados ao assunto, interagiram de forma positiva com o EDH.

No segundo semestre letivo de 2013 os alunos da turma de Climatologia Geral responderam, na primeira prova da disciplina, dez itens com respostas dicotômicas sobre média, variância, desvio padrão e coeficiente de variação e estes itens, conforme já salientado, foram aplicados no teste 2. Na seção 3.4 deste trabalho foram apresentados os resultados obtidos da análise realizada. No que segue, será feita a mesma análise, porém com os dados 
dos 32 alunos que realizaram o teste 2 . A questão 1 com os dez itens podem ser vistos no Apêndice 16 ou na Figura 52, com o gabarito dos itens.

O número médio de itens respondidos corretamente foi 5,00 com desvio padrão 2,46 e coeficiente de variação 48,46\%. Vinte alunos acertaram cinco ou mais itens, o que pode indicar um razoável padrão de acertos. Se for considerado que um número razoável de acertos seja sete ou mais para aceitar que o aluno entendeu o conteúdo, foram sete os alunos com este escore de itens corretos, o que corresponde a apenas $21,88 \%$ dos alunos que realizaram o teste 2. Comparando-se estas estatísticas com a turma de 2013, nota-se que esta apresentou performance melhor, conforme se observa na Tabela 60 .

Tabela 60 - Estatísticas de respondentes à questão (apresentada na Figura 52) com dez itens dicotômicos sobre média, desvio padrão e coeficiente de variação aplicada em 2013 e em 2015

\begin{tabular}{|c|c|c|}
\hline & $\begin{array}{c}\text { Respondentes } \\
\text { em 2/2013 }\end{array}$ & $\begin{array}{c}\text { Respondentes } \\
\text { em } 1 / 2015\end{array}$ \\
\hline Total de respondentes & 29 & 32 \\
\hline Número médio de acertos & 6,02 & 5,00 \\
\hline Desvio padrão & 2,46 & 2,42 \\
\hline Coeficiente de variação & $40,71 \%$ & $48,46 \%$ \\
\hline $\begin{array}{l}\text { Total de respondentes que } \\
\text { acertaram cinco ou mais itens }\end{array}$ & $25(86,21 \%)$ & $20(62,50 \%)$ \\
\hline $\begin{array}{l}\text { Total de respondentes que } \\
\text { acertaram sete ou mais itens }\end{array}$ & $13(44,82 \%)$ & $7(21,88 \%)$ \\
\hline
\end{tabular}

Foi realizado o teste estatístico não paramétrico de Komolgorov-Smirnoff para saber se amostra de 29 alunos de 2013 apresentou desempenho melhor que a turma de 32 alunos de 2015. Neste teste a hipótese nula é $\mathrm{H}_{0}=$ não há diferença de performance de acertos entre as turmas. E a hipótese alternativa é $\mathrm{H}_{1}=$ a turma de 2013 apresentou melhor performance que a turma de 2015. Foi executado o teste no ambiente do software R e o valor da estatística D do teste foi $\mathrm{D}=0,7091$ correspondendo a um $\mathrm{p}$-valor $\mathrm{p}=2,273 \times 10^{-7}$. Isto significa rejeitar $\mathrm{H}_{0} \mathrm{e}$ 
aceitar $\mathrm{H}_{1}$, ou seja, o desempenho da turma de 2013 foi melhor que o da turma de 2015, embora não se dimensione a intensidade de quão melhor foi.

Aceitando-se este fato, uma possível explicação poderia ser que em 2013 o uso do EDH foi feito de forma supervisionada: na condição de instrutor do assunto, usei o EDH em sala de aula e enfatizei verbalmente determinadas partes do assunto do EDH, ao passo que em 2015 os alunos tiveram que ler por conta própria, sem qualquer tipo de instrutoria (a não ser eventualmente entre eles mesmos). Assim, os alunos de 2013 teoricamente foram mais direcionados para o teste se comparados com os alunos de 2015.

É possível, como também foi possível de ocorrer em 2013, que alguns acertos dos alunos tenham sido obtidos pelo "chute", mesmo sob pena de perda de outro item da questão, caso o "chute" fosse incorreto. Para analisar se houve "chute" ou se o aluno de fato interpretou e entendeu o item, foi feita uma verificação das respostas dadas pelos alunos entre os itens cujo conteúdo e raciocínio são muito similares. Se de fato o aluno entende o conceito, então é de se esperar que o aluno acerte os itens que tratem do mesmo tema e exijam raciocínio similar para resolução.

Os itens 1, 2 e 6 tratam do desvio padrão (e variância indiretamente), porém o raciocínio para resolução é diferente em cada item. Desta forma, considerou-se que o aluno respondeu estes itens de forma independente um do outro.

Os itens 3 e 5 tratam de variância de forma mais direta. Bastaria saber que a variância é o desvio padrão elevado ao quadrado. Se o aluno soubesse isto, muito provavelmente marcaria as respostas corretas: C para o item 3 e E para o item 5. A Tabela 61 mostra as marcações dos alunos para os itens 3 e 5 .

Observa-se na Tabela 61 que apenas 10 dos 32 alunos acertaram os itens 3 e 5 , o que representa um percentual de $31,25 \%$. Assim, inicialmente, a priori supõe-se que apenas $30 \%$ estavam entendendo a ideia numérica da relação entre variância e desvio padrão. 
Tabela 61 - Marcações dos 32 alunos nos itens 3 e 5

\begin{tabular}{ccc}
\hline $\begin{array}{c}\text { Item 3 } \\
\text { (resposta: } \mathbf{C})\end{array}$ & $\begin{array}{c}\text { Item 5 } \\
\text { (resposta: } \mathbf{E})\end{array}$ & $\begin{array}{c}\text { Total de } \\
\text { respondentes }\end{array}$ \\
\hline C & C & 2 \\
C & E & 10 \\
C & X & 2 \\
E & C & 2 \\
E & E & 4 \\
E & X & 3 \\
X & C & 3 \\
X & E & 1 \\
X & X & 5 \\
\hline
\end{tabular}

Obs.: C - Certo; E - Errado; X - em branco

Os itens 4, 7 e 8 tratavam do coeficiente de variação. Noções conceituais de maior/menor heterogeneidade/homogeneidade de grupos de dados. Se o aluno soubesse esses conceitos muito provavelmente marcaria as respostas corretas: C para o item 4, C para o item 7 e E para o item 8. A Tabela 62 mostra as marcações dos alunos para os itens 4,7 e 8.

Observa-se na Tabela 62 que 14 dos 32 alunos acertaram os itens 4, 7 e 8 , o que representa um percentual de 43,75\%. Assim, inicialmente, a priori supõe-se que pouco menos da metade dos alunos entenderam os conceitos de heterogeneidade/homegeneidade medidos pelo coeficiente de variação.

Tabela 62 - Marcações dos 32 alunos nos itens 4, 7 e 8

\begin{tabular}{cccc}
\hline $\begin{array}{c}\text { Item 4 } \\
\text { (resposta: C) }\end{array}$ & $\begin{array}{c}\text { Item 7 } \\
\text { (resposta: C) }\end{array}$ & $\begin{array}{c}\text { Item 8 } \\
\text { (resposta: E) }\end{array}$ & $\begin{array}{c}\text { Total de } \\
\text { respondentes }\end{array}$ \\
\hline C & C & C & 1 \\
C & C & E & 14 \\
C & X & C & 1 \\
E & C & C & 2 \\
E & C & E & 7 \\
E & C & X & 1 \\
E & E & C & 1 \\
E & X & E & 1 \\
X & C & E & 1 \\
X & X & E & 1 \\
X & X & X & 2 \\
\hline
\end{tabular}

Obs.: C - Certo; E - Errado; X - em branco 
Finalmente, os itens 9 e 10 lidavam com heterogeneidade/homegeneidade analisados por meio do coeficiente de variação. Mas nestes itens o aluno deveria saber também a relação matemática onde o coeficiente de variação é o valor do desvio padrão dividido pela média. Se $\mathrm{o}$ aluno soubesse esses conceitos muito provavelmente marcaria as respostas corretas: $\mathrm{C}$ para o item 9 e E para o item 10. A Tabela 63 mostra as marcações dos alunos para os itens 9 e 10.

Tabela 63 - Marcações dos 32 alunos nos itens 9 e 10

\begin{tabular}{ccc}
\hline $\begin{array}{c}\text { Item 9 } \\
\text { (resposta: C) }\end{array}$ & $\begin{array}{c}\text { Item 10 } \\
\text { (resposta: E) }\end{array}$ & $\begin{array}{c}\text { Total de } \\
\text { respondentes }\end{array}$ \\
\hline C & E & 7 \\
C & X & 3 \\
E & C & 2 \\
E & E & 5 \\
X & C & 3 \\
X & E & 4 \\
X & X & 8 \\
\hline
\end{tabular}

Obs.: C - Certo; E - Errado; X - em branco

Observa-se na Tabela 63 que apenas 7 dos 32 alunos acertaram os itens 9 e 10 , o que representa um percentual de 21,88\%. Assim, inicialmente, a priori supõe-se que aproximadamente $20 \%$ dos alunos estavam entendendo a ideia numérica do coeficiente de variação. E chama a atenção também que este foi praticamente o mesmo percentual de alunos que deixou os dois itens em branco, demonstrando desconhecimento do assunto.

Com base nos valores das tabelas 61, 62 e 63 foi elaborada a tabela 64 sintetizando os resultados obtidos. Além disso, nesta tabela reapresentam-se os mesmos resultados da turma de 2013. 
Tabela 64 - Síntese dos principais resultados obtidos

Pelas turmas de 2013 e 2015 na questão 1 do teste 2

\begin{tabular}{cccc}
\hline $\begin{array}{c}\text { Alunos que } \\
\begin{array}{c}\text { acertaram sete ou } \\
\text { mais itens }\end{array}\end{array}$ & $\begin{array}{c}\text { Alunos que } \\
\text { acertaram os } \\
\text { Itens 3 e 5 } \\
\text { (conceito de } \\
\text { desvio padrão) }\end{array}$ & $\begin{array}{c}\text { Alunos que } \\
\text { acertaram os } \\
\text { Itens 4, 7 e 8 } \\
\text { (conceito de } \\
\text { coeficiente de } \\
\text { variação) }\end{array}$ & $\begin{array}{c}\text { Alunos que } \\
\text { acertaram os } \\
\text { Itens 9 e 10 } \\
\text { (conceito de } \\
\text { coeficiente de } \\
\text { variação) }\end{array}$ \\
\hline \multicolumn{4}{c}{ Turma de 2015 } \\
\hline 7 & 10 & 14 & 7 \\
$(21,88 \%)$ & $(31,25 \%)$ & $(43,75 \%)$ & $(21,88 \%)$ \\
\hline \multicolumn{4}{c}{ Turma de 2013 } \\
$(44,82 \%)$ & 7 & 16 & 8 \\
$(24,13 \%)$ & $(55,19 \%)$ & $(27,56 \%)$ \\
\hline
\end{tabular}

Observando-se o percentual de itens iguais respondidos corretamente (itens 3 e 5, itens 4,7 e 8 e itens 9 e 10) chamou a atenção o baixo resultado de aproveitamento obtido pelos alunos. O mesmo diagnóstico foi dado aos 29 alunos respondentes de 2013. Mas se for considerado que em 2013 os alunos usaram o EDH em sala de aula juntamente com instrutor, e os 32 alunos de 2015 tiveram que realizar autoestudo do material, a diferença na proporção de resultados talvez possa ser assumida como semelhante entre os 2 grupos de amostra, exceto pelo fato de em 2013 proporcionalmente mais alunos acertaram sete ou mais itens.

Não é possível afirmar categoricamente sobre a utilidade ou não do EDH mas, se for levado em consideração que o teste 2 não teve um poder coercitivo suficiente para forçar o aluno a utilizar o EDH, pode ter ocorrido que poucos alunos interagiram efetivamente com o software, e foram estes poucos alunos que apresentaram bom desempenho nas questões, o que sinalizaria assim que o EDH pode ter sido útil.

Finalizando a análise do teste 2 , foi feita a verificação dos acertos e erros dos três primeiros itens dicotômicos da questão 2. O propósito destes itens foi verificar a capacidade de leitura e interpretação do aluno de dados dispostos em formato tabular e com o conceito de somatório $\left(\sum\right)$, que está presente na lição 7 (sobre média aritmética) do EDH. Na Figura 116 encontra-se a definição da questão e os três itens considerados, denominados de item (11), (12) e (13). 
Questão 2 - Observe a tabela abaixo e responda ao que se pede:
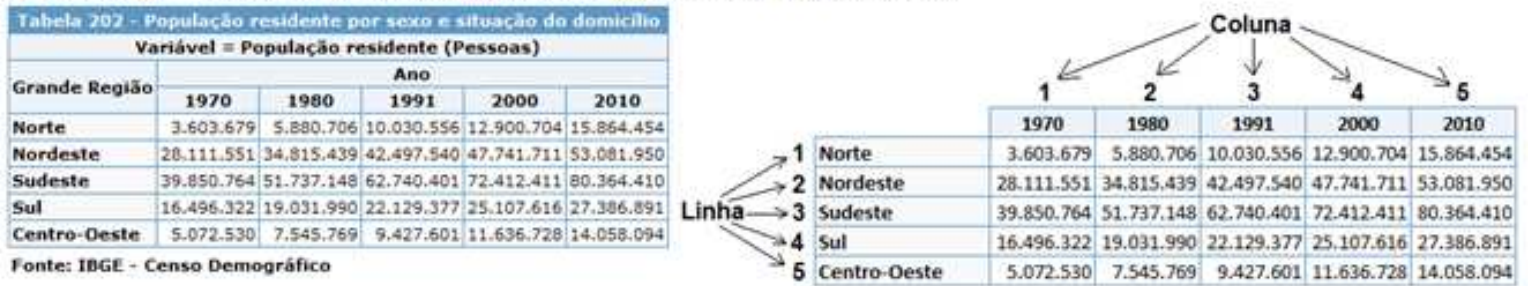

Obs.: leitura de valores em tabela de dupla entrada (linhas e colunas) :

$X_{i k}$ onde: $i$-linha $k$-coluna Exemplos: $X_{34}=72.412 .411$ - populaçäo na regiäo Sudeste em 2000

$X_{43}=22.129 .377$ - populaçäo na regiảo Sul em 1991

Julgue as assertivas abaixo em certo (C) ou errado (E) ou deixe em branco caso não saiba a resposta. Atenção!!!

Uma resposta incorreta anula uma resposta correta

(11) [C] $\sum_{m=3}^{5} X_{2 m}$ representa a soma da populaçăo da regiăo Nordeste nos anos de 1991, 2000 e 2010

(12) [E] $\sum_{m=3}^{5} X_{m 2}$ representa a soma da populaçäo da regiäo Nordeste nos anos de 1991,2000 e 2010

(13) [C] $\sum_{m=3}^{5} X_{m 2}$ representa a soma da populaçăo das regiōes Sudeste, Sul e Centro-Oeste em 1980

Figura 116 - A questão 2 do teste 2 e os três primeiros itens, denominados de (11), (12) e (13) com respectivos gabaritos.

Fonte: Elaborado pelo autor.

Pode-se observar, na Figura 116 que os itens poderiam ser respondidos corretamente por meio de do entendimento da explicação da leitura de elementos da tabela (em linha e coluna) e conhecimento do conceito de somatório $\left(\sum\right)$,tratado na lição 7 do EDH. Foi verificada a marcação destes três itens por parte dos 32 respondentes do teste 2 . A Tabela 65 mostra as respostas doa alunos. 
Tabela 65 - Marcações dos 32 alunos nos itens (11), (12) e (13)

\begin{tabular}{cccc}
\hline $\begin{array}{c}\text { Item (11) } \\
\text { (resposta: C) }\end{array}$ & $\begin{array}{c}\text { Item (12) } \\
\text { (resposta: E) }\end{array}$ & $\begin{array}{c}\text { Item (13) } \\
\text { (resposta: C) }\end{array}$ & $\begin{array}{c}\text { Total de } \\
\text { respondentes }\end{array}$ \\
\hline C & C & C & 1 \\
C & C & E & 1 \\
C & E & C & 5 \\
C & E & E & 3 \\
C & E & X & 2 \\
E & C & C & 1 \\
E & C & X & 2 \\
E & E & E & 2 \\
E & E & X & 1 \\
E & X & C & 1 \\
E & X & X & 1 \\
X & X & C & 1 \\
X & X & X & 11 \\
\hline
\end{tabular}

Obs.: C - Certo; E - Errado; X - em branco

Observa-se da Tabela 65 que apenas cinco dos 32 alunos acertaram os itens (11), (12) e (13), o que representa um percentual de 15,63\%. Assim, inicialmente, a priori supõe-se que aproximadamente $15 \%$ dos alunos souberam ler a informação tabular. Observando-se a performance dos cinco alunos no teste 1, quatro apresentaram boa performance e o quinto aluno (A34) não realizou o teste 1.

Por outro lado, 11 dos 32 alunos $(34,38 \%)$ deixaram os três itens em branco, demonstrando não terem entendimento do tema. Destes 11 alunos, um havia apresentado boa performance no teste 1, outro, performance razoável, cinco apresentaram performance nula ou insuficiente, e os quatro restantes não participaram do teste 1. Estes dados reforçam a ideia de que a falta de conceitos subsunçores por parte do aluno pode representar a ausência de aprendizagem significativa por parte do aluno, ou os 11 alunos não leram o EDH. 


\subsection{SOBRE A FORMAÇÃO ACADÊMICA DO GEÓGRAFO PARA COMPREENSÃO DAS TÉCNICAS QUANTITATIVAS DE ANÁLISE ESPACIAL DE DADOS GEOGRÁFICOS}

Uma das hipóteses de pesquisa deste trabalho foi considerar que se a escolarização formal do geógrafo for insuficiente em conteúdos de técnicas quantitativas, então a capacitação do geógrafo para realização de análises espaciais de dados geográficos será nula ou insuficiente.

$\mathrm{Na}$ amostra de matrizes curriculares levantadas de cursos de Geografia no Brasil, verificou-se que em geral há apenas uma única disciplina que trata de quantificação (Estatística Aplicada, Estatística para Geociências, etc). Talvez seja possível rotular os cursos de Geografia com esta característica de cursos de disciplina "única" de quantificação.

Ora, conforme salientado anteriormente, a análise espacial de dados geográficos envolve análise de padrões pontuais, padrões de áreas com contagens, padrões de superfícies contínuas e interação espacial. E foi visto que o arsenal de técnicas quantitativas para estas atividades analíticas envolve diversos conceitos matemáticos e estatísticos de complexidades diversas. Por exemplo, basta relembrar o que foi colocado por Bettini (2007) ao citar o que se espera de um leitor que deseje aprender os conceitos básicos de geoestatística:

Admitem-se conhecidos os conceitos de variável aleatória (VA),
distribuições de probabilidade de VAs discretas e contínuas, uni e
multivariadas, bem como seus modelos e parâmetros. São
particularmente importantes as noções de momentos, quantis,
covariância, correlação, dependência linear, amostragem, estatísticas e
estimadores. Caso o leitor não esteja à vontade com esses termos,
deverá consultar textos básicos de Estatística (BETTINI, 2007, p.193)

Considerando as colocações de Bettini, que representam uma parte do que é necessário para realizar análise espacial de dados geográficos, fica claro que um curso de Geografia de disciplina única de quantificação dificilmente conseguirá formar o geógrafo para trabalhar a contento com quantificação em Geografia. A disciplina "única" muitas vezes é a disciplina 
"genérica" de estatística, obrigatória para diversos cursos da universidade: Geografia, Turismo, Engenharia Florestal, Geologia, Economia, Administração, Pedagogia, etc.

Não surpreende que hajam críticas a esta disciplina única como foi manifestado por alguns estudantes entrevistados (ver Apêndice 15) : "o professor parece 'cuspir' a matéria"; "conteúdo passado muito rapidamente"; "falta de foco para o caráter geográfico"; "detalhes matemáticos são irrelevantes aos estudos de um geógrafo"; "poderia ter uma estatística própria para o curso de geografia, facilitaria a assimilação"; "só existe essa matéria obrigatória de cálculo. Poderia ter mais algumas".

Assim, uma disciplina única de estatística, de caráter genérico voltada para diversos cursos, com muitos alunos em sala de aula, e com grande parte do conhecimento transmitido focando apenas aspectos "marginais" da estatística (decoreba de fórmulas, cliques em softwares aplicativos, exemplos não contextualizados no curso específico do indivíduo, etc) certamente pouco contribuirá para o raciocínio, pensamento e letramento estatístico. Consequentemente, a capacitação do geógrafo para análise espacial de dados geográficos certamente será insuficiente em cursos com disciplina única de quantificação. 


\section{CAPÍTULO 4}

\section{CONSIDERAÇÕES FINAIS}

O geógrafo é um cientista social, é um analista das organizações socioespaciais e suas dinâmicas. Segundo Rosa (2009), o perfil desejado de um geógrafo deve ser o de "um mapeador consciente, leitor e usuário de mapas na busca da construção de novos significados em seu cotidiano" (ROSA, 2009, p.42). Ressalta-se aqui que o contexto dos mapas citados pelo autor vai além dos mapas pictóricos e deve ser entendido também como números oriundos de técnicas de quantificação que auxiliam na compreensão da forma e da estrutura das organizações espaciais.

Neste trabalho, uma questão investigada foi: a formação acadêmica que o geógrafo recebe em seu curso de graduação o capacita a realizar quantificação na análise espacial de dados geográficos?

E no escopo deste trabalho, para tentar responder a esta pergunta, diversas atividades foram realizadas no intuito de obter uma radiografia, ainda que superficial, do perfil do graduando de Geografia com relação à temática da quantificação aplicada à Geografia. A maioria das amostras de alunos avaliados eram compostas por alunos da UnB, pela relativa facilidade de acesso a estes alunos.

Apenas no questionário de mapeamento de familiaridade de conceitos matemáticos básicos, aplicado em 384 alunos em 2013 e em abril de 2014, foi possível avaliar alguns alunos de outras instituições. Neste questionário, 211 eram alunos da UnB e os demais 173, eram alunos de outras seis instituições. A Tabela 66 apresenta resultados do grupo de 211 alunos da UnB comparados com os resultados dos 173 alunos das demais instituições. Nota-se que a performance dos alunos da UnB percentualmente foi superior a dos alunos das demais instituições. Deve-se notar que apesar de superior em relação às demais instituições, a performance dos alunos da UnB no questionário apresenta o padrão geral de baixa familiaridade de conceitos matemáticos básicos.

O número médio de acertos dos 211 alunos da UnB foi de 2,56, enquanto que os 173 alunos das outras instituições acertaram, em média, 1,90 questões das seis consideradas no questionário. 
Tabela 66 - Frequência absoluta e relativa de respondentes em relação ao total de questões respondidas corretamente pelos 211 alunos da UnB e 173 alunos das demais instituições no questionário de mapeamento de familiaridade de conceitos matemáticos básicos aplicado em 2013 e abril/2014

\begin{tabular}{|c|c|c|c|c|}
\hline \multirow[b]{2}{*}{$\begin{array}{c}\text { Total de questões } \\
\text { respondidas corretamente }\end{array}$} & \multicolumn{2}{|c|}{$\begin{array}{l}\text { Amostra de } \\
\text { respondentes da } \\
\text { Unb }\end{array}$} & \multicolumn{2}{|c|}{$\begin{array}{c}\text { Amostra de } \\
\text { respondentes outras } \\
\text { instituições }\end{array}$} \\
\hline & $\begin{array}{c}\text { Freq. } \\
\text { Absoluta }\end{array}$ & $\begin{array}{c}\text { Freq. } \\
\text { Relativa }(\%)\end{array}$ & $\begin{array}{c}\text { Freq. } \\
\text { Absoluta }\end{array}$ & $\begin{array}{c}\text { Freq. } \\
\text { Relativa(\%) }\end{array}$ \\
\hline 0 & 11 & $5,21 \%$ & 21 & $12,14 \%$ \\
\hline 1 & 35 & $16,59 \%$ & 52 & $30,06 \%$ \\
\hline 2 & 62 & $29,38 \%$ & 44 & $25,43 \%$ \\
\hline 3 & 52 & $24,64 \%$ & 38 & $21,97 \%$ \\
\hline 4 & 32 & $15,17 \%$ & 15 & $8,67 \%$ \\
\hline 5 & 16 & $7,58 \%$ & 3 & $1,73 \%$ \\
\hline 6 & 3 & $1,42 \%$ & 0 & $0,00 \%$ \\
\hline Total & 211 & $100 \%$ & 173 & $100 \%$ \\
\hline
\end{tabular}

Como o desempenho geral dos alunos da UnB mostrou - com base nas amostras coletadas - ser um pouco melhor que o desempenho dos alunos amostrados de outras instituições, foram feitas considerações sobre as demais atividades com base em amostras de alunos da UnB e, a priori, talvez seja possível estender tais considerações para o universo das outras instituições que tiveram participação no questionário de 2013, e mesmo diversas outras instituições do País cujos cursos de Geografia apresentam o mesmo padrão com relação à quantificação em Geografia.

Assim, fazendo-se uma avaliação global dos resultados obtidos das diversas atividades realizadas neste trabalho, as amostras apontaram que, em geral, o perfil do graduando de Geografia, tem pouca afetividade por matemática: "gosto um pouco" foi a resposta mais comum declarada pelos alunos nas diversas atividades realizadas. Em geral, apesar de "gostarem um pouco" os alunos parecem reconhecer a importância da quantificação para a Geografia. Mas o principal problema detectado nas amostras em geral foi a pouca familiaridade de conceitos matemáticos básicos a nível de Ensino Fundamental e Médio. 
Esta pouca familiaridade (em geral) de conceitos matemáticos básicos implica em ausência de conceitos subsunçores essenciais para a aprendizagem significativa de técnicas de quantificação voltadas à análise espacial de dados geográficos. Como consequência, o aluno não aprende, ainda mais quando faz um curso com matriz curricular composta de uma única disciplina ligada à temática da quantificação. Em suma, o aluno (em geral) conclui o curso de Geografia com baixa (ou mesmo nula) capacidade de realizar quantificação em Geografia.

Então, respondendo de forma mais direta a pergunta, a resposta seria que, com base nas amostras de alunos avaliadas, se as mesmas forem realmente representativas das instituições dos alunos participantes das diversas amostras, ou mesmo representativas de outras instituições, há indícios de que a formação acadêmica que o geógrafo recebe em seu curso de graduação não o capacita a realizar quantificação na análise espacial de dados geográficos. Isto se deve devido a combinação de três fatores já comentados: o primeiro e mais importante fator é a pouca familiaridade do graduando de geografia com conceitos básicos de matemática em nível de Ensino Fundamental e Médio. O segundo fator refere-se à pouca afetividade do graduando de Geografia com Matemática. E o terceiro e último fator refere-se à matriz curricular dos cursos de Geografia que, em geral, compõe-se de apenas uma única disciplina ligada à quantificação, sendo pouco para se trabalhar com os diversos temas ligados a esta temática.

A outra questão analisada neste trabalho foi: O uso de software tutor para ensino de conceitos básicos de técnicas quantitativas de análise espacial de dados geográficos pode auxiliar na efetiva aprendizagem de tais conceitos?

O software tutor desenvolvido, denominado EDH (Estatísticas em Doses Homeopáticas) é constituído de 14 lições que tratam, em essência, de Estatística Descritiva. Conforme comentado, este foi o tema escolhido, ao invés de algum tema diretamente ligado à análise espacial de dados geográficos (análise de padrões pontuais de eventos, de superfícies contínuas, de áreas com contagens, interação espacial) pelo fato de os resultados do questionário de mapeamento da familiaridade de conceitos matemáticos dos graduandos do curso de Geografia ter indicado pouca familiaridade com tais conceitos, segundo a amostra de 384 respondentes. Daí a escolha por alguns tópicos de Estatística Descritiva, por abranger conteúdos mais básicos e menos complexos, mas que são importantes para a quantificação.

$\mathrm{O}$ uso do $\mathrm{EDH}$ demonstrou ser válido e serviu de forma positiva no auxílio de aprendizagem significativa. As evidências desta validade do EDH ficam por conta da análise dos pontos positivos e negativos citados pelos alunos do referido software. Verifica-se, pelo 
padrão de diversos comentários, que o aluno realmente interagiu com o material e seu comentário é consistente para se levar em conta na avaliação da utilidade do EDH.

Como comentários positivos sobre o EDH emitidos pelos alunos, em geral, pode-se destacar que a forma predominantemente imagética de transmissão de conteúdo foi fundamental para prender a atenção do aluno e proporcionar alguma intensidade de aprendizagem significativa do assunto tratado. É plausível admitir que o conteúdo imagético proporcionou reflexão por parte do aluno sobre o assunto que, de fato, tenha lido (média, variância, centro médio espacial, coeficiente de Gini, etc). E isto pode ter desencadeado afetividade do aluno pelo tema, pelo fato de o mesmo talvez ter entendido algo novo e isto, por sua vez, pode ter engendrado um processo de aprendizagem significativa que contribui, em doses homeopáticas, para o desenvolvimento do raciocínio, pensamento e letramento estatístico.

Os pontos negativos do EDH citados pelo alunos, em geral, recaíram sobre a interface "pobre" do software mas, conforme previamente comentado, este era de fato o objetivo do EDH: ter uma interface "pobre", com "poucas cores", para evitar a existência de artefatos imagéticos meramente decorativos, que nada acrescentam ao ensino do assunto abordado, forçando então o aluno fixar a atenção na mensagem central do tema tratado na tela do EDH.

Com relação ao desempenho não satisfatório dos alunos que usaram o EDH para realizar o teste, e os alunos que o utilizaram no curso de extensão, conforme já comentado, há fatores externos que podem ter proporcionado o desempenho não satisfatório. Em geral, os alunos com tal desempenho nos testes/questionários apresentavam limitada familiaridade de conceitos matemáticos básicos, (em geral) "gostavam um pouco" de matemática, e muito provavelmente se sentiam sem obrigação de dedicação de interação com o EDH, e mesmo sem motivação diante de tema que não é de sua preferência.

Em geral, os alunos com bom desempenho apresentavam razoável familiaridade de conceitos matemáticos básicos, e no curso de extensão apresentaram motivação para aprender. Por tudo isso, pode-se afirmar que há indícios de que o uso de um software tutor para auxílio no ensino de técnicas de quantificação, com base em conteúdo imagético pode proporcionar a aprendizagem significativa de técnicas ligadas à quantificação com potencial para ser aplicada na análise espacial de dados geográficos.

De forma mais objetiva e direta, pode-se dizer que a combinação da baixa familiaridade de conceitos matemáticos por parte dos alunos graduandos de Geografia aliada a cursos de Geografia com disciplina única voltada à quantificação certamente resulta em 
baixa capacitação do Geógrafo para realização de análises espaciais de dados geográficos. Assim, conforme diversas vezes comentado este trabalho, o desvelamento da forma e estrutura das organizações espaciais muito provavelmente será feito de forma superficial por parte do geógrafo.

O que poderia ser feito para tentar reverter o quadro da possível formação do geógrafo sem capacitação para realizar quantificação na análise espacial de dados geográficos?

Uma sugestão para tentar reverter este quadro, seria trabalhar alguns aspectos de quantificação em diversas disciplinas da matriz curricular. Destra forma a disciplina única de quantificação seria ministrada no primeiro semestre do curso, e seria disciplina de prérequisito para outras disciplinas tais como Climatologia Geral, Geografia Humana, Geografia Agrária, Geografia Biológica, Geomorfologia, Geografia Urbana, Geografia Política e Geografia Aplicada ao Planejamento dentre outras. Estas disciplinas teriam suas ementas alteradas para que se fosse feita a inclusão de atividades práticas versando sobre quantificação.

Assim, por exemplo, em Geografia Política poderia ser proposta como atividade ligada à quantificação, a elaboração do mapa da distribuição espacial dos votos para presidente do Brasil em 2014 por setores censitários. Os dados poderiam ser obtidos junto ao IBGE. Os alunos teriam a oportunidade de, por exemplo, realizar uma simples quantificação, calculando o centro médio espacial ponderado dos votos dos candidatos. Um simples trabalho de estatística descritiva espacial que apontaria o espaço geográfico onde cada candidato teve mais preponderância ajudaria no entendimento da forma e estrutura daquela conjuntura espaço-temporal. E este simples trabalho auxiliaria na formação do geógrafo, exercitando-o com quantificação, solidificando aos poucos seu raciocínio, pensamento e letramento estatístico.

Outra sugestão para tentar reverter o quadro de formação insuficiente do geógrafo em quantificação poderia ser uma mudança na matriz curricular dos cursos de Geografia do País. Conforme comentado anteriormente, não se trata de inserir na matriz curricular diversas disciplinas voltadas para quantificação mas, muito provavelmente apenas a disciplina única de quantificação na matriz curricular está insuficiente como bem apontou o respondente 92 (ver Apêndice 15) do questionário de mapeamento da importância de quantificação: "Só existe essa matéria obrigatória de cálculo. Poderia ter mais algumas".

Quantas disciplinas de quantificação poderiam então ser inseridas? A pouca familiaridade de conceitos matemáticos básicos em nível de Ensino Fundamental e Médio 
detectada nas amostras deste trabalho indica que, infelizmente, com o intuito de corrigir, ou ao menos minimizar esta distorção, é necessária uma disciplina, com nome aqui proposto de "Fundamentos Matemáticos para Geografia". Existem cursos na área de Ciências Exatas que inserem na matriz curricular, disciplinas de nivelamento como por exemplo "Pré Cálculo" e "Fundamentos Matemáticos para a Ciência da Computação". E como se observa no Quadro 20 no Capítulo 3, a grade curricular de Geografia da Universidade Federal da Bahia possui como disciplina obrigatória "Complementos de Matemática I", que muito provavelmente é uma disciplina que tem o propósito de suprir a pouca familiaridade de conceitos matemáticos (em nível de Ensino Fundamental e Médio) por parte do aluno graduando em Geografia.

O conhecimento de noções básicas de estatística descritiva e inferencial é importante e fundamental para a realização de quantificação. Em geral, as disciplinas únicas dos cursos de Geografia apresentam como estrutura básica da ementa, tópicos envolvendo aspectos descritivos e inferenciais. Esta disciplina única deve ser mantida, sendo portanto a segunda disciplina ligada à quantificação. Mas, conforme já comentado, a disciplina única tem um caráter genérico sendo oferecida para cursos diversos além de Geografia. E neste ponto vale a pena considerar a crítica do respondente 28 (ver Apêndice 15) do questionário de mapeamento da importância de quantificação: “Acho que poderia ter uma estatística própria para o curso de Geografia, facilitaria a assimilação". Esta disciplina única, que na UnB é denominada "Estatística Aplicada" poderia ser denominada "Estatística Aplicada em Geografia" ou "Quantificação em Geografia 1" por exemplo. A ideia seria ensinar conceitos com exemplos voltados para a área da Geografia.

Finalmente, conforme visto, a análise espacial de dados geográficos envolve o processamento de padrões espaciais, pontuais, de áreas com contagens, superfícies contínuas e interação espacial. Então a terceira disciplina relativa à quantificação poderia ser denominada de "Estatística Espacial” ou "Quantificação em Geografia 2" e englobar estas temáticas. Desta forma, a matriz curricular dos cursos de Geografia teria três disciplinas ligadas diretamente à quantificação.

Normalmente os cursos atuais de Geografia apresentam na matriz curricular as disciplinas "Sistemas de Informação Geográfica (SIG)" e "Sensoriamento Remoto", ou disciplinas com nomes similares e/ou temáticas similares. Certamente o aproveitamento do aluno nestas disciplinas pode ser melhorado se o mesmo já tiver cursado a disciplina "Estatística Aplicada à Geografia". Na Figura 117 é apresentada de forma esquemática a proposta de fluxo de disciplinas ligadas à quantificação para os cursos de Geografia. 


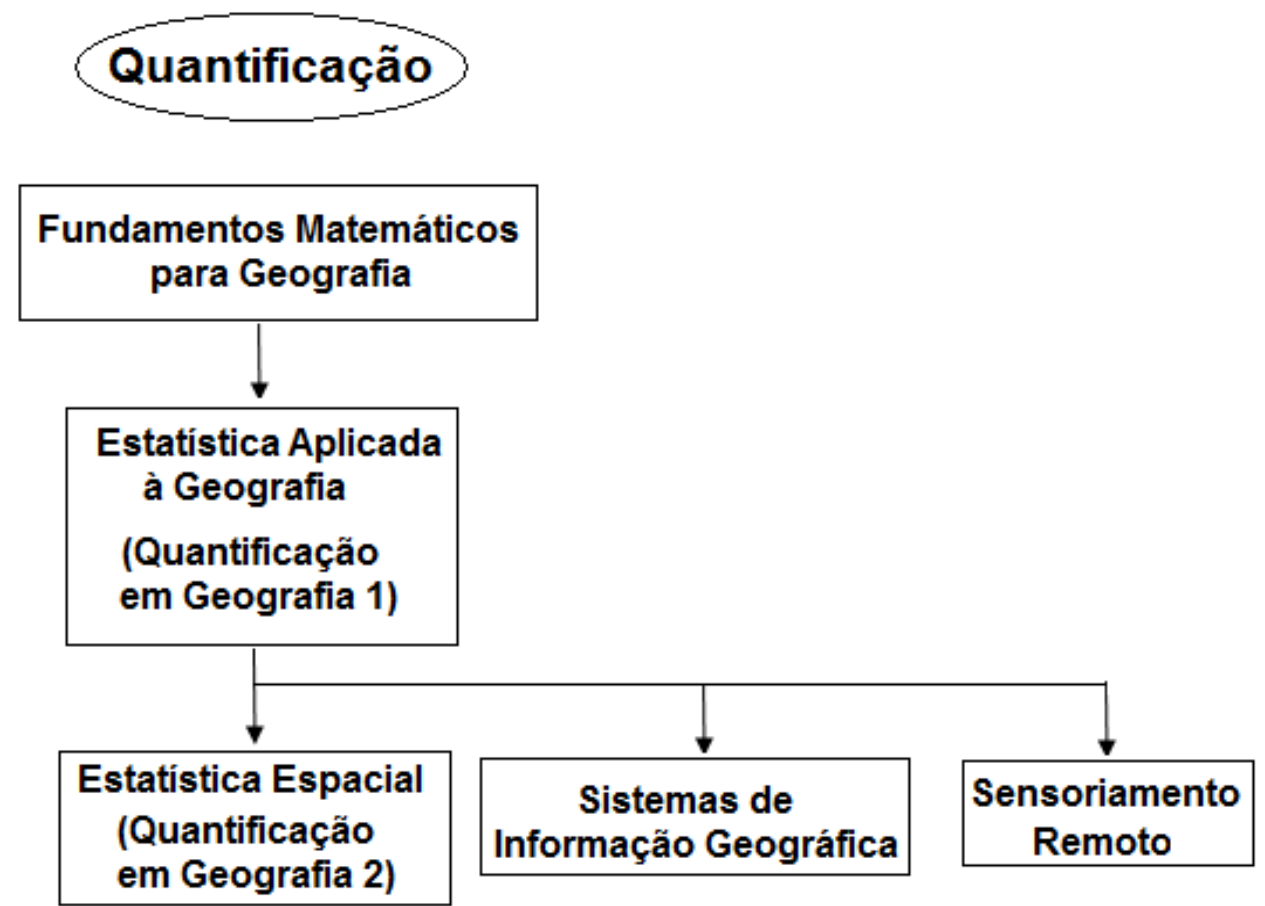

Figura 117 - Proposta de disciplinas ligadas à quantificação para cursos de graduação em Geografia.

Fonte: Elaborado pelo autor.

Alguns temas para composição da ementa das disciplinas "Fundamentos Matemáticos para Geografia", "Estatística Aplicada à Geografia" e "Estatística Espacial" são aqui sugeridos, mas são ideias surgidas em estágio inicial, com base nos resultados das atividades desenvolvidas neste trabalho. A Tabela 67 apresenta os assuntos. 
Tabela 67 - Alguns temas para composição da ementa das disciplinas "Fundamentos Matemáticos para Geografia", "Estatística Aplicada à Geografia" e "Estatística Espacial"

\begin{tabular}{|c|c|c|}
\hline Fundamentos & Estatística Aplicada & Estatística \\
\hline Matemáticos para & à Geografia & Espacial \\
\hline \multicolumn{3}{|l|}{ Geografia } \\
\hline - $\quad$ Frações/proporções & - Estatistica descritiva & - Estatistica descritiva \\
\hline - Medidas lineares, & $\checkmark$ Média, etc & espacial \\
\hline superficiais e & $\checkmark$ Variância/desvio & - Padrões pontuais \\
\hline volumétricas & padrão,etc & espaciais \\
\hline - Funções de $1^{\circ}$ e $2^{o}$ & $\checkmark$ Separatrizes, etc & - Padrões de superfícies \\
\hline grau & - Indicadores (índices, taxas) & contínuas \\
\hline - Gráficos de & - Estatística inferencial & - Padrões de áreas com \\
\hline funções & - Variáveis aleatóreas & contagens \\
\hline - Matrizes e & - Distribuições de & - Padrões locacionais \\
\hline determinantes & probabilidade & espaciais (interação \\
\hline - Análise & - Testes de hipóteses & espacial) \\
\hline combinatória & - Estatística multivariada & \\
\hline
\end{tabular}

A Tabela 67 tem o propósito de direcionar os temas a serem abordados nas três disciplinas. A disciplina de Fundamentos Matemáticos para Geografia, conforme já comentado, tem o propósito de suprir as deficiências dos alunos em assuntos em nível fundamental e médio e realmente se faz necessário em vista do que as amostras deste trabalho apontaram sobre este nível de conhecimento dos alunos.

A disciplina de Estatística Aplicada à Geografia deve englobar o que atualmente as disciplinas únicas se propõem a abordar. E a disciplina "Estatística Espacial" trataria dos temas de padrões pontuais e de áreas. Inicialmente esta disciplina poderia ter como referencial norteador o livro de Meirelles (2007) intitulado "Geomática - modelos e aplicações ambientais".

Finalmente, vale ressaltar que a eficácia de capacitação do geógrafo em quantificação em Geografia com base nestas três disciplinas, muito provavelmente poderá ser alcançada se o material de referência a ser utilizado for de natureza preponderantemente imagética. $\mathrm{O}$ atual patamar tecnológico da sociedade proporciona maciça comunicação por meio das redes 
sociais onde voz e imagem se misturam para proporcionar entretenimento, notícia, negócios, enfim, informação. Com o atual aparato tecnológico, é possível montar facilmente conteúdo imagético combinando num mesmo meio (tela do computador) imagem, texto, símbolo e eventualmente acompanhado de som, além de interatividade com o meio (via cliques do mouse, ou tela touchscreen, por exemplo). Assim o conteúdo imagético pode ser um produto com enorme poder para propiciar aprendizagem significativa.

A geração que hoje encontra-se na faixa etária de 20 anos e as gerações que se seguem a essa, são (serão) diariamente cada vez mais bombardeadas pelo conteúdo imagético das redes sociais mundiais e esta parece ser uma tendência irreversível. O padrão geral de "gosto um pouco de matemática" que foi detectado nas amostras deste trabalho, e os elogios à dinamicidade de telas do EDH pelos alunos que participaram da experiência de aprendizagem de quantificação via conteúdo imagético, propicia credibilidade para uma tentativa de ensino que proporcione uma aprendizagem significativa daquilo que o aluno diz "gostar um pouco".

Não se trata portanto de simplesmente acrescentar uma disciplina antes e outra depois da atual disciplina única de quantificação. Trata-se desta disciplina única (e as outras duas) ser apresentada não com base em um livro-texto e um software de ensino de "aspectos marginais", mas sim com base em um material com conteúdo imagético em que apresente contextos ligados a problemas abordados pela Geografia. O livro-texto e o software de ensino de "aspectos marginais" é o que deve ser material de apoio. O material principal é o produto imagético.

Trata-se, portanto, de propiciar aprendizagem significativa por meio de laboriosa montagem artesanal de conteúdos imagéticos que transmitam de forma concreta o conceito abstrato de quantificação considerado. Estes conteúdos imagéticos podem ajudar aos graduandos em Geografia que "gostam um pouco" de matemática a aprender significativamente aspectos de quantificação, fazendo-os, aos poucos (em doses homeopáticas), usarem quantificação no entendimento da forma e estrutura das organizações espaciais, ao mesmo tempo em que, pouco a pouco desenvolvam o raciocínio, pensamento e letramento estatístico.

A proposta destas disciplinas, ensinadas de forma imagética, visa então preparar o geógrafo para ser verdadeiro interpretador de "mapas" que retratam o cotidiano das organizações espaciais, contribuindo verdadeiramente de forma proativa para a sociedade no exercício de sua profissão. 


\section{REFERÊNCIAS BIBLIOGRÁFICAS}

ALMEIDA, C.M.; CÂMARA, G.; MONTEIRO, A.M.V.; FILHO, B.S.S.; CERQUEIRA, G.C. Modelos celulares de dinâmicas espaço-temporais: aplicações em estudos urbanísticos. In: Meirelles, M.S.P.; Câmara, G.; Almeida, C.M. (eds). Geomática : Modelos e aplicações ambientais, Brasília-DF, Embrapa Informação Tecnológica, 593p., 2007, p.446-496.

ASSUNÇÃO, R.M. Estatística espacial com aplicações em epidemiologia. São Carlos: UFSCar, 2001, 131p.

AUSUBEL, D.P., The psychology of meaningful verbal learning, New York, Grune and Stratton, 1963, 225p.

AUSUBEL, D.P., Educational psychology: a cognitive view, New York, Holt, Rinehart and Winston, 1968, 685p.

AUSUBEL, D.P.; NOVAK, J.D; HANESIAN, H. Educational psychology: a cognitive view. 2nd. ed. New York, Holt Rinehart and Winston, 1978, 733p.

BANDO, D. H. Padrões espaciais do suicídio na cidade de São Paulo e seus correlatos socioeconômico-culturais. 2008. 114 f. Dissertação (Mestrado) - Faculdade de Filosofia Letras e Ciências Humanas, Universidade de São Paulo, São Paulo, 2008.

BETTINI, C. Conceitos básicos de Geoestatística. In: MEIRELLES, M.S.P.; CÂMARA, G.; ALMEIDA, C.M. (eds). Geomática: modelos e aplicações ambientais, Brasília-DF: Embrapa Informação Tecnológica, 593p., 2007, p.193-234.

BORBA, R., MONTEIRO, C., GUIMARÃES, G., COUTINHO, C., KATAOKA, V.Y. Educação estatística no ensino básico: currículo, pesquisa e prática em sala de aula, EM TEIA - Revista de Educação Matemática e Tecnológica Iberoamericana, v.2, $\mathrm{n}^{\mathrm{o}} .2$, Recife, 2011. (versão on-line) 
BRASIL. Secretaria de Educação Fundamental. Parâmetros curriculares nacionais : introdução aos parâmetros curriculares nacionais / Secretaria de Educação Fundamental. Brasília : MEC/SEF, 1997a. 126p. Disponível em: http://portal.mec.gov.br/seb/arquivos/pdf/livro01.pdf. Acesso em: 14 abr. 2013.

CÂMARA, G. Geometrias não são Geografias: o legado de Milton Santos, InfoGeo, 20: 3435., 2001.

CÂMARA, G., MONTEIRO A. M., FUCKS, S. D., CARVALHO, M. S. Análise espacial de áreas. In DRUCK, S; CARVALHO, M.S., CÂMARA; MONTEIRO, A. M. V., (orgs.) Análise Espacial de Dados Geográficos, Empresa Brasileira de Pesquisa Agropecuária, Planaltina, 2004, p. 108-150.

CÂMARA, G., MONTEIRO A. M., FUCKS, S. D., CARVALHO, M. S. Análise espacial e geoprocessamento. In DRUCK, S; CARVALHO, M.S., CÂMARA; MONTEIRO, A. M. V., (orgs.) Análise Espacial de Dados Geográficos, Empresa Brasileira de Pesquisa Agropecuária, Planaltina, 2004, p. 5-30.

CAMPOS, C.R. A Educação Estatística: uma investigação acerca dos aspectos relevantes à didática da Estatística em cursos de graduação. 2007. 256f. Tese (Doutorado em Educação Matemática). Universidade Estadual Paulista, Rio Claro, 2007.

CAMPOS, M.R.; VALENCIA, L.I.V.; FORTES, B.P.M.D.; BRAGA, R.C.C.; MEDRONHO, R. A.. Distribuição espacial da infecção por Ascaris lumbricoides, Revista de Saúde Pública v.36, $n^{\circ}$.1, São Paulo, 2002. (versão on-line)

CECATTO, A. O ensino da utilização de imagens pelos professores de História da Universidade Federal do Ceará (UFC). In: SIMPÓSIO NACIONAL DE HISTÓRIA, XXVII, 2013, Natal. Anais... Natal: ANPUH, 2013. p. 1-16.

CHANCE, B.L. Components of Statistical Thinking and Implications for Instruction and Assessment. Journal of Statistics Education v. 10, n.3 (2002). Disponível em: < http://www.amstat.org/publications/jse/v10n3/chance.html>. Acesso em: 17 mai. 2013. 
COSTA, G.C. Crítica da crítica dos PCNS: Uma concepção dialética. <http://groupsbeta.google.com/group/digitalsource>. Acesso em: 20 abril 2013

COSTA NETO, P.L.O. Estatística, São Paulo, Ed. Edgard Blucher, 1977, 264p.

C.P. GEOGRAFIA. A revolução tecnológica da Geografia. Conhecimento Prático Geografia, n. 24, p.50-54, São Paulo: Ed. Escala Educacional, 2009.

COUTINHO, F.A. Análise do valor didático de imagens presentes em livros de Biologia para o ensino médio. Revista Brasileira de Pesquisa em Educação em Ciências, v. 10, n. 3, p.1-18, 2010.

delMAS, R.C. Statistical Literacy, Reasoning, and Learning: A Commentary. Journal of Statistics Education v. 10, n.3 (2002). Disponível em:

<http://www.amstat.org/publications/jse/v10n3/delmas_discussion.html>. Acesso em: 18 mai. 2013.

DRUCK, S.; CARVAlHO, M.S.; CÂMARA, G.; MONTEIRO, A.M.V. (orgs.) Análise Espacial de Dados Geográficos, Planaltina, Empresa Brasileira de Pesquisa Agropecuária, 2004, 208p.

FARIAS, P.R.S.; NOCITI, L.A.S.; BARBOSA, J.C.; PERECIN, D. Agricultura de precisão: mapeamento da produtividade em pomares cítricos usando geoestatística. Revista Brasileira de Fruticultura, v.25, $\mathrm{n}^{\mathrm{o}}$.2, Jaboticabal, 2003. (versão on-line)

GAL, I. Adults' Statistical Literacy: Meanings, Components, Responsibilities. International Statistical Review, 70(1), pp. 1-25, 2002.

GARFIELD, J. Components of Statistical Thinking and Implications for Instruction and Assessment. Journal of Statistics Education v. 10, n.3 (2002). Disponível em: <http://www.amstat.org/publications/jse/v10n3/garfield.html>. Acesso em: 18 mai. 2013. 
GERARDI, L.H.O., SILVA, B.C.N. Quantificação em Geografia, São Paulo: Difel, 1981, $161 \mathrm{p}$.

GIBIN, G.B., FERREIRA, L.F. Avaliação dos estudantes sobre o uso de imagens como recurso auxiliar no ensino de conceitos químicos, Química Nova na Escola v.35, nº 1 , pp. 19-26, 2013. (versão on-line)

GODOY, A.S. Pesquisa qualitativa. Tipos fundamentais. Revista de Administração de Empresas v.35, nº.3, p. 20-29, mai-jun 1995.

GOLLEDGE, R.G.; The nature of geographic knowledge. Annals of the Association of American Geographers, 92(1), pp. 1-14, 2002.

GRATRELL A.C., BAILEY, T.C., DIGGLE, P.J., ROWLINGSON, B.S. Spatial point pattern analysis and its application in geographical Epidemiology. Trans. Inst. Br. Geogr, NS 21 p.256-274 1996.

GRIZZI-CAMPOS, F.; BARROZO, L.V.; RUIZ, T.; CÉSAR, C.L.G.; BARROS, M.B.A.; AZEVEDO, M.B.; Distribuição espacial dos idosos de um município de médio porte do interior paulista segundo algumas características sócio-demográficas e de morbidade, Cadernos de Saúde Pública, 25(1), pp. 77-86, 2009.

GUEDES, J.A., Resenha do livro "Métodos estatísticos para a Geografia: um guia para o estudante”. Revista Brasileira de Educação Geográfica, Campinas, v. 3, n. 5, p. 158-160, jan./jun., 2013.

HECKLER, V., SARAIVA, M.F.O., FILHO, K.S.O. Uso de simuladores, imagens e animações como ferramentas auxiliares no ensino/aprendizagem de óptica, Revista Brasileira de Ensino de Física v.29, nº.2, pp. 267-273, 2007.

HONDA, A.M.C. Matemática e Geografia: uma interdisciplinariedade. 2013. 108 f. Dissertação (Mestrado) - Universidade Estadual de Londrina, Londrina, 2013 . 
JOHNSTON, R.J. Multivariate statistical analysis in Geography. New York, Longman, 1978, 280p.

LOPES, C.E. O ensino da estatística e da probabilidade na educação básica e a formação dos professores, Cadernos Cedes, vol. 28, n. 74, p. 57-73, Campinas, 2008.

LOPES, C.E; MEIRELLES, E. O desenvolvimento da probabilidade e da estatística. In: Anais do XVIII Encontro Regional de Professores de Matemática, Campinas, 20 e 21 de maio de 2005.

MEIRELLES, M.S.P. Geomática: modelos e aplicações ambientais, Meirelles, M.S.P.; Câmara, G.; Almeida, C.M. (eds), Brasília-DF, Embrapa Informação Tecnológica, 593p., 2007 .

MOIMAZ, E.R. O uso da imagem no Ensino Médio: uma avaliação sobre essa contribuição para a aprendizagem dos conteúdos em história. 2009. 179f. Dissertação (Mestrado História Social). Universidade Estadual de Londrina, Paraná, 2009 .

MOREIRA, M.A., Aprendizagem Significativa: um conceito subjacente. In: MOREIRA, M.A., CABAllero, M.C. e RODRÍGUEZ, M.L. (orgs.) Actas del Encuentro Internacional sobre el Aprendizaje Significativo. Burgos, Espanha, 1997, pp. 19-44.

NYSTUEN, J.D. (1963) Identification of some fundamental spatial concepts. Papers of the Michigan Academy of Science, Arts, Letters, 48: pp.373-384

OLIVEIRA, J.B.A., CHADWICK, C.B. Tecnologia educacional - Teorias da instrução, Petrópolis-RJ, Vozes, 1982, 283p.

PAGAN, M.A. A interdisciplinaridade como proposta pedagógica para o ensino de Estatística na Educação Básica. 2010. 243f. Dissertação (Mestrado Profissional em Ensino da Matemática). Pontifícia Universidade Católica de São Paulo, São Paulo, 2010 . 
PARÂMETROS CURRICULARES NACIONAIS - ENSINO MÉDIO. Parâmetros Curriculares Nacionais - Ensino Médio - Parte III - Ciências da Natureza, Matemática e Suas Tecnologias. 2013. Disponível em:

< http://portal.mec.gov.br/seb/arquivos/pdf/ciencian.pdf >. Acesso em: 15 abr. 2013.

PCN+. PCN+ - Ensino Médio - Ciências da Natureza, Matemática e Suas Tecnologias. 2013. Disponível em: <http://portal.mec.gov.br/seb/arquivos/pdf/CienciasNatureza.pdf>. Acesso em: 15 abr. 2013.

PEREDA, A.S.A. Aspectos afetivos na aprendizagem da Estatística: atitudes e suas forma de avaliação, Dissertação de Mestrado, 97p., Universidade de São Paulo, 2006 .

POZZER-ARDENGHI, L., ROTH, W. M. Photographs in lectures: gestures as meaningmaking resources. Linguistics and Education, v. 5, p. 275-293, 2005.

RIBEIRO, L.C.Q.; Moura, R.; Delgado, P., Silva, E.T.; Rodrigues, J.M.; Ribeiro, M.G.; Cintra, A.; Costa, G.; Zaninelli, L. Níveis de integração dos municípios brasileiros em RM, RIDEs e AU à dinâmica da metropolização. Observatório das Metrópoles, Relatório de pesquisa, Rio de Janeiro, 2012.

ROSA, M.C.A. O ensino da Geografia no mundo globalizado. Conhecimento Prático Geografia, n. 24, p.41-43, São Paulo: Ed. Escala Educacional, 2009.

ROSA, R. O geógrafo: atividades e mercado de trabalho. Educação e Filosofia, n. 2, v.4, p.79-84, Uberlândia, 1988.

SANTOS, M. Espaço e método. Nobel, São Paulo, 1985.

SOUZA, P.M.; PONCIANO, N.J.; MATA, H.T.C.; BRITO, M.N.; GOLINSKI, J. Padrão de desenvolvimento tecnológico dos municípios das Regiões Norte e Noroeste do Rio de Janeiro. Revista de Economia e Sociologia Rural, v.47, nº.4, Brasília, 2009. (versão on-line) 
TAYLOR, P.J. Quantitative Methods in Geography, Atlanta-USA, Houghton Mifflin Co., 377p., 1977.

TAVARES, R. Aprendizagem significativa. Revista Conceitos, ADUFPB, João Pessoa, julho de 2003/junho de 2004, p.55-60

UNIVERSIDADE DE BRASÍLIA (UnB). Listagem de ementa/programa - Estatística Aplicada. 2013a. Disponível em:

$<$ https://condoc.unb.br/matriculaweb/graduacao/disciplina.aspx?cod=115011 >. Acesso em: 29 ago. 2013.

UNIVERSIDADE DE BRASÍLIA (UnB). Listagem de fluxo de habilitação - bacharelado em Estatística. 2013b. Disponível em:

<https://condoc.unb.br/matriculaweb/graduacao/fluxo.aspx?cod=1716>. Acesso em: 29 ago. 2013.

UNIVERSIDADE DE SÃO PAULO (USP). Bacharelado em Estatística - Informações básicas do currículo. 2013. Disponível em:

<https://uspdigital.usp.br/jupiterweb/listarGradeCurricular?codcg=8\&codcur=8021\&codhab $=$ 101\&tipo=N>. Acesso em: 30 ago. 2013.

UNIVERSIDADE ESTADUAL PULISTA - CAMPUS OURINHOS (UNESP). Projeto político e pedagógico - Curso de Geografia (licenciatura e bacharelado). 2013. Disponível em:

<http://www.ourinhos.unesp.br/Home/Graduacao/Geografia/projeto_pedagogico.pdf>. Acesso em: 30 ago. 2013.

UNIVERSIDADE ESTADUAL PULISTA - CAMPUS PRESIDENTE PRUDENTE (UNESP). Estatística Aplicada à Geografia. 2013. Disponível em:

<http://www.fct.unesp.br/Home/Graduacao/Geografia/estatistica-aplicada-a-Geografia.pdf>. Acesso em: 30 ago. 2013. 
UNIVERSIDADE FEDERAL DA BAHIA (UFBA). Grade curricular - bacharelado em Geografia. 2013. Disponível em:

<http://www.twiki.ufba.br/twiki/pub/IGeo/GeogGradeCurricular/gradecurricularGeografiabacharelado109130.pdf>. Acesso em: 31 ago. 2013.

UNIVERSIDADE FEDERAL DE ALAGOAS (UFAL). Curso de Geografia - bacharelado - projeto plítico-pedagógico. 2013. Disponível em:

<http://www.ufal.edu.br/arquivos/prograd/cursos/campus-maceio/Geografia-bacharelado2011>. Acesso em: 31 ago. 2013.

UNIVERSIDADE FEDERAL DE GOIÁS (UFG). Curso de Geografia - projeto político e pedagógico. 2013. Disponível em: < http://www.iesa.ufg.br/pages/4019>. Acesso em: 30 ago. 2013.

UNIVERSIDADE FEDERAL DE MATO GROSSO (UFMT). Reestruturação do projeto político do Curso de Bacharelado em Geografia. 2013. Disponível em:

$<$ http://www.Geografia.ufmt.br/docs/PPP_BACHARELADO.pdf $>$. Acesso em: 31 ago. 2013.

UNIVERSIDADE FEDERAL DE MINAS GERAIS (UFMG). Geografia Bacharelado Diurno - disciplinas obrigatórias. 2013. Disponível em:

$<$ http://www.igc.ufmg.br/cursos/Geografia-bacharelado-diurno-obrigatorias.htm>. Acesso em: 30 ago. 2013.

UNIVERSIDADE FEDERAL DE SANTA CATARINA (UFSC). GCN 7901 - Análise Estatística em Geociências. 2013. Disponível em:

< http://Geografia.ufsc.br/files/2012/03/GCN-7901.pdf>. Acesso em: 29 ago. 2013.

UNIVERSIDADE FEDERAL DE UBERLÃNDIA (UFU). Disciplina: Geoestatística. 2013. Disponível em:

$<$ http://www.ig.ufu.br/sites/ig.ufu.br/files/Anexos/Bookpage/Geoestatistica.pd>. Acesso em: 29 ago. 2013. 
UNIVERSIDADE FEDERAL DO AMAZONAS (UFAM). Curriculum de Curso Bacharelado em Geografia. Disponível em: <http://www.sie.ufam.edu.br/curriculo_cursov2.php>. Acesso em: 31 ago. 2013.

UNIVERSIDADE FEDERAL DO CEARÁ (UFC). Integralização Curricular \& Ementas Bacharelado em Geografia. Disponível em:

$<$ http://www.Geografia.ufc.br/portal/index.php?option=com_content\&view=article\&id=56\&I temid=86>. Acesso em: 31 ago. 2013.

UNIVERSIDADE FEDERAL DO PARANÁ (UFPR). Disciplinas do curso de Geografia Ementas das disciplinas obrigatórias. 2013. Disponível em:

<http://www.Geografia.ufpr.br/portal/wp-content/uploads/2013/04/Ementas-das-Disciplinasdo-Curso-de-Geografia2.pdf>. Acesso em: 29 ago. 2013.

UNIVERSIDADE FEDERAL DO RIO DE JANEIRO (UFRJ). Bacharelado em Geografia - Grade Curricular. 2013. Disponível em:

$<$

http://www.Geografia.ufrj.br/index.php?option=com_content $\& v i e w=\operatorname{article} \& i d=64 \& I t e m i d=$ 32>. Acesso em: 30 ago. 2013.

UNIVERSIDADE FEDERAL DO RIO GRANDE DO SUL (UFRGS). Bacharelado em Geografia - 2013/2. 2013. Disponível em:

<http://www1.ufrgs.br/PortalEnsino/GraduacaoCurriculos/plone.php?r=grade\&curso=331\&h abilitacao $=43 \&$ curriculo=128>. Acesso em: 29 ago. 2013.

UNWIN, D.J. Numbers aren't nasty: a workbook of spatial concepts. [S.I.] : University of Leicester, 2010. Disponível em:

<http://www.teachspatial.org/sites/teachspatial.org/files/Unwin_WorkbookOfSpatialConcepts .pdf>. Acesso em: 19 ago. 2013

VALE, C.C. Teoria Geral do Sistema: histórico e correlações com a Geografia e com o estudo da paisagem. Entre-Lugar, Dourados, MS, ano 3, n.6, p 85-108, $2^{\circ}$ semestre de 2012. 
VASCONCELOS, T.S.; ROSSA-FERES, D.C. Diversidade, distribuição espacial e temporal de anfíbios anuros (Amphibia, Anura) na região noroeste do estado de São Paulo, Brasil. Biota Neotropica, v.5, $\mathrm{n}^{\mathrm{o}}$.2, Campinas, 2005. (versão on-line)

VERRI, L.B. Os Fundamentos do Raciocínio Estatístico. Disponível em:

<http://www.clubedeautores.com.br/book/145189--

Os_Fundamentos_do_Raciocinio_Estatistico\#.Vhe87W7wpak>. Acesso em: 26 jul. 2013.

VITIELLO, M. A. Outras formações da Terra. Discutindo Geografia, ${ }^{0}$ 21, ano 4, p.10-14, São Paulo: Ed. Escala Educacional, 2008. 


\section{APÊNDICE 1}

\section{QUESTIONARIO DE ENTRADA DO CURSO DE EXTENSÃO}

\begin{tabular}{|c|c|}
\hline 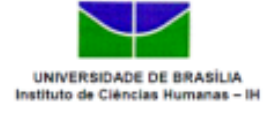 & $\begin{array}{c}\text { Curso de Extensão - Introdução à Quantificação em Geografia - Set/Noy } 2014 \\
\text { Questionário para mapeamento de familiaridade } \\
\text { de alguns conceitos matemáticos }\end{array}$ \\
\hline
\end{tabular}

Identificação do participante

(1) Nome completo:

(2) Idade: anos completos

(3) Sexo: [ ] Feminino [ ] Masculino

(4) Curso:

(5) Já cursou alguma disciplina ligada à estatística (Estatística Exploratória, Estatística Aplicada, Métodos Estatísticos, Probabilidade e Estatística, Estatística Para Geociências, etc) ?

[ ] $\operatorname{Sim}[\quad]$ Não

(6) Você gosta de matemática e/ou estatística?

[ ] Detesto [ ] Gosto um pouco [ ] Gosto [ ] Gosto muito

Quadro de Respostas (por favor anote suas respostas neste quadro)

\begin{tabular}{|l|l|l|l|l|}
\hline Questão 1 & Questão 2 & Questão 3 & Questão 4 & Questão 5 \\
\hline & & & & \\
& & & & \\
\hline
\end{tabular}

Caso não saiba a resposta marque um $X$ 


\section{APÊNDICE 2}

\section{QUESTIONARIO DE ENTRADA DO CURSO DE EXTENSÃO QUESTÃO 1}

Questão 1 Situação hipotética: a tabela abaixo apresenta a produção em toneladas de 4 produtos (arroz, feijão, soja e milho) no quadriênio 2000-2003. Assinale a alternativa correta. (não se esquega de marcar sua resposta no Quadro de Respostas !!!)

\begin{tabular}{c|cccc|c} 
& 2000 & 2001 & 2002 & 2003 & Total \\
\hline Arroz & 200 & 300 & 100 & $?$ & 1000 \\
Feijão & 200 & $?$ & 400 & 200 & $?$ \\
Soja & 300 & $?$ & 300 & 400 & 1100 \\
Milho & 400 & 300 & 200 & $?$ & 1000 \\
\hline Total & 1100 & $?$ & 1000 & 1100 & 4000
\end{tabular}

Obs.: ? - informação intencionalmente não apresentada na tabela

(A) Em 2002 o país produziu no total 1000 toneladas dos 4 produtos, ou seja, em média 250 toneladas de cada produto. Mas não podemos calcular a mesma média para o ano de 2001 pois não há informação suficiente para realização do cálculo.

(B) Em 2001 o pais produziu entre $25 \%$ e $30 \%$ do total produzido dos 4 produtos no quadriênio 2000-2003.

(C) Em 2003 a soma da produção de arroz e milho foi $10 \%$ maior que a soma da produção de soja e feijão.

(D) Em 2001 a soja e o feijão contribuíram, juntos, com apenas $25 \%$ do total produzido en tre os 4 produtos.

(E) No quadriênio 2000-2003 a produção de arroz e milho, conjuntamente foi responsável por mais da metade da produção dos 4 produtos 
Resolução Vamos inicialmente descobrir os valores A, B, C, D, E e F da tabela:

\begin{tabular}{c|cccc|r} 
& 2000 & 2001 & 2002 & 2003 & Total \\
\hline Arroz & 200 & 300 & 100 & ? D & 1000 \\
Feijão & 200 & ? A & 400 & 200 & ? F \\
Soja & 300 & ? B & 300 & 400 & 1100 \\
Milho & 400 & 300 & 200 & $? \mathbf{E}$ & 1000 \\
\hline Total & 1100 & ? C & 1000 & 1100 & 4000
\end{tabular}

Item A Conhecemos C... podemos calcular a média em 2001: $800 / 4=200$

$\begin{aligned} 200+300+100+D=1000 & \Rightarrow D=400 \\ 1000+F+1100+1000=4000 & \Rightarrow F=900 \\ 200+A+400+200=F & \Rightarrow A=100 \\ 300+B+300+400=1100 & \Rightarrow B=100 \\ 400+300+200+E=1000 & \Rightarrow E=100 \\ 1100+C+1000+1100=4000 & \Rightarrow C=800\end{aligned}$

Item B O total produzido no quadriênio 2000-2003 foi 4000 ton. Em 2001 o total foi 800 ton.

Então a proporção de contribuição do ano de 2001 foi: $\frac{800}{4000}=0,2=20 \%$

Item C Em 2003: Arroz + Milho $=\mathrm{D}+\mathrm{E}=\mathbf{4 0 0 + 1 0 0 = 5 0 0}$

Feijão + Soja $=200+400=600$

Arroz+Milho foi $\frac{1}{6}$ menor comparado Feijão+Soja $\sim 16,666 \%$ menor

Item D Em 2001: Soja + Feijão $=A+B=200$ Total em 2001 $=\mathrm{C}=800$

Então a proporção de Soja+Feijão em 2001 é $\frac{200}{800}=0,25=25 \%$

Item E Arroz + Milho no quadriênio 2000-2003 $=1000+1000=2000$

No quadriênio, todos os produtos $=4000$. Assim, Arroz + milho

respondem por EXATAMENTE a metade do que foi produzido !!!

Resposta: D 


\section{APÊNDICE 3}

\section{QUESTIONARIO DE ENTRADA DO CURSO DE EXTENSÃO QUESTÃO 2}

Questão 2 Situação hipotética: o serviço de defesa agropecuária de um pais inspecionou 640 municípios e detectou o seguinte: 80 municípios apresentavam a presença da praga A e da praga B. 160 municípios apresentavam a presença somente da praga $A$ e 200 municípios somente da praga B. Os 200 municípios restantes estava livres das pragas A e B. Para escolher um município para um projeto piloto de estudo de pragas o serviço de defesa agropecuária escreveu o nome de cada um dos 640 municípios num papel e colocou os papeis numa urna para sorteio. Assinale a al ternativa corre ta. (não se esqueça de marcar sua resposta no Quadro de Respostas !!!)

(2.1) sorteando-se um papel com o nome de um município, qual a probabilidade do município sorteado apresentar somente a ocorrência da praga A ?

(2.2) sorteando-se um papel com o nome de um município, qual a probabilidade do município sorteado apresentar a ocorrência da praga A ?

(2.3) sorteando-se um papel com o nome de um município, o sujeito que sorteou falou: "o município sorteado apesenta a praga $\mathrm{A}^{\prime \prime}$. Qual a probabilidade de o município sorteado apresentar também a ocorrência da praga $B$ ?

As respostas dos itens 2.1, 2.2 e 2.3 são, respectivamente: (não se esqueça de marcar sua resposta no Quadro de Respostas !!!!)

(A) (2.1) entre $20 \%$ e $30 \%$; (2.2) entre $20 \%$ e $30 \%$; (2.3) entre $20 \%$ e $30 \%$

(B) (2.1) entre $25 \%$ e $35 \%$; (2.2) entre $30 \%$ e $35 \%$; (2.3) entre $40 \%$ e $50 \%$

(C) (2.1) entre $20 \%$ e $30 \%$; (2.2) entre $40 \%$ e $50 \%$; (2.3) entre $15 \%$ e $25 \%$

(D) (2.1) entre $20 \%$ e $30 \%$; (2.2) entre $35 \%$ e $45 \%$; (2.3) entre $25 \%$ e $35 \%$

(E) (2.1) entre $35 \%$ e $45 \%$; (2.2) entre $20 \%$ e $30 \%$; (2.3) entre $25 \%$ e $35 \%$ 


\section{$\underline{\text { Resolução }}$}

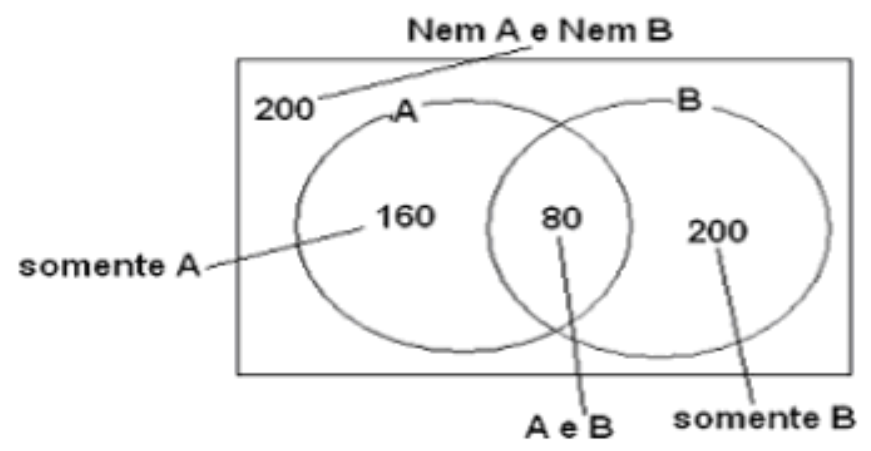

(2.1) $P($ somente $A)=\frac{160}{640}=0,25=25 \%$

(2.2) $P(A)=P($ somente $A+A$ e $B)=\frac{160+80}{640}=\frac{240}{640}=0,375=37,5 \%$

(2.3) Redução do espaço amostral: Sabe-se que ocorre A. O espaço amostral de 640 passa a ser $160+80=240$ (somente $A+A$ e B). Assim:

$$
P(B \mid A)=\frac{P(A \text { e } B)}{P(A)}=\frac{80}{240}=0,33333=33,33 \%
$$

Resposta: 


\section{APÊNDICE 4}

\section{QUESTIONARIO DE ENTRADA DO CURSO DE EXTENSÃO \\ QUESTÃO 3}

Questão 3 Situação hipotética: os Mapas 1 e 2 abaixo apresentados representam a mesma região, porém encon tram-se em escalas distintas. Existem quatro pontos fixos na região, $A, B, C$ e $D$, que são vértices de um retângulo imaginário conforme mostrado nos Mapas 1 e 2 . Sabe-se que a escala do Mapa 1 é de $1 \mathrm{~cm}=3.000$ metros e que no Mapa 1 a distância do segmento de reta $A D$ $=B C=2 \mathrm{~cm}$. No Mapa 2 a distância do segmento de reta $A B=C D=0,75 \mathrm{~cm}$. Sabe-se ainda que a área real do quadrilátero $\mathrm{ABCD}$ é de $54 \mathrm{Km}^{2}$. Assinale a alternativa correta. (não se esqueça de marcar sua resposta no Quadro de Respostas [!!)

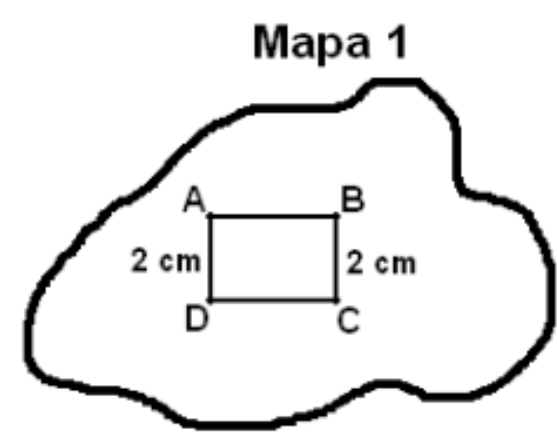

Escala: $1 \mathrm{~cm}=3000 \mathrm{~m}$

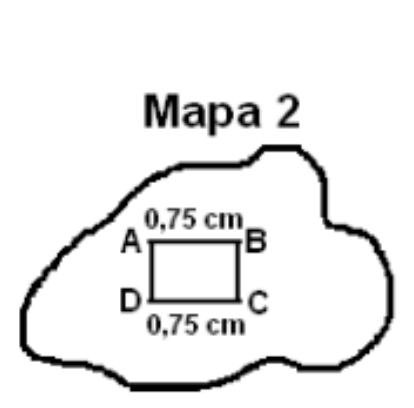

$\underline{\text { Resolução }}$

(A) A escala do Mapa 2 é: $1 \mathrm{~cm}=800.000 \mathrm{~cm}$ $1^{\circ}$ passo: No Mapa 1 temos que:

(B) A escala do Mapa 2 é: $1 \mathrm{~cm}=120.000 \mathrm{~cm}$

(C) A escala do Mapa 2 é: $1 \mathrm{~cm}=8.000 .000 \mathrm{~cm}$

(D) A escala do Mapa 2 é: $1 \mathrm{~cm}=1.200 .000 \mathrm{~cm}$

(E) A escala do Mapa 2 é: $1 \mathrm{~cm}=240.000 \mathrm{~cm}$

Resposta: D

$2{ }^{\circ}$ passo: $A$ área do quadrilátero $A B C D$ vale $54 \mathrm{Km}^{2}$

$A$ àrea de $A B C D$, que é um retângulo vale $\overline{A D} \times \overline{A B}$. Entäo:

$\overline{\mathrm{AD}} \times \overline{\mathrm{AB}}=54 \mathrm{~km}^{2} \Longrightarrow 6.000 \mathrm{~m} \times \overline{\mathrm{AB}}=54.000 .000 \mathrm{~m}^{2} \Rightarrow \overline{\mathrm{AB}}=9.000 \mathrm{~m}$

$3^{\circ}$ passo: No Mapa 2 temos que $\overline{\mathrm{AB}}=0,75 \mathrm{~cm}$. Como $\overline{\mathrm{AB}}=9.000 \mathrm{~m}$ então:

$\begin{aligned} & 0,75 \mathrm{~cm}-\cdots \\ & 1 \mathrm{~cm}-\ldots .000 \mathrm{~m}\end{aligned} \quad X X=12.000 \mathrm{~m} \quad$ Ou seja: $1 \mathrm{~cm}: 12.000 \mathrm{~m}$ $1 \mathrm{~cm}: 1.200 .000 \mathrm{~cm}$ 


\section{APÊNDICE 5}

\section{QUESTIONARIO DE ENTRADA DO CURSO DE EXTENSÃO \\ QUESTÃO 4}

Questão 4 Situação hipotética: No dia 01/01/2013 foi feita a medida anual da área de vegetação nativa em determinada região verificando-se que havia $2000 \mathrm{~km}^{2}$ da vegetação nativa. Em 01/01/2014 mediu-se novamente na região a área de vegetação nativa e verificou-se que houve uma redução de $10 \%$ da vegetação nativa em relação à medição anterior. Supondo que a taxa anual de redução da vegetação nativa na região seja constante e seja $10 \%$, em que medição anual a área de vegetação nativa remanescente será menos de $3 / 4$ da área medida em 01/01/2013 ? (não se esqueça de marcar sua resposta no Quadro de Respostas !'!)

\section{Resolução}

(A) Num ano após 2020

(B) $\operatorname{Em~01/01/2018~}$

(C) $\operatorname{Em~01/01/2017~}$

(D) $\operatorname{Em~01/01/2016~}$

(E) $\operatorname{Em~01/01/2015~}$

Resposta:
- Em 01/01/2013 - $2000 \mathrm{~km}^{2}$ $3 / 4 \mathrm{da}$ área de 01/01/2013: $3 \times 2000 \mathrm{~km}^{2}=1500 \mathrm{~km}^{2}$ (Quando a área será menor que $1500 \mathrm{~km}^{2}$ ?)

- Em 01/01/2014 sobrou 90\% da vegetação de 01/01/2013:

$$
0,90 \times 2000=1800 \mathrm{~km}^{2}
$$

-Em 01/01/2015 sobrou 90\% da vegetação de 01/01/2014:

$$
0,90 \times 1800=1620 \mathrm{~km}^{2}
$$

- Em 01/01/2016 soboru 90\% da vegetação de 01/01/2015:

$$
0,90 \times 1620=1458 \mathrm{~km}^{2} \sim_{1458}<1500 \mathrm{em} 01 / 01 / 2016
$$




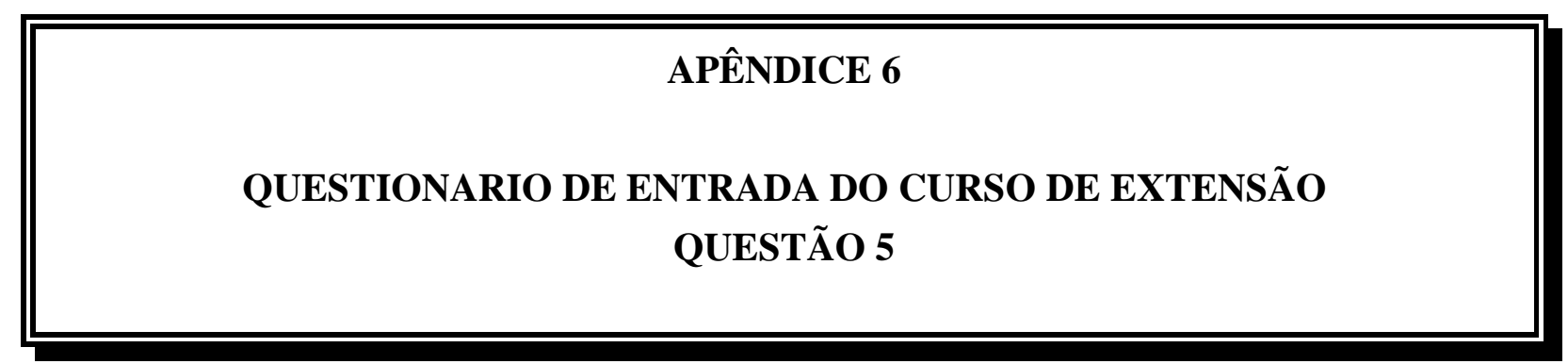

Questão 5 Situação hipotética: Foi realizado um levantamento de renda em determinada cidade com 4000 indivíduos, registrando-se o valor da renda mensal, em salários mínimos (SM) dos entrevistados. Os entrevistados foram ordenados de modo crescente conforme o valor da renda mensal. Verificou-se que os $20 \%$ com menor renda recebem, conjuntamente, $8000 \mathrm{SM}$. Já os $10 \%$ com maior renda recebem, conjuntamente, 14000 SM. A soma da renda de todos os 4000 entrevistados foi de 78000 SM. Com base nestas informações assinale a alternativa correta. (não se esqueça de marcar sua resposta no Quadro de Respostas (!!!)

(A) A razão de renda conjunta entre o grupo dos $20 \%$ com menor renda e o grupo dos $10 \%$ com maior renda é maior que 2 .

(B) A razão de renda conjunta entre o grupo dos $10 \%$ com maior renda e o grupo dos $20 \%$ com menor renda é maior que 2 .

(C) Os entrevistados que se encontram no grupo dos $10 \%$ com maior renda recebem, em média, $40 \mathrm{SM}$.

(D) Os entrevistados que se encontram no grupo dos $20 \%$ com menor renda recebem, em média, $15 \mathrm{SM}$

(E) Os entrevistados que não se encontram no grupo dos $20 \%$ com menor renda, nem no grupo dos $10 \%$ com maior renda recebem, em média, $20 \mathrm{SM}$. 


\section{Resolução}

4000 indivíduos

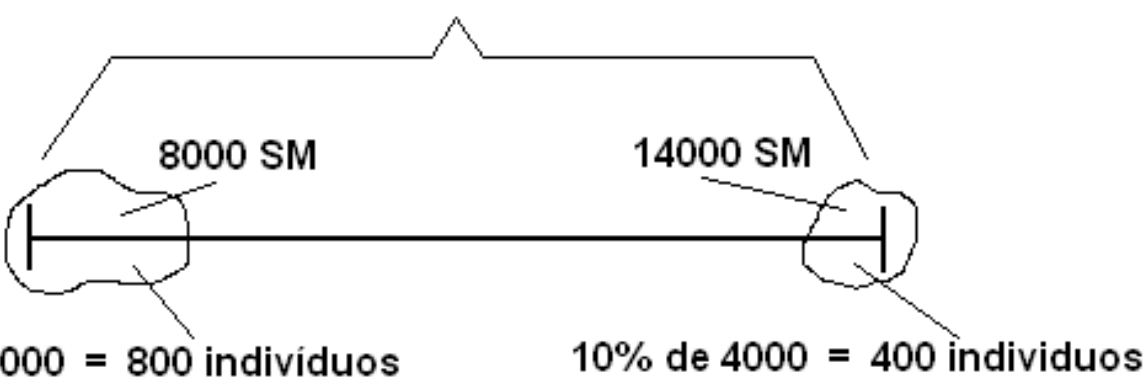

$20 \%$ de $4000=800$ indivíduos

$10 \%$ de $4000=400$ individuos

Item $A$ Razão de renda $=\frac{R_{20} \%}{R_{10}}=\frac{8000 S M}{14000 S M}=0,5714$

Item $B$ Razão de renda $=\frac{R_{10 \%}}{R_{20 \%}}=\frac{14000 \mathrm{SM}}{8000 \mathrm{SM}}=1,75$

Item $C$ Média do grupo $\mathrm{R}_{10 \%}: \frac{14000 \mathrm{SM}}{400}=35 \mathrm{SM} /$ individuo

Item D Média do grupo $\mathrm{R}_{20 \%}: \frac{8000 \mathrm{SM}}{800}=10 \mathrm{SM} /$ individuo

Item E Fora do grupo $R_{20 \%}$ e $R_{10 \%}: 4000-800-400=2800$ individuos Renda de fora destes grupos: $78000-8000-14000=56000 \mathrm{SM}$ Média do grupo $\mathrm{R}_{\mathrm{Fora}}: \frac{56000 \mathrm{SM}}{2800}=20 \mathrm{SM} /$ individuo

Resposta: E 


\section{APÊNDICE 7}

\section{QUESTIONARIO 2 - Sobre objetos, variáveis, população e amostra}

\begin{tabular}{|c|c|}
\hline 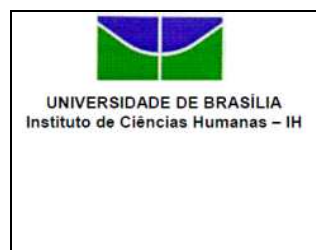 & $\begin{array}{l}\text { Curso de Extensão - Introdução à Quantificação em Geografia - } \\
\text { Set/Nov } 2014 \\
\text { Questionário para mapeamento de entendimento de conceitos } \\
\text { apresentados no software EDH - objetos, variáveis, população e } \\
\text { amostra }\end{array}$ \\
\hline
\end{tabular}

Nome completo:

Questão 1 - Leia abaixo o resumo de uma tese de doutorado e depois responda ao que se pede:

Título: Aplicação de geotecnologias na seleção de sítios para o cultivo de camarões marinhos e o planejamento da atividade.

Autor: Elpídio Beltrme - Tese aprovada após defesa pública em 09/06/2003 - UFSC

Resumo - Com base em informações obtidas por sensoriamento remoto e levantamentos de campo, foi estruturado um Sistema de Informação Geográfica (SIG) para a seleção de áreas aptas ao desenvolvimento da carcinicultura na região do Complexo Lagunar, localizado no Sul do Estado de Santa Catarina. Realizou-se o estudo em três escalas: Regional (1:250.000), Local (1:50.000) e de Implantação das unidades de produção de camarões em viveiros de cultivo (1:10.000). A escala Regional permitiu a identificação das áreas viáveis para a posterior seleção de sítios na escala Local e detalhamento do projeto na escala de Implantação. Para a escala Local os critérios utilizados na classificação das áreas foram: disponibilidade de água salgada, facilidade de captação e drenagem da água, topografia, tipos de solo, vegetação e uso do solo e restrições legais. Com a estruturação dos Planos de Informação em um SIG foi possível quantificar as áreas com aptidão para o desenvolvimento da carcinicultura no município de Laguna. (...)

Questão 1.1 - "Tudo é objeto... e objeto tem atributos". Qual o objeto de estudo de interesse nesta tese?

Questão 1.2 - Cite 10 (dez) atributos (variáveis) do objeto de estudo, incluindo todos os atributos citados na tese. Para completar 10 atributos cite outros atributos que você identifica no objeto:

\begin{tabular}{|l|l|l|l|}
\hline 1 & 2 & 3 & 4 \\
\hline 5 & 6 & 7 & 8 \\
\hline
\end{tabular}


Questão 1.3 - Escolha uma variável qualquer do objeto e cite 4 valores possíveis que ela pode assumir. Esta variável que você escolheu é numérica ou não ?

Questão 1.4 - Após a estruturação do SIG foi "mapeada" a população de objetos de interesse ou foi "mapeada" uma amostra de objetos de interesse ? Justifique sua resposta

Questão 2 - Leia abaixo o resumo de uma tese de doutorado e depois responda ao que se pede:

Título: Espacialização dos acidentes de trânsito em Uberlândia (MG): técnicas de geoprocessamento como instrumento de análise - 2000 a 2004

Autora: Andrea Rispoli Bernardino - USP 2007 - Tese de doutorado

Resumo - Os números de ocorrências em acidentes de trânsito são assustadores. Avalia-se que o custo dos acidentes aproxime de $1 \%$ do PIB em países pobres e $2 \%$ nas nações desenvolvidas. Em termos globais, são gastos U\$ 518 bilhões anuais. (...) Considerado como um desafio pelos órgãos gestores do planejamento urbano viário, a redução das ocorrências de acidentes de trânsito torna-se um tema discutido, incessantemente, na administração pública. Diante dessa leitura urbana, este estudo propõe conhecer as características dos acidentes de trânsito ocorridos na área urbana da cidade de Uberlândia entre os anos de 2000 e 2004, bem como espacializar as vias, os trechos e os cruzamentos com maior número de acidentes com o intuito de identificá-los por meio de técnicas disponíveis em BRASIL (2002) e Gold (1998), que, adaptadas ao banco de dados disponíveis pela SETTRAN, determinaram as vias, os trechos e os cruzamentos críticos. Por meio desses procedimentos, apresenta-se a identificação de vinte vias, vinte trechos e vinte cruzamentos que foram palco dos maiores números de acidentes ocorridos no trânsito (...)

Questão2.1 - "Tudo é objeto... e objeto tem atributos". Qual o objeto de estudo de interesse nesta tese?

Questão 2.2 - Cite 4 (quatro) atributos (variáveis) do objeto de estudo, incluindo o(s) atributo(s) citado(s) na tese.

Questão 2.3 - Escolha uma variável qualquer do objeto e cite 4 valores possíveis que ela pode assumir. Esta variável que você escolheu é numérica ou não ? 
Questão 2.4 - No contexto desta tese, qual seria a população de interesse ? Você acha que a autora teve acesso a toda população de interesse ou a apenas uma amostra do objeto de interesse ? Justifique sua "intuição" a esta resposta

Questão 3 - Imagine que você esteja fazendo alguma pesquisa/estudo sobre algum tema (pode ser sua ideia de trabalho de conclusão de curso, de trabalho em disciplina, de dissertação ou tese).

Questão 3.1 - Cite muuuuuuuito suscintamente o tema desta pesquisa.

Questão 3.2 - “Tudo é objeto... e objeto tem atributos”. Qual seria o objeto de estudo de interesse neste seu trabalho?

Questão 3.3 - Cite 4 (quatro) atributos (variáveis) do objeto de estudo.

Questão 3.4 - Escolha uma variável qualquer do objeto e cite 4 valores possíveis que ela pode assumir. Esta variável que você escolheu é numérica ou não ?

Questão 3.5 - No contexto deste seu trabalho você acessaria a população de interesse ou apenas uma amostra? Justifique sua resposta.

\section{MAPEAMENTO DA SUA DINÂMICA DE APRENDIZAGEM}

(assinale as opções que julgar pertinentes mesmo que sejam mais de uma num mesmo item)

Item 01 - Leitura de material para responder as questões

\begin{tabular}{|ll|l|}
\hline[ & {[} & Não li nenhum material: nem o do software EDH, nem qualquer outro material. \\
\hline[ & {[} & Li somente o material do software EDH. \\
\hline[ & ] & Li somente outro material diferente do software EDH. \\
\hline
\end{tabular}




\begin{tabular}{|ll|l|}
\hline[ & ] & Li parcialmente o material do software EDH. \\
\hline[ & ] & Li parcialmente outro material diferente do software EDH. \\
\hline[ & ] & $\begin{array}{l}\text { Li o material do software EDH e também outro material diferente do software } \\
\text { EDH. }\end{array}$ \\
\hline
\end{tabular}

Item 02 - Eu lembrava e/ou conhecia e/ou entendia o assunto

\begin{tabular}{|ll|l|}
\hline[ & ] & $\begin{array}{l}\text { Como assinalei antes, não li nenhum material, mas eu lembrava das noções } \\
\text { conceituais de população, amostra e variável que estudei em outra oportunidade. }\end{array}$ \\
\hline[ & ] & $\begin{array}{l}\text { Antes mesmo da leitura, eu lembrava/entendia as noções conceituais de } \\
\text { população, amostra e variável. }\end{array}$ \\
\hline[ & ] & $\begin{array}{l}\text { Durante e depois da leitura, eu lembrei das noções conceituais de população, } \\
\text { amostra e variável que estudei em outra oportunidade. }\end{array}$ \\
\hline
\end{tabular}

Item 03 - Eu não conhecia ou não entendia o assunto antes da leitura

\begin{tabular}{|l|l|}
\hline$[\quad]$ & $\begin{array}{l}\text { Antes da leitura, eu não conhecia as noções conceituais de população, amostra e } \\
\text { variável pois jamais as estudei em outra oportunidade. }\end{array}$ \\
\hline
\end{tabular}

\section{Item 04 - Eu entendi o assunto durante e/ou após a leitura}

\begin{tabular}{|c|c|}
\hline$\left[\begin{array}{ll}{[} & ]\end{array}\right.$ & $\begin{array}{l}\text { Foi durante e/ou após a leitura que eu entendi as noções conceituais de } \\
\text { população, amostra e variável, pois antes da leitura, apesar de ter estudado, eu } \\
\text { não entendia tais noções conceituais }\end{array}$ \\
\hline$\left[\begin{array}{ll}{[} & ]\end{array}\right.$ & $\begin{array}{l}\text { Foi durante e/ou após a leitura que eu entendi as noções conceituais de } \\
\text { população, amostra e variável. Antes da leitura, como disse antes, eu não } \\
\text { conhecia tais noções conceituais }\end{array}$ \\
\hline
\end{tabular}

Item 05 - Não entendi o assunto mesmo após a leitura

\begin{tabular}{|l|l|}
\hline$[\quad]$ & $\begin{array}{l}\text { Mesmo após minha leitura, continuei a não entender as noções conceituais de } \\
\text { população, amostra e variável. Minhas respostas às questões foram baseadas no } \\
\text { "chute”. }\end{array}$ \\
\hline
\end{tabular}

Item 06 - Com relacão ao uso do software EDH (se você fez a leitura do material)

\begin{tabular}{|c|c|}
\hline \begin{tabular}{|ll} 
& ]
\end{tabular} & $\begin{array}{l}\text { Não tentei usar efetivamente o EDH por já entender os conceitos, por isso não } \\
\text { me considero apto a fazer alguma avaliação sobre o EDH. }\end{array}$ \\
\hline$\left[\begin{array}{ll}{[} & ]\end{array}\right.$ & $\begin{array}{l}\text { Para entendimento das noções conceituais de população, amostra e variável o } \\
\text { EDH não foi útil. Ao contrário, acredito que me confundiu mais ainda sobre os }\end{array}$ \\
\hline
\end{tabular}




\begin{tabular}{|ll|l|}
\hline & conceitos que tentou apresentar. \\
\hline [ & ] & $\begin{array}{l}\text { Para entendimento das noções conceituais de população, amostra e variável o } \\
\text { EDH foi útil. Acredito que o material ajudou na fixação dos conceitos. }\end{array}$ \\
\hline[ & ] & $\begin{array}{l}\text { Para entendimento das noções conceituais de população, amostra e variável o } \\
\text { EDH foi útil. Mas outro material que li sobre o assunto aborda de forma melhor } \\
\text { que o EDH. }\end{array}$ \\
\hline[ & ] & $\begin{array}{l}\text { Para entendimento das noções conceituais de população, amostra e variável o } \\
\text { EDH foi útil. E o EDH aborda o assunto melhor que outro material que li sobre o } \\
\text { assunto. }\end{array}$ \\
\hline[ & ] & $\begin{array}{l}\text { Para entendimento das noções conceituais de população, amostra e variável o } \\
\text { EDH foi útil. Acredito que a abordagem do assunto tentando apresentar os } \\
\text { conceitos prinmordialmente via imagens ajudou na fixação dos conteúdos. }\end{array}$ \\
\hline
\end{tabular}

\section{$\underline{O}$ uso do software EDH (se você fez a leitura do material)}

Caso tenha usado o EDH, por favor relate brevemente os pontos positivos (interface estática e interativa, exemplos para abordagem, atividades propostas, etc) que o mesmo tenha apresentado para auxiliar a fixar os conceitos de população, amostra, variável e objeto

\begin{tabular}{|l|}
\hline \\
\hline
\end{tabular}

Caso tenha usado o EDH, por favor relate brevemente os pontos negativos (interface estática e interativa, exemplos para abordagem, atividades propostas, etc) que o mesmo tenha apresentado para auxiliar a fixar os conceitos de população, amostra, variável e objeto

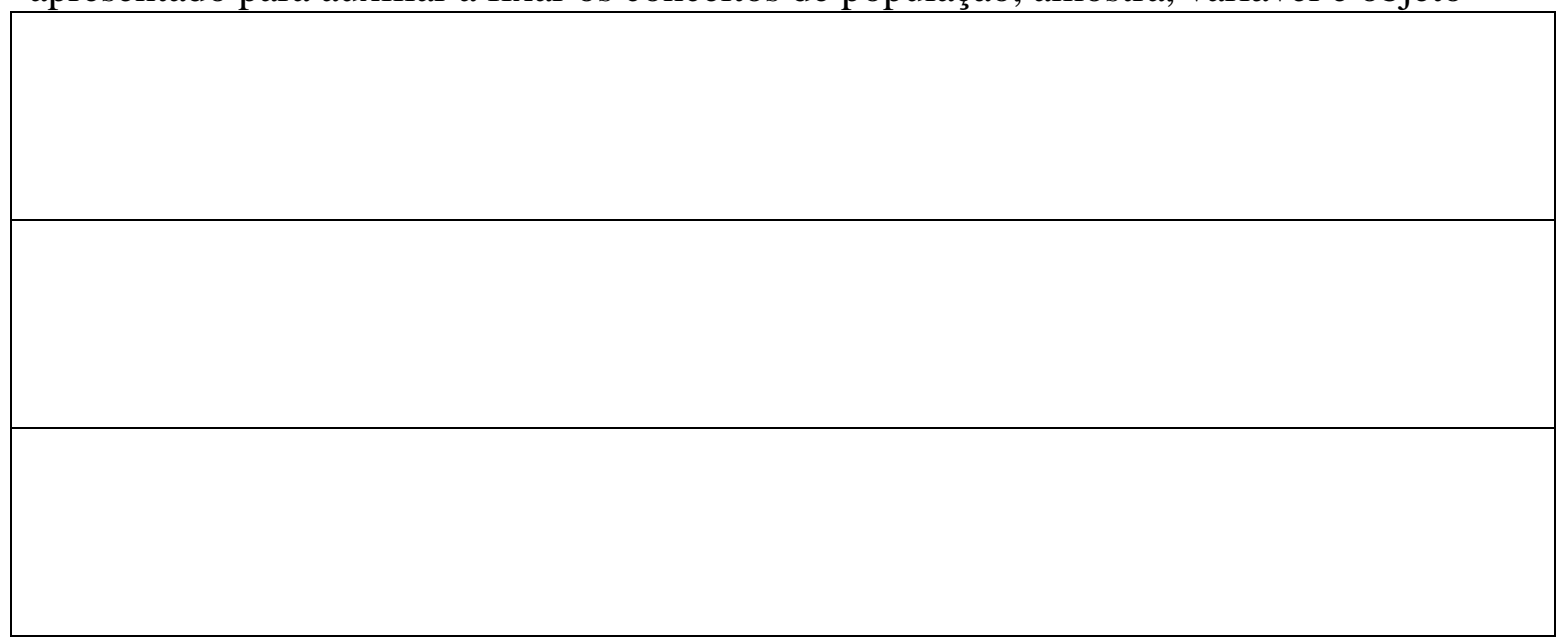




\section{APÊNDICE 8}

QUESTIONARIO 3 - Média aritmética simples

(com respostas aos itens das questões)

\begin{tabular}{|c|c|}
\hline $\begin{array}{c}\text { UNIVERSDADE DE BRASiLA } \\
\text { Instituto de Ciencias Humanas }\end{array}$ & $\begin{array}{l}\text { Curso de Extensão - Introdução à Quantificação em Geografia - } \\
\text { Set/Nov } 2014 \\
\text { Questionário para mapeamento de entendimento de conceitos } \\
\text { apresentados no software EDH - Média aritmética simples }\end{array}$ \\
\hline
\end{tabular}

Nome completo:

Questão 1 - Observe a tabela abaixo e responda ao que se pede:

\begin{tabular}{|c|c|c|c|c|c|c|c|c|c|c|c|c|}
\hline \multicolumn{6}{|c|}{ Variável = População residente (Pessoas) } & & & & \multirow{2}{*}{2} & \multirow{2}{*}{3} & \multirow{2}{*}{4} & \multirow{2}{*}{5} \\
\hline \multirow{2}{*}{ Grande Região } & \multicolumn{5}{|c|}{ Ano } & & & & & & & \\
\hline & 1970 & 1980 & 1991 & 2000 & 2010 & & & & 1980 & 1991 & 2000 & 2010 \\
\hline \begin{tabular}{|l|} 
Norte \\
Nordeste \\
\end{tabular} & \begin{tabular}{|r|}
3.603 .679 \\
28.111 .551 \\
\end{tabular} & \begin{tabular}{|r|}
5.880 .706 \\
34.815 .439 \\
\end{tabular} & \begin{tabular}{|l|}
10.030 .556 \\
42.497 .540 \\
\end{tabular} & \begin{tabular}{|l|}
12.900 .704 \\
47.741 .711 \\
\end{tabular} & $\begin{array}{l}15.864 .454 \\
53.081 .950 \\
\end{array}$ & \multirow{4}{*}{$\mathrm{Linha}_{-3} 3$} & Norte & 3.603 .679 & 5.880 .706 & 10.030 .556 & 12.900 .704 & 15.864 .454 \\
\hline Sudeste & 39.850 .764 & 51.737 .148 & 62.740 .401 & 72.412 .411 & 80.364 .410 & & Nordeste & 28.111 .551 & 34.815 .439 & 42.497 .540 & 47.741 .711 & 53.081 .950 \\
\hline Sul & 16.496 .322 & 19.031 .990 & 22.129 .377 & 25.107 .616 & 27.386 .891 & & Sudeste & 39.850 .764 & 51.737 .148 & 62.740 .401 & 72.412 .411 & 80.364 .410 \\
\hline Centro-Oeste & 5.072 .530 & 7.545 .769 & 9.427 .601 & 11.636 .728 & 14.058 .094 & & Sul & 16.496 .322 & 19.031 .990 & 22.129 .377 & 25.107 .616 & 27.386 .891 \\
\hline \multicolumn{6}{|c|}{ Fonte: IBGE - Censo Demográfico } & ; & Centro-Oeste & 5.072 .530 & 7.545 .769 & 9.427 .601 & 11.636 .728 & 14.058 .094 \\
\hline
\end{tabular}

Obs.: leitura de valores em tabela de dupla entrada (linhas e colunas) :

$X_{i k}$ onde: $\mathrm{i}$-linha $k$-coluna Exemplos: $X_{34}=72.412 .411$ - população na região Sudeste em 2000

$X_{43}=22.129 .377$ - população na região Sul em 1991

Julgue as assertivas abaixo em certo (C) ou errado (E) ou marque $\mathbf{X}$ caso não saiba a resposta. 
[C] $\sum_{m=3}^{5} X_{2 m}$ representa a soma da população da região Nordeste nos anos de 1991, 2000 e 2010 [E] $\sum_{m=3}^{5} X_{m 2}$ representa a soma da população da região Nordeste nos anos de 1991, 2000 e 2010 [C] $\sum_{m=3}^{5} X_{m 2}$ representa a soma da população das regiōes Sudeste, Sul e Centro-Oeste em 1980 $[E] \frac{\sum_{m=3}^{5} x_{m 2}}{5}$ representa a média da população das regiōes Sudeste, Sul e Centro-Oeste em 1980 $[C] \frac{\sum_{m=2}^{4} x_{5 m}}{3}$ representa a média da população da região Centro-Oeste em 1980, 1991 e 2000 $[C] \sum_{m=1}^{5} X_{1 m}+\sum_{m=1}^{5} X_{3 m} \begin{aligned} & \text { representa a soma da população das regiōes norte e } \\ & \text { sudeste nos anos de 1970,1980,1991,2000 e } 2010\end{aligned}$ $[C] \frac{\sum_{m=1}^{5} X_{m 1}}{5}$ representa a média da população brasileira nas regiões em 1970 $[E] \frac{\sum_{m=1}^{5} X_{1 m}}{5}$ representa a média da população brasileira nas regiões em 1970 $[C] \frac{\sum_{m=1}^{2} X_{4 m}+\sum_{m=4}^{5} X_{4 m}}{4} \quad \begin{gathered}\text { representa a média da popualção na região } \\ \text { Sul nos anos de 1970, 1980, 2000 e 2010 }\end{gathered}$ 
Questão 2 - Observe a tabela abaixo apresentando uma situação hipotética e responda ao que se pede:

\begin{tabular}{|c|c|c|c|c|c|}
\hline \multirow[b]{2}{*}{ Grande Região } & \multicolumn{4}{|c|}{ Qtde (toneladas) } & \multirow[b]{2}{*}{ |Total } \\
\hline & Arroz & Feijão & Soja & Trigo & \\
\hline Norte & $?$ & $?$ & $?$ & $?$ & 1100 \\
\hline Nordeste & ? & $?$ & $?$ & $?$ & 1200 \\
\hline Sudeste & $?$ & $?$ & $?$ & $?$ & 1400 \\
\hline Sul & ? & $?$ & $?$ & ? & 1050 \\
\hline Centro-Oeste & $?$ & $?$ & $?$ & $?$ & 1900 \\
\hline Total & 1700 & 1900 & 1350 & 1700 & \\
\hline
\end{tabular}

Julgue as assertivas abaixo em certo (C) ou errado (E) ou marque $\mathbf{X}$ caso não saiba a resposta.

\begin{tabular}{|l|l|}
\hline [ C ] & $\begin{array}{l}\text { É possível, apenas observando a tabela, sem efetuar qualquer cálculo mental e } \\
\text { sem usar calculadora, afirmar que, nas 5 regiões, a produção média de feijão } \\
\text { foi maior do que a produção média das demais culturas }\end{array}$ \\
\hline [ C ] & $\begin{array}{l}\text { É possível, apenas efetuando cálculo mental ou usando calculadora, afirmar } \\
\text { que, nas 5 regiões, a produção média de feijão foi maior do que a produção } \\
\text { média das demais culturas }\end{array}$ \\
\hline [ E ] & $\begin{array}{l}\text { Não é possível calcular a produção média de feijão das 5 regiões pois não } \\
\text { foram informados os valores de produção para as 5 regiões }\end{array}$ \\
\hline
\end{tabular}

\begin{tabular}{|l|l|}
\hline [ C ] & $\begin{array}{l}\text { É possível, apenas observando a tabela, sem efetuar qualquer cálculo mental e } \\
\text { sem usar calculadora, afirmar que, dentre as 5 regiões, foi a região Sul que } \\
\text { apresentou menor produção média das 4 culturas }\end{array}$ \\
\hline [ E ] & $\begin{array}{l}\text { Não é possível identificar qual dentre as 5 regiões que apresentou menor } \\
\text { produção média das 4 culturas }\end{array}$ \\
\hline [ C ] & $\begin{array}{l}\text { Dentre as } 5 \text { regiões, foi a região Sul que apresentou menor produção média das } \\
\text { 4 culturas. Apesar disso, é possível ocorrer que a produção de arroz na região } \\
\text { Sul seja a maior dentre todas as regiões }\end{array}$ \\
\hline [ E ] & $\begin{array}{l}\text { A produção média de arroz e trigo nas 5 regiões é a mesma. Então podemos } \\
\text { afirmar que o valor da quantidade produzida de arroz na região Norte é o } \\
\text { mesmo valor da quantidade produzida de trigo na região Norte }\end{array}$ \\
\hline [ E ] & $\begin{array}{l}\text { O valor da produção média de todas as culturas pelas 5 regiões é o mesmo } \\
\text { valor da produção média de todas as regiões para as 4 culturas }\end{array}$ \\
\hline
\end{tabular}

\section{MAPEAMENTO DA SUA DINÂMICA DE APRENDIZAGEM}

(assinale as opções que julgar pertinentes mesmo que sejam mais de uma num mesmo item)

\section{Item 01 - Leitura de material para responder as questões}

\begin{tabular}{|ll|l|}
\hline[ & ] & Não li nenhum material: nem o do software $\mathrm{EDH}$, nem qualquer outro material. \\
\hline[ & ] & Li somente o material do software EDH. \\
\hline[ & ] & Li somente outro material diferente do software EDH. \\
\hline[ & ] & Li parcialmente o material do software EDH. \\
\hline
\end{tabular}




\begin{tabular}{|ll|l|}
\hline[ & ] & Li parcialmente outro material diferente do software EDH. \\
\hline[ & ] & $\begin{array}{l}\text { Li o material do software EDH e também outro material diferente do software } \\
\text { EDH. }\end{array}$ \\
\hline
\end{tabular}

Item 02 - Eu lembrava e/ou conhecia e/ou entendia o assunto

\begin{tabular}{|ll|l|}
\hline[ & ] & $\begin{array}{l}\text { Como assinalei antes, não li nenhum material, mas eu lembrava das noções } \\
\text { conceituais de média aritmética simples. }\end{array}$ \\
\hline [ & ] & $\begin{array}{l}\text { Antes mesmo da leitura, eu lembrava/entendia as noções conceituais de média } \\
\text { aritmética simples. }\end{array}$ \\
\hline [ & ] & $\begin{array}{l}\text { Durante e depois da leitura, eu lembrei das noções conceituais de média aritmética } \\
\text { simples que estudei em outra oportunidade. }\end{array}$ \\
\hline
\end{tabular}

Item 03 - Eu não conhecia ou não entendia o assunto antes da leitura

\begin{tabular}{|l|l|}
\hline$[\quad]$ & $\begin{array}{l}\text { Antes da leitura, eu não conhecia as noções conceituais de média aritmética } \\
\text { simples. }\end{array}$ \\
\hline
\end{tabular}

\section{Item 04 - Eu entendi o assunto durante e/ou após a leitura}

\begin{tabular}{|l|l|}
\hline$[\quad]$ & $\begin{array}{l}\text { Foi durante e/ou após a leitura que eu entendi as noções conceituais de média } \\
\text { aritmética simples, pois antes da leitura, apesar de ter estudado, eu não entendia } \\
\text { tais noções conceituais }\end{array}$ \\
\hline$[\quad$ ] & $\begin{array}{l}\text { Foi durante e/ou após a leitura que eu entendi as noções conceituais de média } \\
\text { aritmética simples. Antes da leitura, como disse antes, eu não conhecia tais noções } \\
\text { conceituais }\end{array}$ \\
\hline
\end{tabular}

Item 05 - Não entendi o assunto mesmo após a leitura

[ ] $\quad$ Mesmo após minha leitura, continuei a não entender as noções conceituais de média aritmética simples. Minhas respostas às questões foram baseadas no "chute".

\section{Item 06 - Com relacão ao uso do software EDH (se você fez a leitura do material)}

\begin{tabular}{|ll|l|}
\hline[ & [ & $\begin{array}{l}\text { Não tentei usar efetivamente o EDH por já entender os conceitos, por isso não me } \\
\text { considero apto a fazer alguma avaliação sobre o EDH. }\end{array}$ \\
\hline [ & ] & $\begin{array}{l}\text { Para entendimento das noções conceituais de média aritmética simples o EDH não } \\
\text { foi útil. Ao contrário, acredito que me confundiu mais ainda sobre os conceitos } \\
\text { que tentou apresentar. }\end{array}$ \\
\hline [ & ] & $\begin{array}{l}\text { Para entendimento das noções conceituais de média aritmética simples o EDH foi } \\
\text { útil. Acredito que o material ajudou na fixação dos conceitos. }\end{array}$ \\
\hline
\end{tabular}




\begin{tabular}{|ll|l|}
\hline [ & ] & $\begin{array}{l}\text { Para entendimento das noções conceituais de média aritmética simples o EDH foi } \\
\text { útil. Mas outro material que li sobre o assunto aborda de forma melhor que o } \\
\text { EDH. }\end{array}$ \\
\hline [ & ] & $\begin{array}{l}\text { Para entendimento das noções conceituais de média aritmética simples o EDH foi } \\
\text { útil. E o EDH aborda o assunto melhor que outro material que li sobre o assunto. }\end{array}$ \\
\hline [ & ] & $\begin{array}{l}\text { Para entendimento das noções conceituais de média aritmética simples o EDH foi } \\
\text { útil. Acredito que a abordagem do assunto tentando apresentar os conceitos } \\
\text { primordialmente via imagens ajudou na fixação dos conteúdos. }\end{array}$ \\
\hline
\end{tabular}

Item 07 - O software EDH e a apresentacão do conceito de somatório $\left(\sum\right)$

\begin{tabular}{|ll|l|}
\hline[ & ] & $\begin{array}{l}\text { A apresentação sobre o somatório, representado por } \sum \text {, pelo software EDH não foi } \\
\text { útil. Não entendi os conceitos apresentados no software. }\end{array}$ \\
\hline[ & {[} & $\begin{array}{l}\text { A apresentação sobre o somatório, representado por } \sum \text {, pelo software EDH foi útil, } \\
\text { apesar de eu já anteriormente entender seu significado }\end{array}$ \\
\hline[ & ] & $\begin{array}{l}\text { A apresentação sobre o somatório, representado por } \sum \text {, pelo software EDH foi útil. } \\
\text { Entendi conceitos sobre o somatório que antes estavam obscuros para mim. }\end{array}$ \\
\hline[ & ] & $\begin{array}{l}\text { A apresentação sobre o somatório, representado por } \sum \text {, pelo software EDH foi útil. } \\
\text { Entendi conceitos sobre o somatório que antes eu desconhecia completamente. }\end{array}$ \\
\hline
\end{tabular}

\section{O uso do software EDH (se você fez a leitura do material)}

Caso tenha usado o EDH, por favor relate brevemente os pontos positivos (interface estática e interativa, exemplos para abordagem, atividades propostas, etc) que o mesmo tenha apresentado para auxiliar a fixar os conceitos média aritmética simples

\begin{tabular}{|l|}
\hline \\
\hline 2
\end{tabular}


Caso tenha usado o EDH, por favor relate brevemente os pontos negativos (interface estática e interativa, exemplos para abordagem, atividades propostas, etc) que o mesmo tenha apresentado para auxiliar a fixar os conceitos média aritmética simples

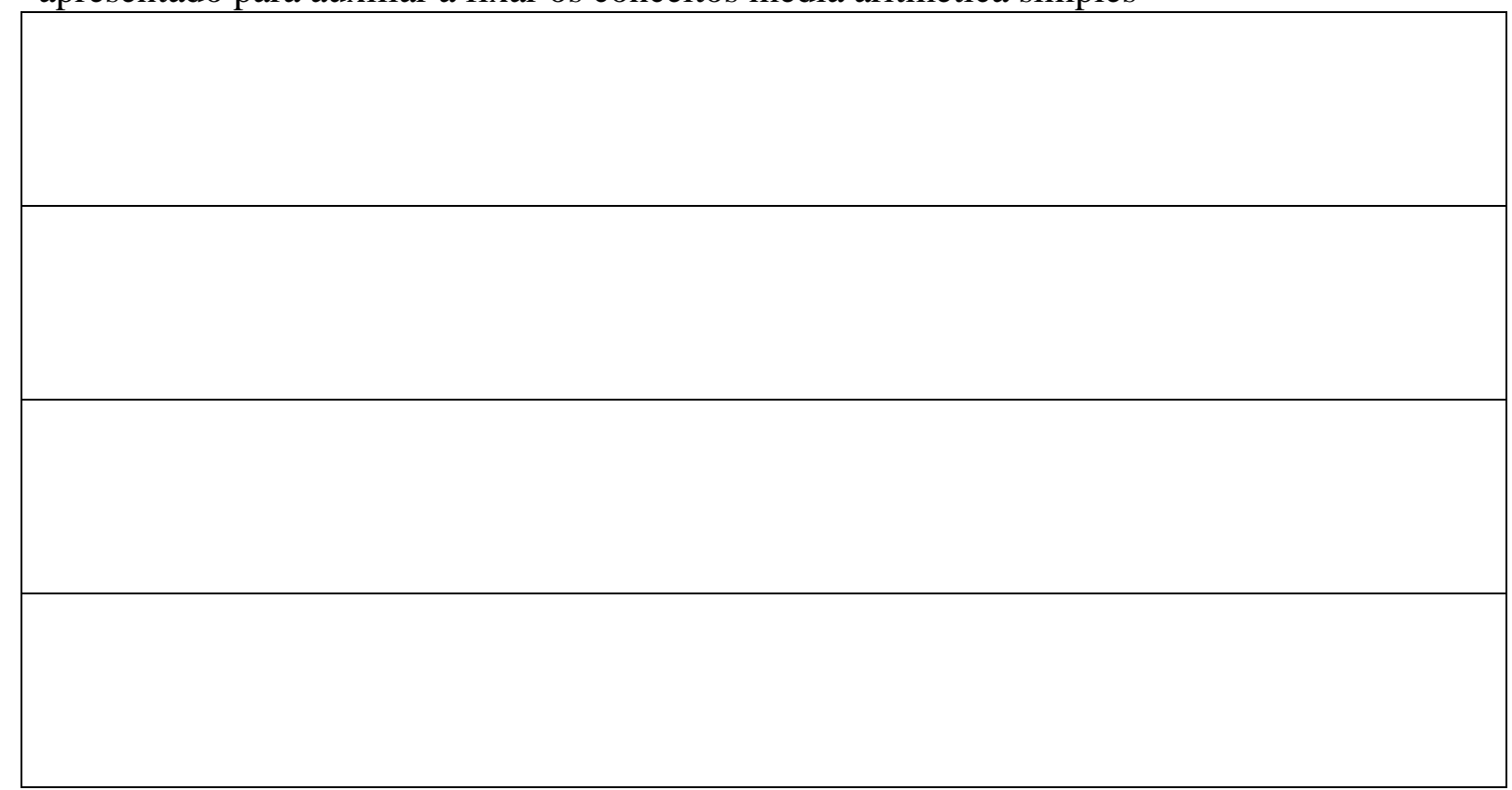




\section{APÊNDICE 9}

\section{QUESTIONARIO 4 - Variância e desvio padrão (com respostas aos itens das questões)}

\begin{tabular}{|c|c|}
\hline 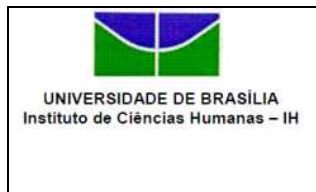 & $\begin{array}{l}\text { Curso de Extensão - Introdução à Quantificação em Geografia - } \\
\text { Set/Nov } 2014 \\
\text { Questionário para mapeamento de entendimento de conceitos } \\
\text { apresentados no software EDH - Variância, desvio padrão }\end{array}$ \\
\hline
\end{tabular}

Nome completo:

Questão 1 - Suponha que tomou-se uma amostra de 30 municípios brasileiros e calculou-se a quantidade média produzida de feijão pelos 30 municípios, obtendo-se o valor de 350 toneladas. Julgue as assertivas abaixo em certo $(\mathbf{C})$ ou errado (E) ou marque $\mathbf{X}$ caso não saiba a resposta.

\begin{tabular}{|l|l|}
\hline [ E ] & $\begin{array}{l}\text { Se tomarmos o valor de mais um município além dos } 30 \text { já selecionados e a } \\
\text { quantidade produzida de feijão deste município for } 420 \text { toneladas, então significa } \\
\text { que a média de amostra dos } 31 \text { municípios é certamente menor que } 350 \text { toneladas }\end{array}$ \\
\hline [ E ] & $\begin{array}{l}\text { Se tomarmos o valor de mais um município além dos } 30 \text { já selecionados e a } \\
\text { quantidade produzida de feijão deste município for } 420 \text { toneladas, então significa } \\
\text { que a média de amostra dos } 31 \text { municípios pode ser menor que } 350 \text { toneladas }\end{array}$ \\
\hline [ E ] & $\begin{array}{l}\text { Por se tratar de uma amostra de } 30 \text { municípios, devemos dividir o somatório dos } \\
\text { quadrados dos desvios entre observações e a média por } 30 \text { para obter o valor da } \\
\text { variância }\end{array}$ \\
\hline [ C ] & $\begin{array}{l}\text { Por se tratar de uma amostra de } 30 \text { municípios, devemos dividir o somatório dos } \\
\text { quadrados dos desvios entre observações e a média por } 29 \text { para obter o valor da } \\
\text { variância }\end{array}$ \\
\hline [ E ] & $\begin{array}{l}\text { Por se tratar de uma amostra de } 30 \text { municípios, devemos dividir o somatório dos } \\
\text { quadrados dos desvios entre observações e a média por } 30 \text { e depois tirar a raiz } \\
\text { quadrada desta divisão para obter o valor da variância }\end{array}$ \\
\hline [ E ] & $\begin{array}{l}\text { Por se tratar de uma amostra de } 30 \text { municípios, devemos dividir o somatório dos } \\
\text { quadrados dos desvios entre observações e a média por } 29 \text { e depois tirar a raiz } \\
\text { quadrada desta divisão para obter o valor da variância }\end{array}$ \\
\hline
\end{tabular}


Questão 2 - Sejam três populações: uma de valores de precipitação pluviométrica (medida em $\mathrm{mm}$ ), outra de valores de temperatura (medida em ${ }^{\circ} \mathrm{C}$ ) e outra de valores de insolação mensal (medida em horas) apresentadas abaixo:

\begin{tabular}{|l|c|c|c|c|c|c|c|c|c|c|}
\hline & \multicolumn{7}{|c|}{ Observação (elemento da população) } & \multicolumn{1}{c|}{} & & \\
\hline \multicolumn{1}{|c|}{ Variável } & 1 & 2 & 3 & 4 & 5 & 6 & 7 & Média & $\begin{array}{c}\text { Desvio } \\
\text { Padrão }\end{array}$ & $\begin{array}{c}\text { Coef. } \\
\text { Var. }\end{array}$ \\
\hline $\begin{array}{l}\text { Precipitação } \\
(\mathrm{mm})\end{array}$ & $\mathrm{X}_{1}=52$ & $\mathrm{X}_{2}=64$ & $\mathrm{X}_{3}=52$ & $\mathrm{X}_{4}=80$ & $\mathrm{X}_{5}=49$ & $\mathrm{X}_{6}=51$ & $\mathrm{X}_{7}=44$ & 56 & 11,28 & $20,14 \%$ \\
\hline $\begin{array}{l}\text { Temperatura } \\
\left({ }^{\circ} \mathrm{C}\right)\end{array}$ & $\mathrm{Y}_{1}=20$ & $\mathrm{Y}_{2}=22$ & $\mathrm{Y}_{3}=24$ & $\mathrm{Y}_{4}=22$ & $\mathrm{Y}_{5}=21$ & $\mathrm{Y}_{6}=20$ & $\mathrm{Y}_{7}=18$ & 21 & 1,77 & $8,44 \%$ \\
\hline $\begin{array}{l}\text { Insolação } \\
\text { (horas) }\end{array}$ & $\mathrm{Z}_{1}=?$ & $\mathrm{Z}_{2}=?$ & $\mathrm{Z}_{3}=?$ & $\mathrm{Z}_{4}=?$ & $\mathrm{Z}_{5}=?$ & $\mathrm{Z}_{6}=?$ & $\mathrm{Z}_{7}=?$ & 230 & 25,00 & $10,87 \%$ \\
\hline
\end{tabular}

Julgue as assertivas abaixo em certo (C) ou errado (E) ou marque $\mathbf{X}$ caso não saiba a resposta.

1. [ E ] $\frac{\sum_{i=4}^{6} x_{i}}{3}=60 \mathrm{~mm}$ é o valor do desvio padrão de 3 elementos da população de precipitação

2. [ E ] a população de insolação apresenta maior variabilidade (maior "espalhamento" de dados) que as populaçőes de precipitação e temperatura, pois apresenta o maior valor de desvio padrão $(25,00$ horas $)$

3. [ C ] se o desvio padrão da população de insolação fosse 9 horas, então sua variância valeria 81 horas $^{2}$

4. [ C ] quanto mais heterogêneo o grupo de dados, maior será seu coeficiente de variação. Por isso, a população de precipitação apresenta maior heterogeneidade que as populações de temperatura e insolação

5. [ E ] não é possivel calcular o valor da variância da população de insolação pois não foram informados os valores $\mathrm{Z}_{1}, \mathrm{z}_{2}, \mathrm{Z}_{3}, \mathrm{Z}_{4}, \mathrm{z}_{5}, \mathrm{z}_{6}$ e $\mathrm{Z}_{7}$

6. [ E ] $\frac{(20-21)^{2}+(22-21)^{2}+(24-21)^{2}+(22-21)^{2}+(21-21)^{2}+(20-21)^{2}+(18-21)^{2}}{7}=1,77^{\circ} \mathrm{C}$

7. [ C ] a temperatura é o grupo de dados que apresenta maior homogeneidade (menor "espalhamento" de dados) uma vez que apresenta o menor coeficiente de variação entre as 3 popualções consideradas

8. [ E ] a temperatura é o grupo de dados que apresenta maior homogeneidade (menor "espalhamento" de dados) uma vez que apresenta a menor média entre as 3 popualções consideradas

9. [C] Se a população de temperatura apresentasse média $18 \circ \mathrm{C}$ e desvio padrão 6 oC, então seria o grupo com maior heterogeneidade entre as 3 populações.

10. [ E ] Se a população de insolação mantivesse a média de 230 horas, porém com desvio padrão de 69 horas, etntão seria o grupo com maior homogeneidade entre as 3 populações

\section{MAPEAMENTO DA SUA DINÂMICA DE APRENDIZAGEM}

(assinale as opções que julgar pertinentes mesmo que sejam mais de uma num mesmo item)

Item 01 - Leitura de material para responder as questões

\begin{tabular}{|ll|l|}
\hline[ & {[} & Não li nenhum material: nem o do software $\mathrm{EDH}$, nem qualquer outro material. \\
\hline[ & ] & Li somente o material do software $\mathrm{EDH}$. \\
\hline[ & ] & Li somente outro material diferente do software EDH. \\
\hline[ & ] & Li parcialmente o material do software $\mathrm{EDH}$. \\
\hline
\end{tabular}




\begin{tabular}{|ll|l|}
\hline[ & ] & Li parcialmente outro material diferente do software EDH. \\
\hline[ & ] & $\begin{array}{l}\text { Li o material do software EDH e também outro material diferente do software } \\
\text { EDH. }\end{array}$ \\
\hline
\end{tabular}

Item 02 - Eu lembrava e/ou conhecia e/ou entendia o assunto

\begin{tabular}{|ll|l|}
\hline[ & ] & $\begin{array}{l}\text { Como assinalei antes, não li nenhum material, mas eu lembrava das noções } \\
\text { conceituais de variância, desvio padrão e coeficiente de variação }\end{array}$ \\
\hline [ & ] & $\begin{array}{l}\text { Antes mesmo da leitura, eu lembrava/entendia as noções conceituais de variância, } \\
\text { desvio padrão e coeficiente de variação. }\end{array}$ \\
\hline [ & ] & $\begin{array}{l}\text { Durante e depois da leitura, eu lembrei das noções conceituais de variância, desvio } \\
\text { padrão e coeficiente de variação que estudei em outra oportunidade. }\end{array}$ \\
\hline
\end{tabular}

Item 03 - Eu não conhecia ou não entendia o assunto antes da leitura

\begin{tabular}{|l|l|}
\hline [ ] & $\begin{array}{l}\text { Antes da leitura, eu não conhecia as noções conceituais de variância, desvio padrão } \\
\text { e coeficiente de variação. }\end{array}$ \\
\hline
\end{tabular}

\section{Item 04 - Eu entendi o assunto durante e/ou após a leitura}

\begin{tabular}{|c|c|}
\hline $\begin{array}{ll}{[} & ]\end{array}$ & $\begin{array}{l}\text { Foi durante e/ou após a leitura que eu entendi as noções conceituais de variância, } \\
\text { desvio padrão e coeficiente de variação, pois antes da leitura, apesar de ter } \\
\text { estudado, eu não entendia tais noçôes conceituais }\end{array}$ \\
\hline$\left[\begin{array}{ll}{[} & ]\end{array}\right.$ & $\begin{array}{l}\text { Foi durante e/ou após a leitura que eu entendi as noções conceituais de variância, } \\
\text { desvio padrão e coeficiente de variação. Antes da leitura, como disse antes, eu não } \\
\text { conhecia tais noções conceituais }\end{array}$ \\
\hline
\end{tabular}

\section{Item 05 - Não entendi o assunto mesmo após a leitura}

[ ] $\quad$ Mesmo após minha leitura, continuei a não entender as noções conceituais de variância, desvio padrão e coeficiente de variação simples. Minhas respostas às questões foram baseadas no "chute".

\section{Item 06 - Com relacão ao uso do software EDH (se você fez a leitura do material)}

\begin{tabular}{|ll|l|}
\hline[ & {[} & $\begin{array}{l}\text { Não tentei usar efetivamente o EDH por já entender os conceitos, por isso não me } \\
\text { considero apto a fazer alguma avaliação sobre o EDH. }\end{array}$ \\
\hline[ & ] & $\begin{array}{l}\text { Para entendimento das noções conceituais de variância, desvio padrão e coeficiente } \\
\text { de variação o EDH não foi útil. Ao contrário, acredito que me confundiu mais ainda } \\
\text { sobre os conceitos que tentou apresentar. }\end{array}$ \\
\hline [ & ] & $\begin{array}{l}\text { Para entendimento das noções conceituais de variância, desvio padrão e coeficiente } \\
\text { de variação o EDH foi útil. Acredito que o material ajudou na fixação dos }\end{array}$ \\
\hline
\end{tabular}




\begin{tabular}{|c|c|}
\hline & conceitos. \\
\hline $\begin{array}{ll}{[} & ]\end{array}$ & $\begin{array}{l}\text { Para entendimento das noções conceituais de variância, desvio padrão e coeficiente } \\
\text { de variação o EDH foi útil. Mas outro material que li sobre o assunto aborda de } \\
\text { forma melhor que o EDH. }\end{array}$ \\
\hline \begin{tabular}{|ll}
{[} & ]
\end{tabular} & $\begin{array}{l}\text { Para entendimento das noções conceituais de variância, desvio padrão e coeficiente } \\
\text { de variação o EDH foi útil. E o EDH aborda o assunto melhor que outro material } \\
\text { que li sobre o assunto. }\end{array}$ \\
\hline$\left[\begin{array}{ll} & \end{array}\right.$ & $\begin{array}{l}\text { Para entendimento das noções conceituais de variância, desvio padrão e coeficiente } \\
\text { de variação o EDH foi útil. Acredito que a abordagem do assunto tentando } \\
\text { apresentar os conceitos primordialmente via imagens ajudou na fixação dos } \\
\text { conteúdos. }\end{array}$ \\
\hline
\end{tabular}

Item 07 - IMAGENS do software EDH - cite abaixo as imagens do EDH que você lembra e que acredita ter sido útil para entender conceitos de variância, e/ou desvio padrão, e/ou coeficiente de variacão

\begin{tabular}{|l|}
\hline \\
\hline 2
\end{tabular}

Item 08 - tente escrever abaixo as fórmulas da variância e do desvio padrão

Item 09 - Sobre as fórmulas da variância e desvio padrão

\begin{tabular}{|ll|l|}
\hline[ & {[} & Não lembro das fórmulas \\
\hline[ & {[} & Decorei as fórmulas que escrevi acima no Item 08 \\
\hline[ & {[} & $\begin{array}{l}\text { Memorizei as fórmulas. Por memorizar quero dizer que entendi os conceitos } \\
\text { matemáticos envolvidos nas fórmulas. Mas entendi em outra oportunidade em que } \\
\text { estudei o assunto }\end{array}$ \\
\hline
\end{tabular}


[ ] ] Memorizei as fórmulas. Por memorizar quero dizer que entendi os conceitos matemáticos envolvidos nas fórmulas. E entendi por meio de do uso do software $\mathrm{EDH}$

\section{O uso do software EDH (se você fez a leitura do material)}

Caso tenha usado o EDH, por favor relate brevemente os pontos positivos (interface estática e interativa, exemplos para abordagem, atividades propostas, etc) que o mesmo tenha apresentado para auxiliar a fixar os conceitos de VARIÂNCIA, DESVIO PADRÃO e COEFICIENTE DE VARIAÇÃO

\begin{tabular}{|l|}
\hline \\
\hline \\
\hline \\
\hline
\end{tabular}

Caso tenha usado o EDH, por favor relate brevemente os pontos negativos (interface estática e interativa, exemplos para abordagem, atividades propostas, etc) que o mesmo tenha apresentado para auxiliar a fixar os conceitos de VARIÂNCIA, DESVIO PADRÃO e COEFICIENTE DE VARIAÇÃO 


\section{APÊNDICE 10}

\section{QUESTIONARIO 5 - Estatística espacial - centro médio espacial (com respostas aos itens das questões)}

\begin{tabular}{|l|l|}
\hline $\begin{array}{c}\text { UnIVERIDADE DERASILA } \\
\text { Instituto de Ciencias Humanas }-\mathrm{IH}\end{array}$ & $\begin{array}{c}\text { Curso de Extensão - Introdução à Quantificação em Geografia - } \\
\text { Set/Nov } 2014\end{array}$ \\
& $\begin{array}{c}\text { Questionário para mapeamento de entendimento de conceitos } \\
\text { apresentados no software EDH - Centro médio espacial ponderado }\end{array}$ \\
\hline
\end{tabular}

Nome completo:

Questão 1 - A Figura (A) abaixo mostra o mapa das 66 microrregiões de Minas Gerais com os pontos centroides de cada microrregião. Suponha que foi realizado o estudo de um determinado fenômeno ocorrente nas microrregiões, digamos, a quantidade anual produzida de carne bovina. Suponha ainda, que das 66 microrregiões, apenas as microrregiões A, B, C, D, E, F, G, H, I, J, K e L mostradas na Figura (B) produzem carne bovina. As demais regiões nunca produzem carne bovina.

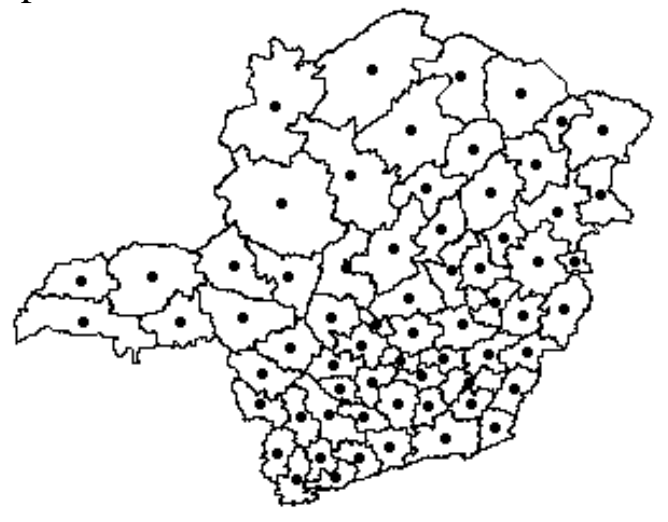

(A)

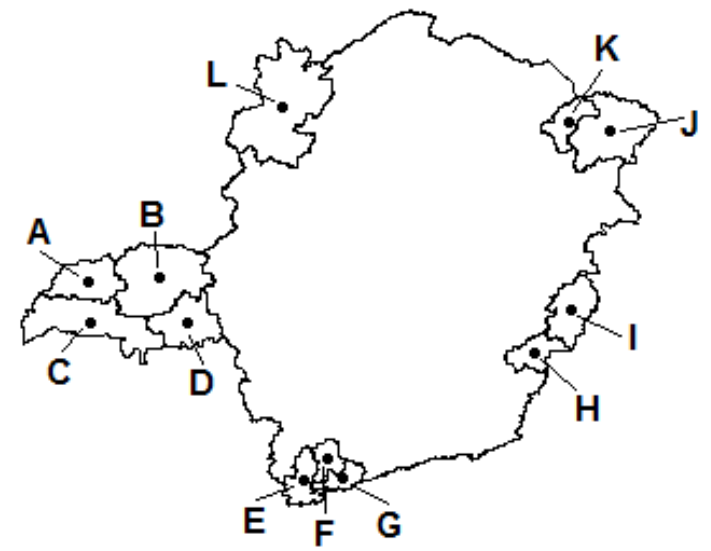

(B)

No estudo realizado, verificou-se a quantidade anual produzida de carne bovina na área das microrregiões e supôs-se que toda a quantidade produzida de cada microrregião encontrava-se espacialmente localizada em seu ponto centroide espacial. Foram calculados os centros médios espaciais ponderados da quantidade anual produzida de carne bovina nas microrregiões mineiras para os anos de 2000, 2003, 2006 e 2009.

Nas situações a seguir, julgue as assertivas abaixo em certo (C) ou errado (E) ou marque $X$ caso não saiba a resposta. 


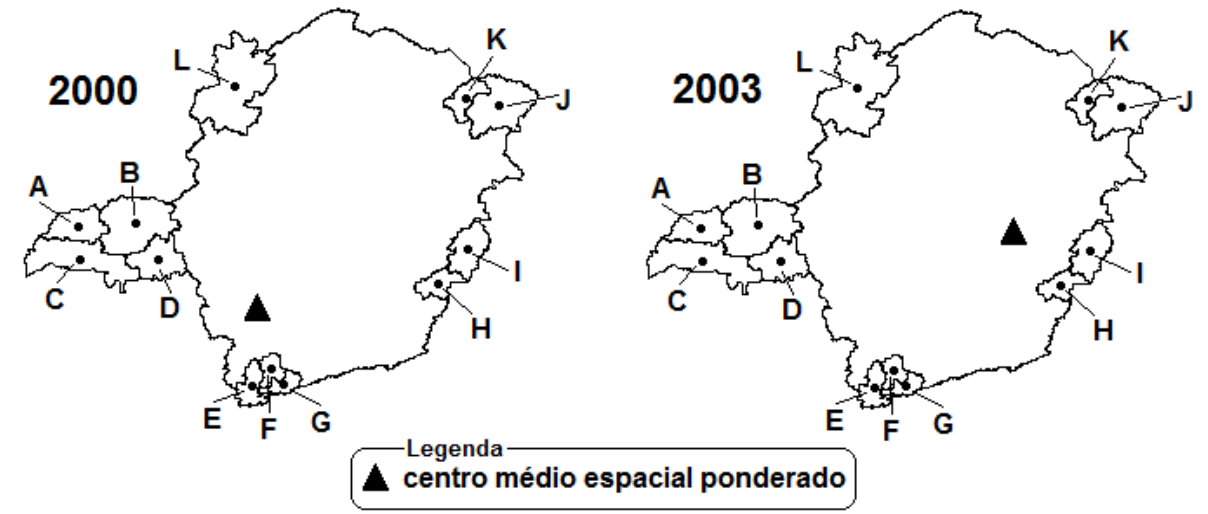

\begin{tabular}{|c|c|}
\hline [ E ] & $\begin{array}{l}\text { É possível afirmar com certeza que de } 2000 \text { para } 2003 \text { as microrregiões H e I } \\
\text { tiveram um aumento expressivo de produção de carne e as microrregiões A, } \\
\text { B, C, D, E, F, G, J, K e L tiveram um redução da produção de } 2000 \text { para } 2003\end{array}$ \\
\hline$[\mathrm{C}]$ & $\begin{array}{l}\text { É possível ter ocorrido que de } 2000 \text { para } 2003 \text { as microrregiões H e I tiveram } \\
\text { um aumento expressivo de produção de carne e as microrregiões A, B, C, D, } \\
\text { E, F, G, J, K e L tiveram um redução da produção de } 2000 \text { para } 2003\end{array}$ \\
\hline$[\mathrm{C}]$ & $\begin{array}{l}\text { É possível ter ocorrido que de } 2000 \text { para } 2003 \text { as microrregiões H e I tiveram } \\
\text { um aumento expressivo de produção de carne e as microrregiões A, B, C, D, } \\
\text { E, F, G, J, K e L mantiveram inalteradas a quantidade produzida de } 2000 \text { para } \\
2003\end{array}$ \\
\hline$[\mathbf{E}]$ & $\begin{array}{l}\text { É possível ter ocorrido que de } 2000 \text { para } 2003 \text { as microrregiões H e I tiveram } \\
\text { uma redução expressiva de produção de carne e as microrregiões A, B, C, D, } \\
\text { E, F, G, J, K e L tiveram um aumento expressivo da produção de } 2000 \text { para } \\
2003\end{array}$ \\
\hline$[\mathrm{C}]$ & $\begin{array}{l}\text { É possível ter ocorrido que de } 2000 \text { para } 2003 \text { apenas a microrregião I tenha } \\
\text { experimentado um aumento expressivo de produção de carne e as } \\
\text { microrregiões A, B, C, D, E, F, G, H, J, K e L tiveram uma redução da } \\
\text { produção de } 2000 \text { para } 2003\end{array}$ \\
\hline [ E ] & $\begin{array}{l}\text { É possível ter ocorrido que de } 2000 \text { para } 2003 \text { todas as microrregiões tenham } \\
\text { experimentado um aumento de, digamos } 20 \% \text { da produção de carne }\end{array}$ \\
\hline$[\mathbf{E}]$ & $\begin{array}{l}\text { É possível ter ocorrido que de } 2000 \text { para } 2003 \text { todas as microrregiões tenham } \\
\text { experimentado um aumento de, digamos } 95 \% \text { da produção de carne }\end{array}$ \\
\hline$[\mathbf{E}]$ & $\begin{array}{l}\text { e de } 2000 \text { para } 2003 \text { todas as microrregiões tenham } \\
\text { uição de, digamos } 20 \% \text { da produção de carne }\end{array}$ \\
\hline [ C ] & $\begin{array}{l}\text { É possível ter ocorrido que de } 2000 \text { para } 2003 \text { as microrregiões H e I } \\
\text { mantiveram inalteradas a quantidade produzida de carne e as microrregiões } \\
\text { A, B, C, D , E, F, G, J, K e L tiveram um redução da produção de } 2000 \text { para } \\
2003\end{array}$ \\
\hline
\end{tabular}




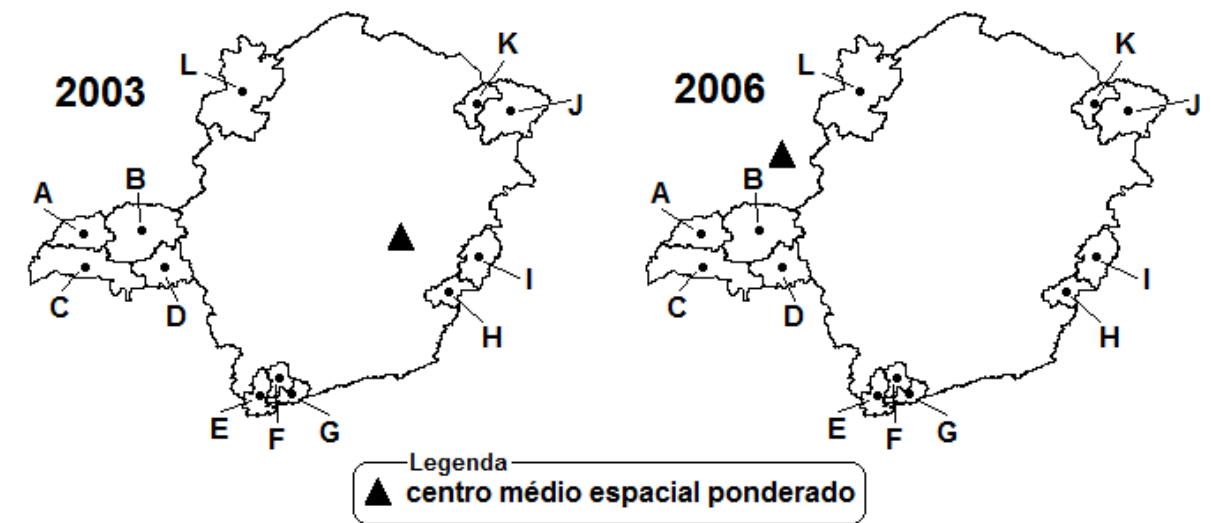

\begin{tabular}{|l|l|}
\hline [ E ] & $\begin{array}{l}\text { É certo que de } 2003 \text { para } 2006 \text { as microrregiões K, J e L tiveram um aumento } \\
\text { expressivo de produção de carne e as microrregiões A, B, C e D mantiveram } \\
\text { inalteradas a quantidade de carne produzida }\end{array}$ \\
\hline [ C ] & $\begin{array}{l}\text { É certo que em } 2006 \text { a soma conjunta da quantidade produzida de carne das } \\
\text { microrregiões A,B,C,D e L foi maior que a soma conjunta da quantidade } \\
\text { produzida de carne das microrregiões E, F, G, H, I, J e K }\end{array}$ \\
\hline [ C ] & $\begin{array}{l}\text { É possível ter ocorrido que de } 2003 \text { para } 2006 \text { as microrregiões A, B, C, D e L } \\
\text { tiveram um aumento expressivo de produção de carne e as demais } \\
\text { microrregiões, se apresentaram aumento da produção de carne, apresentaram } \\
\text { um aumento não expressivo }\end{array}$ \\
\hline
\end{tabular}

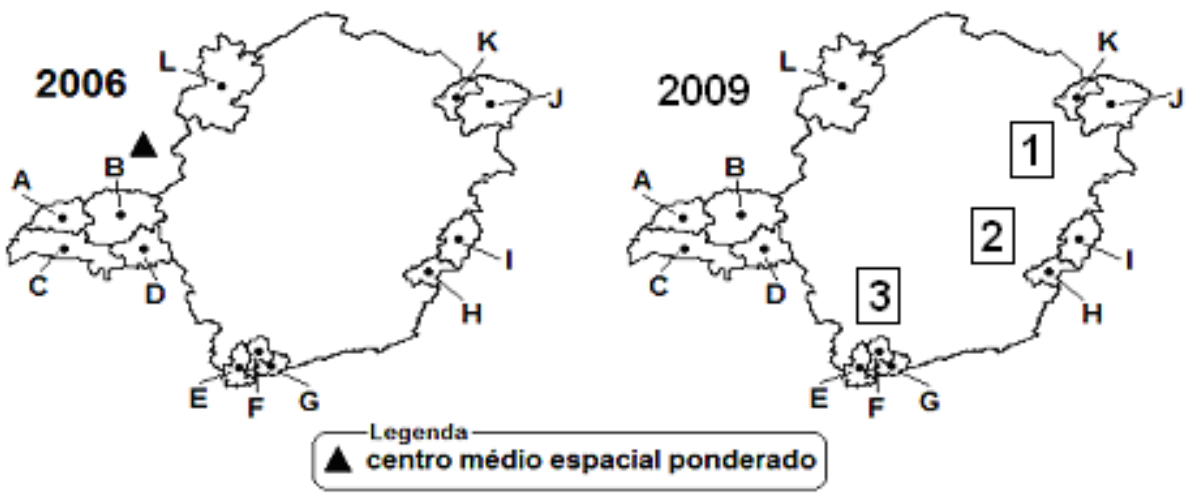

\begin{tabular}{|l|l|l|}
\hline [ E ] & $\begin{array}{l}\text { Se de } 2006 \text { para 2009 a quantidade produzida de carne aumentou } \\
\text { proporcionalmente em 50\% para todas as microrregiões, então o novo centro } \\
\text { médio espacial ponderado em } 2009 \text { esteve mais próximo da posição [1] } \\
\text { mostrada no mapa de 2009 }\end{array}$ \\
\hline [ E ] & $\begin{array}{l}\text { Se de 2006 para 2009 a quantidade produzida de carne diminuiu } \\
\text { proporcionalmente em 50\% para todas as microrregiões, então o novo centro } \\
\text { médio espacial ponderado em } 2009 \text { esteve mais próximo da posição [3] } \\
\text { mostrada no mapa de 2009 }\end{array}$ \\
\hline
\end{tabular}




\section{MAPEAMENTO DA SUA DINÂMICA DE APRENDIZAGEM}

(assinale as opções que julgar pertinentes mesmo que sejam mais de uma num mesmo item)

Item 01 - Leitura de material para responder as questões

\begin{tabular}{|ll|l|}
\hline[ & ] & Não li nenhum material: nem o do software EDH, nem qualquer outro material. \\
\hline[ & ] & Li $\underline{\text { somente }}$ o material do software EDH. \\
\hline[ & ] & Li $\underline{\text { somente }}$ outro material diferente do software EDH. \\
\hline[ & ] & Li parcialmente o material do software EDH. \\
\hline[ & ] & Li parcialmente outro material diferente do software EDH. \\
\hline[ & ] & $\begin{array}{l}\text { Li o material do software EDH e também outro material diferente do software } \\
\text { EDH. }\end{array}$ \\
\hline
\end{tabular}

Item 02 - Eu lembrava e/ou conhecia e/ou entendia o assunto

\begin{tabular}{|ll|l|}
\hline[ & ] & $\begin{array}{l}\text { Como assinalei antes, não li nenhum material, mas eu lembrava das noções } \\
\text { conceituais de centro médio espacial ponderado }\end{array}$ \\
\hline[ & ] & $\begin{array}{l}\text { Antes mesmo da leitura, eu lembrava/entendia as noções conceituais de centro } \\
\text { médio espacial ponderado }\end{array}$ \\
\hline[ & ] & $\begin{array}{l}\text { Durante e depois da leitura, eu lembrei das noções conceituais centro médio } \\
\text { espacial ponderado }\end{array}$ \\
\hline
\end{tabular}

Item 03 - Eu não conhecia ou não entendia o assunto antes da leitura

\begin{tabular}{|l|l|}
\hline$[\quad]$ & $\begin{array}{l}\text { Antes da leitura, eu não conhecia as noções conceituais de centro médio espacial } \\
\text { ponderado }\end{array}$ \\
\hline
\end{tabular}

\section{Item 04 - Eu entendi o assunto durante e/ou após a leitura}

\begin{tabular}{|l|l|}
\hline$[\quad[$ & $\begin{array}{l}\text { Foi durante e/ou após a leitura que eu entendi as noções conceituais de centro } \\
\text { médio espacial ponderado, pois antes da leitura, apesar de ter estudado, eu não } \\
\text { entendia tais noções conceituais }\end{array}$ \\
\hline$[\quad]$ & $\begin{array}{l}\text { Foi durante e/ou após a leitura que eu entendi as noções conceituais de centro } \\
\text { médio espacial ponderado. Antes da leitura, como disse antes, eu não conhecia } \\
\text { tais noções conceituais }\end{array}$ \\
\hline
\end{tabular}

\section{Item 05 - Não entendi o assunto mesmo após a leitura}

\begin{tabular}{|l|l|}
\hline$[\quad]$ & $\begin{array}{l}\text { Mesmo após minha leitura, continuei a não entender as noções conceituais centro } \\
\text { médio espacial ponderado. Minhas respostas às questões foram baseadas no } \\
\text { "chute". }\end{array}$ \\
\hline
\end{tabular}


Item 06 - Com relacão ao uso do software EDH (se você fez a leitura do material)

\begin{tabular}{|ll|l|}
\hline[ & {[} & $\begin{array}{l}\text { Não tentei usar efetivamente o EDH por já entender os conceitos, por isso não me } \\
\text { considero apto a fazer alguma avaliação sobre o EDH. }\end{array}$ \\
\hline[ & {[} & $\begin{array}{l}\text { Para entendimento das noções conceituais de centro médio espacial ponderado o } \\
\text { EDH não foi útil. Ao contrário, acredito que me confundiu mais ainda sobre os } \\
\text { conceitos que tentou apresentar. }\end{array}$ \\
\hline [ & ] & $\begin{array}{l}\text { Para entendimento das noções conceituais de centro médio espacial ponderado o } \\
\text { EDH foi útil. Acredito que o material ajudou na fixação dos conceitos. }\end{array}$ \\
\hline[ & ] & $\begin{array}{l}\text { Para entendimento das noções conceituais de centro médio espacial ponderado o } \\
\text { EDH foi útil. Mas outro material que li sobre o assunto aborda de forma melhor } \\
\text { que o EDH. }\end{array}$ \\
\hline[ & ] & $\begin{array}{l}\text { Para entendimento das noções conceituais de centro médio espacial ponderado o } \\
\text { EDH foi útil. E o EDH aborda o assunto melhor que outro material que li sobre o } \\
\text { assunto. }\end{array}$ \\
\hline[ & ] & $\begin{array}{l}\text { Para entendimento das noções conceituais de centro médio espacial ponderado o } \\
\text { EDH foi útil. Acredito que a abordagem do assunto tentando apresentar os } \\
\text { conceitos primordialmente via imagens ajudou na fixação dos conteúdos. }\end{array}$ \\
\hline
\end{tabular}

Item 07 - IMAGENS do software EDH - cite abaixo as imagens do EDH que você lembra e que acredita ter sido útil para entender conceitos de centro médio espacial ponderado

\begin{tabular}{|l|}
\hline \\
\hline 2
\end{tabular}

Item 08 - tente escrever abaixo a fórmula do centro médio espacial ponderado

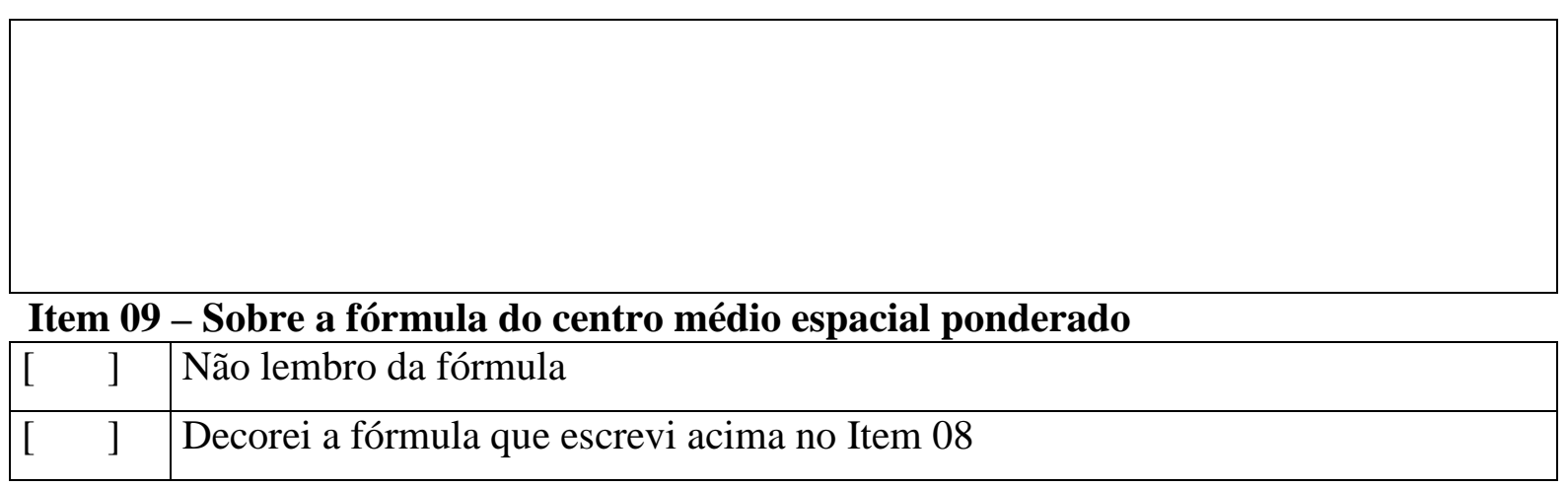




\begin{tabular}{|ll|l|}
\hline[ & ] & $\begin{array}{l}\text { Memorizei a fórmula. Por memorizar quero dizer que entendi os conceitos } \\
\text { matemáticos envolvidos na fórmula. Mas entendi em outra oportunidade em que } \\
\text { estudei o assunto }\end{array}$ \\
\hline [ & ] & $\begin{array}{l}\text { Memorizei a fórmula. Por memorizar quero dizer que entendi os conceitos } \\
\text { matemáticos envolvidos na fórmula. E entendi por meio de do uso do software } \\
\text { EDH }\end{array}$ \\
\hline
\end{tabular}

\section{O uso do software EDH (se você fez a leitura do material)}

Caso tenha usado o $\mathrm{EDH}$, por favor relate brevemente os pontos positivos (interface estática e interativa, exemplos para abordagem, atividades propostas, etc) que o mesmo tenha apresentado para auxiliar a fixar os conceitos de CENTRO MÉDIO RESPACIAL PONDERADO

Caso tenha usado o EDH, por favor relate brevemente os pontos negativos (interface estática e interativa, exemplos para abordagem, atividades propostas, etc) que o mesmo tenha apresentado para auxiliar a fixar os conceitos de CENTRO MÉDIO RESPACIAL PONDERADO

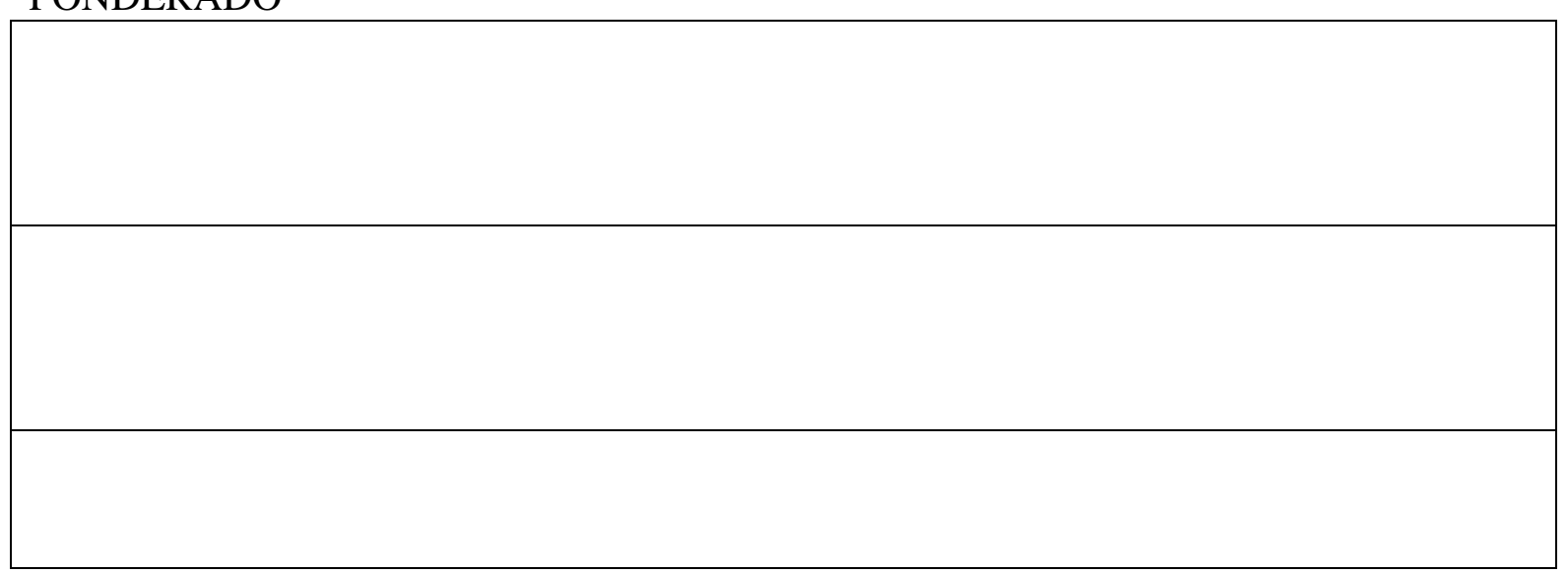




\section{APÊNDICE 11}

\section{QUESTIONARIO 6 - Estatística espacial - distância padrão (com respostas aos itens das questões)}

\begin{tabular}{|c|c|}
\hline 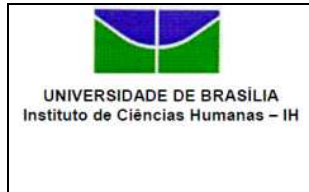 & $\begin{array}{l}\text { Curso de Extensão - Introdução à Quantificação em Geografia - } \\
\text { Set/Nov } 2014 \\
\text { Questionário para mapeamento de entendimento de conceitos } \\
\text { apresentados no software EDH - Distância padrão }\end{array}$ \\
\hline
\end{tabular}

Nome completo:

Questão 1 - Situação hipotética: As Figuras (A), (B) e (C) abaixo apresentam uma região fictícia em 3 momentos distintos (2010, 2011 e 2012) apresentando a quantidade de casos de dengue em 7 localidades (pontos pretos no mapa) distintas (A, B, C, D, E, F e G).

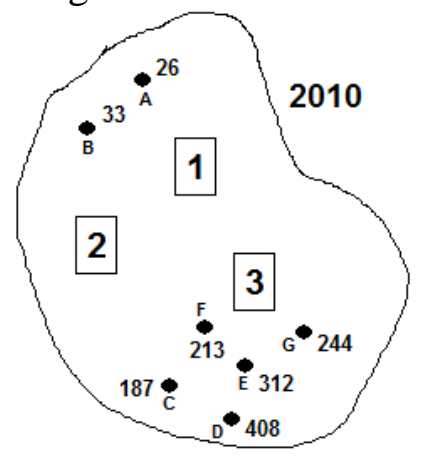

(A)

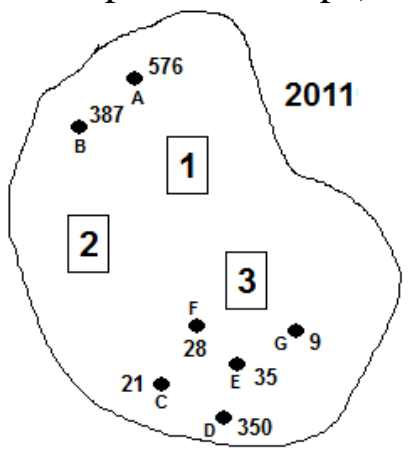

(B)

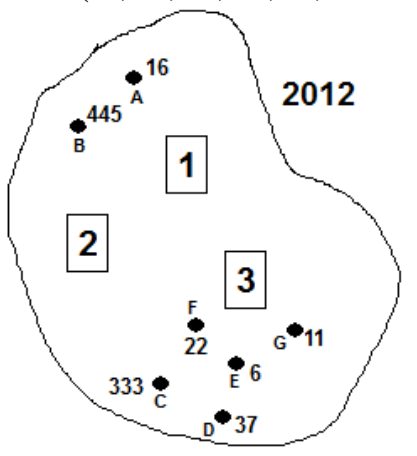

(C)

Nas situações a seguir, julgue as assertivas abaixo em certo (C) ou errado (E) ou marque $X$ caso não saiba a resposta.

\begin{tabular}{|l|l|}
\hline [ C ] & $\begin{array}{l}\text { Não é possível calcular nem o centro médio espacial (ponderado ou não), nem a } \\
\text { distância padrão (ponderada ou não) pois não são informados os valores de } \\
\text { latitude/longitude das localidades A, B, C, D, E, F e G }\end{array}$ \\
\hline [ C ] & $\begin{array}{l}\text { O centro médio espacial (não ponderado) das localidades A, B, C, D, E, F e G é } \\
\text { um ponto que não se altera ao longo dos anos de 2010, 2011 e 2012 }\end{array}$ \\
\hline [ C ] & $\begin{array}{l}\text { A distância padrão (não ponderada) das localidades A, B, C, D, E, F e G é um } \\
\text { valor que não se altera para os anos de 2010, 2011 e 2012 }\end{array}$ \\
\hline [ E ] & $\begin{array}{l}\text { Em 2010, o centro médio espacial ponderado pelos casos de dengue das } \\
\text { localidades A, B, C, D, E, F e G está mais próximo do retângulo 2 do que dos } \\
\text { retângulos 1 e 3 da figura (A) }\end{array}$ \\
\hline [ C ] & $\begin{array}{l}\text { Em 2010, a distância padrão ponderada pelos casos de dengue das localidades A, } \\
\text { B, C, D, E, F e G é menor que a mesma distância calculada para 2011 }\end{array}$ \\
\hline [ E ] & $\begin{array}{l}\text { Não é possível saber se em 2010 a distância padrão ponderada pelos casos de } \\
\text { dengue das localidades A, B, C, D, E, F e G é menor que a mesma distância } \\
\text { calculada para 2011, pois não foram informados os valores de latitude/longitude } \\
\text { das localidades A, B, C, D, E, F e G }\end{array}$ \\
\hline
\end{tabular}


ATENÇÃO !!! REPETIÇÃO DA FIGURA ANTERIOR (para facilitar a resolução dos itens)

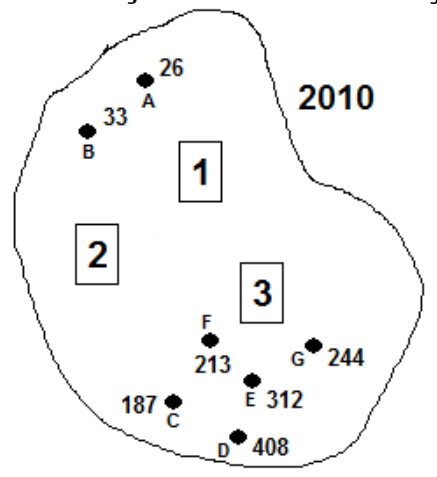

(A)

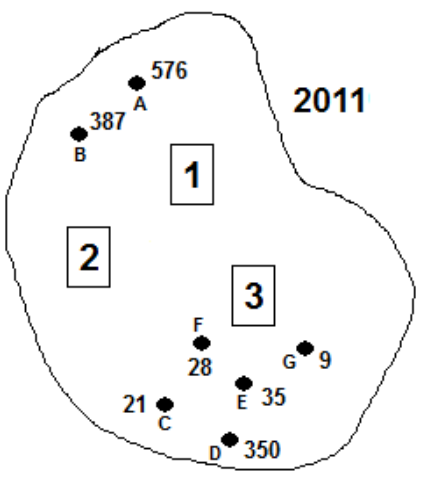

(B)

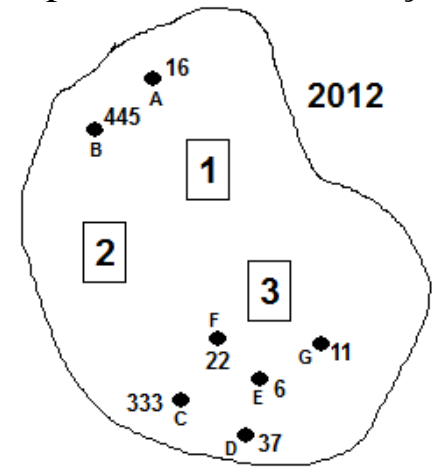

(C)

\begin{tabular}{|l|l|}
\hline [ E ] & $\begin{array}{l}\text { Em 2011, o centro médio espacial ponderado pelos casos de dengue das } \\
\text { localidades A, B, C, D, E, F e G está mais próximo do retângulo } 3 \text { do que dos } \\
\text { retângulos 1 e 2 da figura (B) }\end{array}$ \\
\hline [ E ] & $\begin{array}{l}\text { As distâncias padrão ponderadas pelos casos de dengue das localidades A, B, } \\
\text { C, D, E, F e G para os anos de } 2010 \text { e } 2011 \text { são maiores que a mesma } \\
\text { distância calculada para 2012 }\end{array}$ \\
\hline [ C ] & $\begin{array}{l}\text { Em 2012, o centro médio espacial ponderado pelos casos de dengue das } \\
\text { localidades A, B, C, D, E, F e G está mais próximo do retângulo } 2 \text { do que dos } \\
\text { retângulos 1 e 3 da figura (C) }\end{array}$ \\
\hline
\end{tabular}

Questão 2 - Situação hipotética: suponha 3 espaços geográficos EG1, EG2 e EG3 mostrados na figura abaixo. O triângulo representa o centro médio espacial ponderado da ocorrência de determinada praga agrícola que assola os 3 EGs. O círculo tem como raio a distância padrão ponderada e a área do círculo tem interseção com os 3 EGs. $\mathrm{O}$ valor da área A do círculo é o mesmo da área B. E o valor da área $\mathrm{C}$ do círculo é o dobro da área $\mathrm{A}$. Finalmente, a área de EG1 é o triplo de EG2 e a área de EG3 é o quádruplo de EG2. Denote por $\boldsymbol{\alpha}$ a variabilidade relativa espacial do problema da praga em EG2. Qual a variabilidade relativa espacial de EG1 em termos de EG2 ? E a variabilidade relativa espacial de EG3 em termos de EG2 ? Em qual EG o problema da praga é relativamente maior ? E em qual EG o problema da praga é relativamente menor?

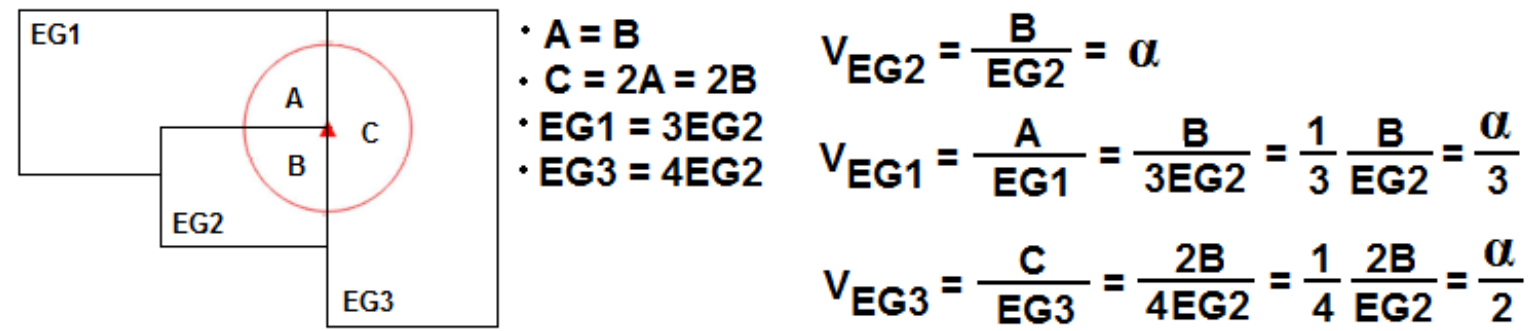

\section{$\Rightarrow \mathrm{v}_{\mathrm{EG} 1}<\mathrm{v}_{\mathrm{EG} 3}<\mathrm{v}_{\mathrm{EG} 2}$}




\section{MAPEAMENTO DA SUA DINÂMICA DE APRENDIZAGEM}

(assinale as opções que julgar pertinentes mesmo que sejam mais de uma num mesmo item)

Item 01 - Leitura de material para responder as questões

\begin{tabular}{|c|c|}
\hline$\left[\begin{array}{ll} & ]\end{array}\right.$ & Não li nenhum material: nem o do software EDH, nem qualquer outro material. \\
\hline ] & Li somente o material do software EDH. \\
\hline ] & Li somente outro material diferente do software EDH. \\
\hline ] & Li parcialmente o material do software EDH. \\
\hline$[\quad]$ & Li parcialmente outro material diferente do software EDH. \\
\hline$\left[\begin{array}{ll}{[} & ]\end{array}\right.$ & $\begin{array}{l}\text { Li o material do software EDH e também outro material diferente do software } \\
\text { EDH. }\end{array}$ \\
\hline
\end{tabular}

Item 02 - Eu lembrava e/ou conhecia e/ou entendia o assunto

\begin{tabular}{|ll|l|}
\hline[ & {[} & $\begin{array}{l}\text { Como assinalei antes, não li nenhum material, mas eu lembrava das noções } \\
\text { conceituais de distância padrão }\end{array}$ \\
\hline[ & ] & $\begin{array}{l}\text { Antes mesmo da leitura, eu lembrava/entendia as noções conceituais de distância } \\
\text { padrão }\end{array}$ \\
\hline [ & ] & $\begin{array}{l}\text { Durante e depois da leitura, eu lembrei das noções conceituais de distância padrão } \\
\text { que estudei em outra oportunidade. }\end{array}$ \\
\hline
\end{tabular}

Item 03 - Eu não conhecia ou não entendia o assunto antes da leitura

\begin{tabular}{|l|l|l}
\hline [ ] Antes da leitura, eu não conhecia as noções conceituais distância padrão
\end{tabular}

\section{Item 04 - Eu entendi o assunto durante e/ou após a leitura}

\begin{tabular}{|ll|l|}
\hline[ & {[} & $\begin{array}{l}\text { Foi durante e/ou após a leitura que eu entendi as noções conceituais de distância } \\
\text { padrão, pois antes da leitura, apesar de ter estudado, eu não entendia tais noções } \\
\text { conceituais }\end{array}$ \\
\hline [ & ] & $\begin{array}{l}\text { Foi durante e/ou após a leitura que eu entendi as noções conceituais de distância } \\
\text { padrão. Antes da leitura, como disse antes, eu não conhecia tais noções conceituais }\end{array}$ \\
\hline
\end{tabular}

\section{Item 05 - Não entendi o assunto mesmo após a leitura}

\begin{tabular}{|l|l|}
\hline$[\quad$ ] & $\begin{array}{l}\text { Mesmo após minha leitura, continuei a não entender as noções conceituais de } \\
\text { distância padrão. Minhas respostas às questões foram baseadas no "chute". }\end{array}$ \\
\hline
\end{tabular}


Item 06 - Com relacão ao uso do software EDH (se você fez a leitura do material)

\begin{tabular}{|ll|l|}
\hline[ & [ & $\begin{array}{l}\text { Não tentei usar efetivamente o EDH por já entender os conceitos, por isso não } \\
\text { me considero apto a fazer alguma avaliação sobre o EDH. }\end{array}$ \\
\hline[ & ] & $\begin{array}{l}\text { Para entendimento das noções conceituais de distância padrão o EDH não foi } \\
\text { útil. Ao contrário, acredito que me confundiu mais ainda sobre os conceitos que } \\
\text { tentou apresentar. }\end{array}$ \\
\hline[ & ] & $\begin{array}{l}\text { Para entendimento das noções conceituais de distância padrão o EDH foi útil. } \\
\text { Acredito que o material ajudou na fixação dos conceitos. }\end{array}$ \\
\hline[ & ] & $\begin{array}{l}\text { Para entendimento das noções conceituais de distância padrão o EDH foi útil. } \\
\text { Mas outro material que li sobre o assunto aborda de forma melhor que o EDH. }\end{array}$ \\
\hline[ & ] & $\begin{array}{l}\text { Para entendimento das noções conceituais de distância padrão o EDH foi útil. E } \\
\text { o EDH aborda o assunto melhor que outro material que li sobre o assunto. }\end{array}$ \\
\hline [ & ] & $\begin{array}{l}\text { Para entendimento das noções conceituais de distância padrão o EDH foi útil. } \\
\text { Acredito que a abordagem do assunto tentando apresentar os conceitos } \\
\text { primordialmente via imagens ajudou na fixação dos conteúdos. }\end{array}$ \\
\hline
\end{tabular}

Item 07 - IMAGENS do software EDH - cite abaixo as imagens do EDH que você lembra e que acredita ter sido útil para entender conceitos de distância padrão

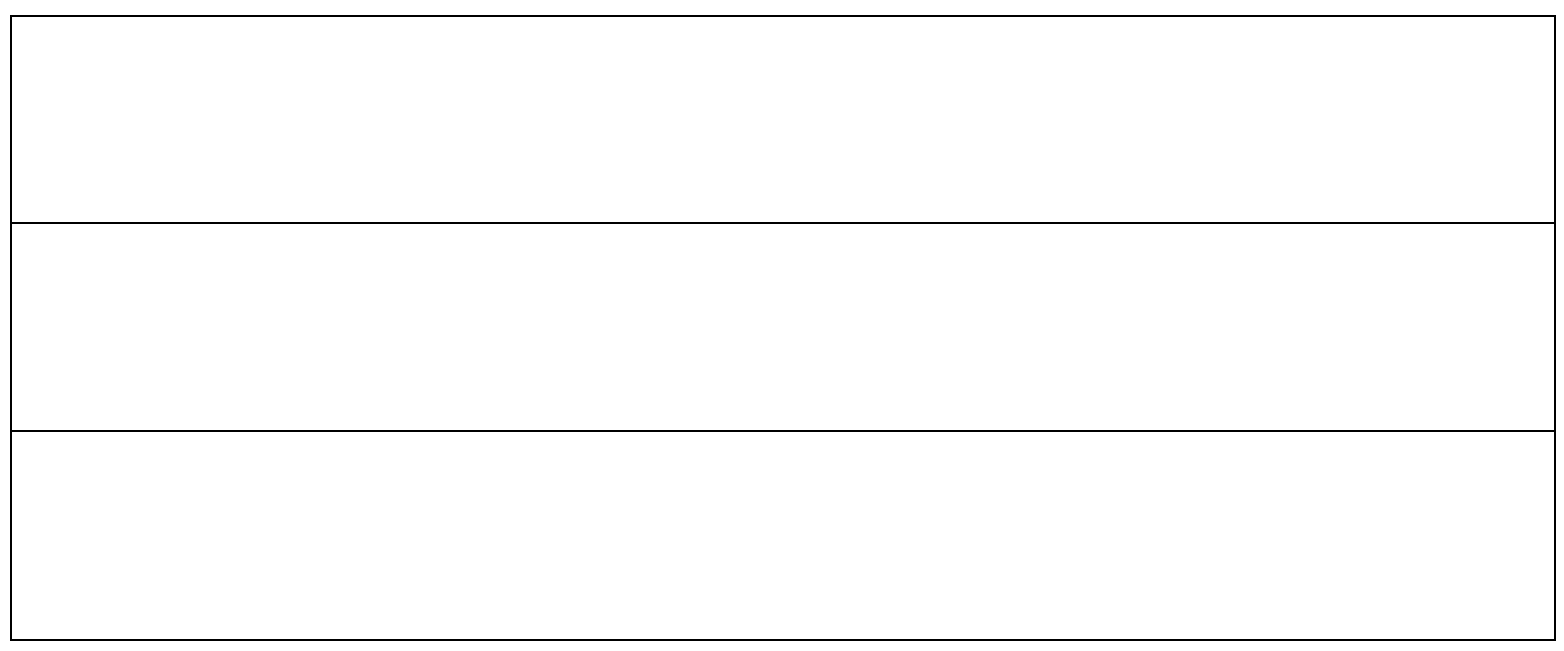

Item 08 - tente escrever abaixo a fórmula da distância padrão 
Item 09 - Sobre a fórmula da distância padrão

\begin{tabular}{|ll|l|}
\hline[ & {[} & Não lembro da fórmula \\
\hline[ & {[} & Decorei a fórmula que escrevi acima no Item 08 \\
\hline[ & {[} & $\begin{array}{l}\text { Memorizei a fórmula. Por memorizar quero dizer que entendi os conceitos } \\
\text { matemáticos envolvidos na fórmula. Mas entendi em outra oportunidade em que } \\
\text { estudei o assunto }\end{array}$ \\
\hline[ & {[} & $\begin{array}{l}\text { Memorizei a fórmula. Por memorizar quero dizer que entendi os conceitos } \\
\text { matemáticos envolvidos nas fórmulas. E entendi por meio de do uso do software } \\
\text { EDH }\end{array}$ \\
\hline
\end{tabular}

\section{O uso do software EDH (se você fez a leitura do material)}

Caso tenha usado o EDH, por favor relate brevemente os pontos positivos (interface estática e interativa, exemplos para abordagem, atividades propostas, etc) que o mesmo tenha apresentado para auxiliar a fixar os conceitos de DISTÂNCIA PADRÃO

Caso tenha usado o EDH, por favor relate brevemente os pontos negativos (interface estática e interativa, exemplos para abordagem, atividades propostas, etc) que o mesmo tenha apresentado para auxiliar a fixar os conceitos de DISTÂNCIA PADRÃO

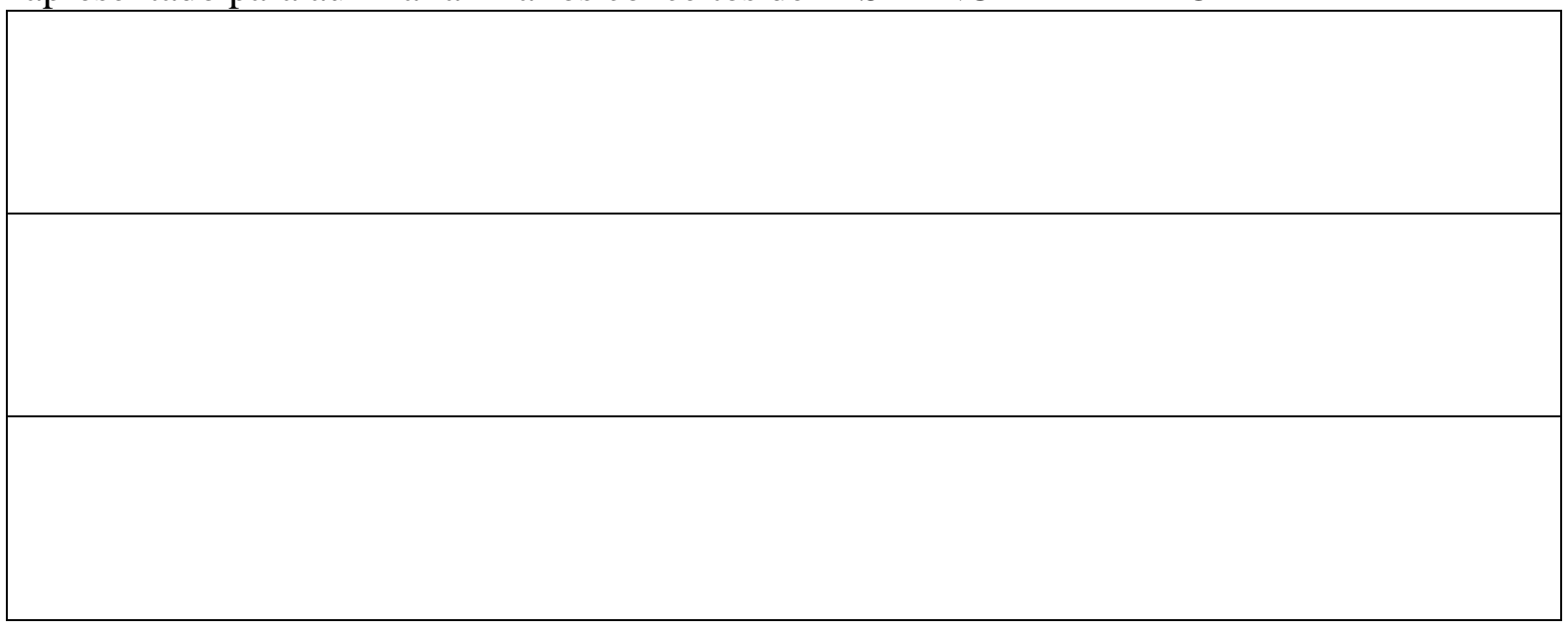




\section{APÊNDICE 12}

\section{QUESTIONARIO 7 - Medidas de posição (separatrizes) e box plot}

(com respostas aos itens das questões)

\begin{tabular}{|c|c|}
\hline 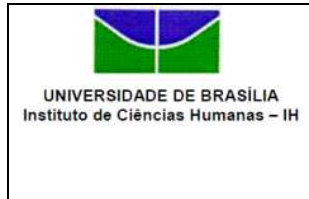 & $\begin{array}{l}\text { Curso de Extensão - Introdução à Quantificação em Geografia - } \\
\text { Set/Nov } 2014 \\
\text { Questionário para mapeamento de entendimento de conceitos } \\
\text { apresentados no software EDH - Separatrizes }\end{array}$ \\
\hline
\end{tabular}

Nome completo:

Questão 1 - A tabela abaixo apresenta a taxa de alfabetização de pessoas de 10 ou mais anos de idade nas 18 microrregiões geográficas de Goiás, segundo o Censo do IBGE de 2010. Responda :

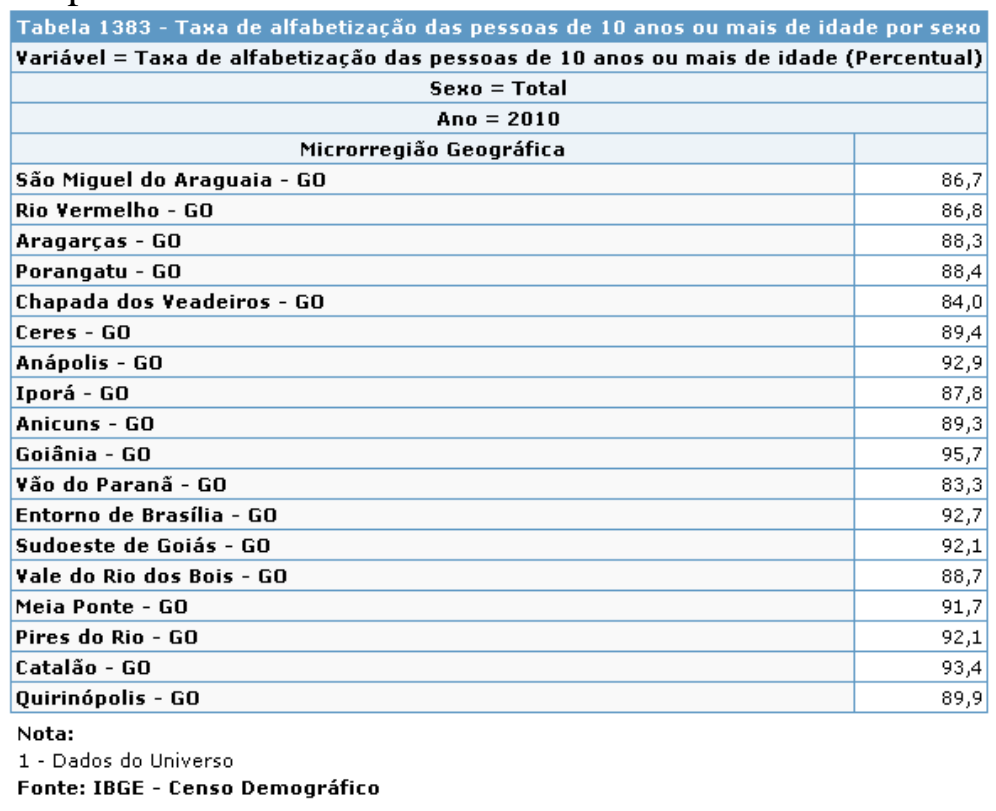

Série ordenada
\begin{tabular}{|l|l|}
\hline 1 & 83.3 \\
\hline 2 & 84.0 \\
\hline 3 & 86.7 \\
\hline 4 & 86.8 \\
\hline 5 & 87.8 \\
\hline 6 & 88.3 \\
\hline 7 & 88.4 \\
\hline 8 & 88.7 \\
\hline 9 & 89.3 \\
\hline 10 & 89.4 \\
\hline 11 & 89.9 \\
\hline 12 & 91.7 \\
\hline 13 & 92.1 \\
\hline 14 & 92.1 \\
\hline 15 & 92.7 \\
\hline 16 & 92.9 \\
\hline 17 & 93.4 \\
\hline 18 & 95.7 \\
\hline
\end{tabular}

1.1) Qual o valor da mediana (Md) da série ? 89.35

1.2) Qual o valor do primeiro quartil (Q1) da série ? 88.3

1.3) Qual o valor do terceiro quartil (Q3) da série ? 92.1

1.4) Qual o valor do intervalo interquartílico $(\mathrm{dq})$ da série ? 92.1 - $88.3=3.8$ 
Questão 2 - Na figura abaixo observam-se 4 diagramas de caixa (box plot), denominados de (A), (B), (C) e (D) representando, cada um deles, séries de teor de fósforo (P) medidas em amostras de solo de determinado espaço geográfico. O box plot (A) refere-se 61 amostras de solo. Os box plot (C) e (D) referem-se, respectivamente, a 82 e 45 amostras de solo. Não se tem informação sobre a quantidade de amostras da série do box plot (B).

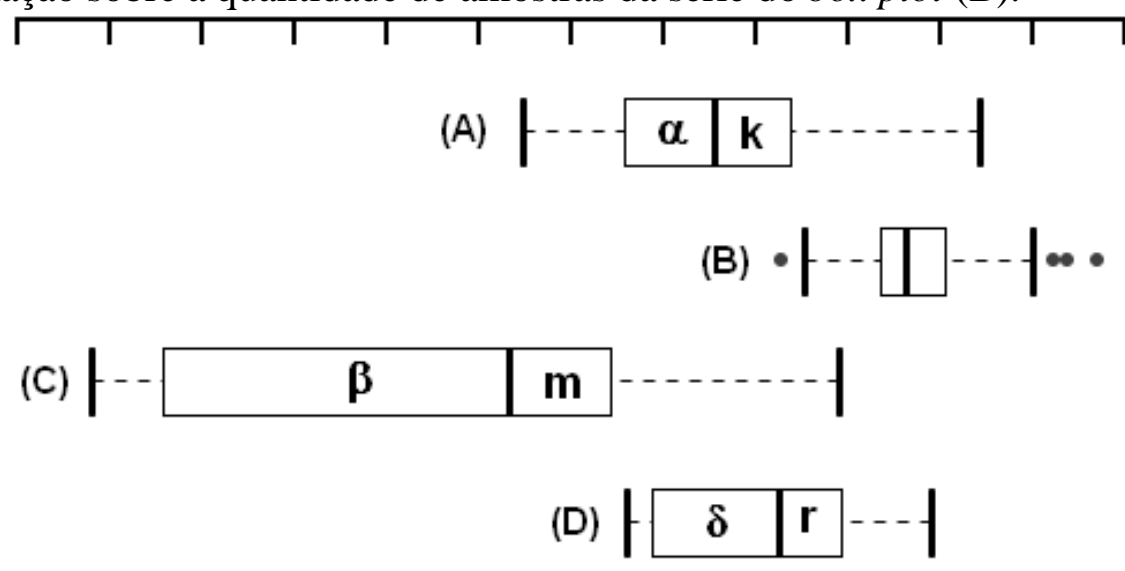

Julgue as assertivas abaixo em certo $(\mathbf{C})$ ou errado (E) ou marque $\mathbf{X}$ caso não saiba a resposta.

\begin{tabular}{|l|l|}
\hline [ E ] & $\begin{array}{l}\text { A série de dados (B) apresenta certamente menos que 41 amostras, pois o box } \\
\text { plot da série tem a menor amplitude entre as 4 séries }\end{array}$ \\
\hline [ C ] & A série de dados (B) pode ser composta de mais de 500 amostras \\
\hline [ C ] & $\begin{array}{l}\text { A série de dados (C) poderia ser composta de, por exemplo 15 amostras e ainda } \\
\text { assim apresentar o mesmo box plot que apresenta para as suas } 82 \text { amostras }\end{array}$ \\
\hline [ E ] & $\begin{array}{l}\text { A variabilidade da metade inferior da série (C) é certamente maior que } \\
\text { variabilidade da metade inferior da série (A) }\end{array}$ \\
\hline [ C ] & $\begin{array}{l}\text { A série de dados (A) é a mais simétrica em relação à mediana que as demais } \\
\text { séries }\end{array}$ \\
\hline [ C ] & $\begin{array}{l}\text { Existem } 22 \text { elementos abaixo da mediana na série de dados (D). E existem } 22 \\
\text { elementos acima do segundo quartil (Q2) na série de dados (D) }\end{array}$ \\
\hline [ E ] & $\alpha=30, \beta=41$ e $\delta=22$. \\
\hline [ C ] & $\begin{array}{l}\alpha+\mathbf{k}, \beta+\mathbf{m} \text { e } \delta+\mathbf{r} \text { abrangem } 50 \% \text { das observações das séries (A), (C) e (D) } \\
\text { respectivamente }\end{array}$ \\
\hline [ C ] & Em valores absolutos, $\alpha+\mathbf{k}+\beta+\mathbf{m}+\delta+\mathbf{r}>90$ amostras de solo \\
\hline
\end{tabular}

\section{MAPEAMENTO DA SUA DINÂMICA DE APRENDIZAGEM}

(assinale as opções que julgar pertinentes mesmo que sejam mais de uma num mesmo item)

\section{Item 01 - Leitura de material para responder as questões}

\begin{tabular}{|ll|l|}
\hline[ & ] & Não li nenhum material: nem o do software EDH, nem qualquer outro material. \\
\hline[ & ] & Li somente o material do software $\mathrm{EDH}$. \\
\hline[ & ] & Li somente outro material diferente do software $\mathrm{EDH}$. \\
\hline[ & ] & Li parcialmente o material do software EDH. \\
\hline[ & ] & Li parcialmente outro material diferente do software EDH. \\
\hline
\end{tabular}


[ ] Li o material do software EDH e também outro material diferente do software EDH.

Item 02 - Eu lembrava e/ou conhecia e/ou entendia o assunto

\begin{tabular}{|ll|l|}
\hline[ & {[} & $\begin{array}{l}\text { Como assinalei antes, não li nenhum material, mas eu lembrava das noções } \\
\text { conceituais de separatrizes }\end{array}$ \\
\hline[ & {[} & Antes mesmo da leitura, eu lembrava/entendia as noções conceituais de separatrizes \\
\hline[ & ] & $\begin{array}{l}\text { Durante e depois da leitura, eu lembrei das noções conceituais de separatrizes que } \\
\text { estudei em outra oportunidade. }\end{array}$ \\
\hline
\end{tabular}

Item 03 - Eu não conhecia ou não entendia o assunto antes da leitura

[ ] Antes da leitura, eu não conhecia as noções conceituais de separatrizes

\section{Item 04 - Eu entendi o assunto durante e/ou após a leitura}

\begin{tabular}{|l|l|}
\hline$[\quad]$ & $\begin{array}{l}\text { Foi durante e/ou após a leitura que eu entendi as noções conceituais de separatrizes, } \\
\text { pois antes da leitura, apesar de ter estudado, eu não entendia tais noções conceituais }\end{array}$ \\
\hline [ $\quad$ ] & $\begin{array}{l}\text { Foi durante e/ou após a leitura que eu entendi as noções conceituais de separatrizes. } \\
\text { Antes da leitura, como disse antes, eu não conhecia tais noções conceituais }\end{array}$ \\
\hline
\end{tabular}

Item 05 - Não entendi o assunto mesmo após a leitura

[ ] Mesmo após minha leitura, continuei a não entender as noções conceituais de separatrizes. Minhas respostas às questões foram baseadas no "chute".

Item 06 - Com relacão ao uso do software EDH (se você fez a leitura do material)

\begin{tabular}{|ll|l|}
\hline [ & ] & $\begin{array}{l}\text { Não tentei usar efetivamente o EDH por já entender os conceitos, por isso não me } \\
\text { considero apto a fazer alguma avaliação sobre o EDH. }\end{array}$ \\
\hline [ & ] & $\begin{array}{l}\text { Para entendimento das noções conceituais de separatrizes o EDH não foi útil. Ao } \\
\text { contrário, acredito que me confundiu mais ainda sobre os conceitos que tentou } \\
\text { apresentar. }\end{array}$ \\
\hline [ & ] & $\begin{array}{l}\text { Para entendimento das noções conceituais de separatrizes o EDH foi útil. Acredito } \\
\text { que o material ajudou na fixação dos conceitos. }\end{array}$ \\
\hline [ & ] & $\begin{array}{l}\text { Para entendimento das noções conceituais de separatrizes o EDH foi útil. Mas outro } \\
\text { material que li sobre o assunto aborda de forma melhor que o EDH. }\end{array}$ \\
\hline [ & ] & $\begin{array}{l}\text { Para entendimento das noções conceituais de separatrizes o EDH foi útil. E o EDH } \\
\text { aborda o assunto melhor que outro material que li sobre o assunto. }\end{array}$ \\
\hline [ & ] & $\begin{array}{l}\text { Para entendimento das noções conceituais de separatrizes o EDH foi útil. Acredito } \\
\text { que a abordagem do assunto tentando apresentar os conceitos primordialmente via } \\
\text { imagens ajudou na fixação dos conteúdos. }\end{array}$ \\
\hline
\end{tabular}


Item 07 - IMAGENS do software EDH - cite abaixo as imagens do EDH que você lembra e que acredita ter sido útil para entender conceitos de separatrizes

\section{O uso do software EDH (se você fez a leitura do material)}

Caso tenha usado o EDH, por favor relate brevemente os pontos positivos (interface estática e interativa, exemplos para abordagem, atividades propostas, etc) que o mesmo tenha apresentado para auxiliar a fixar os conceitos de SEPARATRIZES

\begin{tabular}{|l|}
\hline \\
\hline
\end{tabular}

Caso tenha usado o EDH, por favor relate brevemente os pontos negativos (interface estática e interativa, exemplos para abordagem, atividades propostas, etc) que o mesmo tenha apresentado para auxiliar a fixar os conceitos de SEPARATRIZES 


\section{APÊNDICE 13}

\section{QUESTIONARIO 8 - Curva de Lorenz e coeficiente de Gini (com respostas aos itens das questões)}

\begin{tabular}{|l|l|}
\hline $\begin{array}{c}\text { UnIVERIOADE DE BRASIIAA } \\
\text { Instituto do Ciencias Humanas }-1 \mathrm{H}\end{array}$ & $\begin{array}{c}\text { Curso de Extensão - Introdução à Quantificação em Geografia - } \\
\text { Set/Nov 2014 } \\
\text { Questionário para mapeamento de entendimento de conceitos } \\
\text { apresentados no software EDH - Curva de Lorenz/coeficiente de Gini }\end{array}$ \\
\hline
\end{tabular}

Nome completo:

Questão 1 - Situação hipotética: na figura abaixo observamos as curvas de Lorenz dos anos de 1980, 1990, 2000 e 2010 referentes a ocorrência de determinada praga agrícola (insetos) nos municípios de Goiás mostrados na figura em [A]. Julgue as assertivas abaixo em certo $(C)$ ou errado (E) ou marque $X$ caso não saiba a resposta.
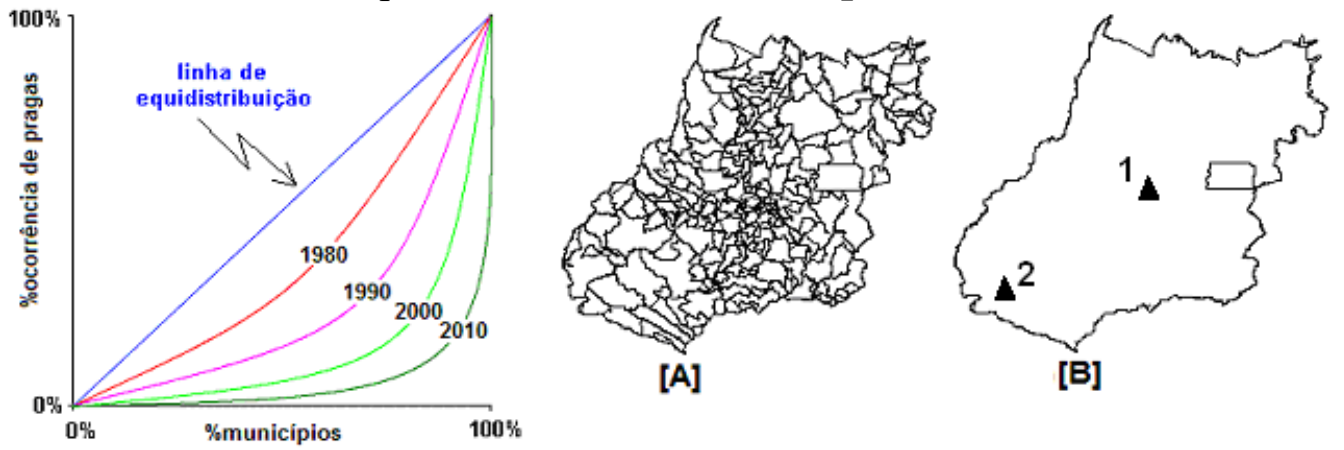

\begin{tabular}{|l|l|}
\hline [ E ] & $\begin{array}{l}\text { A distribuição da quantidade de insetos (pragas) pelos municípios goianos em } \\
\text { 1990 é mais desigual do que a distribuição ocorrida em 2000 }\end{array}$ \\
\hline [ C ] & $\begin{array}{l}\text { A distribuição da quantidade de insetos (pragas) pelos municípios goianos em } \\
\text { 2010 é mais desigual do que a distribuição ocorrida em 1980 }\end{array}$ \\
\hline [ C ] & $\begin{array}{l}\text { De 1980 a 2010 podemos afirmar que a dinâmica da praga, distribuída em 1980 de } \\
\text { forma relativamente homogênea pelos municípios goianos, foi se concentrando } \\
\text { em determinados municípios - que não podemos indicar quais são - de modo que } \\
\text { tornou a distribuição da praga mais desigual pelos municípios goianos em 2010 }\end{array}$ \\
\hline [ E ] & $\begin{array}{l}\text { Considerando-se a analogia do "bolo" e dos "convidados" para construção da } \\
\text { curva de Lorenz, é possível afirmar que o "bolo" é representado pelos municípios } \\
\text { goianos e os "convidados" são as pragas (insetos) detectadas }\end{array}$ \\
\hline [ E ] & $\begin{array}{l}\text { E possível que o centro médio espacial ponderado pela quantidade de insetos dos } \\
\text { municípios goianos em 1980 esteja mais próximo do ponto 2 do que do ponto 1 } \\
\text { da figura [B] }\end{array}$ \\
\hline [ C ] & $\begin{array}{l}\text { Com certeza o centro médio espacial ponderado pela quantidade de insetos dos } \\
\text { municípios goianos em 1980 está mais próximo do ponto 1 do que do ponto } 2 \text { da } \\
\text { figura [B] }\end{array}$ \\
\hline
\end{tabular}




\begin{tabular}{|l|l|}
\hline [ E ] & $\begin{array}{l}\text { Com certeza o centro médio espacial ponderado pela quantidade de insetos dos } \\
\text { municípios goianos em } 2010 \text { está mais próximo do ponto } 2 \text { do que do ponto } 1 \\
\text { da figura [B] }\end{array}$ \\
\hline [ C ] & $\begin{array}{l}\text { É possível que o centro médio espacial ponderado pela quantidade de insetos dos } \\
\text { municípios goianos em } 2010 \text { esteja mais próximo do ponto } 1 \text { do que do ponto } 2 \\
\text { da figura [B] }\end{array}$ \\
\hline
\end{tabular}

Questão 2 - Situação hipotética: numa determinada localidade, denominada aqui de $\boldsymbol{A}$, foram registradas as ocorrências mensais de sequestros relâmpagos dos 12 meses do ano de 2011 . Calculou-se então o coeficiente de Gini relativo à distribuição dos sequestros relâmpagos pelos meses obtendo-se o valor $\mathbf{G}_{\boldsymbol{A}}=0,215$. Os dados para o mesmo evento para a localidade $\boldsymbol{B}$ ao longo dos 12 meses de 2011 estão apresentados na tabela abaixo:

\begin{tabular}{|c|c|}
\hline $\begin{array}{c}\text { \%meses } \\
\text { (acumulado) }\end{array}$ & $\begin{array}{c}\text { \%sequestros relâmpagos } \\
\text { (acumulado) }\end{array}$ \\
\hline $30 \%$ & $0 \%$ \\
\hline $40 \%$ & $20 \%$ \\
\hline $80 \%$ & $50 \%$ \\
\hline $100 \%$ & $100 \%$ \\
\hline
\end{tabular}

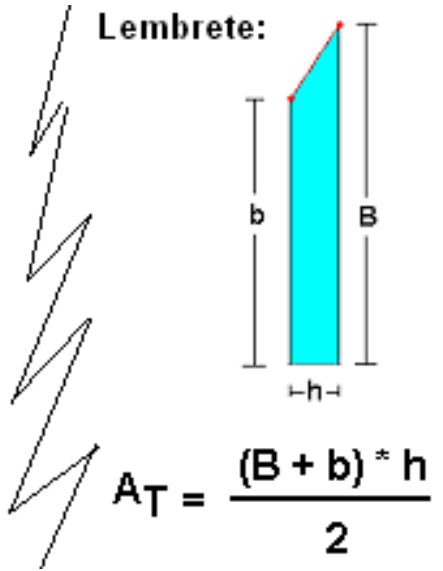

2.1) No contexto acima o que seria "o bolo" e o que seria "os convidados" ?

Bolo = total de ocorrências de sequestro relâmpago

Convidados = 12 meses de 2011

2.2) Calcule o coeficiente de Gini $\mathbf{G}_{\boldsymbol{B}}$ da localidade $\boldsymbol{B}$.

Beta $=[\{(0,4-0,3) * 0,2\} / 2]+[\{(0,5+0,2) *(0,8-0,4)\} / 2]+[\{(1,0+0,5) *(1,0-0,8)\} /$ 2]

Beta $=0,01+0,14+0,30=0,45$

Alfa + Beta $=0,5 \Rightarrow$ Alfa $=0,5-$ Beta $\Rightarrow$ Alfa $=0,5-0,45 \Rightarrow$ Alfa $=0,05$

$\mathrm{G}_{\mathrm{B}}=2 *$ Alfa $\Rightarrow \mathrm{G}_{\mathrm{B}}=\mathbf{0 , 1 0 0}$

2.3) Em 2011, em qual localidade os sequestros relâmpagos ficaram mais concentrados temporalmente (ocorreram com maior frequência em determinados meses) ? A priori, com base apenas nos coeficientes calculados, em qual localidade seria mais "perigoso" morar ? Justifique suas respostas.

Como $G_{A}=0,215>G_{B}=0,100$ então maior concentração em A.

Mais perigoso morar em $B$ pois os sequestros ocorrem mais uniformemente espalhados ao longo dos 12 meses se comparados com o "espalhamento" de sequestros ao longo dos meses em A 


\section{MAPEAMENTO DA SUA DINÂMICA DE APRENDIZAGEM}

(assinale as opções que julgar pertinentes mesmo que sejam mais de uma num mesmo item)

Item 01 - Leitura de material para responder as questões

\begin{tabular}{|ll|l|}
\hline[ & ] & Não li nenhum material: nem o do software EDH, nem qualquer outro material. \\
\hline[ & ] & Li somente o material do software EDH. \\
\hline[ & ] & Li somente outro material diferente do software EDH. \\
\hline[ & ] & Li parcialmente o material do software EDH. \\
\hline[ & ] & Li parcialmente outro material diferente do software EDH. \\
\hline [ & ] & Li o material do software EDH e também outro material diferente do software EDH. \\
\hline
\end{tabular}

Item 02 - Eu lembrava e/ou conhecia e/ou entendia o assunto

\begin{tabular}{|ll|l|}
\hline[ & ] & $\begin{array}{l}\text { Como assinalei antes, não li nenhum material, mas eu lembrava das noções } \\
\text { conceituais de separatrizes }\end{array}$ \\
\hline[ & {[} & Antes mesmo da leitura, eu lembrava/entendia as noções conceituais de separatrizes \\
\hline[ & ] & $\begin{array}{l}\text { Durante e depois da leitura, eu lembrei das noções conceituais de separatrizes que } \\
\text { estudei em outra oportunidade. }\end{array}$ \\
\hline
\end{tabular}

Item 03 - Eu não conhecia ou não entendia o assunto antes da leitura

[ ] $\quad$ Antes da leitura, eu não conhecia as noções conceituais de curva de Lorenz/coeficiente de Gini

\section{Item 04 - Eu entendi o assunto durante e/ou após a leitura}

\begin{tabular}{|l|l|}
\hline$[\quad]$ & $\begin{array}{l}\text { Foi durante e/ou após a leitura que eu entendi as noções conceituais de curva de } \\
\text { Lorenz/coeficiente de Gini, pois antes da leitura, apesar de ter estudado, eu não } \\
\text { entendia tais noções conceituais }\end{array}$ \\
\hline$[\quad]$ & $\begin{array}{l}\text { Foi durante e/ou após a leitura que eu entendi as noções conceituais de curva de } \\
\text { Lorenz/coeficiente de Gini. Antes da leitura, como disse antes, eu não conhecia tais } \\
\text { noções conceituais }\end{array}$ \\
\hline
\end{tabular}

Item 05 - Não entendi o assunto mesmo após a leitura

\begin{tabular}{|l|l|}
\hline$[\quad]$ & $\begin{array}{l}\text { Mesmo após minha leitura, continuei a não entender as noções conceituais de curva } \\
\text { de Lorenz/coeficiente de Gini. Minhas respostas às questôes foram baseadas no } \\
\text { "chute". }\end{array}$ \\
\hline
\end{tabular}


Item 06 - Com relacão ao uso do software EDH (se você fez a leitura do material)

\begin{tabular}{|ll|l|}
\hline[ & ] & $\begin{array}{l}\text { Não tentei usar efetivamente o EDH por já entender os conceitos, por isso não me } \\
\text { considero apto a fazer alguma avaliação sobre o EDH. }\end{array}$ \\
\hline[ & ] & $\begin{array}{l}\text { Para entendimento das noções conceituais de curva de Lorenz/coeficiente de Gini o } \\
\text { EDH não foi útil. Ao contrário, acredito que me confundiu mais ainda sobre os } \\
\text { conceitos que tentou apresentar. }\end{array}$ \\
\hline[ & ] & $\begin{array}{l}\text { Para entendimento das noções conceituais de curva de Lorenz/coeficiente de Gini o } \\
\text { EDH foi útil. Acredito que o material ajudou na fixação dos conceitos. }\end{array}$ \\
\hline[ & ] & $\begin{array}{l}\text { Para entendimento das noções conceituais de curva de Lorenz/coeficiente de Gini o } \\
\text { EDH foi útil. Mas outro material que li sobre o assunto aborda de forma melhor que } \\
\text { o EDH. }\end{array}$ \\
\hline[ & ] & $\begin{array}{l}\text { Para entendimento das noções conceituais de curva de Lorenz/coeficiente de Gini o } \\
\text { EDH foi útil. E o EDH aborda o assunto melhor que outro material que li sobre o } \\
\text { assunto. }\end{array}$ \\
\hline & ] & $\begin{array}{l}\text { Para entendimento das noções conceituais de curva de Lorenz/coeficiente de Gini o } \\
\text { EDH foi útil. Acredito que a abordagem do assunto tentando apresentar os conceitos } \\
\text { primordialmente via imagens ajudou na fixação dos conteúdos. }\end{array}$ \\
\hline
\end{tabular}

Item 07 - IMAGENS do software EDH - cite abaixo as imagens do EDH que você lembra e que acredita ter sido útil para entender conceitos de curva de Lorenz/coeficiente de Gini

\section{O uso do software EDH (se você fez a leitura do material)}

Caso tenha usado o EDH, por favor relate brevemente os pontos positivos (interface estática e interativa, exemplos para abordagem, atividades propostas, etc) que o mesmo tenha apresentado para auxiliar a fixar os conceitos de CURVA DE LORENZ/COEFICIENTE DE GINI

\begin{tabular}{|l|}
\hline 1 \\
\hline 2
\end{tabular}


Caso tenha usado o EDH, por favor relate brevemente os pontos negativos (interface estática e interativa, exemplos para abordagem, atividades propostas, etc) que o mesmo tenha apresentado para auxiliar a fixar os conceitos de CURVA DE LORENZ/COEFICIENTE DE GINI

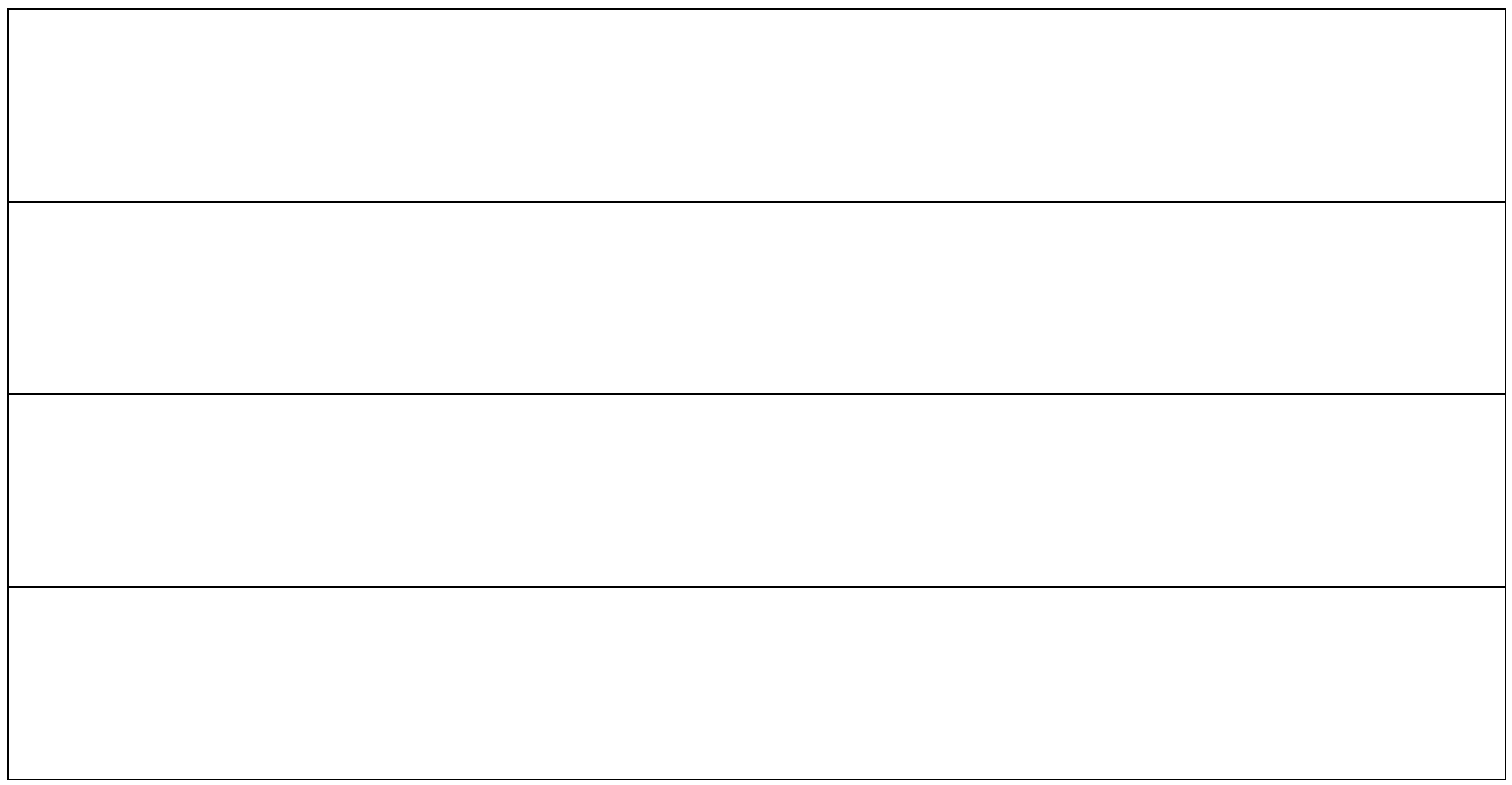




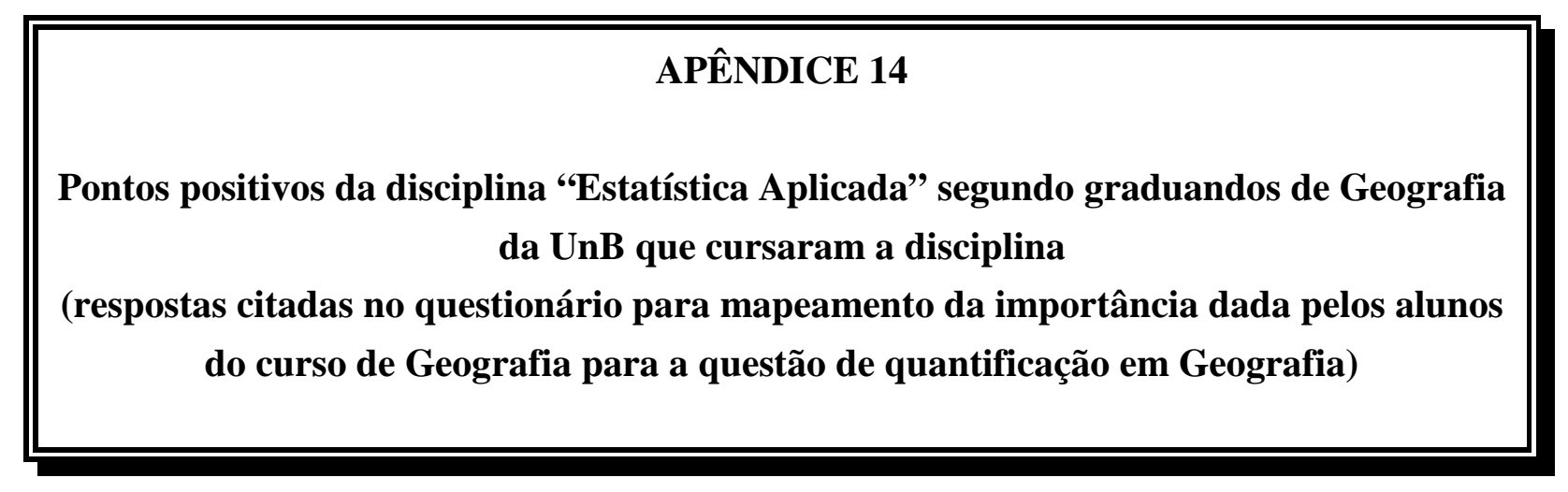

\begin{tabular}{|c|c|}
\hline Respondente & Pontos positivos \\
\hline 1 & O geógrafo precisa levar em consideração os métodos quantitativos \\
\hline 3 & É razoavelmente útil para o curso \\
\hline 4 & Aplicar as teorias a pesquisa em SIG; levantamento de dados \\
\hline 5 & Iremos usar o aprendizado mais na frente \\
\hline 6 & $\begin{array}{l}\text { Estatística é a base do método quantitativo/qualitativo para uma pesquisa de } \\
\text { dados. Como a pesquisa Geografia deve organizar os dados, a estatística, em } \\
\text { seu viés positivista, ajuda nesta apuração e análise }\end{array}$ \\
\hline 7 & $\begin{array}{l}\text { Estar apto a utilizar estatística em seus estudos e pesquisas de campo da } \\
\text { Geografia }\end{array}$ \\
\hline 8 & $\begin{array}{l}\text { A estatística aplicada é importante para entendermos a ação das pessoas } \\
\text { como coletivo e suas influências no espaço }\end{array}$ \\
\hline 9 & De forma a auxiliar a Geografia física \\
\hline 10 & Para entender os processos a partir de dados estatísticos \\
\hline 21 & A estatística é da grande importância na formação do geógrafo \\
\hline 30 & $\begin{array}{l}\text { Entendimento das técnicas e suas aplicações em diferentes áreas do } \\
\text { conhecimento }\end{array}$ \\
\hline 31 & Ajuda a compreender melhor Geografia biológica \\
\hline 32 & Utilizo curva de dispersão e distribuição na minha área \\
\hline 34 & Importante para melhor entender os dados \\
\hline 35 & $\begin{array}{l}\text { Entender o processo de elaboração dos dados estatísticos e interpretálos de } \\
\text { maneira correta }\end{array}$ \\
\hline 37 & Entender alguns conceitos aplicados a diversos métodos técnico-cintíficos \\
\hline 38 & $\begin{array}{l}\text { Maior conhecimento e melhor compreensão para realizar pesquisas e análises } \\
\text { nas áreas da Geografia física }\end{array}$ \\
\hline 39 & Planejamento de acordo com a variabilidade, previsibilidade dos eventos \\
\hline 43 & $\begin{array}{l}\text { Estatística aplicada foi uma disciplina útil pois aprender a interpretar e } \\
\text { coletar dados já se mostrou importante nas outras disciplinas tanto humanas } \\
\text { quanto exatas }\end{array}$ \\
\hline 45 & $\begin{array}{l}\text { Esta disciplina traz uma base para a coleta de dados propícios à pesquisa de } \\
\text { campo }\end{array}$ \\
\hline 46 & É de suma importância \\
\hline 47 & Sim, pois para a ciência geográfica é extremanente importante \\
\hline 48 & Para fazer leituras de gráficos e tabelas \\
\hline 49 & $\begin{array}{l}\text { Saber como deve ser utilizado questionários, pelo tipo de perguntas e como } \\
\text { elas devem ser realizadas }\end{array}$ \\
\hline
\end{tabular}




\begin{tabular}{|c|l|}
\hline 50 & $\begin{array}{l}\text { Sim, pois o conhecimento adquirido ajudou-me a resolver diversas questões } \\
\text { de concurso entre outros }\end{array}$ \\
\hline 54 & Método avaliativo com três provas e diferentes pesos \\
\hline 83 & $\begin{array}{l}\text { Disciplina fundamental na utilização de dados numéricos, estatísticos, } \\
\text { econômicos, etc }\end{array}$ \\
\hline 84 & $\begin{array}{l}\text { Compreender os métodos que a estatística possui, sua abordagem e forma de } \\
\text { trabalho }\end{array}$ \\
\hline 85 & $\begin{array}{l}\text { Considero positivo, hoje todas as ciências utilizam dados numéricos como } \\
\text { forma de interpretação }\end{array}$ \\
\hline 92 & $\begin{array}{l}\text { São teoria importantes para a qualificação de qualquer profissional. E é } \\
\text { muito utilizado na Geografia }\end{array}$ \\
\hline 93 & $\begin{array}{l}\text { É importante para a aquisição de dados, trabalhar em cima destes, com fatos } \\
\text { concretos da realidade }\end{array}$ \\
\hline 96 & Facilitar entendimento de conceitos; análise de gráficos \\
\hline 97 & Ajudou nos cálculos de frequência \\
\hline 98 & Compreendi os métodos estatísticos e pude utilizá-los a meu favor \\
\hline 99 & Sem dúvida me auxiliou na interpretação e elaboração de dados \\
\hline 101 & A disciplina contribui para o trabalho com dados quantitativos em Geografia \\
\hline 103 & Execução de tarefas, manuseio de programas \\
\hline 107 & Para elaboração de gráficos e estudos relacionados a área \\
\hline 109 & Achei tão importante que penso em mudar o curso para Estatística \\
\hline
\end{tabular}




\section{APÊNDICE 15}

Pontos negativos da disciplina "Estatística Aplicada" segundo graduandos de Geografia da UnB que cursaram a disciplina

(respostas citadas no questionário para mapeamento da importância dada pelos alunos do curso de Geografia para a questão de quantificação em Geografia)

\begin{tabular}{|c|c|}
\hline Respondente & Pontos negativos \\
\hline 4 & É chato \\
\hline 5 & Alto índice de reprovação dos alunos da Geografia \\
\hline 8 & $\begin{array}{l}\text { Vários aspectos, especialmente de detalhes matemáticos são irrelevantes } \\
\text { aos estudos de um geógrafo }\end{array}$ \\
\hline 9 & A Unb foca em Geografia humana \\
\hline 11 & Como a disciplina é dada se torna monótona \\
\hline 20 & Não há utilidade \\
\hline 21 & $\begin{array}{l}\text { Poderia haver uma turma específica para métodos quantitativos para a } \\
\text { Geografia }\end{array}$ \\
\hline 26 & $\begin{array}{l}\text { Conteúdo passado muito rapidamente, bases não muito boas acerca do } \\
\text { conteúdo }\end{array}$ \\
\hline 28 & $\begin{array}{l}\text { Acho que poderia ter uma estatística própria para o curso de Geografia, } \\
\text { facilitaria a assimilação }\end{array}$ \\
\hline 30 & A falta de prática durante o curso, formas de utilização em outras matérias \\
\hline 32 & $\begin{array}{l}\text { Não consegui aprender todos os conceitos básicos e tenho dificuldades em } \\
\text { muitos aspectos }\end{array}$ \\
\hline 34 & Falta entender melhor a estatística aplicada diretamente à Geografia \\
\hline 37 & $\begin{array}{l}\text { Limitação no aprofundamento de determinados métodos, pela falta de base } \\
\text { no Ensino Médio e também no ensino superior }\end{array}$ \\
\hline 39 & Metodologia trabalhada em sala de aula, turma com muitos alunos \\
\hline 46 & O professor não sabia explicar a matéria \\
\hline 49 & A dificuldade com a disciplina e seus conteúdos \\
\hline 54 & Didática dos professores \\
\hline 84 & $\begin{array}{l}\text { Considero negativo não ter aprendido nem metade do que deveria ter } \\
\text { aprendido, mas isso decorre do curto tempo do curso e da abordagem do } \\
\text { professor }\end{array}$ \\
\hline 86 & $\begin{array}{l}\text { Gostaria que tivesse sido utilizado exemplos mais específicos da nossa área } \\
\text { de atuação para compreender a aplicação de muitos dos conceitos de } \\
\text { estatística }\end{array}$ \\
\hline 87 & Devido a falta de foco para o caráter geográfico \\
\hline 89 & $\begin{array}{l}\text { Tive dificuldade em compreender as fórmulas, os cálculo e o sentido que } \\
\text { eles têm }\end{array}$ \\
\hline 91 & $\begin{array}{l}\text { Acho que o método de ensino na Estatística Aplicada está errado, o } \\
\text { professor parece 'cuspir' a matéria sem querer saber sobre se os alunos } \\
\text { aprenderam de verdade }\end{array}$ \\
\hline
\end{tabular}




\begin{tabular}{|c|l|}
\hline 92 & Só existe essa matéria obrigatória de cálculo. Poderia ter mais algumas \\
\hline 97 & A estatística foi muito superficial \\
\hline 98 & $\begin{array}{l}\text { O método de ensino da matéria é falho. Não possibilitou o aprendizado } \\
\text { completo dos métodos }\end{array}$ \\
\hline 100 & $\begin{array}{l}\text { É uma disciplina a qual os alunos, principalmente da Geografia dão pouca } \\
\text { importância sendo que é essencial }\end{array}$ \\
\hline
\end{tabular}




\section{APÊNDICE 16}

Teste 2 aplicado aos alunos de Climatologia Geral no semestre letivo 1/2015 sobre média variância, desvio padrão e coeficiente de variação

\begin{tabular}{|c|c|}
\hline 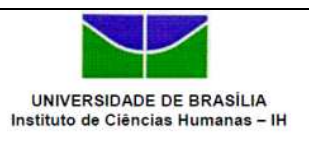 & $\begin{array}{l}\text { Teste } 02 \text { - Média, variância, desvio padrão, coeficiente de variação } \\
\text { Valor do teste: } 1,5 \text { ponto }\end{array}$ \\
\hline
\end{tabular}

\section{Identificação do aluno}

Nome completo:

Questão 1 - Sejam três populações: uma de valores de precipitação pluviométrica (medida em $\mathrm{mm}$ ), outra de valores de temperatura (medida em ${ }^{\circ} \mathrm{C}$ ) e outra de valores de insolação mensal (medida em horas) apresentadas abaixo:

\begin{tabular}{|l|c|c|c|c|c|c|c|c|c|c|}
\hline & \multicolumn{7}{c|}{ Observação (elemento da população) } & & \\
\hline \multicolumn{1}{|c|}{ Variável } & 1 & 2 & 3 & 4 & 5 & 6 & 7 & Média & $\begin{array}{c}\text { Desvio } \\
\text { Padrão }\end{array}$ & $\begin{array}{c}\text { Coef. } \\
\text { Var. }\end{array}$ \\
\hline $\begin{array}{l}\text { Precipitação } \\
(\mathrm{mm})\end{array}$ & $\mathrm{X}_{1}=52$ & $\mathrm{X}_{2}=64$ & $\mathrm{X}_{3}=52$ & $\mathrm{X}_{4}=80$ & $\mathrm{X}_{5}=49$ & $\mathrm{X}_{6}=51$ & $\mathrm{X}_{7}=44$ & 56 & 11,28 & $\begin{array}{c}20,14 \\
\%\end{array}$ \\
\hline $\begin{array}{l}\text { Temperatura } \\
\left({ }^{\circ} \mathrm{C}\right)\end{array}$ & $\mathrm{Y}_{1}=20$ & $\mathrm{Y}_{2}=22$ & $\mathrm{Y}_{3}=24$ & $\mathrm{Y}_{4}=22$ & $\mathrm{Y}_{5}=21$ & $\mathrm{Y}_{6}=20$ & $\mathrm{Y}_{7}=18$ & 21 & 1,77 & $8,44 \%$ \\
\hline $\begin{array}{l}\text { Insolação } \\
\text { (horas) }\end{array}$ & $\mathrm{Z}_{1}=?$ & $\mathrm{Z}_{2}=?$ & $\mathrm{Z}_{3}=?$ & $\mathrm{Z}_{4}=?$ & $\mathrm{Z}_{5}=?$ & $\mathrm{Z}_{6}=?$ & $\mathrm{Z}_{7}=?$ & 230 & $\begin{array}{c}25,00 \\
10,87 \\
\%\end{array}$ \\
\hline
\end{tabular}

Julgue as assertivas abaixo em certo $(\mathbf{C})$ ou errado (E) ou deixe em branco caso não saiba a resposta. (Atenção!!! Uma resposta incorreta anula uma resposta correta) 
1. [ ] $\frac{\sum_{i=4}^{6} x_{i}}{3}=60 \mathrm{~mm}$ é o valor do desvio padrão de 3 elementos da população de precipitação

2. [ ] a população de insolação apresenta maior variabilidade (maior "espalhamento" de dados) que as

2. [ populaçōes de precipitação e temperatura, pois apresenta o maior valor de desvio padrão $(25,00$ horas $)$

3. [ ] se o desvio padrão da população de insolação fosse 9 horas, então sua variância valeria 81 horas $^{2}$

4. [ quanto mais heterogêneo o grupo de dados, maior será seu coeficiente de variação. Por isso, a população de precipitação apresenta maior heterogeneidade que as populações de temperatura e insolação

5. [ ] não é possivel calcular o valor da variância da população de insolação pois não foram informados os valores $\mathrm{Z}_{1}, \mathrm{Z}_{2}, \mathrm{Z}_{3}, \mathrm{Z}_{4}, \mathrm{z}_{5}, \mathrm{z}_{6}$ e $\mathrm{Z}_{7}$

6. [ ] $\frac{(20-21)^{2}+(22-21)^{2}+(24-21)^{2}+(22-21)^{2}+(21-21)^{2}+(20-21)^{2}+(18-21)^{2}}{7}=1,77^{\circ} \mathrm{C}$

7. [ ] a temperatura é o grupo de dados que apresenta maior homogeneidade (menor "espalhamento" de dados)

8. [ ] a temperatura é o grupo de dados que apresenta maior homogeneidade (menor "espalhamento" de dados) uma vez que apresenta a menor média entre as 3 popualçōes consideradas 9. [ ] Se a população de temperatura apresentasse média $18 \circ \mathrm{C}$ e desvio padrão $6 \circ \mathrm{C}$, então seria o

10. [ Se a população de insolação mantivesse a média de 230 horas, porém com desvio padrão de 69 horas, etntão seria o grupo com maior homogeneidade entre as 3 populações

Questão 2 - Observe a tabela abaixo e responda ao que se pede:

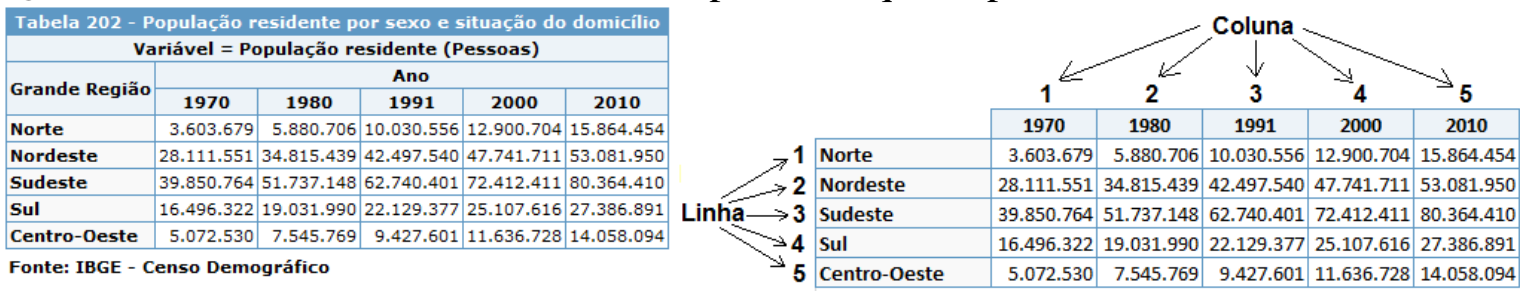

Obs.: leitura de valores em tabela de dupla entrada (linhas e colunas) :

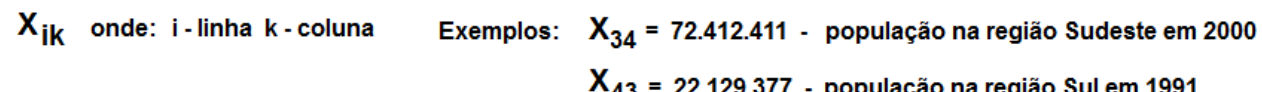

Julgue as assertivas abaixo em certo (C) ou errado (E) ou deixe em branco caso não saiba a resposta. Atenção!!! Uma resposta incorreta anula uma resposta correta 


$$
\begin{aligned}
& \text { [ }] \sum_{m=3}^{5} X_{2 m} \text { representa a soma da população da regiäo Nordeste nos anos de 1991, } 2000 \text { e } 2010 \\
& \text { [ }] \sum_{m=3}^{5} X_{m 2} \text { representa a soma da população da região Nordeste nos anos de 1991, } 2000 \text { e } 2010 \\
& \text { [ } \sum_{\mathrm{m}=3}^{5} \mathrm{X}_{\mathrm{m} 2} \text { representa a soma da populaçăo das regiōes Sudeste, Sul e Centro-Oeste em } 1980 \\
& {\left[\frac{\sum_{m=3}^{5} x_{m 2}}{5} \text { representa a média da população das regiões Sudeste, Sul e Centro-Oeste em } 1980\right.} \\
& \text { 【 }\rfloor \frac{\sum_{\mathrm{m}=2}^{4} \mathrm{x}_{5 \mathrm{~m}}}{3} \text { representa a média da população da regiäo Centro-Oeste em 1980, } 1991 \text { e } 2000 \\
& {[] \sum_{m=1}^{5} X_{1 m}+\sum_{m=1}^{5} X_{3 m} \begin{array}{l}
\text { representa a soma da populaçäo das regiöes norte e } \\
\text { sudeste nos anos de 1970, 1980, 1991, 2000 e 2010 }
\end{array}} \\
& {\left[\frac{\sum_{m=1}^{5} X_{m 1}}{5} \text { representa a média da população brasileira nas regiöes em } 1970\right.} \\
& {\left[\frac{\sum_{m=1}^{5} x_{1 m}}{5} \text { representa a média da populaçăo brasileira nas regiões em } 1970\right.} \\
& {\left[\frac{\sum_{m=1}^{2} X_{4 m}+\sum_{m=4}^{5} X_{4 m}}{4} \quad \begin{array}{c}
\text { representa a média da popualçăo na regiăo } \\
\text { Sul nos anos de 1970, 1980, 2000 e 2010 }
\end{array}\right.}
\end{aligned}
$$


Questão 3 - Suponha que tomou-se uma amostra de 30 municípios brasileiros e calculou-se a quantidade média produzida de feijão pelos 30 municípios, obtendo-se o valor de 350 toneladas. Julgue as assertivas abaixo em certo $(\mathbf{C})$ ou errado (E) ou deixe em branco caso não saiba a resposta. Atenção!!! Uma resposta incorreta anula uma resposta correta

\begin{tabular}{|c|c|}
\hline$\left[\begin{array}{ll}{[} & ]\end{array}\right.$ & $\begin{array}{l}\text { Se tomarmos o valor de mais um município além dos } 30 \text { já selecionados e a } \\
\text { quantidade produzida de feijão deste município for } 420 \text { toneladas, então } \\
\text { significa que a média de amostra dos } 31 \text { municípios é certamente menor que } \\
350 \text { toneladas }\end{array}$ \\
\hline$\left[\begin{array}{ll}{[} & ]\end{array}\right.$ & $\begin{array}{l}\text { Se tomarmos o valor de mais um município além dos } 30 \text { já selecionados e a } \\
\text { quantidade produzida de feijão deste município for } 420 \text { toneladas, então } \\
\text { significa que a média de amostra dos } 31 \text { municípios pode ser menor que } 350 \\
\text { toneladas }\end{array}$ \\
\hline$\left[\begin{array}{ll}{[} & ]\end{array}\right.$ & $\begin{array}{l}\text { Por se tratar de uma amostra de } 30 \text { municípios, devemos dividir o somatório } \\
\text { dos quadrados dos desvios entre observações e a média por } 30 \text { para obter o } \\
\text { valor da variância }\end{array}$ \\
\hline$\left[\begin{array}{ll} & ]\end{array}\right.$ & $\begin{array}{l}\text { Por se tratar de uma amostra de } 30 \text { municípios, devemos dividir o somatório } \\
\text { dos quadrados dos desvios entre observações e a média por } 29 \text { para obter o } \\
\text { valor da variância }\end{array}$ \\
\hline$\left[\begin{array}{ll} & ]\end{array}\right.$ & $\begin{array}{l}\text { Por se tratar de uma amostra de } 30 \text { municípios, devemos dividir o somatório } \\
\text { dos quadrados dos desvios entre observações e a média por } 30 \text { e depois tirar a } \\
\text { raiz quadrada desta divisão para obter o valor da variância }\end{array}$ \\
\hline$\left[\begin{array}{ll}{[} & ]\end{array}\right.$ & $\begin{array}{l}\text { Por se tratar de uma amostra de } 30 \text { municípios, devemos dividir o somatório } \\
\text { dos quadrados dos desvios entre observações e a média por } 29 \text { e depois tirar a } \\
\text { raiz quadrada desta divisão para obter o valor da variância }\end{array}$ \\
\hline
\end{tabular}

Questão 4 - Observe a tabela abaixo apresentando uma situação hipotética e responda ao que se pede: (Atenção!!! Uma resposta incorreta anula uma resposta correta)

\begin{tabular}{l|cccc|c} 
& \multicolumn{5}{|c}{ Qtde (toneladas) } \\
Grande Região & Arroz & Feijão & Soja & Trigo & Total \\
\hline Norte & $?$ & $?$ & $?$ & $?$ & 1100 \\
Nordeste & $?$ & $?$ & $?$ & $?$ & 1200 \\
Sudeste & $?$ & $?$ & $?$ & $?$ & 1400 \\
Sul & $?$ & $?$ & $?$ & $?$ & 1050 \\
Centro-Oeste & $?$ & $?$ & $?$ & $?$ & 1900 \\
\hline Total & 1700 & 1900 & 1350 & 1700 &
\end{tabular}


Julgue as assertivas abaixo em certo (C) ou errado (E) ou deixe em branco caso não saiba a resposta.

\begin{tabular}{|c|c|}
\hline [ ] & $\begin{array}{l}\text { É possível afirmar que, nas } 5 \text { regiões, a produção média de feijão foi maior do } \\
\text { que a produção média das demais culturas }\end{array}$ \\
\hline [ ] & $\begin{array}{l}\text { Não é possível calcular a produção média de feijão das } 5 \text { regiões pois não } \\
\text { foram informados os valores de produção para as } 5 \text { regiões }\end{array}$ \\
\hline [ ] & $\begin{array}{l}\text { É possível afirmar que, dentre as } 5 \text { regiões, foi a região Sul que apresentou } \\
\text { menor produção média das } 4 \text { culturas }\end{array}$ \\
\hline [ ] & $\begin{array}{l}\text { Não é possível identificar qual dentre as } 5 \text { regiões que apresentou menor } \\
\text { produção média das } 4 \text { culturas }\end{array}$ \\
\hline$\left[\begin{array}{ll}{[} & \end{array}\right.$ & $\begin{array}{l}\text { Dentre as } 5 \text { regiões, foi a região Sul que apresentou menor produção média das } \\
4 \text { culturas. Apesar disso, é possível ocorrer que a produção de arroz na região } \\
\text { Sul seja a maior dentre todas as regiões }\end{array}$ \\
\hline$\left[\begin{array}{ll}\text { l } \\
\text { ] }\end{array}\right.$ & $\begin{array}{l}\text { A produção média de arroz e trigo nas } 5 \text { regiões é a mesma. Então podemos } \\
\text { afirmar que o valor da quantidade produzida de arroz na região Norte é o } \\
\text { mesmo valor da quantidade produzida de trigo na região Norte }\end{array}$ \\
\hline ] & $\begin{array}{l}\text { O valor da produção média de todas as culturas pelas } 5 \text { regiões é o mesmo } \\
\text { valor da produção média de todas as regiões para as } 4 \text { culturas }\end{array}$ \\
\hline
\end{tabular}

